NIST NCSTAR 1-6A

Federal Building and Fire Safety Investigation of the World Trade Center Disaster

\title{
Passive Fire Protection
}

\author{
Nicholas J. Carino \\ Monica A. Starnes \\ John L. Gross \\ Jiann C. Yang \\ Scott R. Kukuck \\ Kuldeep R. Prasad \\ Richard W. Bukowski
}





\section{Federal Building and Fire Safety Investigation of the World Trade Center Disaster}

\section{Passive Fire Protection}

Nicholas J. Carino*

Monica A. Starnes ${ }^{\star \star}$

John L. Gross

Jiann C. Yang

Scott R. Kukuck ${ }^{* *}$

Kuldeep R. Prasad

Richard W. Bukowski

Building and Fire Research Laboratory

National Institute of Standards and Technology

${ }^{*}$ Retired

**Current affiliation:

Johns Hopkins University

Applied Physics Laboratory

Laurel, Maryland

${ }^{\star \star *}$ Current affiliation:

U.S. Army Research Laboratory

Aberdeen Proving Grounds, Maryland

September 2005

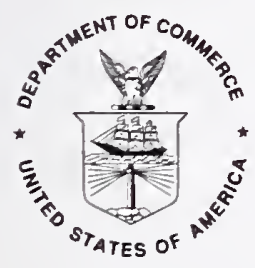

U.S. Department of Commerce

Carlos M. Gutierrez, Secretary

Technology Administration

Michelle O' Neill, Acting Under Secretary for Technology

National Institute of Standards and Technology

William Jeffrey, Director 


\title{
Disclaimer No. 1
}

Certain commercial entities, equipment, products, or materials are identified in this document in order to describe a procedure or concept adequately or to trace the history of the procedures and practices used. Such identification is not intended to imply recommendation, endorsement, or implication that the entities, products, materials, or equipment are necessarily the best available for the purpose. Nor does such identification imply a finding of fault or negligence by the National Institute of Standards and Technology.

\section{Disclaimer No. 2}

The policy of NIST is to use the International System of Units (metric units) in all publications. In this document, however, units are presented in metric units or the inch-pound system, whichever is prevalent in the discipline.

\section{Disclaimer No. 3}

Pursuant to section 7 of the National Construction Safety Team Act, the NIST Director has determined that certain evidence received by NIST in the course of this Investigation is "voluntarily provided safety-related information" that is "not directly related to the building failure being investigated" and that "disclosure of that information would inhibit the voluntary provision of that type of information" (15 USC 7306c).

In addition, a substantial portion of the evidence collected by NIST in the course of the Investigation has been provided to NIST under nondisclosure agreements.

\section{Disclaimer No. 4}

NIST takes no position as to whether the design or construction of a WTC building was compliant with any code since, due to the destruction of the WTC buildings, NIST could not verify the actual (or as-built) construction, the properties and condition of the materials used, or changes to the original construction made over the life of the buildings. In addition, NIST could not verify the interpretations of codes used by applicable authorities in determining compliance when implementing building codes. Where an Investigation report states whether a system was designed or installed as required by a code provision, NIST has documentary or anecdotal evidence indicating whether the requirement was met, or NIST has independently conducted tests or analyses indicating whether the requirement was met.

\section{Use in Legal Proceedings}

No part of any report resulting from a NIST investigation into a structural failure or from an investigation under the National Construction Safety Team Act may be used in any suit or action for damages arising out of any matter mentioned in such report (15 USC 281a; as amended by P.L. 107-231).

National Institute of Standards and Technology National Construction Safety Team Act Report 1-6A Natl. Inst. Stand. Technol. Natl. Constr. Sfty. Tm. Act Rpt. 1-6A, 326 pages (September 2005) CODEN: NSPUE2

\author{
U.S. GOVERNMENT PRINTING OFFICE
}

WASHINGTON: 2005

For sale by the Superintendent of Documents, U.S. Government Printing Office Internet: bookstore.gpo.gov — Phone: (202) 512-1800 - Fax: (202) 512-2250

Mail: Stop SSOP, Washington, DC 20402-0001 


\section{ABSTRACT}

This report deals with the passive fire protection used in the World Trade Center (WTC) towers. The main objective is to provide background information that can be used to assess the in-place conditions of the passive protection before and after aircraft impact. The report includes a review of key building code provisions related to structural fire protection. It also includes a review of key decisions related to passive fire protection made during design, construction, and occupancy of the towers. Copies of documents to support key findings are included in an Appendix. A summary is provided of available data on in-place measurements of the sprayed fire-resistive materials (SFRMs) applied to the floor trusses and to core members. Measurements of thermophysical properties of the passive fire protection materials, including gypsum panels, are presented. The effects of gaps in thermal insulation and the effects of variability of insulation thickness are evaluated. The rationale for selecting the effective thickness of thermal insulation for use in thermal-structural analyses is presented. Measurements of adhesive and cohesive strengths of a selected SFRM are summarized. Simplified models are presented for estimating the acceleration required to dislodge SFRM from planar surfaces and encased round bars. The report concludes with a summary of key findings.

Keywords: adhesive strength. building code, cohesive strength, construction classification, density, equivalent thickness, retrofit, specific heat capacity, sprayed fire-resistive materials (SFRM), thermal conductivity, thermal insulation, thickness, thickness variability, World Trade Center. 
This page intentionally left blank. 


\section{TABLE OF CONTENTS}

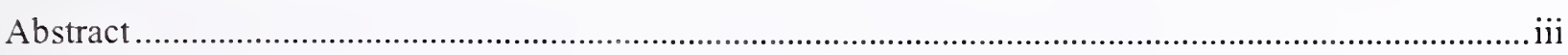

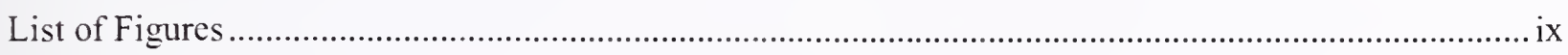

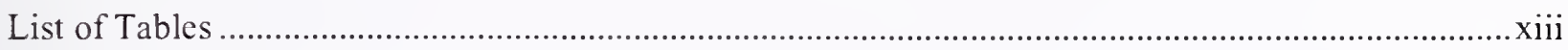

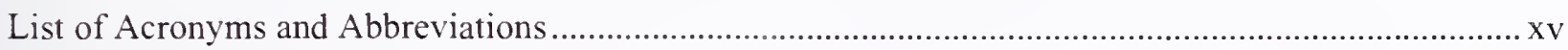

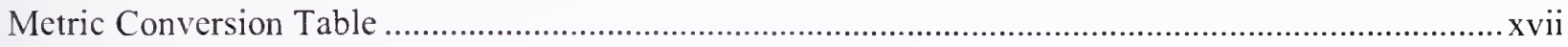

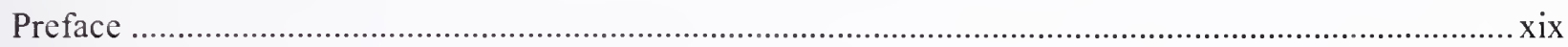

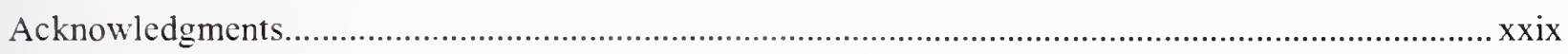

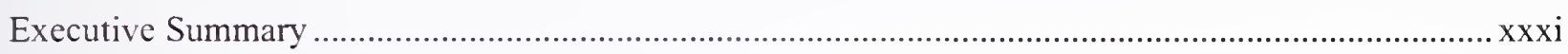

Chapter 1

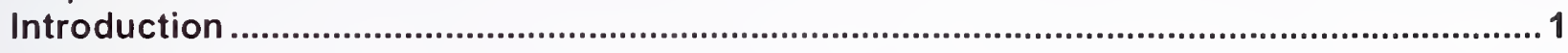

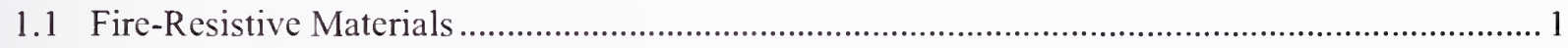

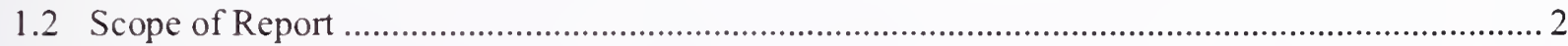

\section{Chapter 2}

Building Code Concepts for Structural Fire Resistance ............................................... 5

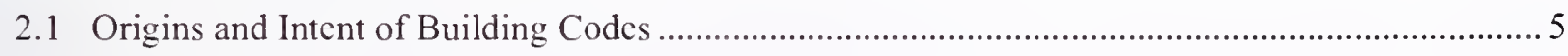

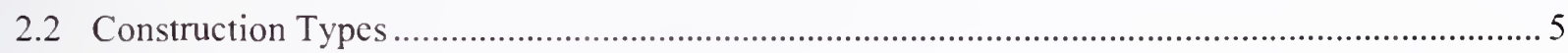

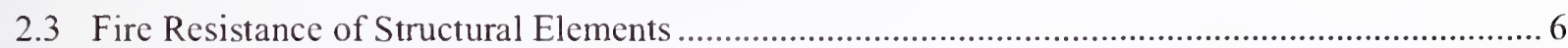

\section{Chapter 3}

Historical Review Related to Passive Fire Protection of WTC Towers ...............................9

3.1 Agreements Between Port Authority and New York City Department of Buildings and Fire

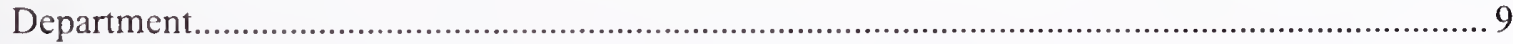

3.2 New York City Building Code Requirements ................................................................. 10

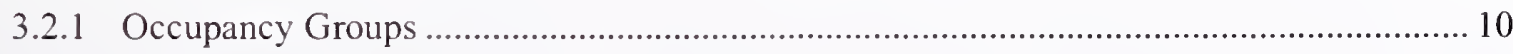

3.2.2 Construction Classification and Fire Rating........................................................ 11

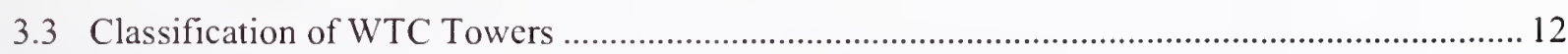

3.3.1 Specifications for Passive Fire Protection ................................................................. 12

3.3.2 Response to Local Law 5/1973 …....................................................................... 13

3.4 Selection of Fire-resistive Materials .................................................................................. 14

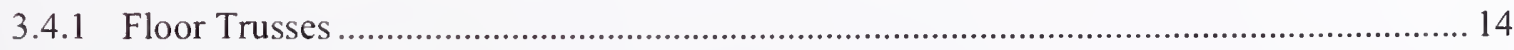

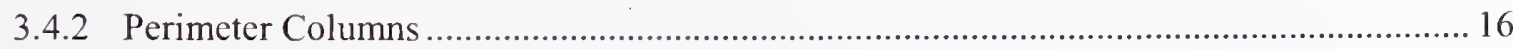

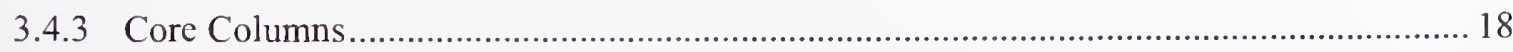


3.5 Specified Thickness of Fire-resistive Materials .................................................................. 18

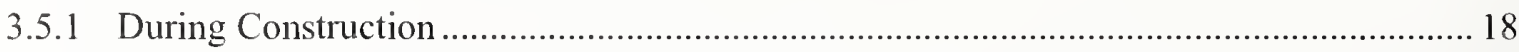

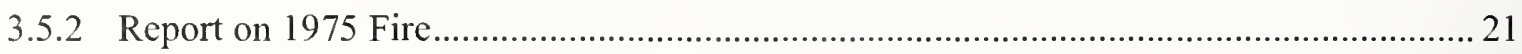

3.5.3 In-Place Thickness and Upgrading of SFRM.................................................... 24

3.5.4 Need for Fire Endurance Tests ......................................................................... 26

3.5.5 Calculations of SFRM Thickness for Core Members .................................................. 26

3.6 Maintenance of SFRM in Elevator Shafts .............................................................................2

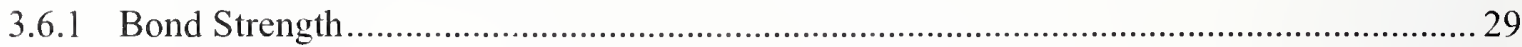

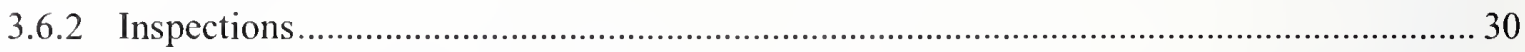

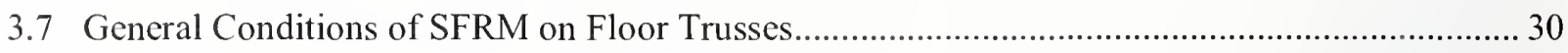

Chapter 4

As-Applied Thickness of SFRM ...................................................................... 37

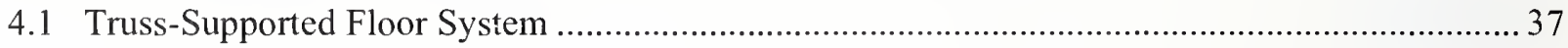

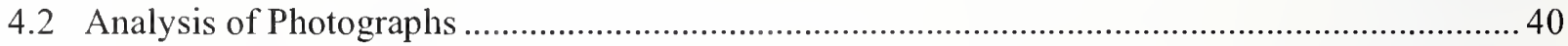

4.3 Port Authority Data on Upgraded SFRM on Trusses ........................................................ 42

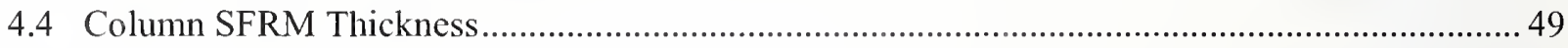

\section{Chapter 5}

Effect of SFRM Geometry on Thermal Response ................................................................51

5.1 Effects of Thickness Variability and Gaps in SFRM........................................................ 51

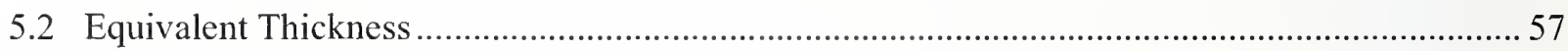

5.3 Recommended Thickness of SFRM for Thermal Analyses............................................. 60

\section{Chapter 6}

Thermophysical Properties....................................................................................63

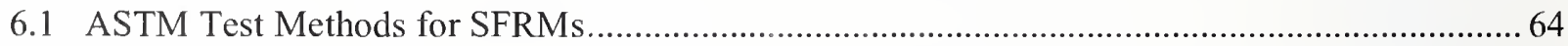

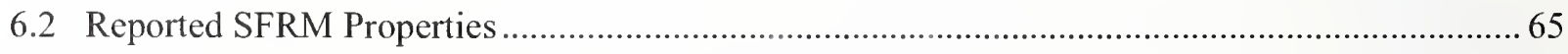

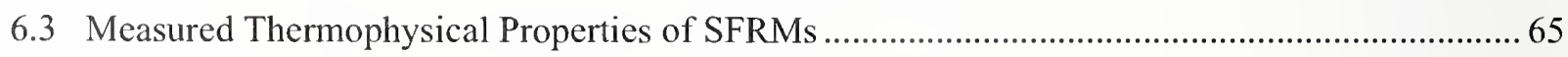

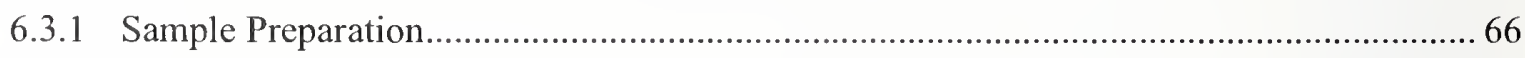

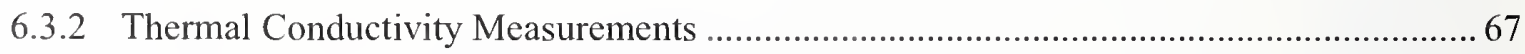

6.3.3 Specific Heat Capacity Measurements ................................................................... 69

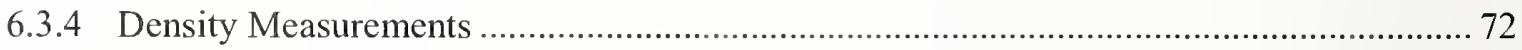

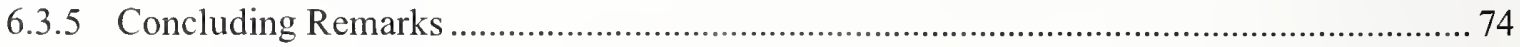

6.4 Thermophysical Properties of Gypsum Panels .............................................................. 75

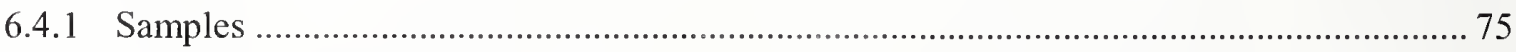

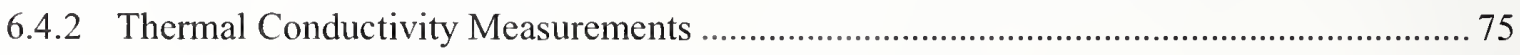


6.4.3 Specific Heat Capacity Measurements .................................................................. 78

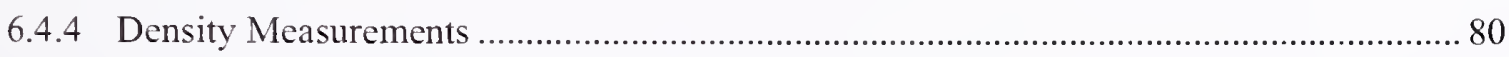

\section{Chapter 7}

Adhesive and Cohesive Strength 83

7.1 Reported In-Place Density and Bond Strength .83

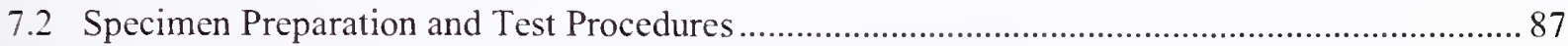

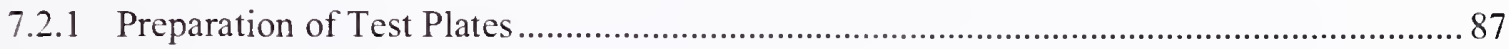

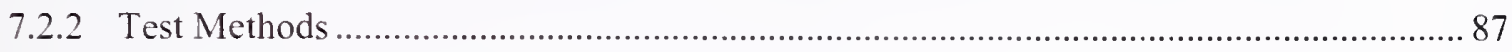

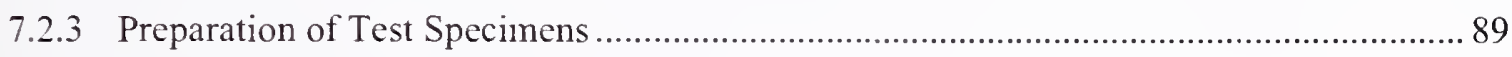

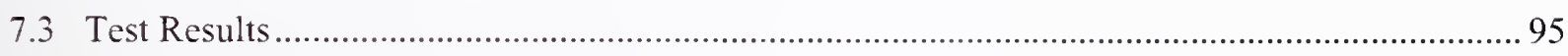

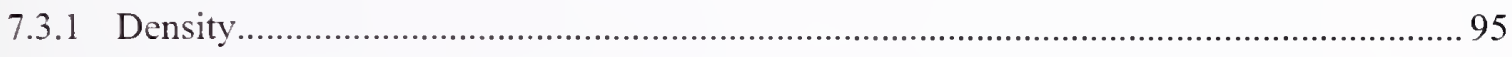

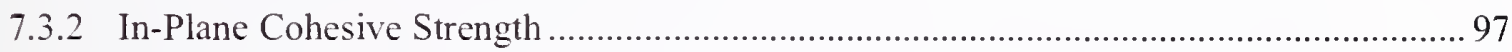

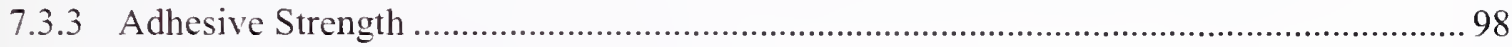

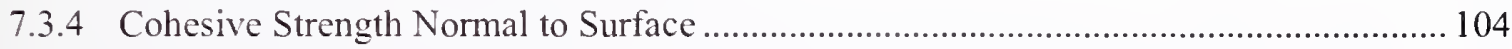

7.3.5 Adhesive Strength Versus Cohesive Strength Normal to Surface................................ 107

7.4 Simplified Approach to Predict Dislodging of SFRM .......................................................... 108

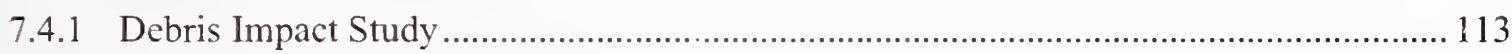

Chapter 8

Summary.

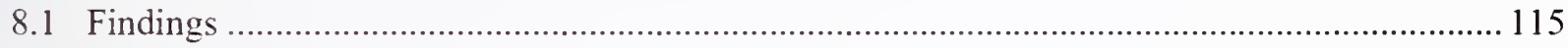

Chapter 9

References

\section{Appendix A}

Referenced Documents

Appendix B

Thermophysical Properties Test Data 
This page intentionally left blank. 


\section{LIST OF FIGURES}

Figure $\mathrm{P}-1$. The eight projects in the federal building and fire safety investigation of the WTC disaster.

Figure 1-1. Examples of sprayed fire-resistive materials: (left) material based on gypsum and vermiculite aggregate; (right) material based on mineral fibers and cementitious binder.

Figure 3-1. Mock up of floor truss system

Figure 3-2. Schematic of composite floor truss system.

Figure 3-3. Demonstration of application of Monokote sprayed fire-resistive material to floor trusses

Figure 3-4. Thermal insulation for perimeter columns.

Figure 3-5. Intersection of main truss and bridging truss showing general good coverage of SFRM on truss members but thickness varies on web bars.

Figure 3-6. Intersection of main truss and bridging truss showing thinner SFRM on members of bridging truss

Figure 3-7. Connection of main truss to spandrel beam showing relatively thin SFRM on truss seat and no SFRM on damper.

Figure 3-8. End of main truss showing low thickness of SFRM on truss members and no SFRM on damper saddle.

Figure 3-9. Intersection of main truss and bridging truss showing thin SFRM on the ends of some web bars: SFRM was not applied to the metal decking. 35

Figure 3-10. Example of damage to SFRM during installation of utilities 35

Figure 4-1. (a) Dotplot of average thickness from floor trusses for floors 23 and 24, (b) normal probability plot of all average thickness values, and (c) normal probability plot of average thickness with four values (six points) excluded.

Figure 4-2. Example of measurement procedure used to estimate SFRM thickness from photographs

Figure 4-3. (a) Normal probability plot of estimated SFRM thickness based on photographs, and

(b) normal probability plot of natural logarithms of thickness (Data provided by PANYNJ).

Figure 4-4. (a) Dotplot of individual thickness measurements on floor trusses from Port Authority Construction Audit Reports, (b) histogram of thickness measurements, (c) normal probability plot of thickness measurements, (d) histogram of natural logarithms of thickness measurements, and (e) normal probability plot of natural logarithm of thickness measurements. 
Figure 4-5. SFRM thickness on floor trusses in upgraded portions of WTC towers: (a) individual measurements in WTC 1, (b) average thickness in WTC 1, (c) individual measurements in WTC 2, and (d) average thickness in WTC 2 (data provided by PANYNJ).

Figure 4-6. Thickness of re-applied SFRM in elevator shaft 10/11 of WTC 1: (a) Individual and average thickness for core columns, (b) normal probability plot of individual measurements on columns, (c) individual and average thickness for core beams, and (d) normal probability plot of individual measurements on beams (data provided by PANYNJ).

Figure 5-1. Model used to study effects of SFRM thickness and variability of thickness on steel temperature: (a) physical model used in analyses (points 1 to 5 are locations where temperatures are monitored), (b) finite element mesh used to represent physical model, and (c) finite element model to represent variable thickness of SFRM (purple) (the elements in red represent material of high thermal conductivity).

Figure 5-2. Temperature distribution after $1 \mathrm{~h}$ of exposure to gas temperature of $1,100{ }^{\circ} \mathrm{C}$ $(1,373 \mathrm{~K})$.

Figure 5-3. Variation of steel temperature (at a point 6 in. from end of plate) with time for different average thicknesses of fire-resistive material (shown as numbers on the curves): (a) uniform thickness, and (b) variable thickness with standard deviation $=$ 1 in.

Figure 5-4. Example of "gap" in fire-resistive material on diagonal member of a bridging floor truss.

Figure 5-5. Effects of gap in fire-resistive material: (a) model of plate with SFRM having 2 in. uniform thickness and 12 in. gap, (b) isotherms $(\mathrm{K})$ at time $=50 \mathrm{~min}$ with 12 in. gap, and (c) isotherms without gap.

Figure 5-6. Example of plot matrix from sensitivity study of the effects of missing SFRM and variability of SFRM thickness on steel temperature. Each graph is a temperature history of the steel at point \#2 (see Fig. 5-5 for location) for different thicknesses of SFRM.

Figure 5-7. (a) Randomly generated thickness profiles with average thickness of 0.75 in. and standard deviation of 0.3 in., (b) cumulative element size, and (c) deformation of 1 in. bar compared with deformation for uniform thickness of thermal insulation.

Figure 5-8. (a) Randomly generated thickness profiles with average thickness of $2.5 \mathrm{in}$. and standard deviation of 0.6 in., (b) normal probability plots of thickness values, and (c) deformation of $1 \mathrm{in}$. bar compared with deformation for uniform thickness of thermal insulation.

Figure 6-1. BLAZE-SHIELD DC/F sample used for thermophysical property measurements. 66

Figure 6-2. BLAZE-SHIELD II sample used for thermophysical property measurements. .66

Figure 6-3. Monokote MK-5 sample used for thermophysical property measurements. 67

Figure 6-4. Thermal conductivities of the three SFRMs as a function of temperature .68 
Figure 6-5. Comparison of BLAZE-SHIELD DC/F specific heat capacity measurements from Harmathy (1983) with present results from Laboratory A.

Figure 6-6. Comparison of specific heat capacity measurements from Laboratory B with results from Laboratory A.

Figure 6-7. Comparison of specific heat capacity measurements for BLAZE-SHIELD DC/F from Laboratory B with the results from Harmathy (1983). 72

Figure 6-8. Bulk densities of the three SFRMs as a function of temperature. 74

Figure 6-9. Thermal conductivities of the four gypsum materials as a function of temperature. .76

Figure 6-10. Comparison of the thermal conductivity measurements from Laboratory B with the data from Mehaffey et al. (1994) for 5/8 in. thick gypsum panel A.

Figure 6-11. Comparison of thermal conductivity measurements from Laboratory B with other literature values for $1 / 2$ in. thick gypsum panel and $5 / 8$ in. thick gypsum panel B.............. 78

Figure 6-12. Comparison of specific heat capacities for the four gypsum materials.............................. 79

Figure 6-13. Bulk densities of the four gypsum materials as a function of temperature. 81

Figure 7-1. Bond strength test using screw cap in accordance with ASTM E 736.

Figure 7-2. Cohesive failure of SFRM using ASTM E 736 test (dashed circle is approximate location of cap before being pulled off.

Figure 7-3. In-place density of BLAZE-SHIELD Type Il on floor trusses from Port Authority test reports during the period 1997-1999.

Figure 7-4. In-place bond strength of BLAZE-SHIELD Type II using ASTM E 736 from Port Authority test reports during the period 1997-1999.

Figure 7-5. Spraying steel plates with BLAZE-SHIELD DC/F.

Figure 7-6. Schematic of "pull-off" test method used to measure cohesive and adhesive strengths. .......88

Figure 7-7. Technique used to measure both "adhesive" and "cohesive" strength in the same specimen.

Figure 7-8. Method to measure cohesive strength parallcl to SFRM surface (in-plane cohesive strength).

Figure 7-9. Cutting the SFRM layer into five strips.

Figure 7-10. Five specimens obtained from single plate; top three specimens are used for density and in-plane cohesive strength, bottom specimens are used for adhesion/cohesion tests.

Figure 7-11. Aluminum plate being bonded to the top surface of SFRM specimen: the wooden fixture is used to maintain the correct alignment of the plate.

Figure 7-12. Preparing the SFRM specimen for adhesion/cohesion test.

Figure 7-13. Manual application of tensile load using digital force gauge.

Figure 7-14. Results of first loading: specimen on left had a cohesive failure in the bulk SFRM, specimen on right failed near the SFRM/steel interface. 
Figure 7-15. Results of second tests after repair: specimen on left had adhesive failure and specimen on right had cohesive failure

Figure 7-16. SFRM specimen after measuring in-plane cohesive strength. ..................................... 94

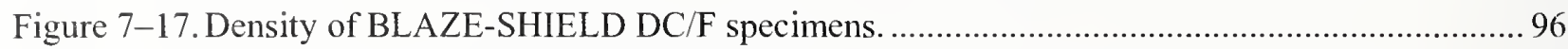

Figure 7-18. Air-dry density of BLAZE-SHIELD DC/F from NIST/UL floor truss fire endurance

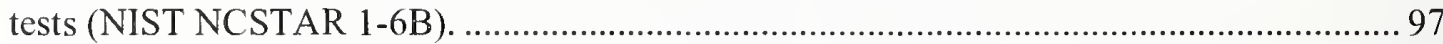

Figure 7-19. In-plane cohesive strength for BLAZE-SHIELD DC/F specimens................................ 98

Figure 7-20. Example of "adhesive" failure of SFRM (original location of test specimens are the gaps in the two strips); photo on left is magnified view of thin layer of paste and fibers (the marks around the perimeter is red ink used to locate field of view).

Figure 7-21. Example of lack of adhesion in 1 1 $\frac{1}{2} \mathrm{in}$. SFRM on steel plate with primer. 100

Figure 7-22. Examples of good adhesion in specimens with unprimed steel plates: (top) $3 / 4$ in. SFRM specimen before testing; (bottom) $1 \frac{1}{2}$ in. SFRM specimen after completion of tests.

Figure 7-23. Adhesive strength of BLAZE-SHIELD DC/F specimens for primed and unprimed steel plates.

Figure 7-24. Examples of cohesive failure in $1 \frac{1}{2}$ in. SFRM specimens. 104

Figure 7-25. Comparative testing: current method versus ASTM E 736 method: (top) locations of two screw cap tests; (bottom) after completion of tests.

Figure 7-26. Cohesive strength normal to surface for BLAZE-SHIELD DC/F specimens for primed and unprimed steel plates.

Figure 7-27. Comparison of adhesive strength with cohesive strength normal to surface $(\mathrm{P}=$ primed steel, NP = bare steel). 108

Figure 7-28. Derivation of acceleration to dislodge SFRM from planar substrate. 110

Figure 7-29. Derivation of acceleration to dislodge SFRM surrounding a round bar. 


\section{LIST OF TABLES}

Table P-1. Federal building and fire safety investigation of the WTC disaster.....................................

Table P-2. Public meetings and briefings of the WTC Investigation. .............................................xxiii

Table 3-1. Area and height limitations for unsprinklered buildings for Noncombustible Construction (Group 1) with a Business occupancy (NYCBC 1968).............................. 12

Table 3-2. Specified fire-resistive materials after April 1970 .................................................... 21

Table 3-3. Information in Sweets Catalogs regarding BLAZE-SHIELD products applied directly to beams, girders, or spandrels (with protected deck) from 1960 to 1972.

Table 3-4. Design thickness of thermal insulation for reapplication to accessible columns in elevator shafts 12 and 13 of WTC 1

Table 3-5. Design thickness of thermal insulation for reapplication to accessible columns and beams in elevator shafts 6 and 7 of WTC1.

Table 4-1. Average fireproofing thickness from six measurements taken in 1994 on each of

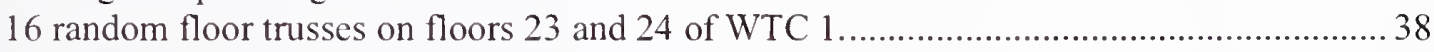

Table 4-2. Summary of Port Authority test reports for upgraded SFRM on floor trusses (30-P). 45

Table 6-1. Summary of SFRMs used in WTC. 63

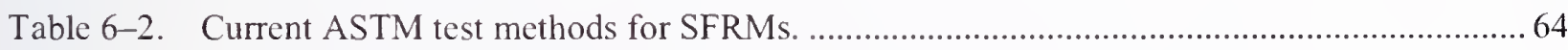

Table 6-3. Properties from tests of SFRMs reported by manufacturers. ............................................. 65

Table 6-4. Measured thermal conductivity as a function of temperature............................................ 68

Table 6-5. Calculated specific heat capacity of the three SFRMs....................................................69

Table 6-6. Mass loss of SFRMs with increasing temperature..................................................... 73

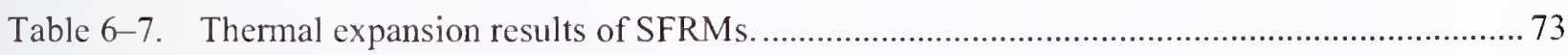

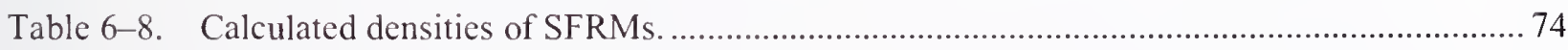

Table 6-9. Thermal conductivities of gypsum materials. ....................................................... 76

Table 6-10. Bulk densities of the four gypsum materials.............................................................. 80

Table 7-1. Density and bond strength of SFRM on floor trusses reported by the Port Authority of New York and New Jersey (30-P). ........................................................................ 85

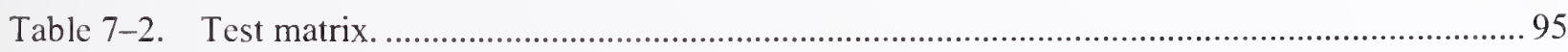

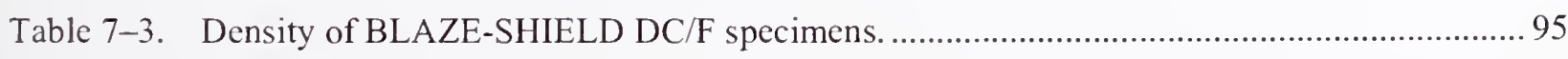

Table 7-4. In-plane cohesive strength for BLAZE-SHIELD DC/F specimens............................... 98 
Table 7-5. Adhesive strength of BLAZE-SHIELD DC/F specimens.............................................. 103

Table 7-6. Summary of adhesive strength results.......................................................................... 104

Table 7-7. Cohesive strength normal to surface for BLAZE-SHIELD DC/F specimens................... 106

Table 7-8. Summary of cohesive strengths normal to surface.................................................... 107

Table 7-9. Comparison of average adhesive strength and average cohesive strength normal to

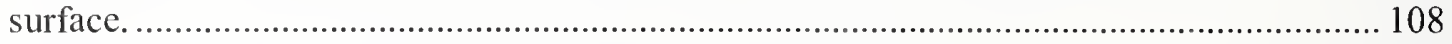

Table 7-10. Acceleration required to dislodge SFRM from planar surface for different values of density, thickness, and bond strength (adhesive or cohesive)......

Table 7-11. Acceleration required to dislodge SFRM from encased bar for different values of bar diameter, SFRM thickness, SFRM in-plane cohesive strength, and strength ratio (alpha). 


\section{LIST OF ACRONYMS AND ABBREVIATIONS}

\section{Acronyms}

\begin{tabular}{|c|c|}
\hline ASTM & ASTM International (formerly American Society for Testing and Matcrials) \\
\hline BFRL & Building and Fire Research Laboratory \\
\hline BOCA & Building Officials and Code Administrators \\
\hline DSC & Differential Scanning Calorimetry \\
\hline DTA & Differential Thermal Analysis \\
\hline ER\&S & Emory Roth \& Sons \\
\hline FDNY & New York City Fire Department \\
\hline IBC & International Building Code \\
\hline $\mathrm{ICBO}$ & International Conference of Building Officials \\
\hline ICC & International Code Council \\
\hline LERA & Leslie E. Robertson Associates \\
\hline NCST & National Construction Safety Team \\
\hline NIST & National Institute of Standards and Technology \\
\hline NYCDOB & New York City Department of Buildings \\
\hline SHCR & Skilling, Helle, Christiansen, \& Robertson \\
\hline SFRM & sprayed fire-resistive material \\
\hline STA & Simultaneous Thermal Analyzer \\
\hline TGA & Thermal Gravimetric Analysis \\
\hline $\mathrm{UBC}$ & Uniform Building Code \\
\hline UL & Underwriters Laboratories, Inc. \\
\hline USM & United States Mineral Products Co. \\
\hline WF & $\begin{array}{l}\text { wide flange (a type of structural steel shape now usually called a W-shape). ASTM A } 6 \\
\text { defines them as "doubly-symmetric, wide-flange shapes with inside flange surfaces that } \\
\text { are substantially parallel." }\end{array}$ \\
\hline WTC & World Trade Center \\
\hline WTC 1 & World Trade Center 1 (North Tower) \\
\hline WTC 2 & World Trade Center 2 (South Tower) \\
\hline TC 7 & World Trade Center 7 \\
\hline
\end{tabular}




\section{Abbreviations}

$a$

acceleration

Btu

British thermal unit

${ }^{\circ} \mathrm{C}$

degrees Celsius

$d_{i}$

steel bar diameter

$d_{0}$

outside diameter of SFRM on round bar

${ }^{\circ} \mathrm{F}$

degrees Fahrenheit

$f_{b}$

cohesive strength normal to surface or adhesive strength

$f_{t}$

in-plane cohesive strength of SFRM

$\mathrm{ft}$

foot

$\mathrm{ft}^{2}$

square foot

$g$

acceleration of gravity

g

gram

$\mathrm{h}$

hour

in.

inch

J

joule

K

kelvin (absolute temperature)

$\mathrm{kg}$

kilogram

$\mathrm{lb}$

pound

$\mathrm{m}$

meter

$\mathrm{m}^{2}$

square meter

$\mathrm{m}^{3}$

cubic meter

$\min$

minute

pcf

pounds per cubic foot

psf

pounds per square foot

psi

pounds per square inch

s

second

thickness of SFRM

$\mathrm{W}$

watt

$\alpha$

ratio of adhesive strength to in-plane cohesive strength of SFRM

$\rho$

mass density of SFRM 


\section{Metric Conversion TABLE}

\section{To convert from}

inch (in.)

degree Fahrenheit $\left({ }^{\circ} \mathrm{F}\right)$

foot (ft)

pcf (pound per cubic foot) $\left(\mathrm{lb} / \mathrm{ft}^{3}\right)$

Btur $\cdot$ in. $/\left(\mathrm{ft}^{2} \cdot \mathrm{h} \cdot{ }^{\circ} \mathrm{F}\right)$

psf (pound-force per square foot) $\left(\mathrm{lbf} / \mathrm{ft}^{2}\right)$

psi (pound-force per square inch) $\left(\mathrm{lbf} / \mathrm{in}^{2}\right)$ to

meter $(\mathrm{m})$

degree Celsius $\left({ }^{\circ} \mathrm{C}\right)$

meter $(\mathrm{m})$

kilogram per cubic meter $\left(\mathrm{kg} / \mathrm{m}^{3}\right)$

$\mathrm{W} /(\mathrm{m} \cdot \mathrm{K})$

kilopascal ( $\mathrm{kPa})$

kilopascal $(\mathrm{kPa})$

\section{Multiply by}

$2.54 \mathrm{E}-02$

$\mathrm{t} /{ }^{\circ} \mathrm{C}=\left(\mathrm{t} /{ }^{\circ} \mathrm{F}-32\right) / 1.8$

$3.048 \mathrm{E}-01$

$1.601846 \mathrm{E}+01$

$1.442279 \mathrm{E}-01$

$4.788026 \mathrm{E}-02$

$6.894757 \mathrm{E}+00$ 
This page intentionally left blank. 


\section{PREFACE}

\section{Genesis of This Investigation}

Immediately following the terrorist attack on the World Trade Center (WTC) on September 1 1, 2001, the Federal Emergency Management Agency (FEMA) and the American Society of Civil Engineers began planning a building performance study of the disaster. The week of October 7 , as soon as the rescue and search efforts ceased. the Building Performance Study Team went to the site and began its assessment. This was to be a brief effort, as the study team consisted of experts who largely volunteered their time away from their other professional commitments. The Building Performance Study Tcam issued its report in May 2002, fulfilling its goal "to determine probable failure mechanisms and to identify areas of future investigation that could lead to practical measures for improving the damage resistance of buildings against such unforeseen events."

On August 21, 2002, with funding from the U.S. Congress through FEMA, the National Institute of Standards and Technology (NIST) announced its building and fire safety investigation of the WTC disaster. On October 1, 2002, the National Construction Safety Team Act (Public Law 107-231), was signed into law. The NIST WTC Investigation was conducted under the authority of the National Construction Safety Team Act.

The goals of the investigation of the WTC disaster were:

- To investigate the building construction, the materials used, and the technical conditions that contributed to the outcome of the WTC disaster.

- To serve as the basis for:

- Improvements in the way buildings are designed, constructed, maintained, and used;

- Improved tools and guidance for industry and safety officials;

- Recommended revisions to current codes, standards, and practices; and

- Improved public safety.

The specific objectives were:

1. Determine why and how WTC 1 and WTC 2 collapsed following the initial impacts of the aircraft and why and how WTC 7 collapsed;

2. Determine why the injuries and fatalities were so high or low depending on location, including all technical aspects of fire protection. occupant behavior, evacuation, and emergency response;

3. Determine what procedures and practices were used in the design, construction, operation, and maintenance of WTC 1,2, and 7; and

4. Identify, as specifically as possible, areas in current building and fire codes, standards, and practices that warrant revision. 
NIST is a nonregulatory agency of the U.S. Department of Commerce's Technology Administration. The purpose of NIST investigations is to improve the safety and structural integrity of buildings in the United States, and the focus is on fact finding. NIST investigative teams are authorized to assess building performance and emergency response and evacuation procedures in the wake of any building failure that has resulted in substantial loss of life or that posed significant potential of substantial loss of life. NIST does not have the statutory authority to make findings of fault nor negligence by individuals or organizations. Further, no part of any report resulting from a NIST investigation into a building failure or from an investigation under the National Construction Safety Team Act may be used in any suit or action for damages arising out of any matter mentioned in such report (15 USC 281a, as amended by Public Law 107-231).

\section{Organization of the Investigation}

The National Construction Safety Team for this Investigation, appointed by the then NIST Director, Dr. Arden L. Bement, Jr., was led by Dr. S. Shyam Sunder. Dr. William L. Grosshandler served as Associate Lead Investigator, Mr. Stephen A. Cauffman served as Program Manager for Administration, and Mr. Harold E. Nelson served on the team as a private sector expert. The Investigation included eight interdependent projects whose leaders comprised the remainder of the team. A detailed description of each of these eight projects is available at http:/wtc.nist.gov. The purpose of each project is summarized in Table $\mathrm{P}-1$, and the key interdependencies among the projects are illustrated in Fig. $\mathrm{P}-1$.

Table P-1. Federal building and fire safety investigation of the WTC disaster.

Technical Area and Project Leader

Analysis of Building and Fire Codes and Practices; Project Leaders: Dr. H. S. Lew and Mr. Richard W. Bukowski

Baseline Structural Performance and Aircraft Impact Damage Analysis; Project Leader: Dr. Fahim H. Sadek

Mechanical and Metallurgical Analysis of Structural Steel; Project Leader: Dr. Frank W. Gayle Investigation of Active Fire Protection Systems; Project Leader: Dr. David D. Evans; Dr. William Grosshandler Reconstruction of Thermal and Tenability Environment; Project Leader: Dr. Richard G. Gann

Structural Fire Response and Collapse Analysis; Project Leaders: Dr. John L. Gross and Dr. Therese P. McAllister

Occupant Behavior, Egress, and Emergency Communications; Project Leader: Mr. Jason D. Averill

Emergency Response Technologies and Guidelines; Project Leader: Mr. J. Randall Lawson

\section{Project Purpose}

Document and analyze the code provisions, procedures, and practices used in the design, construction, operation, and maintenance of the structural, passive fire protection, and emergency access and evacuation systems of WTC 1,2 , and 7 .

Analyze the baseline performance of WTC 1 and WTC 2 under design, service, and abnormal loads, and aircraft impact damage on the structural, fire protection, and egress systems.

Determine and analyze the mechanical and metallurgical properties and quality of steel, weldments, and connections from steel recovered from WTC 1,2 , and 7.

Investigate the performance of the active fire protection systems in WTC 1,2, and 7 and their role in fire control, emergency response, and fate of occupants and responders.

Reconstruct the time-evolving temperature, thermal environment, and smoke movement in WTC 1,2, and 7 for use in evaluating the structural performance of the buildings and behavior and fate of occupants and responders.

Analyze the response of the WTC towers to fires with and without aircraft damage, the response of WTC 7 in fires, the performance of composite steel-trussed floor systems, and determine the most probable structural collapse sequence for WTC 1,2, and 7.

Analyze the behavior and fate of occupants and responders, both those who survived and those who did not, and the performance of the evacuation system.

Document the activities of the emergency responders from the time of the terrorist attacks on WTC 1 and WTC 2 until the collapse of WTC 7, including practices followed and technologies used. 


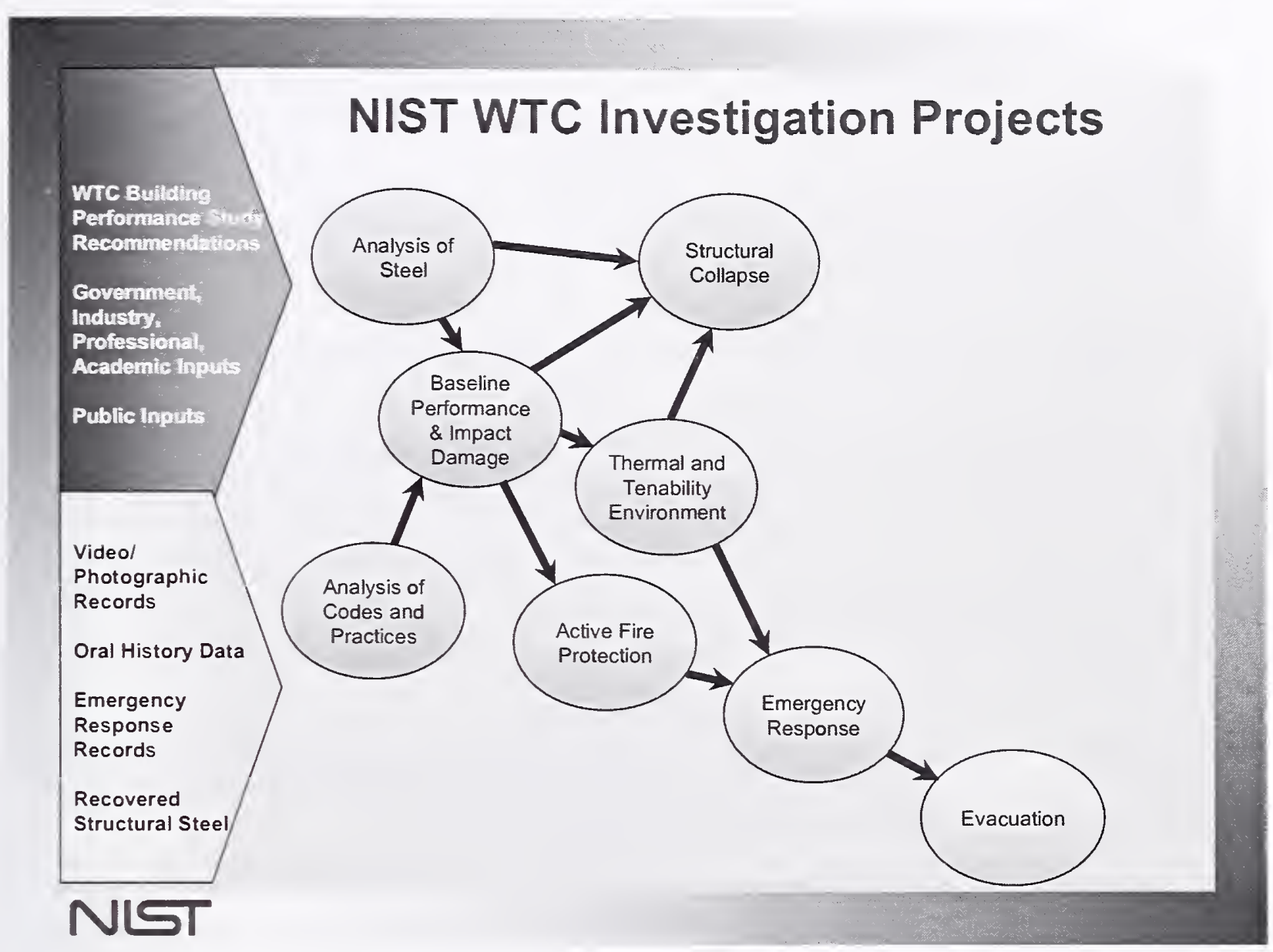

Figure $\mathrm{P}-1$. The eight projects in the federal building and fire safety investigation of the WTC disaster.

\section{National Construction Safety Team Advisory Committee}

The NIST Director also established an advisory committee as mandated under the National Construction Safety Team Act. The initial members of the committee were appointed following a public solicitation. These were:

- Paul Fitzgerald, Executive Vice President (retired) FM Global, National Construction Safety Team Advisory Committee Chair

- John Barsom. President, Barsom Consulting, Ltd.

- John Bryan, Professor Emeritus, University of Maryland

- David Collins, President, The Preview Group, Inc.

- Glenn Corbett. Professor, John Jay College of Criminal Justice

- Philip DiNenno, President, Hughes Associates, Inc. 
- Robert Hanson, Professor Emeritus, University of Michigan

- Charles Thornton, Co-Chairman and Managing Principal, The Thornton-Tomasetti Group, Inc.

- Kathleen Tierney, Director, Natural Hazards Research and Applications Information Center, University of Colorado at Boulder

- Forman Williams, Director, Center for Energy Rcsearch, University of California at San Diego

This National Construction Safety Team Advisory Committee provided technical advice during the Investigation and commentary on drafts of the Investigation reports prior to their public release. NIST has benefited from the work of many people in the preparation of these reports, including the National Construction Safety Team Advisory Committee. The content of the reports and recommendations, however, are solely the responsibility of NIST.

\section{Public Outreach}

During the course of this Investigation, NIST held public briefings and meetings (listed in Table P-2) to solicit input from the public, present preliminary findings, and obtain comments on the direction and progress of the Investigation from the public and the Advisory Committee.

NIST maintained a publicly accessible Web site during this Investigation at http://wtc.nist.gov. The site contained extensive information on the background and progress of the Investigation.

\section{NIST's WTC Public-Private Response Plan}

The collapse of the WTC buildings has led to broad reexamination of how tall buildings are designed, constructed, maintained, and used, especially with regard to major events such as fires, natural disasters, and terrorist attacks. Reflecting the enhanced interest in effecting necessary change, NIST, with support from Congress and the Administration, has put in place a program, the goal of which is to develop and implement the standards, technology, and practices needed for cost-effective improvements to the safety and security of buildings and building occupants, including evacuation, emergency response procedures, and threat mitigation.

The strategy to meet this goal is a three-part NIST-led public-private response program that includes:

- A federal building and fire safety investigation to study the most probable factors that contributed to post-aircraft impact collapse of the WTC towers and the 47-story WTC 7 building, and the associated evacuation and emergency response experience.

- A research and development (R\&D) program to (a) facilitate the implementation of recommendations resulting from the WTC Investigation, and (b) provide the technical basis for cost-effective improvements to national building and fire codes, standards, and practices that enhance the safety of buildings, their occupants, and emergency responders. 
Table P-2. Public meetings and briefings of the WTC Investigation.

\begin{tabular}{|c|c|c|}
\hline Date & Location & Principal Agenda \\
\hline June 24,2002 & New York City, NY & $\begin{array}{l}\text { Public meeting: Public comments on the Draft Plan for the } \\
\text { pending WTC Investigation. }\end{array}$ \\
\hline August 21,2002 & Gaithersburg, MD & Media briefing announcing the formal start of the Investigation. \\
\hline December 9, 2002 & Washington, DC & $\begin{array}{l}\text { Media briefing on release of the Public Update and NIST request } \\
\text { for photographs and videos. }\end{array}$ \\
\hline April 8, 2003 & New York City, NY & $\begin{array}{l}\text { Joint public forum with Columbia University on first-person } \\
\text { interviews. }\end{array}$ \\
\hline April 29-30,2003 & Gaithersburg, MD & $\begin{array}{l}\text { NCST Advisory Committee meeting on plan for and progress on } \\
\text { WTC Investigation with a public comment session. }\end{array}$ \\
\hline May 7,2003 & New York City, NY & Media briefing on release of May 2003 Progress Report. \\
\hline August 26-27, 2003 & Gaithersburg, MD & $\begin{array}{l}\text { NCST Advisory Committee meeting on status of the WTC } \\
\text { investigation with a public comment session. }\end{array}$ \\
\hline September 17,2003 & New York City, NY & $\begin{array}{l}\text { Media and public briefing on initiation of first-person data } \\
\text { collection projects. }\end{array}$ \\
\hline December $2-3,2003$ & Gaithersburg, MD & $\begin{array}{l}\text { NCST Advisory Committee meeting on status and initial results } \\
\text { and release of the Public Update with a public comment session. }\end{array}$ \\
\hline February 12,2004 & New York City, NY & $\begin{array}{l}\text { Public meeting on progress and preliminary findings with public } \\
\text { comments on issues to be considered in formulating final } \\
\text { recommendations. }\end{array}$ \\
\hline June 18,2004 & New York City, NY & Media/public briefing on release of June 2004 Progress Report. \\
\hline June $22-23,2004$ & Gaithersburg, MD & $\begin{array}{l}\text { NCST Advisory Committee meeting on the status of and } \\
\text { preliminary findings from the WTC Investigation with a public } \\
\text { comment session. }\end{array}$ \\
\hline August 24, 2004 & Northbro & $\begin{array}{l}\text { Public viewing of standard fire resistance test of WTC floor } \\
\text { system at Underwriters Laboratories, lnc. }\end{array}$ \\
\hline October 19-20,2004 & Gaithersburg, MD & $\begin{array}{l}\text { NCST Advisory Committee meeting on status and near complete } \\
\text { set of preliminary findings with a public comment session. }\end{array}$ \\
\hline November 22, 2004 & Gaithersburg, MD & $\begin{array}{l}\text { NCST Advisory Committee discussion on draft annual report to } \\
\text { Congress, a public comment session, and a closed session to } \\
\text { discuss pre-draft recommendations for WTC Investigation. }\end{array}$ \\
\hline April 5, 2005 & New York City, NY & $\begin{array}{l}\text { Media and public briefing on release of the probable collapse } \\
\text { sequence for the WTC towers and draft reports for the projects on } \\
\text { codes and practices, evacuation, and emergency response. }\end{array}$ \\
\hline June 23,2005 & New York City, NY & $\begin{array}{l}\text { Media and public briefing on release of all draft reports for the } \\
\text { WTC towers and draft recommendations for public comment. }\end{array}$ \\
\hline $\begin{array}{l}\text { September 12-13, } \\
2005\end{array}$ & Gaithersburg, MD & $\begin{array}{l}\text { NCST Advisory Committee meeting on disposition of public } \\
\text { comments and update to draft reports for the WTC towers. }\end{array}$ \\
\hline $\begin{array}{l}\text { September 13-15, } \\
2005\end{array}$ & Gaithersburg, MD & $\begin{array}{l}\text { WTC Technical Conference for stakeholders and technical } \\
\text { community for dissemination of findings and recommendations } \\
\text { and opportunity for public to make technical comments. }\end{array}$ \\
\hline
\end{tabular}

- A dissemination and technical assistance program (DTAP) to (a) engage leaders of the construction and building community in ensuring timely adoption and widespread use of proposed changes to practices, standards, and codes resulting from the WTC Investigation and the R\&D program, and (b) provide practical guidance and tools to better prepare facility owners, contractors, architects, engineers, emergency responders, and regulatory authorities to respond to future disasters.

The desired outcomes are to make buildings, occupants, and first responders safer in future disastcr events. 


\section{National Construction Safety Team Reports on the WTC Investigation}

A final report on the collapse of the WTC towers is being issued as NIST NCSTAR 1. A companion report on the collapse of WTC 7 is being issued as NIST NCSTAR 1A. The present report is one of a set that provides more detailed documentation of the Investigation findings and the means by which these technical results were achieved. As such, it is part of the archival record of this Investigation. The titles of the full set of Investigation publications are:

NIST (National Institute of Standards and Technology). 2005. Federal Building and Fire Safety Investigation of the World Trade Center Disaster: Final Report on the Collapse of the World Trade Center Towers. NIST NCSTAR 1. Gaithersburg, MD, September.

NIST (National Institute of Standards and Technology). 2006. Federal Building and Fire Safety Investigation of the World Trade Center Disaster: Final Report on the Collapse of World Trade Center 7. NIST NCSTAR 1A. Gaithersburg, MD.

Lew, H. S., R. W. Bukowski, and N. J. Carino. 2005. Federal Building and Fire Safety Investigation of the World Trade Center Disaster: Design, Construction, and Maintenance of Structural and Life Safety Systems. NIST NCSTAR 1-1. National Institute of Standards and Technology. Gaithersburg, MD, September.

Fanella, D. A., A. T. Derecho, and S. K. Ghosh. 2005. Federal Building and Fire Safety Investigation of the World Trade Center Disaster: Design and Construction of Structural Systems. NIST NCSTAR 1-1A. National Institute of Standards and Technology. Gaithersburg, MD, September.

Ghosh, S. K., and X. Liang. 2005. Federal Building and Fire Safety Investigation of the World Trade Center Disaster: Comparison of Building Code Structmral Requirements. NIST NCSTAR 1-1B. National Institute of Standards and Technology. Gaithersburg, MD, September.

Fanella, D. A., A. T. Derecho, and S. K. Ghosh. 2005. Federal Building and Fire Safety Investigation of the World Trade Center Disaster: Maintenance and Modifications to Structural Systems. NIST NCSTAR 1-1C. National Institute of Standards and Technology. Gaithersburg, MD, September.

Grill, R. A., and D. A. Johnson. 2005. Federal Building and Fire Safety Investigation of the World Trade Center Disaster: Fire Protection and Life Safety Provisions Applied to the Design and Construction of World Trade Center 1, 2, and 7 and Post-Construction Provisions Applied after Occupancy. NIST NCSTAR 1-1D. National Institute of Standards and Technology. Gaithersburg, MD, September.

Razza, J. C., and R. A. Grill. 2005. Federal Building and Fire Safety Investigation of the World Trade Center Disaster: Comparison of Codes, Standards, and Practices in Use at the Time of the Design and Construction of World Trade Center 1, 2, and 7. NIST NCSTAR 1-1E. National Institute of Standards and Technology. Gaithersburg, MD, September.

Grill, R. A., D. A. Johnson, and D. A. Fanella. 2005. Federal Building and Fire Safety Investigation of the World Trade Center Disaster: Comparison of the 1968 and Current (2003) New 
York City Brilding Code Provisions. NIST NCSTAR 1-1F. National Institute of Standards and Technology. Gaithersburg, MD, September.

Grill, R. A., and D. A. Johnson. 2005. Federal Brilding and Fire Safety Investigation of the World Trade Center Disaster: Amendments to the Fire Protection and Life Safety Provisions of the New York City Building Code by Local Law's Adopted While World Trade Center 1, 2, and 7 Were in Use. NIST NCSTAR 1-1G. National Institute of Standards and Technology. Gaithersburg, MD, September.

Grill, R. A., and D. A. Johnson. 2005. Federal Building and Fire Safety Investigation of the World Trade Center Disaster: Post-Construction Modifications to Fire Protection and Life Safety Systems of World Trade Center 1 and 2. NIST NCSTAR 1-1H. National Institute of Standards and Technology. Gaithersburg, MD, September.

Grill. R. A., D. A. Johnson, and D. A. Fanella. 2005. Federal Brilding and Fire Safety Investigation of the World Trade Center Disaster: Post-Constriction Modifications to Fire Protection, Life Safety, and Structural Systems of World Trade Center 7. NIST NCSTAR 1-1I. National Institute of Standards and Technology. Gaithersburg, MD, September.

Grill, R. A., and D. A. Johnson. 2005. Federal Bwilding and Fire Safety Investigation of the World Trade Center Disaster: Design, Installation, and Operation of Fuel System for Emergency Power in World Trade Center 7. NIST NCSTAR 1-1 J. National Institute of Standards and Technology. Gaithersburg. MD, September.

Sadek, F. 2005. Federal Brilding and Fire Safety Investigation of the World Trade Center Disaster: Baseline Strnctural Performance and Aircraft Impact Damage Analysis of the World Trade Center Towers. NIST NCSTAR 1-2. National Institute of Standards and Technology. Gaithersburg, MD, September.

Faschan, W. J., and R. B. Garlock. 2005. Federal Building and Fire Safety Investigation of the World Trade Center Disaster: Reference Strmctural Models and Baseline Performance Amalysis of the World Trade Center Towers. NIST NCSTAR 1-2A. National Institute of Standards and Technology. Gaithersburg, MD, September.

Kirkpatrick, S. W., R. T. Bocchieri, F. Sadek, R. A. MacNeill, S. Holmes, B. D. Peterson, R. W. Cilke, C. Navarro. 2005. Federal Building and Fire Safety Investigation of the World Trade Center Disaster: Analysis of Aircraft Impacts into the World Trade Center Towers, NIST NCSTAR 1-2B. National Institute of Standards and Technology. Gaithersburg, MD, September.

Gayle, F. W., R. J. Fields, W. E. Luecke, S. W. Banovic, T. Foecke, C. N. McCowan, T. A. Siewert, and J. D. McColskey. 2005. Federal Building and Fire Safety Investigation of the World Trade Center Disaster: Mechanical and Metallurgical Analysis of Strnctural Steel. NIST NCSTAR 1-3. National Institute of Standards and Technology. Gaithersburg, MD, September.

Luecke, W. E., T. A. Siewert, and F. W. Gayle. 2005. Federal Building and Fire Safety Investigation of the World Trade Center Disaster: Contemporaneons Stritural Steel Specifications. NIST Special Publication 1-3A. National Institute of Standards and Technology. Gaithersburg, MD, September. 
Banovic, S. W. 2005. Federal Building and Fire Safety Imestigation of the World Trade Center Disaster: Steel Inventory and Identification. NIST NCSTAR 1-3B. National Institute of Standards and Technology. Gaithersburg, MD, September.

Banovic, S. W., and T. Foecke. 2005. Federal Building and Fire Safety Imvestigation of the World Trade Center Disaster: Damage and Failure Modes of Structural Steel Components. NIST NCSTAR 1-3C. National Institute of Standards and Technology. Gaithersburg, MD, September.

Luecke, W. E., J. D. McColskey, C. N. McCowan, S. W. Banovic, R. J. Fields, T. Foecke, T. A. Siewert, and F. W. Gayle. 2005. Federal Building and Fire Safety Investigation of the World Trade Center Disaster: Mechanical Properties of Structural Steels. NIST NCSTAR 1-3D. National Institute of Standards and Technology. Gaithersburg, MD, September.

Banovic, S. W., C. N. McCowan, and W. E. Luecke. 2005. Federal Building and Fire Safety Investigation of the World Trade Center Disaster: Physical Properties of Structural Steels. NIST NCSTAR 1-3E. National Institute of Standards and Technology. Gaithersburg, MD, September.

Evans, D. D., R. D. Peacock, E. D. Kuligowski, W. S. Dols, and W. L. Grosshandler. 2005. Federal Building and Fire Safety Investigation of the World Trade Center Disaster: Active Fire Protection Systemis. NIST NCSTAR 1-4. National Institute of Standards and Technology. Gaithersburg, MD, September.

Kuligowski, E. D., D. D. Evans, and R. D. Peacock. 2005. Federal Brilding and Fire Safety Investigation of the World Trade Center Disaster: Post-Construction Fires Prior to September 11, 2001. NIST NCSTAR 1-4A. National Institute of Standards and Technology. Gaithersburg, MD, September.

Hopkins, M., J. Schoenrock, and E. Budnick. 2005. Federal Building and Fire Safety Investigation of the World Trade Center Disaster: Fire Suppression Systems. NIST NCSTAR 1-4B. National Institute of Standards and Technology. Gaithersburg, MD, September.

Keough, R. J., and R. A. Grill. 2005. Federal Building and Fire Safety Investigation of the World Trade Center Disaster: Fire Alarm Systems. NIST NCSTAR 1-4C. National Institute of Standards and Technology. Gaithersburg, MD, September.

Ferreira, M. J., and S. M. Strege. 2005. Federal Building and Fire Safety Investigation of the World Trade Center Disaster: Smoke Management Systems. NIST NCSTAR 1-4D. National Institute of Standards and Technology. Gaithersburg, MD, September.

Gann, R. G., A. Hamins, K. B. McGrattan, G. W. Mulholland, H. E. Nelson, T. J. Ohlemiller, W. M. Pitts, and K. R. Prasad. 2005. Federal Building and Fire Safety Investigation of the World Trade Center Disaster: Reconstruction of the Fires in the World Trade Center Towers. NIST NCSTAR 1-5. National Institute of Standards and Technology. Gaithersburg, MD, September.

Pitts, W. M., K. M. Butler, and V. Junker. 2005. Federal Building and Fire Safety Investigation of the World Trade Center Disaster: Visual Evidence, Damage Estimates, and Timeline Analysis.

NIST NCSTAR 1-5A. National Institute of Standards and Technology. Gaithersburg, MD, September. 
Hamins. A., A. Maranghides, K. B. McGrattan, E. Johnsson, T. J. Ohlemiller, M. Donnelly, J. Yang, G. Mulholland, K. R. Prasad, S. Kukuck, R. Anleitner and T. McAllister. 2005. Federal Building and Fire Safety Investigation of the World Trade Center Disaster: Experiments and Modeling of Strictwral Steel Elements Exposed to Fire. NIST NCSTAR 1-5B. National Institute of Standards and Technology. Gaithersburg, MD, September.

Ohlemiller, T. J., G. W. Mulholland, A. Maranghides. J. J. Filliben, and R. G. Gann. 2005. Federal Building and Fire Safety Investigation of the World Trade Center Disaster: Fire Tests of Single Office Workstations. NIST NCSTAR 1-5C. National Institute of Standards and Technology. Gaithersburg, MD, September.

Gann. R. G., M. A. Riley, J. M. Repp, A. S. Whittaker, A. M. Reinhorn, and P. A. Hough. 2005. Federal Building and Fire Safety Investigation of the World Trade Center Disaster: Reaction of Ceiling Tile Systems to Slocks. NIST NCSTAR 1-5D. National Institute of Standards and Technology. Gaithersburg, MD, September.

Hamins, A., A. Maranghides. K. B. McGrattan, T. J. Ohlemiller, and R. Anleitner. 2005. Federal Building and Fire Safety Investigation of the World Trade Center Disaster: Experiments and Modeling of Multiple Workstations Burning in a Compartment. NIST NCSTAR 1-5E. National Institute of Standards and Technology. Gaithersburg, MD, September.

McGrattan, K. B., C. Bouldin, and G. Forney. 2005. Federal Building and Fire Safety Investigation of the World Trade Center Disaster: Computer Simnlation of the Fires in the World Trade Center Towers. NIST NCSTAR 1-5F. National Institute of Standards and Technology. Gaithersburg, MD, September.

Prasad, K. R., and H. R. Baum. 2005. Federal Building and Fire Safety Investigation of the World Trade Center Disaster: Fire Structure Interface and Thermal Response of the World Trade Center Towers. NIST NCSTAR 1-5G. National Institute of Standards and Technology. Gaithersburg, $\mathrm{MD}$, September.

Gross, J. L., and T. McAllister. 2005. Federal Building and Fire Safety Investigation of the World Trade Center Disaster: Structmral Fire Response and Probable Collapse Sequence of the World Trade Center Towers. NIST NCSTAR 1-6. National Institute of Standards and Technology. Gaithersburg, MD, September.

Carino, N. J.. M. A. Starnes, J. L. Gross, J. C. Yang, S. Kukuck, K. R. Prasad, and R. W. Bukowski. 2005. Federal Building and Fire Safety Investigation of the World Trade Center Disaster: Passive Fire Protection. NIST NCSTAR 1-6A. National Institute of Standards and Technology. Gaithersburg, MD, September.

Gross, J., F. Hervey, M. Izydorek. J. Mammoser, and J. Treadway. 2005. Federal Building and Fire Safety Investigation of the World Trade Center Disaster: Fire Resistance Tests of Floor Truss Systems. NIST NCSTAR 1-6B. National Institute of Standards and Technology. Gaithersburg, MD, September.

Zarghamee, M. S., S. Bolourchi, D. W. Eggers, Ö. O. Erbay, F. W. Kan, Y. Kitane, A. A. Liepins, M. Mudlock, W. I. Naguib, R. P. Ojdrovic, A. T. Sarawit, P. R Barrett, J. L. Gross, and 
T. P. McAllister. 2005. Federal Burlding and Fire Safety Investigation of the World Trade Center Disaster: Component, Connection, and Subsystem Structural Analysis. NIST NCSTAR 1-6C. National Institute of Standards and Technology. Gaithersburg, MD, September.

Zarghamee, M. S., Y. Kitane, Ö. O. Erbay, T. P. McAllister, and J. L. Gross. 2005. Federal Building and Fire Safety Investigation of the World Trade Center Disaster: Global Structural Analysis of the Response of the World Trade Center Towers to Impact Damage and Fire. NIST NCSTAR 1-6D. National Institute of Standards and Technology. Gaithersburg, MD, September.

McAllister, T., R. W. Bukowski, R. G. Gann, J. L. Gross, K. B. McGrattan, H. E. Nelson, L. Phan, W. M. Pitts, K. R. Prasad, F. Sadek. 2006. Federal Building and Fire Safety Investigation of the World Trade Center Disaster: Structural Fire Response and Probable Collapse Sequence of World Trade Center 7. (Provisional). NIST NCSTAR 1-6E. National Institute of Standards and Technology. Gaithersburg, MD.

Gilsanz, R., V. Arbitrio, C. Anders, D. Chlebus, K. Ezzeldin, W. Guo, P. Moloney, A. Montalva, J. Oh, K. Rubenacker. 2006. Federal Building and Fire Safety Investigation of the World Trade Center Disaster: Structural Analysis of the Response of World Trade Center 7 to Debris Danage and Fire. (Provisional). NIST NCSTAR 1-6F. National Institute of Standards and Technology. Gaithersburg, MD.

Kim, W. 2006. Federal Building and Fire Safety Investigation of the World Trade Center Disaster: Analysis of September 11, 2001, Seismogram Data. (Provisional). NIST NCSTAR 1-6G. National Institute of Standards and Technology. Gaithersburg, MD.

Nelson, K. 2006. Federal Building and Fire Safety Investigation of the World Trade Center Disaster: The Con Ed Substation in World Trade Center 7. (Provisional). NIST NCSTAR 1-6H. National Institute of Standards and Technology. Gaithersburg, MD.

Averill, J. D., D. S. Mileti, R. D. Peacock, E. D. Kuligowski, N. Groner, G. Proulx, P. A. Reneke, and H. E. Nelson. 2005. Federal Building and Fire Safety Investigation of the World Trade Center Disaster: Occupant Behavior, Egress, and Emergency Communication. NIST NCSTAR 1-7. National Institute of Standards and Technology. Gaithersburg, MD, September.

Fahy, R., and G. Proulx. 2005. Federal Building and Fire Safety Investigation of the World Trade Center Disaster: Analysis of Published Accounts of the World Trade Center Evacuation. NIST NCSTAR 1-7A. National Institute of Standards and Technology. Gaithersburg, MD, September.

Zmud, J. 2005. Federal Building and Fire Safety Investigation of the World Trade Center Disaster: Technical Doctmentation for Survey Administration. NIST NCSTAR 1-7B. National Institute of Standards and Technology. Gaithersburg, MD, September.

Lawson, J. R., and R. L. Vettori. 2005. Federal Building and Fire Safety Investigation of the World Trade Center Disaster: The Emergency Response Operations. NIST NCSTAR 1-8. National Institute of Standards and Technology. Gaithersburg, MD, September. 


\section{ACKNOWLEDGMENTS}

Mr. Dale Bentz, Research Chemical Engineer in the Inorganic Materials Group of the Building and Fire Research Laboratory at NIST, is acknowledged for his contributions in conducting thermophysical property tests for gypsum materials. 
This page intentionally left blank. 


\section{EXECUTIVE SUMMARY}

The structural steel in the World Trade Center (WTC) towers was protected against the effects of fire with sprayed fire-resistive materials (SFRMs) or rigid fire-rated gypsum panels. The majority of the types of SFRMs used in the WTC towers are packaged as dry ingredients composed of a binder and insulation materials. At the job site, water is added by a pressurized system as the materials are sprayed onto the steel. The water mixes with the cementitious materials and provides "stickiness" that allows the SFRM to adhere weakly to the steel. With time, the cementitious materials harden, and excess water evaporates. When dry, SFRMs provide an insulation barrier to limit excessive temperature rise in the protected steel member during a fire.

The thermal-structural analysis of the WTC towers focused on two objectives: (1) analysis of the undamaged buildings exposed to conventional building fires, and (2) analysis of the buildings damaged by the aircraft impact and exposed to the subsequent fires. To reduce the uncertainties in the calculated thermal histories of various structural elements, the condition of the passive fire protection as it existed on September 11, 2001, was estimated as accurately as possible. In addition, reasonable estimates of the extent of SFRM dislodged by aircraft impact and the resulting debris field had to be made.

To provide context for the information in this report, an overview of concepts used in U.S. building codes for structural fire resistance is presented first. This is followed with a summary of the construction history of the sprayed fire-resistive materials in WTC 1 and WTC 2. To gain an understanding of the effect of SFRM thickness and its variability on the steel temperature during exposure to fire, results are presented of a sensitivity study based on a simple finite-element model. This is followed by a quantitative assessment of in-place thickness and its variability based on available data. The rationale for the thickness of SFRM to be used in the structural fire endurance analyses is presented. The tests conducted to determine the thermal properties of insulation materials similar to those used in the WTC towers are reviewed. The results of mechanical property tests conducted on laboratory specimens are presented, and a simplified approach for estimating the acceleration required to dislodge thermal insulation during impact is discussed.

\section{BUILDING CODE CONCEPTS FOR STRUCTURAL FIRE RESISTANCE}

Fire-induced collapse of buildings is regulated generally through limits on the height and the area per floor as a function of the types and degree of fire resistance of materials used in the structural elements. These material characteristics are categorized as types of construction, and the associated limits are contained in so-called "heights and areas tables," which are a cornerstone of most prescriptive building codes.

The intent of building height limits is to restrict taller buildings to non-combustible structural members, and the greatest fire resistance is assigned to members supporting multiple floors. The primary concern with combustible structural members is that they can become ignited by an exposing fire and can continue to burn (often in concealed spaces) even after the exposing fire has been extinguished, leading to collapse. The intent of increased fire resistance for members supporting multiple floors is directly related to the 
higher risk of property loss in the event of failure of multiple floors. Fire resistance requirements, however, do not take into account the actual number of stories being supported by these elements.

\section{Construction Types}

The main categories of constructions defined in model building codes are Type I (fire resistive), Type II (non-combustible), Type III (ordinary), Type IV (heavy timber), and Type V (combustible). Construction Types I and II include non-combustible exterior and interior bearing walls and columns, where fire resistance ratings are greatest for Type I, and Type II is any (non-combustible) construction not meeting Type I requirements. Within each construction type are several sub-categories determined by the fire resistance ratings of the columns (vertical structural elements that support gravity loads and resist the actions of lateral loads), beams (horizontal structural elements that support predominantly gravity loads), and floor systems. In some model codes these sub-categories are identified by letters following the type (e.g., 1B or 3A) (IBC 2003) or by a set of three numbers that represent the fire resistance required (in hours) of exterior bearing walls; columns, beams, girders, trusses, and arches, supporting bearing walls, columns or loads from more than one floor; and floor construction, respectively (e.g., Type I [3,3,2]).

\section{Fire Resistance of Structural Elements}

Building codes require that structural elements be protected to achieve a specified fire resistance rating, expressed in hours. The fire rating of structural materials and assemblies is generally determined through testing, and in the United States, such testing is frequently conducted in accordance with ASTM Test Methods E 119. The intent is for the building to withstand design loads (including fire) without local structural collapse until occupants can escape and the fire service can complete search and rescue operations.

Building codes generally require the highest fire resistance for columns and elements supporting multiple floors, and somewhat less resistance for columns supporting single floors, for beams, and for floors. The required fire resistance ratings have been reduced in recent years as fire sprinklers have become universal in new high-rise buildings and common in most other commercial buildings. In the past, high-rise buildings generally required a $4 \mathrm{~h}$ rating for columns; this was reduced to $3 \mathrm{~h}$ in recent model codes, and can be as low as $2 \mathrm{~h}$ in current model codes based on the additional mandatory requirement for sprinklers. Some model codes allow a reduction in fire-resistance rating for high-rise buildings that have been retrofitted with sprinklers.

\section{HISTORICAL REVIEW RELATED TO PASSIVE FIRE PROTECTION}

\section{Port Authority Relationships with New York City Department of Buildings and Fire Department}

As an interstate agency, The Port Authority of New York and New Jersey (Port Authority or PANYNJ) was not required to comply with the New York City Building Code or any other building code in the design and construction of the WTC towers. The Port Authority, however, made explicit statements that it would comply with the New York City Code. In a letter dated May 15, 1963, the Port Authority instructed its consulting engineers and architects to comply with the New York City Building Code. In the areas where the Code was not explicit or where technological advances made portions of the Code 
obsolete, it directed that design could be based on acceptable engineering practice. At this time, the 1938 edition of the New York Building Code was in effect and a revised Code was being drafted. In September 29, 1965, the Port Authority instructed its consultants to revise WTC design plans to comply with the second and third drafts of the Code revision. The revised Building Code became effective in December 1968 .

In 1993, the Port Authority and the New York City Department of Buildings entered into a memorandum of understanding to establish procedures to be followed by the Port Authority for any building construction project located in the City's jurisdiction. Among the key points, it was agreed that:

- Each project would be reviewed and examined for compliance with the Code:

- All plans would be prepared, sealed, and reviewed by Nexv York State licensed professional engineers or architects; and,

- The Port Authority engineer or architect approving the plans would be licensed in the State of New York and would not have assisted in the preparation of the plans.

A supplement to this memorandum of understanding was executed in June 1995, which permitted tenants to use New York State licensed architects or engineers, in lieu of a Port Authority review, to certify that construction plans conformed to the Code and that construction was performed in accordance with the plans. In September 1995, the supplement was modified to permit a single licensed consultant to certify the plans and the construction, except if the alteration would change the occupancy group of the space.

In 1993, the Port Authority signed a memorandum of understanding with The Fire Department of the City of New York (FDNY). The agreement restated the Port Authority's policy to implement recommendations after a fire safety inspection of a Port Authority facility by a local fire department. The agreement included the following points:

- The FDNY shall have the right to conduct fire safety inspections at any Port Authority facility in New York City.

- FDNY will issue to the Port Authority a letterhead report of its fire safety inspections for correction of any deficiencies.

- The Port Authority will continue to assure that new or modified fire safety systems comply with "local codes and regulations."

In 1995, the memorandum of understanding with FDNY was amended with respect to additions to or modifications of fire safety systems. The Port Authority agreed to notify the Bureau of Fire Protection prior to installing new systems or modifying existing systems. In addition, plans for these systems were to be prepared by New York State licensed professional engineers or architects.

\section{New York City Building Code Requirements}

Application of the 1968 New York City Building Code provisions affected the assigned building classification and, thus, the required fire rating of the WTC towers and their structural members. The 
WTC towers were classified as Occupancy Group E-Business. The 1968 Code identified two construction groups: Noncombustible Construction (Group 1) and Combustible Construction (Group 2). The WTC towers were classified as Construction Group 1 because their walls, exit ways, shafts, structural members, floors, and roofs were constructed of noncombustible materials. At the time of design and construction, the towers were not sprinklered.

The 1968 New York City Building Code defined five Classes within Construction Group 1. For Business occupancy, each Class required a fire endurance rating as follows:

- Class 1A: 4 hour protected

- Class 1B: 3 hour protected

- Class 1C: 2 hour protected

- Class 1D: 1 hour protected

- Class 1E: unprotected

Construction Classes 1A and 1B permitted buildings of unlimited height. Thus, the WTC towers could have been designed to meet either Class 1A or Class 1B requirements.

\section{Classification of WTC Towers}

It was the practice at the time, and continues to be the practice, for the architect to establish the building classification, fire rating of members and systems, and thermal protection requirements. The review of documents uncovered during the investigation indicated a discrepancy in the classification, and, therefore, in the fire ratings to be used in the design of the towers. Documents issued in the early stages of the design appear to indicate that the towers were classified as Class 1A. With the directive in 1965 to comply with the 1968 New York City Building Code, it appears that the towers were classified ultimately as Class $1 \mathrm{~B}$.

According to Section C26-314.1 of the 1968 New York City Building Code, construction classification $1 \mathrm{~B}$ provided, in part, the following fire protection requirements:

- Columns, girders, trusses, other than roof trusses, and framing supporting more than one floor shall have 3 hour fire endurance;

- Columns, girders, trusses, other than roof trusses, and framing supporting one floor shall have 2 hour fire endurance

- Floor construction including beams shall have 2 hour fire endurance.

- Enclosure of vertical shafts, exits, passage-ways, and hoistways shall have 2 hour fire endurance; and 
- Roof construction including beams, trusses, and framing including arches, domes, shells, cable supported roofs, and roof decks (for buildings over one story in height) shall have 2 hour fire endurance.

Thus, the columns were required to have a 3 hour fire endurance rating, and the floor system was required to a have a 2 hour rating when tested in accordance with ASTM E 119.

\section{Response to Local Law 5/1973}

In 1973, New York City Local Law No. 5 amended the New York City Building Code (effective January 18, 1973). Local Law No. 5 required, in part, the retrofit of existing unsprinklered office buildings $100 \mathrm{ft}$ or higher. The New York City Department of Buildings permitted either:

- Subdividing the floor area into compartments of specified square footage by fire separations ( $1 \mathrm{~h}$ or $2 \mathrm{~h}$ fire rated depending on the size of the compartment), or

- Providing sprinkler protection.

A code compliance evaluation conducted in 1997 indicated that that all tenant floors in the two towers had been retrofitted with sprinklers (sprinklered) with the exception of four floors in WTC 1. In a 1999 update by the Port Authority it was noted that all tenant floors had been sprinklered and work was underway to complete sprinklering of the sky lobbies. In 2000, a property condition assessment report stated that the WTC towers were classified as "Class IB - noncombustible, fire-protected, retrofitted with sprinklers in accordance with New York City Local Law 5/1973."

\section{Selection of Fire-Resistive Materials}

Classification of a building leads to its overall fire endurance rating and ratings of the various structural components. The New York City Building Code, however, does not prescribe how the required fire endurance rating is to be achieved. The Port Authority chose to protect the main structural components such as columns, spandrel beams, and floor trusses with sprayed fire-resistive material. This thermal protection technique was an established method for protecting columns, beams, and walls. In the 1960s, however, composite steel joist-supported floor systems were usually protected using "lath and plaster" enclosures or fire-rated ceiling tiles.

Since application of sprayed fire-resistive materials to floor trusses was an innovative fire protection method, the Port Authority arranged for demonstrations to establish its feasibility for the World Trade Center. The demonstrations were considered to be successful and in November 1968, the Port Authority awarded the contract for "spray fireproofing" of the interior portions (floor system and core) of the WTC towers. The fire protection of the exterior columns was included in the contract for the exterior aluminum cladding.

Several materials were considered for the sprayed thermal insulation. The exterior columns required insulation not only for fire protection but also to control column temperatures under service conditions. Alcoa recommended for the exterior columns the use of a sprayed material produced by U.S. Mineral Products, Co. known as BLAZE-SHIELD Type D. The same material was eventually selected for the floor trusses and core beams and columns. This product, however, contained asbestos fibers. On April 
13, 1970, New York City issued restrictions on the application of sprayed thermal insulation containing asbestos. The use of BLAZE-SHIELD Type D was discontinued in 1970 at the 38th floor of WTC 1. The asbestos-containing material was subsequently encapsulated with a sprayed material that provided a hard coating. A green dye was added to the encapsulating material so that the asbestos containing SFRM could be identified. Thermal protection of the remaining floors of WTC 1 and all of WTC 2 was carried out using BLAZE-SHIELD Type DC/F, a product that contained mineral wool (glassy fibers) in place of the crystalline asbestos fibers. On the basis of tests, it was reported that the thermal properties of BLAZE-SHIELD Type DC/F were equal to or "slightly better" than those of BLAZE-SHIELD Type D.

\section{Specified Thickness of Fire-Resistive Material}

The thickness of fire-resistive material necessary to achieve the required fire endurance was assessed in 1965, more than three years before the award of the thermal protection contract. At that time, the Architect of Record recommended 1 in. of thermal protection for the top and bottom chords of the floor trusses and $2 \mathrm{in}$. for other members of the trusses. WTC project specifications for sprayed fire protection do not provide required material thickness or hourly ratings. In October 1969, the manager of project planning for the WTC provided the following instructions to the contractor applying the sprayed fire protection:

"...Tower ' $A$ ' columns that are less than 14WF228 will require $23 / 16$ " thick of 'Cafco Glaze [sic]-Shield 'Type D' spray-on fireproofing. All Tower columns equal to or greater than 14WF228 will require $13 / 16^{\prime \prime}$ of fireproofing...

All Tower beams, spandrels and bar joists requiring spray-on fireproofing are to have a $1 / 2$ " covering of 'Cafco.'

The above requirements must be adhered to in order to maintain the Class 1-A Fire Rating of the New York City Building Code."

NIST's review of available documents has not uncovered the reasons for selecting BLAZE-SHIELD or the technical basis for specifying $1 / 2$ in. thickness of insulation for the floor trusses. The last sentence in the above excerpt indicates that in October 1969, the towers were considered as Class 1A construction.

In February 1975, a fire occurred in WTC 1, spreading from the 9th to the 19th floor. After the fire, the Port Authority contracted Skilling, Helle, Christiansen, Robertson (SHCR), the Structural Engineer of Record for the design of the WTC towers, to assess the resulting structural damage and to report, in general, on the fire resistivity of the floor system. In its report dated April 1, 1975, SHCR communicated to the Port Authority that the fire did not cause structural damage, but it caused buckling of some top chord members of main trusses, buckling of bridging trusses, and distortion of deck support angles. The report provided valuable information on the history of the passive fire protection of the towers.

The 1975 post-fire report by SCHR stated further that thermal protection of the top chords of the floor trusses was not necessary, except for the corners of the buildings where the floor acted as a two-way system in bending. Additionally, it was stated that protection of the bridging trusses was not required because the bridging trusses were "not required as a part of the structural system." 
In February 2003, NIST asked the Port Authority a series of questions related to the sprayed thermal protection for the floor system. The Port Authority replied in March that the top chords of the main trusses and the bridging trusses were protected.

\section{Upgrading SFRM on Floor Trusses}

In 1995. the Port Authority performed a study to establish requirements for retrofit of sprayed insulation to the floor trusses during major alterations (new construction) when tenants vacated spaces in the towers. The study estimated the thermal protection requirements based on "the fireproofing requirements" for Design No. G805 contained in the Fire Resistance Directory published by Underwriters Laboratories. The study concluded that "a two hour fire rating for the steel floor joist trusses can be achievcd by applying a $1 \frac{1}{2}$ inch thickness of spray-on mineral fiber fire protection material directly to the steel truss chords and webs." In the years between 1995 and 2001, thermal protection was upgraded in a number of the floors affected by the fires on September 11, 2001. Specifically, in WTC 1, floors 92 through 100 and 102 were upgraded: and in WTC 2, floors 77, 78, 88, 89, 92, 96, and 97 were upgraded.

In 1999, the Port Authority established "guidelines regarding fireproofing repairs, replacemcnt, and upgrades" for the towers. The guidelines for in tenant spaces may be summarized as follows:

- For full floors undergoing new construction or renovation, the floor trusses should be protccted with $1 \frac{1}{2}$ in. of sprayed mineral fiber fire-resistive material. Retrofit of thermal protection requires removal of existing material and controlled inspection.

- For "tenant spaces less than a full floor undergoing either new construction or renovation," the floor trusses "need only meet the original construction standard. Fireproofing shall be inspected and patched as required to the greater of $3 / 4$ in. or to match existing" if it has already been upgraded to $1 \frac{1}{2}$ in.

In July 2000, an engineering consultant, commissioned by the Port Authority to conduct a fireengineering assessment of the fire protection of the floor trusses, issued a report on the requirements of the fire resistance of the floor system of the towers. This report stated that BLAZE-SHIELD DC/F was used on the majority of the floor trusses. Based on calculations and risk assessment, the consultant concluded that:

- "The structural design has sufficient inherent fire performance to ensure that the fire condition is never the critical condition with respect to loading allowances.

- A single coat application is possible.

- Significant savings are possible.

- The target reduction of fiber content and increased long term durability can be achieved.

- Alternative materials should be considered."

As quoted, the report states that significant savings were possible by reducing the fiber content and considering alternative materials. The report suggested that the thickness of the SFRM could be reduced to $1 / 2$ in. if the material properties at ambient temperature are applicable at higher temperatures. The 
report recognized the lack of available temperature-dependent material data for BLAZE-SHIELD Type $\mathrm{DC} / \mathrm{F}$. Thus, considering the uncertainties in the material properties and having the understanding of material degradation with temperature and time, it was recommended that $1.3 \mathrm{in}$. of fire-resistive material be used for the floor trusses.

Later, in December 2000, the final draft of a report on Property Condition Assessment of World Trade Center Portfolio stated that, based on existing conditions "The rating of the structural fireproofing in the Towers and subgrade has been judged to be an adequate 1 hour rating considering the fact that all Tower floors are now sprinklered." The report also noted the ongoing Port Authority program to upgrade the fire-resistive material thickness to $1 \frac{1}{2}$ in. in order to achieve a 2 hour fire rating.

\section{Need for Fire Endurance Tests}

The fire protection of a truss-supported floor system by directly applying sprayed fire-resistive material to the trusses was innovative and not consistent with prevailing practice at the time the WTC towers were designed and constructed. While the benefits of conducting fire endurance tests were realized by individuals involved in the 1967 demonstrations of the application of SFRM, apparently no tests were conducted on the floor system used in the WTC towers. The Architect of Record and the Structural Engineer of Record stated that the fire rating of the floor system of the WTC towers could not be determined without testing. Communication from the Port Authority in 2003 confirms that there is no record of fire endurance testing of assemblies representing the thermally protected floor system.

\section{Maintenance of SFRM in Elevator Shafts}

Throughout the life of the WTC towers, the structural members that required the largest amount of inspection and maintenance within the core were the exposed columns and beams within the elevator shafts. These columns and beams were the only accessible fire-protected elements in the buildings. Adhesion failures were common, likely because of the exposed conditions of the columns and the inherently low strength of the SFRM.

Inspections of the shafts and accessible columns were reported as early as 1971. Problems were noted in the form of fallen insulation or with the over-spray material used to provide a harder surface. In 1993, the Port Authority commissioned Leslie E. Robertson Associates to carry out a continuing program to appraise the condition of the accessible columns located in the cores of the towers. The columns were inspected visually for signs of rusting, cracking, bowing, and loss of thermal insulation. During the first inspection, carried out in 1993, particular shafts were chosen based on the quantity and types of accessible columns, and the convenience to the Port Authority. Subsequent inspections involved sampling of the structural components and assemblies, which were more important to the structural integrity of the towers, and at locations with a relatively higher potential for defects and problems. The inspection report stated that the accessible columns in selected elevator shafts in WTC 1 and WTC 2 were "generally in good condition, no structural deficiencies such as cracking or bowing were found, the most common irregularities observed were missing fireproofing and light surface rusting of the exposed steel." Based on the inspections, LERA recommended "that remedial action to be taken where spray fireproofing is damaged, deteriorated or missing and where there is corrosion of the column base due to water leaks at elevator pits." Earlier in 1992, LERA performed calculations to determine the thickness of replacement thermal insulation for selected beams and columns within elevator shafts. 


\section{AS-APPLIED THICKNESS OF SFRM}

\section{Measurements from WTC 1 Floors 23 and 24}

In its search of documents, NIST found no information related to measurements of the thickness of thermal insulation taken during original construction. Reviewed documents, however, indicate that thickness appears to have been checked during construction. Recorded information on the in-place condition of the sprayed thermal insulation for the floor system first appeared in 1990 in the form of "Sample Area Data Sheets," which provided qualitative comments on the state of the in-place SFRM. Information regarding quantitative inspection of existing fire-resistive material appeared in documentation from 1994. That year, the Port Authority performed a series of thickness measurements of the existing SFRM on floors 23 and 24 of WTC 1. Six measurements were taken from "both flanges and web" of each of 16 randomly chosen trusses on each floor. Measured average thickness varied between $0.52 \mathrm{in}$. and $1.17 \mathrm{in}$. For the 32 measurements ( 16 on each floor), the overall average was $0.74 \mathrm{in}$., and the standard deviation of these averages was 0.16 in. Four of the 32 floor trusses had average thicknesses between $0.52 \mathrm{in}$. and $0.56 \mathrm{in}$. These measurements suggest that the minimum average thickness exceeded $1 / 2$ in. Analysis of the reported mean thicknesses indicated that a lognormal distribution gave a better representation of the distribution rather than did a normal distribution.

\section{Analysis of Photographs}

Additional SFRM thickness data were developed by evaluating photographs of floor trusses taken during inspections. Two groups of photographs were used. The first group included images of floor trusses from WTC 1 (floors 22, 23, and 27). These photographs were taken in the mid-1990s and illustrated conditions before the upgrade carried out by the Port Authority. Thus, SFRM thickness on the photographed trusses would be expected be at least $1 / 2$ in. The second group of photographs, taken in 1998 , illustrated conditions after the upgrade program that was initiated in 1995 . The photographs were of trusses for floor 31 and below in WTC 1. Selection of the photographs to be used to estimate thickness of SFRM was based on clarity of SFRM edges and the presence of a feature of known dimensions to provide a reference measurement.

For floors that had not been upgraded, it was observed that the estimated thickness of SFRM on the webs (inclined bars) of the main trusses tended to be greater than that on either the diagonal struts or on the webs of the bridging trusses. Hence, estimates of SFRM thickness for non-upgraded floors were divided into three groups:

- Webs (inclined bars) of main trusses,

- Webs (inclined bars) of bridging trusses, and

- Diagonal strut at the exterior wall end of the truss.

It was not possible to estimate the thickness of the SFRM on any truss element except the round web bars. Consequently, for the upgraded floors in WTC 1 that were included in the second group of photographs, only estimates of the thickness on the web bars of the main trusses were made. The average, standard 
deviation, and coefficient of variation were computed for the total number of measurements in each of these groups. The results are summarized as follows:

- Main trusses before upgrade (85 measurements): Average thickness 0.6 in., standard deviation $=0.3$ in., and coefficient of variation $=0.5$.

- Bridging trusses before upgrade (52 measurements): Average thickness 0.4 in., standard deviation $=0.25 \mathrm{in}$., and coefficient of variation $=0.6$.

- Diagonal struts before upgrade (26 measurements): Average thickness 0.4 in., standard deviation $=0.2$ in., and coefficient of variation $=0.5$.

- Main trusses after upgrade (52 measurements): Average thickness 1.7 in., standard deviation $=0.4$ in., and coefficient of variation $=0.2$.

\section{Port Authority Data on Upgraded SFRM on Trusses}

In the $1990 \mathrm{~s}$, the thermal protection for some floor trusses was upgraded to a specified thickness of $1 \frac{1}{2} \mathrm{in}$. as tenants vacated their spaces. According to the Port Authority, 18 floors of WTC 1 and 13 floors of WTC 2 were upgraded. The Port Authority also stated that: "The entire impact zone for Tower 1 (92-99) was upgraded with $1 \frac{1}{2}$ " spray-on fireproofing. Only the $78^{\text {th }}$ floor was upgraded with the $1 \frac{1}{2}$ " spray-on fireproofing within the impact zone in Tower 2 (78-84)." The Port Authority provided Construction Audit Reports that included the density, average thickness, and strength characteristics of the upgraded SFRM (BLAZE-SHIELD II) as of 2000. In 2004, the Port Authority provided NIST reports of the individual measurements for many of the average thicknesses recorded in the Construction Audit Reports. These individual measurements permitted analysis of the variation of thickness at a cross section of a truss member and the variation in average thickness from truss to truss. A total of 18 data sets for WTC 1 (including floors 93, 95, 98, 99, and 100) and 14 data sets for WTC 2 (including floors 77, 78, 88, 89, and 92) were analyzed.

Data analysis indicated that the thickness measurements from the two towers represented similar distributions, and so the data were combined. It was also found that the distribution of thickness values could be approximated as lognormal distribution.

The overall average thickness determined from the 256 individual measurements was found to be $2.5 \mathrm{in}$. with a standard deviation of 0.6 in. Thus, the average thickness on the upgraded upper floors appears to be greater than that estimated from photographs taken on upgraded lower floors.

The overall standard deviation of 0.6 in. includes two contributions: (1) the variation of thickness at a cross section (within-truss variability), and (2) the variation of average thickness between trusses (between-truss variability). From analysis of variance, it was found that the within-truss standard deviation was $0.4 \mathrm{in}$, and the between-truss standard deviation was also $0.4 \mathrm{in}$. The within-truss standard deviation of $0.4 \mathrm{in}$. is similar to the standard deviation of the estimated individual thicknesses obtained from analysis of the photographs of upgraded main trusses. 


\section{Column SFRM Thickness}

NIST requested that the Port Authority provide available information on the actual thickness of fireresistive material on the exterior and interior columns of the WTC towers. The Port Authority replied that, due to inaccessibility of exterior columns and core columns, there were no records of SFRM thickness measurements for these elements. The only available measurements were for thickness of SFRM that was reapplied to accessible beams and columns within elevator shafts.

The most complete data set included measurements on beams and columns taken within shaft 10/11 in WTC 1. These measurements were taken in April 1999 and included measurements from floor 1 to floor 45 . The thicknesses were recorded to the nearest $1 / 8 \mathrm{in}$, with a few thicknesses recorded to the nearest $1 / 16$ in. The columns included 10 to 18 replicate measurements, and the beams included 11 to 16 replicate measurements.

The average thickness for the columns was found to be $0.82 \mathrm{in}$., with a standard deviation of 0.20 , resulting in a coefficient of variation is 0.24 . The average thickness for the beams was $0.97 \mathrm{in}$, with a standard deviation is $0.21 \mathrm{in}$., for a coefficient of variation is 0.21 . The information from the Port Authority indicated that the minimum required thicknesses for the SFRM (Monokote Type Z-106) that was reapplied to the columns and beams were $1 / 2$ in. and $3 / 4$ in., respectively.

The data described above may not have a direct bearing on the outcome of the investigation because they deal with lower stories. They do, however, provide some useful information on the variability of SFRM applied to beams and columns. As might be expected, the variation in thickness of SFRM for the beams and columns is lower than the variation computed for the floor trusses. The flat surfaces of the beams and columns result in more uniform application of the sprayed fire-resistive material than for the slender truss members.

\section{EFFECT OF SFRM GEOMETRY ON THERMAL RESPONSE}

As would be expected, and as confirmed by analyses of available data, the thickness of thermal insulation can have high variability. The effects of thickness variation on thermal response of a member are not well known. A sensitivity study using the finite element analysis to simulate heat transfer was conducted to investigate the sensitivity of steel temperature rise to the variability in SFRM thickness.

\section{Effects of Thickness Variability and Gaps in SFRM}

A finite element model for thermal analysis was developed for a plate protected on both faces with SFRM of variable thickness. A random number generator was used to assign a lognormally distributed random thickness of insulation along the length of the plate, and the plate was subjected to a thermal flux representative of a $1,100{ }^{\circ} \mathrm{C}$ fire. A parametric study was conducted with average thickness of fireresistive material varying from 0 in. to $2 \mathrm{in}$. in increments of $1 / 4 \mathrm{in}$. and a standard deviation varying from 0 to $1 \mathrm{in}$. Steel temperatures at five locations in the plate were recorded at $30 \mathrm{~min}, 60 \mathrm{~min}, 90 \mathrm{~min}$, and $120 \mathrm{~min}$ of exposure to the thermal flux.

The simulations showed that when the SFRM thickness is variable, the isotherms in the steel follow the shape of the SFRM surface contour. Thus, the temperature history at any point in the steel depends on the 
local thickness of the insulation. If the time to reach a specified high temperature is used as an indicator of protection efficiency, it was shown that an increase in thickness variability reduced the time to reach the critical temperature. Conversely, for a given time to reach a critical temperature, the required average thickness of thermal insulation increased with increasing variability in thickness of SFRM.

In addition to the effect of variation in thickness, the effect of missing SFRM over a portion of a member was studied. As cxpected, the bare steel at the missing insulation reached the gas temperature quickly, but more importantly the "gap" in the insulation led to transmission of heat into the interior steel.

The combined effects of variation in insulation thickness and extent of missing material were examined by a factorial study with the following factors:

- Average thickness of insulation varying from 0 in. to 2.0 in. in $1 / 4$ in. increments;

- Standard deviation of insulation thickness of $0 \mathrm{in.,} 0.25 \mathrm{in.,} 0.5 \mathrm{in} ., 0.75 \mathrm{in} .$, and $1.0 \mathrm{in}$. ; and

- Length of missing insulation varying from 0 in. to 30 in., in 6 in. increments.

The results were summarized by a series of temperature-time plots representing the response for different combinations of the three factors. As expected, increasing the variability of insulation thickness or gap length reduced the time to reach a given critical temperature. Because there was not sufficient information to determine the frequency of occurrence of these gaps or their typical locations, gaps in insulation were not considered in the thermal modeling.

\section{Thermally Equivalent Thickness of SFRM}

The sensitivity study indicated that increased variation in thickness reduced the "effective thickness" of the SFRM. It would be impractical to attempt to account for the variation in SFRM thickness in the thermal modeling of the WTC towers by introducing variable thickness insulation material in the finiteelement models. As an alternative, a "thermally equivalent uniform thickness" was determined that would result in the same thermo-mechanical response of a member as the variable thickness thermal protection. In the analyses, an insulated 1 in. diameter by $60 \mathrm{in}$. long steel bar was subjected to the heat flux arising from a $1,100^{\circ} \mathrm{C}$ fire. The thermal history along the length of the bar was calculated, and that history was used to calculate the length change of the unrestrained bar under a tensile stress of 12,500 psi. The bar was assumed to be similar to the steel used in the WTC floor trusses, and the temperature dependence of the coefficient of thermal expansion and the modulus of elasticity were based on NIST measurements.

The average SFRM thickness and variability in thickness used in the models were based on the measurements for the web bars of the main trusses with both the original insulation and upgraded insulation. The following values were investigated:

- Original conditions: Average thickness $=0.75$ in., standard deviation $=0.3$ in., lognormal distribution.

- Upgraded conditions: Average thickness $=2.5$ in., standard deviation $=0.6$ in., lognormal distribution. 
The variation of thermal insulation thickness along the length of the bar was established by using a pseudo random number generator to select values from a lognormal distribution with central value and dispersion consistent with the above average values and standard deviation. Three sets of random data were generated for each condition.

When the randomly selected thicknesses of each element were applied to the bar, it resulted in abrupt changes in insulation thickness along the length of the bar. This resulted in a "rough" surface texture that was not representative of actual conditions. As an alternative, five-point averaging was used to reduce the roughness of the insulation profile and produce a profile that was consistent with photographic evidence. Care was taken to ensure the "smoothed" profiles maintained the required dispersion.

The calculated thermal histories of the bar elements were used to calculate the unrestrained length changes of the bar due to thermal expansion and the applied stress. For comparison, elongations of the bar with different uniform thicknesses of thermal insulation were calculated. The "thermally equivalent thickness" was taken as the uniform thickness that resulted in approximately the same elongation of the bar as produced with the variable thickness insulation.

On the basis of these analyses, it was concluded that SFRM with an average thickness of $0.75 \mathrm{in}$. and a standard deviation of $0.3 \mathrm{in}$. provides protection equivalent to $0.6 \mathrm{in}$. of uniform thickness. Similarly, an average SFRM thickness of $2.5 \mathrm{in}$. with a standard deviation of $0.6 \mathrm{in}$. is equivalent to $2.2 \mathrm{in}$. of uniform thickness.

\section{Recommended Thickness of SFRM for Thermal Analyses}

Analyses of available data on SFRM thickness in the WTC towers and thermal modeling revealed the following:

- From measurements of SFRM thickness, the average values exceeded the specified thickness.

- SFRM thickness was variable, and the distribution of thickness in the floor trusses appeared to be described best by a lognormal distribution.

- The standard deviation of SFRM thickness on the trusses varied between about $0.3 \mathrm{in}$. and 0.6 in.

- The standard deviation of SFRM on columns and beams from the core tended to be lower, with a value of $0.2 \mathrm{in}$. for the available data.

- No information was available on the SFRM thickness on the exterior columns and spandrel beams.

- Variation in thickness reduces the effectiveness of SFRM, and the equivalent uniform thickness was less than the average thickness.

Based on findings stated above, the following uniform thicknesses for the undamaged SFRM were determined for use in calculating thermal response of the WTC towers under various fire scenarios:

- Original SFRM thickness on floor trusses: 0.6 in. 
- Upgraded SFRM thickness on floor trusses: 2.2 in.

- Thermal protection on other elements: the specified thickness.

The choice of specified thickness for those members lacking data is justified by the following offsetting factors: (1) measured average thicknesses exceed specified values, and (2) variation in thickness reduces the effectiveness of the SFRM.

\section{THERMOPHYSICAL PROPERTIES}

To provide thermophysical property data for modeling the fire-structure interaction of the towers, the thermal conductivity, specific heat capacity, and density of the SFRMs used in the WTC towers were determined as a function of temperature up to $1,200^{\circ} \mathrm{C}\left(2,190^{\circ} \mathrm{F}\right)$. Since there are no ASTM test methods for characterizing the thermophysical properties of SFRMs as a function of temperature, ASTM test methods developed for other materials were used. Samples were prepared by the manufacturers of the fire-resistive materials, which included BLAZE-SHIELD DC/F, BLAZE-SHIELD II, and Monokote MK-5. Since Monokote MK-5 is no longer on the market, the samples were manufactured specially for this study according to the original MK-5 formulation. Testing services were provided under contract by a commercial testing agency.

\section{Thermal Conductivity}

The thermal conductivity measurements were performed according to ASTM C 1113, Standard Test Method for Thermal Conductivity of Refractories by Hot Wire (Platinum Resistance Thermometer Technique). The room temperature values were in general agreement with the manufacturer's published values for BLAZE-SHIELD DC/F and BLAZE-SHIELD II. No published values were available for Monokote MK-5. The thermal conductivities increased with temperature.

\section{Specific Heat Capacity}

Specific heat capacity determinations wcre made with the same instrument as for thermal conductivity with a slight modification. A thermocouple was added to the system, which permitted determination of the thermal diffusivity of the material. Knowing the thermal conductivity, the thermal diffusivity, and the density obtained from other tests, the specific heat capacity was calculated. The inhercntly indirect nature of the technique used precluded the direct measurements of specific heat capacity peaks associated with chemical reactions.

To examine the chemical reactions associated with heating of SFRMs, samples were sent to another laboratory under contract to perform differential scanning calorimetry (DSC) measurements in accordance with ASTM E 1269, Standard Test Method for Determining Specific Heat Capacity by Differential Scanning Calorimetry. Differential thermal analysis (DTA) is a "fingerprinting" technique that provides information on the chemical reactions, phase transformations, and structural changes that occur in a specimen during a heating or a cooling cycle. These tests revealed large peaks in the specific heat capacities in the range of $125^{\circ} \mathrm{C}$ to $140^{\circ} \mathrm{C}$. 


\section{Density}

Bulk densities of the SFRMs were not measured directly (except at room temperature) but were calculated from thermal gravimetric analysis (TGA) and thermal expansion measurements. The TGA tests to measure mass loss were performed according to ASTM E 1131, Standard Test Method for Compositional Analysis by Thermogravimetry. Thermal expansion measurements were performed according to ASTM E 228, Standard Test Method for Linear Thermal Expansion of Solid Materials. Since the materials were not isotropic, separate measurements were performed in the plane of the SFRM sample and perpendicular to the free surface of the sample. From the thermal expansion measurements, the change in volume for each material was calculated at each temperature. The density values were calculated from the results of the TGA and thermal expansion. The room temperature densities were $15.7 \mathrm{pcf}$ for BLAZE-SHIELD DC/F, $20.8 \mathrm{pcf}$ for BLAZE-SHIELD II, and $19.4 \mathrm{pcf}$ for Monokote MK-5.

\section{Thermophysical Properties of Gypsum Panels}

Thermophysical properties of four representative types of commercially available gypsum panels were examined. The materials were:

1. $5 / 8$ in. thick gypsum panel $\mathrm{A}$,

2. $1 / 2$ in. thick gypsum panel,

3. $5 / 8$ in. thick gypsum panel $\mathrm{B}$, and

4. 1 in. thick gypsum liner panel.

Thermal conductivity was measured using the heated probe technique described in ASTM D 5334, Standard Test Method for Determination of Thermal Conductivity of Soil and Soft Rock by Thermal Needle Probe Procedure. In general, the thermal conductivity initially decreased as the temperature increased to $200{ }^{\circ} \mathrm{C}$ and then increased with increasing temperature above $300{ }^{\circ} \mathrm{C}$.

Specific heat capacities of the cores of the four gypsum panel samples were measured using a differential scanning calorimeter according to ASTM E 1269, Standard Test Method for Determining Specific Heat Capacity by Differential Scanning Calorimetry. The four panels had similar specific heat capacities as a function of temperature, with a high peak at about $150^{\circ} \mathrm{C}$ and a smaller peak at about $250^{\circ} \mathrm{C}$.

Densities were calculated from the thermogravimetric analysis (TGA) and linear thermal expansion measurements. All four materials show the same trend as a function of temperature. The variation of density with temperature is associated with the mass loss and the change in volume of the gypsum material.

\section{ADHESIVE AND COHESIVE STRENGTH}

To analyze the thermo-structural response of the WTC towers during the fires after the aircraft impacts, it was necessary to estimate the extent of dislodged thermal insulation on structural members. 
Dislodgement could occur as a result of direct impact by debris or due to inertial forces as a result of the aircraft impact. Photographic evidence suggested that thermal insulation was dislodged from portions of exterior columns of the towers that were likely not subjected to direct impact by debris. This study focused on dislodgement due to inertial forces.

The magnitude of the inertial forces depends on the density and thickness of the thermal insulation. The insulation would dislodge if the stresses resulting from inertial forces exceed the strength of the insulation. Therefore, the focus of the NIST study was to determine tensile strength characteristics of the thermal insulation. In addition, a simplified approach was developed for estimating the magnitude of accelerations required to dislodge thermal insulation.

\section{In-place Density and Bond Strength}

The Port Authority provided data on in-place density and bond strength characteristics of the thermal insulation (BLAZE-SHIELD II) applied to the floor trusses during tenant alterations. According to the manufacturer, BLAZE-SHIELD II is about 20 percent denser and has about 20 percent greater adhesive/cohesive strength than BLAZE-SHIELD DC/F. The Port Authority test reports indicate that bond strength was determined in accordance with ASTM E 736, Standard Test Method for Cohesion/Adhesion of Sprayed Fire Resistance Materials Applied to Structural Members. The method involves gluing a jar screw cap to the surface of the thermal insulation, and after the glue has cured, the cap is pulled. The force required to pull off the cap is divided by the area of the cap and reported as the "cohesive/adhesive strength." Failure is described as "cohesive" if it occurs within the insulation and is defined as "adhesive" if it occurs at the interface with the substrate.

Analysis of the reported density values indicated no statistically significant differences between the average SFRM densities in the two towers. The overall average density was $18.9 \mathrm{pcf}$ with a standard deviation of $3.2 \mathrm{pcf}$, giving a coefficient of variation of 16 percent.

Analysis of the bond strength values indicated that there were statistically significant differences between the average bond strengths for the different floors, but there was no statistically significant difference between the average bond strengths for the two towers. The overall average bond strength was $302 \mathrm{psf}$, with a standard deviation of 91 psf, giving a coefficient of variation of 30 percent. This average value is less than the "tested performance" value of 360 psf indicated in the manufacturer's catalogs, but this published value is for tests under controlled conditions and may not be representative of field strengths. The manufacturer's product literature dated February 2002 refers to average bond strength of 150 psf as "standard performance," and the same value is used in its guide specification for BLAZE-SHEILD II.

\section{Specimen Preparation and Test Procedures}

While the in-place bond strength data for BLAZE-SHIELD II reported by the Port Authority appear to indicate acceptable performance, ASTM E 736 tests do not provide sufficicnt information for predicting whether insulation would be dislodged from structural members under various impact conditions. The standard test does not provide unambiguous values of cohesive and adhesive strengths and it does not provide tensile strength in a direction parallel to the surface, that is, the in-plane cohesive strength. Thus, tests were conducted by NIST to determine different tensile strength properties of sprayed thermal 
insulation. BLAZE-SHIELD DC/F was used because the Port Authority data did not include tests of this material.

Test specimens were made by applying the SFRM to $1 / 4$ in. steel plates measuring 8 in. by 16 in. One half of the plates were coated with primer paint. Nominal SFRM thicknesses of $3 / 4$ in. and $1 \frac{1}{2} \mathrm{in}$. wcre applied. Thickncss was built up in several passes of the spray nozzle. Gentle hand rubbing was used to remove local high spots and produce reasonably uniform thicknesses. The plate specimens were allowed to dry for over five months in the laboratory before testing. Companion specimens were weighed periodically for loss of water and it was found that the $1 \frac{1}{2} \mathrm{in}$. thick specimen reached equilibrium in about one month.

Tests were devised to determine adhesive strength, cohesive strength normal to the surface, and cohesive strength parallel to the surface of the SFRM. The first two properties were determined by adapting the pull-off test method described in ASTM C 1583, Standard Test Method for Tensile Strcngth of Concrete Surfaces and the Bond Strength or Tensile Strength of Concrete Repair and Overlay Materials by Direct Tension (Pull-off Method). The SFRM layer was cut carefully in two orthogonal directions to create a prismatic test specimen, and a $3 / 8 \mathrm{in}$. by $2.7 \mathrm{in}$. by $2.7 \mathrm{in}$. aluminum plate was glued to the surface. The advantages of this approach over the ASTM 736 technique are that the resisting area is easily determined and it offers the ability to measure both adhesive and cohesive strengths.

From each plate, three specimens were prepared for measuring both density and in-plane cohesive strength, and two specimens were prepared for measuring adhesive strength and cohesive strength normal to the surface. Prismatic specimens were prepared by carefully removing strips of SFRM from the steel plates and sanding them to obtain uniform thickness. These specimens were weighed to determine their densities. Then the specimens were glued to a steel plate and a small plate was glucd to the other cnd for application of a tensile load.

The adhesive strength and cohesive strength normal to the surface were obtained using the modificd pulloff procedure. An aluminum plate was bonded to the top surface of the SFRM using a fast curing, twocomponcnt urethane foam adhesive. After the adhcsive had cured, the SFRM layer was cut to produce a prismatic test specimen. A hook was screwed into the aluminum plate, and a load was applied by hand using a 50-1b digital force gauge. The average length and width of the failure area was measurcd and used to compute the adhcsive or cohesive strcngth. After the first test, the spccimen was repaircd with the same polyurethane adhesive and the test was repeated. If the first test was an adhesive failure, the second test of the repaired specimen measured cohesive strength of the bulk SFRM. If the first test rcsulted in cohesive failure, the spccimens were repaired and retested until an adhesive failure was obtained.

\section{Test Results}

Table E-1 summarizes the results of the test described in the previous section.

Table E-1. Summary of physical characteristics of BLAZE-SHIELD DC/F specimens tested at NIST.

\begin{tabular}{|l|c|c|c|c|}
\hline \multirow{2}{*}{\multicolumn{2}{|c|}{ Property }} & \multicolumn{2}{|c|}{ Bare Steel } & \multicolumn{2}{c|}{ Primed Steel } \\
\cline { 2 - 5 } & $3 / 4$ in. & $11 / 2$ in & $3 / 4$ in. & $11 / 2$ in. \\
\hline Density (pcf) & & & $27.2(0.8)^{\mathrm{a}}$ & $29.7(1.3)$ \\
\hline
\end{tabular}




\begin{tabular}{|l|c|c|c|c|}
\hline In-plane cohesive strength $(\mathrm{psf})$ & & & $1120(390)$ & $1740(540)$ \\
\hline Adhesive strength $(\mathrm{psf})$ & $450(63)$ & $666(151)$ & $185(96)$ & $171^{\mathrm{b}}(196)$ \\
\hline Cohesive strength normal to surface (psf) & $433(99)$ & $610(142)$ & $367(79)$ & $595(163)$ \\
\hline
\end{tabular}

a. First number is the average and the number in parentheses is the standard deviation.

b. Based on testing selected samples.

The densities of the BLAZE-SHIELD DC/F measured in this study were higher than published in the manufacturer's catalogs and higher than the in-place average density of 18.9 pcf reported in Port Authority test reports for BLAZE-SHIELD II. The difference in average densities of the two thicknesses was statistically significant. The higher values in this study are attributed to the details of the specimen preparation procedures, which tended to result in dcnser test specimens than would be representative of field application.

The difference in average adhesive strength for the two SFRM thicknesses is statistically significant. The relative strengths are consistent with the difference in density for the two thicknesses.

The presence of primer reduced the adhesive strength, especially for the $1 \frac{1}{2} \mathrm{in}$. thick specimens. Twothirds of the thicker SFRM plates had no adhesion to the coated steel plates.

Analysis of the cohesive strength normal to the surface indicated that there was no statistically significant effect due to the presence or absence of primer. This is logical, because the condition of the steel surface is not expected to influence the properties of the bulk SFRM. There was a statistically significant difference in the average strengths for the two thicknesses, with the $1 \frac{1}{2} \mathrm{in}$. SFRM having higher strength.

For comparison with the measured cohesive strength normal to the surface, two tests were done in accordance with ASTM E 736. The results of the two tests were in agreement with those obtained by the pull-off technique. This suggests that the ASTM E 736 procedure probably provides a measure of cohesive strength.

A comparison was made of the adhesive strength and cohesive strength normal to the surface for the plates made with bare steel. A formal analysis of variance indicated that there is an 8 percent probability that the difference could be the result of randomness. Generally, if this probability is greater than 5 percent, it can be concluded that the difference is not statistically significant. Thus, for the case of good adhesion, the test results do not contradict the assumption that the adhesive strength and cohesive strength normal to the surface are equal. If this assumption is accepted, the average of the adhesive and cohesive

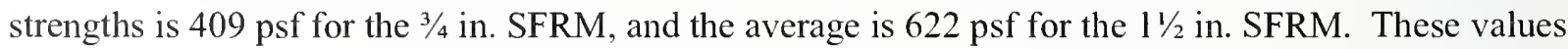
are considerably greater than the manufacturer's published strength of 295 psf obtained using the ASTM E 736 method under laboratory conditions.

\section{Simplified Approach to Predict Dislodging of SFRM}

When a member is subjected to an impact, it will undergo various modes of vibration. These vibrations result in local cyclic accelerations that are transferred to the SFRM by forces at the interface between the steel and the SFRM. The forces are proportional to the mass of the SFRM, and if they exceed the adhesive or cohesive strength of the SFRM, the SFRM will separate from the member. Two limiting cases are considered: 
- Case 1 is a planar element with SFRM applied to one face of the element. This would be representative of SFRM applied to large webs and flanges of beams and columns. In this case, adhesive strength or cohesive strength normal to the surface would be the controlling SFRM properties.

- Case 2 is a slender bar encased with SFRM. This would be representative of SFRM applied to elements of the floor trusses. In this case, in-plane tensile strength and bond strength are the controlling SFRM properties.

To arrive at the ranges of accelerations that could be expected to dislodge SFRM from a planar surface, the following plausible ranges of values were assumed:

- $\quad$ SFRM thickness: 0.75 in and 2.5 in.;

- $\quad$ SFRM density: 15 pcf and 25 pcf ';

- SFRM bond strength: 100 psf and 500 psf

For the combination of low thickness, low density, and high bond strength, the required acceleration is about $530 \mathrm{~g}$, where $\mathrm{g}$ is the gravitational acceleration. For the other extreme combination of high thickness, high density, and low strength, the required acceleration is about $20 \mathrm{~g}$. For values representative of the upgraded thermal insulation on the floor trusses, an acceleration of about $80 \mathrm{~g}$ would be required to dislodge a 2.5 in. thick layer of well-bonded SFRM from a planar surface.

To arrive at the ranges of accelerations that could be expected to dislodge SFRM from a round bar, the following ranges of values were assumed:

- $\quad$ Bar diameter: 0.9 in. and 1.2 in;

- SFRM thickness: 0.75 in. and 2.5 in.;

- Density: 15 pcf and 25 pcf;

- In-plane cohesive strength: 500 pcf and 2,000 psf; and

- Ratio of bond strength to in-plane cohesive strength: 0 and 0.3 .

The smallest required acceleration is about $40 \mathrm{~g}$, which corresponds to a large bar having a thick layer of the higher density SFRM with low strength. At the other extreme, the required acceleration is about $730 \mathrm{~g}$. For a $1.2 \mathrm{in}$. diameter bar with $2.5 \mathrm{in}$. thickness of SFRM and density of $19 \mathrm{pcf}$, which are representative of the conditions of the upgraded insulation on the floor trusses, the acceleration required to dislodge the SFRM would vary from $55 \mathrm{~g}$ to $230 \mathrm{~g}$, depending on the strength characteristics within the assumed ranges given above.

These simplified models are intended to provide insight into the important variables that affect the magnitude of the disturbance (that is, acceleration) required to dislodge SFRM from different kinds of

${ }^{1}$ These numbers need to be converted to units of mass by dividing by the gravitational acceleration. 
structural members. These models do not consider the fact that the applied acceleration in an actual structure subjected to impact would vary with time. Also these models apply to members not directly impacted by debris. 


\section{Chapter 1 \\ INTRODUCTION}

When steel is heated it loses strength and stiffness. This characteristic allows steel to be formed into different shapes with relatively little effort. When steel is used in a structure, however, measures have to be taken to protect the steel from premature temperature rise in case of fire. The objective is for the structure to remain stable for the time needed to permit evacuation of occupants and for fire service personnel to complete search and rescue operations. This report deals with the passive fire protection materials used in the WTC towers.

\section{$1.1 \quad$ FIRE-RESISTIVE MATERIALS}

The investigation revealed that structural steel in the World Trade Center (WTC) towers was protected against the effects of fire with sprayed fire-resistive materials (SFRMs) ${ }^{2}$ or rigid fire-rated gypsum panels. There are many types of SFRMs, but they can be characterized in terms of how they protect the steel and their density (Gewain et al. 2003). One class of SFRMs protects the steel by providing a material with a low thermal conductivity, such as mineral fibers. The fibers and binder are packaged as dry ingredients, and water is added by a pressurized system as the materials are sprayed onto the steel. The water mixes with the binder materials and provides "stickiness" that allows the SFRM to adhere weakly to the steel. With time, the binder hardens, and excess water evaporates. When dry, these SFRMs provide a low thermal conductivity barrier to reduce the rate of temperature rise during a fire.

The other class of SFRMs can be termed as "energy absorbing" (Gewain et al. 2003). This means that they incorporate cementitious materials that have chemically bound water (water of crystallization). When the material is heated, energy is absorbed in transforming the chemically bound water to free water, and this hinders the temperature rise of the coated steel. Examples of cementitious materials that have been used successfully include gypsum and magnesium oxychloride (Gewain et al. 2003). These types of SFRMs may also include very low-density aggregate particles, such as vermiculite or perlite, to reduce density and thermal conductivity. Cementitious SFRMs are typically mixed with water to produce a cohesive and pumpable mixture that is sprayed onto the steel.

Figure 1-1 is a photograph of two types of SFRMs. The material on the left is a gypsum based cementitious SFRM containing vermiculite aggregate, and the material on the right is a fibrous SFRM. Note that the cementitious SFRM specimen in the photograph was prepared by casting in a mold, not by spraying onto a surface. Thus, the surface texture is not represcntative of what would bc obtained in the field.

Sprayed fire-resistive materials are also characterized by their density. Low-density materials have densities in the range of $15 \mathrm{lbs} / \mathrm{ft}^{3}$ to $20 \mathrm{lbs} / \mathrm{ft}^{3}$; medium density materials are generally in the range of $20 \mathrm{lbs} / \mathrm{ft}^{3}$ to $40 \mathrm{lbs} / \mathrm{ft}^{3}$. The density of the SFRM is closely related to its cohesive strength and its

2 These sprayed fire-resistive materials are commonly referred to as "fireproofing." This term is, however, not used in the technical literature. In this report "SFRM" and "thermal insulation" are used to refer to the passive fire protection materials. 
durability. Low-density SFRMs can be removed readily with hand tools and are not suitable for applications where the surface is exposed to weather or abrasion in service (Gewain et al. 2003).

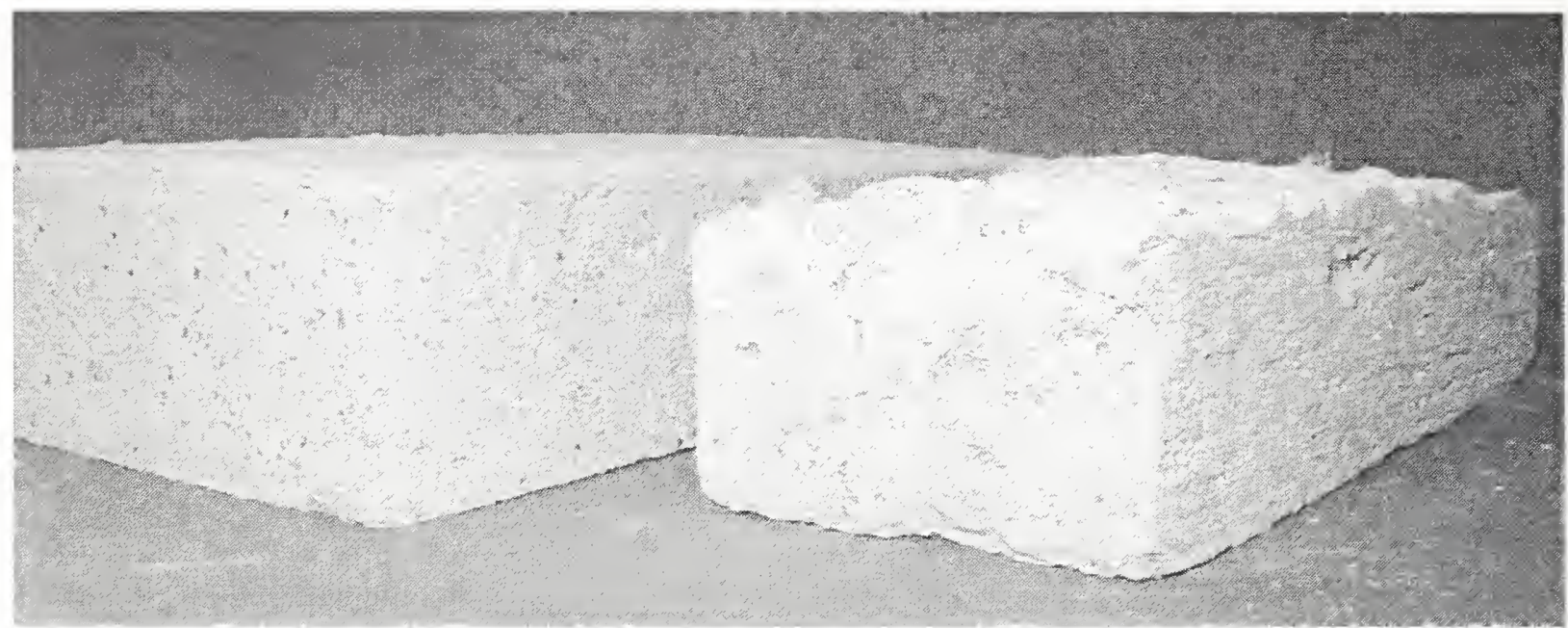

Source: NIST.

Figure 1-1. Examples of sprayed fire-resistive materials: (left) material based on gypsum and vermiculite aggregate; (right) material based on mineral fibers and cementitious binder.

Analysis of the effects of the fires on the structural capacity of the damaged WTC towers as a function of time requires knowledge about the condition of fire-resistive materials on the various structural components, namely, the exterior columns, the spandrel beams, the floor trusses, and the core columns. Because of the method of application, sprayed fire-resistive material will have variable thickness, especially when applied to long, thin elements such as the diagonals and chords of the floor trusses. In addition, some insulation was dislodged during the impact, either from direct impact by debris or from vibrations of the members. The thermal properties of the insulation also need to be known as a function of temperature.

\subsection{SCOPE OF REPORT}

The thermal-structural analysis of the WTC towers focused on two objectives: (1) analysis of the undamaged buildings exposed to conventional building fires, and (2) analysis of the buildings damaged by the aircraft impact exposed to the subsequent fires. To reduce the uncertainties in the calculated thermal histories of various structural elements, the thermophysical properties and condition of the passive fire protection as it existed on September 11,2001, had to be estimated as accurately as possible. In addition, reasonable estimates of the extent of SFRM dislodged by the aircraft impact and the resulting debris field had to be made.

To provide context for the information in this report, an overview of concepts used in U.S. building codes for structural fire resistance is presented first. This is followed with a summary of the construction history of the sprayed fire-resistive material in WTC 1 and WTC 2. To gain an understanding of the effect of SFRM thickness and its variability on the steel temperature during exposure to fire, results are presented of a sensitivity study based on a simple finite-element model. This is followed by a quantitative assessment of in-place thickness and its variability based on available data. The rationale for 
the thickness of SFRM to be used in the structural fire endurance analyses is presented. The tests conducted to determine the thermal properties of insulation materials similar to those used in the WTC towers are reviewed. The results of mechanical property tests conducted on laboratory specimens are presented, and a simplified approach for estimating the acceleration required to dislodge thermal insulation during impact is discussed. 
This page intentionally left blank. 


\section{Chapter 2 \\ BUILDING CODE CONCEPTS FOR STRUCTURAL FIRE RESISTANCE}

\section{$2.1 \quad$ ORIGINS AND INTENT OF BUILDING CODES}

Fire-induced collapse of buildings is regulated generally through limits on the height and the area per floor as a function of the types and degree of fire resistance of materials used in the structural elements. These material characteristics are categorized as types of construction, and the associated limits are contained in so-called "heights and areas tables," which are a cornerstone of most prescriptive building codes.

As discussed in NIST NCSTAR $1-1,{ }^{3}$ the origins of building codes in the United States can be traced to insurance regulations developed in the late 19th century to limit property losses in fires (Bukowski 1997). Thus, the intent of building height limits is to restrict taller buildings to non-combustible structural members, and the greatest fire resistance is assigned to members supporting multiple floors. The primary concern with combustible structural members is that they can become ignited by an exposing fire and can continue to burn (often in concealed spaces) even after the exposing fire has been extinguished, leading to collapse. The intent of increased fire resistance for members supporting multiple floors is directly related to the higher risk of property loss in the event of failure of multiple floors. Fire resistance requirements, however, do not take into account the actual number of stories being supported by these elements. Thus, the same ratings are required irrespective of whether columns support 10 stories or 100 stories.

The other important height factor is the definition of a high-rise building. This is based generally on the height above which fire department ladders will not reach, requiring that fires be fought from inside, which is significantly less effective (and more dangerous for the firefighters). In an exterior attack, hose streams can be brought to bear from several sides, and so-called master streams can apply large volumes of water. An interior attack is limited to hand-held hoses supplied from standpipes and working from interior stairways. Traditionally, high-rise buildings have been defined as those that exceed $75 \mathrm{ft}$ (or six stories above grade) in height, but some newer model codes increase this height to $100 \mathrm{ft}$ as modern fire department ladders are taller.

The intent of floor area limits is less obvious, but is generally attributed to limiting property risk and to limiting the size (area involved on any floor) of the fire to that which can be dealt with by the fire department, with the number of people and equipment typical of an initial response.

\section{$2.2 \quad$ CONSTRUCTION TYPES}

Construction types (or groups) are defined in the model building codes and in NFPA 220 (NFPA 220, 1999 ) and, while there are some variations in categories, they are reasonably consistent. The main

\footnotetext{
${ }^{3}$ This reference is to one of the companion documents from this Investigation. A list of these documents appears in the Preface to this report.
} 
categories are Type I (fire resistive), Type II (non-combustible), Type III (ordinary), Type IV (heavy timber) and Type V (combustible).

Types I and II are constructed with non-combustible exterior and interior bearing walls and columns, where fire resistance ratings are greatest for Type I, and Type II is any (non-combustible) construction not meeting Type I requirements. Type III is where exterior bearing walls are non-combustible, and interior bearing walls and some columns may employ approved combustible materials. Type IV is known as heavy timber, which utilizcs large, solid cross section wooden members such as in post-and-beam construction. Type V is traditional wood frame construction. Common non-combustible structural elements employ steel or reinforced concrete. Combustible structural elements are usually solid wood, engineered wood, and laminates.

Combustibility of the materials in the structural element is determined in accordance with ASTM E 136 (ASTM 2004a) in which the material is placed in a furnace at $750^{\circ} \mathrm{C}\left(1,380^{\circ} \mathrm{F}\right)$. Some minor surface burning (e.g., from paint or coatings) is allowed in the first 30 seconds, but there cannot be any significant energy released as determined by more than $30^{\circ} \mathrm{C}\left(54^{\circ} \mathrm{F}\right)$ increase in the furnace temperature, and the sample cannot lose more than half its initial mass. Materials that pass are designated non-combustible, and the rest are combustible. In 1973, an in-between category of "limited combustible" was added to ASTM E 136 to regulate some structural materials.

Within each construction type are several sub-categories determined by the fire resistance ratings of the columns (vertical structural elements that support predominantly gravity loads and the actions of lateral loads), beams (horizontal structural elements that support predominantly live loads), and floor supports. In some model codes these sub-categories are identified by letters following the type (e.g., IB or IIIA) (IBC 2003) or by a set of three numbers that represent the fire resistance required (in hours) of the exterior bearing walls; columns, beams, girders, trusses and arches supporting bearing walls, columns, or loads from more than one floor; and floor construction, respectively (e.g., Type I [3, 3, 2]) (NFPA 5000, 2003). The Annex of NFPA 220 (2006 Edition) includes a table that cross-references different construction types in various model codes.

\subsection{FIRE RESISTANCE OF STRUCTURAL ELEMENTS}

Building codes require that structural elements be protected to achieve a specified fire resistance rating, expressed in hours (Buchanan 2001; Bukowski 2003). The fire resistance rating of structural materials and assemblies is generally determined through testing, and in the United States, such testing is frequently conducted in accordance with ASTM Test Method E 119 (refer to NIST NCSTAR 1-6B ${ }^{4}$ for a discussion of this procedure). The objective of requiring minimum fire ratings is for the building to support design loads (including fire) without local structural collapse until occupants can escape and the fire service can complete search and rescue operations. Further, in high-rise buildings, local collapse is to be prevented while the fire service undertakes suppression operations.

With regard to total collapse, the intent of the code is for this not to occur for any design condition (including design fires), but it is recognized that collapse might occur in an extreme event

4 This reference is to one of the companion documents from this Investigation. A list of these comments appears in the Preface to this report. 
(Buchanan 2001; Bukowski 2003). For an extreme event, collapse should not occur until the building has been evacuated of both occupants and firefighters.

Building codes generally require the highest fire resistance for columns and elements supporting multiple floors, and somewhat less resistance is required for columns supporting single floors, for beams, and for floors. For example, NFPA 5000, Building Construction and Safety Code (NFPA 5000, 2003), requires exterior bearing walls or columns supporting one or more floors to have the same fire resistance rating, but for interior bearing walls or columns the fire resistance rating is one hour less if only a single floor is supported. Historically, similar requirements were found in other model codes such as the Building Officials and Code Administrators (BOCA) Basic Building Code and the Southern Building Code Congress International (SBCCI) Standard Building Code, which have been replaced by the International Code Council's International Building Code (Bukowski 1997).

The required fire resistance ratings have been reduced in recent years as fire sprinklers have become universal in high-rise buildings and common in most other commercial buildings (Messersmith 2002). Where high-rise buildings generally required a $4 \mathrm{~h}$ rating for columns, this has been reduced to $3 \mathrm{~h}$ in recent codes, and can be as low as $2 \mathrm{~h}$ in current model codes based on the additional mandatory requirement for sprinklers. This reduction in fire rating requirements for structural components in sprinklered buildings is usually referred to as sprinkler "trade-offs" (Buchanan 2001; Messersmith 2002). 
This page intentionally left blank. 


\section{Chapter 3 \\ Historical ReView Related to Passive Fire Protection of WTC TOWERS}

\subsection{AGREEMENTS BETWEEN PORT AUTHORITY AND NEW YORK CITY DEPARTMENT OF BUILDINGS AND FIRE DEPARTMENT}

The World Trade Center (WTC) towers were built by the Port of New York Authority, which in 1972 became known as the Port Authority of New York and New Jersey and is hereinafter referred to as the Port Authority. As an interstate agency created under a clause of the U.S. Constitution permitting compacts between states, the Port Authority is not bound by any local authority having jurisdiction, in this case the New York City (City) Department of Buildings. Thus, the Port Authority was not required to comply with the New York City Building Code or any other building code; howevcr, the Port Authority made explicit statements that it would comply with the Code.

In a letter dated May 15, 1963 (see Appendix A Fig. A-1), the Port Authority instructed its consulting engineers and architects to comply with the New York City Building Code. In the areas where the Code was not explicit or where technological advances made portions of the Code obsolete, it directed that design may be based on acceptable engineering practice. At that time, the 1938 edition of the New York Building Code was in effect, and a revised code was being drafted. On September 29, 1965, in a letter from Malcolm P. Levy to Minoru Yamasaki, the Port Authority instructed the designers of the WTC towers to revise the design plans to comply with the second and third drafts of the Code revision (see Appendix A Fig. A-2). The rcvised Building Code becamc effective in Deccmber 1968.

In 1993, the Port Authority and the New York City Department of Buildings entered into a Memorandum of Understanding (see Appendix A Fig. A-3) establishing procedures to be followed by the Port Authority for any building construction project undertaken by the Port Authority or any of its tenants at buildings owned or operated by the Port Authority and located in the City's jurisdiction. While the long-standing policy of the Port Authority was that its buildings meet or exceed the New York City Building Code (Code) requirements, the 1993 agreement restated the commitment. Among other key points, it was agreed that:

- Each project would be reviewed and examined for compliance with the Code;

- All plans would be prepared, sealed, and reviewed by New York State licensed professional engineers or architects; and,

- The Port Authority engineer or architect approving the plans would be licensed in the State of New York and would not have assisted in the preparation of the plans.

A supplement to this memorandum of understanding was executed in June 1995, which permitted tenants to use New York State licensed architects or engineers, in lieu of a Port Authority review, to certify that construction plans conformed to the Code and that construction was performed in accordance with the plans (see Appendix A Fig. A-4). In September 1995, the supplement was modified to pcrmit a single 
licensed consultant to certify the plans and the construction, except if the alteration would change the occupancy group of the space.

"In order to maintain and enhance the safety" of its facilities, the Port Authority "adopted a policy providing for the implementation of fire safety recommendations made by local government fire departments after a fire safety inspection of a Port Authority facility" as stated in the introduction of a Memorandum of Understanding between The Fire Department of the City of New York (FDNY) and the Port Authority of New York and New Jersey executed on December 30, 1993 (see Appendix A Fig. A-5). The purpose of the agreement was to restate the Port Authority's commitment to the policy, and the agreement included the following statements:

- "FDNY, acting through its Bureau of Fire Prevention ("BFP"), shall have the right to conduct fire safety inspections at any Port Authority facility located in the City of New York..."

- "BFP will issue a lettcrhead report of its fire safety findings and recommendations for corrective action with respect to any deficiencies forming a part of such findings addressed to the Port Authority's General Manager of Risk Management operations..."

- “...The Port Authority policy is and will continue to be to assure that such new or modified fire safety systems are in compliance with local codes and regulations..."

In 1995, the Memorandum of Understanding between FDNY and the Port Authority was amended with respect to additions to or modifications of fire safety systems. The Port Authority was required to notify the Bureau of Fire Protection prior to installing new systems or modifying existing systems. In addition, plans for these systems were to be prepared by New York State licensed professional engineers or architects (see Appendix A Fig. A-5).

\subsection{NEW YORK CITY BUILDING CODE REQUIREMENTS}

\subsubsection{Occupancy Groups}

Application of the New York City Building Code provisions affected, among other things, the assigned building classification and, thus, the required fire rating of the WTC towers and their structural members. It should be recalled that the Code was under revision during the design of the WTC towers.

Sub-article 301.0 of the 1968 New York City Building Code established occupancy classifications based on the use of a building and spaces. It divided occupancy into nine groups, A through I, as follows:

- A-High Hazard;

- B-Storage;

- C-Mercantile;

- D-Industrial;

- E-Business; 
- F-Assembly;

- G-Educational;

- H-lnstitutional; and,

- I-Residential.

As office buildings, the WTC towers were classified as Occupancy Group E. This classification was confirmed in a letter dated May 14, 1969 from Malcolm P. Levy of the World Tradc Department to Milton Gerstman of Tishman Realty \& Construction Company, Inc. (see Appendix A Fig. A-6).

\subsubsection{Construction Classification and Fire Rating}

Additionally, there were other factors that determined the "classification" of a building and, consequently, its required fire rating: combustible versus noncombustible construction, sprinklered versus unsprinklered spaces, and building height and floor area limitations. Sub-articles 314.0 and 315.0 of the 1968 Code identified two construction groups: Noncombustible Construction (Group 1) and Combustible Construction (Group 2). The WTC towers were classified as Construction Group 1 because their walls, exit ways, shafts, structural members, floors, and roofs were constructed of noncombustible materials. The investigation revealed that at the time of design and construction, the towers were not sprinklered.

The 1968 New York City Building Code defined five Classes within Construction Group 1. For Business occupancy, each Class required a fire endurance rating as follows (NYCBC 1968):

- Construction Group 1A: 4 hour protected

- Construction Group 1B: 3 hour protected

- Construction Group 1C: 2 hour protected

- Construction Group 1D: 1 hour protected

- Construction Group 1E: unprotected

As mentioned in Section 2.3, fire endurance is a rating, given in hours, established in accordance with the ASTM E 119. Fire endurance is also referred to as fire rating or fire index.

To provide perspective, the 1961-1962 revision to the 1938 New York City Building Code rcquired that the 110 story towers be classified as "Class 1 - Fireproof Structures," which includes office buildings (NYCBC 1961-1962). This meant that the columns were required to have 4 hour fire endurance while the floor system was required to have 3 hour fire endurance.

In Sub-articles 405.0 and 406.0 of the 1968 New York City Building Code, area and height limitations for unsprinklered buildings of Construction Group 1 with a Business Occupancy were as presented in Table 3-1 (NYCBC 1968). The WTC towers, WTC 1 and WTC 2, had roof heights of 1,368 ft and $1,362 \mathrm{ft}$, respectively, and each tower had a floor area of approximately $43,100 \mathrm{ft}^{2}$. As Table $3-1$ indicates, the WTC towers could have been classified as either Class 1A or Class 1B. 
Table 3-1. Area and height limitations for unsprinklered buildings for Noncombustible Construction (Group 1) with a Business occupancy (NYCBC 1968).

\begin{tabular}{|l|l|l|l|l|l|}
\hline & \multicolumn{1}{|c|}{ Class 1A } & \multicolumn{1}{|c|}{ Class 1B } & \multicolumn{1}{|c|}{ Class 1C } & \multicolumn{1}{|c|}{ Class 1D } & \multicolumn{1}{|c|}{ Class 1E } \\
\hline Area & No Limit & No Limit & No Limit & $17,500 \mathrm{ft}^{2}$ & $10,500 \mathrm{ft}^{2}$ \\
\hline Height & No Limit & No Limit & $85 \mathrm{ft}$ & $75 \mathrm{ft}$ & $40 \mathrm{ft}$ \\
\hline
\end{tabular}

\subsection{CLASSIFICATION OF WTC TOWERS}

It was the practice at the time, and continues to be the practice, for the architect to establish the building classification, fire rating of members and systems, and thermal protection requirements. On the subject of fire rating in accordance with the New York City Building Code revision effective December 6, 1968, a Port Authority memorandum dated January 15, 1987, from Lester S. Feld to Robert J. Linn states that Emery Roth \& Sons (ER\&S), the Architect of Record for the towers, had classified the WTC towers as Class 1B since there was "no economic advantage in using Class 1A Construction" (see Appendix A Fig. A-7).

According to the 1968 New York City Building Code, construction classification 1B provided, in part, the following fire protection requirements:

- Enclosure of vertical shafts, exits, passage-ways, and hoistways shall have a 2 hour fire endurance;

- Columns, girders, trusses, other than roof trusses, and framing supporting one floor shall have a 2 hour fire endurance;

- Columns, girders, trusses, other than roof trusses, and framing supporting more than one floor shall have a 3 hour fire endurance; and

- Floor construction including beams shall have a 2 hour fire endurance.

- Roof construction including beams, trusses, and framing including arches, domes, shells, cable supported roofs, and roof decks (for buildings over one story in height) shall have a 2 hour fire endurance.

Generally, fire ratings would appear on the application submitted for approval to the New York City Department of Buildings. In the case of the towers, however, no plans or forms were filed because the Port Authority was not subject to the New York City Building Code (see Appendix A Fig. A-7).

\subsubsection{Specifications for Passive Fire Protection}

In the case of the WTC towers, there appears to have been a problem related to the sprayed fire-resistive material specifications. A letter dated February 11, 1969, from Douglas Fernández of Emery Roth \& Sons to Joseph A. Schwartzman of the Port Authority indicates that in early 1969 the Port Authority had rewritten the SFRM specifications (see Appendix A Fig. A-8). In the process of rewriting, the following key paragraph specifying the fire rating requirements for the structural members was apparently omitted: 
"Finished thicknesses of applied material over the various component steel parts requiring fireproofing shall be great enough to qualify the fireproofed parts for a three (3) hour rating (support beams, steel deck work) and a four (4) hour rating for all pick-up girders, if any, and columns."

ER\&S continued:

"We cannot be expected to accept responsibility for specifications which have been revised in such a manner; that which we originally stated clearly and simply, has become a meaningless document."

\subsubsection{Response to Local Law $5 / 1973$}

In 1973. New York City Local Law No. 5 amended the New York City Building Code (effective January 18, 1973). Local Law No. 5/1973 required, in part, the retrofit of existing unsprinklered office buildings $100 \mathrm{ft}$ or higher and having heating, ventilating, and air conditioning (HVAC) systems that serve more than the floor on which the equipment is located. To conform to Local Law 5/1973, the New York City Department of Buildings permitted either (NYCLL5/73 1973):

- Subdividing the floor area into compartments of specified square footage by fire separations ( $1 \mathrm{~h}$ or $2 \mathrm{~h}$ fire rated depending on the size of the compartment), or

- Providing sprinkler protection.

Owners of unsprinklered buildings were required to comply according to the following timetable from the effective date of the law (NYCLL5/73 1973):

- At least $1 / 3$ of the non-complying floor area shall be completed in 5 years;

- At least $2 / 3$ of the non complying floor area shall be completed in 10 years; and,

- The entire building shall be completed in 15 years.

A code compliance evaluation conducted in 1997 indicated that that all tenant floors in the two towers had been retrofitted with sprinklers (sprinklered) with the exception of four floors in WTC 1. In a 1999 update by the Port Authority it was noted that all tenant floors had been sprinklered and work was underway to complete sprinklering of the sky lobbies (see Appendix A Fig. A-9).

The 1999 revision of the New York City Building Code placed a $75 \mathrm{ft}$ height limitation on unsprinklered buildings of Construction Groups 1A, 1B. 1C, and 1D. Sprinklered buildings, however, had no height limitations for Construction Group 1A, 1B, and 1C. Thus, the retrofitted WTC towers could have been reclassified as Class $1 \mathrm{C}$ ( 2 hour protected) (NYCBC 2001). As Class 1C, the columns and floor systems would have required $2 \mathrm{~h}$ and $1 \frac{1}{2} \mathrm{~h}$ fire ratings, respectively.

In preparation for leasing the WTC buildings to Silverstein Properties in 2000, the Port Authority commissioned a property condition assessment. The report titled "Property Condition Assessment of World Trade Center Portfolio," which was prepared for the Port Authority by Merritt \& Harris, Inc. states 
that the WTC towers were classified as "Class $1 \mathrm{~B}$ - noncombustible, fire-protected, retrofitted with sprinklers in accordance with New York City Local Law 5/1973" (see Appendix A Fig. A-10).

\subsection{SELECTION OF FIRE-RESISTIVE MATERIALS}

\subsubsection{Floor Trusses}

Classification of a building leads to its overall fire endurance rating and ratings of the various structural components. The New York City Building Code, however, does not prescribe how the required fire endurance rating is to be achieved. Rather, the means for providing passive fire protection is established by the Architect of Record and depends, in part, on the structural materials used in the construction.

In the case of the WTC towers, the primary structural material was steel. Steel, in general, requires passive fire protection to achieve code-prescribed fire ratings. The Port Authority chose to protect the main structural components such as columns, spandrel beams, and floor trusses with sprayed fire-resistive material. This thermal protection technique was an established method for protecting columns, beams, and walls. In the 1960s, however, composite steel truss-supported floor systems were usually protected using "lath and plaster" enclosures or fire-rated ceiling tiles.

Based on copies of construction drawings provided to NIST, it was established that the floor system used in the towers consisted of open-web floor trusses acting as a composite system with a $4 \mathrm{in}$. thick reinforced lightweight concrete slab over metal decking. The main composite trusses, which were used in pairs, were spaced $6 \mathrm{ft} 8 \mathrm{in}$. on center and had a nominal clear span of either $60 \mathrm{ft}$ or $35 \mathrm{ft}$. The steel floor trusses were fabricated with double-angles for the top and bottom chords and round bars for the webs. Additionally, the floor system included bridging trusses (perpendicular to main trusses) spaced $13 \mathrm{ft} 4 \mathrm{in}$. on center. Figure 3-1 shows a mock-up of the floor truss system that was manufactured for the WTC towers by Laclede Steel Co. Figure 3-2 shows the basic configuration of the composite floor truss system.

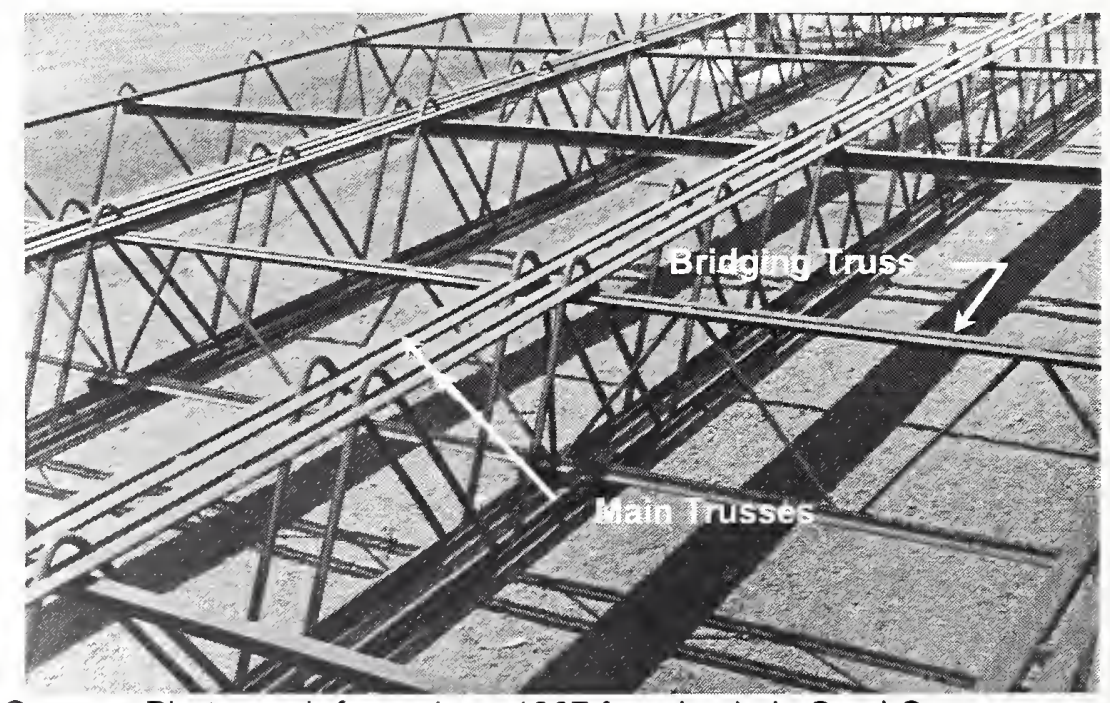

Source: Photograph from about 1967 from Laclede Steel Co.

Figure 3-1. Mock up of floor truss system. 


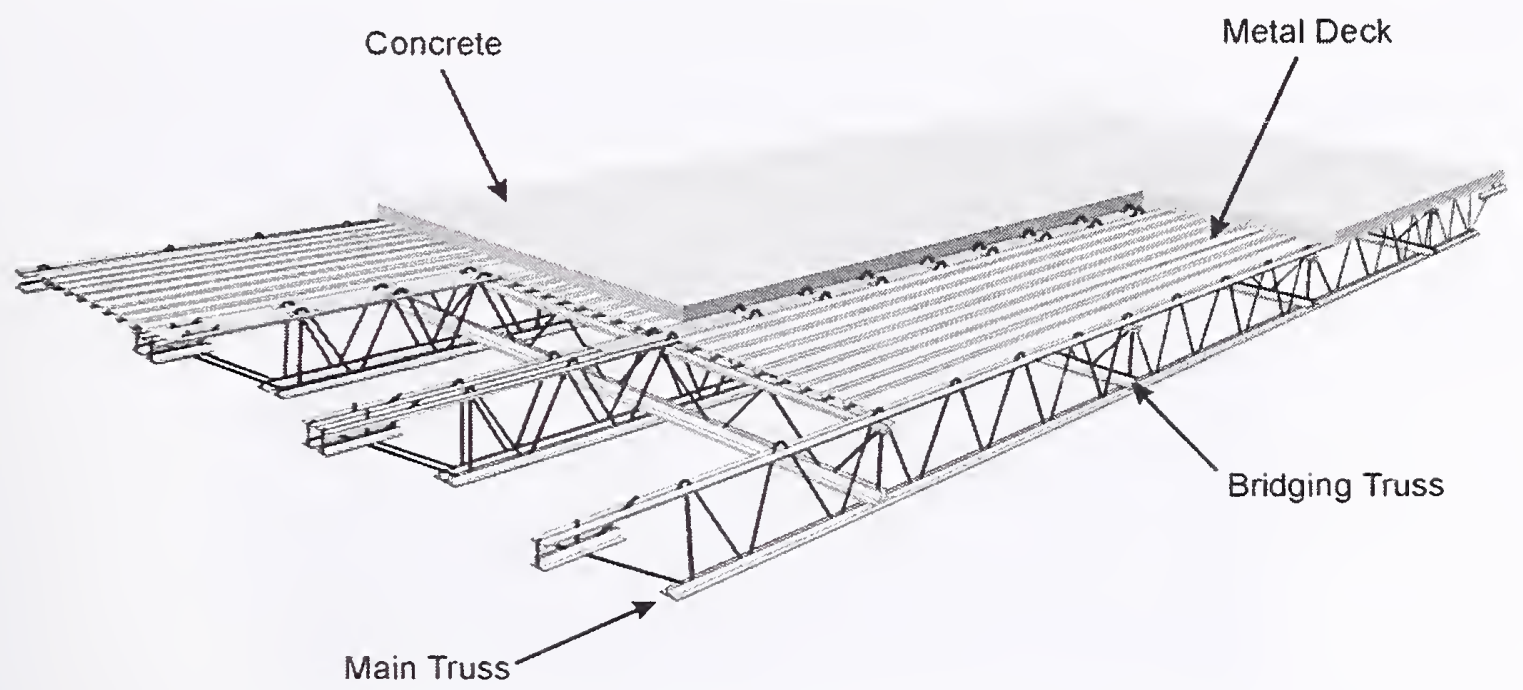

Figure 3-2. Schematic of composite floor truss system.

A review of the process involved in the selection of the thermal protection for the floor trusses is provided in a 1975 report by Skilling, Helle, Christiansen, Robertson (see Appendix A Fig. A-11). According to the report, the use of "demountable ceilings" was considered as a possible method by the Port Authority and its consultants as early as 1963, but other "efficient and economical" protection methods were sought. By late 1965, the use of sprayed fire-resistive material applied directly to the floor trusses "appears to have been selected."

Since application of sprayed fire-resistive materials to slender steel members, as in the floor trusses, was an innovative fire protection method and not consistent with prevailing practicc, the Port Authority arranged for demonstrations to establish its feasibility for the World Trade Center. These demonstrations were mentioned in intra-office correspondence by Laclede Steel Co. (see Appendix A Fig. A-12). The demonstrations also aimed to provide information on the amount of material loss that could be expected when spraying the floor truss elements. In August of 1967, application of Zonolite's Monokote was demonstrated to the Port Authority's engineers (Fig. 3-3) at the Madison, IL plant of Laclcde Steel Co. After observing the demonstrations, Laclede Steel stated:

"With the successful application of spray-on insulation an entire new scheme of fire safe building construction is possible for steel joists in that the fire protection of the joists would permit the installation of low cost acoustical ceilings with access to utility lines that have not be[en] possible in the two hour rated buildings before."

and

"In any event, the fireproofing of joists seems to be a problcm now solved, and in the World Trade Center as well as in other stecl joist structures, we may be sure that an economical fireproofing can be effected in the field without the expense of heavy ceiling construction." 


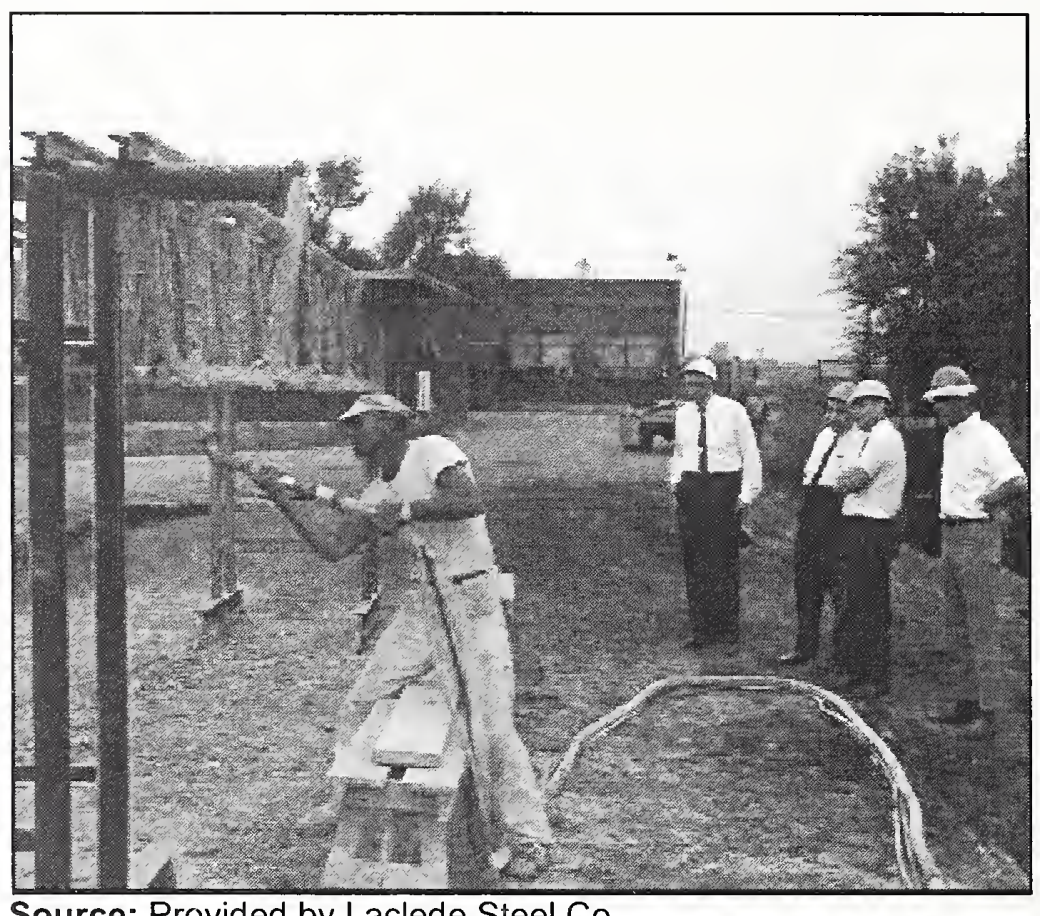

Source: Provided by Laclede Steel Co.

\section{Figure 3-3. Demonstration of application of Monokote sprayed fire-resistive material to floor trusses.}

A similar demonstration of a sprayed thermal insulation from U.S. Mineral Products Co. was conducted in September 1967 (see Appendix A Fig. A-13). In other construction documents and correspondence reviewed by NIST, this material produced by U.S. Mineral Products Co. was identified typically as CAFCO D or CAFCO Type D. ${ }^{5}$

In November 1968, the Port Authority authorized award of Contract WTC-113.00 on Spray Fireproofing to Mario \& Di Bono Plastering Co., Inc. (see Appendix A Fig. A-14). The company was the subcontractor to Alcoa for application of sprayed thermal insulation to the exterior columns, and the Port Authority reasoned that "contract administration problems would be minimized and coordination between fireproofing work on the interior structural steel and the exterior columns would be facilitated if a single contractor were to perform such work" (see Appendix A Fig. A-15).

\subsubsection{Perimeter Columns}

By May 1966, several thermal insulation materials were being considered for the perimeter columns (see Appendix A Fig. A-16). This insulation was needed not only for fire protection but also to control steel temperatures under service conditions (see next paragraph). The materials under consideration were Spraycraft (sprayed asbestos fiber), Monokote $^{6}$ (sprayed cementitious vermiculite), U.S. Gypsum Fire Code (laminated gypsum board), Vonco (sprayed magnesium oxychloride material), and BLAZE-

\footnotetext{
CAFCO is the acronym for Columbia Acoustics and Fireproofing Co., a subsidiary of U.S. Mineral Products Co. In other NIST NCSTAR reports and elsewhere in this report, the same material may be referred to as BLAZE-SHIELD D (or BLAZESHIELD Type D)

${ }^{6}$ The document shown in Fig. A-16, refers to this material as "Monocoat."
} 
SHIELD Type D. The thermal insulation for the inside face of the columns was assumed to be $13 / 8$ in. gypsum plaster, having a conductivity of $1.56 \mathrm{Btu} \cdot \mathrm{in} / \mathrm{hr} \cdot \mathrm{ft}^{2} \cdot{ }^{\circ} \mathrm{F}$. An overall transmission coefficient of $0.396 \mathrm{Btu} / \mathrm{hr} \cdot \mathrm{ft}^{2} \cdot{ }^{\circ} \mathrm{F}$ between the room and column was also assumed for calculation purposes (see Appendix A Fig. A-17).

In December 1966, Aluminum Company of America (Alcoa) presented its proposal for participation in the wall construction of the World Trade Center towers. The proposal stated (see Appendix A Fig. A-18):

"The "insulation materials applied to the structural steel components of the wall (columns and spandrels) must serve to control column temperature to a minimum of $50^{\circ}$ with $70^{\circ}$ inside and $0^{\circ}$ outside, provide fireproofing to meet a four hour test on a heavy column, and minimize heat loss and gain to satisfy HVAC requirements."

Alcoa proposed the application of BLAZE-SHIELD (of a type described in UL report R3749-10) to three sides of exterior columns. The fire-resistive material would be thick enough to provide $4 \mathrm{~h}$ fire rating. Specifically, Alcoa proposed fire-resistive material thicknesses of $17 / 16$ in. for exterior columns and $1 / 2$ in. for spandrels (see Appendix A Fig. A-18).

For the inside face of the columns, Alcoa proposed to apply a high " $k$ " value (thermal conductivity) material. This application would provide thermal protection while permitting heat migration from the room air to the column steel under service conditions. Figure 3-4 illustrates the thermal protection design for the perimeter columns.

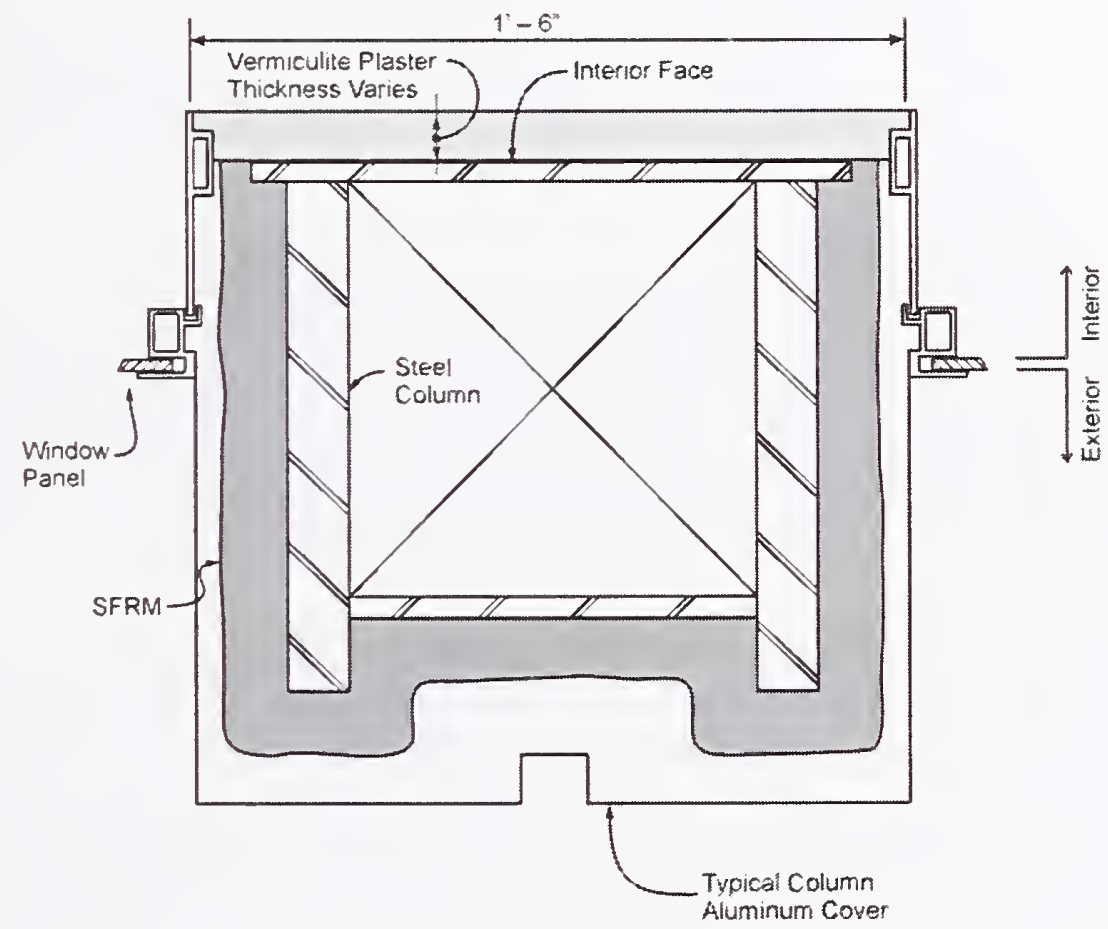

Figure 3-4. Thermal insulation for perimeter columns. 
On August 3-4, 1967, an inspection of the quality of fire-resistive material application on an exterior column and spandrel was carried out on a mock-up developed at the Alcoa-Cupples plant in St. Louis, MO. Representatives of Mario \& Di Bono Plastering Co., Inc, United States Mineral Products Co., and the Port Authority were present during the inspection. Columns and spandrels were sprayed using BLAZE-SHIELD Type D. In an internal Port Authority memorandum dated August 8, 1967, it was noted that the application of thermal insulation "was done in a workmanship like manner... with ease and very little spillage" (see Appendix A Fig. A-19).

\subsubsection{Core Columns}

Copies of architectural drawings provided to NIST indicated that the core columns were protected with fire-rated gypsum wallboard, sprayed fire-resistive material, or a combination of these. Core columns located in rentable and public spaces, in closets, and mechanical shafts were enclosed typically with two layers of $1 / 2$ in. gypsum wallboard and were inaccessible for inspection. The extent of gypsum enclosure around a core column varied depending on the location of the column within the core (see NIST NCSTAR 1-6). In all cases, however, sprayed fire-resistive material was applied on those faces that were not in direct contact with the gypsum enclosure. Again, the selected sprayed fire-resistive material was BLAZE-SHIELD Type D.

Columns located at the elevator shafts were the only columns in the core that were not enclosed and thus were accessible for routine inspections. The columns located at the elevator shafts were protected originally with BLAZE-SHIELD Type D., but other materials were used when dislodged thermal insulation was reapplied (see Chapter 4).

\subsection{SPECIFIED THICKNESS OF FIRE-RESISTIVE MATERIALS}

\subsubsection{During Construction}

The thickness of fire-resistive material necessary to achieve the required fire endurance was being assessed in 1965, more than three years before the award of the thermal protection contract. Correspondence from Julian Roth (ER\&S) to Malcolm P. Levy (Port Authority) stated that "the one-inch thick material meets the 3 hour requirements of both the new code and Underwriters. (See Appendix A Fig. A-20). Follow-on correspondence from Julian Roth to Malcolm Levy stated the following (see Appendix A Fig. A-21):

"Although the one-inch spray-on fireproofing meets the 3 hour requirements of both the proposed Building Code and Underwriters, advance information from manufacturers indicates that if the truss were required to be fire-tested, then two inches of material would be required for the light angle members. We are therefore revising our working drawings to indicate a one inch thickness of spray-on fireproofing around the top and bottom chords of the trusses, and two-inch thickness for all other members of the trusses."

Neither of these communications identified the manufacturer or type of fire-resistive material. 
WTC project specifications for spray-applied fire-resistive material do not provide required material thickness or hourly ratings. Correspondence in September 1969 from Mario \& Di Bono Plastering Co. to Tishman Realty \& Construction Co. indicated the following thicknesses (see Appendix A Fig. A-22):

"1. Beams throughout buildings $-1 / 2$ inch.

2. Columns $13 / 16$ inches.

3. Elevator columns -1 inch total including overspray.

4. Bar joist -1 inch overall thickness.

5. All beams in MER rooms and utility rooms will be $1 / 2$ inch thickness with overspray. No tamping or shaping of Cafco type D."

A letter dated October 30, 1969, from Robert J. Linn (manager, Project Planning, WTC) to Mario \& Di Bono Plastering Co. stated, in part (see Appendix A Fig. A-23):

"...Tower ' $\mathrm{A}$ ' columns that are less than $14 \mathrm{WF} 228$ will require $23 / 16$ " thick of "Cafco Glaze-Shield 'Type D' spray-on fireproofing. All Tower columns equal to or greater than 14WF228 will require $13 / 16^{\prime \prime}$ of fireproofing...

All Tower beams, spandrels and bar joists requiring spray-on fireproofing are to have a $1 / 2$ " covering of 'Cafco.'

The above requirements must be adhered to in order to maintain the Class 1-A Fire Rating of the New York City Building Code."

NIST's review of available documents has not uncovered the reasons for selecting BLAZE-SHIELD Type $\mathrm{D}$ or the technical basis for specifying $1 / 2 \mathrm{in}$. thickness of insulation for the floor trusses. Note that this letter indicates that in October 1969 it appeared that the towers were considered as Class $1 \mathrm{~A}$ construction.

Technical literature from U. S. Mineral Products Co. (USM) dated 1966-1967, included a table indicating that $1 / 2$ in. of BLAZE-SHIELD Type D would provide a 4 hour rating for beams, girders and spandrels, citing authority of UL tests performed according to ASTM E 119 (see Appendix A Fig. A-24). The 1966-1967 USM product literature does not address bar joists with thermal insulation sprayed directly on the truss members. Instead, the fire protection for joists was shown as an enclosure of thermal insulation. By way of comparison. the product catalog recommended 2-3/16 in. of BLAZE-SHIELD Type D for light columns (columns lighter than W14×228) to achieve the same 4 hour rating.

The October 30, 1969 letter from Linn to Di Bono did not make explicit reference to the required thickness of thermal insulation for core box columns or exterior built-up columns. Alcoa was the supplier of the aluminum cladding on the exterior columns (Contract WTC 400.00). As indicated in Fig. A-18 of Appendix A, Alcoa's contract included providing thermal insulation for the exterior columns and spandrels. The following "Note 11 " was included among the "General Notes" of the Alcoa drawings for exterior cladding (See Appendix A Fig. A-25):

11. Exterior column and spandrel fireproofing-Cafco Blaze Shield Type D Fireproofing. Interior column and spandrel fireproofingVermiculite plaster aggregate fireproofing with finished plaster coat on exposed areas of columns. ( $3 \mathrm{hr}$ on spandrels, $4 \mathrm{hr}$ on cols) 


\begin{tabular}{llc} 
& \multicolumn{2}{l}{ Fireproofing Thickness } \\
Rating & Cafco & Vermiculite Aggregate \\
$4 \mathrm{hr}$ (heavy column) & $13 / 16^{\prime \prime}$ & $7 / 8^{\prime \prime}$ \\
$3 \mathrm{hr}$ (spandrels) & $1 / 2^{\prime \prime}$ & $1 / 2^{\prime \prime}$
\end{tabular}

Note the $4 \mathrm{~h}$ and $3 \mathrm{~h}$ ratings within the parentheses are consistent with Class $1 \mathrm{~A}$ construction.

In a letter dated July 25, 1966, from Emery Roth and Sons to the Port of New York Authority, it is stated "Since the deck is non-structural it will not be fire proofed" (see Appendix A Fig. A-26). As discussed in Section 3.7, photographs taken after construction show that in some areas the underside of the metal deck was not protected, while in other areas fire-resistive material appears to be present but of undetermined thickness and possibly resulting from over spray. Photographs also show that the dampers and damper saddles were not protected. Additionally, it is unclear whether the bridging trusses were required to be protected in all areas.

On April 13, 1970, New York City issued restrictions on the application of sprayed thermal insulation containing asbestos. Since asbestos fiber was a key component of BLAZE-SHIELD Type D, the use of this material was discontinued in 1970 at the 38 th floor of WTC 1 (see Appendix A Fig. A-27). The asbestos-containing material was "subsequently encapsulated with a spray-on hardening material" and left in place. Thermal protection of the remaining floors of WTC 1 and all of WTC 2 was carried out using BLAZE-SHIELD Type DC/F, a product that contained mineral wool (glassy fibers) in place of the crystalline asbestos fibers. In May 1970, the construction manager for the World Trace Center wrote a memorandum that summarized considerations in changing from Type D to Type DC/F (see Appendix A Fig. A-28). Correspondence dated April 24, 1970 from Underwriters Laboratories, Inc. to the Port Authority) stated that the thermal properties of BLAZE-SHIELD Type DC/F were equal to or "slightly better" than those of BLAZE-SHIELD Type D (see Appendix A Fig. A-29). There is no record that the required thickness of the fire-resistive material was reconsidered following the change to Type DC/F.

Table 3-2 summarizes information on the fire-resistive materials for the WTC towers after April 1970 based on the reviewed construction documents and correspondence. The "Implied Class" refers to the construction classification implied by the hourly ratings or classification mentioned in correspondence and construction documents. 
Table 3-2. Specified fire-resistive materials after April 1970.

\begin{tabular}{|c|c|c|c|c|c|}
\hline $\begin{array}{l}\text { Structural } \\
\text { Component }\end{array}$ & Members & Material & $\begin{array}{l}\text { Thickness } \\
\text { (in.) }\end{array}$ & $\begin{array}{l}\text { Implied } \\
\text { Class }\end{array}$ & $\begin{array}{l}\text { Rating } \\
\text { (h) }\end{array}$ \\
\hline Floor trusses & All & BLAZE-SHIELD DC/F & $1 / 2$ & $1 \mathrm{~A}$ & 3 \\
\hline \multirow{3}{*}{$\begin{array}{l}\text { Interior } \\
\text { columns }\end{array}$} & $<14$ WF228 & BLAZE-SHIELD DC/F & $23 / 16$ & $1 \mathrm{~A}$ & 4 \\
\hline & $\geq 14 W F 228$ & BLAZE-SHIELD DC/F & $13 / 16$ & $1 \mathrm{~A}$ & 4 \\
\hline & $\begin{array}{l}\text { Box } \\
\text { columns }\end{array}$ & BLAZE-SHIELD DC/F & $\mathrm{NA}^{\mathrm{a}}$ & $1 \mathrm{~A}$ & 4 \\
\hline Interior beams & All & BLAZE-SHIELD DC/F & $1 / 2$ & $1 \mathrm{~A}$ & 3 \\
\hline \multirow{2}{*}{$\begin{array}{l}\text { Exterior } \\
\text { columns }\end{array}$} & $\begin{array}{l}\text { "Heavy" } \\
\text { Exterior } \\
\text { faces }\end{array}$ & BLAZE-SHIELD DC/F & $13 / 16$ & $1 \mathrm{~A}$ & 4 \\
\hline & $\begin{array}{l}\text { "Heavy" } \\
\text { Interior face }\end{array}$ & Vermiculite aggregate & $7 / 8$ & $1 \mathrm{~A}$ & 4 \\
\hline \multirow{2}{*}{$\begin{array}{l}\text { Spandrel } \\
\text { beams }\end{array}$} & $\begin{array}{l}\text { Exterior } \\
\text { face }\end{array}$ & BLAZE-SHIELD DC/F & $1 / 2$ & $1 \mathrm{~A}$ & 3 \\
\hline & Interior face & Vermiculite aggregate & $1 / 2$ & $1 \mathrm{~A}$ & 3 \\
\hline
\end{tabular}

a. NA, not available.

\subsubsection{Report on 1975 Fire}

In February 1975, a fire took place in WTC 1, spreading from the 9th to the 19th floor (Powers 1975) ${ }^{7}$ Most of the damage occurred on the 11 th floor where the fire affected 9,000 $\mathrm{ft}^{2}$. After the fire, the Port Authority contracted Skilling, Helle, Christiansen, Robertson (SHCR) to assess the resulting structural damage and to report, in general, on the fire resistance of the floor system. In its report dated April 1, 1975, SHCR communicated to the Port Authority that the fire did not cause structural damage, but it caused buckling of some top chord members of main trusses, buckling of bridging trusses, and distortion deck support angles (see Appendix A Fig. A-30). The SHCR transmittal letter for the report stated that it was "intended to provide background ... as to the development of the fire-resistive standards for World Trade Center and looks also at the adequacy of existing systems."

In the transmittal letter, SHCR also indicated that it held itself "as a reporter of facts -- as presented in communications gleaned from the files of Port Authority," the architects, and its own files, and that it did "not purport to have any special expertise not commonly held by other structural engineers."

Furthermore, the letter stated that "The only way to assure the existence of the fire safety of floor systems is to be found through the participation of a fire safety engineer and/or fire testing."

The SHCR report suggested that the required thickness of BLAZE-SHIELD for the various structural members could have been determined from catalog information (1966-1967 BLAZE-SHIELD product literature, U.S. Mineral Products Co. [USM]). As mentioned previously, USM's catalog from 1967 indicated that the product had been tested by Underwriters Laboratories, and that for beams, girders, and spandrels, a thickness of $1 / 2$ in. of BLAZE-SHIELD Type D provided a $4 \mathrm{~h}$ rating. As mentioned, the catalog did not provide any information on thermal protection applied directly to members of bar joists.

\footnotetext{
${ }^{7}$ See also NIST NCSTAR 1-4A.
} 
Table 3-3 summarizes the "fire retardant ratings" obtained from Sweets Catalogs ${ }^{8}$ from about 1960 to 1972 for USM's BLAZE-SHIELD products applied directly to beams, girders, and spandrels. The information is based primarily on ASTM E 119 fire endurance tests. The table also presents the thermal conductivity, $k$, for some of the fire-resistive material (the higher the value of $k$, the lower the thermal insulation). Two items are particularly noteworthy. First, the thickness requirement was nearly halved for BLAZE-SHIELD Type D from 1965 to 1966 based on two different test results. Second, the 19661967 fire rating, based on two different test results, using $1 / 2$ in. of the Standard product (with better insulation properties) is one-half of that with $1 / 2$ in. of the BLAZE-SHIELD Type D product.

The 1975 post-fire report by SCHR stated further that thermal protection of the top chord of the floor trusses was not necessary, cxcept for the corner $60 \mathrm{ft} \times 35 \mathrm{ft}$ quadrants of the buildings, where the floor acted as a two-way system in bending. In the one-way portion of the floor, "the concrete slab becomes the dominant element of the top chord." Thus, if the shear knuckle remains intact, "the structural integrity of the top chord is not required." Additionally, for resistance to wind load "the structural steel top chord provides only a small increment in the diaphragm strength," so the insulation may be omitted. (see Appendix A Fig. A-30). The report also stated that fire protection of the bridging trusses was not required because they were used "for reduction in floor 'tremor' and to reduce the effects of differential deflections associated with gravity loads." Bridging trusses were "not required as a part of the structural system" and, therefore, insulation could be omitted from them.

The report also addressed the performance of the floor system in the 1975 fire, stating,

"The fire of February, while reported in the press to have been very hot, did not damage a single primary, fireproofed element. Some top chord members (not needed for structural integrity), some bridging members (used to reduce floor tremor and the like), and some deck support angles (used only as construction devices) were buckled in the fire - all were unfireproofed steel."

In February 2003, NIST asked the Port Authority a series of questions related to the sprayed thermal protection for the floor system. The Port Authority replied in March, and indicated that the top chords of the main trusses and the bridging trusses were protected (see Appendix A Fig. A-31).

\footnotetext{
${ }^{8}$ McGraw Hill Construction, http://sweets.construction.com
} 
Table 3-3. Information in Sweets Catalogs regarding BLAZE-SHIELD products applied directly to beams, girders, or spandrels (with protected deck) from 1960 to 1972.

\begin{tabular}{|c|c|c|c|c|c|c|}
\hline Year & Product & $\begin{array}{l}\text { Reported Thermal } \\
\text { Conductivity, } k \\
\left(\text { Btu.in } /\left(\mathbf{h} \cdot \mathrm{ft}^{2} \cdot{ }^{\circ} \mathrm{F}\right)\right)^{\dagger \S}\end{array}$ & $\begin{array}{c}\text { Hour } \\
\text { Rating } \\
\text { (h) }\end{array}$ & $\begin{array}{c}\text { SFRM } \\
\text { Thickness } \\
\text { (in.) }\end{array}$ & Authority & $\begin{array}{c}\text { UL Design } \\
\text { No. }\end{array}$ \\
\hline \multirow{4}{*}{1960} & \multirow{4}{*}{ BLAZE-SHIELD } & \multirow{4}{*}{0.26} & 4 & $21 / 8$ & UL test R3749-3 & \\
\hline & & & 3 & $17 / 16$ & UL test CR193-2 & \\
\hline & & & 2 & $1 \mathrm{I} / 8$ & UL test CR193-3 & \\
\hline & & & 1 & $3 / 4$ & Extr.BMS-92 & \\
\hline
\end{tabular}

\begin{tabular}{|c|l|l|l|l|l|l|}
\hline \multirow{3}{*}{1965} & \multirow{2}{*}{ BLAZE-SHIELD } & 0.27 & 4 & 1 & ULl \#R3749-8 & \\
\cline { 3 - 7 } & & 3 & $7 / 8$ & UL1\# R3789-2 & \\
\cline { 2 - 7 } & $\begin{array}{l}\text { BLAZE-SHIELD } \\
\text { Type D }\end{array}$ & None & 2 & $1 / 2$ & ULI\# R3749-6 & \\
\hline
\end{tabular}

\begin{tabular}{|l|l|l|l|l|l|l|}
\hline 1966 & $\begin{array}{l}\text { BLAZE-SHIELD } \\
\text { Type D }\end{array}$ & None & 4 & $1 / 2$ & ULI\# R3749-13 & \\
\hline
\end{tabular}

\begin{tabular}{|l|l|l|l|l|l|l|}
\hline \multirow{2}{*}{$1966-$} & $\begin{array}{l}\text { BLAZE-SHIELD } \\
\text { Standard }\end{array}$ & 0.27 & 3 & $7 / 8$ & UL1\# R3789-2 & \\
\cline { 2 - 7 } & $\begin{array}{l}\text { BLAZE-SHIELD } \\
\text { Type D }\end{array}$ & 0.34 & 2 & $1 / 2$ & ULI\# R3749-6 & \\
\hline
\end{tabular}

\begin{tabular}{|c|l|l|l|l|l|l|}
\hline \multirow{2}{*}{1968} & $\begin{array}{l}\text { BLAZE-SHIELD } \\
\text { Standard }\end{array}$ & 0.27 & 2 & $1 / 2$ & ULI\# R3749-6 & \\
\cline { 2 - 7 } & $\begin{array}{l}\text { BLAZE-SHIELD } \\
\text { Type D }\end{array}$ & 0.34 & 4 & $9 / 16$ & ULI\# R3749-20 & \\
\cline { 3 - 7 } & & 4 & $1 / 2$ & ULI\# R3749-13 & \\
\hline
\end{tabular}

\begin{tabular}{|l|l|l|l|l|l|l|}
\hline \multirow{3}{*}{1970} & \multirow{2}{*}{$\begin{array}{l}\text { BLAZE-SHIELD } \\
\text { Type D }\end{array}$} & \multirow{2}{*}{ None } & 4 & $9 / 16$ & & $98-3 \mathrm{HR}$ \\
\cline { 4 - 7 } & & 4 & $1 / 2$ & & $86-3 \mathrm{HR}$ \\
\cline { 3 - 7 } & & 2 & $1 / 2$ & $54-2 \mathrm{HR}$ \\
\hline
\end{tabular}

\begin{tabular}{|l|l|l|l|l|l|l|}
\hline 1971 & $\begin{array}{l}\text { BLAZE-SHIELD } \\
\text { Type DC/F }\end{array}$ & 0.29 & 4 & $1 / 2$ & & $86-3 \mathrm{HR}$ \\
\cline { 3 - 7 } & & 4 & $9 / 16$ & & $98-3 \mathrm{HR}$ \\
\cline { 3 - 7 } & 2 & $5 / 16$ & & $310-2 \mathrm{HR}$ \\
\hline
\end{tabular}

\begin{tabular}{|l|l|l|l|l|l|l|}
\hline 1972 & \multirow{2}{*}{$\begin{array}{l}\text { BLAZE-SHIELD } \\
\text { Type DC/F }\end{array}$} & 0.29 & 4 & $1 / 2$ & & $86-3 \mathrm{HR}$ \\
\cline { 3 - 6 } & & 4 & $9 / 16$ & & $98-3 \mathrm{HR}$ \\
\cline { 3 - 6 } & 2 & $5 / 16$ & & $310-2 \mathrm{HR}$ \\
\hline
\end{tabular}

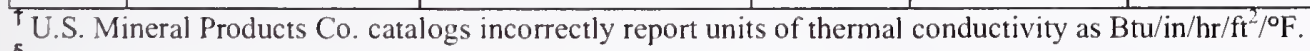

${ }^{5}$ Thermal conductivities are reported only at ambient temperature.

${ }^{\ddagger}$ Reported to be extrapolations based on formulae contained in National Bureau of Standards Rcport, Fire Resistance Classifications of Building Constructions, Building Materials Structures Report, BMS-92, Washington, DC 1942.

"Underwriters Laboratory Inc. 


\subsubsection{In-Place Thickness and Upgrading of SFRM}

No information has been found related to the results of measurements during construction of the thickness of thermal insulation, although thickness appears to have been checked during construction (see Appendix A Fig. A-32). Recorded information on the in-place condition of the sprayed thermal insulation for the floor system first appears in Sample Area Data Sheets from 1990 (see Appendix A Fig. A-33). The data sheets commented on the state of the in-place SFRM. As an example, the data sheet for floor 29 of WTC 1 states the following for the South West quadrant of the floor:

"Fluffy spray-on fireproofing coating the support beams, joists, and deck above the ceiling. The thickness of the material on the beams and joists was consistently about $1 / 2^{\prime \prime}$. Regarding the deck it ranged from very sparse [sic] in areas to $1 / 4 "$ in other areas. The areas we sampled were coated with a light green encapsulant."

Similar statements were recorded for the remaining quadrants of the floor. These inspections were related to litigation related to asbestos and focused on the lower floors of WTC 1, where BLAZE-SHIELD Type D had been applied.

In 1995, the Port Authority performed a study to establish requirements for retrofit of sprayed insulation to the floor trusses during major alterations (new construction) when tenants vacated spaces in the towers (see Appendix A Fig. A-34). The study estimated the thermal protection requirements for the floor trusses of the towers based on "the fireproofing requirements" for Design No. G805 contained in the Fire Resistance Directory (UL 2002) published by Underwriters Laboratories (see Appendix A Fig. A-35). The study concluded that "a two hour fire rating for the steel floor joist trusses can be achieved by applying a $1 \frac{1}{2}$ inch thickness of spray-on mineral fiber fire protection material directly to the steel truss chords and webs." In the years between 1995 and 2001, thermal protection was upgraded in a number of the floors affected by the fires on September 11, 2001. Chapter 4 discusses data made available by the Port Authority on the thickness of the upgraded SFRM.

In 1999, the Port Authority established "guidelines regarding fireproofing repairs, replacement, and upgrades" for the towers (see Appendix A Fig. A-36). The guidelines for tenant spaces may be summarized as follows:

- For full floors undergoing new construction or renovation, the floor trusses should be protected with $1 \frac{1}{2}$ in. of sprayed mineral fiber fire-resistive material. Retrofit of thermal protection requires removal of existing material and controlled inspection.

- For "tenant spaces that are less than a full floor, undergoing either new construction or renovation," the floor trusses "need only meet the original construction standard. Fireproofing shall be inspected and patched as required to the greater of $3 / 4$ " or to match existing" if it has already been upgraded to $1 \frac{1}{2}$ in.

While the primary material used to provide thermal protection to the floor system was BLAZE-SHIELD DC/F, small areas with damaged SFRM were patched using the Monokote fire-resistive material instead of BLAZE-SHIELD. For patching, Monokote was trowelled on rather than sprayed. In February 2000, a consultant to the Port Authority reported that, in the majority of the cases, the existing fire-resistive material required so much patching that it was more effective to replace it (see Appendix A Fig. A-37). 


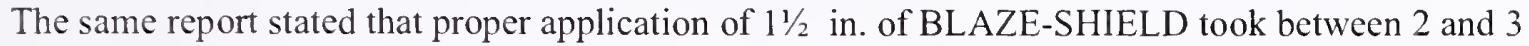
passes. When fewer passes were used, the material usually failed the adhesion tests conducted after application.

The Port Authority provided examples of specifications used in alterations that required reapplication of thermal insulation. Figure A-38 in Appendix A is an excerpt from the specifications related to 1998 upgrades to public corridors and bathrooms on the $15^{\text {th }}, 18^{\text {th }}$, and $22^{\text {nd }}$ floors of WTC 2 . In this case the specified fire resistive material was Monokote 6. Figure A-39 is an excerpt from the specifications for a tenant alteration in 2001 on the $48^{\text {th }}$ floor of WTC 2. It is seen that the 2001 specifications are not as detailed as the 1998 specifications with respect to application of fire resistive material.

Buro Happold, an engineering consultant, was commissioned by the Port Authority to "conduct a fireengineering assessment of the fire-proofing requirements of the open-web, steel joists that support the floors in the tenant areas of Towers 1 and 2 of the World Trade Center." The final report issued in July 2000 , focused on the requirements of the fire resistance of the floor system of the towers. This report stated that BLAZE-SHIELD DC/F was used on the majority of the floor trusses. Based on calculations and risk assessment, the consultant concluded that (see Appendix A Fig. A-40).

- "The structural design has sufficient inherent fire performance to ensure that the fire condition is never the critical condition with respect to loading allowances.

- A single coat application is possible.

- Significant savings are possible.

- The target reduction of fiber content and increased long term durability can be achieved.

- Alternative materials should be considered."

As quoted, the report states that significant savings could be possible by reducing the fiber content and considering alternative materials. The report suggested that the thickness of the SFRM could be reduced to $1 / 2$ in. if the material properties at ambient temperature are valid at higher temperatures (see Appendix A Fig. A-40). The report recognized the lack of available temperature-dependent material data for BLAZE-SHIELD Type DC/F. Thus, considering the uncertainties in the material properties and having the understanding of material degradation with temperature and time, Buro Happold recommended a thickness of $1.3 \mathrm{in}$. of fire-resistive material for the floor trusses.

Later, in December 2000, the final draft of the Property Condition Assessment of World Trade Center Portfolio, prepared by Merritt \& Harris, Inc., was presented to the Port Authority. The report stated that, based on existing conditions (see Appendix A Fig. A-41): "The rating of the structural fireproofing in the Towers and subgrade has been judged to be an adequate 1 hour rating considering the fact that all Tower floors are now sprinklered." The report also noted the ongoing program, established by the Port Authority, to upgrade the fire-resistive material thickness to $1 \frac{1}{2}$ in. in order to achieve a 2 hour fire rating. 


\subsubsection{Need for Fire Endurance Tests}

Section C26-501.1 of the 1968 New York City Building Code had the following requirement with respect to testing to establish fire resistance ratings:

"Tests-Sample of all materials or assemblies of materials required by this code to have a fire-resistance rating, or flame spread rating, or required to be noncombustible, fire-retardant treated, or slow burning shall be tested under the applicable test procedures specified herein... The fire resistance rating of materials and assemblies listed in reference standard RS $5-1^{9}$ may be use to determine conformance with the fire resistance requirements of this code..."

The fire protection of a truss-supported floor system by directly applying sprayed fire-resistive material to the trusses was innovative and not consistent with prevailing practice at the time the WTC towers were designed and constructed. While the benefits of conducting a full-scale fire endurance test were realized by individuals involved in the 1967 demonstrations of the application of SFRM (see Appendix A Fig. A-42), apparently no tests were conducted on the specific floor system used in the WTC towers. Emery Roths \& sons (ER\&S), the Architect of Record, and SHCR, the Structural Engineer of Record, both stated that the fire rating of the floor system of the WTC towers could not be determined without testing (see Appendix A Figs. A-26 and A-43). Communication from the Port Authority in 2003 (see Appendix A Fig. A-31) confirms that there is no record of fire endurance testing of assemblies representing the thermally protected floor system.

In the 1975 post-fire report, the Structural Engineer of Record noted that a floor truss system similar to that used in the WTC had been tested in $1970^{10}$ by Underwriters Laboratories (see Appendix A Fig. A44). This test was unrelated to the WTC project, but the test assembly included trusses from Laclede Steel Co., a normal density concrete floor slab on steel decking, and sprayed thermal insulation. The thermal insulation was Mono-Kote, a gypsum-based product containing vermiculite aggregate. The thermal insulation was $1 \frac{1}{2}$ in. thick on the web bars and $1 / 2$ in. on the sheet metal deck. The test assembly attained a $3 \mathrm{~h}$ rating. In the same 1975 post-fire report, the Structural Engineer of Record noted that Mono-Kote had about twice the thermal conductivity of BLAZE-SHIELD. Based on "many simplifying assumptions" and approximate calculations, it was estimated that $1 / 2 \mathrm{in}$. of BLAZE-SHIELD applied to 1 in. diameter web bars and chord angles thicker than $3 / 16$ in. would provide a $3 \mathrm{~h}$ fire rating (see Appendix A Fig. A-46). He emphasized "however, that theoretical extrapolations of fire endurance tests must the viewed with caution." He stated further in another section of the 1975 report that: "Without benefit of a full-scale fire test we cannot establish a rating for the floor assembly."

\subsubsection{Calculations of SFRM Thickness for Core Members}

In the 1990s, the Port Authority commissioned Leslic E. Robertson Associates (LERA) to perform a series of structural integrity inspections on the WTC towers (see Section 3.6 and NIST NCSTAR 1-1C). One of the tasks was to determine the thickness of fire-resistive material required to re-coat accessible

\footnotetext{
9 Reference Standard 5-1 lists the applicable fire protection standards and includes ASTM Test Method E 119.

${ }^{10}$ The 1975 report refers to the testing date as June 26, 1969. The actual testing date was February 27,1970 . The former date was that of a drawing that was used in designing the fire endurance test. See Appendix A Fig. A-45 for clarification.
} 
beams and columns that had missing thermal insulation within the elevator shafts. Calculations presented in a 1992 report illustrate the accepted procedure used to determine the required thickness based on the size of the members and designs that had been tested and were listed in the Fire Resistance Directory published by Underwriters Laboratory, Northbrook, Illinois. Extracts from the 1992 report are shown in Appendix A Fig. A-47 to illustrate the procedure. The underlying principle is that the SFRM thickness used in the UL fire resistance tests can be modified to provide the same fire resistance rating for similar shaped members, but with different dimensions. These calculations involve a cross-sectional property known as $W / D$, where $W$ is the weight of the structural member per foot and $D$ is the perimeter of the member through which heat is transferred to the steel. A higher value of $W / D$ means that the member has a higher ratio of volume to fire exposed surface area and would require less thickness of thermal insulation to have the same fire rating as a member with a lower $W / D$ value. The UL Fire Resistance Directory, for example, provides equations for computing the required thickness of SFRM for beams and columns that are similar to those in the UL designs, but with different $W / D$ values.

The 1992 LERA calculations were for the accessible columns in elevator shafts 12 and 13 in WTC 1. Thicknesses were determined for four types of fire-resistive materials: Monokote Type Z-106, CAFCO 560, ALBI Duraspray, and ALBI Duraspray 30. These materials are denser and more durable than the SFRM used to protect the floor trusses, and were intended to provide for better performance within the elevator shafts. Table 3-4 lists the calculated thickness of Monokote Z-106 to achieve a 3 h fire rating for the accessible columns in shafts 12 and 13. As noted in Appendix A Fig. A-47, the UL directory provided a thickness conversion equation only for columns protected with Monokote Type Z-106. For the other fire-resistive materials, the required thickness was the same as in the UL listed designs. even if the $W / D$ values of the WTC columns were different. The following were the required thicknesses on the columns for the other SFRMs:

- $\quad$ AAFC 560: thickness $=211 / 16$ in.

- $\quad$ ALBI Duraspray and Duraspray 30: thickness $=111 / 16$ in.

Another example of re-application of SFRM to core members is a 1994 document on "Refireproofing Elevator Shafts $6 \& 71$ WTC" produced for the Port Authority by LERA. The document reported the required thickness of Monokote Z-106 for columns 903 and 904 and for beams A and B in shafts 6 and 7 of Tower 1 (see Appendix A Fig. A-48). Table 3-5 summarizes the thermal insulation thickness requirements for those members. Only floors from the second basement to floor 33 were scheduled for reapplication of thermal insulation. 
Table 3-4. Design thickness of thermal insulation for reapplication to accessible columns in elevator shafts 12 and 13 of WTC 1.

\begin{tabular}{|c|c|c|}
\hline \multirow[b]{2}{*}{ Floor } & \multicolumn{2}{|c|}{ Monokote Type Z-106 } \\
\hline & UL-Design & $\begin{array}{l}\text { Calculated } \\
\text { Thickness }\end{array}$ \\
\hline \multicolumn{3}{|c|}{ Column 601} \\
\hline $69-79$ & $15 / 16$ in. & $15 / 16$ in. \\
\hline $63-68$ & $15 / 16$ in. & $13 / 16$ in. \\
\hline $48-62$ & $15 / 16$ in. & $11 / 16$ in. \\
\hline $43-47$ & $15 / 16$ in. & $9 / 16$ in. \\
\hline 41,42 & $15 / 16$ in. & $7 / 16$ in. \\
\hline $33-40$ & $15 / 16$ in. & $9 / 16$ in. \\
\hline $18-32$ & $15 / 16$ in. & $7 / 16$ in. \\
\hline $7-17$ & $3 / 8$ in. & $3 / 8$ in. \\
\hline Elevation $274-6$ & $3 / 8$ in. & $3 / 8$ in. \\
\hline \multicolumn{3}{|c|}{ Column 602} \\
\hline $69-79$ & $15 / 16$ in. & $7 / 8$ in. \\
\hline $54-68$ & $15 / 16$ in. & $5 / 8$ in. \\
\hline $43-53$ & $15 / 16$ in. & $9 / 16$ in. \\
\hline 41,42 & $3 / 8 \mathrm{in}$. & $3 / 8$ in. \\
\hline $36-40$ & $15 / 16$ in. & $9 / 16$ in. \\
\hline $18-35$ & $15 / 16$ in. & $7 / 16$ in. \\
\hline $7-17$ & $3 / 8$ in. & $3 / 8$ in. \\
\hline Elevation $274-6$ & $3 / 8$ in. & $3 / 8$ in. \\
\hline \multicolumn{3}{|c|}{ Columns 501 and 502} \\
\hline Elevation 310 & $3 / 8$ in. & $3 / 8$ in. \\
\hline
\end{tabular}

${ }^{11}$ This refers to the ID number in the NIST document database. 
Table 3-5. Design thickness of thermal insulation for reapplication to accessible
columns and beams in elevator shafts 6 and 7 of WTC1.

\begin{tabular}{|c|c|c|c|c|}
\hline Floor & Column 903 & Column 904 & Beam A & Beam B \\
\hline B2 & $3 / 8$ in. & $7 / 16$ in. & Note 1 & $15 / 16$ in. \\
\hline B1 & $3 / 8$ in. & $7 / 16$ in. & $1 / 2$ in. & Note 1 \\
\hline Elevation 294 & $3 / 8$ in. & $7 / 16$ in. & $7 / 16$ in. & $15 / 16$ in. \\
\hline 1 & $3 / 8$ in. & $7 / 16$ in. & $7 / 16$ in. & $11 / 16$ in. \\
\hline Intermediate & $3 / 8$ in. & $7 / 16$ in. & $1 / 2$ in. & Note 1 \\
\hline 2 & $3 / 8$ in. & $7 / 16$ in. & $1 / 2$ in. & 1 in. \\
\hline $3-7$ & $3 / 8$ in. & $7 / 16$ in. & $1 / 2$ in. & $13 / 16$ in. \\
\hline $8-18$ & $3 / 8$ in. & $1 / 2$ in. & $1 / 2$ in. & $13 / 16$ in. \\
\hline $19-33$ & $3 / 8$ in. & $5 / 8$ in. & $1 / 2$ in. & $13 / 16$ in. \\
\hline
\end{tabular}

Key: Note $1=$ Beams are concrete encased. Source: 1994 LERA calculations (659-P).

\section{6}

\section{MAINTENANCE OF SFRM IN ELEVATOR SHAFTS}

Based on inspection reports reviewed by the investigation team, the structural members that required the largest amount of inspection and maintenance within the core were the exposed columns and beams within the elevator shafts (see also NIST NCSTAR 1-1C). These columns and beams were the only accessible fire-protected elements in the buildings. Adhesion failures were common, likely because of the exposed conditions of the columns (see Appendix A Fig. A-49) and the inherently low strength of the SFRM.

\subsubsection{Bond Strength}

Internal memoranda from U.S. Mineral Products Co., dating from 1960 to 1969, warned of the poor adherence or bond performance of BLAZE-SHIELD, and specifically BLAZE-SHIELD Type D. As communicated in an intra-office memorandum dated July 29, 1960, vibration tests performed in 1960 apparently indicated poor bond characteristics of CAFCCO BLAZE-SHIELD as manufactured in the plant compared with laboratory mixtures (see Appendix A Fig. A-50).

In March 1968, the Port Authority investigated the adherence of BLAZE-SHIELD Type D under field conditions. Based on letters from both U.S. Mineral Products Co. and Mario \& Di Bono Plastering Co. relative to an "on-the-job" application of BLAZE-SHIELD in January 1968 to evaluate the ability of the material to adhere to the steel and to itself, the Port Authority stated in March 1968 that "this material can be applied successfully to the exterior steel under adverse weather conditions" (see Appendix A Fig. A-51). The Port Authority transmitted this information to the New York City Department of Buildings in January 1970 along with a U.S. Mineral Products Co. report on the material and application techniques and a product catalog (see Appendix A Fig. A-52).

Adhesion problems with BLAZE-SHIELD Type D, however, were reported in December 1969 during construction of the World Trade Center. U.S. Mineral Products Co. intra-office correspondence on December 11, 1969 stated that "Of the 20 tons [ $800 \mathrm{bags}$ ] of material sprayed to the $10^{\text {th }}$ floor exterior 
columns on this project, approximately 600-700 bags of the material washed off as clean as a whistle from the exterior columns on this job" (see Appendix A Fig. A-53).

\subsubsection{Inspections}

Personnel of the World Trade Center Department inspected sprayed thermal insulation during construction. After one of these inspections in 1971, the inspector wrote "it was noted that the Cafco fireproofing treated with Mark II overspray had not cured or hardened according to specifications" due to the extremely cold temperature conditions existing during construction (see Appendix A Fig. A-54). The inspector recommended that shafts 39,40 , and 41 of WTC 1 be re-sprayed with Mark II sealer. Additional WTC office correspondence dated September 24, 1973 mentioned that the sprayed thermal insulation had come loose and fallen from perimeter box beams in elevator shafts 10 and 11 of WTC 2 (see Appendix A Fig. A-55).

In 1993, the Port Authority commissioned Leslie E. Robertson Associates to carry out a continuing program to appraise the condition of the accessible columns in the World Trade Center complex. These inspection programs are described in greater detail in NIST NCSTAR 1-1C. Accessible columns were those columns that were not enclosed in any kind of architectural finish and could be inspected visually. All accessible columns were located in the core of the towers. The columns were inspected visually for signs of rusting, cracking, bowing, and loss of thermal insulation. During the first inspection, carried out in 1993, particular shafts were chosen based on the quantity and types of accessible columns, and convenience to the Port Authority. The findings were summarized in LERA's Structural Integrity Inspection Report for Accessible Columns at 1, 2, 4, and 5 WTC dated 29 January 1993 (see Appendix A Fig. A-56).

Subsequent inspections involved sampling of the structural components and assemblies, which were more important to the structural integrity of the towers, and at locations with a relatively higher potential for defects and problems. As indicated in the Structural Integrity Inspection Report dated 14 April 1995, a statistical sampling approach was used since concurrent visual inspection of all the accessible columns was "not a practical goal" (see Appendix A Fig. A-57). The report stated that the accessible columns in selected elevator shafts in WTC 1 and 2 were "generally in good condition, no structural deficiencies such as cracking or bowing were found, the most common irregularities observed were missing fireproofing and light surface rusting of the exposed steel." Based on the inspections, LERA recommended "that remedial action to be taken where spray fireproofing is damaged, deteriorated or missing and where there is corrosion of the column base due to water leaks at elevator pits." LERA also recommended painting steel with a zinc-rich paint on areas affected by water leaks prior to re-fireproofing. Refer to NIST NCSTAR 1-1C for a comprehensive discussion of the structural integrity inspection reports.

\subsection{GENERAL CONDITIONS OF SFRM ON FLOOR TRUSSES}

In accordance with the descriptions of the structural systems described in NIST NCSTAR 1-2A, it was estimated that each floor that was supported by trusses contained about 4,350 lineal $\mathrm{ft}$ of main trusses. Since main trusses are composed of two trusses side-by-side (see Fig. 3-2), there were over 8,700 ft of main trusses per floor. In addition, each floor contained about 2,000 lineal $\mathrm{ft}$ of bridging trusses. Thus, each floor contained over 10,500 lineal feet (or about two miles) of floor trusses. The actual length of members that had to be protected with SFRM was, however, at least twice this length, because each truss 
cross section included two chord members and a web bar. In order to understand whether the condition of the thermal insulation played a dominant role in the outcomes on September 11, it was desirable to have information on the general conditions of the SFRM. Since the total collapses of the buildings dislodged the SFRM, it was necessary to rely on available photographic evidence.

Two series of photographs provided some insight on the prevailing conditions of the SFRM on the floor system. One of these was a series of photographs was taken in the mid-1990s by Morse Zehtner Associates and included images from floors 12, 22, 23, and 27 of WTC 1 and floor 26 of WTC 2. These photographs showed the following conditions of the thermal protection applied to the truss-supported floors:

- Some floor trusses had good coverage with SFRM, but the average thickness was not uniform along the lengths of web bars (see Fig. 3-5).

- Bridging trusses did not appear to have as much SFRM applied (see Fig. 3-6). As mentioned in Section 3.5.2, the Engineer of Record stated that bridging trusses did not require thermal protection.

- $\quad$ The SFRM applied to the truss seats at the spandrel beams appeared to be thin (see Fig. 3-7).

- In some cases, the ends of main trusses near the spandrel beams appeared to have thinner SFRM, and the saddles and dampers were not protected (see Fig. 3-7 and Fig. 3-8).

- The SFRM thickness on web bars appeared low in the vicinity of where they connected to the chords (see Fig. 3-5 and Fig. 3-9).

- The metal decking did not appear to have been protected, which is consistent with the requirements stated by the Architect of Record (see Section 3.5.1).

- Some damage to SRM was caused when utilities (HVAC, electrical, network cabling, and so forth) were installed within the ceiling space occupied by the floor trusses (see Fig. 3-10).

A second series of photographs showed the conditions on the $85^{\text {th }}$ floor of WTC 2 prior to removal (by water blast) of SFRM by the tenant, who was conducting a major alteration of the space including an upgrade to the thermal insulation in accordance with the guidelines discussed in Section 3.5.3. Photographs $^{12}$ and video were taken on March 8, March 20, April 13, and July 17, 2001. The photographs include close-up views of different features of the thermal insulation applied to the floor trusses and overall views of large sections of the floor truss system, before and aftcr removal of the SFRM. Based on these photographs, the following observations were made:

- There were no examples of total absence of SFRM on trusses that had not becn cleaned by water blasting.

\footnotetext{
${ }^{12}$ Photographs and videotapes were provided by the former tenant, Harris Beach LLP. They were taken for the tenant by a hired photographer (Forensic Photography International). NIST was not able to locate the photographer to obtain permission to reproduce the photographs in this report. The photographs, however, are available for viewing at NIST and have been assigned ID number 223-I.
} 
- Areas where SFRM had been dislodged had been repaired using a trowel-applied material. Some of the repairs on lower chords were incomplete, but it is not known whether these repairs had failed or if the repair material had purposely not been applied to some portions of the chords.

- There were many instances where SFRM had obviously been dislodged in the process of installing utilities. In some cases hardware was attached directly to the lower chords and SFRM was dislodged. These damaged areas should have been repaired when the various trades had completed their work.

- The overall views of the trusses showed that regions of missing insulation where minor in extent when compared with the total area of applied SFRM.

In comparing the overall condition of the SFRM as indicated by these two series of photographs, the following differences were noted:

- The photographs taken in the 1990 s of the lower floors appeared to show more instances of thinly applied SFRM than the photographs of the $85^{\text {th }}$ floor taken in 2001.

- The photographs taken in the 1990s appeared to show less damage as a result of installation of utilities and other services within the space occupied by the trusses. 


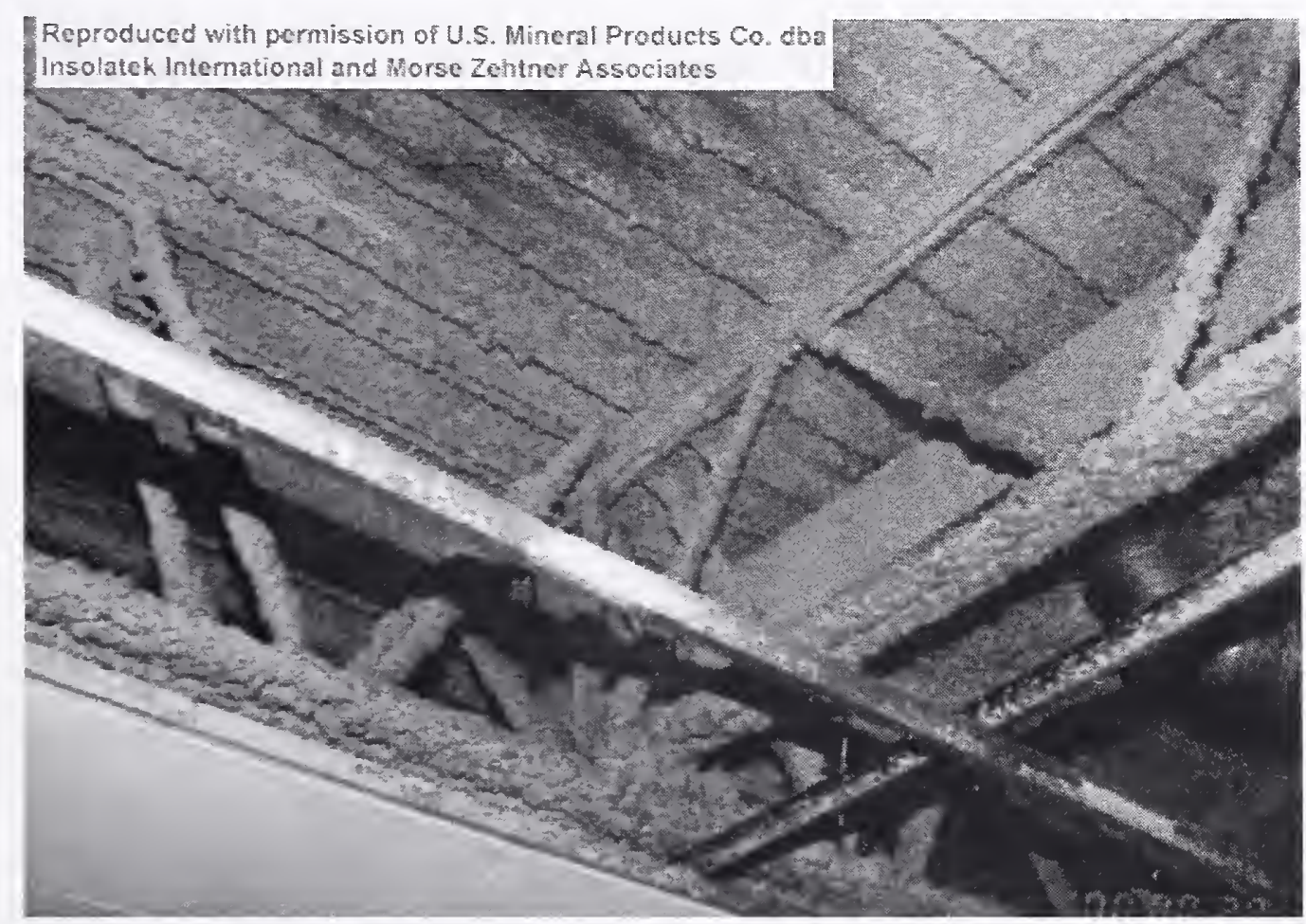

Figure 3-5. Intersection of main truss and bridging truss showing general good coverage of SFRM on truss members but thickness varies on web bars.

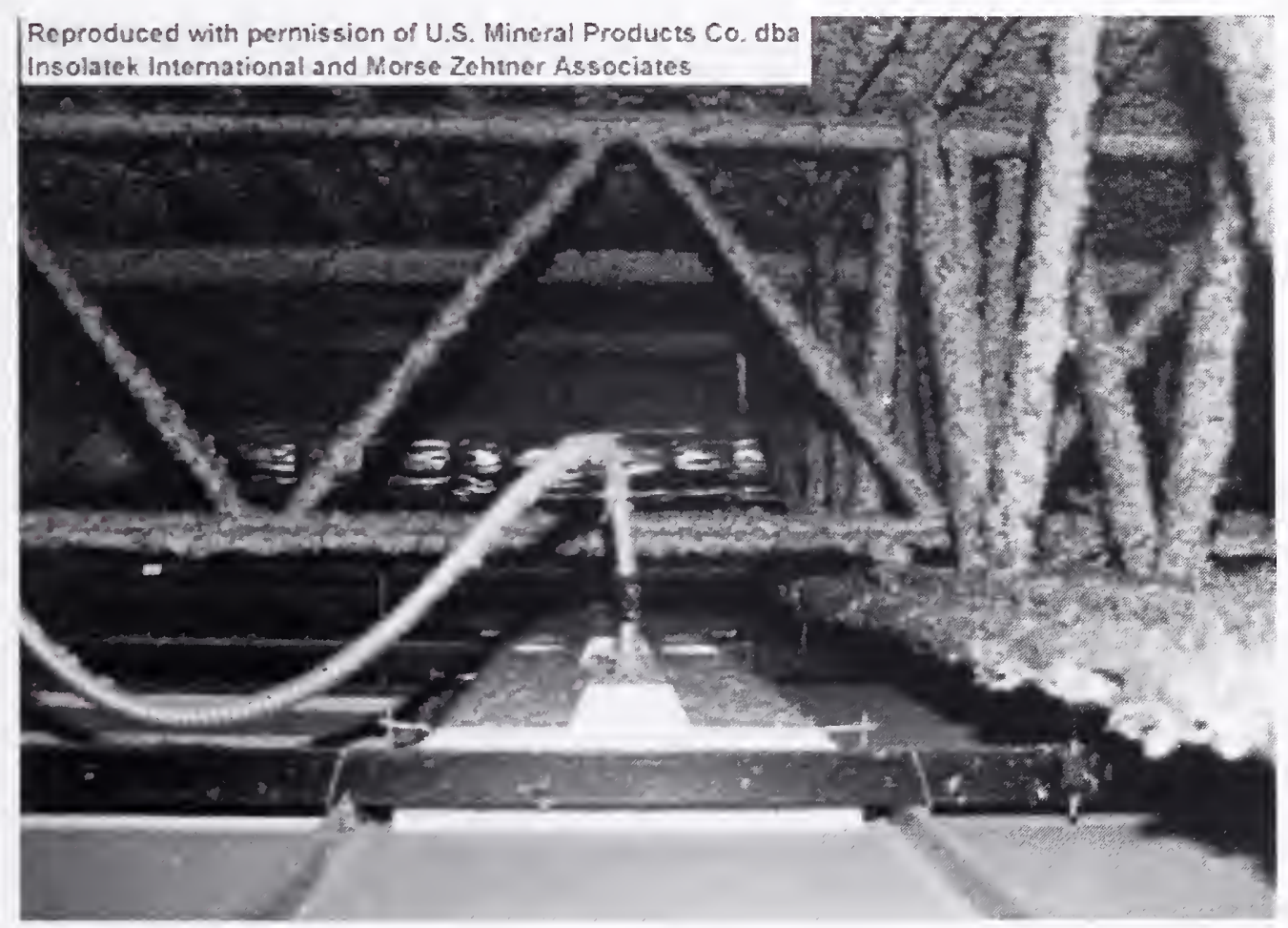

Figure 3-6. Intersection of main truss and bridging truss showing thinner SFRM on members of bridging truss. 


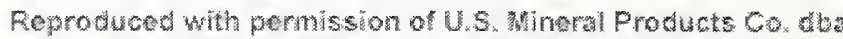
Insolwtok International and Mors Zehtnor Associates

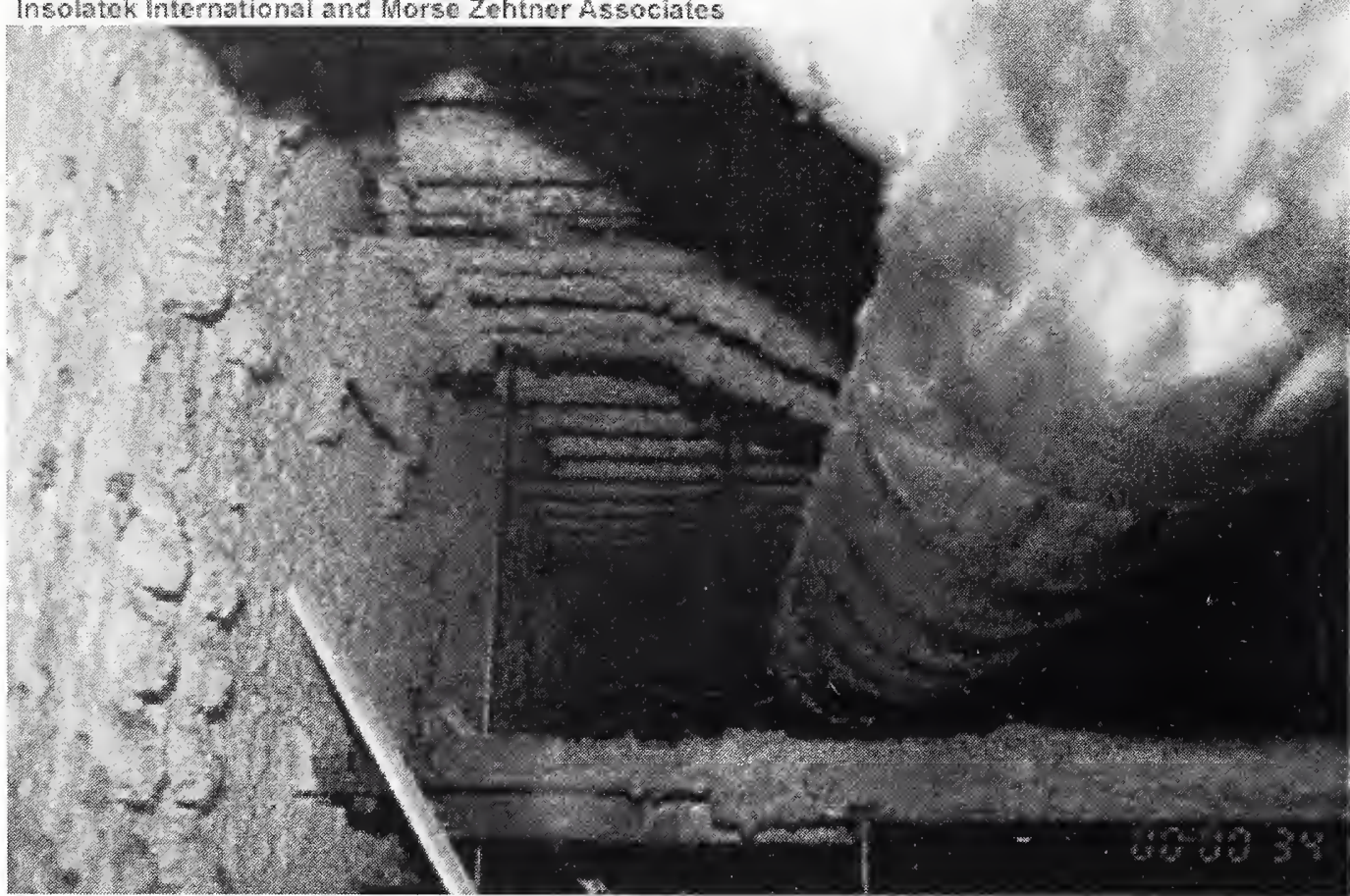

Figure 3-7. Connection of main truss to spandrel beam showing relatively thin SFRM on truss seat and no SFRM on damper.

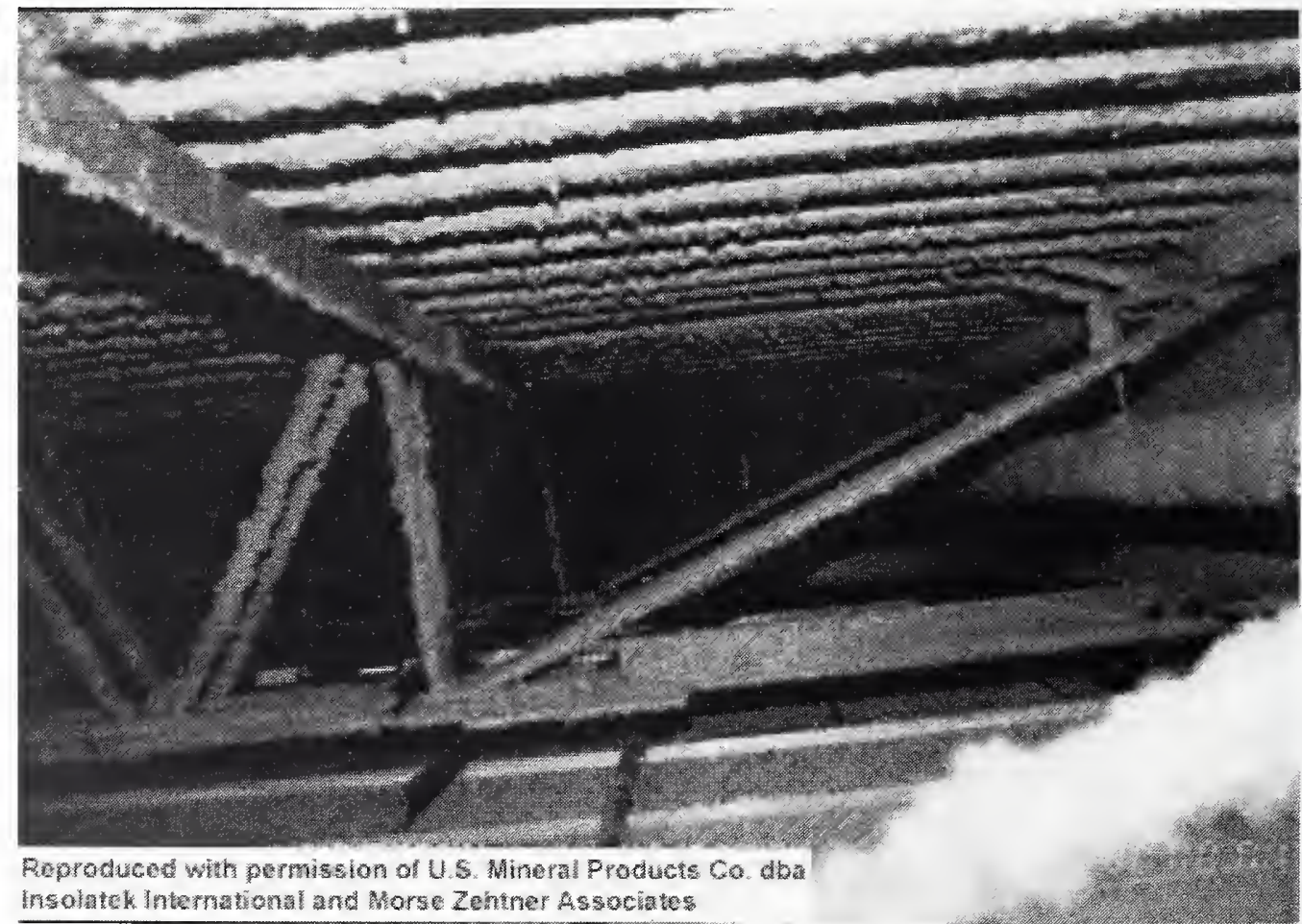

Figure 3-8. End of main truss showing low thickness of SFRM on truss members and no SFRM on damper saddle. 


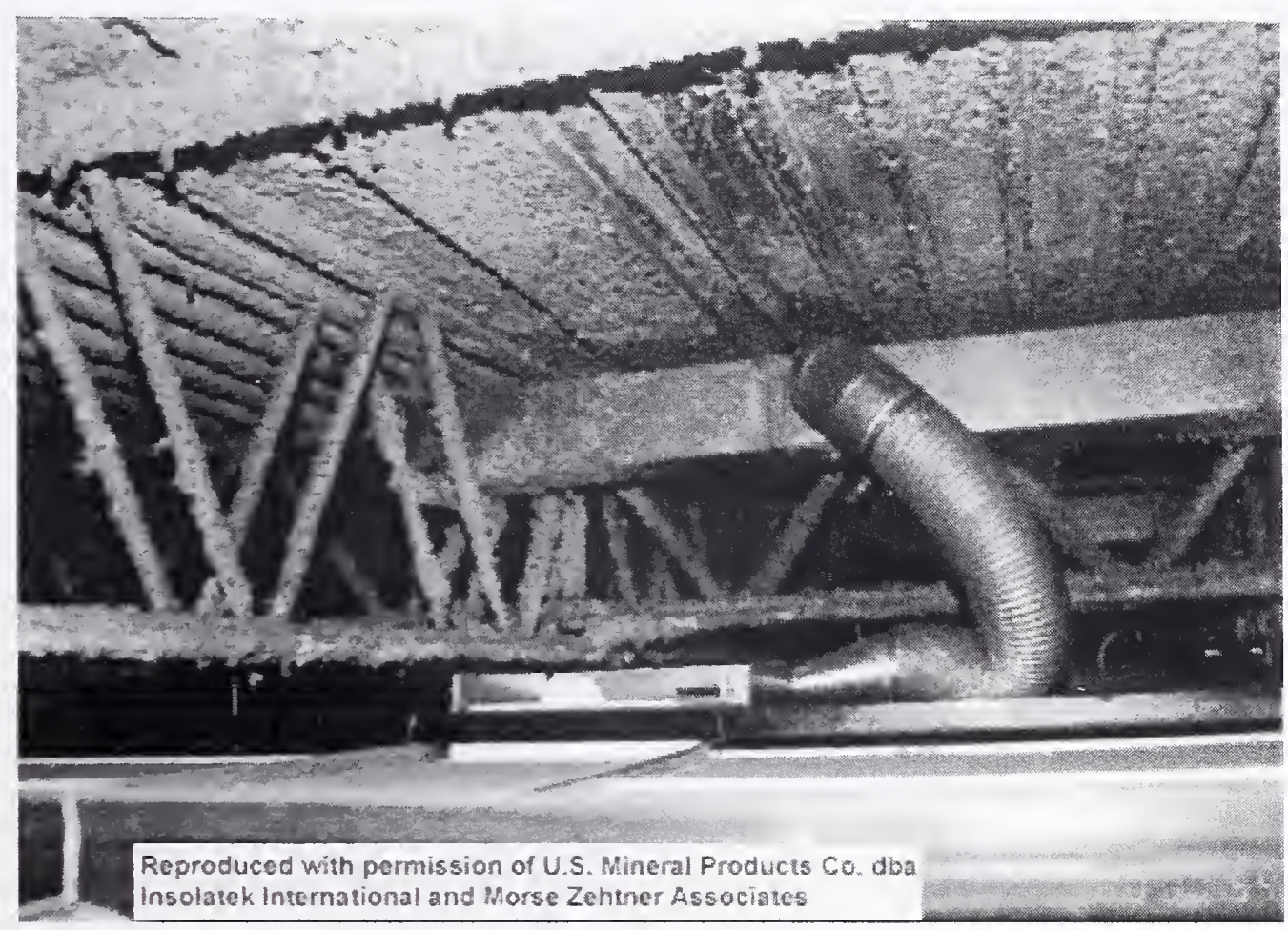

Figure 3-9. Intersection of main truss and bridging truss showing thin SFRM on the ends of some web bars; SFRM was not applied to the metal decking.

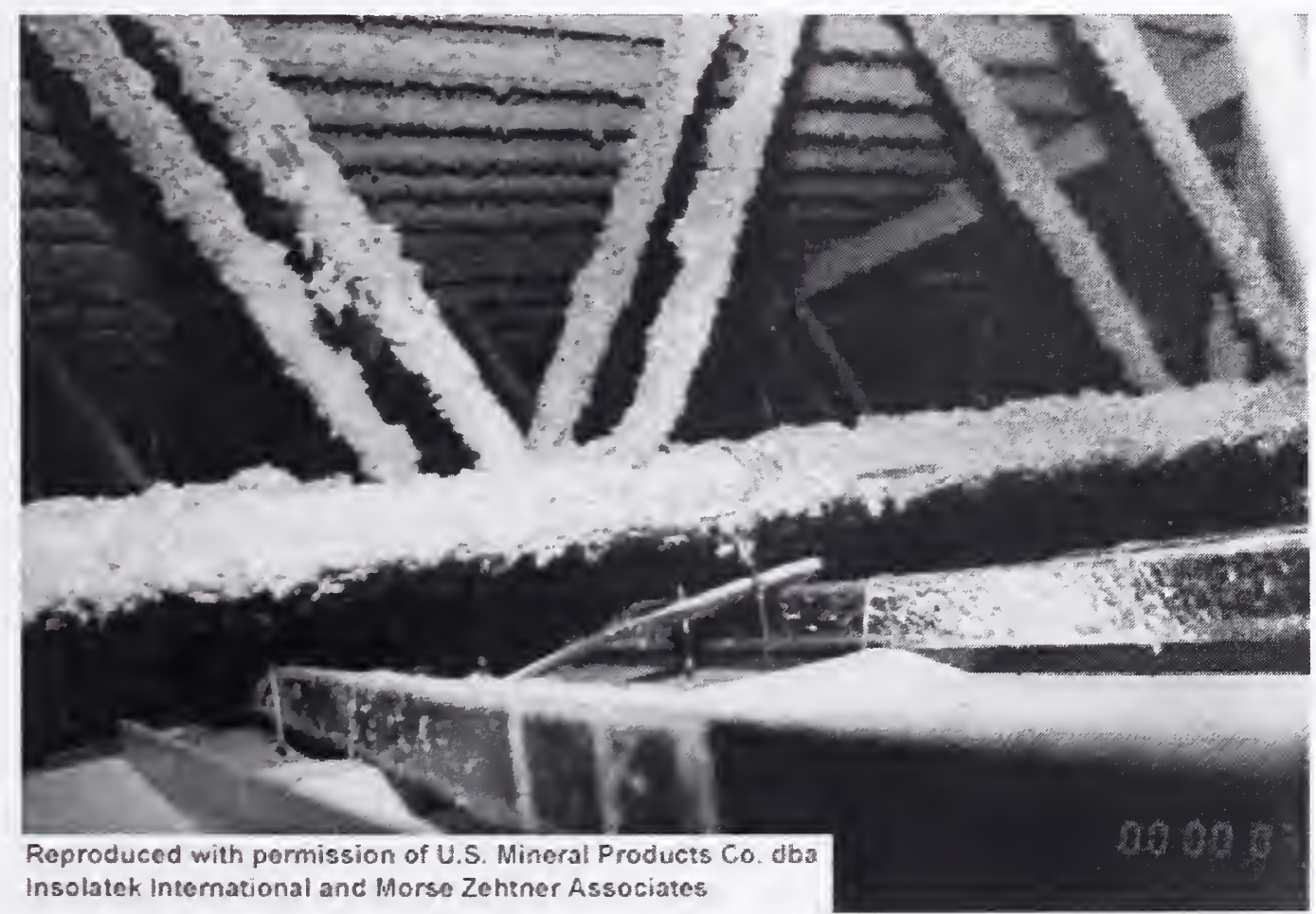

Figure 3-10. Example of damage to SFRM during installation of utilities. 
This page intentionally left blank. 


\section{Chapter 4 \\ AS-APPLIED THICKNESS OF SFRM}

Because both towers collapsed totally on September 11, 2001, and most of the spraycd fire-resistive material (SFRM) was either dislodged or abraded (or scraped) off in the collapse, no examples remain of the "as installed" condition of the SFRM. To make an estimate of the as-applied thickness and variability in thickness, several sources of information were used, including measurements taken by the Port Authority, condition surveys and anecdotal information, and photographs and video clips showing the condition of the fire-resistive material in selected areas. Each of the structural components or systems is considered here separately.

\section{$4.1 \quad$ TRUSS-SUPPORTED FLOOR SYSTEM}

As mentioned in Section 3.5.3, qualitative information on the in-place condition of the SFRM for the floor system first appeared in Sample Area Data Sheets from 1990. Information regarding quantitative inspection of existing fire-resistive material appears in documentation from 1994. That ycar, the Port Authority performed a series of thickness measurements of the existing SFRM on floors 23 and 24 of WTC 1 (see Appendix A Fig. A-58). Six measurements were taken from "both flanges and web" of each of 16 randomly chosen trusses on each floor at those locations where the SFRM was not damaged or absent. The averages of six measurements per joist that were recorded on the two floors are presented in Table 4-1. Measured average thickness varied between 0.52 in. and $1.17 \mathrm{in}$. For the 32 measurcments ( 16 on each floor), the overall average was $0.74 \mathrm{in.} \mathrm{Four} \mathrm{of} \mathrm{the} 32$ floor trusses had averagc thicknesses between $0.52 \mathrm{in}$. and $0.56 \mathrm{in}$. These measurements suggest that the minimum average thickness exceeded $1 / 2$ in.

As shown in Fig. A-58 in Appendix A, it was stated that, on floor 23,

"... truss members located adjacent to the outside walls (within $3 \mathrm{ft}$ ) are devoid of fireproofing material. Visual inspection on floor 24 was not possible, as this area still has a lowered ceiling in place."

The data in Table 4-1 can be examined further to understand the variability of the SFRM thickness in the non-upgraded locations. Figurc 4-1 (a) shows the average thicknesses measured on the floor trusscs of floors 23 and 24. The values appear to be similar for the two locations in terms of overall average thicknesses and the variation in average thickness. A formal analysis of variance indeed indicated no statistically significant differences between thc overall mean thicknesses for the two floors. Thus, the two groups of data can be combined into one group.

Figure 4-1(b) is a normal probability plot of the average thicknesses shown in Table 4-1. If the data were from the same distribution they would fall approximately on a straight line in the normal probability plot. This is expected from the central limit theorem, which states that the sampling distribution of the average of $N$ samples from a distribution with mean $\mu$ and variance $\sigma^{2}$ approaches a normal distribution with mean $\mu$ and variance $\sigma^{2} / \mathrm{N}$ as $\mathrm{N}$ increases (Miller and Freund 1965). It is seen that four points deviate from an approximately linear relationship. It is, therefore, reasonable to conclude that those points do not 
belong to the same distribution. These four values are identified with an asterisk in Table 4-1.

Figure 4-1(c) is a normal probability plot with the four values (actually six points) excluded. It is seen that the remaining points fall close to a straight line. The intercept $(0.74 \mathrm{in})$ and slope $(0.12 \mathrm{in}$.) of the straight line are the mean and standard deviation of the distribution, respectively. Since each of the averages in Table 4-1 is obtained from six individual measurements, an estimate of the standard deviation of the individual measurements of SFRM thickness is $0.12 \sqrt{6} \approx 0.3 \mathrm{in}$.

Table 4-1. Average fireproofing thickness from six measurements taken in 1994 on each of 16 random floor trusses on floors 23 and 24 of WTC 1.

\begin{tabular}{|c|c|}
\hline \multicolumn{2}{|c|}{ Fireproofing Thickness (in.) } \\
\hline Floor 23 & Floor 24 \\
\hline 0.60 & 0.76 \\
\hline $0.53^{*}$ & 0.60 \\
\hline 0.70 & 0.90 \\
\hline 0.76 & 0.72 \\
\hline 0.88 & 0.64 \\
\hline 0.89 & 0.80 \\
\hline 0.83 & 0.68 \\
\hline $1.17^{*}$ & 0.65 \\
\hline 0.88 & 0.67 \\
\hline 0.71 & 0.77 \\
\hline 0.82 & 0.96 \\
\hline $0.52^{*}$ & 0.66 \\
\hline 0.69 & 0.65 \\
\hline $0.52^{*}$ & $1.11^{*}$ \\
\hline 0.64 & 0.95 \\
\hline $0.52^{*}$ & 0.56 \\
\hline
\end{tabular}

*Not considered in estimating thickness variability.

Source: Data provided by Port Authority of New York and New Jersey. 

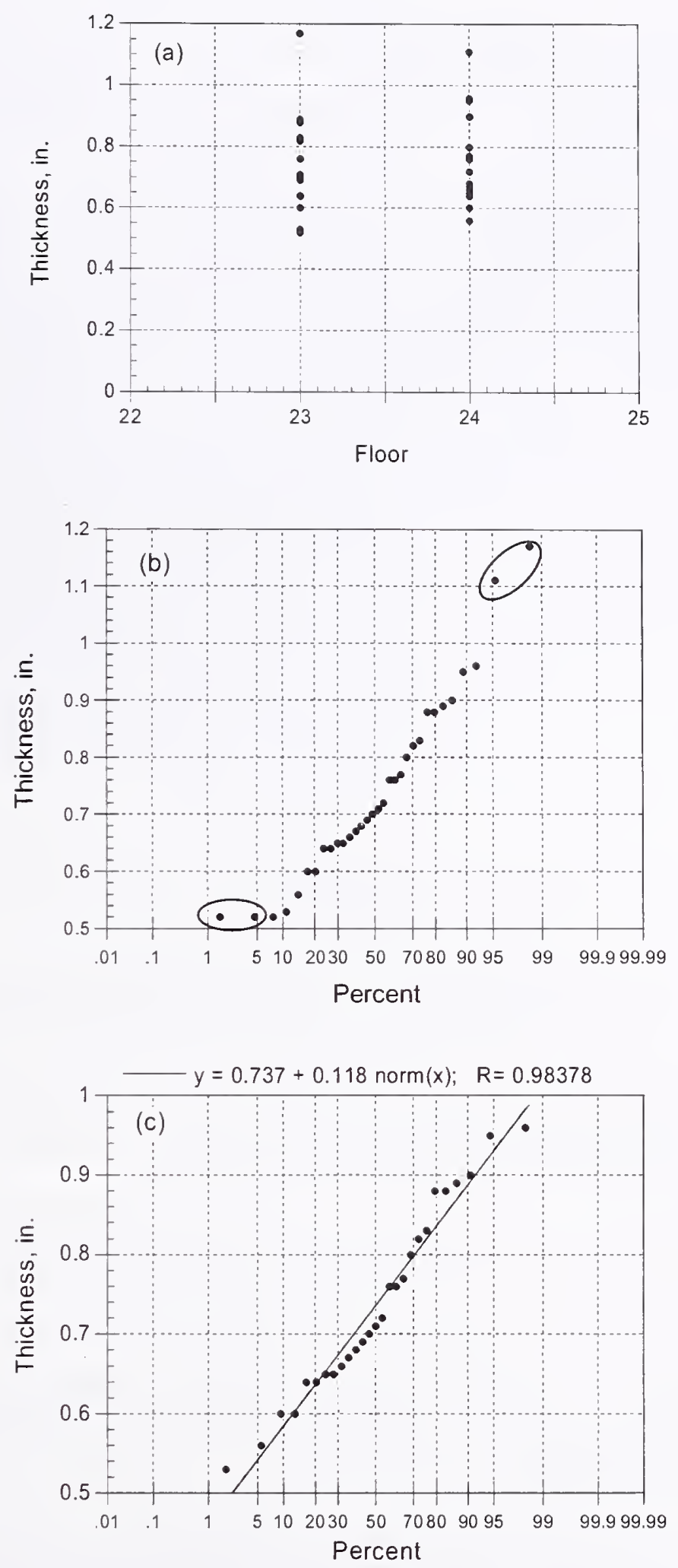

Figure 4-1. (a) Dotplot of average thickness from floor trusses for floors 23 and 24, (b) normal probability plot of all average thickness values, and (c) normal probability plot of average thickness with four values (six points) excluded. 


\subsection{ANALYSIS OF PHOTOGRAPHS}

Additional data regarding the thickness of SFRM was gathered by evaluating photographic evidence. Although photographic evidence of the state of the SFRM was limited, two groups of photographs were located and used for estimating SFRM thickness.

The first group of photographs was provided to NIST by Morse Zehnter Associates and includes images of floor trusses from WTC 1 (floors 12, 22, 23, and 27) and WTC 2 (floor 26). From this group, only photographs from floors 22, 23, and 27 of WTC 1 were analyzed. Photographs provided by Morse Zehnter Associates were taken in the mid-1990s and illustrate the fire-resistive material conditions prior to the upgrade carried out by the Port Authority. Thus, SFRM thickness on the photographed trusses would be expected to be at least $1 / 2$ in. as specified by the Port Authority on October 1969.

The second group of photographs, taken in 1998, was provided by Gilsanz Murray Steficek (consulting engineers). This group illustrates the state of fire-resistive material after the upgrade program that was initiated in 1995. The photographs were of trusses for floor 31 and below in WTC 1.

Selection of which photographed trusses were used to estimate thickness of SFRM was based on clarity of SFRM edges and whether a feature of known dimensions was present to provide a reference measurement. Thus, only photographs where reference measurements could be performed were used. The general approach to the analysis involved the estimation of distances based on the computed reference length per pixel. The procedure is summarized as follows:

- A feature of known dimension (based on construction drawings) that could be used as reference was located in the photograph. For example, the dimension of the bare vertical leg of a damper saddle was a dimension that could be obtained from shop drawings.

- In the photograph, the length of the reference dimension was measured in pixels.

- The scaling factor of length per pixel was computed by dividing the known dimension in inches by the number of pixels. For example, if the vertical leg of the damper saddle was measured as 48.2 pixels in the photograph, and it is known that the actual size of the leg was 3.13 in., the scaling factor would be $3.13 \mathrm{in} . / 48.2$ pixels $=0.065 \mathrm{in} . / \mathrm{pixel}$.

- Only truss webs or struts (diagonal bar at end of truss) located near and in the same plane as the reference object were selected for analysis. This selection was made to minimize error due to perspective.

- It was assumed that the fire-resistive material on web bars was applied evenly around the perimeter of the bar. Based on this assumption, a "virtual" centerline along the length of the bar was drawn in the photograph.

- Lines were drawn perpendicular to the "virtual" centerline. The number of pixels along the lines from the "virtual" centerline to the edge of the SFRM was determined from the cursor positions indicated by the software. Measurements were made at regularly spaced intervals to avoid bias. Figure 4-2 is an example of a series of measurements made on a strut. 
- Each measurement in pixels was multiplied by the scaling factor (in./pixel) to estimate the bar radius plus SFRM thickness. This provides two measurements at each cross section.

- The radius of the bar was subtracted to provide the estimate of the SFRM thickness.

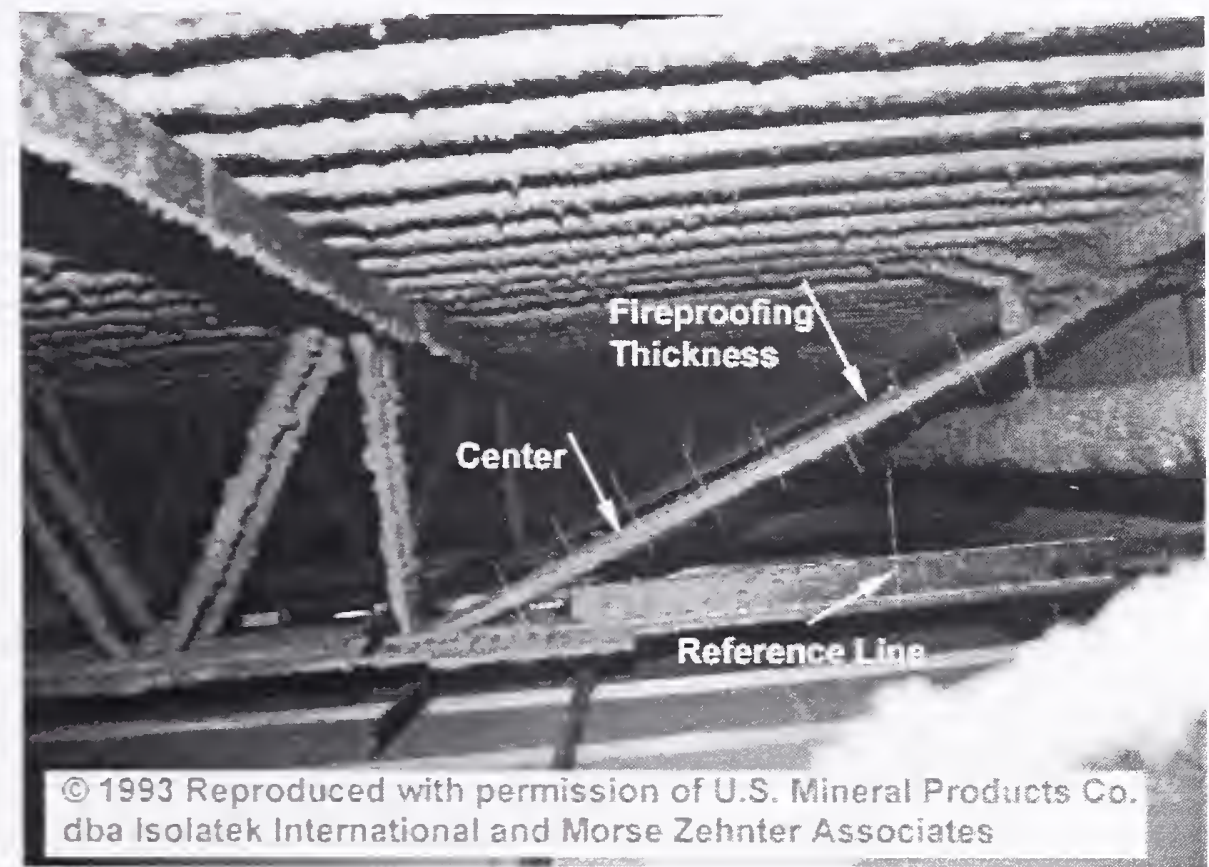

Figure 4-2. Example of measurement procedure used to estimate SFRM thickness from photographs.

For floors that had not been upgraded, it was observed that the estimated thickness of SFRM on the webs of the main trusses tended to be greater than that on either the diagonal struts or on the webs of the bridging trusses. Hence, estimates of SFRM thickness for non-upgraded floors were divided into three groups:

- Webs of main trusses,

- Webs of bridging trusses, and

- Diagonal strut at the exterior wall end of the truss.

It was not possible to estimate the thickness of the SFRM on any truss element except the round web bars Consequently, for the upgraded floors in WTC 1 that were included in the second group of photographs, only estimates of the thickness on the web bars of the main trusses were made. Figure 4-3 (a) shows normal probability plots of the SFRM thickness estimated from the photographs. It is seen that the points for the "upgraded" main trusses follow a generally linear trend, which indicates that the estimated thicknesses for the upgraded main trusses are approximately normally distributed. The estimated thicknesses from the non-upgraded floors, however, do not follow linear trends on the normal probability plot. Figure 4-3 (b) shows normal probability plots of the natural logarithms of the thicknesses. The transformed values for the non-upgraded thermal protection now follow generally linear trends, which 
means that a lognormal distribution is more appropriate for the non-upgraded floors. Thus, there is evidence that the original SFRM thickness on the floor trusses follows a log normal distribution.

The reason for a lognormal distribution for SFRM thickness on the non-upgraded floor trusses can be explained as follows. It is expected that the thickness of SFRM will be variable due to the difficulty in spraying the material on the relatively thin members. If the overall thickness is low and the variability is high, a normal distribution would require a fraction of the surfaces to have negative values of SFRM thickness, which is not possible. If the thickness distribution is lognormal, the thickness cannot be zero, and there is a low likelihood of having thickness close to zero. Thus, from a physical point of view, a lognormal distribution of SFRM thickness is more logical than a normal distribution. If the underlying distribution of SFRM thickness is lognormal, the average thickness overestimates the thickness expected to be exceeded with 50 percent probability, and the median is the appropriate statistic for the 50-percentile value (Melchers 1999).

The average, standard deviation, and coefficient of variation were computed for the total number of measurements in each of these groups. The results are summarized as follows:

- Main trusses before upgrade (85 measurements): Average thickness 0.6 in., standard deviation $=0.3$ in., and coefficient of variation $=0.5 ;$ median $=0.55 \mathrm{in}$.

- Bridging trusses before upgrade (52 measurements): Average thickness 0.4 in., standard deviation $=0.25 \mathrm{in}$., and coefficient of variation $=0.6$; median $=0.36 \mathrm{in}$.

- Diagonal struts before upgrade (26 measurements): Average thickness 0.4 in., standard deviation $=0.2 \mathrm{in}$., and coefficient of variation $=0.5 ;$ median $=0.38 \mathrm{in}$.

- Main trusses after upgrade (52 measurements): Average thickness 1.7 in., standard deviation $=0.4 \mathrm{in}$., and coefficient of variation $=0.2 ;$ median $=1.80 \mathrm{in}$.

\subsection{PORT AUTHORITY DATA ON UPGRADED SFRM ON TRUSSES}

In the 1990s, the floor trusses of several floors were upgraded to a specified thickness of $1 \frac{1}{2} \mathrm{in}$. of fireresistive material as tenants vacated their space. According to correspondence in 2002 (see Appendix A Fig. A-59), the Port Authority indicated that 18 floors of WTC 1 and 13 floors of WTC 2 had been upgraded. The Port Authority also stated that: "The entire impact zone for Tower 1 (92-99) was upgraded with $1 \frac{1}{2}$ " spray-on fireproofing. Only the $78^{\text {th }}$ floor was upgraded with the $1 \frac{1}{2}$ " spray-on fireproofing within the impact zone in Tower 2 (78-84)." The Port Authority provided information from Construction Audit Reports regarding the characteristics of SFRM that was upgraded as of 2000 in the aircraft impacted regions of the WTC towers. The provided test reports state that the material used for the upgrade was BLAZE-SHIELD II (see Appendix A Fig. A-60 for an example of such a report). 

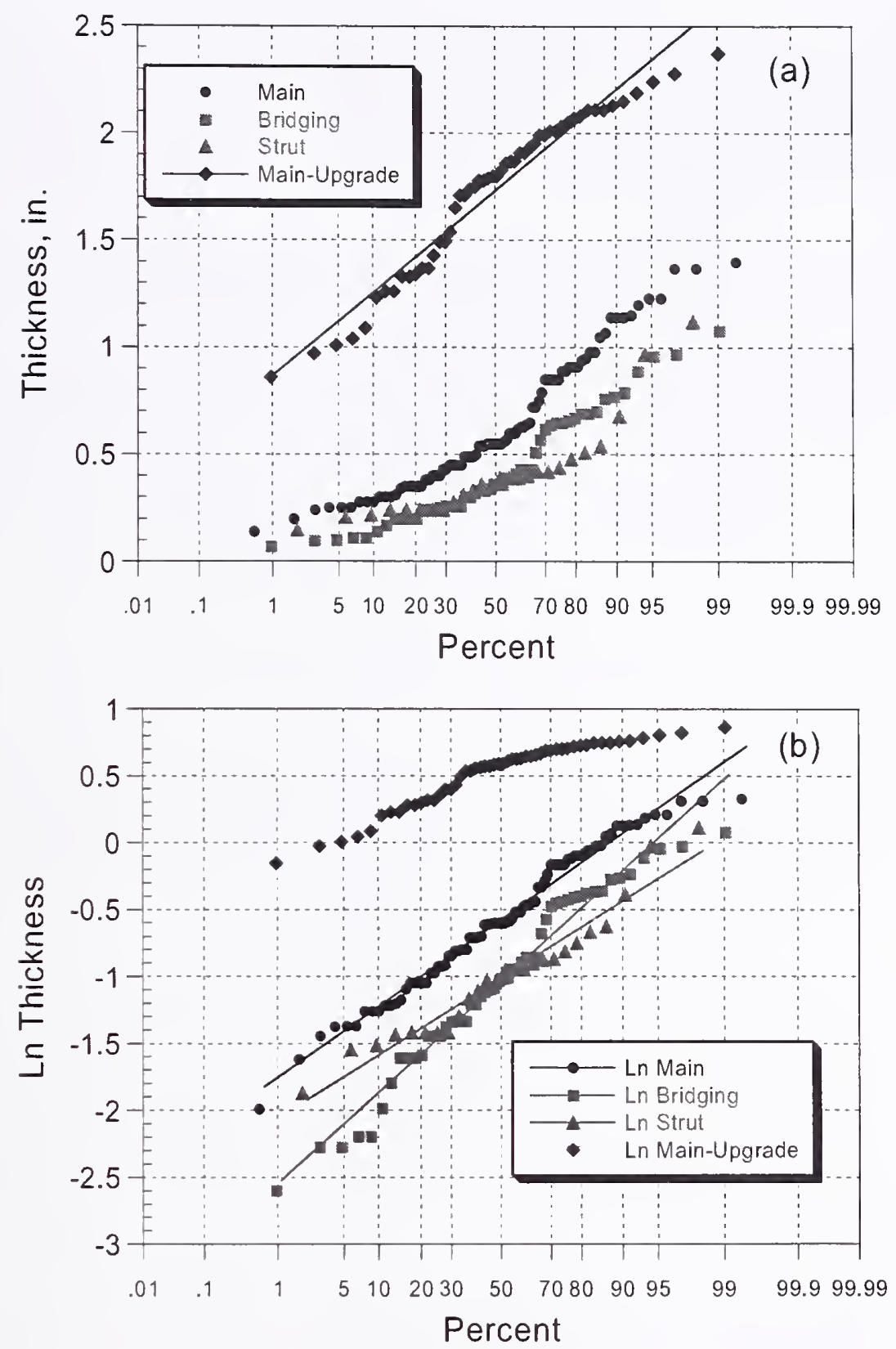

Figure 4-3. (a) Normal probability plot of estimated SFRM thickness based on photographs, and (b) normal probability plot of natural logarithms of thickness (Data provided by PANYNJ).

Port Authority test reports state that tests of upgraded SFRM were performed in accordance with ASTM E 605 for thickness and density (ASTM 1993) and in accordance with ASTM E 736 for adhesive/cohesive strength (ASTM 1992). Section 8.1.1 of ASTM E 605-93 requires that thickness measurements be taken at "One bay per floor or one bay for each $10,000 \mathrm{ft}^{2}$, whichever provides the greater number of tests." In addition, the test method states that: "Thickness determinations for the following structural elements shall be conducted in each randomly selected bay: one selected area of metal deck, concrete slab, or wall section; one column; and one beam (joist or truss)." For each 
preselected joist (or truss), Section 8.1.5.2 of the test method requires that one $12 \mathrm{in}$. length be laid out and seven thickness measurements be taken at each end of the $12 \mathrm{in.} \mathrm{length.} \mathrm{Thus,} \mathrm{two} \mathrm{sets} \mathrm{of} \mathrm{thickness}$ readings are expected for each truss if ASTM E 605-93 were followed. Figure 4 of ASTM E 605-93 shows that there should be seven measurements at each cross section, which are to be distributed as follows: two at the top chord, two at the web, and three at the bottom chord.

Table 4-2 shows the test data provided by the Port Authority for the impact-affected floors. ${ }^{13}$ Shown are the average thickness, bond strength, and density for each test area on a given floor. The specified minimum requirements are $1 \frac{1}{2} \mathrm{in}$. for thickness, $150 \mathrm{psf}$ for bond strength, and $15 \mathrm{lb} / \mathrm{ft}^{3}$ for density. Correspondence from the Port Authority in March 2004, clarified that the words "bottom truss" in the test reports referred to the location of the bond test and where the sample was removed for density measurement (see Appendix A, Fig. A-61). Note that some of the average thicknesses shown in Table 4-2 equal or exceed $3.5 \mathrm{in}$. No photos were available of upgraded floors to show the appearance of a truss with such high average thickness of SFRM. There is no record in the test reports of whether the top chord and bridging trusses were protected in the upgraded floors.

In 2004, the Port Authority provided NIST reports of the individual measurements for many of the average thicknesses shown in Table 4-2. ${ }^{14}$ With the individual measurements, it was possible to investigate the variation of thickness at a cross section of a truss member and the variation in average thickness from truss to truss. To permit such analyses, only those data having the same number of individual measurements at each cross section were used. This resulted in 18 data sets for WTC 1 (including floors 93, 95, 98, 99, and 100) and 14 data sets for WTC 2 (including floors 77, 78, 88, 89, and 92).

\footnotetext{
13 Transmittal of construction audit material testing reports by Saroj Bhol (PANYNJ), January 21, 2003 (30-P).

${ }^{14}$ Electronic file of individual thickness values transmitted by Frank Lombardi (PANYNJ) to NIST on April 7, 2004 (682-P).
} 


\section{Table 4-2. Summary of Port Authority test reports for upgraded SFRM on floor trusses (30-P).}

\begin{tabular}{|c|c|c|c|c|c|c|}
\hline $\begin{array}{l}\text { WTC } \\
\text { Tower }\end{array}$ & $\begin{array}{c}\text { Floor } \\
\text { Number }\end{array}$ & Specific Location /Tenant & $\begin{array}{l}\text { Date of } \\
\text { Report }\end{array}$ & $\begin{array}{c}\text { Average SFRM } \\
\text { thickness (in.) }\end{array}$ & $\begin{array}{c}\text { Adhesion/ } \\
\text { Cohesion }\left(\| \mathrm{b} / \mathrm{ft}^{2}\right)\end{array}$ & $\begin{array}{l}\text { Density } \\
\left(\mathbf{l b} / \mathrm{ft}^{3}\right)\end{array}$ \\
\hline 1 & 79 & Multiple tenant floor & $11 / 24 / 99$ & 2.4 & 333 & 16.6 \\
\hline 1 & 80 & Multiple tenant floor & & & & \\
\hline 1 & 81 & Multiple tenant floor & $10 / 24 / 96$ & 2.7 & 270 & 19.0 \\
\hline 1 & 81 & Multiple tenant floor & $7 / 16 / 99$ & $2.3 .2 .4,3.0$ & $352,463,315$ & $17.4,17.6,17.4$ \\
\hline 1 & 83 & Suite 8331 & $12 / 15 / 99$ & 2.2 & 259 & 16.0 \\
\hline 1 & 85 & Multiple tenant floor & $12 / 24 / 97$ & $3.5,2.9 .2 .9$ & $162,180,288$ & $28.7,23.7,18.6$ \\
\hline 1 & 85 & Multiple tenant floor & $6 / 12 / 99$ & 2.9 & 278 & 15.8 \\
\hline 1 & 85 & $\begin{array}{l}\text { Multiple tenant floor } \\
\text { Suite } 8563\end{array}$ & $8 / 16 / 99$ & 2.8 & 259 & 16.4 \\
\hline 1 & 86 & Julien Studley lnc. $\left(7000 \mathrm{ft}^{2}\right)$ & & & & \\
\hline 1 & 92 & Full floor & $4 / 2 / 97$ & $3.0,2.8,2.8$ & $360,324,360$ & $20.3,15.4,18.0$ \\
\hline 1 & 93 & Full floor & $8 / 28 / 98$ & $\begin{array}{l}1.8,2.0,1.8,2.2 \\
1.8,1.9,2.9\end{array}$ & $\begin{array}{l}117(153)^{\dagger}, 207, \\
216,234,162, \\
180,216\end{array}$ & $\begin{array}{l}14.2,16.6,16.1, \\
18.4,15.1,17.4, \\
21.3\end{array}$ \\
\hline 1 & 94 & Full floor & $12 / 27 / 96$ & $4.3,3.8,4.3$ & $486,504,288$ & $21.2,20.5,20.1$ \\
\hline 1 & 95 & Full floor & $8 / 24 / 98$ & $2.2,2.4,3.3$ & $270,306,198$ & $18.0,20.1,20.4$ \\
\hline 1 & 96 & Full floor & $10 / 22 / 98$ & $3.0,3.2,3.2$ & $486,288,324$ & $20.5,19.8,19.9$ \\
\hline 1 & 97 & Full floor & $10 / 22 / 98$ & $2.6,2.2,2.2$ & $360,468,468$ & $26.5,20.0,23.9$ \\
\hline 1 & 98 & Full floor & $11 / 19 / 98$ & $2.9,2.8,2.5$ & $407,351,518$ & $31.3,16.8,19.6$ \\
\hline 1 & 99 & Full floor & $11 / 20 / 98$ & $2.8,2.2,2.2$ & $204,222,204$ & $18.8,16.6,18.4$ \\
\hline 1 & 100 & Full floor & $11 / 20 / 98$ & $2.8,3.2,3.4$ & $278,278,333$ & $16.4,17.3,19.9$ \\
\hline 1 & 102 & Full floor & $9 / 28 / 99$ & $3.2,3.2,2.1$ & $333,333,315$ & $16.5,16.9,15.9$ \\
\hline 2 & 77 & Full floor & $6 / 9 / 98$ & $2.7,2.1,2.6$ & $351,198,297$ & $19.4,19.4,17.2$ \\
\hline 2 & 78 & Full floor & $4 / 3 / 98$ & $2.5,2.8$ & 288,270 & $17.0,18.1$ \\
\hline 2 & 85 & Full Floor & & & & \\
\hline 2 & 88 & Full floor & $7 / 5 / 00$ & $1.9,2.4,2.1$ & $167,333,157$ & $18,16,15$ \\
\hline 2 & 89 & Full floor & $5 / 5 / 99$ & $2.8,2.7,3.0$ & $370,333,270$ & $22.4,15.8,15.3$ \\
\hline 2 & 92 & Full floor & $2 / 26 / 98$ & $2.8,3.0,2.7$ & $342,360,297$ & $19.7,21.1,19.7$ \\
\hline 2 & 96 & Full floor & & & & \\
\hline 2 & 97 & Full floor & & & & \\
\hline 2 & 98 & $?$ & & & & \\
\hline 2 & 99 & Half floor & $7 / 28 / 97$ & $2.1,3.0$ & 315,252 & $19.5,22.7$ \\
\hline 2 & 99 & Half floor & $4 / 3 / 98$ & $1.8,1.7$ & 306,270 & $21.9,19.5$ \\
\hline
\end{tabular}

Repeated test 
An analysis of the individual measurements was carried out to determine the underlying distribution for the measured thicknesses. Figure 4-4(a) is a dotplot of the individual measurements in WTC 1 (144 measurements) and in WTC 2 (112 measurements). It is observed that the central values and ranges are similar for the two towers, and the two groups of measurements were combined into one group. Figure 4-4 (b) is the histogram of the individual measurements, and Fig. 4-4 (c) is the corresponding normal probability plot. A straight line fit to the normal probability plot shows a tendency of the points to deviate from the line. Figure 4-4 (d) is a histogram of the natural logarithms of the individual thickness values, and Fig. 4-4 (e) is the corresponding lognormal probability plot. A comparison of the probability plots shows that natural logarithms fall closer to a straight line. Thus, it appears that the thickness of the upgraded SFRM on the floor trusses is described by a lognormal distribution. This contradicts the observation based on analysis of photographs from lower floors discussed in the previous section. The overall average thickness of the 256 individual measurements is $2.5 \mathrm{in}$. with a standard deviation of 0.6 in. The median was also $2.5 \mathrm{in}$. Thus, the average thickness on the upgraded upper floors appears to be greater than that estimated from photographs taken on upgraded lower floors.

As shown in Fig. 4-4, there were a number of points representing individual thicknesses of $31 / 2$ in. or greater. As mentioned, there are no corroborating data, such as photographs, of such reported high thicknesses. The probability distributions in Fig. 4-4 show, however, that the high thicknesses were consistent with the remainder of the distributions. In any case, statistics were recomputed after removing thicknesses of $3 \frac{1}{2}$ in. and greater (this amounted to 20 out 256 points). The resulting average thickness was reduced to $2.4 \mathrm{in}$, and the standard deviation was reduced to $0.5 \mathrm{in}$. The median remained unchanged. Thus, it was concluded that the high reported thicknesses would not have a dramatic effect on the overall statistics of the SFRM thickness in the upgraded floors.

The overall standard deviation of 0.6 in. includes two contributions: (1) the variation of thickness at the cross section (within-truss variability), and (2) the variation of average thickness between trusses (between-truss variability). Figure 4-5 shows these two components of the thickness variability for the two towers. Figures 4-5 (a) and (c) show the within-truss variability, and Figs. 4-5 (b) and (d) show the variation of average thickness of each truss. From analysis of variance, it was found that the within-truss standard deviation is $0.4 \mathrm{in}$, and the between-truss standard deviation is also $0.4 \mathrm{in}$. The within-truss standard deviation of $0.4 \mathrm{in}$. is similar to the standard deviation of the estimated individual thicknesses obtained from analysis of the photographs of upgraded main trusses. 


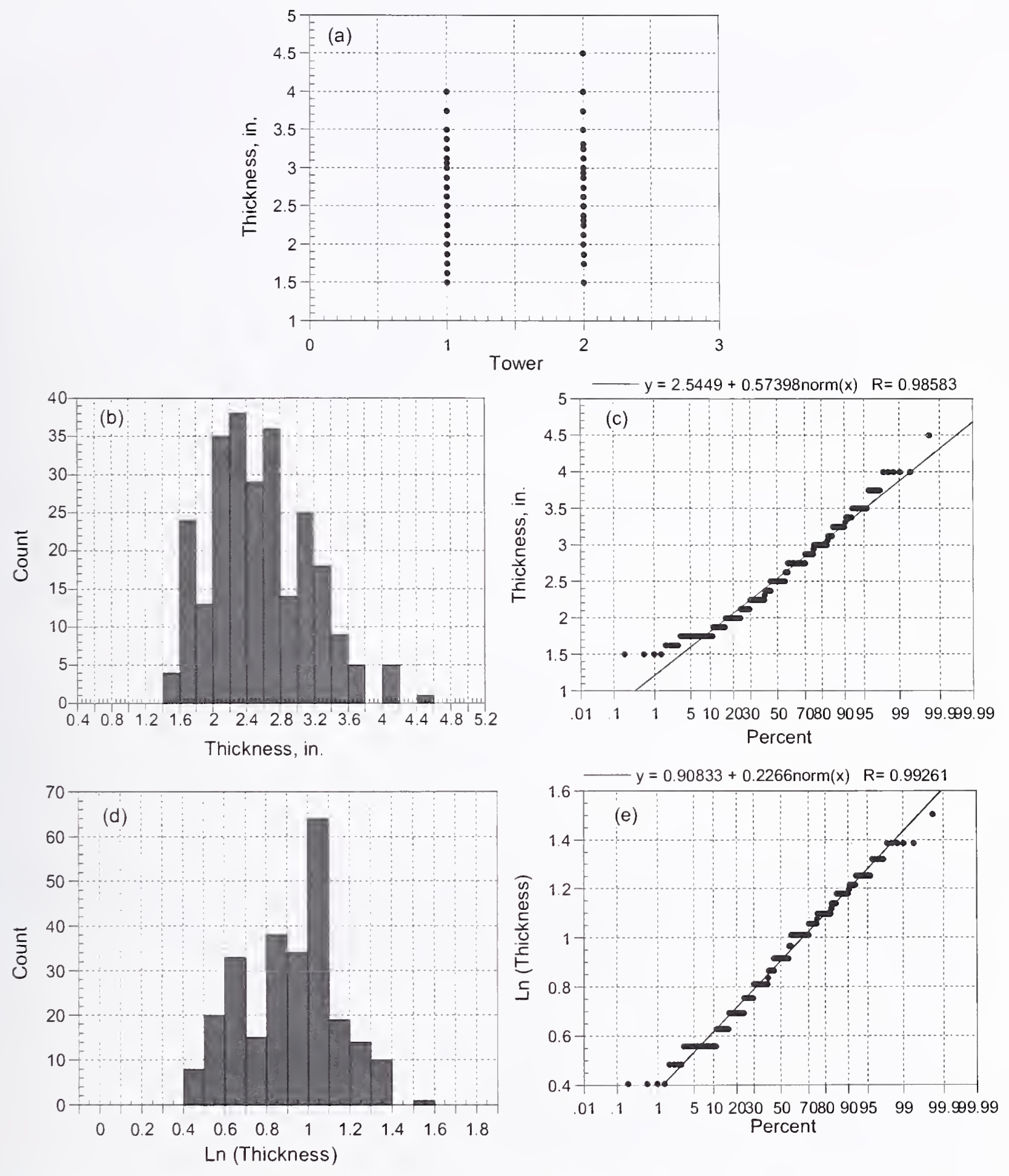

Figure 4-4. (a) Dotplot of individual thickness measurements on floor trusses from Port Authority Construction Audit Reports, (b) histogram of thickness measurements, (c) normal probability plot of thickness measurements, (d) histogram of natural logarithms of thickness measurements, and (e) normal probability plot of natural logarithm of thickness measurements. 

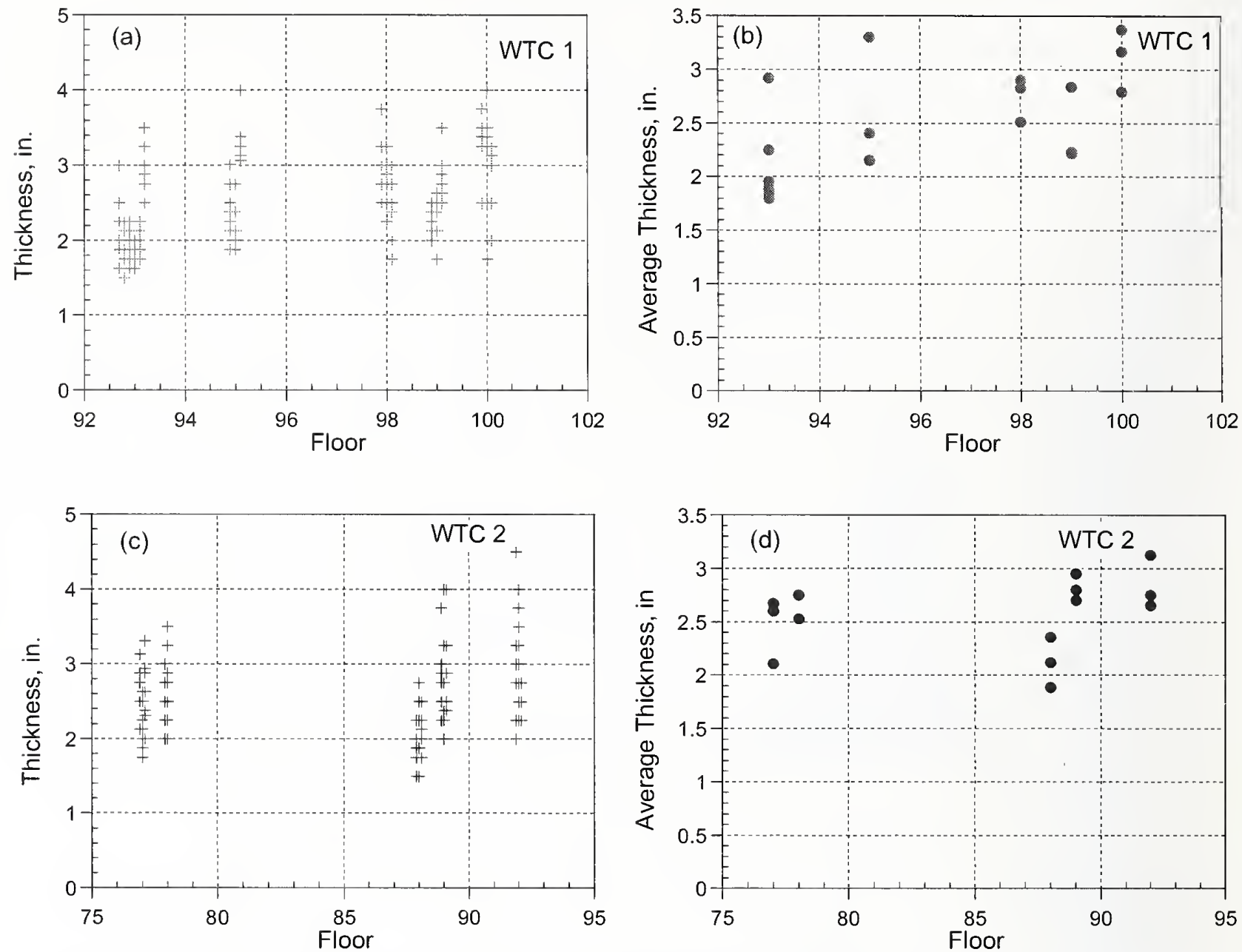

Figure 4-5. SFRM thickness on floor trusses in upgraded portions of WTC towers: (a) individual measurements in WTC 1, (b) average thickness in WTC 1, (c) individual measurements in WTC 2, and (d) average thickness in WTC 2 (data provided by PANYNJ). 


\subsection{COLUMN SFRM THICKNESS}

NIST requested that the Port Authority provide available information on the thickness of fire-resistive material for the exterior and interior columns of the WTC towers (see Appendix A Fig. A-62).

Specifically, the request included the following:

- The fire-resistive material used and the thickness on the various plates comprising the exterior columns and spandrels.

- The fire-resistive material used and the thickness on core columns.

- Confirmation that the wide flange column sections were protected with BLAZE-SHIELD Type DC/F with specified thickness of $23 / 16$ in. for sections smaller than 14 WF228 and $13 / 16$ in. for 14 WF228 and larger.

- Information on in-place SFRM thickness.

The Port Authority replied that, due to inaccessibility of exterior columns and core columns, there were no recent records of SFRM thickness for these elements (see Appendix A Fig. A-62). The only available measurements of SFRM thickness were for beams and columns accessible within elevator shafts. These measurements were, however, for re-applied thermal insulation.

The most complete data set included measurements on beams and columns taken within shaft 10/11 in WTC 1. These measurements were taken in April 1999 and included measurements from floor 1 to floor 45 . The thicknesses were recorded to the nearest $1 / 8$ in., with a few thicknesses recorded to the nearest $1 / 16$ in. The columns included 10 to 18 replicate measurements, and the beams included 11 to 16 replicate measurements.

Figure 4-6 (a) shows the individual and average SFRM thickness on the core columns. Analysis of variance indicated no statistically significant differences among the average values, and all data were pooled together. The average thickness for the columns is $0.82 \mathrm{in}$., the standard deviation is 0.20 , and the coefficient of variation is 0.24 . The information from the Port Authority indicated that the "minimum thickness required" for the columns was $1 / 2$ in. As noted in Appendix A Fig. A-62, the required thickness was based on calculations performed by LERA for re-applied thermal insulation (Monokote Type Z-106), similar to what was discussed in Section 3.5.5. Figure 4-6 (b) is the normal probability plot of the individual thickness measurements. Because most of the thicknesses were reported to the nearest $1 / 8 \mathrm{in}$., the points are staggered in steps instead of uniformly distributed. The plot, however, shows that the points follow a linear trend, and it appears that the thickness of the reapplied SFRM on the core columns could be described by a normal distribution. Figures 4-6 (c) and (d) show the corrcsponding plots for the thickness of SFRM reapplied to beams surrounding shaft $10 / 11$ of WTC 1 . The average thickness is $0.97 \mathrm{in}$., the standard deviation is $0.21 \mathrm{in}$. and the coefficient of variation is 0.21 . The information from the Port Authority indicated that the "minimum thickness required" for the thermal insulation reapplied to the beams was $3 / 4$ in.

The data described above may not have a direct bearing on the outcome of the investigation because they deal with lower stories. They do, however, provide some useful information on the variability of SFRM applied to beams and columns. The variation in SFRM thickness for the beams and columns shown in 
Fig. 4-6 is lower than the variation observed in the floor trusses. This is not unexpected because the planar surfaces of the beams and columns result in more uniform application of the sprayed fire-resistive material than for the slender truss members. This results in reduced differences in the average thickness of SFRM on different members and less variability within a member.
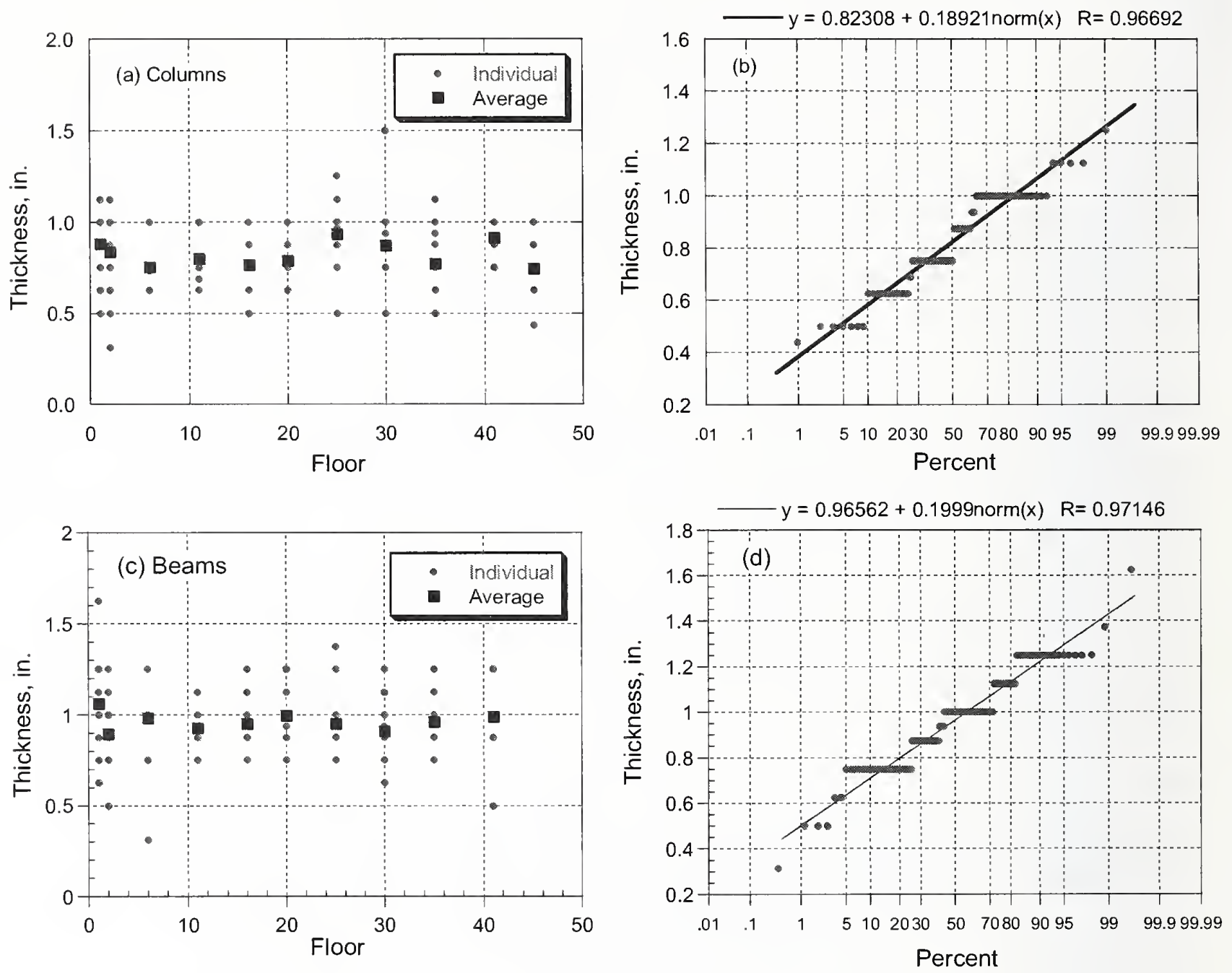

Figure 4-6. Thickness of re-applied SFRM in elevator shaft 10/11 of WTC 1: (a) Individual and average thickness for core columns, (b) normal probability plot of individual measurements on columns, (c) individual and average thickness for core beams, and (d) normal probability plot of individual measurements on beams (data provided by PANYNJ). 


\section{Chapter 5 \\ EFFECT OF SFRM GEOMETRY ON THERMAL RESPONSE}

The thickness of sprayed fire-resistive material (SFRM) has a great effect on the thermal response of the structural protected elements for a given fire condition. The effect of the variation of thickness along the length of a member is, however. not well known. A sensitivity study using finite element modeling of heat transfer was conducted to investigate the sensitivity of steel temperature to the variability in SFRM thickness.

\subsection{EFFECTS OF THICKNESS VARIABILITY AND GAPS IN SFRM}

The simplified model that was used is shown in Fig. 5-1. A 1 in. thick, 60 in. long steel plate (cyan color) was coated with fire-resistive material (purple color) and subjected to the uniform radiative flux arising from a $1,100{ }^{\circ} \mathrm{C}$ fire. As shown in Fig. $5-1$ (b). the fire-resistive material is modeled with a layer of finite elements ( 0.125 in. thick and $0.6 \mathrm{in.} \mathrm{long}$ ) having the thermal properties of fire-resistive material (purple). A parametric study was conducted with average thickness of fire-resistive material varying from $0 \mathrm{in}$. to $2 \mathrm{in}$. in increments of $1 / 4 \mathrm{in}$. The effect of variability in thickness was modeled by imposing a normal probability distribution on the SFRM thickness along the length of the steel plate. The assumed standard deviation varied from $0 \mathrm{in}$. (uniform thickness) to $1 \mathrm{in.}$ A pseudo-random number generator was employed to determine the thickness at each cross section based on the assumed average thickness and standard deviation. The layer representing SFRM was taken to be twice the average thickness, and the thickness of SFRM at any cross section was modeled by assigning a low heat capacity and a high thermal conductivity to those elements that do not provide thermal protection. Figure 5-1 (c) shows an example of variable thickness SFRM; in this case, the average thickness is $1 \mathrm{in}$. and the standard deviation is $3 / 8$ in.

When the model in Fig. $5-1$ is exposed to the thermal flux representing a $1,100^{\circ} \mathrm{C}$ fire, the surface of the insulation heats up quickly to the gas temperature $(1,100+273=1,373 \mathrm{~K})$. Numerical simulation was performed over a $2 \mathrm{~h}$ period, and the steel temperature at five locations was recorded at $30 \mathrm{~min}, 60 \mathrm{~min}$, $90 \mathrm{~min}$, and $120 \mathrm{~min}$ of exposure. The temperature recording locations are $6 \mathrm{in}$. from each $\mathrm{cnd}$ and at 12 in. intervals, which are shown as numbers 1 to 5 in Fig. 5-1 (a). The initial temperature of the model is $300 \mathrm{~K}$.

Figure 5-2 shows temperature contours (in $\mathrm{K}$ ) through the fire-resistive material and steel at $60 \mathrm{~min}$ after initial exposure for the model shown in Fig. 5-1 (a). The surface temperature of the fire-resistive material is close to the gas temperature of $1,373 \mathrm{~K}$, while the steel temperature is $311 \mathrm{~K}$. If the SFRM were of uniform thickness, the isotherms would be a series of lines parallel to the plate. It is seen that, when the thickness is variable, the isotherms follow the shape of the SFRM surface contour. Thus, the temperature history at any point in the steel depends on the local thickness of the fire-resistive material.

Figure 5-3 shows the steel temperature at the far sensor \#1 (6 in. from the cnd) as a function of time for various insulation thicknesses ranging from $0 \mathrm{in.}$ to $2 \mathrm{in}$. (the thickness is indicated by the numbers on the curves). For the case in Fig. 5-3 (a), the fire-resistive material is of uniform thickness, and for the cases in 
Fig. 5-3 (b), the thickness varies with a standard deviation of 1 in. The time to reach a temperature of $600{ }^{\circ} \mathrm{C}$ is used as a measure of relative performance. It is seen that the presence of high variability in thickness has a detrimental effect on the protection provided by the fire-resistive material. For example, for a uniform thickness of $0.5 \mathrm{in}$., it takes about $60 \mathrm{~min}$ for the steel at point $\# 1$ to reach $600{ }^{\circ} \mathrm{C}$, but when the standard deviation of the thickness is $1 \mathrm{in}$., the average thickness has to be 1.75 for the same level of thermal protection.

(a)

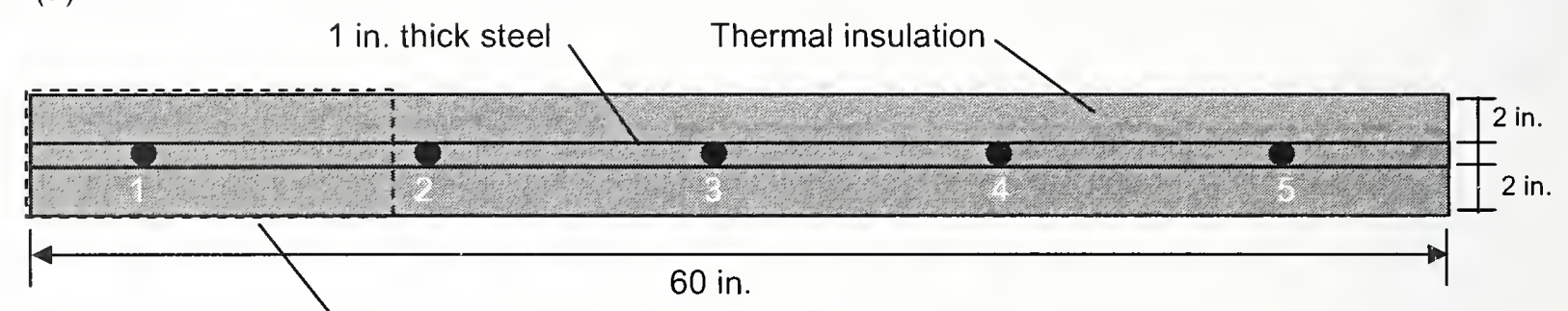

(b)

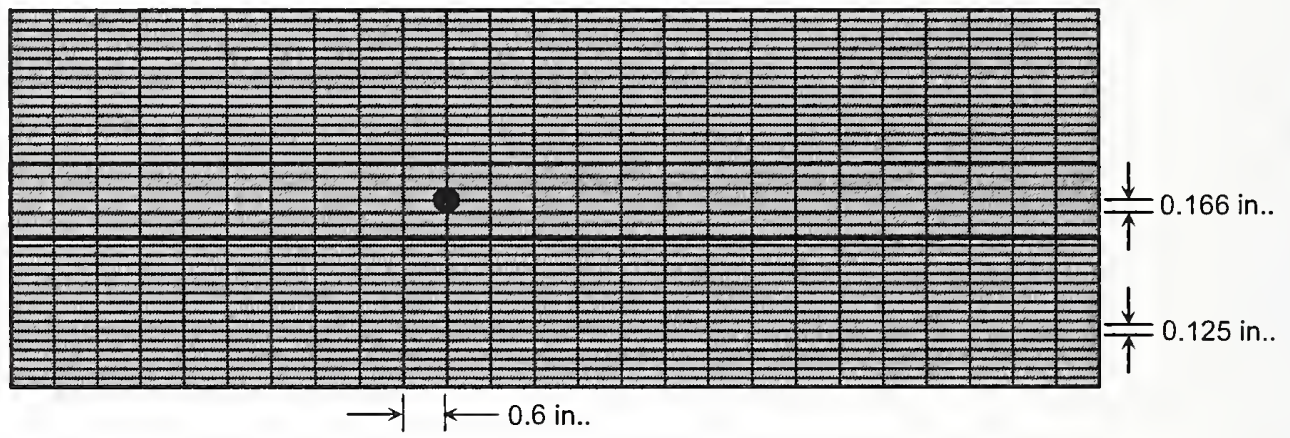

(c)

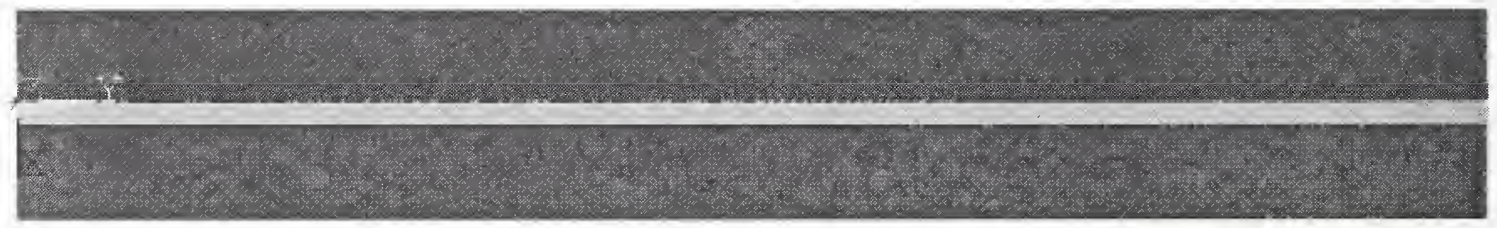

Figure 5-1. Model used to study effects of SFRM thickness and variability of thickness on steel temperature: (a) physical model used in analyses (points 1 to 5 are locations where temperatures are monitored), (b) finite element mesh used to represent physical model, and (c) finite element model to represent variable thickness of SFRM (purple) (the elements in red represent material of high thermal conductivity). 


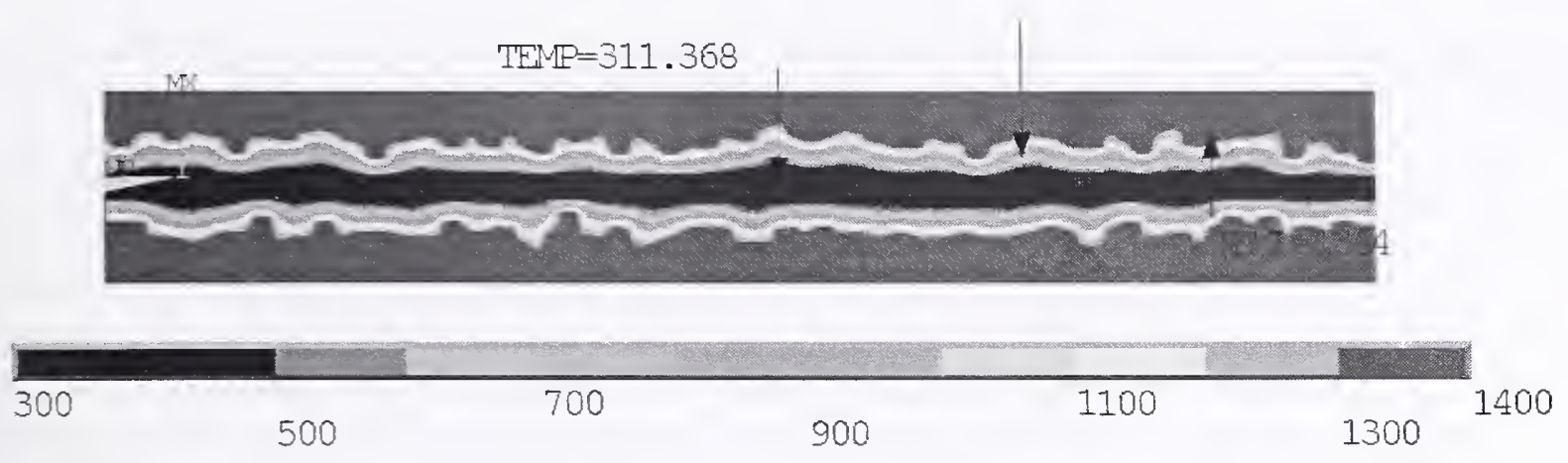

Figure 5-2. Temperature distribution after $1 \mathrm{~h}$ of exposure to gas temperature of $1,100^{\circ} \mathrm{C}(1,373 \mathrm{~K})$. 

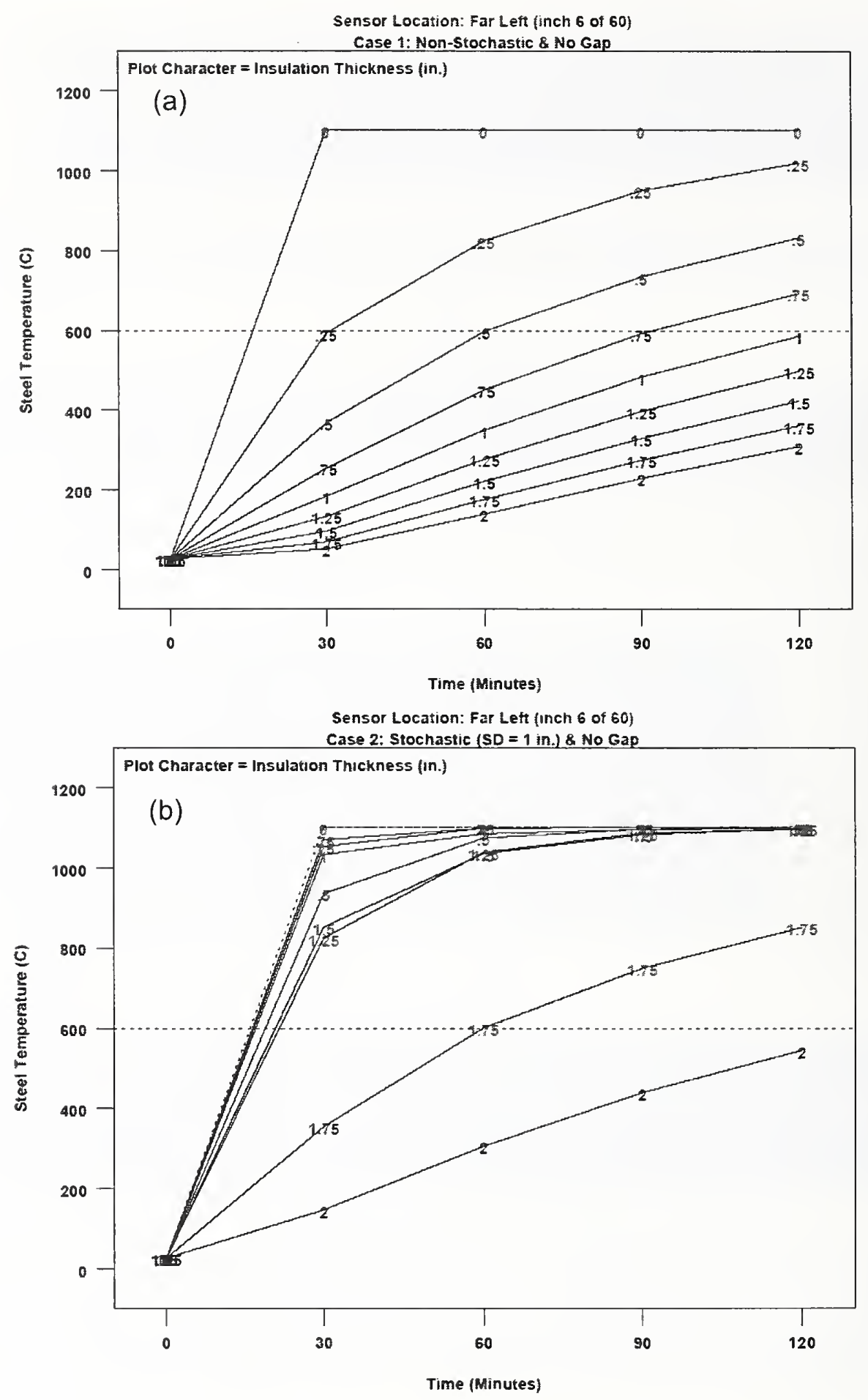

Figure 5-3. Variation of steel temperature (at a point 6 in. from end of plate) with time for different average thicknesses of fire-resistive material (shown as numbers on the curves): (a) uniform thickness, and (b) variable thickness with standard deviation $=1$ in. 
In addition to the effect of variation in thickness, it is important to understand the effect of missing SFRM over a portion of a member. As an example, Fig. 5-4 shows missing SFRM from a diagonal of a bridging truss of the WTC towers floor system. Note that this photograph is from a lower story and may not be representative of conditions in the upper stories, especially following the upgrade of thermal insulation. Figure 5-5 (a) shows an example of a numerical model with missing fire-resistive material. In this case, there is 12 in. of missing SFRM on the steel plate, which is otherwise protected by 2 in. of uniform thickness fire-resistive material. Figure 5-5 (b) shows the temperature contours (isotherms) at time equal to 50 min. For comparison. Fig. 5-5 (c) shows isotherms at the same time in a plate with no gap in the fire-resistive material. As expected, the bare steel at the missing fire-resistive material is at the gas temperature, but more importantly the "gap" in SFRM leads to a "leakage" of heat into the interior steel.

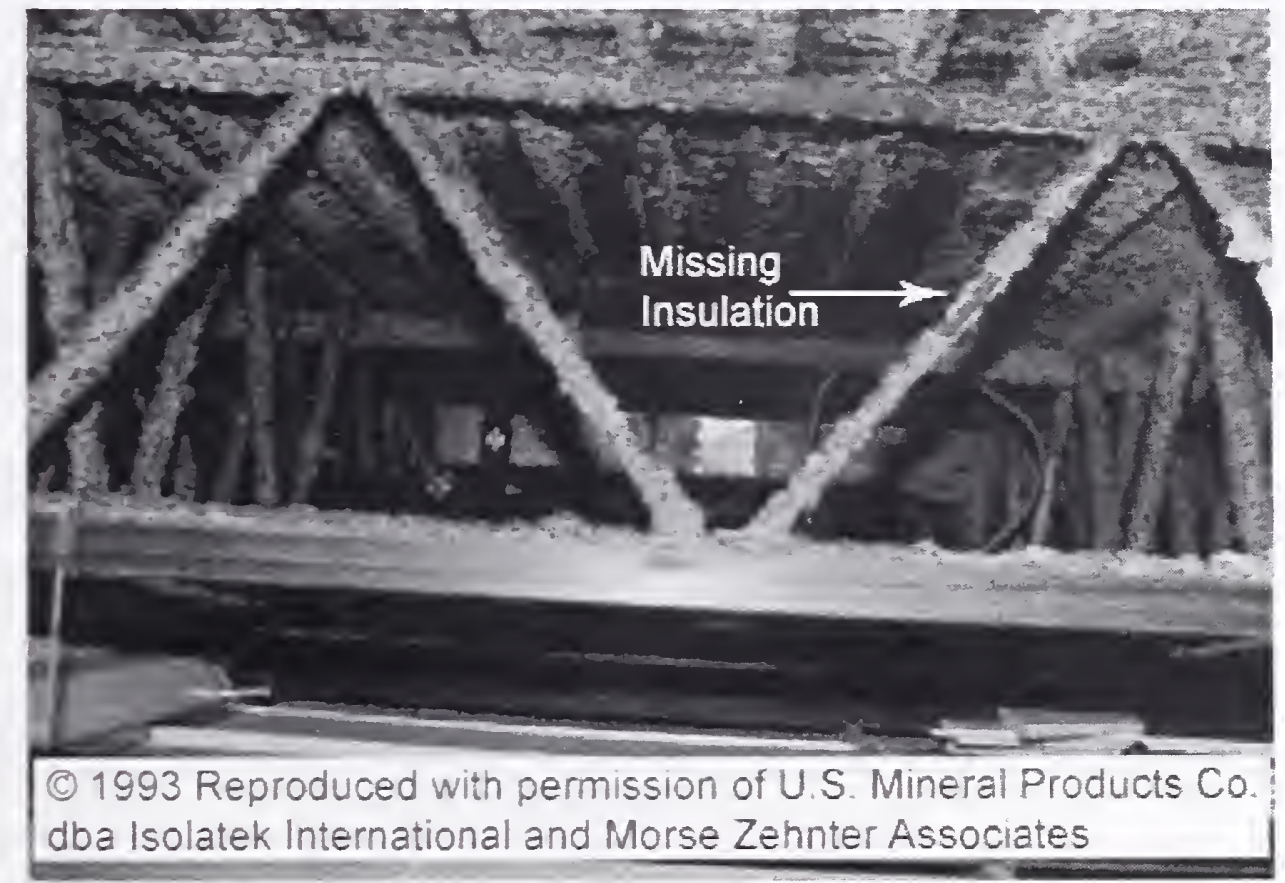

Figure 5-4. Example of "gap" in fire-resistive material on diagonal member of a bridging floor truss.

The combined effects of variation in thickness of the fire-resistive material and length of missing material were examined by a factorial study with the following factors:

- Average thickness of fire-resistive material varying from 0 in. to 2.0 in. in $1 / 4$ in. increments;

- Standard deviation of fire-resistive material thickness of 0 in., 0.25 in., 0.5 in., 0.75 in. and 1.0 in.; and

- Length of missing fire-resistive material varying from 0 in. to 30 in., in 6 in. increments. 


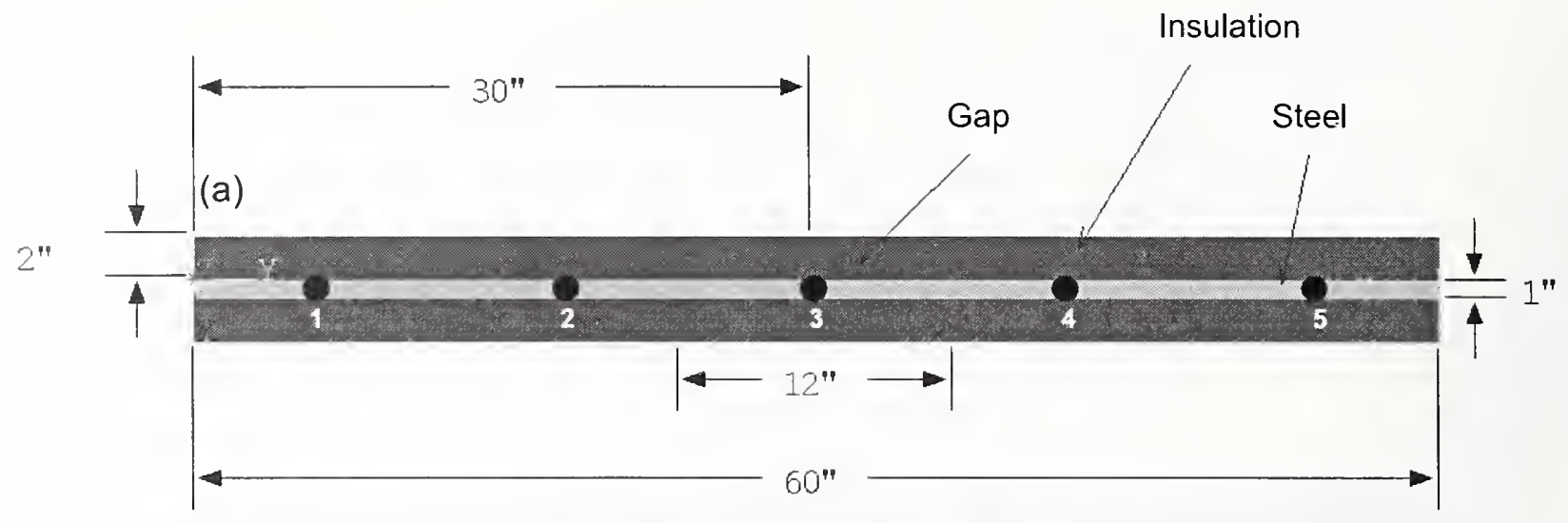

(b)

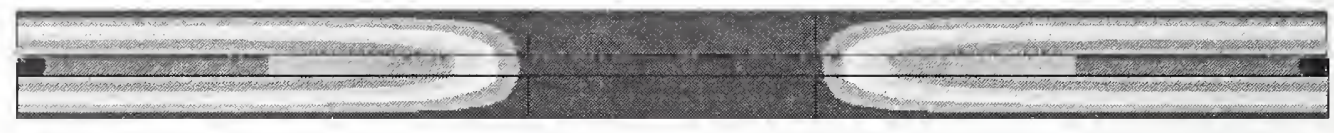

(c)
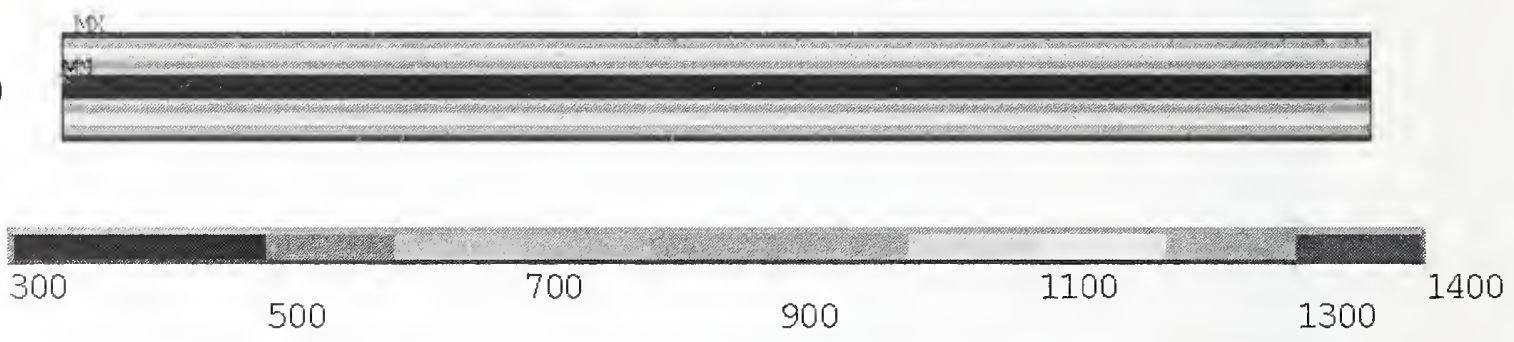

Figure 5-5. Effects of gap in fire-resistive material: (a) model of plate with SFRM having 2 in. uniform thickness and 12 in. gap, (b) isotherms $(K)$ at time $=50$ min with 12 in. gap, and $(c)$ isotherms without gap.

The results of the sensitivity study can be summarized in a series of plot matrices, which show the time histories of the steel temperature for different combinations of gap length and variability in SFRM thickness. For example, Fig. 5-6 shows the plot matrix for the temperature history at point \#2 (18 in. from the end of the plate). Each plot contains a series of curves representing different average thicknesses of fire-resistive material, as in Fig. 5-3. Each column of plots represents a constant value of thickness variability (standard deviation), and each row represents a constant gap length. The plot in the upper left corner represents the casc of uniform thickness of SFRM and no gap, which is the same plot as in Fig. 5-3(a). (Note that for the case of uniform thickness and no gap, the steel temperature at any point in a cross section is the same along the length of the plate, as shown in Fig. 5-5(c).) For gaps of 24 in. and 30 in., the temperature at point \#2 rises rapidly because there is no SFRM on the plate at that location. This explains the shapes of the curves in the two lower rows. In going from left to right in one of the top four rows it is seen that as variability of thickness increases, the time histories shift upward, thereby reducing the time to reach $600^{\circ} \mathrm{C}$. This is the same observation as shown in Fig. 5-3. Moving from the top to the bottom in any column shows the effects of increasing gap length. The effect of gap length depends, of course, on where the steel temperature is measured. At a point within the portion of steel that is bare, the temperature rises quickly. At points within the steel that are surrounded with fire-resistive material, the gap provides a path for heat flow, as shown in Fig. 5-5 (b). As a result, points in the steel within the vicinity of the missing SFRM will experience higher temperatures, as indicated by the rising 
trend of the curves in going downward from the top of a column in Fig. 5-6. The National Institute of Standards and Technology (NIST) does not have sufficient information to determine the frequency of occurrence of these gaps or their typical locations within the fire-affected floors. Therefore, gaps in insulation were not considered in the thermal modeling.

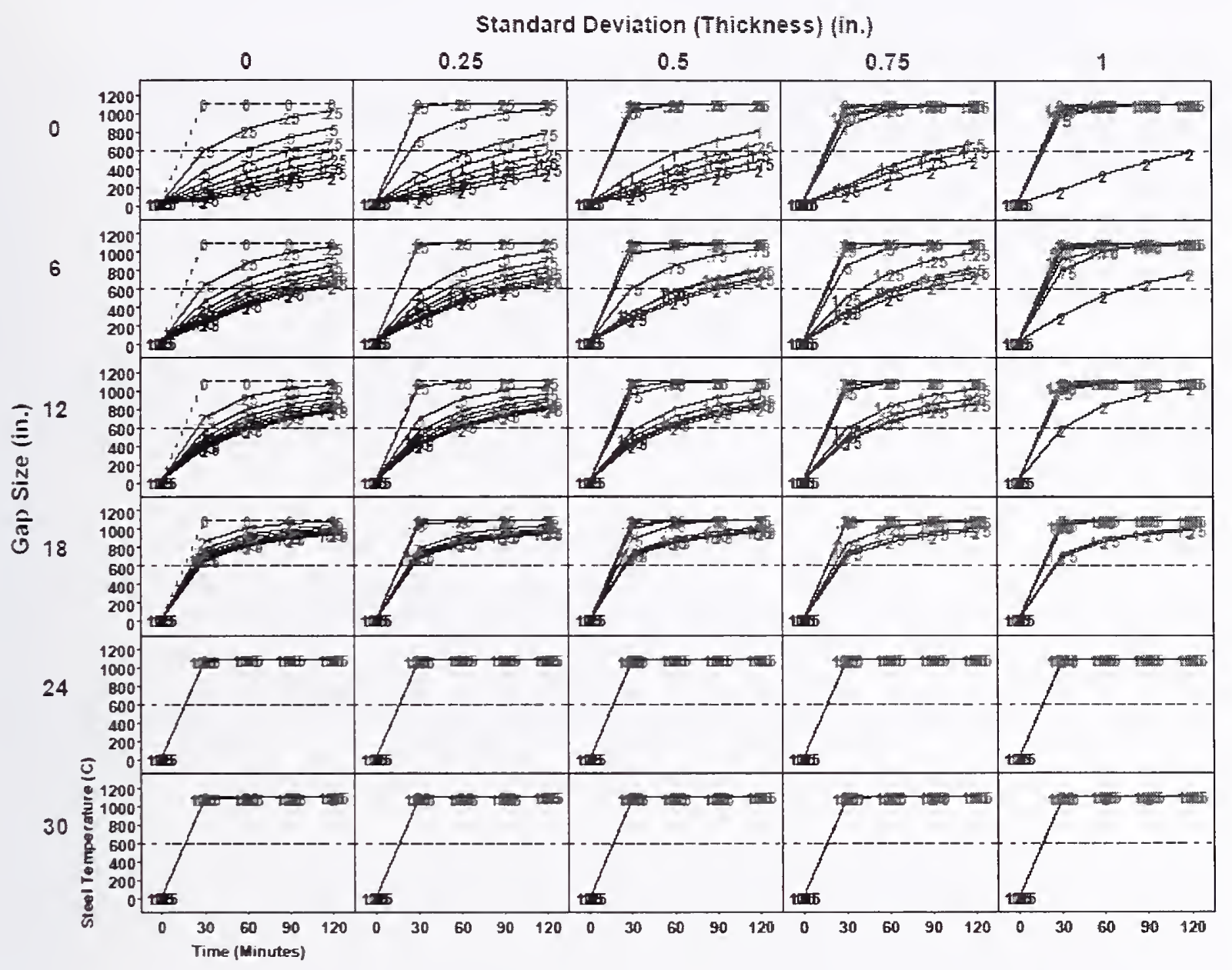

Figure 5-6. Example of plot matrix from sensitivity study of the effects of missing SFRM and variability of SFRM thickness on steel temperature. Each graph is a temperature history of the steel at point \#2 (see Fig. 5-5 for location) for different thicknesses of SFRM.

\subsection{EQUIVALENT THICKNESS}

The sensitivity study summarized in Section 5.1 indicated that variation in the thickness of SFRM reduced the "effective thickness" of the material. It would be impractical to attempt to account for the variation in SFRM thickness in the thermal modeling by introducing variable thickness insulation material in the finite-element models. As an alternative, it was decided to attempt to determine the "equivalent uniform thickness" of fire-resistive material that would result in the same thermo-mechanical response of a member as variable thickness thermal protection. An approach similar to the methodology described in Section 5.1 was used to model a $1 \mathrm{in}$. diameter by $60 \mathrm{in}$. long bar with thermal insulation and subjected to the heat flux arising from a $1,100^{\circ} \mathrm{C}$ fire. The bar was subdivided into $0.6 \mathrm{in}$. long elements, 
so that there were 100 elements along the length of the bar. The thermal history of the bar was calculated, and that history was used to calculate the length change of the unrestrained bar under a tensile stress of 12,500 psi. The bar was assumed to be similar to the steel used in the floor trusses, and the temperature dependence of the coefficient of thermal expansion and the modulus of elasticity were based on NIST measurements.

The thermal insulation thickness in the models was based on the measurements summarized in Chapter 4 for the web bars of main trusses in the original condition and after the upgrade. Specifically, the following target values were investigated:

- Original: average thickness $=0.75$ in., standard deviation $=0.3$ in., lognormal distribution.

- Upgrade: average thickness $=2.5$ in., standard deviation $=0.6$ in., lognormal distribution.

The variation of thermal insulation thickness along the length of the bar was established by using a pseudo random number generator to select values from a lognormal distribution with central value and dispersion consistent with the above average values and standard deviation. Three sets of random data were generated for each condition.

When the randomly selected thicknesses of each element were applied to the bar, it resulted in sudden changes in insulation thickness along the length of the bar. This resulted in a "rough" surface texture as shown by the dotted thickness profile in Fig. 5-7 (a). It was felt that this rough texture (see also Fig. 5-1 (c) might not be representative of actual conditions, so an alternative approach was to use five-point averaging to reduce the roughness of the insulation profile. The solid line in Fig. 5-7 (a) shows such a "smooth" profile. The two profiles in Fig. 5-7 (a) have approximately the same average value and standard deviation and have similar cumulative distribution of thermal protection thickness as shown in Fig. 5-7 (b).

As stated, the calculated thermal histories of the bar elements were used to calculate the unrestrained length change of the bar due to thermal expansion and an applied stress of 12,500 psi. For comparison, the deformation of the bar with different but uniform thickness of thermal insulation was calculated. The "equivalent thickness" was taken as the uniform thickness that resulted in similar deformation as under the variable thickness conditions. Figure 5-7 (c) shows the results of these calculations for the original SFRM thickness. The three continuous curves are the deformation-time relationships for uniform thickness of 0.4 in., 0.5 in., and 0.6 in. The solid symbols represent the results for three cases with "rough" texture, and the open symbols are for the "smooth" texture. The following values summarize the six variable thickness profiles:

- Rough 1: average $=0.79$ in., standard deviation $=0.29 \mathrm{in}$.

- $\quad$ Rough 2: average $=0.77$ in., standard deviation $=0.27$ in.

- Rough 3: average $=0.79$ in., standard deviation $=0.31 \mathrm{in}$. 


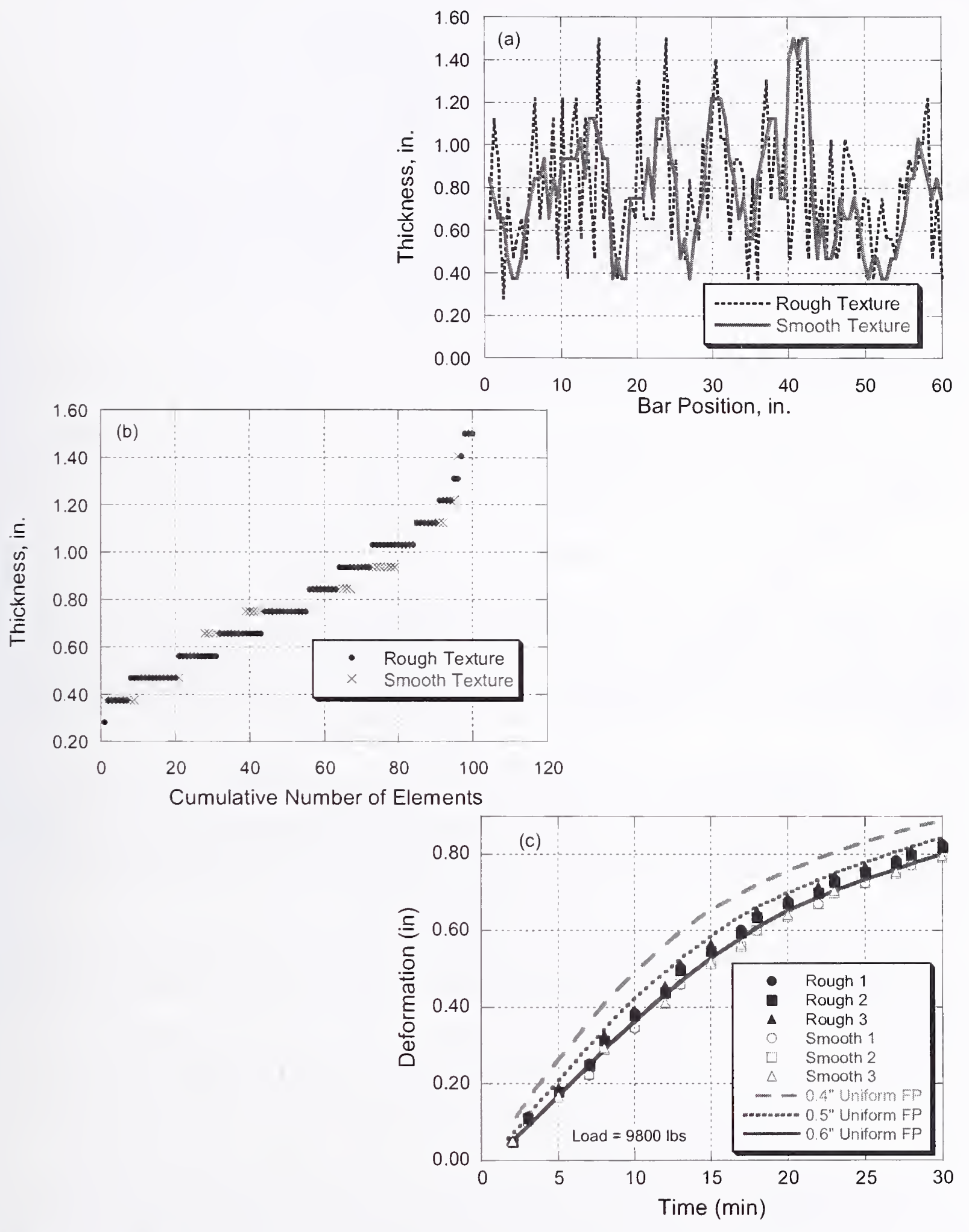

Figure 5-7. (a) Randomly generated thickness profiles with average thickness of $0.75 \mathrm{in}$. and standard deviation of 0.3 in., (b) cumulative element size, and (c) deformation of 1 in. bar compared with deformation for uniform thickness of thermal insulation. 
- Smooth 1: average $=0.79$ in., standard deviation $=0.28$ in

- Smooth 2: average $=0.78$ in., standard deviation $=0.31 \mathrm{in}$.

- Smooth 3: average $=0.78$ in., standard deviation $=0.32$ in

Figure 5-7 (c) shows that the "rough" texture reduces the effectiveness of the insulation by a small amount compared with the "smooth" texture. As noted above, it is believed that the "smooth" texture is more representative of the actual conditions. On the basis of these analyses, it is concluded that SFRM with an average thickness of $0.75 \mathrm{in}$. and a standard deviation of $0.3 \mathrm{in}$. provides protection equivalent to 0.6 in. of uniform thickness.

The results for the upgraded thermal protection are shown in Fig. 5-8. Only the "smooth" texture was used, and the values for the three cases are as follows:

- Case 1: average $=2.50$ in., standard deviation $=0.71$ in .

- Case 2: average $=2.43$ in., standard deviation $=0.51$ in

- Case 3: average $=2.55$ in., standard deviation $=0.63$ in.

Figure 5-8 (a) shows the three profiles, and Fig. 5-8 (b) shows the normal probability plots of thickness values. Because the three randomly generated profiles do not have the same averages and dispersions, the responses show more scatter than in Fig. 5-7 (c). On the basis of these analyses, it is concluded that an average SFRM thickness of $2.5 \mathrm{in}$. with a standard deviation of $0.6 \mathrm{in}$. is equivalent to $2.2 \mathrm{in}$. of uniform thickness.

\subsection{RECOMMENDED THICKNESS OF SFRM FOR THERMAL ANALYSES}

Analyses of available data on SFRM thickness in the WTC towers and thermal modeling revealed the following:

- From measurements of SFRM thickness, the average values exceeded the specified thickness.

- SFRM thickness was variable, and the distribution of thickness in the floor trusses appears to be described best by a lognormal distribution.

- The standard deviation of SFRM thickness on the trusses varied between about $0.3 \mathrm{in}$. and $0.6 \mathrm{in}$.

- The standard deviation of SFRM on columns and beams from the core tended to be lower, with a value of 0.2 in. for the available data.

- No information is available on the SFRM thickness on the exterior columns and spandrel beams.

- Variation in thickness reduces the effectiveness of SFRM, and the equivalent uniform thickness is less than the average thickness. 

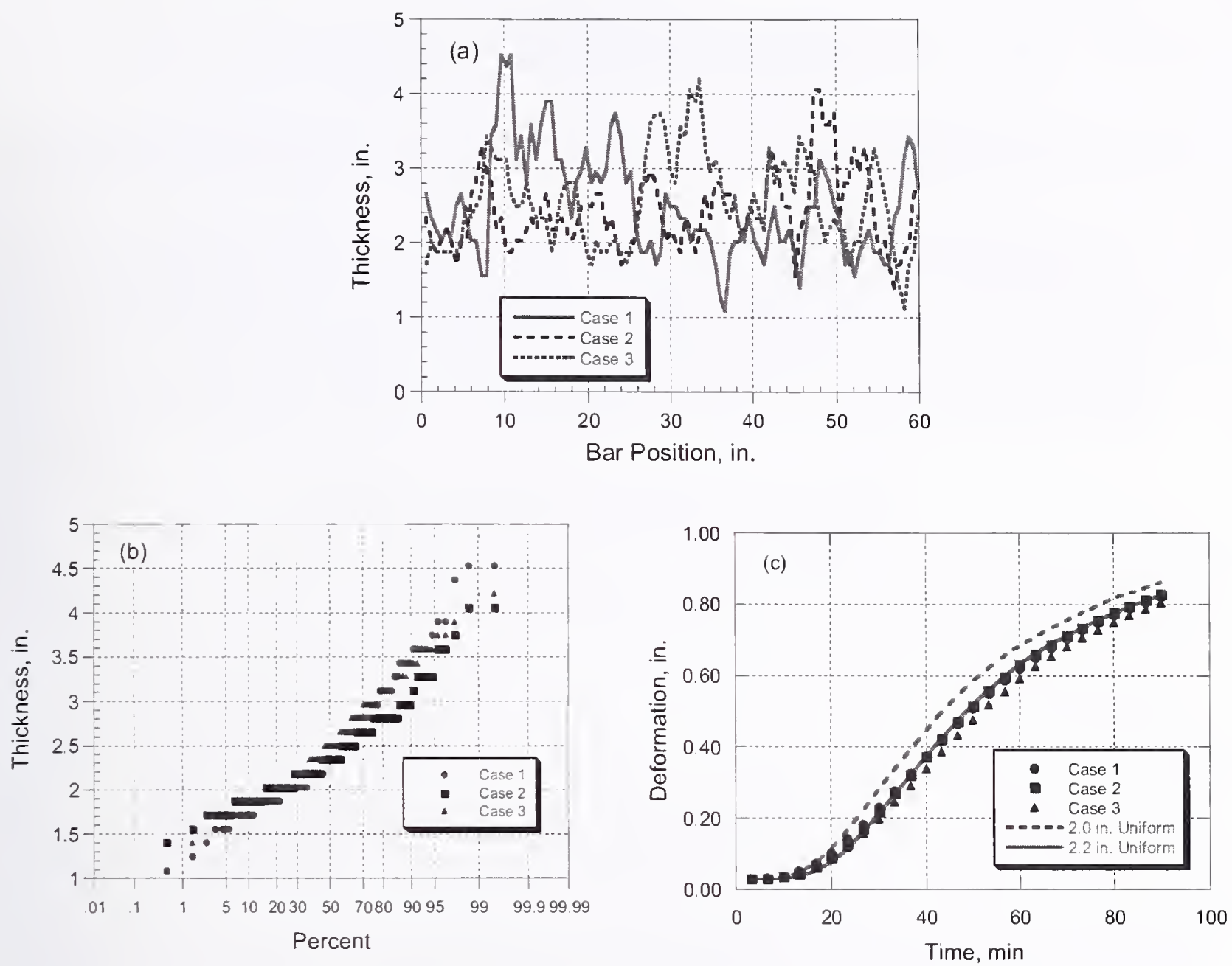

Figure 5-8. (a) Randomly generated thickness profiles with average thickness of 2.5 in. and standard deviation of 0.6 in., (b) normal probability plots of thickness values, and (c) deformation of 1 in. bar compared with deformation for uniform thickness of thermal insulation.

Based on the findings stated above, the following uniform thicknesses for the undamaged SFRM were determined for use in calculating thermal response of the WTC towers under various fire scenarios:

- Original SFRM thickness on floor trusses: 0.6 in.

- Upgraded SFRM thickness on floor trusses: 2.2 in.

- Thermal protection on other elements: the specified thickness.

The choice of specified thickness for those members lacking data is justified by offsetting factors as follows: (1) measured average thicknesses exceed specified values, and (2) variation in thickness reduces the effectiveness of the SFRM. 
This page intentionally left blank. 


\section{Chapter 6 \\ THERMOPHYSICAL PROPERTIES}

Based on information reviewed in this investigation, five sprayed fire-resistive materials (SFRMs) have been identified in WTC 1, 2, and 7: (1) BLAZE-SHIELD Type D. (2) BLAZE-SHIELD Type DC/F, (3) BLAZE-SHIELD Type II, (4) Monokote MK-5, and (5) vermiculite aggregate plaster. As mentioned in Section 3.5.1, the use BLAZE-SHIELD Type D was discontinued in 1978, and it had been used only in the lower stories of WTC 1. Of the four SFRMs, only BLAZE-SHIELD Type II is sold currently in the U.S., and BLAZE-SHIELD Type DC/F is sold in Canada. Table 6-1 summarizes where these materials were used.

Table 6-1. Summary of SFRMs used in WTC.

\begin{tabular}{|l|l|c|c|c|c|}
\hline \multirow{2}{*}{} & \multirow{2}{*}{ Fire-Resistive Material } & \multicolumn{3}{|c|}{ Locations } \\
\cline { 3 - 6 } & & Interior Columns & Floor Systems & \multicolumn{2}{c|}{ Exterior Columns } \\
\hline \multirow{3}{*}{ WTC 1 } & BLAZE-SHIELD DC/F & Yes & Yes & Outside & \\
\cline { 2 - 6 } & BLAZE-SHIELD II & & Yes (Upgrade) & & \\
\cline { 2 - 6 } & Vermiculite plaster & & & & Inside \\
\hline \multirow{2}{*}{ WTC 2 } & BLAZE-SHIELD DC/F & Yes & Yes & Outside & \\
\cline { 2 - 6 } & BLAZE-SHIELD II & & Yes (Upgrade) & & \\
\cline { 2 - 6 } & Vermiculite plaster & & & & Inside \\
\hline \multirow{2}{*}{ WTC 7 } & Monokote MK-5 & Yes & Yes & Yes & Yes \\
\hline
\end{tabular}

BLAZE-SHIELD Type DC/F is manufactured by Isolatek International (formerly U.S. Mineral Products Co., Stanhope, New Jersey) and was used in the interior columns, floor systems, and the exterior faces of the exterior columns of WTC 1 and WTC 2. BLAZE-SHIELD Type II, also from Isolatek, was used in subsequent upgrades of the passive fire protection to WTC 1 and WTC 2 floor systems. BLAZESHIELD Type DC/F and Type II are portland cement based products in which mineral fibers are the primary insulation materials. Monokote MK-5, a gypsum-based SFRM containing vermiculite aggregate, was manufactured by W.R. Grace and Co. (Cambridge, Massachusetts) and used in WTC 7. W.R. Grace stopped the production of Monokote MK-5 in the 1980s. Vermiculite aggregate plaster, manufactured by W.R. Grace until the 1970s, was used on the interior faces of the exterior columns of WTC 1 and WTC 2 (see Fig. 3-4).

No information on the thermophysical properties of vermiculite plaster has been located in the open literature. During the construction of the WTC, the Monokote product was sometimes referred to as sprayed vermiculite. See, for example, Appendix A Fig. A-17, where the description "Sprayed (Cementitious) Vermiculite (Monokote)" is used. Discussions with a former researcher at W. R. Grace and $\mathrm{Co}$. indicated that vermiculite plasters were used before the development of the Monokote product line, and these plasters had densities of 20 pcf to $25 \mathrm{pcf}$; any Monokote product used during construction of the WTC towers would probably have had similar density. ${ }^{15}$ Based on this information, the

\footnotetext{
${ }^{15}$ Personal communication from Arnie Rosenberg, August 30, 2005 (242-I).
} 
thermophysical properties of Monokote MK-5 will be taken to be representative of the vermiculite plaster specified for the interior face of the exterior columns.

In addition to the SFRMs, the thermophysical properties of four representative types of gypsum boards were examined to provide technical support to other aspects of the WTC investigation.

\subsection{ASTM TEST METHODS FOR SFRMS}

Since 1977, a number of ASTM test methods have been developed specifically for testing different characteristics of SFRMs. These methods were developed mainly for characterizing mechanical and physical properties. For completeness, these test methods are summarized in Table 6-2.

Table 6-2. Current ASTM test methods for SFRMs.

\begin{tabular}{|c|c|}
\hline ASTM Designation & Summary of Test Method \\
\hline $\begin{array}{l}\text { ASTM E } 605-93 \text { (Reapproved 2000) } \\
\text { Test Method for Thickness and Density of Sprayed } \\
\text { Fire-Resistive Material (SFRM) Applied to Structural } \\
\text { Members }\end{array}$ & $\begin{array}{l}\text { Density and thickness are determined using a thickness } \\
\text { gauge, scales, steel rules, and templates }\end{array}$ \\
\hline $\begin{array}{l}\text { ASTM E } 736-00 \\
\text { Test Method for Cohesion/Adhesion of Sprayed Fire- } \\
\text { Resistive Materials Applied to Structural Members }\end{array}$ & $\begin{array}{l}\text { The cohesion/adhesion of SFRM to structural members } \\
\text { is determined using a metal or plastic cap with a hook } \\
\text { attached. The cap is attached to the SFRM with a } \\
\text { suitable adhesive. An increasing load, measured by a } \\
\text { scale, is applied manually until failure occurs. }\end{array}$ \\
\hline $\begin{array}{l}\text { ASTM E } 759-92 \text { (Reapproved 2000) } \\
\text { Test Method for Effect of Deflection on Sprayed Fire- } \\
\text { Resistive Material Applied to Structural Members }\end{array}$ & $\begin{array}{l}\text { A cellular steel deck panel sprayed with SFRM is } \\
\text { subjected to bending by a vertical center load while } \\
\text { supported horizontally at its ends. }\end{array}$ \\
\hline $\begin{array}{l}\text { ASTM E } 760-92(\text { Reapproved 2000) } \\
\text { Test Method for Effect of Impact on Bonding of } \\
\text { Sprayed Fire-Resistive Material Applied to Structural } \\
\text { Members }\end{array}$ & $\begin{array}{l}\text { A cellular steel deck with a concrete topping sprayed } \\
\text { with SFRM is subjected to a leather bag drop impact } \\
\text { while supported horizontally at its ends. }\end{array}$ \\
\hline $\begin{array}{l}\text { ASTM E } 761-92 \text { (Reapproved 2000) } \\
\text { Test Method for Compressive Strength of Sprayed } \\
\text { Fire-Resistive Material Applied to Structural Members }\end{array}$ & $\begin{array}{l}\text { The compressive strength of SFRM applied to a steel } \\
\text { sheet is determined by a compressive load normal to } \\
\text { the surface of the specimen. }\end{array}$ \\
\hline $\begin{array}{l}\text { ASTM E } 859 \text { - } 93 \text { (Reapproved 2000) } \\
\text { Test Method for Air Erosion of Sprayed Fire-Resistive } \\
\text { Materials (SFRMs) Applied to Structural Members }\end{array}$ & $\begin{array}{l}\text { The SFRM is subjected to a tangential air stream for a } \\
\text { minimum of } 24 \mathrm{~h} \text {. Collection filters downstream from } \\
\text { the specimen are weighed at frequent intervals to } \\
\text { determine the amount of material removed from the } \\
\text { specimen. }\end{array}$ \\
\hline $\begin{array}{l}\text { ASTM E } 937 \text { - } 93 \text { (Reapproved 2000) } \\
\text { Test Method for Corrosion of Steel by Sprayed Fire- } \\
\text { Resistive Material (SFRM) Applied to Structural } \\
\text { Members }\end{array}$ & $\begin{array}{l}\text { Replicate panels of bare, shop-coated, and galvanized } \\
\text { steel are sprayed with SFRM and subjected to room } \\
\text { temperature and humidity conditions and to } 240 \mathrm{~h} \text { of } \\
\text { conditioning in a chamber with temperature and } \\
\text { humidity control. Corrosion induced under these } \\
\text { conditions is determined by mass loss of the sheets as } \\
\text { related to sheets not so conditioned. }\end{array}$ \\
\hline
\end{tabular}


For comparison with measurements to be reported in this Chapter, the nominal physical and mechanical characteristics taken from product literature (see Appendix A Fig. A-63) ${ }^{16}$ of the manufacturers of the SFRMs are listed in Table 6-3.

Table 6-3. Properties from tests of SFRMs reported by manufacturers.

\begin{tabular}{|c|c|c|c|c|}
\hline \multirow[t]{2}{*}{ Characteristic } & \multirow[t]{2}{*}{ ASTM Method } & \multicolumn{3}{|c|}{ SFRM } \\
\hline & & $\begin{array}{c}\text { BLAZE-SHIELD } \\
\text { DC/F }\end{array}$ & $\underset{\text { II }}{\text { BLAZE-SHIELD }}$ & Monokote MK 5 \\
\hline Cohesion/adhesion & E 736 & $300 \mathrm{psf}^{\mathrm{a}}$ & $360 \mathrm{psf}^{\mathrm{a}}$ & $320 \mathrm{psf}$ \\
\hline Deflection & E 759 & $\begin{array}{l}\text { No cracks or } \\
\text { delaminations }\end{array}$ & $\begin{array}{l}\text { No cracks or } \\
\text { delaminations }\end{array}$ & $\begin{array}{l}\text { No cracks or } \\
\text { delaminations }\end{array}$ \\
\hline Bond impact & E 760 & $\begin{array}{c}\text { No cracks or } \\
\text { delaminations }\end{array}$ & $\begin{array}{l}\text { No cracks or } \\
\text { delaminations }\end{array}$ & $\begin{array}{l}\text { No cracks or } \\
\text { delaminations }\end{array}$ \\
\hline $\begin{array}{l}\text { Compressive } \\
\text { strength }\end{array}$ & E 761 & $830 \mathrm{psf}$ & $2380 \mathrm{psf}$ & $3110 \mathrm{psf}$ \\
\hline $\begin{array}{l}\text { Air erosion } \\
\text { resistance }\end{array}$ & E 859 & $0.000 \mathrm{~g} / \mathrm{m}^{2}$ & $0.000 \mathrm{~g} / \mathrm{m}^{2}$ & $0.022 \mathrm{~g} / \mathrm{m}^{2}$ \\
\hline Density & E 605 & $13 \mathrm{pcf}$ & $16 \mathrm{pcf}$ & 20 to $25 \mathrm{pcf}^{\mathrm{b}}$ \\
\hline Corrosion resistance & E 937 & $\begin{array}{l}\text { Does not promote } \\
\text { corrosion of steel }\end{array}$ & $\begin{array}{l}\text { Does not promote } \\
\text { corrosion of steel }\end{array}$ & Not available \\
\hline $\begin{array}{l}\text { Thermal } \\
\text { conductivity }\end{array}$ & C 518 & $\begin{array}{c}0.042 \mathrm{~W} /(\mathrm{m} \cdot \mathrm{K}) \\
\text { @ } 24{ }^{\circ} \mathrm{C}\end{array}$ & $\begin{array}{c}0.043 \mathrm{~W} /(\mathrm{m} \cdot \mathrm{K}) \\
\text { @ } 24{ }^{\circ} \mathrm{C}\end{array}$ & Not available \\
\hline
\end{tabular}

a. Based on laboratory tests under controlled conditions.

b. Based on information from former employee of W.R. Grace, see previous footnote.

\subsection{MEASURED THERMOPHYSICAL PROPERTIES OF SFRMS}

To provide thermophysical property data for modeling the fire-structure interaction of the towers, the thermal conductivity, specific heat capacity, and density of each SFRM were determined as a function of temperature up to $1,200^{\circ} \mathrm{C}\left(2,190^{\circ} \mathrm{F}\right)$. Since there are no ASTM test methods for characterizing the thermophysical properties of SFRMs as a function of temperature, ASTM test methods developed for other materials were used. Testing services were provided by a commercial testing laboratory, through a competitive open procurement. The laboratory (referred to as Laboratory A in this report) is an ISO 9002 certified company. Test results were presented to NIST in the form of a letter report with data and plots as attachments.

\footnotetext{
${ }^{16}$ In Fig. A-63, thermal conductivity is reported as an R-value per in. thickness. The inverse of this value is the thermal conductivity. Thus, a reported $\mathrm{R}$ value of 3.45 indicates a thermal conductivity of $0.29 \mathrm{Btu}-\mathrm{in} . /\left(\mathrm{ft} 2 \cdot{ }^{\circ} \mathrm{F} \cdot \mathrm{h}\right)$ or $0.042 \mathrm{~W} /(\mathrm{m} \cdot \mathrm{K})$.
} 


\subsubsection{Sample Preparation}

Samples of BLAZE-SHIELD DC/F and II were purchased from Isolatek, Inc. in Stanhope, New Jersey, and samples of Monokote MK-5 were purchased from W.R. Grace and Co. in Cambridge, Massachusetts, according to their respective application manuals. Since Monokote MK-5 is no longer on the market, it was manufactured specially by W.R. Grace according to the original MK-5 formulation. The samples were made from the same batch of raw materials, shipped to NIST for examination and documentation, and sent to Laboratory A for testing. The samples were $9 \mathrm{in.} \mathrm{long,} 4.5 \mathrm{in}$. wide, and $3 \mathrm{in}$. thick. These dimensions were dictated by the test methods used. Three samples of each material were sent for testing. Two of them were used for the thermal conductivity measurements, and the third was used to prepare specimens for the other measurements involved. Figures 6-1, 6-2, and 6-3 show photographs of samples of BLAZE-SHIELD DC/F, BLAZE-SHIELD II, and Monokote MK-5, respectively.

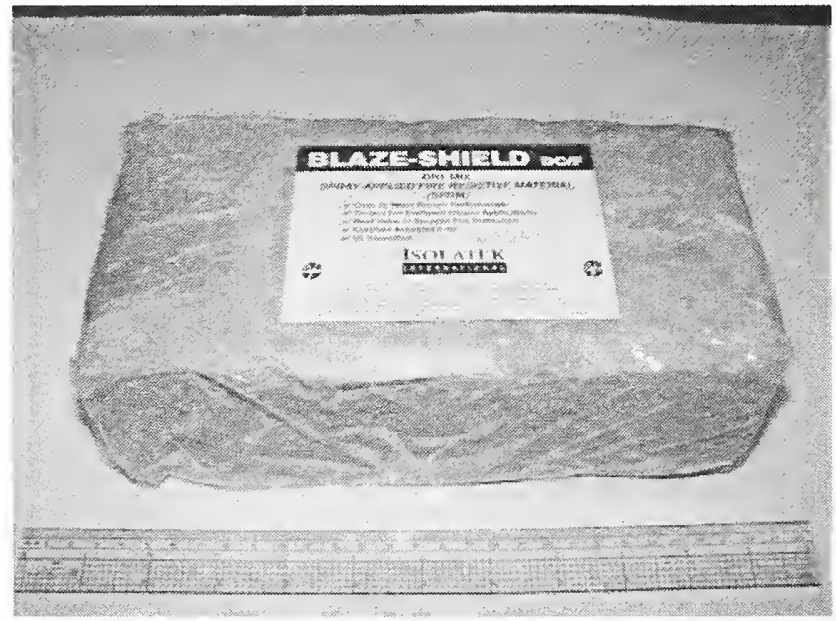

Source: NIST.

Figure 6-1. BLAZE-SHIELD DC/F sample used for thermophysical property measurements.

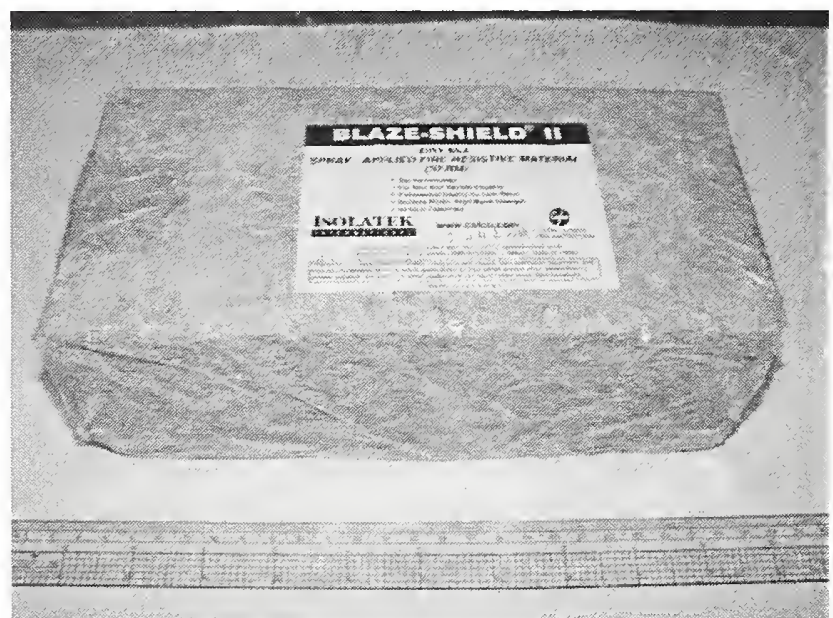

Source: NIST.

Figure 6-2. BLAZE-SHIELD II sample used for thermophysical property measurements. 


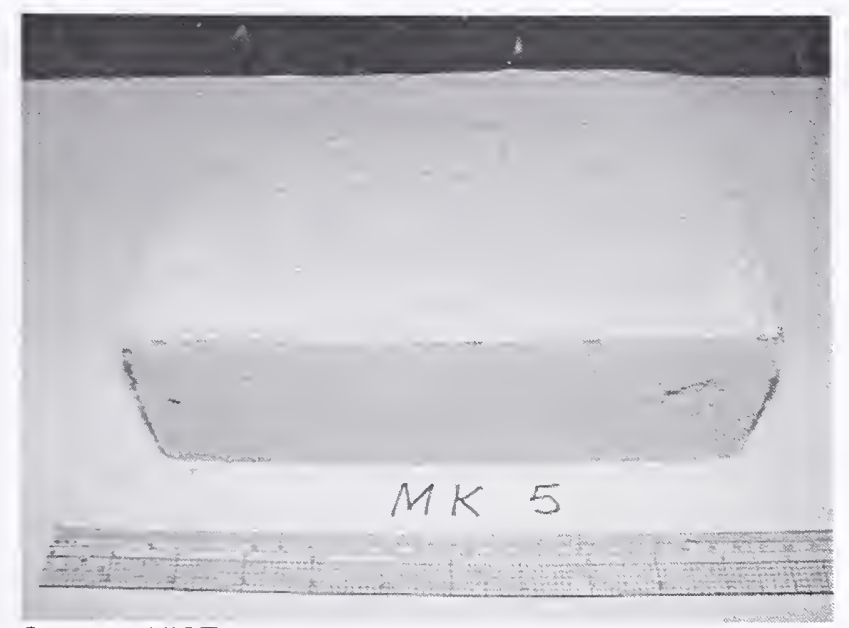

Source: NIST.

Figure 6-3. Monokote MK-5 sample used for thermophysical property measurements.

\subsubsection{Thermal Conductivity Measurements}

The thermal conductivity measurements were performed according to ASTM C 1113 (ASTM 1999). This test method is based on heating two specimens with a platinum wire placed between them. The thin platinum wire serves not only as a heater, but also as a temperature sensor, since the variation of its electrical resistance during the test is converted into variation of temperature. Thermal conductivity is calculated based on the rate of temperature increase of the wire and power input.

Laboratory A reported that substantial shrinkage occurred during the measurements for the three materials. The two MK-5 specimens shrunk. exposing the platinum wire positioned between them. For this reason, no thermal conductivity measurement could be performed for this material at $1,200{ }^{\circ} \mathrm{C}$. Table 6-4 summarizes thermal conductivity as a function of tempcrature. The results are plotted in Fig. 6-4, which also shows the results for BLAZE-SHIELD DC/F from Harmathy, which were obtained using a variable-state method (Harmathy 1983). The results show similar trends of increased thermal conductivity with increasing temperature; however, the Monokote MK-5 specimens had a different behavior than BLAZE-SHIELD Type DC/F and Type II at temperatures above $500{ }^{\circ} \mathrm{C}$. 
Table 6-4. Measured thermal conductivity as a function of temperature.

\begin{tabular}{|c|c|c|c|}
\hline & \multicolumn{3}{|c|}{ Thermal Conductivity $(\mathbf{W} /(\mathbf{m} \cdot \mathbf{K}))^{\mathbf{a}}$} \\
\hline Temperature $\left({ }^{\circ} \mathbf{C}\right)$ & BLAZE-SHIELD DC/F & BLAZE-SHIELD II & Monokote MK-5 \\
\hline 25 & 0.0460 & 0.0534 & 0.0954 \\
\hline 50 & 0.0687 & 0.0745 & 0.0926 \\
\hline 100 & 0.0628 & 0.0921 & 0.1252 \\
\hline 200 & 0.0810 & 0.0895 & 0.0919 \\
\hline 300 & 0.1106 & 0.1057 & 0.1214 \\
\hline 400 & 0.1286 & 0.1362 & 0.1352 \\
\hline 500 & 0.1651 & 0.1689 & 0.1504 \\
\hline 600 & 0.2142 & 0.2156 & 0.1622 \\
\hline 800 & 0.3380 & 0.2763 & 0.1895 \\
\hline 1000 & 0.5010 & 0.3708 & 0.2618 \\
\hline 1200 & 0.5329 & 0.4081 & - \\
\hline
\end{tabular}

a. SI units are used because this system was used to make the measurements. To convert to Btu-in./(h-ft2 $\left.{ }^{\circ} \mathrm{F}\right)$ divide by 0.1442279 .

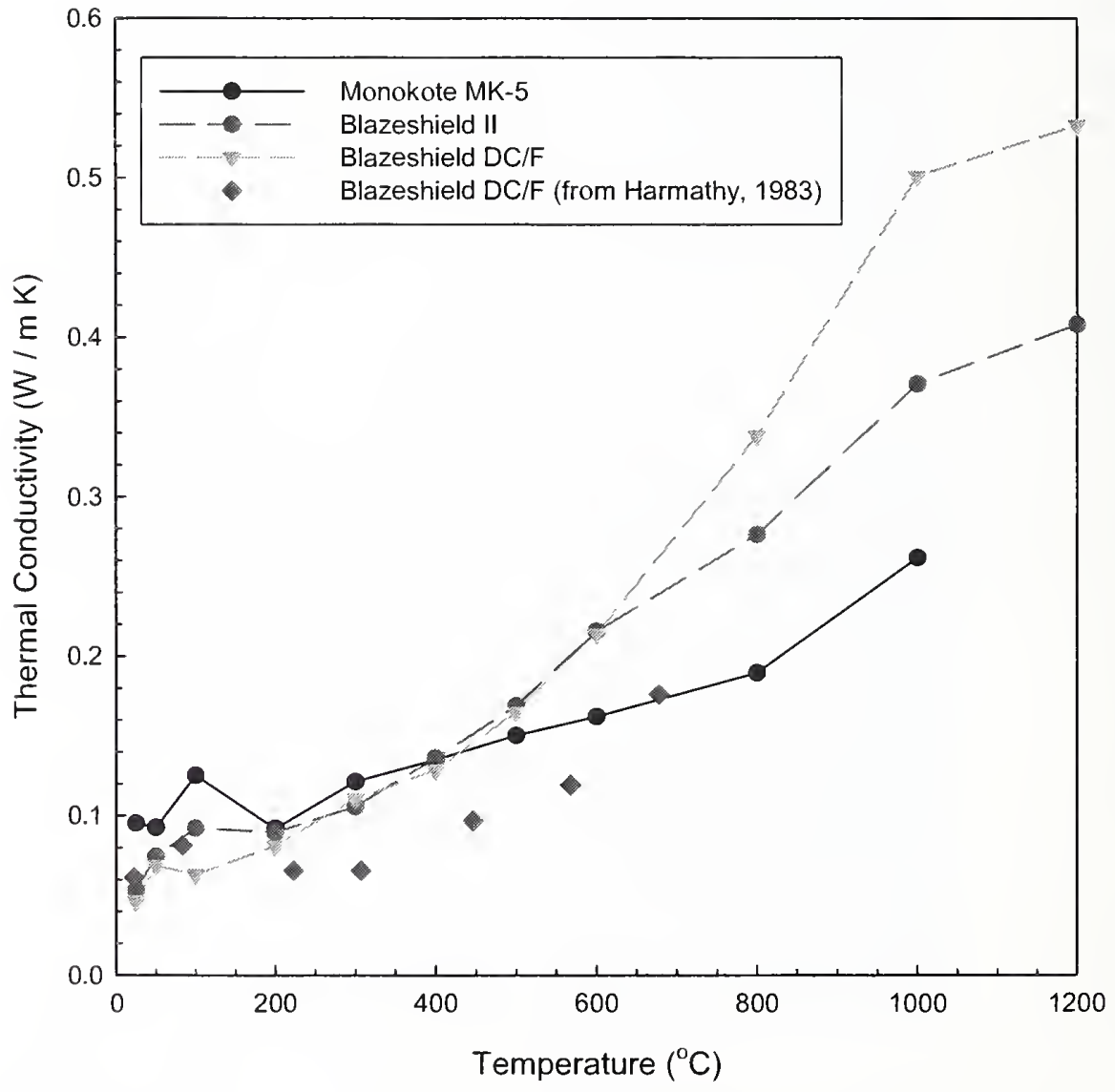

Figure 6-4. Thermal conductivities of the three SFRMs as a function of temperature. 


\subsubsection{Specific Heat Capacity Measurements}

For the specific heat capacity measurements, the same instrument (Unitherm ${ }^{\mathrm{TM}}$ Model QL-3141) was used with a slight modification. A thermocouple was added to the system and mounted on the specimen, parallel with the platinum wire at a known distance from the wire. The test was performed in a similar manner as the thermal conductivity measurements, but from the thermocouple output the thermal diffusivity of the material was derived. Knowing the thermal conductivity, the thermal diffusivity, and the density calculated from the thermal expansion results and the thermogravimetric analysis (see Section 6.3.4), the specific heat capacity of the material was calculated. Table 6-5 tabulates the measurements. Figure 6-5 compares the present results for BLAZE-SHIELD DC/F with those from Harmathy, which were obtained using a DuPont 910 differential scanning calorimeter with a heating rate of $5^{\circ} \mathrm{C} / \mathrm{min}$ (Harmathy 1983). It is clear from the figure that the inherently indirect nature of the technique used by Laboratory A precludes the direct measurements of specific heat capacity associated with chemical reactions (peaks in the figure) when the SFRMs are subjected to heating.

Table 6-5. Calculated specific heat capacity of the three SFRMs.

\begin{tabular}{|c|c|c|c|}
\hline & \multicolumn{3}{|c|}{ Specific heat capacity $(\mathbf{J} /(\mathbf{k g} \mathbf{~ K}))^{\mathbf{a}}$} \\
\hline Temperature $\left({ }^{\circ} \mathbf{C}\right)$ & BLAZE-SHIELD DC/F & BLAZE-SHIELD II & Monokote MK-5 \\
\hline 25 & 826.4 & 801.6 & 841.0 \\
\hline 50 & 941.5 & 868.4 & 1045.8 \\
\hline 100 & 723.9 & 708.4 & 1005.7 \\
\hline 200 & 897.2 & 925.4 & 1205.5 \\
\hline 300 & 1020.2 & 1084.7 & 1253.9 \\
\hline 400 & 1070.6 & 1147.5 & 1302.9 \\
\hline 500 & 1097.6 & 1255.3 & 1331.6 \\
\hline 600 & 1189.7 & 1299.1 & 1400.8 \\
\hline 800 & 1258.6 & 1369.6 & 1520.8 \\
\hline 1000 & 1325.3 & 1411.3 & - \\
\hline 1200 & 1391.7 & 1461.3 & \\
\hline
\end{tabular}

a. SI units are used because this system was used to make the measurements. To convert to Btu /(lb $\left.{ }^{\circ} \mathrm{F}\right)$ divide by 4186.8 . 


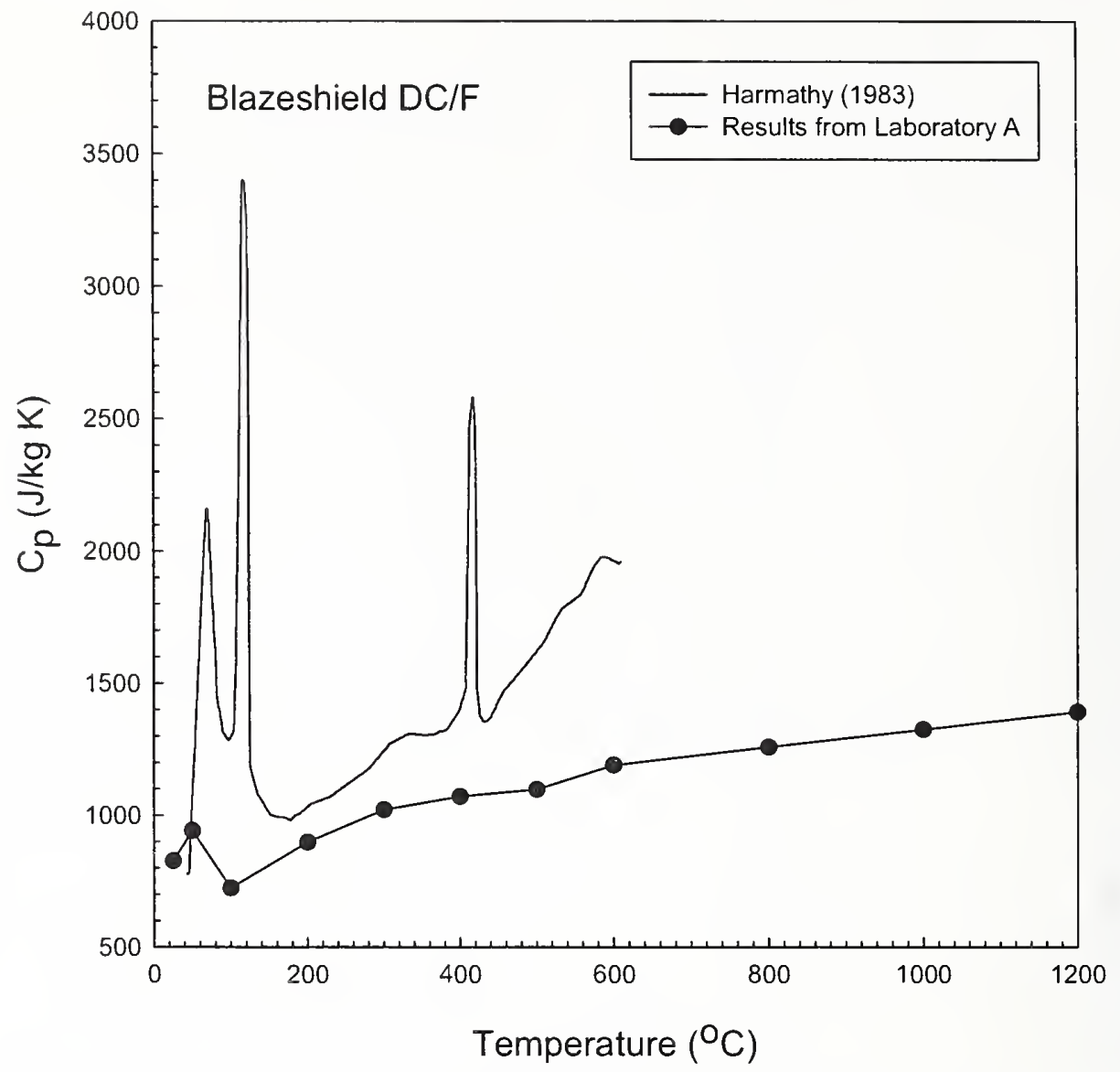

Figure 6-5. Comparison of BLAZE-SHIELD DC/F specific heat capacity measurements from Harmathy (1983) with present results from Laboratory A.

To examine the chemical reactions associated with heating of SFRMs, samples were sent to another laboratory (referred to as Laboratory B) to perform differential scanning calorimetry (DSC) because the DSC in the Building and Fire Research Laboratory at NIST was not working at that time. The specimens for DSC were prepared by removing small pieces from the bulk samples. The pieces were placed into small glass vials and sent to Laboratory B for analysis.

Specific heat capacity was measured in accordance with ASTM E 1269 (ASTM 2001) using a Perkin-Elmer Model DSC-2 Differential Scanning Calorimeter with sapphire as the reference material. The standard and SFRM specimens were subjected to the same heat flux as a blank specimen, and the differential powers required to heat the specimen and the standard at the same rate were determined using the digital data acquisition system. The specific heat capacity of the specimen was computed from the masses of the sapphire standard and the SFRM specimen, the differential power, and the known specific heat capacity of sapphire. The data were displayed visually as the test progressed. All measured quantities were directly traceable to NIST standards.

Differential thermal analysis (DTA), which is a "fingerprinting" technique that provides information on the chemical reactions, phase transformations and structural changes that occur in a specimen during a heat-up or a cool-down cycle, was used to locate the peaks and valleys during continuous heating to $600^{\circ} \mathrm{C}$ at a rate of $10^{\circ} \mathrm{C} / \mathrm{min}$. Once the peak and valley regions were identified, the sensitive DSC was 
used to examine these regions further at a heating rate of $5{ }^{\circ} \mathrm{C} / \mathrm{min}$, first from room temperature to $350^{\circ} \mathrm{C}$ and then from $300^{\circ} \mathrm{C}$ to $580^{\circ} \mathrm{C}$. It was noted by Laboratory $\mathrm{B}$, however, that the DSC results at temperatures greater than $350^{\circ} \mathrm{C}$ were of questionable quality and problematic. Only the results (up to $350^{\circ} \mathrm{C}$ ) are tabulated in Appendix B Table B-1 and are displayed in Fig. 6-6, together with the results from Laboratory A for comparison.

Figure 6-7 shows a comparison of specific heat capacity data for BLAZE-SHIELD DC/F from Harmathy (1983) with the results from Laboratory B. For temperatures up to $350{ }^{\circ} \mathrm{C}$, both results exhibit two peaks although their locations occur at different temperatures, and their magnitudes are different. In general, an increase in the heating rate results in a shift of the peaks toward higher temperatures and in increases of maxima or minima of peaks with narrowing peak widths. Both studies used the same heating rate of $5{ }^{\circ} \mathrm{C} / \mathrm{min}$. however, other procedural and operational factors could have affected the measurements. Since milligram quantities of SFRM are used in DSC, assurance of specimen homogeneity and representativeness of the bulk sample in the specimen holder is essential to the validity of the measurements, especially for inhomogeneous materials like SFRMs. In addition, mass loss from the specimen holder during heating could interfere with the measurements.

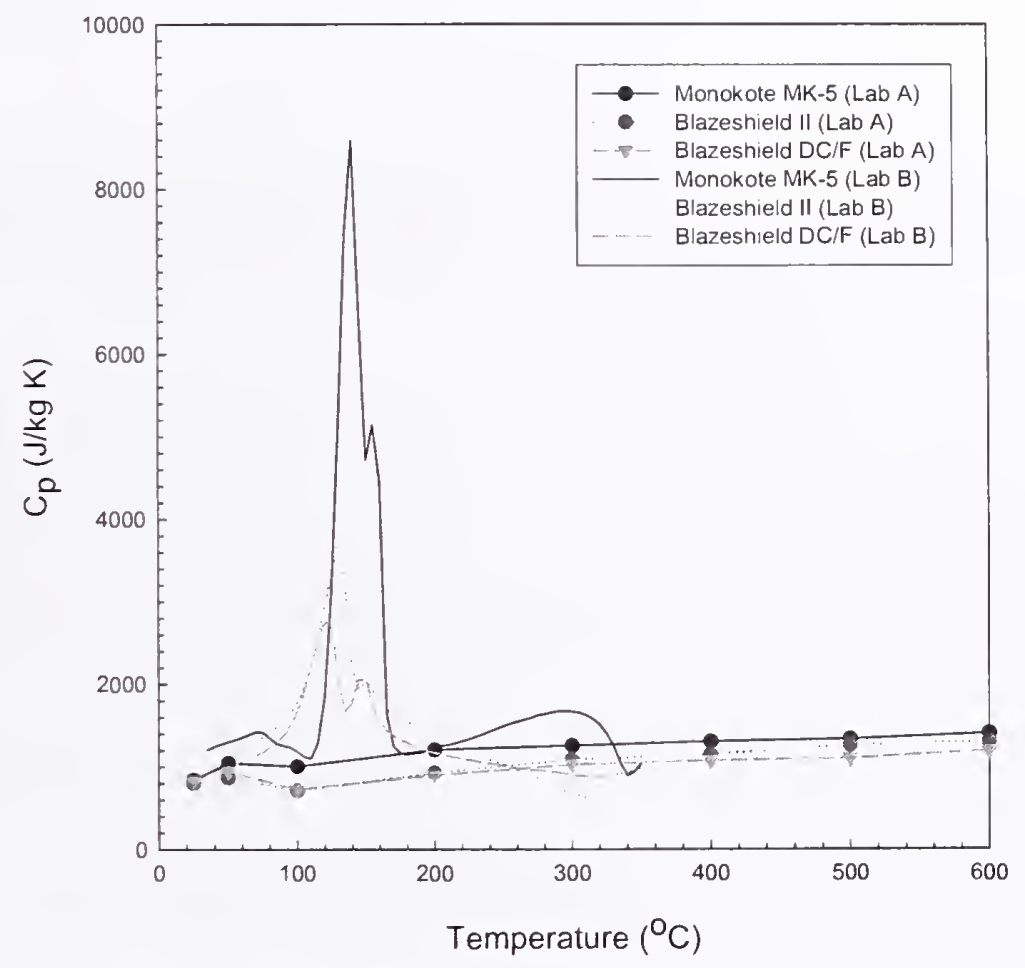

Figure 6-6. Comparison of specific heat capacity measurements from Laboratory B with results from Laboratory $A$. 


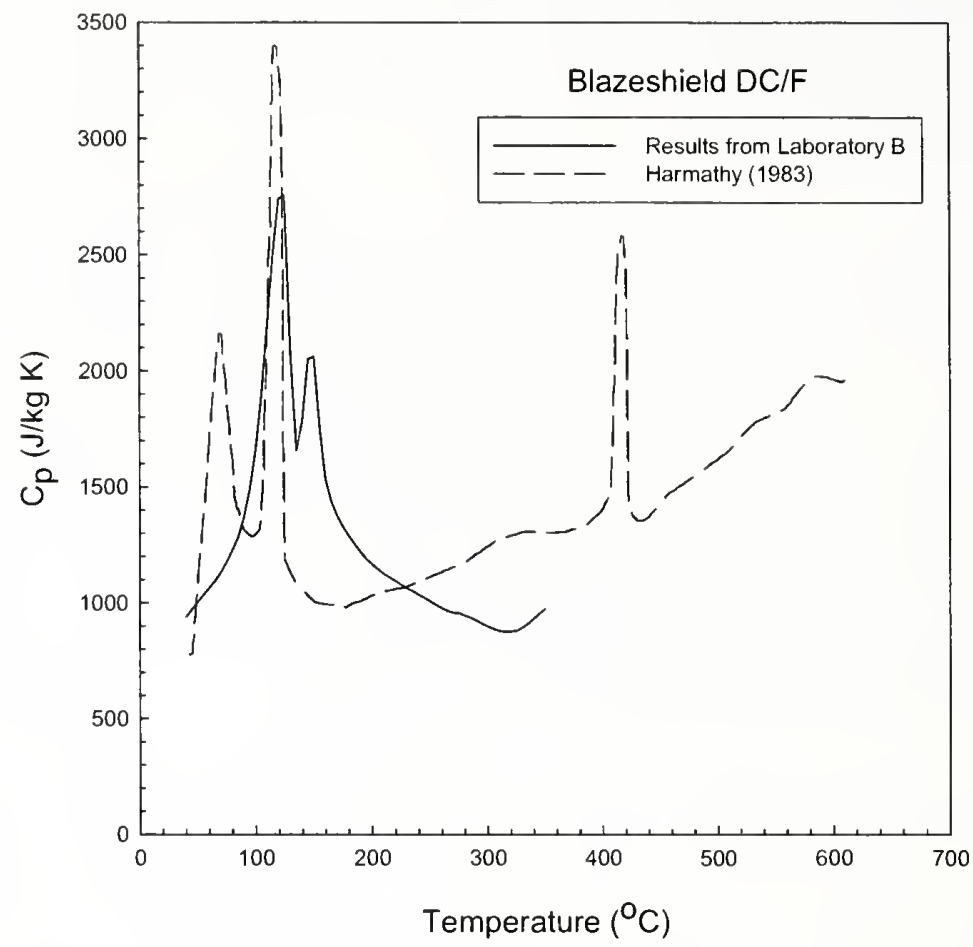

Figure 6-7. Comparison of specific heat capacity measurements for BLAZE-SHIELD DC/F from Laboratory B with the results from Harmathy (1983).

\subsubsection{Density Measurements}

Bulk densities of the SFRMs were not measured directly (except at room temperature) but were calculated from thermal gravimetric analysis (TGA) and thermal expansion measurements. The TGA tests were performed according to ASTM E 1131 (ASTM 1998) using an Orton Model ST-736 TGA. The resulting mass changes are shown in Table 6-6. The thermal expansion measurements were performed according to ASTM E 228 (ASTM 1995) using a Unitherm ${ }^{\mathrm{TM}}$ Model 1161 pushrod dilatometer. Since the materials were not isotropic, separate measurements had to be performed for the $X$ and $\mathrm{Z}$ orientations. It was assumed that the $\mathrm{X}$ and $\mathrm{Y}$ directions had the same thermal expansion. The $\mathrm{Z}$ direction was defined as the direction perpendicular to the fibrous strands in the samples. The specimens were tested from room temperature to $1,200{ }^{\circ} \mathrm{C}$ at a heating rate of $2{ }^{\circ} \mathrm{C} / \mathrm{min}$. All of the specimens shrunk during the tests and in all cases lost contact with the pushrod at temperature about $1,100^{\circ} \mathrm{C}$ before reaching the maximum test temperature. Table 6-7 shows the results of the thermal expansion measurements.

From the thermal expansion measurements, the change in volume for each material was calculated at each temperature. The density values were calculated from the results of the TGA and thermal expansion. Table 6-8 summarizes the calculations, and Fig. 6-8 displays the results. The shrinkage of the material and the specimen mass loss both contribute to the unrealistic variation in density at high temperatures. Thus, the density values are only valid up to $600^{\circ} \mathrm{C}$. 
Table 6-6. Mass loss of SFRMs with increasing temperature.

\begin{tabular}{|c|c|c|c|}
\hline & \multicolumn{3}{|c|}{ Mass Change (percent) } \\
\hline Temperature $\left({ }^{\circ} \mathbf{C}\right)$ & BLAZE-SHIELD DC/F & BLAZE-SHIELD II & Monokote MK-5 \\
\hline 25 & 0.0 & 0.0 & 0.0 \\
\hline 50 & -0.2 & -0.6 & -0.5 \\
\hline 100 & -2.7 & -3.9 & -2.7 \\
\hline 200 & -5.1 & -7.4 & -15.0 \\
\hline 300 & -6.0 & -8.7 & -19.0 \\
\hline 400 & -6.7 & -9.9 & -22.0 \\
\hline 500 & -7.5 & -11.0 & -23.0 \\
\hline 600 & -8.6 & -12.0 & -24.0 \\
\hline 800 & -11.0 & -16.0 & -25.0 \\
\hline 1000 & -11.0 & -16.0 & -27.0 \\
\hline 1200 & -14.0 & -20.0 & -42.0 \\
\hline
\end{tabular}

Table 6-7. Thermal expansion results of SFRMs.

\begin{tabular}{|c|c|c|c|c|c|c|}
\hline & \multicolumn{6}{|c|}{ Thermal Expansion (percent) } \\
\hline \multirow{2}{*}{ Temperature $\left({ }^{\circ} \mathbf{C}\right)$} & \multicolumn{2}{|c|}{ BLAZE-SHIELD DC/F } & \multicolumn{2}{c|}{ BLAZE-SHIELD II } & \multicolumn{2}{c|}{ Monokote M K-5 } \\
\cline { 2 - 7 } & $\begin{array}{c}\text { X and Y } \\
\text { Direction }\end{array}$ & Z direction & $\begin{array}{c}\text { X and Y } \\
\text { Direction }\end{array}$ & Z direction & $\begin{array}{c}\text { X and Y } \\
\text { Direction }\end{array}$ & Z direction \\
\hline 25 & 0.00 & 0.00 & 0.00 & 0.00 & 0.00 & 0.00 \\
\hline 50 & 0.02 & 0.02 & 0.02 & 0.02 & 0.03 & 0.03 \\
\hline 100 & 0.05 & 0.03 & 0.04 & -0.04 & 0.08 & 0.09 \\
\hline 200 & 0.10 & -0.13 & 0.04 & -0.36 & -0.06 & -0.13 \\
\hline 300 & 0.17 & -0.12 & 0.09 & -0.48 & -0.23 & -0.23 \\
\hline 400 & 0.23 & -0.16 & 0.11 & -0.63 & -0.65 & -0.92 \\
\hline 500 & 0.19 & -0.38 & 0.08 & -0.98 & -0.69 & -0.97 \\
\hline 600 & 0.06 & -0.93 & -0.07 & -1.45 & -0.69 & -0.97 \\
\hline 800 & -10.95 & -26.40 & -12.56 & -12.42 & -1.22 & -2.13 \\
\hline 1000 & -11.83 & -27.86 & -12.80 & -13.63 & -7.03 & -8.32 \\
\hline
\end{tabular}


Table 6-8. Calculated densities of SFRMs.

\begin{tabular}{|c|c|c|c|}
\hline & \multicolumn{3}{|c|}{ Density $\left(\mathbf{k g} / \mathbf{m}^{\mathbf{3}}\right)^{\mathbf{a}}$} \\
\hline Temperature $\left({ }^{\circ} \mathbf{C}\right)$ & BLAZE-SHIELD DC/F & BLAZE-SHIELD II & Monokote MK-5 \\
\hline 25 & 236.8 & 313.7 & 292.4 \\
\hline 50 & 236.1 & 311.5 & 290.5 \\
\hline 100 & 230.1 & 301.3 & 283.8 \\
\hline 200 & 224.6 & 291.3 & 249.1 \\
\hline 300 & 222.1 & 287.2 & 238.5 \\
\hline 400 & 220.3 & 283.7 & 233.2 \\
\hline 500 & 219.0 & 281.5 & 230.5 \\
\hline 600 & 218.2 & 280.5 & 227.5 \\
\hline 800 & 361.1 & 393.4 & 229.6 \\
\hline 1000 & 375.8 & 401.1 & 269.3 \\
\hline 1200 & 432.1 & 436.7 & 369.4 \\
\hline
\end{tabular}

a. To convert to pcf multiply by 0.062428 .

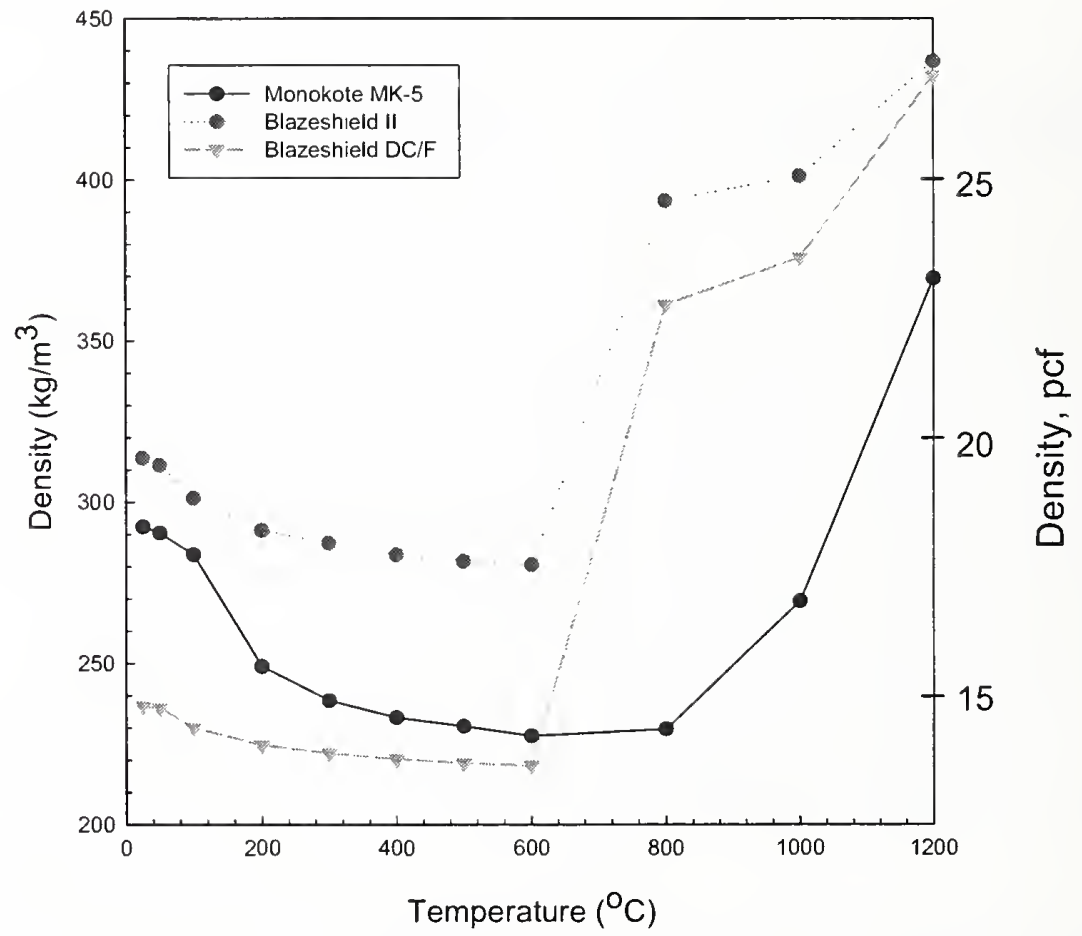

Figure 6-8. Bulk densities of the three SFRMs as a function of temperature.

\subsubsection{Concluding Remarks}

It should be noted that the thermal conductivity and bulk density depend on how the SFRM is sprayed or applied; therefore, it is expected that the results will vary from sample to sample. In general, the thermal conductivity of a porous material is a complex function of bulk density, porosity, and other material 
properties (e.g., Stephenson and Mark 1961). Recent attempts to use existing predictive methods to estimate thermal conductivities of porous media for SFRMs show some promise, and alternative approaches have also been proposed for future research. ${ }^{17}$

\subsection{THERMOPHYSICAL PROPERTIES OF GYPSUM PANELS}

In this section, measurement results of the thermophysical properties of four gypsum materials will be presented. Unless stated otherwise. measurements were performed by Laboratory B. Four representative types of gypsum materials were examined. They were:

1. $5 / 8$ in. thick gypsum panel $\mathrm{A}$,

2. $1 / 2$ in. thick gypsum panel,

3. $5 / 8$ in. thick gypsum panel $\mathrm{B}$, and

4. 1 in. gypsum liner panel.

\subsubsection{Samples}

The gypsum materials were all commercially available and were purchased from a local building supply store in Gaithersburg, Maryland. Samples were cut from the gypsum panel using a box cutter and then sent to the testing laboratory.

\subsubsection{Thermal Conductivity Measurements}

Thermal conductivity was measured using the heated probe technique described in ASTM D 5334 (ASTM 2000h). The following description of the heated probc method is provided by Laboratory $\mathrm{B}:{ }^{18}$

"In the heated probe method, which may be considered as a variant of the line source method, the line source and temperature sensor are combined in one small diameter probe. This probe is inserted into the sample and the heater turned on for a preselected time interval. During this time interval, the rate of heating of the probe is measured. This heating rate quickly becomes semi-logarithmic and from this semi-logarithmic rate, the thermal conductivity of the sample is calculatcd. The probe may be inserted into powders, fluids, small holes drilled into rocks, biological matcrials, etc. A variety of probe sizes, ranging from needle-shaped to rods are available. The data is collected by the PC based digital data acquisition system and the heating rate displayed visually. A semilogarithmic portion of the heating curve is chosen using the mouse and the conductivity calculated based on this portion of the curve."

The measurement results are summarized in Table 6-9, and the results are plotted in Fig. 6-9.

\footnotetext{
${ }^{17}$ Bentz, D. P., Prasad, K. R. and Yang, J.C. 2004. Towards a Methodology for the Characterization of Fire Protection Materials with Respect to Thermal Performance Models. Fire and Materials (accepted for publication).

${ }^{18}$ www.tpfrl.com/heatprb.html
} 
Table 6-9. Thermal conductivities of gypsum materials.

\begin{tabular}{|c|c|c|c|c|c|c|c|}
\hline \multicolumn{2}{|c|}{ 5/8 in. Panel A } & \multicolumn{2}{|c|}{$\mathbf{1} / \mathbf{~ i n . ~ P a n e l ~}$} & \multicolumn{2}{c|}{$\mathbf{5 / 8}$ in. Panel B } & \multicolumn{2}{c|}{1 in. Liner Panel } \\
\hline$\left({ }^{\circ} \mathbf{C}\right)$ & $(\mathbf{W} /(\mathbf{m} \mathbf{~ K}))^{\mathbf{a}}$ & $\left.{ }^{\circ} \mathbf{C}\right)$ & $(\mathbf{W} /(\mathbf{m} \mathbf{K})$ & $\left({ }^{\circ} \mathbf{C}\right)$ & $(\mathbf{W} /(\mathbf{m} \mathbf{K})$ & $\left({ }^{\circ} \mathbf{C}\right)$ & $(\mathbf{W} /(\mathbf{m} \mathbf{K})$ \\
\hline 23 & 0.156 & 23 & 0.194 & 23 & 0.154 & 23 & 0.133 \\
\hline 45 & 0.1533 & 47 & 0.184 & 56 & 0.148 & 48 & 0.135 \\
\hline 100 & 0.1558 & 97 & 0.188 & 103 & 0.156 & 97 & 0.136 \\
\hline 222 & 0.0963 & 200 & 0.100 & 230 & 0.090 & 200 & 0.093 \\
\hline 296 & 0.0976 & 299 & 0.097 & 318 & 0.105 & 293 & 0.089 \\
\hline 384 & 0.0987 & 406 & 0.106 & 428 & 0.113 & 413 & 0.107 \\
\hline 482 & 0.1102 & 496 & 0.113 & 508 & 0.113 & 508 & 0.116 \\
\hline 591 & 0.1276 & 603 & 0.121 & 609 & 0.131 & 598 & 0.134 \\
\hline
\end{tabular}

a. To convert to $\mathrm{Btu} \cdot$ in. $/\left(\mathrm{h} \cdot \mathrm{ft}^{2} \cdot{ }^{\circ} \mathrm{F}\right)$ divide by 0.1442279 .

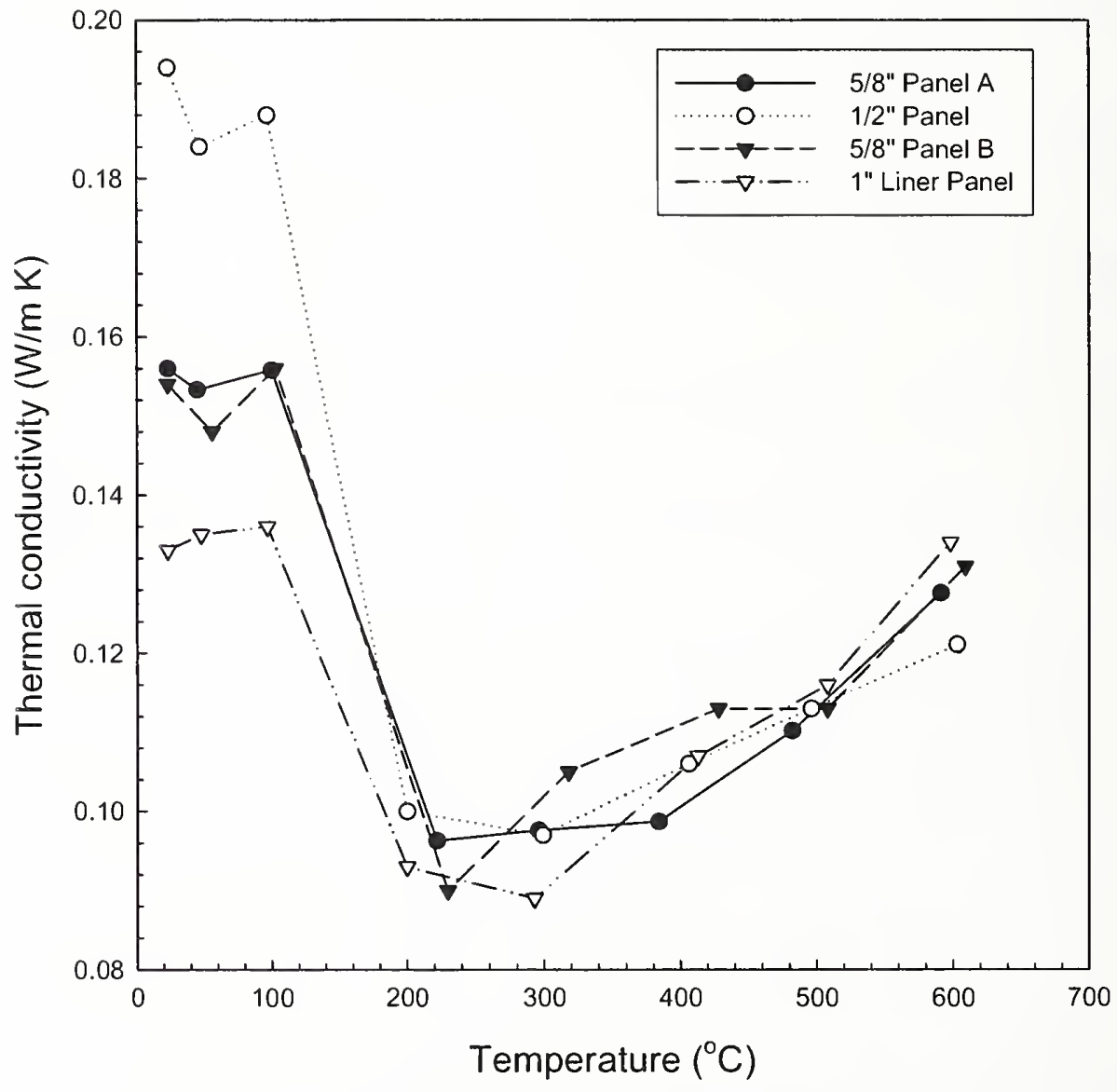

Figure 6-9. Thermal conductivities of the four gypsum materials as a function of temperature. 
Figure 6-10 shows a comparison of the current thermal conductivity measurements with data from Mehaffey et al. (1994) for Firecode Core Type X gypsum panel. The data from Mehaffey et al. were obtained using a commercially available thermal conductivity meter. Both sets of data exhibit similar trends, although, in general, the values from Mehaffey et al. are higher.

A comparison of the current thermal conductivity results with the data obtained from Harmathy (1983) and Mehaffey et al. (1994) for Firecode C Core gypsum panel is shown in Fig. 6-11. The conductivities from Harmathy (1983) are higher than those obtained from other studies. In general, the thermal conductivity initially decreases and then increases with increasing temperature.

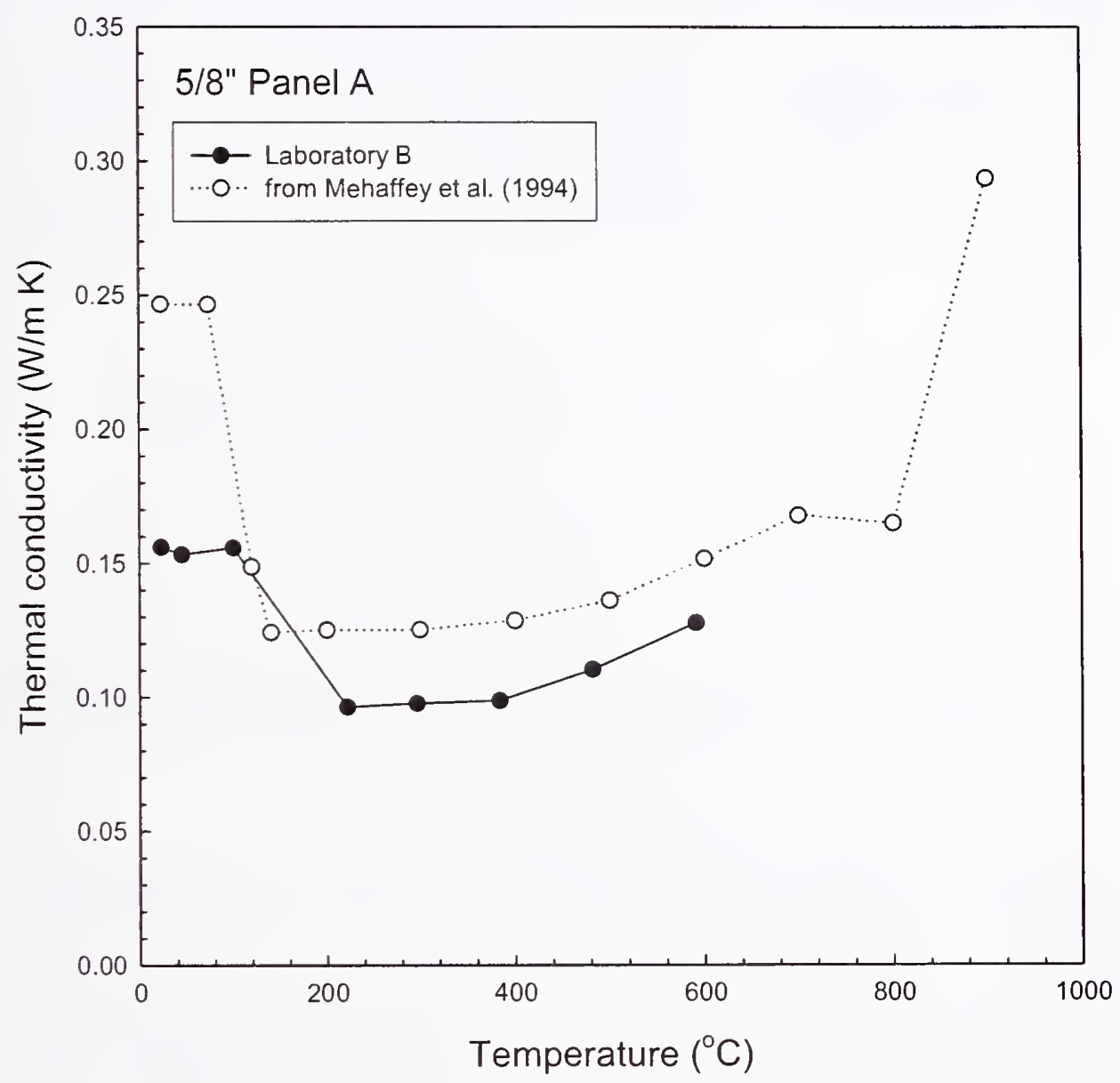

Figure 6-10. Comparison of the thermal conductivity measurements from Laboratory $B$ with the data from Mehaffey et al. (1994) for 5/8 in. thick gypsum panel A. 


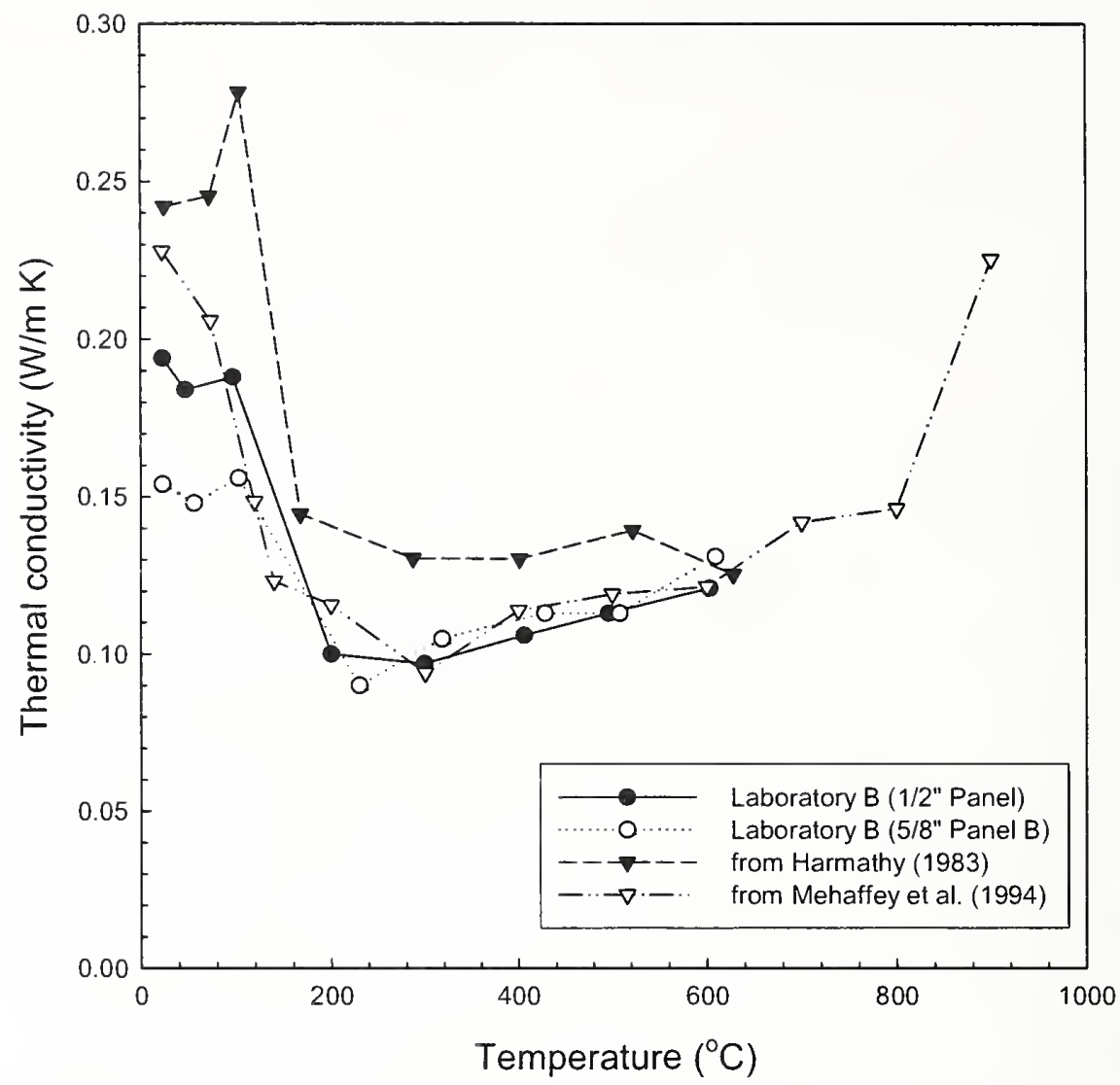

Figure 6-11. Comparison of thermal conductivity measurements from Laboratory B with other literature values for $1 / 2$ in. thick gypsum panel and $5 / 8$ in. thick gypsum panel B.

\subsubsection{Specific Heat Capacity Measurements}

Specific heat capacities of the cores of the four gypsum panel samples were measured using a TA Instruments DSC 2910 differential scanning calorimeter at NIST. Tests were conducted according to the procedure described in ASTM E 1269 (2001). Specimens of approximately $8.4 \mathrm{mg} \pm 0.1 \mathrm{mg}$ in mass were held isothermally at $30{ }^{\circ} \mathrm{C}$ for 5 minutes. The temperatures were then increased at a rate of $20{ }^{\circ} \mathrm{C} / \mathrm{min}$ to a maximum temperature of $600^{\circ} \mathrm{C}$, the operating limit of this instrument. The specimens were held isothermally at $600^{\circ} \mathrm{C}$ for an additional 5 minutes. Single scans of both an empty pan and a pan containing standard reference material SRM 720 (sapphire or $\alpha-\mathrm{Al}_{2} \mathrm{O}_{3}$ ) were conducted prior to testing and used to determine calorimetric sensitivity. The apparent specific heat capacity was calculated according to the formulas presented in the ASTM standard.

An additional modification to the ASTM test procedure was necessitated by the chemical nature of the material comprising the cores of the boards. The dominant material in the cores is gypsum, a naturally occurring mineral composed of calcium sulfate chemically bound to hydrated water (calcium sulfate dihydrate or $\mathrm{CaSO}_{4} \cdot 2 \mathrm{H}_{2} \mathrm{O}$ ). As gypsum is heated, the hydrated water is liberated in two endothermic chemical reactions. If the core materials were contained within sealed hermetic pans, out-gassing of the liberated water would eventually increase the pressure beyond the accepted limits of the pans. Use of an 
open pan is undesirable, however, as the dehydration reactions also depend on the partial pressure of water vapor in the gas surrounding the material. Therefore. aluminum hermetic pans with $50 \mu \mathrm{m}$ diameter pinholes in the lids were used. The small diameter hole allowed pressure to dissipate from the pan, maintaining structural integrity, but retained sufficient water vapor to resolve the two dehydration processes. As the core of the gypsum panel is porous, having a porosity of approximately 0.3 (Blondeau et al. 2003), it is further expected that the liberated water will remain locally in the form of vapor even as pressure diffuses across the porous matrix. The procedure used should, therefore, provide a better estimate of the response of gypsum panel cores to the rapid heating observed in fires.

Results are presented as apparent specific heat capacity of the material with respect to the initial mass of the specimen. Clearly, as the water is driven from the samples and bleeds through the pinhole, the mass of the sample will decrease. Results of thermal gravimetric tests should also be used if the true specific heat capacity of the material is desired. The data are presented in Tables B-2, B-3, B-4 and B-5 and are plotted in Figs. B-1, B-2, B-3, and B-4 in Appendix B. Peaks and valleys attributed to chemical changes are labeled on each graph with the corresponding chemical reaction. Figure 6-12 is a plot of the results for all four gypsum materials. It is seen that the four panels had similar specific heat capacities as a function of temperature.

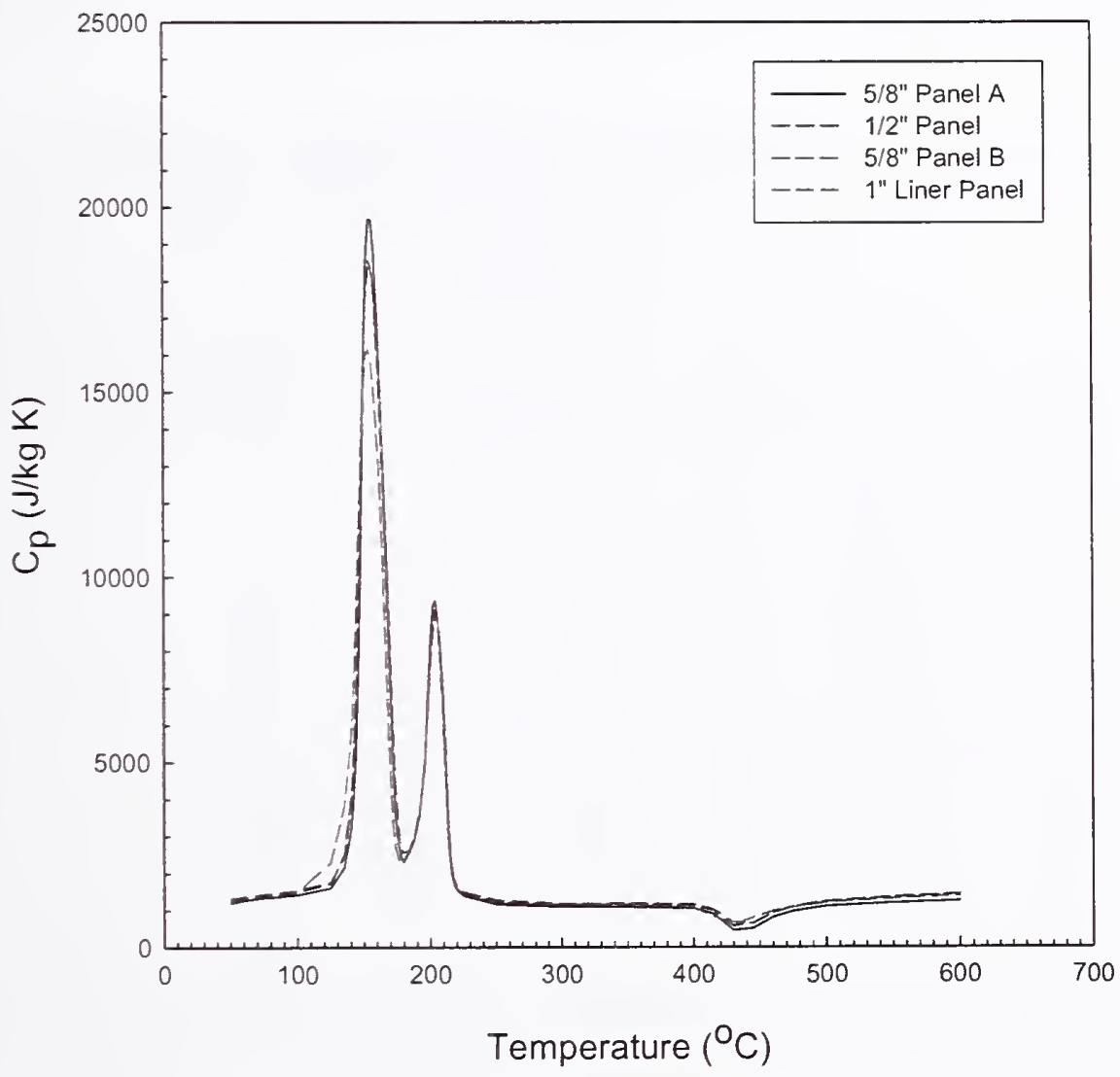

Figure 6-12. Comparison of specific heat capacities for the four gypsum materials. 


\subsubsection{Density Measurements}

Laboratory B used a Netzsch Model 409 Simultaneous Thermal Analyzer (STA) equipped with both high and low temperature furnaces was used to determine mass changes as a function of temperature. The STA is vacuum tight, allowing specimens to be tested in pure inert, reducing, or oxidizing atmospheres as well as under vacuum. The unit can be operated in the differential scanning calorimetric (DSC) or thermogravimetric analysis (TGA) mode.

A dual push-rod dilatometer (Theta Dilatronics II) was used to measure linear thermal expansion following the procedure in ASTM E 228 (ATM 1995). The differential expansion between the gypsum specimen and a known standard reference material was measured as a function of temperature. The expansion of the specimen is computed from this differential expansion and the expansion of the standard. The measurements are made under computer control, and linear expansion is calculated at pre-selected temperatures. Six standard reference materials for expansion were obtained from NIST and these include materials with low, moderate, and large expansions. For the purposes of calibration and checkout, one NIST standard was measured against another NIST standard.

Densities were calculated from the TGA results and linear thermal expansion measurements. Table 6-10 summarizes the calculated results, which are also plotted in Fig. 6-13. All four materials show the same trend as a function of temperature. The variation of density with temperature is associated with the mass loss and the change in volume of the gypsum material.

Table 6-10. Bulk densities of the four gypsum materials.

\begin{tabular}{|c|c|c|c|c|}
\hline & \multicolumn{4}{|c|}{ Density $\left(\mathbf{k g} / \mathbf{m}^{\mathbf{3}}\right)^{\mathbf{a}}$} \\
\hline $\begin{array}{c}\text { Temperature } \\
\left({ }^{\circ} \mathbf{C}\right)\end{array}$ & $\mathbf{5 / 8}$ in. Panel A & $\mathbf{1} / \mathbf{~ i n . P a n e l}$ & $\mathbf{5 / 8}$ in. Panel B & 1 in. Liner Panel \\
\hline 23 & 709 & 760 & 787 & 770 \\
\hline 50 & 706 & 759 & 785 & 767 \\
\hline 100 & 680 & 754 & 780 & 759 \\
\hline 150 & 629 & 725 & 752 & 721 \\
\hline 200 & 586 & 668 & 691 & 664 \\
\hline 250 & 580 & 636 & 656 & 638 \\
\hline 300 & 581 & 634 & 654 & 636 \\
\hline 350 & 582 & 634 & 654 & 638 \\
\hline 400 & 597 & 659 & 679 & 659 \\
\hline 450 & 600 & 665 & 684 & 663 \\
\hline 500 & 600 & 664 & 682 & 664 \\
\hline 550 & 599 & 663 & 681 & 664 \\
\hline 600 & 605 & 663 & 682 & 664 \\
\hline
\end{tabular}

\footnotetext{
a. To convert to pef multiply by 0.062428 .
} 


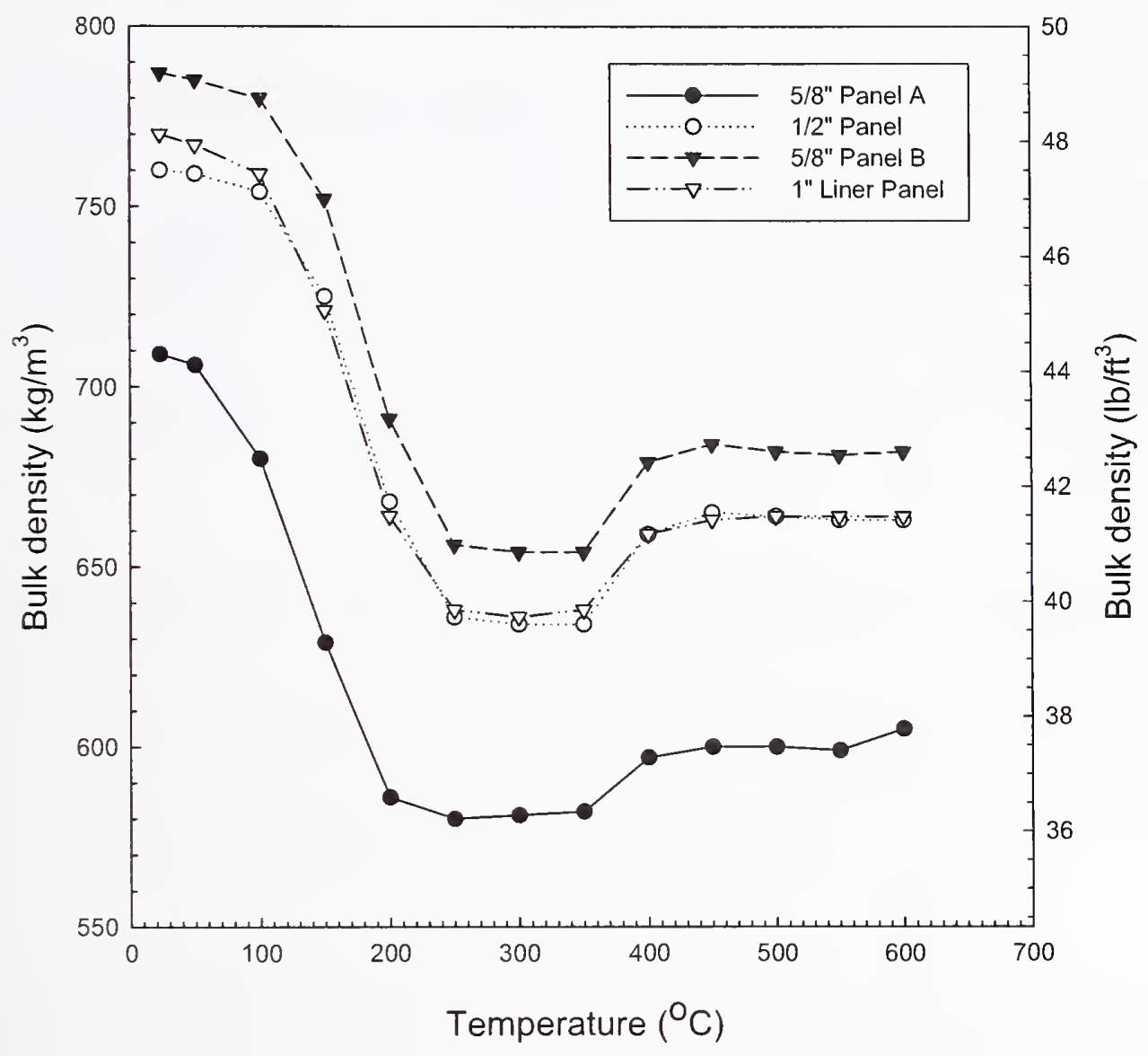

Figure 6-13. Bulk densities of the four gypsum materials as a function of temperature. 
This page intentionally left blank. 


\section{Chapter 7 \\ ADHESIVE AND COHESIVE STRENGTH}

In order to analyze the thermo-structural response of the WTC towers during the fires after the aircraft impacts, it was necessary to estimate the extent of dislodged thermal insulation on structural members. Dislodgement could occur as a result of:

- Direct impact by debris resulting from breakup of the aircraft and its contents and breakup of structural elements, or

- Inertial forces due to vibration of members excited by the impact events.

For a given level of vibration, the magnitude of the inertial forces acting on the insulation depends on the density and thickness of the thermal insulation. The insulation would dislodge if the stresses resulting from inertial forces exceeded the strength of the insulation. The focus of the investigation reported in this chapter was to determine tensile strength characteristics of the thermal insulation. Information on inplace measurements provide by the Port Authority are reviewed. The experimental approach used to obtain additional information is presented along with test results. Finally, a simplified approach is presented for estimating the accelerations required to dislodge the thermal insulation.

\subsection{REPORTED IN-PLACE DENSITY AND BOND STRENGTH}

As was mentioned in Section 4.3, the Port Authority provided data on in-place density and tensile strength characteristics of the thermal insulation applied to the floor trusses during tenant alterations. Figure A-60 in Appendix A shows an example of such test reports. The reports indicated that tests were done in accordance with ASTM E 605 (density) and ASTM E 736 (cohesion/adhesion strength). As mentioned in Chapter 4, BLAZE-SHIELD II was used in the upgrade, and as noted previously in Table 6-3, the manufacturer indicated that BLAZE-SHIELD II is about 20 percent denser and has about 20 percent higher adhesive/cohesive strength compared with BLAZE-SHIELD DC/F.

According to ASTM E 605 (ASTM 2000a), density is determined by removing a rectangular portion of the insulation after taking 12 thickness measurements to obtain the average thickness. The length and width of the removed specimen are measured, and the volume is calculated. The equilibrium mass of the specimen is determined, and density is calculated by dividing the mass by the volume. The test reports provided by the Port Authority provided no notes to indicate deviations from the standard procedure.

The technique described in ASTM E 736 (ASTM 2000b) is illustrated in Fig. 7-1. A bottle screw cap is glued to the surface of the thermal insulation, and after the glue has cured, the cap is pulled. The force required to pull off the cap is divided by the area of the cap, and reported as the "cohesive/adhesive strength." Failure is described as "cohesive" if it occurs within the insulation and is defined as "adhesive" if it occurs at the interface with the substrate. Figure 7-2 shows an example of a cohesive failure. 


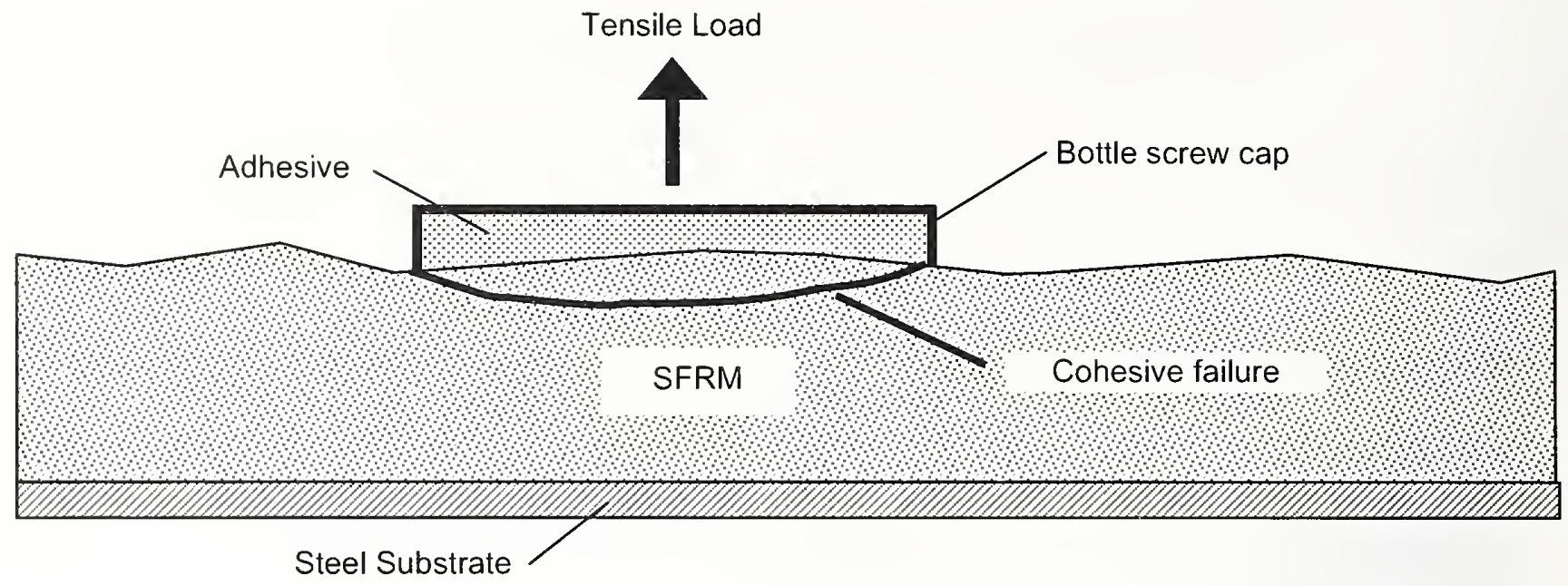

Figure 7-1. Bond strength test using screw cap in accordance with ASTM E 736.

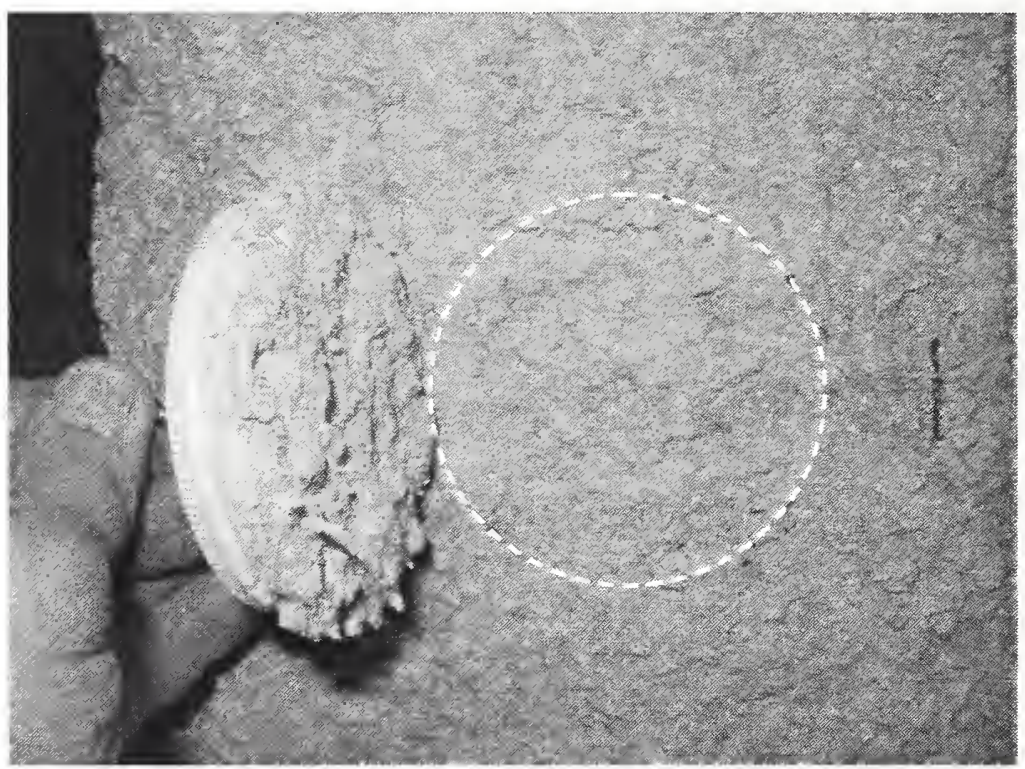

Source: NIST

Figure 7-2. Cohesive failure of SFRM using ASTM E 736 test (dashed circle is approximate location of cap before being pulled off.

Table 7-1 summarizes the density and strength data provided by the Port Authority (see also Table 4-2). The results of the tests are labeled as "bond strength." Test method ASTM E 736 calls for reporting the failure mode, but the Port Authority test reports did not include information on the nature of the failure associated with the reported strengths. The density values in Table 7-1 are plotted in Fig. 7-3 and the bond strength values are plotted in Fig. 7-4. Analysis of the density values indicated no statistically significant differences between the reported densities of the upgrade thermal insulation on floor trusses in the two towers. The overall average density was $18.9 \mathrm{pcf}$ with a standard deviation of $3.2 \mathrm{pcf}$, giving a coefficient of variation of 16 percent. 
Table 7-1. Density and bond strength of SFRM on floor trusses reported by the Port Authority of New York and New Jersey (30-P).

\begin{tabular}{|c|c|c|c|c|c|c|c|}
\hline Tower & Floor & Density, pcf & \begin{tabular}{|c|} 
Bond \\
Strength, psf \\
\end{tabular} & Tower & Floor & Density, pcf & $\begin{array}{c}\text { Bond } \\
\text { Strength, psf }\end{array}$ \\
\hline \multirow{31}{*}{1} & 79 & 16.6 & 333 & \multirow{12}{*}{1} & \multirow{3}{*}{98} & 31.3 & 407 \\
\hline & \multirow{4}{*}{81} & 19.0 & 270 & & & 16.8 & 351 \\
\hline & & 17.4 & 352 & & & 19.6 & 518 \\
\hline & & 17.6 & 463 & & \multirow{3}{*}{99} & 18.8 & 204 \\
\hline & & 17.4 & 315 & & & 16.6 & 222 \\
\hline & 83 & 16.0 & 259 & & & 18.4 & 204 \\
\hline & \multirow{5}{*}{85} & 28.7 & 162 & & \multirow{3}{*}{100} & 16.4 & 278 \\
\hline & & 23.7 & 180 & & & 17.3 & 278 \\
\hline & & 18.6 & 288 & & & 19.9 & 333 \\
\hline & & 15.8 & 278 & & \multirow{3}{*}{102} & 16.5 & 333 \\
\hline & & 16.4 & 259 & & & 16.9 & 333 \\
\hline & \multirow{3}{*}{92} & 20.3 & 360 & & & 15.9 & 315 \\
\hline & & 15.4 & 324 & \multirow{18}{*}{2} & \multirow{3}{*}{77} & 19.4 & 351 \\
\hline & & 18.0 & 360 & & & 19.4 & 198 \\
\hline & \multirow{7}{*}{93} & 14.3 & 153 & & & 17.2 & 297 \\
\hline & & 16.6 & 207 & & \multirow{2}{*}{78} & 17.0 & 288 \\
\hline & & 16.1 & 216 & & & 18.1 & 270 \\
\hline & & 18.4 & 234 & & \multirow{3}{*}{88} & 18.0 & 167 \\
\hline & & 15.1 & 162 & & & 16.0 & 333 \\
\hline & & 17.4 & 180 & & & 15.0 & 157 \\
\hline & & 21.3 & 216 & & \multirow{3}{*}{89} & 22.4 & 370 \\
\hline & \multirow{3}{*}{94} & 21.2 & 486 & & & 15.8 & 333 \\
\hline & & 20.5 & 504 & & & 15.3 & 270 \\
\hline & & 20.1 & 288 & & \multirow{3}{*}{92} & 19.7 & 342 \\
\hline & \multirow{3}{*}{95} & 18.0 & 270 & & & 21.1 & 360 \\
\hline & & 20.1 & 306 & & & 19.7 & 297 \\
\hline & & 20.4 & 198 & & \multirow{4}{*}{99} & 19.5 & 315 \\
\hline & \multirow{3}{*}{96} & 20.5 & 486 & & & 22.7 & 252 \\
\hline & & 19.8 & 288 & & & 21.9 & 306 \\
\hline & & 19.9 & 324 & & & 19.5 & 270 \\
\hline & 97 & 26.5 & 360 & & & & \\
\hline
\end{tabular}




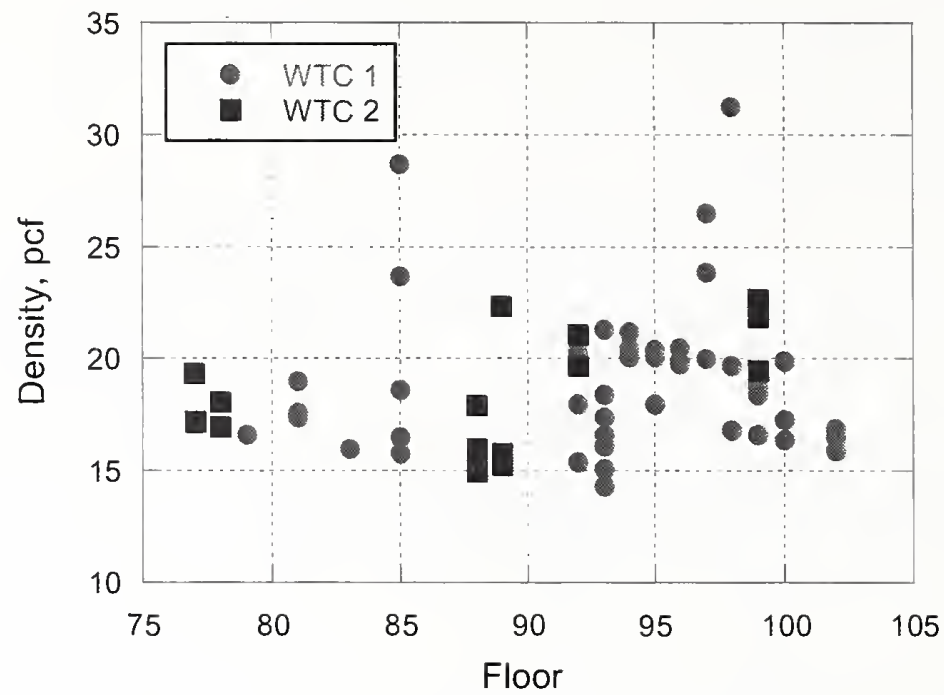

Figure 7-3. In-place density of BLAZE-SHIELD Type II on floor trusses from Port Authority test reports during the period 1997-1999.

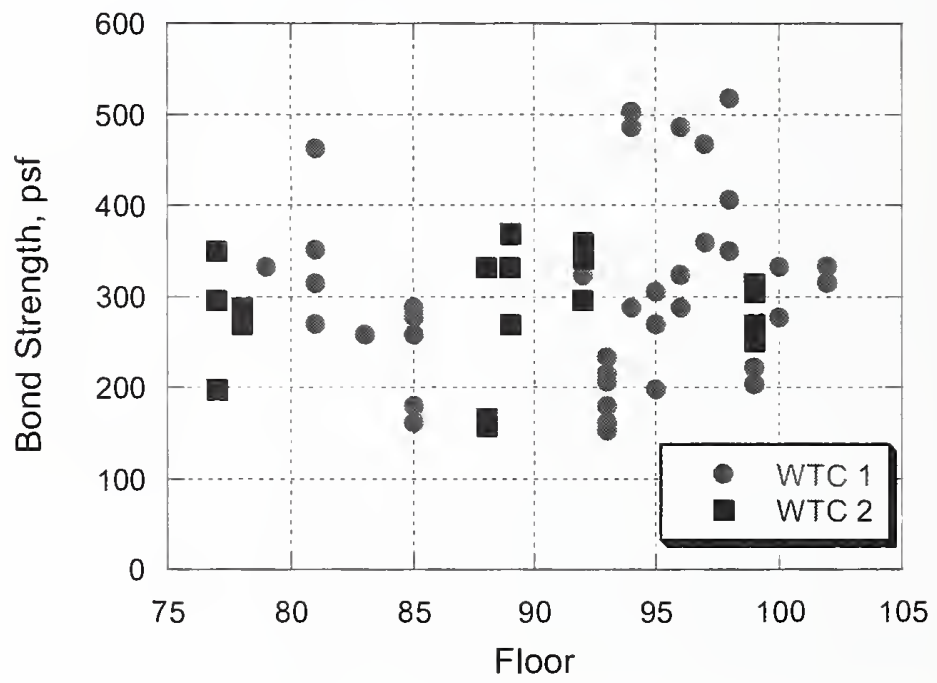

Figure 7-4. In-place bond strength of BLAZE-SHIELD Type II using ASTM E 736 from Port Authority test reports during the period 1997-1999.

Analysis of the bond strength values indicated that there were statistically significant differences between the average bond strengths for the different floors, but here was no statistically significant difference between the average bond strengths for the two towers. The overall average bond strength was $302 \mathrm{psf}$, with a standard deviation of 91 psf, giving a coefficient of variation of 30 percent. This value is less than the value of $360 \mathrm{psf}$ indicated in Table 6-3, but the tabulated values is for tests under controlled conditions (referred to as "tested performance" in the manufacturer's literature) and is not representative of field strengths. ISOLATEK product literature dated February 2002 refers to an average bond strength 
of $150 \mathrm{psf}$ as "standard performance" and this same value is used in its guide specification for BLAZESHEILD II. ${ }^{19}$ Thus, the reported bond strengths shown in Fig. 7-4 are consistent with expectations.

\subsection{SPECIMEN PREPARATION AND TEST PROCEDURES}

While the in-place bond strength data of BLAZE-SHIELD II reported by the Port Authority appear to indicate acceptable performance, results of ASTM E 736 tests do not provide sufficient information for predicting whether insulation would be dislodged from structural members under various impact conditions. The standard test does not provide unambiguous values of cohesive and adhesive strengths, and it does not provide tensile properties in a direction parallel to the surface, that is, in-plane cohesive strength. As was mentioned in Section 6.3.4. because of the way a fibrous SFRM is installed, the resulting material is not isotropic. Layers of fiber bundles are deposited parallel to the surface of the substrate. It is expected that the strength perpendicular to the planes of the layers would be less than the strength parallel to the layers. Thus. a series of tests were conducted that would allow different strength properties to be determined. In addition. it was decided to test BLAZE-SHIELD DC/F because the Port Authority data did not include tests of this material.

\subsubsection{Preparation of Test Plates}

Test specimens were made by applying the SFRM to $1 / 4$ in. steel plates measuring $8 \mathrm{in}$. by $16 \mathrm{in}$. One half of the plates were coated with Series 10 Tnemec Primer $\left(99\right.$ red) ${ }^{20}$, which is the primer that was specified for the exterior columns (see Appendix A Fig. A-63). Nominal SFRM thicknesses of $3 / 4$ in. and $1 \frac{1}{2}$ in. were applied. Thickness was controlled by surrounding the steel plates with wood strips to form molds of the desired depth. Figure 7-5 shows the application of BLAZE-SHIELD DC/F to the steel plates positioned on the floor of the laboratory. Thickness was built up in several passes of the spray nozzle. Gentle hand rubbing was used to reduce local high spots and produce reasonably uniform thicknesses. The average thickness of SFRM for the $3 / 4$ in. plates was $0.85 \mathrm{in}$. with a standard deviation of 0.08 in. For the $1 \frac{1}{2}$ in. plates, the average thickness was $1.62 \mathrm{in}$. with a standard deviation of $0.16 \mathrm{in}$. The plate specimens were allowed to dry for over five months in the laboratory before testing. Companion specimens were weighed periodically for loss of water, and it was found that the $1 \frac{1}{2} \mathrm{in}$. thick specimen reached equilibrium in about one month.

\subsubsection{Test Methods}

It was desired to determine adhesive strength, cohesive strength normal to the surface, and cohesive strength parallel to the surface of the SFRM. Figure 7-6 is a schematic of the method used to measure the first two properties. This approach is based on the standard pull-off test method used in concrete technology to measure the bond strength of overlays applied to concrete substrates (ASTM 2004b). The SFRM layer was cut carefully in two directions, and a $3 / 8$ in. by 2.7 in. by 2.7 in. aluminum plate was glued to the surface. After the adhesive had cured, a tensile load was applied to the plate, and the force required to pull off the SFRM was measured. The advantages of this approach over the ASTM 736

\footnotetext{
${ }^{19}$ Product Manual, Isolatek International, Stanhope, NJ, February, 2002.

${ }^{20}$ Purchased from Tnemec Company Inc., 6800 Corporate Drive, Kansas City, Missouri 64120-1372.
} 
technique are that the resisting area is easily determined and it offers the ability to measure both adhesive and cohesive strengths.

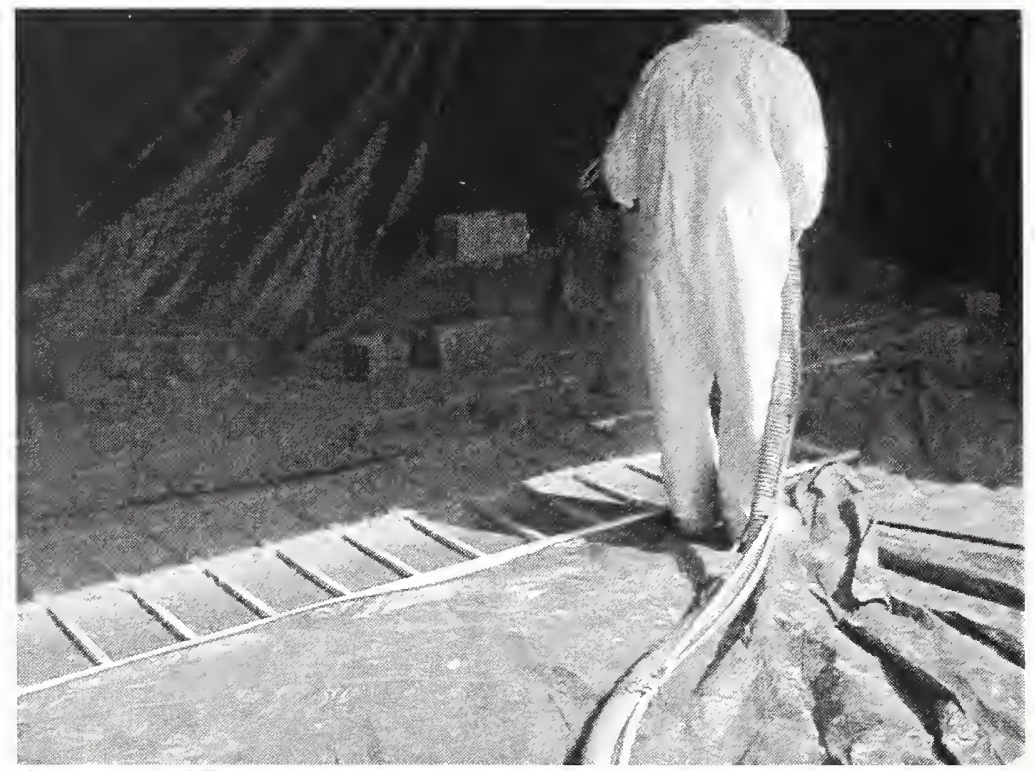

Source: NIST.

Figure 7-5. Spraying steel plates with BLAZE-SHIELD DC/F.

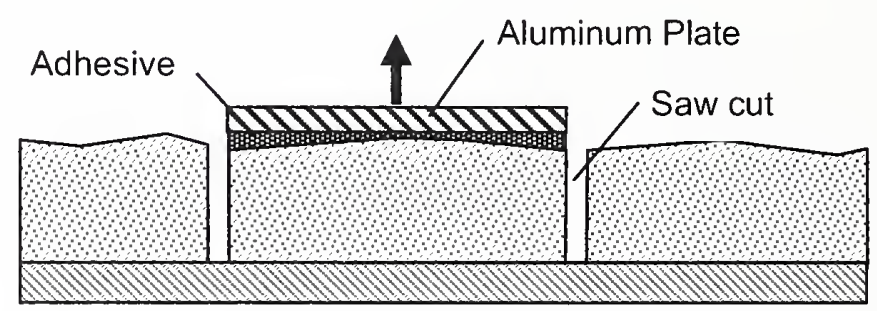

\section{Figure 7-6. Schematic of "pull-off' test method used to measure cohesive and adhesive strengths.}

In using the method shown in Fig. 7-6, one does not know beforehand what type of failure will occur, that is, whether it will be adhesive failure at the SFRM/steel interface or cohesive failure in the bulk SFRM. Failure occurs at the weakest link. It is possible, however, by a simple modification of the usual procedure to measure both strengths in the same specimen. This is accomplished by bonding together the failed specimen after the first test, and performing a second test on the repaired specimen. This approach is illustrated in Fig. 7-7, where the schematics on the left represent the first test and those on the right represent the re-test. Two cases are illustrated:

- Case 1: The initial failure is an adhesive failure near the SFRM/steel interface, and after repairing the specimen the second failure is a cohesive failure in the bulk SFRM.

- Case 2: The initial failure is a cohesive failure in the bulk SFRM, and after specimen repair the second failure is an adhesive failure near the SFRM/steel interface. 
As will be seen, this approach works because adhesive and cohesive strengths are similar in magnitude.

First Test

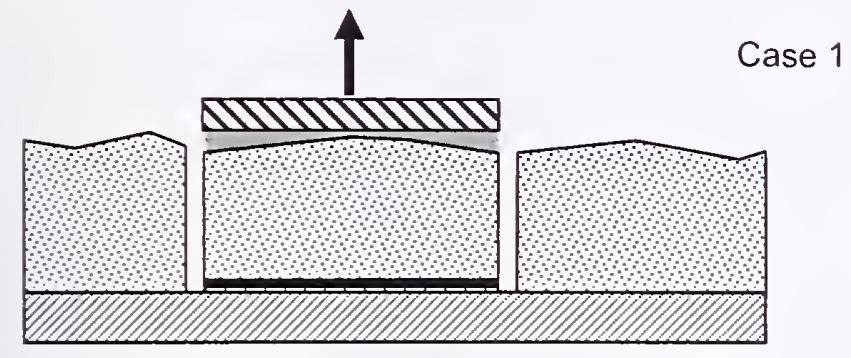

Adhesive failure

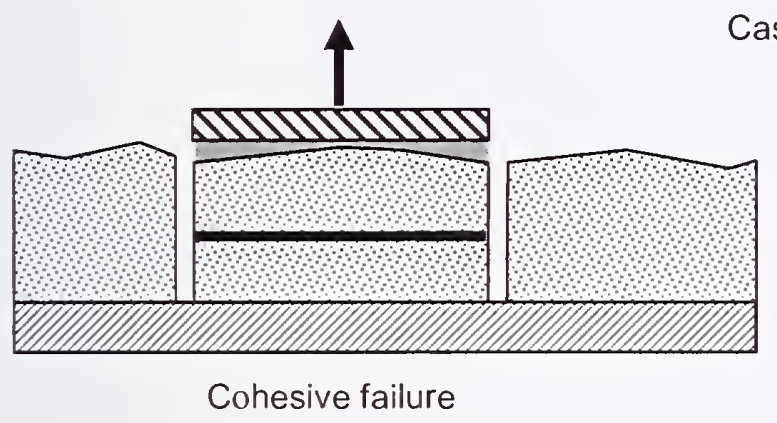

Failure plane

Case 2
Re-Test

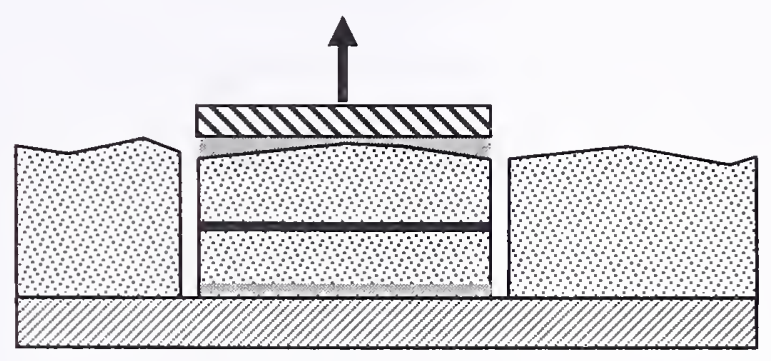

Cohesive failure

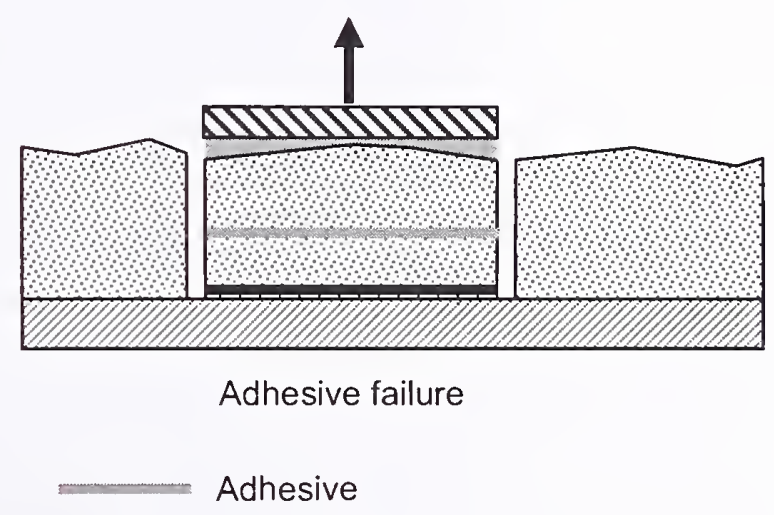

Figure 7-7. Technique used to measure both "adhesive" and "cohesive" strength in the same specimen.

The cohesive strength parallel to the surface was determined on specimens obtained by carefully removing the SFRM layer from the steel and preparing a prism that could be loaded as shown in Fig. 7-8. The following section describes how the test specimens were prepared.

\subsubsection{Preparation of Test Specimens}

From each plate, three specimens were prepared for measuring both density and in-plane cohesive strength, and two specimens were prepared for measuring adhesive strength and cohesive strength normal to the surface. The first step was to cut the SFRM layer into five $2.7 \mathrm{in}$. wide strips. A fine-toothed saw blade was used, and the sawing motion was done carefully so as to minimize damage to the SFRM (see Fig. 7-9). The two outer strips and the middle strip were debonded from the steel plate by using a sharpened putty knife. Care was taken to ensure that the two strips for adhesive/cohesive strength testing were not disturbed (see Fig. 7-10). 


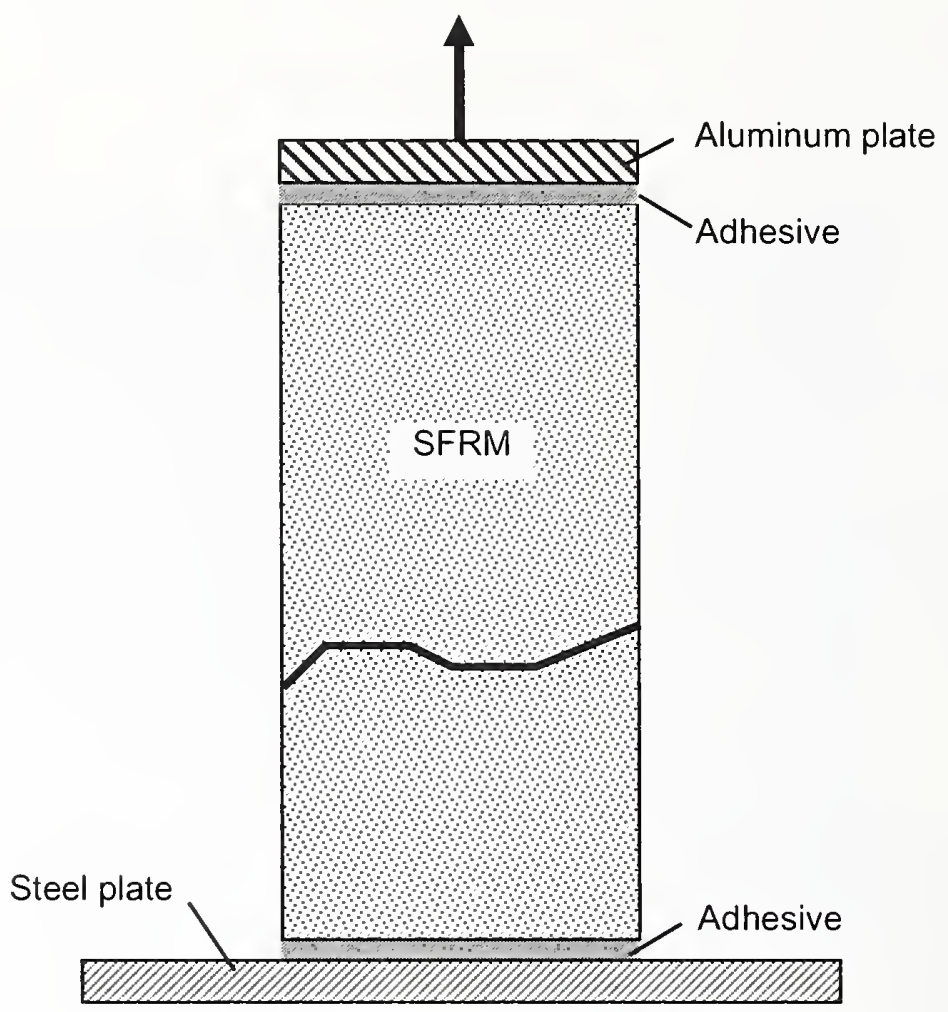

Figure 7-8. Method to measure cohesive strength parallel to SFRM surface (in-plane cohesive strength).

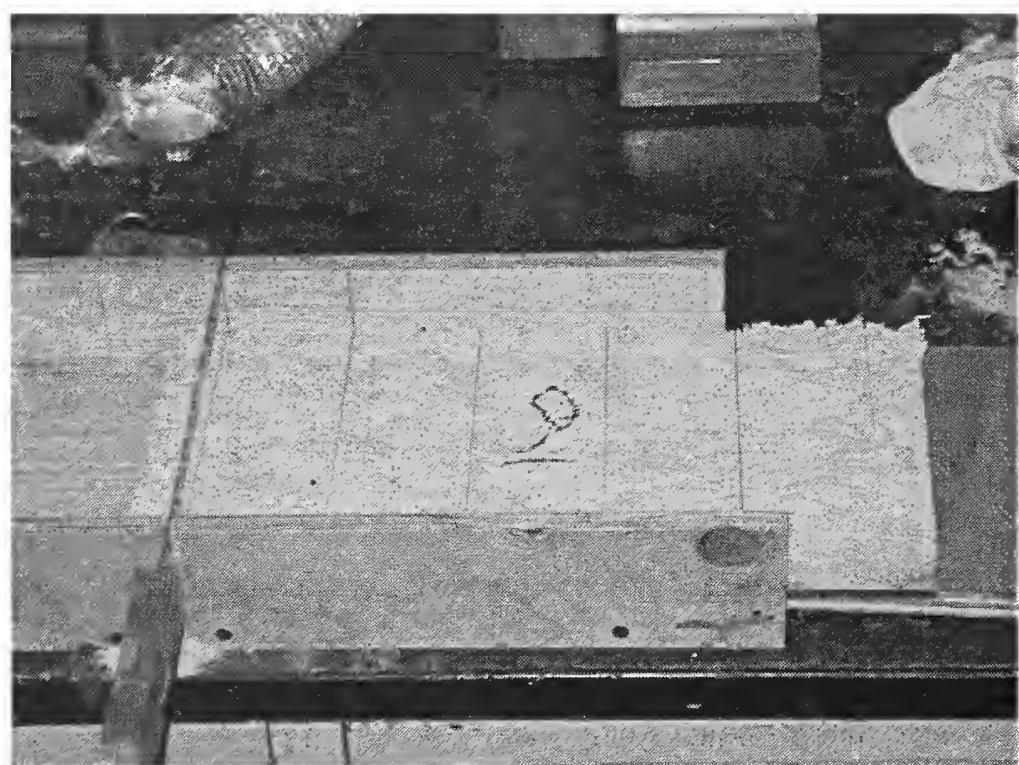

Source: NIST

Figure 7-9. Cutting the SFRM layer into five strips. 


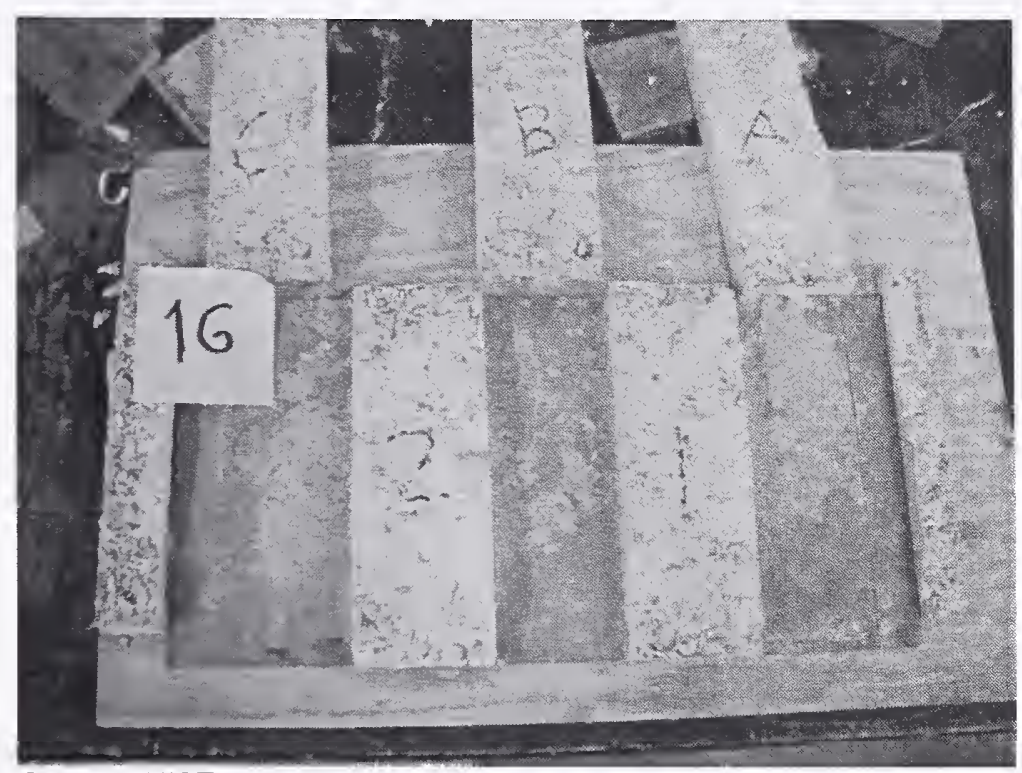

Source: NIST.

\section{Figure 7-10. Five specimens obtained from single plate; top three specimens are used for density and in-plane cohesive strength, bottom specimens are used for adhesion/cohesion tests.}

For the adhesive/cohesive strength tests, an aluminum plate was bonded to the top surface using a fast curing, two-component urethane foam adhesive. Fixtures were used to ensure that the bonded plate was parallel to the steel plate (see Fig. 7-11). After the adhesive had cured, the SFRM layer was cut as shown in Fig. 7-12 so as to produce a prismatic test specimen. A hook was screwed into the aluminum plate and a load was applied by hand using a $50 \mathrm{lb}$ digital force gauge (see Fig. 7-13). The force gauge was able to store the peak load attained during the test. During loading, the steel plate was placed on the floor, and a foot was placed at each end of the plate to provide resistance to the applied tensile load. The average length and width of the failure area was measured and used to compute the adhesive or cohesive strength.

After the first test, the specimen was repaired with the same polyurethane adhesive, and the test was repeated as discussed in Section 7.2.2. Figure 7-14 shows two specimens after the first test. The specimen on the left failed in the bulk material, thereby giving a measure of the cohesive strength normal to the surface. The specimen on the right failed near the SFRM/steel interface, which is taken to be the adhesive strength. Figure 7-15 shows the same two specimens after they had been repaired and subjected to the second loading. Now the specimen on the right shows a crack in the bulk material, and the specimen on the left shows separation near the SFRM/steel interface. Note that for the specimen on the right, which had an adhesive failure during the first loading, the failed specimen was bonded to a bare steel plate (not shown) for the second test to measure cohesive strength. In some cases where the first failure was cohesive, the repeated test also resulted in cohesive failure. In these cases, the specimen was repaired as often as needed until an adhesive failure occurred. 


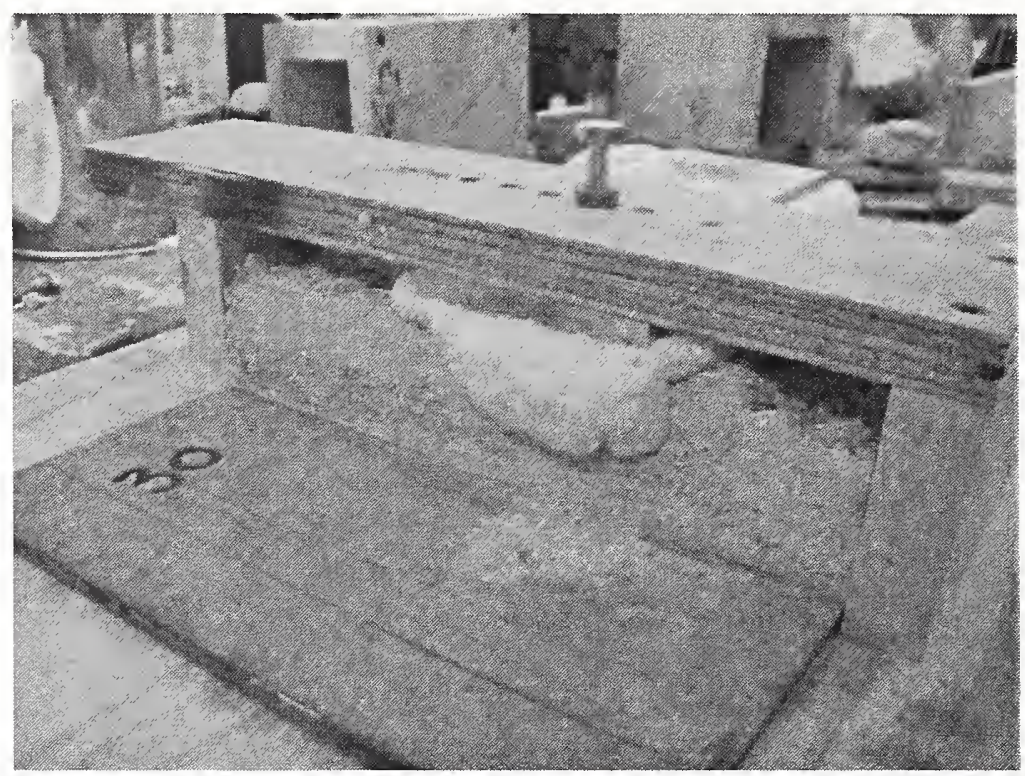

Source: NIST.

Figure 7-11. Aluminum plate being bonded to the top surface of SFRM specimen; the wooden fixture is used to maintain the correct alignment of the plate.

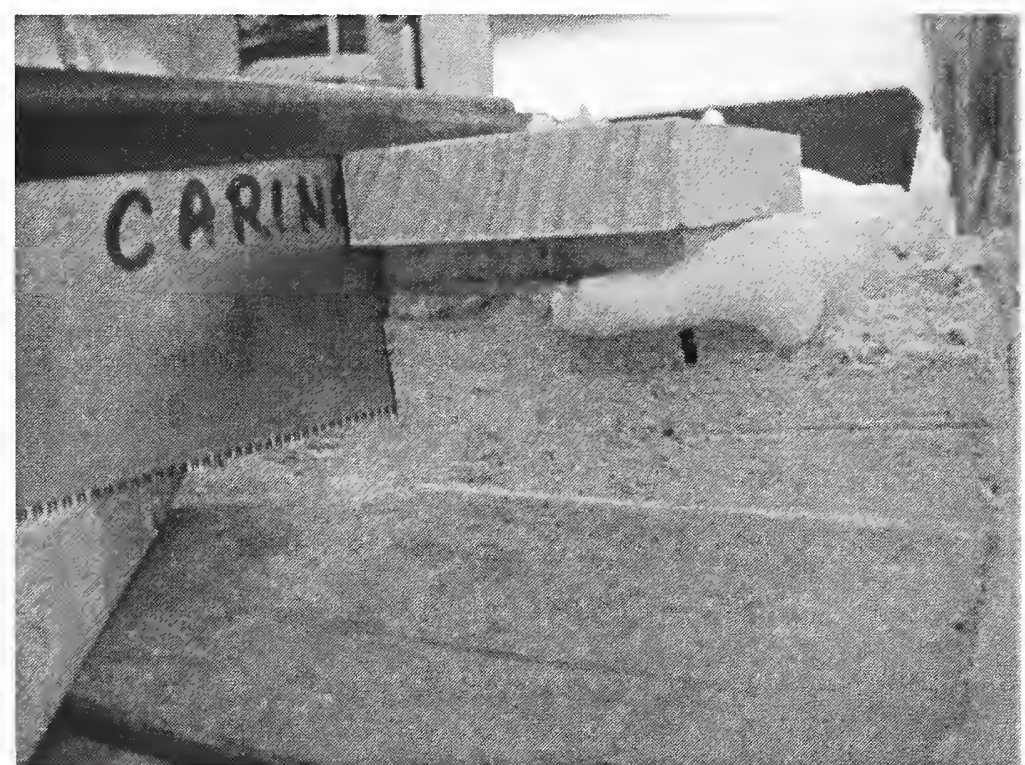

Source: NIST.

Figure 7-12. Preparing the SFRM specimen for adhesion/cohesion test. 


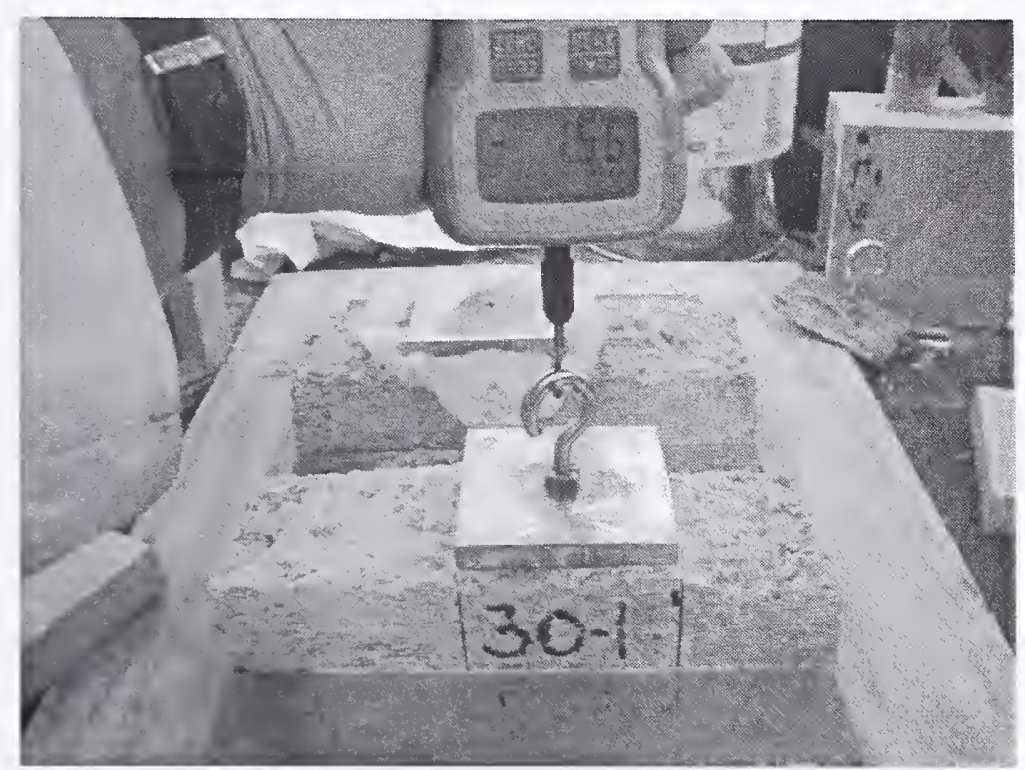

Source: NIST.

Figure 7-13. Manual application of tensile load using digital force gauge.

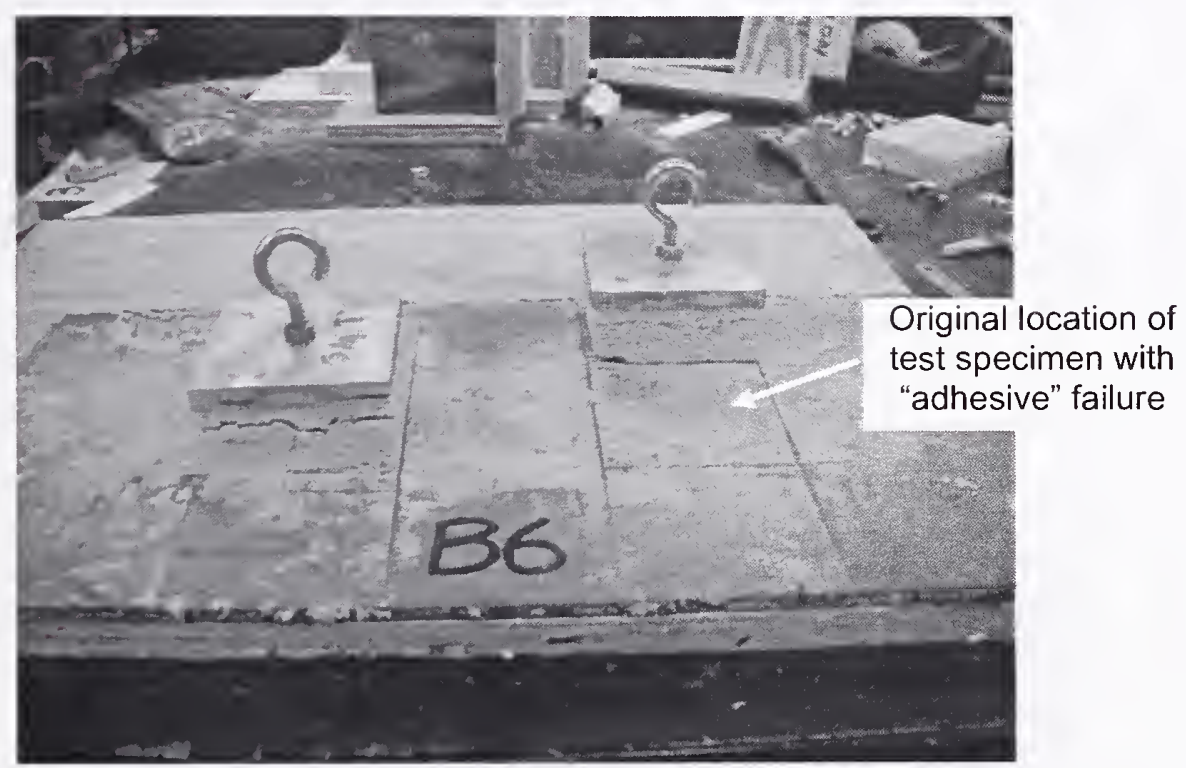

Source: NIST

Figure 7-14. Results of first loading: specimen on left had a cohesive failure in the bulk SFRM, specimen on right failed near the SFRM/steel interface. 


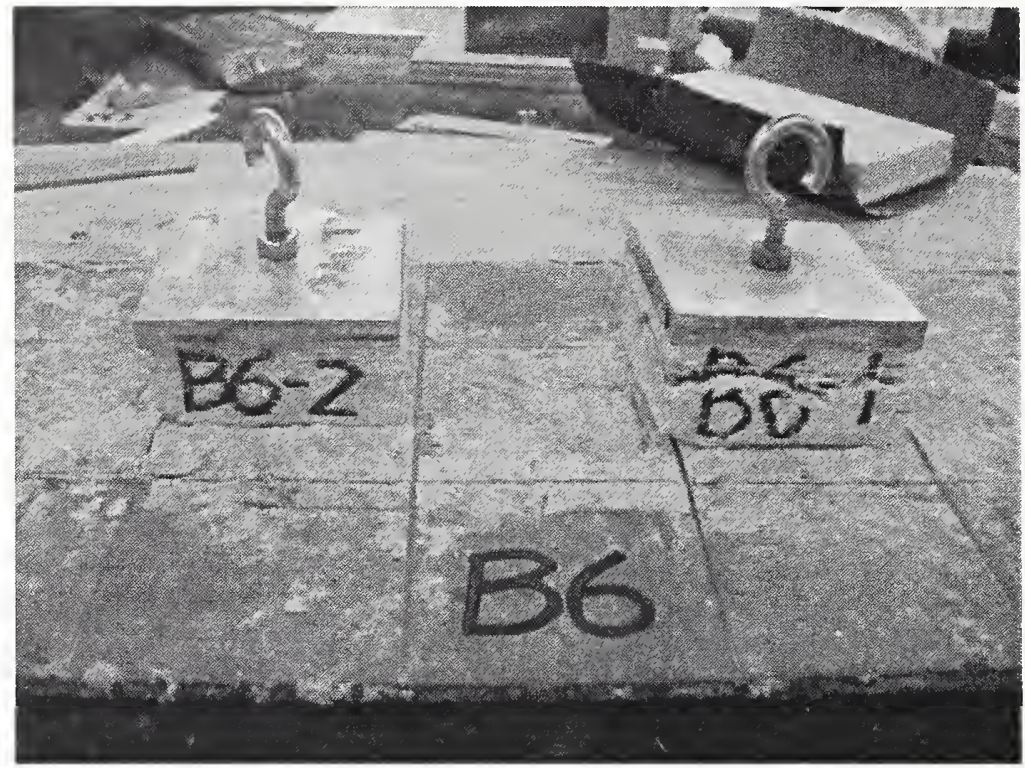

Source: NIST.

Figure 7-15. Results of second tests after repair: specimen on left had adhesive failure and specimen on right had cohesive failure.

The other three strips (see Fig. 7-10) were used for determining density and in-plane cohesive strength. First, the top surfaces of the debonded strips were sanded on a belt sander to obtain prismatic specimens. About 0.2 in. was removed from the $3 / 4$ in. plates, and about 0.4 in. was removed from the $1 \frac{1}{2}$ in. plates. The prisms were weighed and their average dimensions determined. The densities were obtained from the masses and computed volumes. Each prism was then bonded to a steel plate with the polyurethane adhesive. An aluminum plate was bonded to the other end of the specimen. After the adhesive had cured, a tensile load was applied to the aluminum plate until the SFRM failed (see Fig. 7-16). The area of the fracture plane was determined and the in-plane cohesive strength calculated from the recorded maximum load.

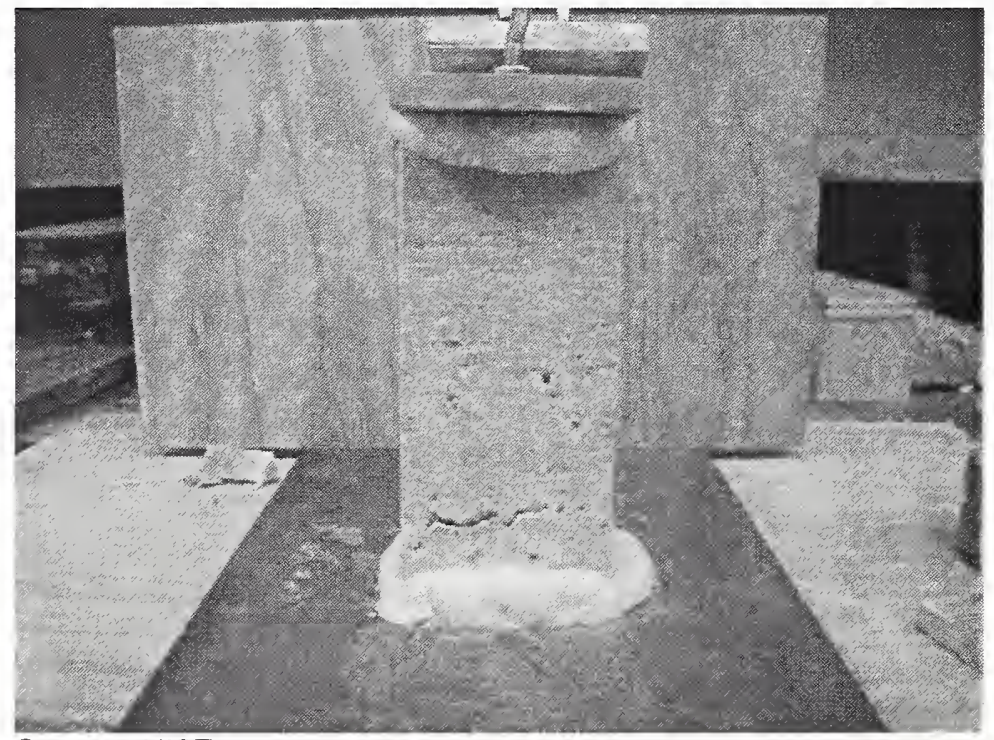

Source: NIST.

Figure 7-16. SFRM specimen after measuring in-plane cohesive strength. 


\subsection{TEST RESULTS}

Table 7-2 summarizes the properties that were measured and the types of SFRM plates that were tested. It was assumed that the presence or absence of primer on the steel plates would not affect density or inplane cohesive strength. Thus, only primed plates were used for these properties. The following sections summarize the test results.

Table 7-2. Test matrix.

\begin{tabular}{|l|c|c|c|c|}
\hline \multirow{2}{*}{ Property } & \multicolumn{2}{|c|}{$3 / 4$ in. Nominal Thickness } & \multicolumn{2}{c|}{$1 \frac{1}{2}$ in. Nominal Thickness } \\
\cline { 2 - 5 } & With Primer & Bare Steel & With Primer & Bare Steel \\
\hline Density & $\mathrm{X}$ & & $\mathrm{X}$ & \\
\hline In-plane cohesive strength & $\mathrm{X}$ & & $\mathrm{X}$ & \\
\hline Adhesive/Cohesive $(\mathrm{N}) *$ strength & $\mathrm{X}$ & $\mathrm{X}$ & $\mathrm{X}$ & $\mathrm{X}$ \\
\hline
\end{tabular}

* $\mathrm{N}$ indicates normal to surface of SFRM

\subsubsection{Density}

As mentioned in Section 7.2.3, density was determined by weighing prismatic specimens prepared by sanding the irregular exposed surface of the SFRM. The specimens were about 5 months old when tested and had attained equilibrium water contents. Five plates with primed steel were chosen at random for each SFRM thickness. Table 7-3 lists the individual determinations, and Fig. 7-17 is a plot of the data. The average density of the $3 / 4$ in. thick specimens is $27.2 \mathrm{pcf}$, with a standard deviation of 0.8 pcf; and for the $1 \frac{1}{2}$ in. thick specimens the average density is $29.7 \mathrm{pcf}$ with a standard deviation of $1.3 \mathrm{pcf}$. The difference in average values for the two thicknesses was found to be statistically significant.

Table 7-3. Density of BLAZE-SHIELD DC/F specimens.

\begin{tabular}{|c|c|c|c|c|c|}
\hline $\begin{array}{c}\text { Nominal } \\
\text { Thickness }\end{array}$ & Specimen & $\begin{array}{c}\text { Density, } \\
\text { pcf }\end{array}$ & $\begin{array}{c}\text { Nominal } \\
\text { Thickness }\end{array}$ & Specimen & $\begin{array}{c}\text { Density, } \\
\text { pcf }\end{array}$ \\
\hline & $7-\mathrm{a}$ & 26.1 & & $24-\mathrm{a}$ & 29.5 \\
& $7-\mathrm{b}$ & 26.0 & & $24-\mathrm{b}$ & 29.2 \\
& $7-\mathrm{c}$ & 26.6 & & $24-\mathrm{c}$ & 29.3 \\
& $6-\mathrm{a}$ & 27.2 & & $29-\mathrm{a}$ & 30.0 \\
& $6-\mathrm{b}$ & 27.2 & & $29-\mathrm{b}$ & 29.0 \\
& $6-\mathrm{c}$ & 26.7 & & $29-\mathrm{c}$ & 29.6 \\
& $18-\mathrm{a}$ & 26.2 & & $10-\mathrm{a}$ & 31.2 \\
& $18-\mathrm{b}$ & 28.1 & $11 / 2$ in. & $10-\mathrm{b}$ & 31.4 \\
& $18-\mathrm{c}$ & 27.2 & & $10-\mathrm{c}$ & 29.9 \\
& $16-\mathrm{a}$ & 27.0 & & $30-\mathrm{a}$ & 26.9 \\
& $16-\mathrm{b}$ & 28.2 & & $30-\mathrm{b}$ & 27.7 \\
& $16-\mathrm{c}$ & 28.3 & & $30-\mathrm{c}$ & 29.5 \\
& 2-a & 27.9 & & $11-\mathrm{a}$ & 31.5 \\
& 2-b & 26.7 & & $11-\mathrm{b}$ & 30.5 \\
& 2-c & 28.0 & & $11-\mathrm{c}$ & 29.7 \\
\hline
\end{tabular}




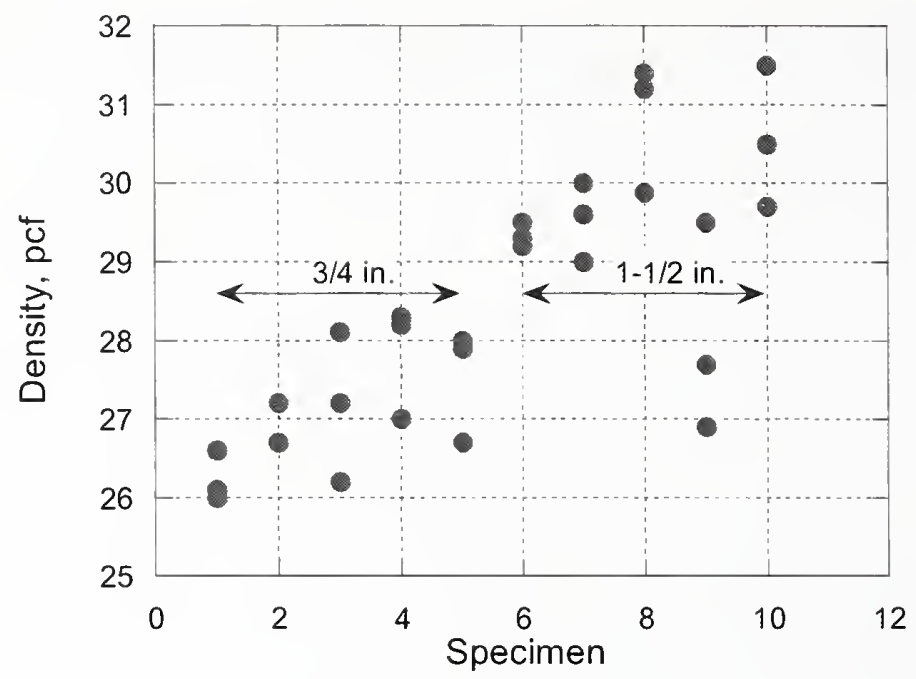

Figure 7-17. Density of BLAZE-SHIELD DC/F specimens.

These measured densities are unexpectedly high compared with published values and the values reported in Table 6-8, which indicates a room temperature density of $14.8 \mathrm{pcf}$. The 2001 ICBO Evaluation Service report E-R 1244, refers to a minimum average density of $13 \mathrm{pcf}$ for BLAZE-SHIELD DC/F (ICBO 2001). The air-dry densities obtained in the NIST/UL fire endurance tests of floor truss assemblies (NIST NCSTAR 1-6B) are shown in Fig. 7-18. Again, those densities are lower than obtained in this study. The exact reason for the higher density in this study is not known, but possible reasons include the following:

- The use of forms, as opposed to only a piece of sheet metal (as in ASTM E 605), may have provided confinement during spraying leading to more consolidation of the SFRM.

- The smoothing of the top surface by sanding removed the less dense material. Recall that about $0.2 \mathrm{in}$. and $0.4 \mathrm{in}$. were removed from the $3 / 4$ in. and $1 \frac{1}{2} \mathrm{in}$. plates, respectively.

- The hand screening that was done to remove local high spots may have resulted in additional consolidation. 


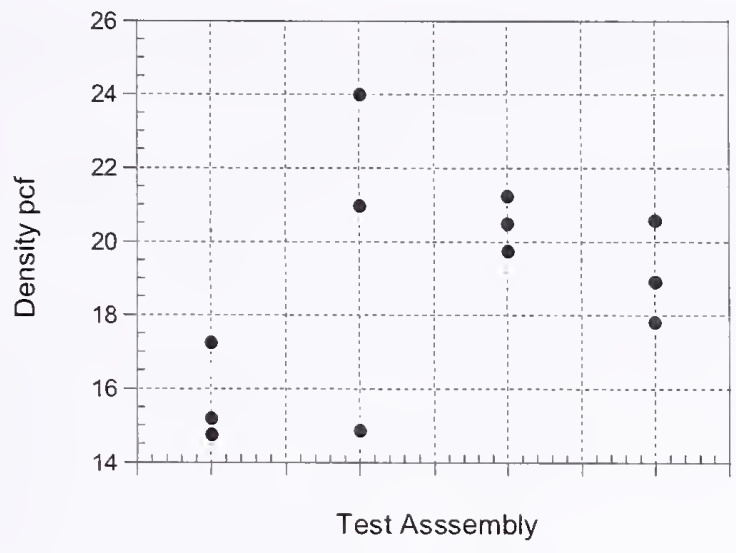

Figure 7-18. Air-dry density of BLAZE-SHIELD DC/F from NIST/UL floor truss fire endurance tests (NIST NCSTAR 1-6B).

\subsubsection{In-Plane Cohesive Strength}

After completing the density determinations the prismatic specimens of SFRM were bonded to a bare steel plate, and an aluminum plate was bonded to the other end (see Fig. 7-8). The steel plate was placed on the floor, and a tensile load was applied to the aluminum plate until the SFRM failcd. The width and thickness of the specimen adjacent to the failure plane was measured, and the in-place cohesive strength was calculated.

Table 7-4 lists the individual values on in-plane cohesive strength, and Fig. 7-19 is a plot of the results. The average strength for the $3 / 4$ in. specimens is $1,120 \mathrm{psf}$ with a standard deviation of $390 \mathrm{psf}$. For the $1 \frac{1}{2}$ in. specimens the average is $1,740 \mathrm{psf}$ with a standard deviation of $540 \mathrm{psf}$. The difference in average strength is statistically significant. The relative strengths are consistent with the differences in density for the two thicknesses. 
Table 7-4. In-plane cohesive strength for BLAZE-SHIELD DC/F specimens.

\begin{tabular}{|c|c|c|l|l|l|}
\hline $\begin{array}{c}\text { Nominal } \\
\text { Thickness }\end{array}$ & Specimen & $\begin{array}{c}\text { Cohesive } \\
\text { Strength, } \\
\text { psf }\end{array}$ & $\begin{array}{c}\text { Nominal } \\
\text { Thickness }\end{array}$ & Specimen & $\begin{array}{c}\text { Cohesive } \\
\text { Strength, } \\
\text { psf }\end{array}$ \\
\hline & $7-\mathrm{a}$ & 1095 & & $24-\mathrm{a}$ & 2279 \\
& $7-\mathrm{b}$ & 1043 & & $24-\mathrm{b}$ & 1607 \\
& $7-\mathrm{c}$ & 689 & & $24-\mathrm{c}$ & 1687 \\
& $6-\mathrm{a}$ & 919 & & $29-\mathrm{a}$ & 1473 \\
& $6-\mathrm{b}$ & 791 & & $29-\mathrm{b}$ & 1986 \\
& $6-\mathrm{c}$ & 1512 & & $29-\mathrm{c}$ & 3101 \\
& $18-\mathrm{a}$ & 1032 & & $10-\mathrm{a}$ & 2006 \\
& $18-\mathrm{b}$ & 701 & $11 / 2$ in. & $10-\mathrm{b}$ & 1876 \\
& $18-\mathrm{c}$ & 953 & & $10-\mathrm{c}$ & 1304 \\
& $16-\mathrm{a}$ & 575 & & $30-\mathrm{a}$ & 1579 \\
& $16-\mathrm{b}$ & 1500 & & $30-\mathrm{b}$ & 636 \\
& $16-\mathrm{c}$ & 1254 & & $30-\mathrm{c}$ & 1630 \\
& $2-\mathrm{a}$ & 1065 & & $11-\mathrm{a}$ & 1902 \\
& $2-\mathrm{b}$ & 1875 & & $11-\mathrm{b}$ & 1226 \\
& $2-\mathrm{c}$ & 1773 & & $11-\mathrm{c}$ & 1861 \\
\hline
\end{tabular}

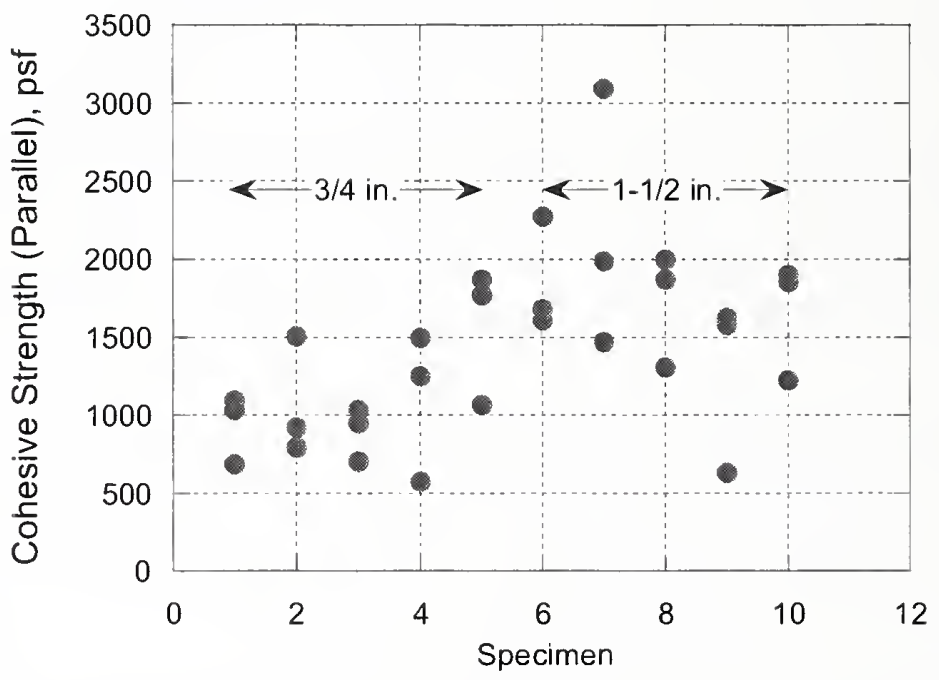

Figure 7-19. In-plane cohesive strength for BLAZE-SHIELD DC/F specimens.

\subsubsection{Adhesive Strength}

Adhesive failure is defined as failure near the SFRM/steel plate interface. In all cases where there was measurable adhesive strength a thin layer of cement paste and mineral fibers remained on the steel plate when the specimen separated. Figure 7-20 shows one of the $3 / 4$ in. specimens (with primed steel) after testing and illustrates "adhesive" failure. The photo on the left is a magnified view of about a 0.4 diameter region and shows the thin layer of mineral fibers and paste. Note in the in the right photograph that there are regions on the steel with no adhering paste, indicating essentially zero adhesive strength. The locations of the specimens for the adhesion/cohesion tests were chosen based on the 
location of the regions with adhesive failure when the three strips used for density determination were removed. This is illustrated in Fig. 7-20, where the specimen on the right was located toward the top of the plate and the one on the left was located at the center.

The plan was to select five plates at random for each combination of SFRM thickness and condition of steel plate (bare versus primed). It was found that for the $1 \frac{1}{2}$ in. plates with primed steel two of the first three specimens had essentially zero bond strength because the SFRM strips were loose after cutting with the saw. Figure 7-21 shows an example of a plate with essentially zero adhesion strength. At this point in the testing. the remaining plates were examined by applying a small force by hand to the SFRM to check whether there was any significant adhesion. Ten of the 15 plates had no adhesion. Plates 30 and 11 appeared to have some adhesion, so these were selected to complete the 5 replicate plates for this group.

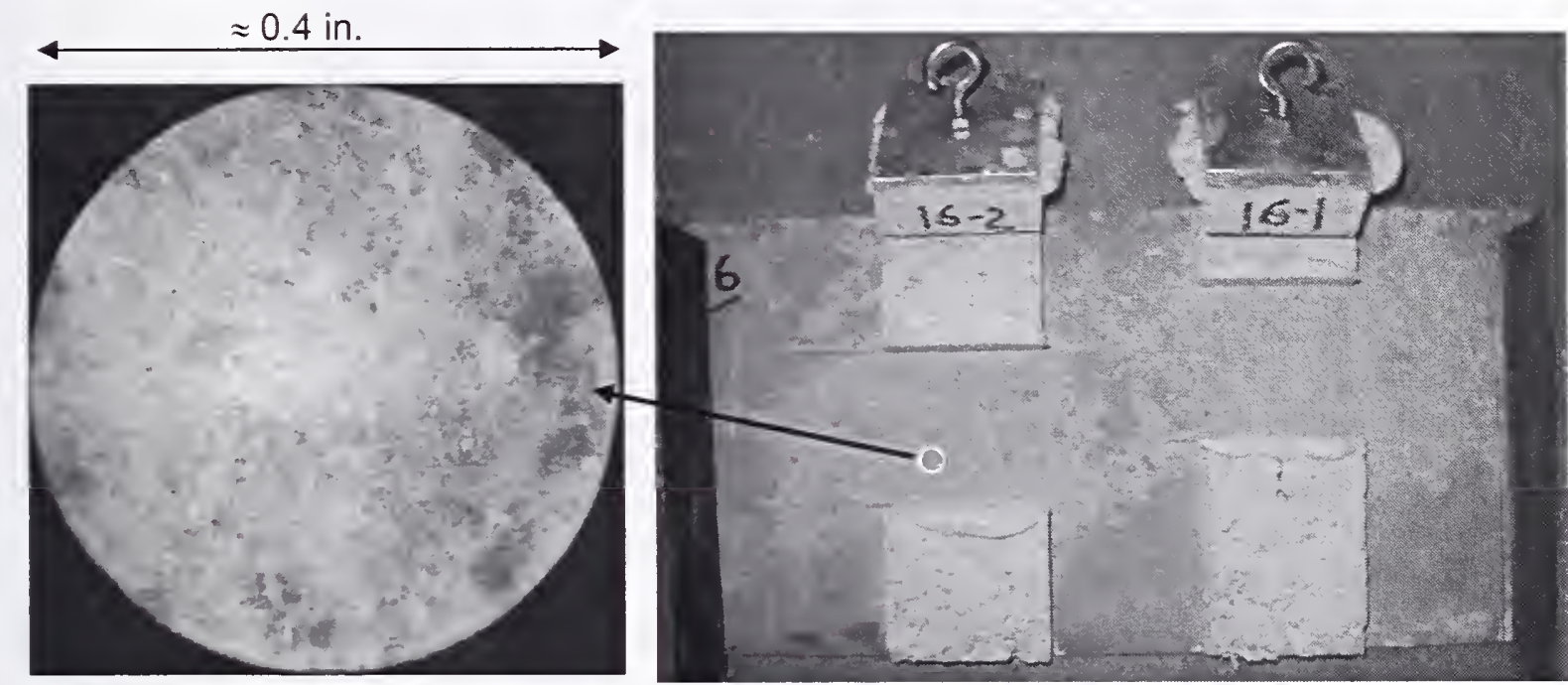

Source: NIST.

Figure 7-20. Example of "adhesive" failure of SFRM (original location of test specimens are the gaps in the two strips); photo on left is magnified view of thin layer of paste and fibers (the marks around the perimeter is red ink used to locate field of view). 


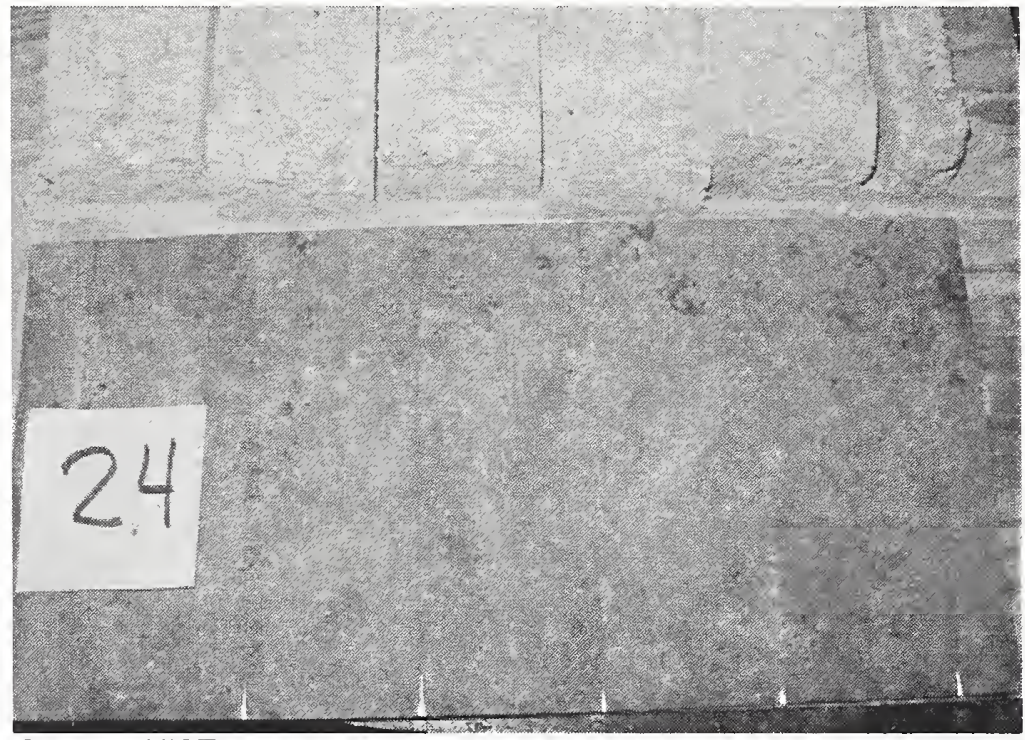

Source: NIST.

Figure 7-21. Example of lack of adhesion in $1 \frac{1}{2}$ in. SFRM on steel plate with primer.

There were no adhesion problems in the specimens made with bare steel. Figure 7-22 shows examples of specimens with bare steel. The top photograph shows the appearance of a $3 / 4$ in. SFRM plate after removal of the three strips to be used for density testing. The regions of the plates with bare steel are due to the action of the putty knife used to debond the three strips. The lower photograph shows the appearance after complction of the adhesion tests on a $1 \frac{1}{2} \mathrm{in}$. SFRM specimen. Again the bare spots are due to scraping by the putty knife.

Table 7-5 shows the adhesive strength results and Fig. 7-23 is a plot of the data. Only four plates were selected for the $3 / 4 \mathrm{in}$. SFRM with bare steel and only three were selected for the $11 / 2 \mathrm{in}$. SFRM with bare steel. Table 7-6 summarizes the adhesive strength test results. As a point of reference, the manufacturer of BLAZE-SHIELD DC/F indicates an adhesion/cohesion value under controlled conditions in accordance with ASTM E 736 of 295 psf (see Appendix A Fig. A-63). In the ASTM standard procedure, the SFRM is applied to a $12 \mathrm{in}$. square galvanized steel sheet $(0.060 \mathrm{in}$. thick) at a thickness of $1 / 2 \mathrm{in}$. to 1 in. Note however, that in the ASTM test method, failure can be cohesive (in the bulk SFRM) as well as combination of adhesive and cohesive failure.

It is clear that the condition of the steel has a significant effect on the SFRM adhesive strength. Typically, manufacturers require that compatibility with primed steel be evaluated to ensure that proper materials are used for adequate adhesion. For example, the following text is taken from the ICBO evaluation of different BLAZE-SHIELD products (ICBO 2001):

\section{"2.2.5 Primed or Painted Surfaces: CAFCO BLAZE-SHIELD} materials are permitted to cover primed or painted wide flange shapes, subject to the following requirements:

1. Beam flange width is 12 inches $(305 \mathrm{~mm})$, maximum.

2. Column flange width is 16 inches $(406 \mathrm{~mm})$, maximum. 
3. Beam or column web depth is 16 inches (406 mm), maximum.

4. Bond tests of five specimens in accordance with ASTM E 736 are used to verify the bond strength of the fire-protection material to a painted or primed steel beam or column at the jobsite. Condition of acceptance is that the average bond strength is 20 times the weight of in-place fire-protection material but not less than $150 \mathrm{psf}\left(7.2 \mathrm{kN} / \mathrm{m}^{2}\right)$, or the minimum average bond strength is 80 percent, with a minimum individual bond strength of 50 percent of the bond strength of fireprotection material applied to bare, clean, $1 / 8$ inch-thick $(3.2 \mathrm{~mm})$ steel plate, whichever is greater. Where bond-strength values are less than these minimums, CAFCO BOND-SEAL Type E.B.S. adhesive is applied to the primed or painted surfaces, and the bond-strength tests are repeated."

The results of these tests show that BLAZE-SHIELD DC/F is not compatible, from an adhesion point of view, with the Tnemec 99 Red Metal Primer used in this study and that was specified for the exterior columns of the WTC towers. 

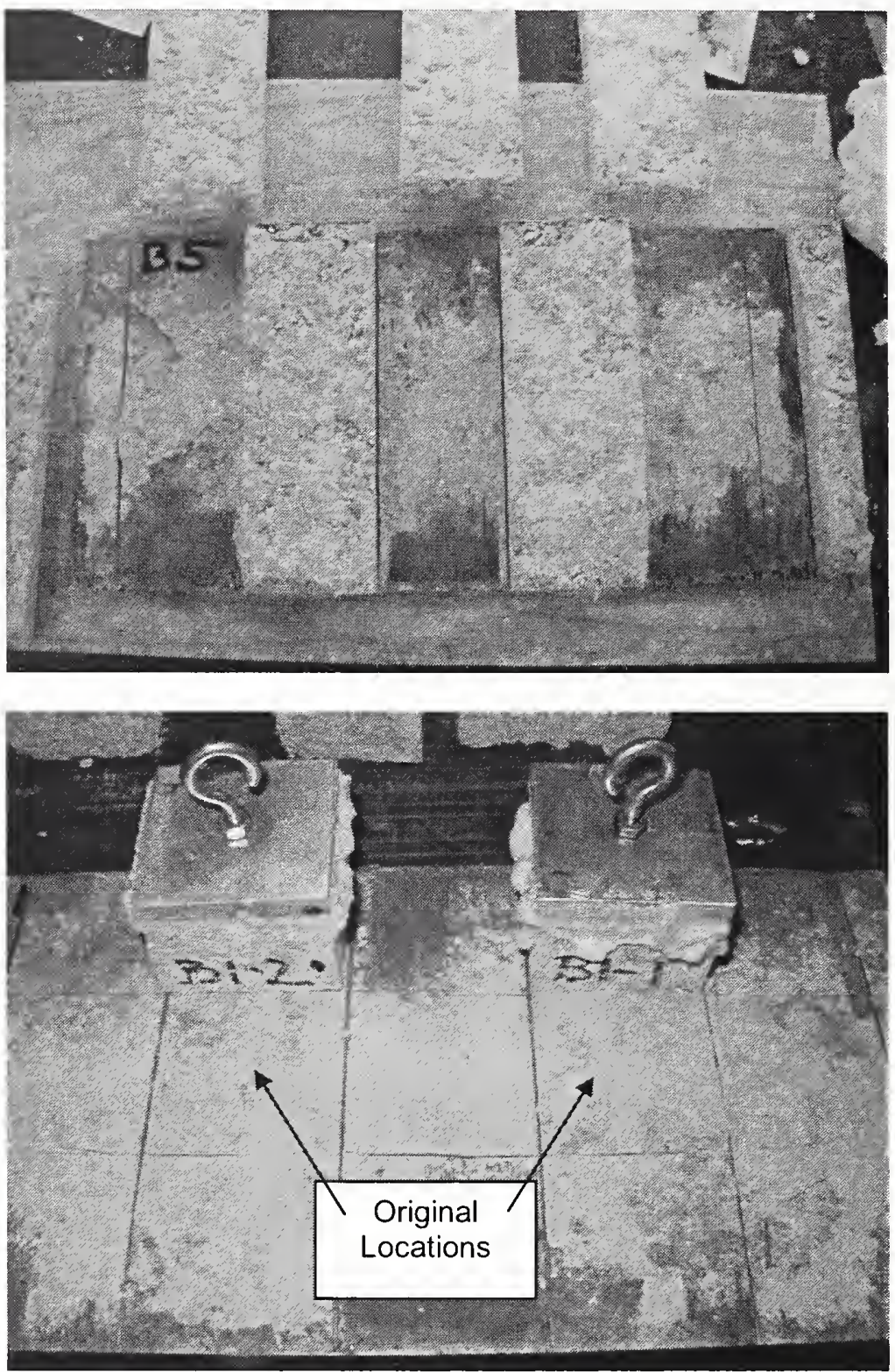

Source: NIST.

Figure 7-22. Examples of good adhesion in specimens with unprimed steel plates: (top) $3 / 4$ in. SFRM specimen before testing; (bottom) $1 \frac{1}{2}$ in. SFRM specimen after completion of tests. 
Table 7-5. Adhesive strength of BLAZE-SHIELD DC/F specimens.

\begin{tabular}{|c|c|c|c|c|c|c|c|}
\hline $\begin{array}{l}\text { Nominal } \\
\text { Thickness }\end{array}$ & Primer & Specimen & $\begin{array}{c}\text { Adhesive } \\
\text { Strength, } \\
\text { psf }\end{array}$ & $\begin{array}{l}\text { Nominal } \\
\text { Thickness }\end{array}$ & Primer & Specimen & $\begin{array}{c}\text { Adhesive } \\
\text { Strength, } \\
\text { psf }\end{array}$ \\
\hline \multirow{18}{*}{$3 / 4$ in. } & \multirow{10}{*}{ Yes } & $7-1$ & 175 & \multirow{18}{*}{$1 \frac{1}{2}$ in. } & \multirow{10}{*}{ Yes } & $24-1$ & 0 \\
\hline & & $7-2$ & 234 & & & $24-2$ & 0 \\
\hline & & $6-1$ & 197 & & & $29-1$ & 378 \\
\hline & & $6-2$ & 267 & & & $29-2$ & 401 \\
\hline & & $18-1$ & 276 & & & $10-1$ & 0 \\
\hline & & $18-2$ & 164 & & & $10-2$ & 0 \\
\hline & & $16-1$ & 257 & & & $30-1^{a}$ & 501 \\
\hline & & $16-2$ & 246 & & & $30-2^{a}$ & 253 \\
\hline & & $2-1$ & 5 & & & $11-1^{a}$ & 130 \\
\hline & & $2-2$ & 32 & & & $11-2^{a}$ & 44 \\
\hline & \multirow{8}{*}{ No } & $4-1$ & 382 & & \multirow{8}{*}{ No } & $1-1$ & 703 \\
\hline & & $4-2$ & 423 & & & $1-2$ & 651 \\
\hline & & $5-1$ & 488 & & & $2-1$ & 543 \\
\hline & & $5-2$ & 493 & & & $2-2$ & 767 \\
\hline & & $6-1$ & 365 & & & $3-1$ & 459 \\
\hline & & $6-2$ & 552 & & & $3-2$ & 876 \\
\hline & & $7-1$ & 425 & & & & \\
\hline & & $7-2$ & 472 & & & & \\
\hline
\end{tabular}

a. Not selected randomly.

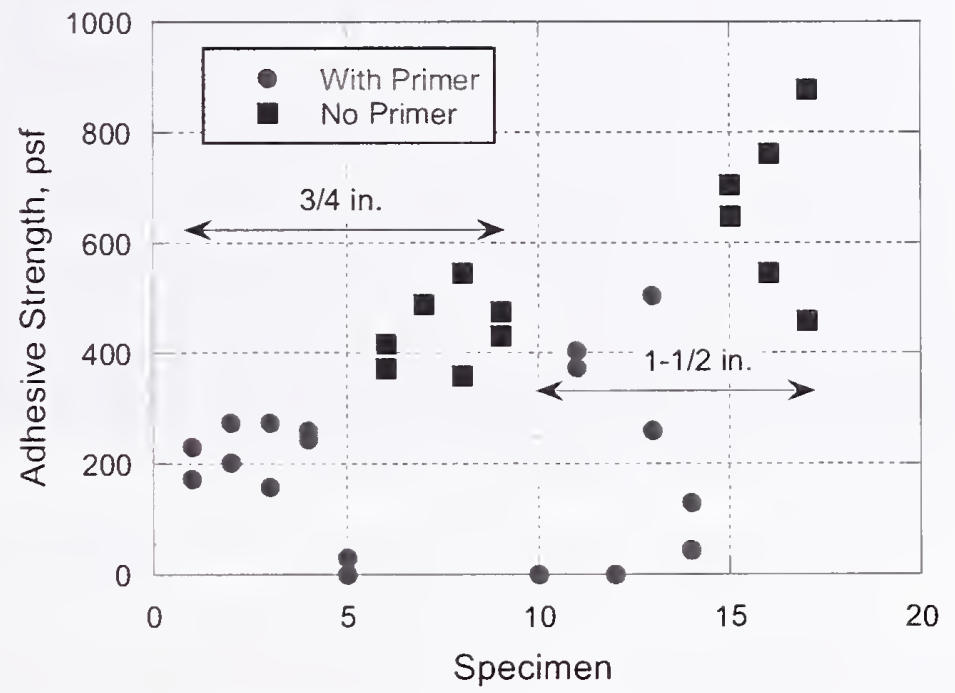

Figure 7-23. Adhesive strength of BLAZE-SHIELD DC/F specimens for primed and unprimed steel plates. 
Table 7-6. Summary of adhesive strength results.

\begin{tabular}{|c|c|c|c|c|}
\hline $\begin{array}{c}\text { Nominal } \\
\text { Thickness }\end{array}$ & Primer & Average, psf & $\begin{array}{c}\text { Standard } \\
\text { Deviation, psf }\end{array}$ & $\begin{array}{c}\text { Coefficient of } \\
\text { Variation, } \\
\text { percent }\end{array}$ \\
\hline \multirow{2}{*}{$3 / 4$ in. } & Yes & 185 & 96 & 52 \\
\cline { 2 - 5 } & No & 450 & 63 & 14 \\
\hline \multirow{2}{*}{$11 / 2$ in. } & Yes & $171^{\mathrm{a}}$ & 196 & 115 \\
\cline { 2 - 5 } & No & 666 & 151 & 23 \\
\hline
\end{tabular}

a. For selected specimens

\subsubsection{Cohesive Strength Normal to Surface}

As discussed in Section 7.2.3, the same specimens were tested twice (in some cases three times) so as to determine the adhesive and cohesive strength normal to the surface. Figure 7-24 shows examples of cohesive failures in $1 \frac{1}{2} \mathrm{in}$. SFRM specimens. These specimens were subsequently repaired with the polyurethane foam adhesive, and the adhesive strength was then determined. In general, cohesive failures tended to occur close to the surface of the SFRM layer. This is logical because less compaction would be expected near the surface and perhaps less hydration of cement due to drying.

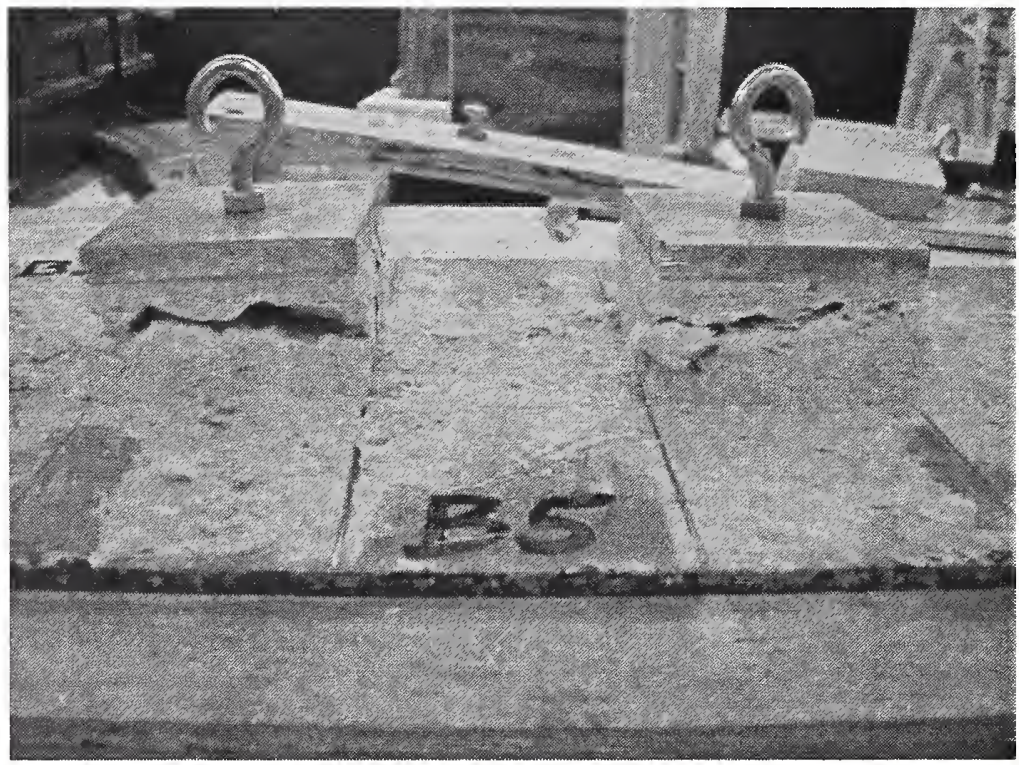

Source: NIST.

Figure 7-24. Examples of cohesive failure in $1 \frac{1}{2}$ in. SFRM specimens.

To compare the results from the current test method, one of the $3 / 4$ in. plates with bare steel was also subjected to an ASTM E 736 type test with round screw cap bonded to the top surface. First, a screw-cap test was conducted at the center of the plate, and then three strips were cut as shown in top photo of Fig. 7-25. Another screw cap test was conducted on the right side of the plate, as shown in the bottom photo of Fig. 7-25. Finally, two tests with the current procedure were done on the strip on the left side of the plate. In the bottom photograph it is seen that the screw-cap pulled away in the bulk material near the top surface. 

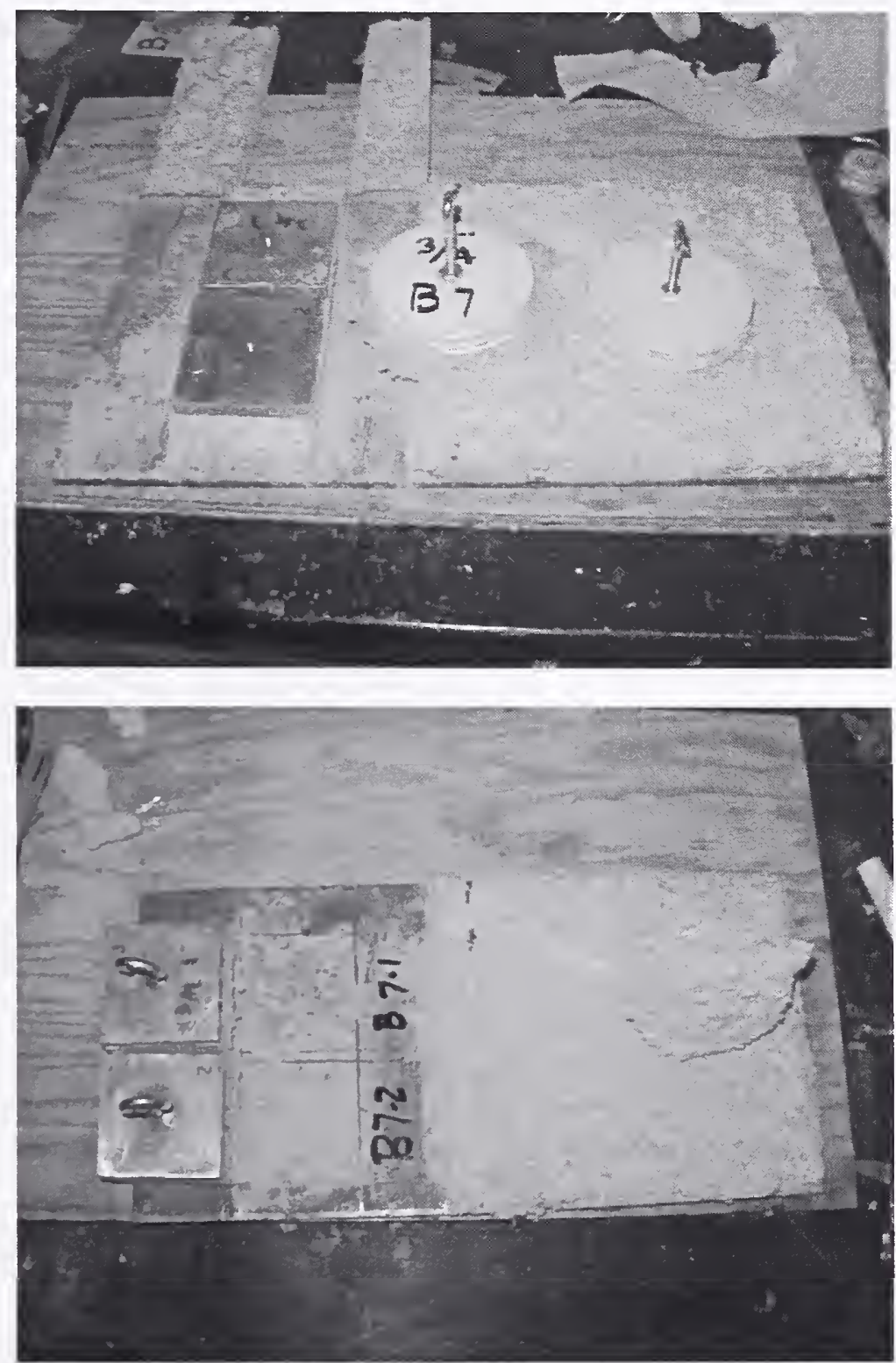

Source: NIST.

Figure 7-25. Comparative testing: current method versus ASTM E 736 method: (top) locations of two screw cap tests; (bottom) after completion of tests.

Table 7-7 shows the individual cohesive strengths normal to the surface, and Fig. 7-26 is a plot of the data. Table 7-8 summarizes the average strength and variability of test results. 
Table 7-7. Cohesive strength normal to surface for BLAZE-SHIELD DCIF specimens.

\begin{tabular}{|c|c|c|c|c|c|c|c|}
\hline $\begin{array}{l}\text { Nominal } \\
\text { Thickness }\end{array}$ & Primer & Specimen & $\begin{array}{c}\text { Cohesive } \\
\text { Strength psf }\end{array}$ & Thickness & Primer & Specimen & $\begin{array}{c}\text { Cohesive } \\
\text { Strength psf }\end{array}$ \\
\hline \multirow{2}{*}{$3 / 4 \mathrm{in}$. } & Yes & $\begin{array}{l}7-1 \\
7-2 \\
6-1 \\
6-2 \\
18-1 \\
18-2 \\
16-1 \\
16-2 \\
2-1 \\
2-2\end{array}$ & $\begin{array}{l}318 \\
324 \\
507 \\
381 \\
503 \\
416 \\
401 \\
548 \\
340 \\
595\end{array}$ & \multirow{2}{*}{$11 / 2$ in. } & Yes & $\begin{array}{l}24-1 \\
24-2 \\
29-1 \\
29-2 \\
10-1 \\
10-2 \\
30-1 \\
30-2 \\
11-1 \\
11-2\end{array}$ & $\begin{array}{l}538 \\
709 \\
463 \\
592 \\
680 \\
834 \\
458 \\
403 \\
755 \\
667\end{array}$ \\
\hline & No & $\begin{array}{l}4-1 \\
4-2 \\
5-1 \\
5-2 \\
6-1 \\
6-2 \\
7-1 \\
7-2 \\
7-3 \\
7-4\end{array}$ & $\begin{array}{c}412 \\
373 \\
349 \\
366 \\
373 \\
264 \\
372 \\
430 \\
419^{a} \\
369^{a}\end{array}$ & & No & $\begin{array}{l}1-1 \\
1-2 \\
2-1 a \\
2-2 a \\
2-1 b \\
2-2 b \\
3-1 a \\
3-2 a \\
3-2 a \\
3-2 b\end{array}$ & $\begin{array}{l}464 \\
574 \\
372 \\
354 \\
661 \\
740 \\
700 \\
530 \\
836 \\
722\end{array}$ \\
\hline
\end{tabular}

a. Using screw cap in accordance with ASTM E 736.

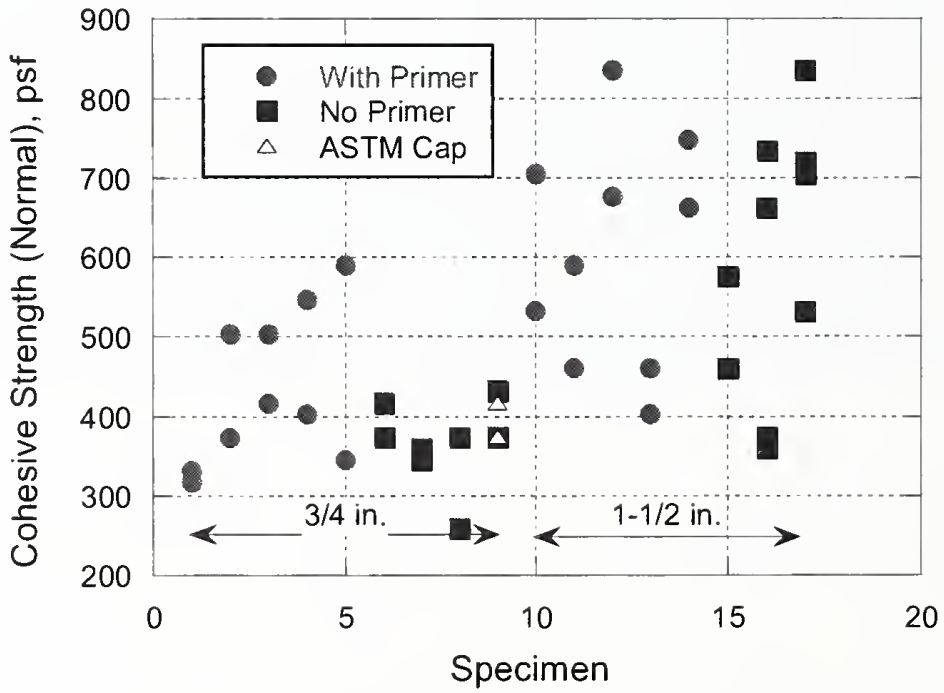

Figure 7-26. Cohesive strength normal to surface for BLAZE-SHIELD DC/F specimens for primed and unprimed steel plates. 
Table 7-8. Summary of cohesive strengths normal to surface.

\begin{tabular}{|c|c|c|c|c|}
\hline $\begin{array}{c}\text { Nominal } \\
\text { Thickness }\end{array}$ & Primer & Average, psf & $\begin{array}{c}\text { Standard } \\
\text { Deviation, psf }\end{array}$ & $\begin{array}{c}\text { Coefficient of } \\
\text { Variation, } \\
\text { percent }\end{array}$ \\
\hline \multirow{2}{*}{$3 / 4$ in. } & Yes & 433 & 99 & 23 \\
\cline { 2 - 5 } & No & 367 & 79 & 13 \\
\hline \multirow{2}{*}{$1 \frac{1}{2}$ in. } & Yes & 610 & 142 & 23 \\
\cline { 2 - 5 } & No & 595 & 163 & 27 \\
\hline
\end{tabular}

Analysis of the results indicated that there was no statistically significant effect due to the presence or absence of primer. This is logical, because the condition of the steel surface is not expected to influence the properties of the bulk SFRM. There was a statistically significant difference in the average strengths for the two thicknesses, with the $1 \frac{1}{2} \mathrm{in}$. SFRM having higher strength. This difference is likely related to the observed difference in density.

Examination of Fig. $7-26$, shows that the two results using the screw caps resulted in values similar to those obtained with the current test method. This agrees with the view that the ASTM E 736 procedure probably provides a measure of cohesive strength.

\subsubsection{Adhesive Strength Versus Cohesive Strength Normal to Surface}

A comparison was made of the adhesive strength and cohesive strength normal to the surface. The individual results previously shown in Fig. 7-23 and Fig. 7-26 are shown as "dotplots" in Fig. 7-27, and the average values from Tables 7-6 and 7-8 are shown in Table 7-9. In Fig. 7-27, the circles indicate results with bare steel plates, and the blue points (darker shade) indicate adhesive strength. For the specimens with primed steel, the average cohesive strength was much greater than the average adhesive strength. For the specimens made with bare steel the difference between the averages for the two types of strength was much smaller. Because of the high variability in individual test results, a formal analysis of variance indicates that there is an 8 percent probability that the difference could be the result of randomness. Generally, if this probability is greater than 5 percent, it can be concluded that the difference is not statistically significant. Thus, for the case of good adhesion, the test results do not contradict the assumption that the adhesive strength and cohesive strength normal to the surface are equal. If this assumption is accepted, the average of the adhesive and cohesive strengths is $409 \mathrm{psf}$ for the $3 / 4 \mathrm{in}$. SFRM, and the average is $622 \mathrm{psf}$ for the $1 \frac{1}{2} \mathrm{in}$. SFRM.

From the measured strength properties, estimates were made of the local accelerations required to damage or dislodge the SFRM, as described in Section 7.4. 


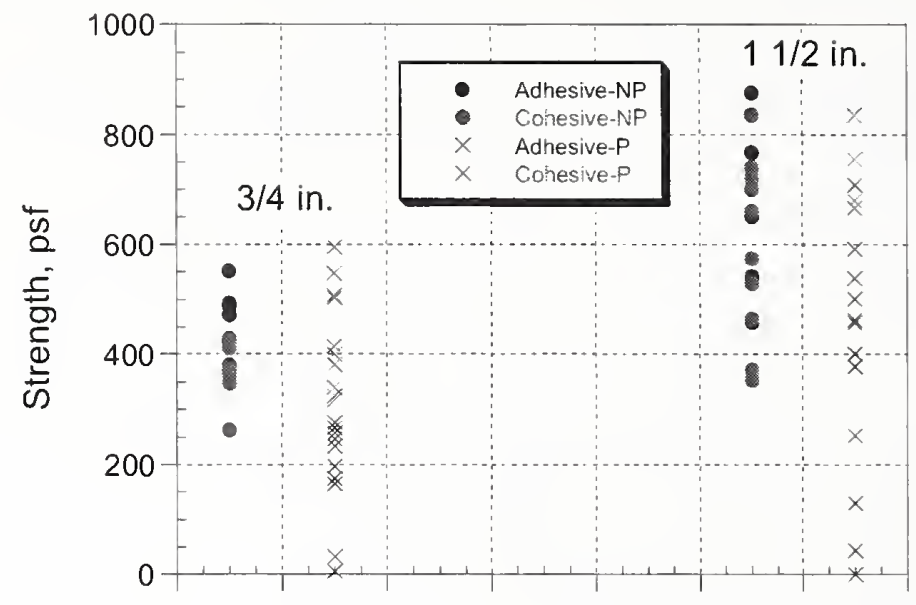

Figure 7-27. Comparison of adhesive strength with cohesive strength normal to surface ( $P$ = primed steel, NP = bare steel).

Table 7-9. Comparison of average adhesive strength and average cohesive strength normal to surface.

\begin{tabular}{|c|c|c|c|c|c|}
\hline \multirow{2}{*}{ Primer } & $\begin{array}{c}\text { Nominal } \\
\text { Thickness, in. }\end{array}$ & $\begin{array}{c}\text { Average } \\
\text { Adhesive } \\
\text { Strength, psf }\end{array}$ & $\begin{array}{c}\text { Standard } \\
\text { Deviation, psf }\end{array}$ & $\begin{array}{c}\text { Average } \\
\text { Cohesive } \\
\text { Strength, psf }\end{array}$ & $\begin{array}{c}\text { Standard } \\
\text { Deviation, psf }\end{array}$ \\
\hline \multirow{2}{*}{ Yes } & $3 / 4$ in. & 185 & 96 & 433 & 99 \\
\cline { 2 - 6 } & $1 \frac{1}{2}$ in. & 171 & 196 & 610 & 142 \\
\hline \multirow{2}{*}{ No } & $3 / 4$ in. & 450 & 63 & 367 & 79 \\
\cline { 2 - 6 } & $11 / 2$ in. & 666 & 151 & 595 & 163 \\
\hline
\end{tabular}

\subsection{SIMPLIFIED APPROACH TO PREDICT DISLODGING OF SFRM}

This section presents a simplified approach for estimating the acceleration required to dislodge SFRM from a structural element. When a member is subjected to an impact, it will undergo various modes of vibration. The vibrations result in local cyclic accelerations. These accelerations are transferred to the SFRM by forces applied at the interface between the steel and the SFRM. Two limiting cases are considered:

- Case 1 is a planar element with SFRM applied to one face of the element. This would be representative of SFRM applied to large webs and flanges of beams and columns. In this case, adhesive strength or cohesive strength normal to the surface would be the controlling SFRM properties.

- Case 2 is a slender bar encased with SFRM. This would be representative of SFRM applied to elements of the floor trusses. In this case, in-plane tensile strength and bond strength are the controlling SFRM properties. 


\section{CASE 1: Planar Element}

The simplified model considers the substrate and SFRM as rigid bodies. The SFRM would dislodge when the inertial force exceeds the smaller of the adhesive bond strength or cohesive strength normal to the surface. Figure 7-28, shows the free body of the thermal insulation being acted upon by its inertial force and the adhesive force. The acceleration to dislodge the SFRM from the substrate is:

$$
a=\frac{f_{b}}{\rho t}
$$

where:

$$
\begin{aligned}
& f_{b}=\text { cohesive strength normal to surface or adhesive strength, whichever is smaller } \\
& t=\text { thickness of SFRM } \\
& \rho=\text { mass density of SFRM. }
\end{aligned}
$$

This equation shows that the acceleration to dislodge the SFRM from a planar surface is directly proportional to the smaller of adhesive or cohesive strength (normal to surface) and inversely proportional to the thickness and density.

To arrive at the ranges of accelerations that could be expected to dislodge SFRM from a planar surface, the following plausible ranges of values were assumed:

- $\quad$ SFRM thickness: 0.75 in. and 2.25 in.;

- $\quad$ SFRM density: 15 pcf and 25 pcf $^{23}$;

- SFRM bond strength: 100 psf and 500 psf

Table 7-10 shows the resulting accelerations expressed as a multiple of $g$, which is the gravitational acceleration. For the combination of low thickness, low density, and high bond strength, the required acceleration is about $530 \mathrm{~g}$. For the other extreme combination of high thickness, high density, and low strength, the required acceleration is about $20 \mathrm{~g}$. This simplified model, thus, gives an approximate range of the amplitude of accelerations required to dislodge the SFRM from a planar surface, depending on the actual values of the key parameters. For example, using the average values of in-place measurements for BLAZE-SHIELD II summarized in Section 7.1, for SFRM with a thickness of 2.5 in., a density of 19 pcf, and an adhesive strength of 300 psf, the SFRM would dislodge from a planar surface at an acceleration of about $80 \mathrm{~g}$.

\footnotetext{
${ }^{21}$ These numbers need to be converted to units of mass by dividing by the gravitational acceleration.
} 


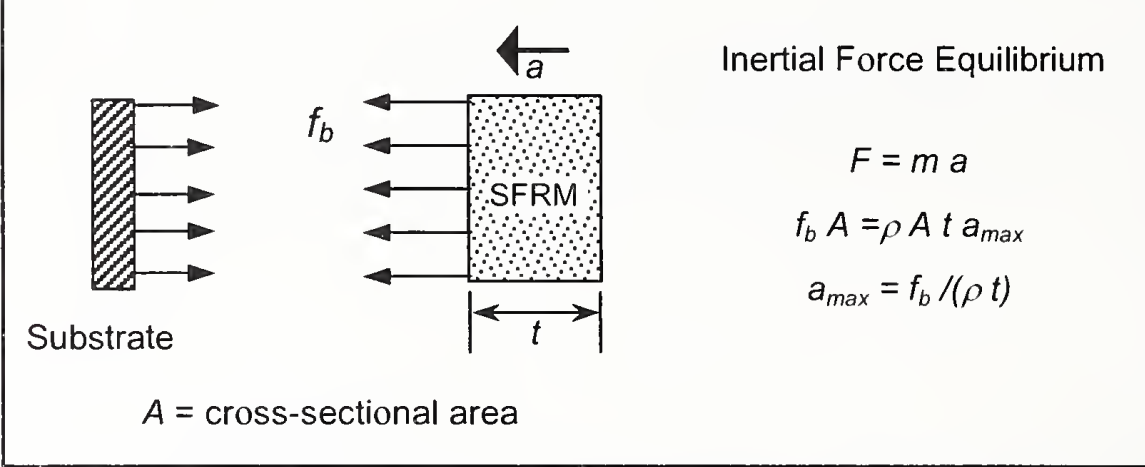

Figure 7-28. Derivation of acceleration to dislodge SFRM from planar substrate.

Table 7-10. Acceleration required to dislodge SFRM from planar surface for different values of density, thickness, and bond strength (adhesive or cohesive).

\begin{tabular}{|c|c|c|c|}
\hline Density, pcf & $\begin{array}{c}\text { Bond } \\
\text { Strength, psf }\end{array}$ & $\begin{array}{c}\text { Thickness, } \\
\text { in. }\end{array}$ & Acceleration/g \\
\hline 15 & 100 & 0.75 & 107 \\
\hline 15 & 100 & 2.25 & 32 \\
\hline 15 & 500 & 0.75 & 533 \\
\hline 15 & 500 & 2.25 & 160 \\
\hline 25 & 100 & 0.75 & 64 \\
\hline 25 & 100 & 2.25 & 19 \\
\hline 25 & 500 & 0.75 & 320 \\
\hline 25 & 500 & 2.25 & 96 \\
\hline 19 & 300 & 2.5 & 76 \\
\hline
\end{tabular}

\section{Case 2: Encased Bar}

The second case is representative of slender elements that would be surrounded by SFRM, such as the chords and diagonals of the floor trusses. In this case, adhesive strength is of minor importance, and the in-plane cohesive strength is of major importance. Figure 7-29 shows the derivation for the relationship between material strengths and acceleration to dislodge the SFRM from a round bar. The required acceleration is as follows:

$$
a=\frac{4 f_{t}\left(d_{0}+(\alpha-1) d_{i}\right)}{\left(d_{0}^{2}-d_{i}^{2}\right) \rho \pi}
$$

where:

$$
\begin{aligned}
& f_{t}=\text { in-plane cohesive strength of SFRM } \\
& d_{0}=\text { outside diameter of SFRM } \\
& d_{i}=\text { steel bar diameter }
\end{aligned}
$$


$\alpha=$ ratio of adhesive strength to in-plane cohesive strength of SFRM

$\rho=$ density of SFRM

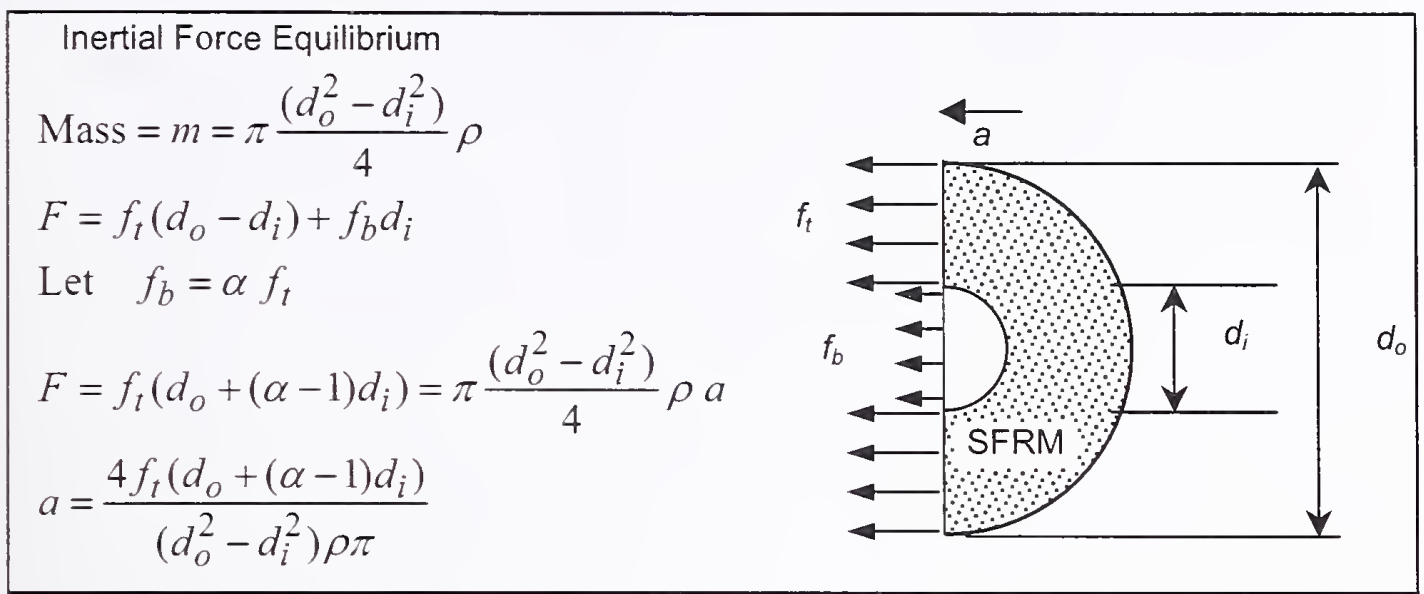

Figure 7-29. Derivation of acceleration to dislodge SFRM surrounding a round bar.

To arrive at the ranges of accelerations that could be expected to dislodge SFRM from a round bar, the following ranges of values were assumed:

- Bar diameter: 0.9 in. and 1.2 in;

- Thickness $\left[\left(d_{0}-d_{i}\right) / 2\right]: 0.75$ in and 2.5 in.;

- Density: 15 pcf and 25 pcf:

- In-plane cohesive strength: 500 psf and 2000 psf: and

- Strength ratio $(\alpha): 0$ and 0.3 .

Table 7-11 shows the results of using these limiting values in Eq. (3). The smallest required acceleration is about $40 \mathrm{~g}$, which corresponds to a large bar having a thick layer of the higher density SFRM with low strength. At the other extreme, the required acceleration is about $730 \mathrm{~g}$. For a $1.2 \mathrm{in}$. diameter bar with 2.5 in. thickness of SFRM and density of $19 \mathrm{pcf}$, the acceleration required to dislodge the SFRM would vary from $55 \mathrm{~g}$ to $230 \mathrm{~g}$, depending on the strength characteristics within the assumed ranges given above.

These simplified models are intended to provide insight into the important variables that affect the magnitude of the disturbance (that is, acceleration) required to dislodge SFRM from different kinds of structural members. These models do not consider the fact that the applied acceleration in an actual structure subjected to impact would vary with time. Also, these models apply to members not directly impacted by debris. As discussed in NIST NCSTAR 1-3C, there was photographic evidence to suggest that thermal insulation was dislodged from exterior columns in regions not likely to have been impacted directly by debris. 
Table 7-11. Acceleration required to dislodge SFRM from encased bar for different values of bar diameter, SFRM thickness, SFRM in-plane cohesive strength, and strength ratio (alpha).

\begin{tabular}{|c|c|c|c|c|c|}
\hline $\begin{array}{c}\text { Bar Diameter, } \\
\text { in }\end{array}$ & $\begin{array}{c}\text { Outer } \\
\text { Diameter, in. }\end{array}$ & Density, pcf & $\begin{array}{c}\text { Cohesive } \\
\text { Strength, psf }\end{array}$ & Alpha & Acceleration/g \\
\hline \multirow{16}{*}{0.9} & \multirow{8}{*}{2.4} & \multirow{4}{*}{15} & \multirow{2}{*}{500} & 0 & 154 \\
\hline & & & & 0.3 & 182 \\
\hline & & & \multirow{2}{*}{2000} & 0 & 617 \\
\hline & & & & 0.3 & 728 \\
\hline & & \multirow{4}{*}{25} & \multirow{2}{*}{500} & 0 & 93 \\
\hline & & & & 0.3 & 109 \\
\hline & & & \multirow{2}{*}{2000} & 0 & 370 \\
\hline & & & & 0.3 & 437 \\
\hline & \multirow{8}{*}{5.9} & \multirow{4}{*}{15} & \multirow{2}{*}{500} & 0 & 75 \\
\hline & & & & 0.3 & 79 \\
\hline & & & \multirow{2}{*}{2000} & 0 & 300 \\
\hline & & & & 0.3 & 316 \\
\hline & & \multirow{4}{*}{25} & \multirow{2}{*}{500} & 0 & 45 \\
\hline & & & & 0.3 & 47 \\
\hline & & & \multirow{2}{*}{2000} & 0 & 186 \\
\hline & & & & 0.3 & 189 \\
\hline \multirow{16}{*}{1.2} & \multirow{8}{*}{2.7} & \multirow{4}{*}{15} & \multirow{2}{*}{500} & 0 & 131 \\
\hline & & & & 0.3 & 162 \\
\hline & & & \multirow{2}{*}{2000} & 0 & 522 \\
\hline & & & & 0.3 & 648 \\
\hline & & \multirow{4}{*}{25} & \multirow{2}{*}{500} & 0 & 78 \\
\hline & & & & 0.3 & 97 \\
\hline & & & \multirow{2}{*}{2000} & 0 & 313 \\
\hline & & & & 0.3 & 389 \\
\hline & \multirow{8}{*}{6.2} & \multirow{4}{*}{15} & \multirow{2}{*}{500} & 0 & 69 \\
\hline & & & & 0.3 & 74 \\
\hline & & & \multirow{2}{*}{2000} & 0 & 275 \\
\hline & & & & 0.3 & 295 \\
\hline & & \multirow{4}{*}{25} & \multirow{2}{*}{500} & 0 & 41 \\
\hline & & & & 0.3 & 44 \\
\hline & & & \multirow{2}{*}{2000} & 0 & 165 \\
\hline & & & & 0.3 & 177 \\
\hline
\end{tabular}




\subsubsection{Debris Impact Study}

A series of simulated debris impact tests were conducted using steel plates and bars covered with BLAZE-SHIELD DC/F. The experimental techniques and results are summarized in Appendix C. 
This page intentionally left blank. 


\section{Chapter 8 \\ SUMMARY}

This report focused on the passive fire protection used in the WTC towers. Specifically, it sought to establish the likely characteristic of the sprayed fire-resistive materials (SFRMs) applied to the structural system. This information was required for calculating the thermal histories of structural members in a conventional building fire and during the fires after the aircraft impact.

To provide context, a brief review of code provisions related to structural fire protection was provided. An effort was made to document key decisions and actions related to passive fire protection during the design, construction, and subsequent occupancy of the towers. Copies of documents that support the findings are provided in Appendix A.

The NIST investigation sought available information on the in-place condition of the SFRM in the WTC towers. Some information was provided by the Port Authority in the form of thickness, density, and bond strength measurements on floor trusses taken at various times during the 1990s. Additional information was obtained from photographs of floor trusses provided to NIST. Analyses of the data indicated that fire-resistive material thickness was variable, as would be expected for application to floor truss members with small cross sections.

Results of simplified finite-element simulations of heat transfer under fire conditions showed that variability in thickness of SFRM reduced the effectiveness of the insulation so that protection was less than implied by the average thickness of the SFRM. A procedure was developed for estimating the equivalent uniform thickness of the variable thickness SFRM.

Tests were done on samples of SFRMs to establish the temperature dependencies of key thermophysical properties that were needed for calculating the thermal-structural response of the towers.

Tests were also done to establish basic tensile strength properties of SFRM, which are necessary to estimate the extent of dislodgement due to aircraft impact. Photographic evidence, documented in another phase of the investigations (see NIST NCSTAR 1-3C), suggested that thermal insulation was dislodged from visible portions of the exterior columns of WTC 1 and WTC 2 that were not impacted directly by debris.

\subsection{FINDINGS}

The following are the key findings based on the information discussed in this report.

- The reviewed documents appear to indicate that the initial design of the towers was based on the 1938 New York City Building Code and predicated on a Class 1A classification, which required a $4 \mathrm{~h}$ fire rating for columns and $3 \mathrm{~h}$ for the floor system. The WTC towers were classified subsequently as Class 1B, as defined by the 1968 New York City Building Code. This required a $3 \mathrm{~h}$ fire rating for columns and $2 \mathrm{~h}$ for the floor system. A condition assessment conducted in 
2000 reported that the WTC towers were classified as Class-1B-noncombustible, fire-protected, retrofitted with sprinklers in accordance with Local Law 5/1973.

- The use of sprayed fire protection for floor trusses was innovative at the time of the design of the WTC and not consistent with prevailing practice, which used enclosures of fire-resistive materials to surround the floor trusses. Trial applications were performed to demonstrate that is was feasible and practicable to use this fire protcction method for the composite floor truss system. Correspondence revealed that adhesion problems were encountered during application of the SFRM to the exterior columns.

- The 1968 New York City Building Code required tcsting of assemblies to establish that their fire rating conformed to Code requirements. The manufacturer of the floor trusses, the Architect of Record, and the Structural Engincer of Record recognized the need for such fire endurance testing of the composite floor system. There were no records of a fire endurance test of the WTC floor system.

- Fire protection of the exterior columns was the responsibility of Alcoa, which sub-contracted the work to Mario \& Di Bono Plastering Co. (Mario \& Di Bono) The sprayed fire protection of the floor trusscs and core members was performed under a separate contract awarded to Mario \& Di Bono. The project specifications for sprayed fire protection of the interior portions of the towers did not specify the type of material or thickness to be applied. Correspondence in 1969, from the construction manager to Mario \& Di Bono, stated (see Appendix A Fig. A-23) that those portions of the floor system requiring thermal protection were "to have a $1 / 2$ in. covering of "Cafco." The product known as "Cafco" was BLAZE-SHIELD Type D supplied by U. S. Mineral Products Co., and was composed of asbestos fibers with a portland cement binder. No evidence was available to provide the technical basis for the value of $1 / 2$ in. thickness indicated in the correspondence. Correspondence indicated that economics was an important factor in the Port Authority's decisions related to passive fire protection.

- Because of the asbestos fibers, the use of BLAZE-SHIELD Type D, was discontinued in 1970 at the $38^{\text {th }}$ floor of WTC 1 . The existing thermal insulation was encapsulated with a coating to contain the asbestos fibers. BLAZE-SHIELD Type DC/F was used as its replacement. This material contained mineral fibers instead of asbestos. Tests conducted by Underwriters Laboratories in 1970 indicated that BLAZE-SHIELD Type DC/F was at least as good as BLAZESHIELD Type D in terms of fire resistance."

- In 1975, the Structural Engineer of Record reported that in March of 1975 he was made aware of a fire endurance test of a floor assembly consisting of composite floor trusses with a normal weight concrete slab on a corrugated steel deck. The trusses were protected with "Mono-Kote," which was described as a "cementitious spray-applied fireproofing" (see Appendix A Fig. A-45). The members of the trusses were coated with $1 \frac{1}{2}$ in. of the insulation and the sheet metal deck had $1 / 2 \mathrm{in}$. The results of the fire endurance test assigned a $3 \mathrm{~h}$ rating to the floor system. It is noted that this test was not related in any way to the floor system in the WTC towers. The Structural Engineer of Record used this test result "with many simplifying assumptions" to demonstrate that $1 / 2$ in. of BLAZE-SHIELD would provide the same $3 \mathrm{~h}$ rating when applied to 1 in. web bars (see Appendix A Fig. A-46). The calculations were said to be based on the differences in the room temperature thermal conductivity of the two insulation materials, with the 
Mono-Kote product having about twice the thermal conductivity of the BLAZE-SHIELD product. He noted: "howcver, that theoretical extrapolations of fire endurance tests must the viewed with caution." He stated further that: "Without benefit of a full-scale fire test we cannot establish a rating for the floor assembly."

- In 1975, the Structural Engineer of Record reported that certain elements of the floor systcm did not require fire protection because those elements were not critical in supporting gravity loads. These included the bridging trusses and the top chords in the one-way portion of the floor system.

- Based on data provided by the Port Authority of insulation thickness on 16 trusses on each of floors 23 and 24 of WTC 1, the average thickness of the original thermal insulation on the floor trusses was estimated to be $0.75 \mathrm{in}$. with a standard deviation of $0.3 \mathrm{in}$. (coefficient of variation $=0.40$ ). The reported average thicknesses ranged from $0.52 \mathrm{in.} \mathrm{to} 1.17 \mathrm{in}$.

- In 1995, the Port Authority performed a study to establish the thickness of fire protection to be applied to the floor trusses during major tenant renovations. On the basis of Design G805 listed in the UL Fire Resistance Directory, the thickness to achieve a $2 \mathrm{~h}$ fire rating was estimated to be $1 \frac{1}{2}$ in. At the time of the WTC disaster, fire protection had been upgraded on floors affected by the aircraft impact. According to information provided by the Port Authority, upgrading had occurred on floors 92 through 100 and 102 of WTC 1 and on floors 77, 78, 88, 89, 92, 96 and 97 of WTC 2 .

- Based on analyses of insulation thickness data contained in Construction Audit Reports provided by the Port Authority, the average thickness of the upgraded thermal insulation (BLAZESHEILD II) on the floor trusses was estimated to be $2.5 \mathrm{in}$. with a standard deviation of 0.6 in. (coefficient of variation $=0.24$ ). The reported average thicknesses ranged from $1.7 \mathrm{in.}$ to $4.3 \mathrm{in}$.

- Based on finite element simulations of a 1 in. round bar covered with SFRM having lognormal distributions for thickness that were consistent with the average values and standard deviations noted above, it was concluded that the original thermal protection on the floor trusses was equivalent to a uniform thickness of 0.6 in. and that the upgraded insulation was equivalent to a uniform thickness of 2.2 in.

- No information is available on in-place conditions of the thermal protection on the exterior columns and spandrel beams, and little information is available on the conditions of fire-resistive material on core beams and columns. For thermal analyses of the towers, the thermal protection on these elements was taken to have uniform thicknesses equal to the specified values. This assumption is justified by the offsetting factors of mcasured average thicknesses tending to be greater than specified thicknesses and the reduced effectiveness of a given average thickness of SFRM due to thickness variability. These were $1 / 2$ in. for beams and spandrels, $21 / 16 \mathrm{in}$. for columns lighter than 14WF228, and $13 / 16$ in. for columns heavier than 14WF228.

- Data provided by the Port Authority on the thickness and density of the upgraded thermal insulation for floor trusses indicated that the average thicknesses excceded the design thickness of $1 \frac{1}{2}$ in. and the bond strength measured according to ASTM E 736 exceeded 150 psf, which was stated to be the "standard performance" of BLAZE-SHIELD II. 
- Results of NIST tests indicated that the thermal conductivity of SFRMs increased significantly at higher temperatures.

- Results of NIST tests indicated that the presence of primer paint caused significant reductions in the adhesive strength of BLAZE-SHIELD DC/F. Good adhesion was found with bare steel, in which case there was not a statistically significant difference between adhesive strength and cohesive strength normal to the surface.

- Results of NIST tests indicated that the in-plane cohesive strength of BLAZE-SHIELD DC/F was almost three times the cohesive strength normal to the surface.

- The density of BLAZE-SHIELD DC/F in the NIST tests for strength properties was greater than the densities in the Port Authority reports or in the manufacturer's catalogs. This may have accounted for the higher strength values obtained by NIST compared with the manufacturer's published values.

- Based on simplified models, the acceleration required to dislodge SFRM from planar surfaces might range from $20 \mathrm{~g}$ to $530 \mathrm{~g}$, depending on the in-place density, thickness, and bond strength. For density of $19 \mathrm{pcf}$, thickness of $2.5 \mathrm{in}$., and bond strength of $300 \mathrm{psf}$, which are representative of the upgraded insulation on the floor trusses, an acceleration of about $40 \mathrm{~g}$ would dislodge the SFRM from a planar surface. For a round bar encased in SFRM, the estimates are $40 \mathrm{~g}$ to $730 \mathrm{~g}$, depending on the bar diameter, insulation thickness, in-plane cohesive strength, and adhesive strength. For a 1.2 in. diameter bar, with 2.5 in. thickness of insulation, having a density of 19 pcf, the acceleration required to dislodge the SFRM was estimated to be between $55 \mathrm{~g}$ and $230 \mathrm{~g}$, depending on the strength characteristics of the SFRM. These models provide insight into the factors that affect SFRM dislodgment due impact-induced vibration. 


\section{Chapter 9 \\ REFERENCES}

ASTM 1961. Standard Test Methods for Fire Tests of Building Construction and Materials.

ASTM E 119-61, ASTM International, West Conshohocken, PA.

ASTM 1973. Standard Test Methods for Fire Tests of Building Construction and Materials, ASTM E 119-73. ASTM International. West Conshohocken, PA.

ASTM 1992. Standard Test Method for Cohesion/Adhesion of Sprayed Fire Resistance Materials Applied to Structural Members, ASTM E 736-92, ASTM International, West Conshohocken, PA.

ASTM 1993. Standard Test Methods for Thickness and Density of Sprayed Fire-Resistive Material (SFRM) Applied to Structural Members, ASTM E 605-93. ASTM International, West Conshohocken. PA.

ASTM 1995. Standard Test Method for Linear Thermal Expansion of Solid Materials With a Vitreous Silica Dilatometer. ASTM E 228-95, ASTM International, West Conshohocken, PA.

ASTM 1998. Standard Test Method for Compositional Analysis by Thermogravimetry, ASTM E 113198. ASTM International, West Conshohocken, PA.

ASTM 1999. Standard Test Method for Thermal Conductivity of Refractories by Hot Wire (Platinum Resistance Thermometer Technique), ASTM C 1113-99. ASTM International, West Conshohocken, PA.

ASTM 2000a. Standard Test Method for Thickness and Density of Sprayed Fire-Resistive Material (SFRM) Applied to Structural Members. ASTM E 605-93 (Reapproved 2000), ASTM International, West Conshohocken, PA.

ASTM 2000b. Standard Test Method for Cohesion/Adhesion of Sprayed Fire-Resistive Materials Applied to Structural Members, ASTM E 736-00, ASTM International, West Conshohocken, PA.

ASTM 2000c. Standard Test Method for Effect of Deflection on Sprayed Fire-Resistive Material Applied to Structural Members, ASTM E 759-92 (Reapproved 2000), ASTM International, West Conshohocken, PA.

ASTM 2000d. Standard Test Method for Effect of Impact on Bonding of Sprayed Fire-Resistive Material Applied to Structural Members, ASTM E 760-92 (Reapproved 2000), ASTM International, West Conshohocken, PA.

ASTM 2000e. Standard Test Method for Compressive Strength of Sprayed Fire-Resistive Material Applied to Structural Members, ASTM E 761-92 (Reapproved 2000), ASTM International, West Conshohocken, PA. 
ASTM 2000f. Standard Test Method for Air Erosion of Sprayed Fire-Resistive Materials (SFRMs) Applied to Structural Members, ASTM E 859-93 (Reapproved 2000), ASTM International, West Conshohocken, PA.

ASTM 2000g. Standard Test Method for Corrosion of Steel by Sprayed Fire-Resistive Material (SFRM) Applied to Structural Members, ASTM E 937-93 (Reapproved 2000), ASTM International, West Conshohocken, PA.

ASTM 2000h. Standard Test Method for Determination of Thermal Conductivity of Soil and Soft Rock by Thermal Needle Probe Procedure, ASTM D 5334-00, ASTM International, West Conshohocken, PA.

ASTM 2001. Standard Test Method for Determining Specific Heat Capacity by Differential Scanning Calorimetry, ASTM E 1269-01, ASTM International, West Conshohocken, PA.

ASTM 2004a. Standard Test Method for Behavior of Materials in a Vertical Tube Furnace at $750{ }^{\circ} \mathrm{C}$, ASTM E 136-04. ASTM International, West Conshohocken, PA.

ASTM 2004b. Standard Test Method for Tensile Strength of Concrete Surfaces and the Bond Strength or Tensile Strength of Concrete Repair and Overlay Materials by Direct Tension (Pull-off Method), ASTM C 1583-04. ASTM International, West Conshohocken, PA.

Blondeau P., A. L. Tiffonnet, A. Damian, O. Amiri, and J. L. Molina. 2003. Assessment of contaminant diffusivities in building materials from porosimetry tests. Indoor Air, 13, 302-310.

Buchanan, A. H. 2001, Structural Design for Fire Safety, John Wiley \& Sons Ltd. West Sussex, England.

Bukowski, R. W. 2003. Prediction of the structural fire performance of buildings, Proceedings, Fire and Materials 2003, $8^{\text {th }}$ International conference, Jan 27-28, 2003, San Francisco, CA Interscience Communications Limited, 8 pp. http://fire.nist.gov/bfrlpubs/fire03/art028.html

Bukowski, R.W. 1997. Progress toward a performance-based code system for the United States, Proc FORUM Symposium on Fire Safety Engineering, Tianjin China, 6-7 October 1997.

Gewain, R.G., Iwankiw, N.R. and Alfawakhiri, F., Facts for Steel Buildings-Fire, American Institute of Steel Construction, Chicago, IL, October 2003. 51 pp.

Harmathy, T. Z. 1983. Properties of Building Materials at Elevated Temperatures. DBR Paper No. 1080. National Research Council of Canada, Division of Building Research. Ottawa, March.

ICBO 2001. ES Report ER-1244, June 1, 2002, ICBO Evaluation Services, Inc., Whittier, CA.

ICC. 2003. International Building Code 2003. International Code Council, Alexandria, VA.

Mehaffey J. R., P. Cuerrier, and G. Carisse. 1994. A Model for Predicting Heat Transfer through Gypsum-Board/Wood-Stud Walls Exposed to Fire. Fire and Materials, 18, 297-305. 
Melchers, R. E., 1999. Strnctmral Reliability Analysis and Prediction. John Wiley \& Sons, New York, NY.

Messersmith, J. J. 2002. Unwarranted relaxation. Concrete Products, September 1, 2002. http://concreteproducts.com/issue_20020901/

Miller, I. and Freund, J. E., 1965. Probability and Statistics for Engineers, Prentice-Hall, Inc., Englewood Cliffs, NJ.

NFPA 5000. 2003. Building Construction and Safety Code, NFPA 5000. National Fire Protection Assn., Quincy, MA.

NFPA.220, 1999. Types of Building Construction, NFPA 220(99), National Fire Protection Assn., Quincy, MA.

NYCBC 1961-1962. Administrative Building Code of the City of New York.

NYCBC 1968. Building Code-Local Law No. 76 of the City of New York. New York, NY.

NYCBC 2001. Building Code of the City of New York, 2001 Edition. Gould Publications, Binghamton, NY.

NYCLL5/73 1973. Local Laws of the City of New York for the year 1973, No.5. Ncw York City Council, December 22, 1972. www.nyc.gov/html/dob/downloads/pdf/ll_0573.pdf

Powers, W. R. 1975. One World Trade Center Fire. Report of The New York Board of Fire Underwriters, New York, NY.

Stephenson, M. E., Jr., and M. Mark. 1961. Thermal Conductivity of Porous Materials. ASHRAE Journal, 3, 75-81.

UL 2002, "Design No. G805," Fire Resistance Directory, Volume 1, Underwriters Laboratories, Inc., pp. $287-288$. 
This page intentionally left blank. 


\section{Appendix A \\ REFERENCED DOCUMENTS}

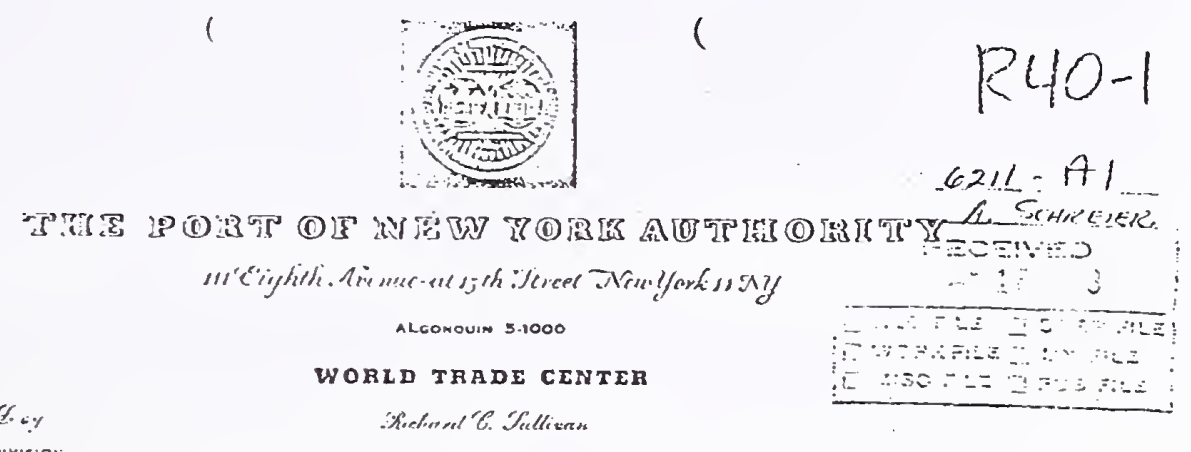

Ilectalom P. E.y

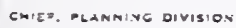

Sheclioned'C. Sullivera

\section{Віпестон}

Mz. Minoru Yanasaki

Minoru Yamasaki \& Associates

1025 East Maple Road

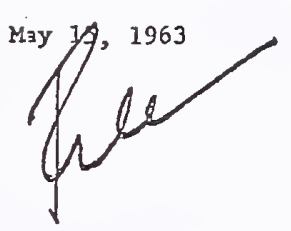

Birwingham, Michigan

Dear Yama:

At a recent meeting with Mr. John Kyle, Chief Engineer, the subject of New York City Code compliance was further amended as follows:

"All consulting engineers and architects working on the World Trade Center have been instructed to comply with the Code in preparing their designs. Questions have arisen, however, in areas where the Gode is not explicit. It was agreed that in such ases and, where technological advances make portions of the Code obsolete, the consultants may propose designs based on acceptable engineering practice. All such Instances will be called to the attention of The World Trade Centcr Planning Division. When preliminary designs have been completed, the Chief Engineer will revier all design concepts with the appropriate municipal agencies before the consultants proceed with the final design".

LF: $\mathrm{db}$

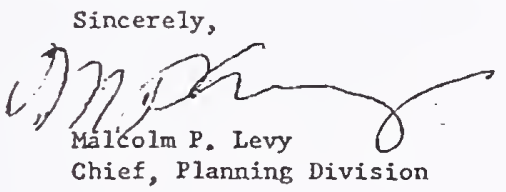

Figure A-1. Port Authority letter instructing consultants to follow New York City Building Code (3-P). 


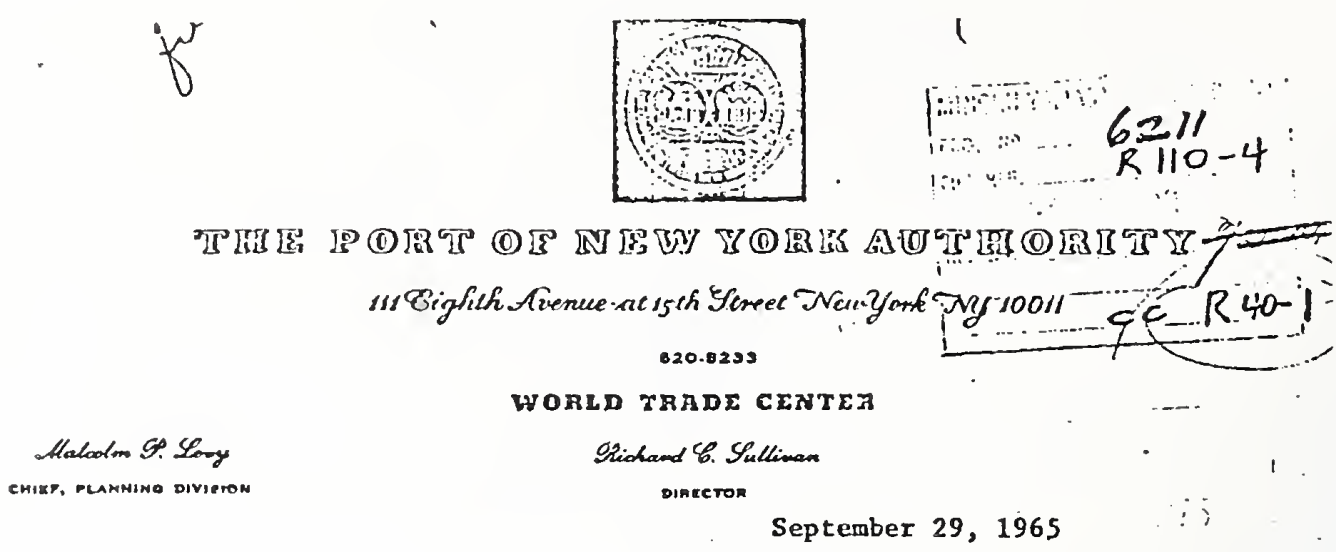

Mr. Minoru Yamasaki

Minoru Yamasaki \& Associates

1025 East Maple Road

Birmingham, Michigan 48011.

Dear Yama:

We have decided to adopt the new Building Code preseritly existing in second and third draft form for The World Trade Center.

The Roth office is requested to revise floor plans as quickly as possible and on an accelerated basis to comply with the provisions of this code. It is my understanding that the present drawings have been prepared to permit rapid conversion to the new code. Generally the tower core should be redesigned to eliminate the fire tovers and to take advantage of the more lenient provisions regarding exit stairs. No other major change to the core should be undertaken without review by this office.

The structural consultants are instructed, by copy of this letter, to revise structural design in accordance with the more realistic critcria for partition weight allowance. The majority of Interfor partitions, as noted in a previous letter, will consist of reinforced gypsum plank.

The Roth office is requested to provide me with the dates on which we can expect revised floor plans and also to indicate any changes in design schedule caused by these instructions.

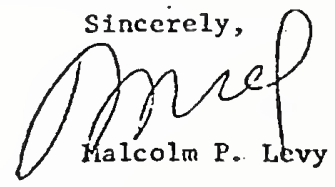

cc: R. Parre (JBB), J. Loring (JRLA), J. Roth (ERS), J. Skilling and L. Robertson (WSHJ)

Similar letter sent to Mr. Julian Roth (ERS)

\section{Figure A-2. Port Authority letter instructing consultant to follow New York City Building Code under development (3-P). ${ }^{22}$}

\footnotetext{
22 Designation in parentheses refers to NIST catalog number for document or group of documents.
} 
MEMORANDUM OF UNDERSTANDING BETWEEN THE NEW YORK CITY DEPARTMENT OF BUILDINGS AND THE PORT AUTHORITY OF NEW YORK AND NEW JERSEY

This Memorandum shall govern the relationship between the New York City Department of Buildings (the "Department") and the Port Authority of New York and New Jersey (the "Port Authority"), both parties entering into this agreement with the intention to establish procedures to be followed by the Port Authority for any building construction project ("Project"), to be undertaken by the Port Authority or any of its tenants at buildings owned or operated by the Port Authority and located in the City of New York (the "City), to assure conformance of Projects at such buildings with the standards set forth in the New York City Building Code (the "Code").

While the facilities of the Port Authority, an agency of the States of New York and New Jersey, are not technically subject to the requirements of local building codes, the long-standing policy of the Port Authority has been to assure that its facilities meet and, where appropriate, exceed Code requirements.

The purpose of this Memorandum is not only to restate that longstanding policy as part of an understanding with the City but to provide specific commitments to the Department, as the agency of the City responsible for assuring compliance with the Code, regarding procedures to be undertaken by the Port Authority for any Project at its facilities in the City to assure that the buildings owned or operated by the Port Authority within the City are in conformance with the Building Standards contained in the Code.

as follows:

Accordingly, the Department and the Port Authority hereby agree

1. Port Authority Review. To assure conformance with the building standards set forth in the Code at the time of the design and construction of any Project, the Port Authority shall, in the case of each Project, thoroughly review and examine all plans in connection with such Project for conformance with the building standards set forth in the Code. Plans prepared for Projects to be undertaken by Port Authority tenants shall be prepared and sealed by a New York State licensed professional engineer or architect retained or employed by tenant: plans prepared for Projects to be undertaken by the Port Authority shall be prepared by a New York State licensed professional engineer or architect employed or retained by the Port Authority. The Port Authority's examination of plans shall be conducted by New York State licensed architects and engineers retained or employed by the Port Authority. The Port Authority engineer or architect approving the plans for any Project from the standpoint of Code conformance shall be a New York State licensed architect or engineer who shall not have assisted in the actual preparation of such plans.

2. Project File. The Port Authority shall maintain a file (the Project File") for each Project which file shall at all times contain the most recently

Figure A-3. 1993 Memorandum of Understanding between Port Authority and New York City Department of Buildings (113-P). 
prepared drawings, plans and any other documents required in connection with the review of the Project from the standpoint of Code conformance. In the case of any Project being effectuated by a tenant of the Port Authority

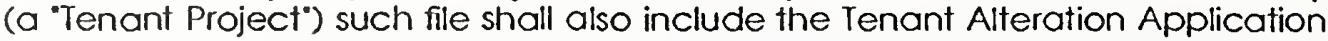
prepared by the Tenant. In the case of any project administered by a line department of the Port Authority, such file shall include any construction application prepared in connection with such Project. The Line Depadments of the Port Authority are currently its World Trade. Aviation, Interstate Transportation, Port, and Regional Development Departments.

3. Project Certification. For each Tenant Project, the Port Authority shall require the Tenant to obtain the certification of a New York State licensed architect or engineer that such Project was constructed in accordance with the approved plans and specifications for such Project. For any Project effectuated by the Port Authority, the Chief Engineer or his successor in duties shall certify that the Project was constructed in accordance with the approved plans and specifications for the Project. Certifications for each Project shall be maintained in the Project File.

4. Copies of Project File. The Department may at any time request the Port Authority to provide it with a copy of any Project File and the Port Authority shall promptly provide a copy of the Project File to it.

5. Variances. The Port Authority shall promptly advise the Department of any Project approved by the Chief Engineer of the Port Authority which involves, in the judgment of the Chief Engineer of the Port Authority or his successor in duties, a variance from the clear requirements of the Code. In the event that the Department disagrees with the manner in which questions of Code conformance have been or are proposed to be dealt with in connection with such Project, it may so advise the Authority. The Port Authority shall seek expeditiously to resolve the matter. Any matter of Code conformance in connection with such Project which the Department believes involves an unacceptable variance from the requirements of the Code shall be subject to the further review of the Port Authority Board of Commissioners. The Commissioners shall be advised of the Department's views on the matter.

6. Inspections and Surveys. The Port Authority shall continue to conduct or cause to be conducted all building inspections, during both construction and post-construction periods, required under the Code. In addition, the Port Authority will continue to perform structural integrity inspections on a cyclical basis for all of its structures located in the City.

7. Port Authority Responsibility. As indicated above, the purpose of this Agreement is to set forth certain basic understandings between the Department and the Port Authority. It is understood, however, that the Port Authority with its tenants shall continue to bear the responsibility for life safety in buildings at its facilities and nothing in this Agreement is intended to impose any obligations of inspection or review on the Department. The Department shall refer back to the Chief Engineer of the Port Authority any requests for New York City Department of Buildings (113-P). 
information or interpretation which it may receive from tenants of the Port Authority with respect to any Project.

8. No Personal Liability. No Commissioner, officer, agent or employee of the Port Authority or the Department shall be held personally liable under any provision of this Agreement or because of its execution or attempted execution or because of any breach or alleged breach thereof.

IN WITNESS WHEREOF, the parties hereto have caused this instrument to be signed, sealed and attested.

ATTEST:

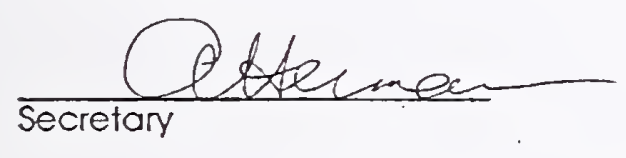

DATE: $\quad 11 / 3 / 93$
THE PORT AUTHORITY OF NEW YORK AND NEW JERSEY

By:

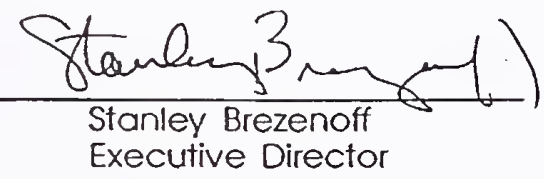

ATTEST:

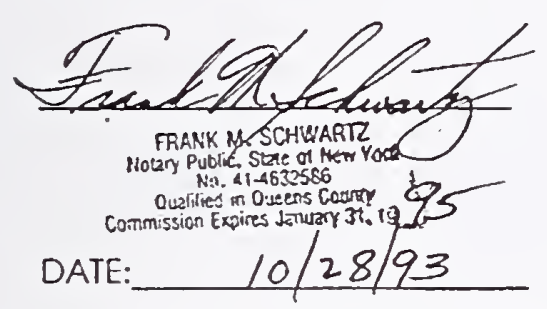

THE NEW YORK CITY DEPARTMENT BUILDINGS
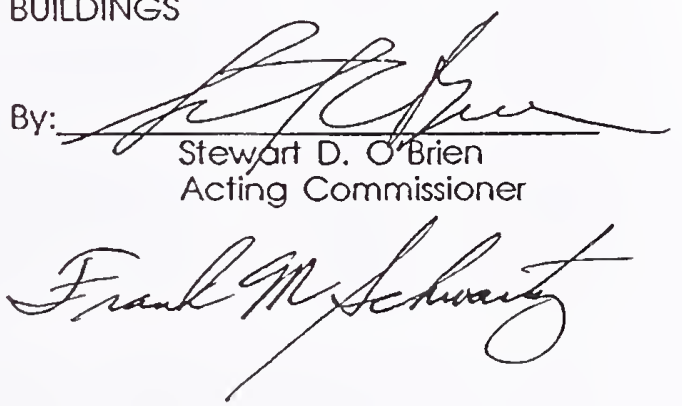


\section{SUPPLEMENT TO MEMORANDUM OF UNDERSTANDING BETWEEN THE NEW YORK CITY DEPARTMENT OF BUILDINGS AND THE PORT AUTHORTY OF NEW YORK AND NEW JERSEY}

In November, 1993 the New York Clty Department of Buildings. (the "Department") and the Port Authority of New York and New Jersey (the "Port Authority") entered into the attached Memorandum of Understanding (the "Memorandum') establishing certain procedures for the purpose of helpling to assure conformance of construction projects to be undertaken of bulldings owned or operated by the Port Authority in New York Clty with the standards set forth in the Now York 'City Buitding Code.

Recentty, the Department Implemented tts own optional plan. revlew system providing for professional certifications of applicatlons and plans and subsequent construction work folling under its jurisdiction.

The purpose of this Supplement to the Memorandum is to provide under the Memorandum for the adoption by the Pot Authority of a procedure under which any Port Authority tenants of the World Trade Center moy utilize New York State llcensed architects or engineors to certify. In lleu of any review by the Port Authority. that (i) the tenant's construction plans are in conformance with the standards set forth in the New York City Bullding Code. and (ii) construction has been performed in accordance with such plans, it beling understood that the persons making the certifications described in (i) and (ID shall not be the same.

Accordingly, the Department and the Port Authortty hereby agree that the Memorandum is amended as follows:

1. Professlonal Certification. Notwithstanding anything to the contrary In the Memorandum, the Port Authority mary, in lieu of any reviews or certifications by the Port Authortty provided for in the Memorandum, provide procedures pursuant to which lts tenants at the World Trade Center may utilize Now York State llcensed archltects or engineers meeting qualifications to be established by the Port Authority to (A) prepare and review such tenant's plans for the construction of ary project and certify that such plans conform with the bullding standords set forth in the New York City Building Code and (B) certify that such project has been constructed in accordance with the approved plans and speciflcations for such project. The person or firm performing the review and certification described in (A) above shall not be the same person or firm providing the certification described in (B) above.

2. Other Provisions. Except as provlded herein. all the terms and conditions of the Memorandum shall remain in full force and effect.

3. No Personal Llabifity. No Commissioner, officer, ogent or employee of the Point Authority or the Department shall be held personally

Figure A-4. 1995 Supplement to Memorandum of Understanding between Port Authority and New York City Department of Buildings (113-P). 
llable under any provision of this Supptement $\propto$ because of ifs execution or attempted execution or becouse of any breach or alleged breach thereof.

IN WINESS WHEREOF, the parties hereto have caused this instrument to be signed, sealed and ottested.

ATIEST:

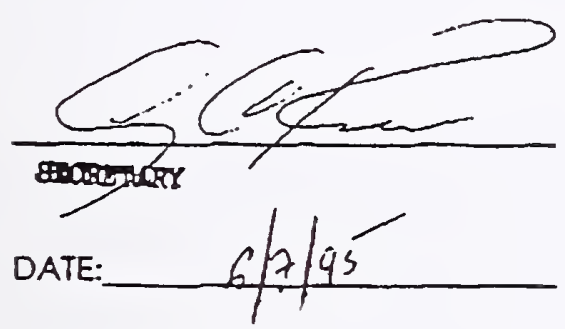

WITNES:

FRANK M. SCHWARIZ Nocery Public. State of Ho York No. 11.4632586 Qualifled In Queens Coust comanlector Explres ran.321097

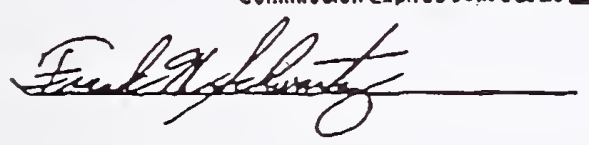

DATE: $6 / 1 / 95$
THE PORT AUTHORIT OF NEW YORK AND NEW JERSEY

By:

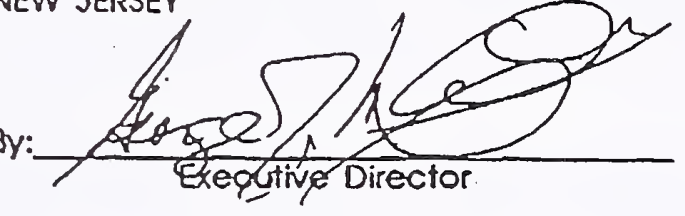

THE NEW YORK CITY DEPARTMENT OF BULLINGS

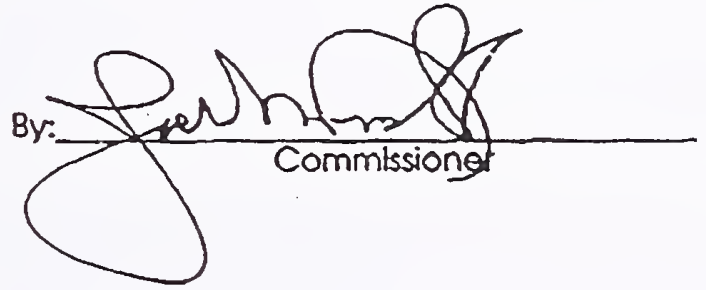

Figure A-4(Contd.). 1995 Supplement to Memorandum of Understanding between Port Authority and New York City Department of Buildings (113-P). 


\section{THE POM AUTHORTY OBNY\&WJ}

September 15, 1995
One World Trade Cenier

Nen York. NY 10048

William $H$ Goldstein

Depuiy Executive Direcior

Capilal Programs

(212) $435-8415$

(201) $961.6000 \times 8415$

Honorable Joel A. Mlele. Sr., Commissloner

Department of Bulldings

Clty of Now York

60 Hudson Streot

New York, New York 10013

Dear Commisstoner Miele:

As you know, the Port Authority of New York and New Jersey (the "Port Authority") and the New York Clty Department of Bulldings (the "Department") recently executed a supplement (the "Supplement") to the Memorandum of Understanding between the Department and the Port Authority to provide that the Port Authority's tenant of the World Trade Center could, In lieu of any revlew by the Port Authortty. use Now York State Ilcensed architects or engineers meeting qualifications to be established by the Port Authority to: (A) prepare and review such tenant's plans for the construction of any project and certify that such plans conform with the bullding standards set forth in the New York Clity Bullding Code and (B) certify that such profect has been constructed in accordance with the approved plans and speclfications for such project.

As you also know. the supplement provides that the person or firm performing the review and certification described in (A) above shatl not be the same person or firm providing the certification described in (B) above. A copy of the supplement is ottached.

This letter will-confirm the agreement of the Port Authority and the Department that, notwithstanding the last sentence of paragraph 1 of the Supplement. a single licensed consultant may make both certfications described in (A) and (B) of such paragraph, except where the alteration would change the character of the occupancy group under paragraph 27-237 of the Now York Clty Bullding Code which would hove been applicable to such space had such space been located in a pirvately owned buliding.

If the foregoing meets with your approval, please be good enough to stgn this letter on behalf of the Department where indicated below and return one of the orlginats to me. In light of the fact that three originals of the supplement were furnished to the Department, we have, for your record purposes, executed in total four orlginals of this letter.

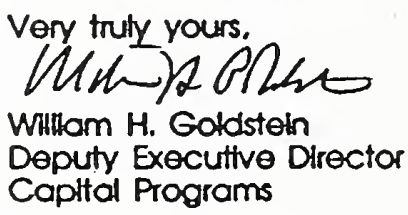

THE NEW YORK CITY DEPARTMEAT OF BUILDINGS

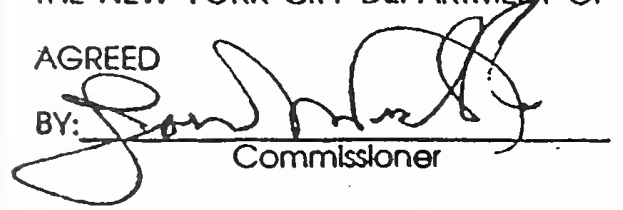

Figure A-4 (Contd.). 1995 Supplement to Memorandum of Understanding between Port Authority and New York City Department of Buildings (113-P). 


\begin{abstract}
MEHORANDUN OF UNDERSTANDING BETURER THB FIRB DBPARTYRNT
(IF THE CITY OF NED YORR AND TER PORT AUTHORITY OF NER YORK AND NEG JERSEX BXRCUTED AS OF DBCEHBER 30, 1993
\end{abstract}

On April 15, 1993, the Port Authority, in order to maintain and enhance the safety of Port Authority facilities, adopted a policy providing for the implementation of fire safety recommendations made by local government fire departments after a fire safety inspection of a Port Authority facilicy and for the prior review by local Eire safety agencies of fire safety systems to be introduced or added to a facility.

The purpose of this Memorandum of Understanding is to reiterate the Port Authority's comitment to this policy and to set forth certain procedures to facilitate the implementation of this policy for buildings at port Authority facilities located in New York City.

Specifically, the Fire Department of the City of New York ("FDN") and the Port Autbority hereby agree as follows:

1. FDNY, acting through its Bureau of Fire Prevention ("BFP"), shall have the right to conduct fire safety inspections at any port Authority facility located in the City of New York. These inspections will generally be coordinated with the Port Authority's General Manager of Risk Management operations, but the BEP, at its option, may conduct inspections without prior notice to the Port Authority.

2. BFP will issue a letterhead report of its fire safety findings and recomendations for corrective action with respect to any deficiencies forming a part of such findings addressed to the Port Authority's General Manager of Risk Management operations. The Port Authority vill promptly undertake the implementation of such findings (including undertaking corrective action with respect to any deficiencies) and shall notify BFP of the actions taken to implement such findings. BFP may at any time conduct follow-up inspections with respect to any matters recommended to the Port Authority for corrective action.

3. Prior to the introduction of a new fire safety system or the introduction of rodifications to an existing fire safety system at any building located at a Port Authority facility in the City of New York, the Port Authority shall provide BFP with copies of the drawings and specifications or other appropriate description of such system or modification for review and approval. The Port Authority policy is and vili continue to be to assure that such new or modified fire safety systems are in compliance with local codes and regulations. When circumstances or conditions are unusual, the Port Authority shall have the right to petition the Bureau of Fire Prevention for a variance in specific cases.

Figure A-5. 1993 Memorandum of Understanding between Port Authority and The Fire Department of New York City and 1995 amendment (160-P). 
4. The Port Authority and BFP will seek to expeditiously resolve any issues arising out of matters covered by this Memorandum of Understanding.

5. Nothing in this Memorandum of Understanding is intended to limit or aiodify in any way any arrangements which the Port Authority currently has with local fire companies in New York City regarding either facility inspections or joint training exercises or any other matters.

6. The Port Authority shall continue to be exempt from all inspection and permit fees for FDNY inspections at its faclilties.

7. No Commissioner, officer, agent or employee of the Port Authority or FDNY shall be held personally liable under any provision of this Memorandum or because of its execution or attempted execution or because of any breach or alleged breach thereof.

IN UITKRSS पHERBOF, the parties here to have caused this instrument to be signed and sealed by duly authorized officers thereof.

THB PORT AUTHORITY OF NEY TORK AND NET JRRSEY

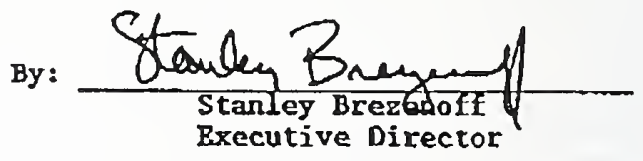

PIRE DEPARTMENT - CITY OF NBW YORR

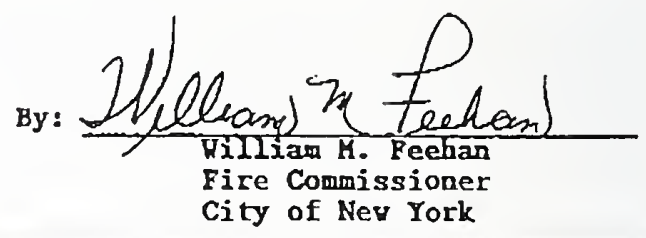

Figure A-5 (Contd.). 1993 Memorandum of Understanding between Port Authority and The Fire Department of New York City and 1995 amendment (160-P). 


\section{FIRST AMENDHENT TO MEAORANDUM OF UNDERSTANDING BETHEEN THE FIRE DEPARTMENT OF THE CITY OF NEH YORK AND THE PORT AUTHORITY OF NEW YORS AND NEW JERSEY EXECUTED AS OE DECEMBER 30, 1993}

On December 30, 1993, the Port Authority of New York and New Jersey (the "Port Authority") and the Fire Department of the City of New York ("FDNY") entered into a Memorandum of Understanding ("MOU") with respect to certain matters relating to the implementation of the policy adopted by the Port Authority on April 15, 1993 regarding the maintenance and enhancement of fire safety at Port Authority facilities.

Under paragraph 3 of the MOU, the FDNY, acting through its Bureau of Fire Prevention ("BFP") was to recelve coples of the drawings and specifications of proposed new or modified fire safety systems for BFP's review and approval. FDNY has requested, and the Port Authority is agreeable, to the following changes to paragraph 3 of the MOU. Accordingly, effective January 1, 1995, FDNY and the Port Authority agree that paragraph 3 of the MOU shall be amended to read as follows:

3. The Port Authority shall notify the BFP in writing prior to the introduction of a new fire safety system or the introduction of modificationsto an existing fire safety system at any building located at a Port Authority facility in the City of New York.

a. Port:Authority Review: To assure conformance with the standards set forth in local codes and regulations at the time of the design and construction of any new or modified fire safety system, the Port Authority shall, in the case of each system, thoroughly review and examine all plan's in connection with such system for conformance with the standards set forth in all applicable local codes and regulations. Plans prepared for new or modified systems to be undertaken by Port Authority tenants shall be prepared and sealed by a New York State licensed professional engineer or architect retained or employed by tenant; plans prepared for new or modified systems to be undertaken by the Port Authority shall be prepared by a New York-State licensed professional engineer or architect employed or retained by the Port Authority. The Port Authority's examination of plans shall be conducted by New York State licensed architects and engineers retained or employed by the Port Authority. The Port Authority engineer or architect approving the plans for any new or modified system from the standpoint of Code conformance shall be a New York State licensed architect or engineer who shall not have assisted in the actual preparation of such plans.

b. New and/or Modified Fire Safety System File: The Port Authority shall maintain a file for each new or modified system which file shall at all times contain the most recently prepared drawings, plans and any other documents required in connection with the review of the systems from the standpoint of Code conformance. In the case of any new or modified system being effectuated by a tenant of the Port Authority, such file shall also include the Tenant Alteration Application prepared by the tenant. In the case of any new or modified system administered by a line department of the Port Authority, such file shall include any application prepared in connection with such new or modified system. The Line Departments of the Port Authority are currently its Horld Trade, Aviation, Interstate Transportation, Port and Regional Development Departments.

Figure A-5 (Contd.). 1993 Memorandum of Understanding between Port Authority and The Fire Department of New York City and 1995 amendment (160-P). 
c. Fire Safety System Certification: For each Tenant System, the Port Authority shall. require the Tenant to obtain the certification. of a New York State licensed architect or engineer that such system was constructed in accordance with the approved plans and specifications. For any system effectuated by the Port. Authority, Risk Management shall certify that the system was constructed in accordance with the approved plans and specifications. Certifications for each System shall be maintained in the New and/or Hodified Fire Safety System File.

d. Copies of New and/or Modified Fire Safety System File: The BFP may at any time request the Port Authority to provide it with a copy of any Fire Safety System File and the Port Authority shall promptly provide a copy of the File as requested. The BFP reserves the right to audit any new or modifled fire safety system to assure conformance with the standards set forth in local codes and regulations.

e. Varlance: The Port Authority pollcy is and will continue to be to assure that such new or modified fire safety systems are in conformance with the local codes and regulations. When circumstances or conditions are unusual, the Port Authority shall have the: right to petition the BEP for a variance in speciflc cases.

IN HITNESS WHEREOF, the Port Authority and FDNY have caused this First Amendment to the MOU to be signed by duly authorized officers thereof.

Dated: $2 / 2 / 85$

THE PORT AUTHORITY OF NEW YORK AND NEW JERSEY

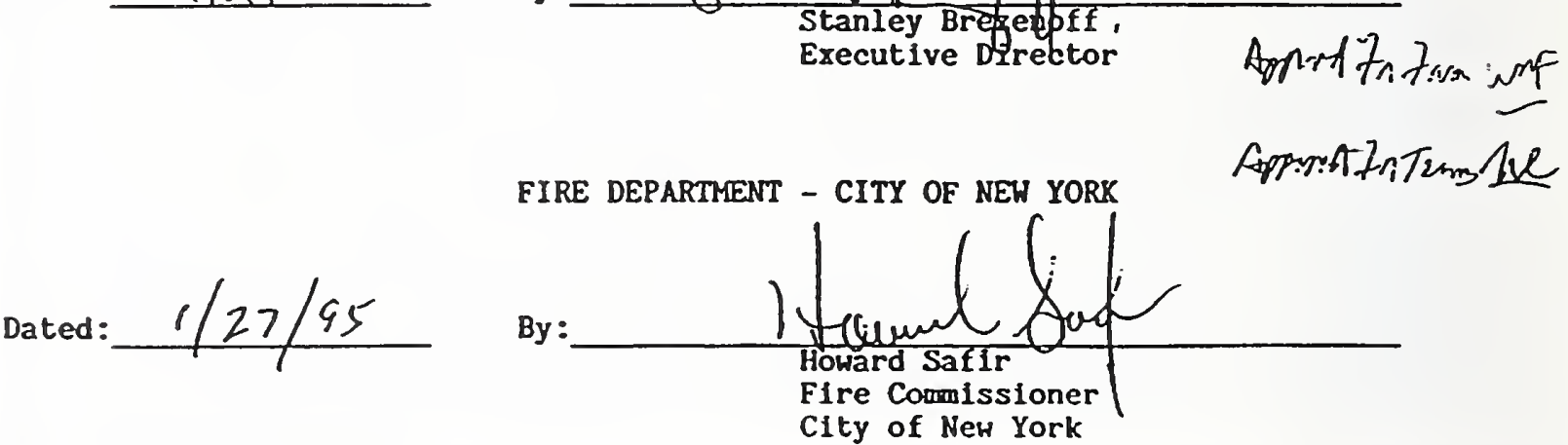

Figure A-5 (Contd.). 1993 Memorandum of Understanding between Port Authority and The Fire Department of New York City and 1995 amendment (160-P). 


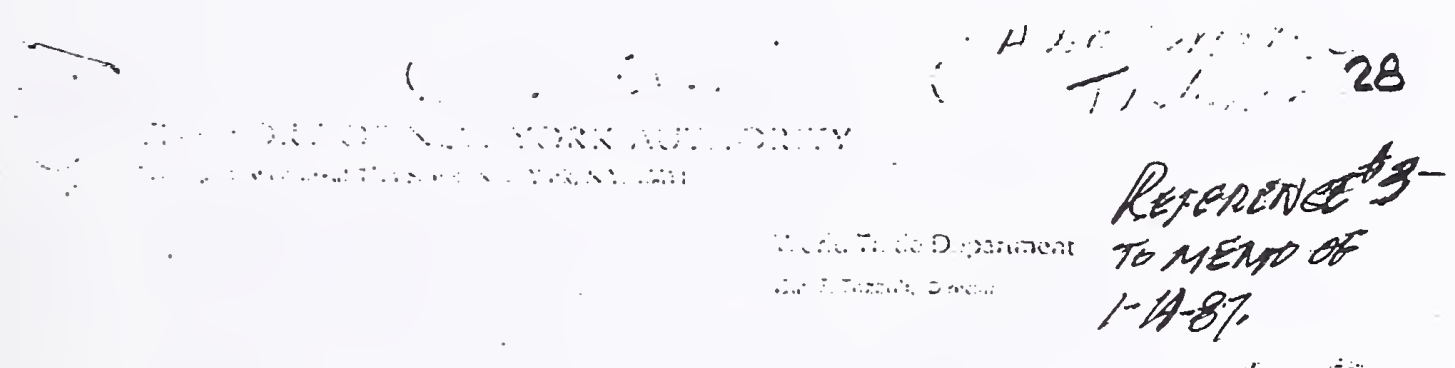

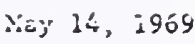

$\therefore$. Zi:ton Gerstman

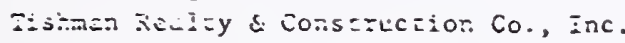

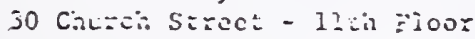

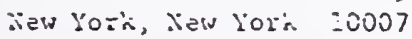

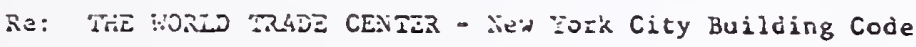

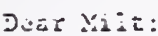

A. conpizison of the recer: $y$ y zevised lew York City

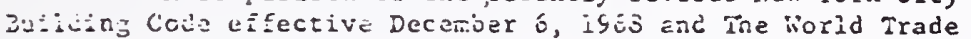
Cercez Dasign Stancazds, witis respect $=0$ ienant demising wa:-s, ieads co some $i$ ileerestiñz questions.

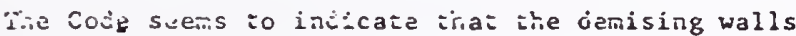
jetreen tenan: spaces in tire Towers could be non-combustible and not firc-raced it the Cocie were a?jicable.

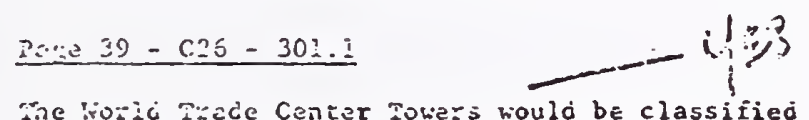

The trozic Tacde Center Tohezs rould be classified as Uecirancy Group "E" (Bisitiess) with a fire inces of 2 bours.

Pase $39-\mathrm{C} 26-302.4(\mathrm{E})$

in Occlpancy Group "¿", zena:=s shall be separated I:on cacin other by constriction meeting the fire resistance rating reçireseat for a "Fire Separation".

Pag: $53-C 20-504$ (B)

The minimu recuizement For a "Fire Separation" is that it oc non-corbustible.

$\because \because$ Ara

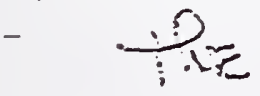

\author{
Fínilifal \\ MAYG \& 5 IYGS

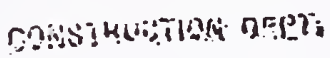

Figure A-6. Letter from Port Authority to Tishman Realty \& Construction Co. regarding
Occupancy Group for WTC towers (3-P). 


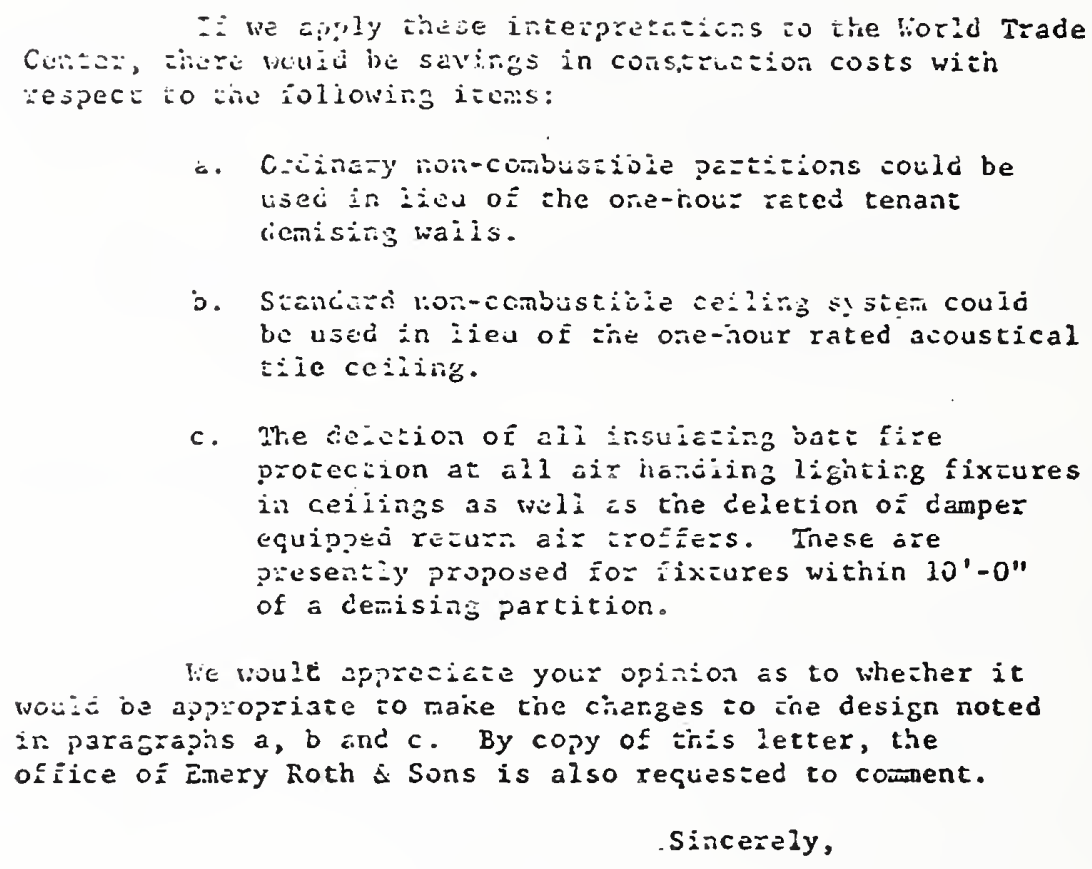

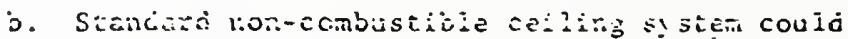
be usél in ileu of tât one-hour rated acoustical sic ceiling.

c. The dejazion of aii irsuiazing bate rize protecition at ail air hardiing ligintirg fixzures ia ceilings as rieli as the celetion ö damper equip?od rezur:- air zrozze:s. These are pacseatil proposed joz "ixzures within 10'-0" of a cemising partition.

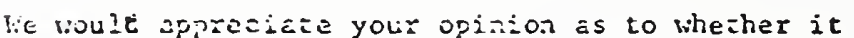
woiti da appopriate to maike the charges to ine design noted ir parazáajis $a$, b and $c$. By copy of titis letter, the

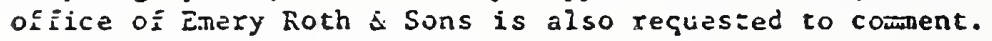

Sinceraly,

Yàcoin. P. Ievy

cc: Xix. Joseph SOIJmon (ER\&S)

Figure A-6 (Contd.). Letter from Port Authority to Tishman Realty and Construction Co. regarding Occupancy Group for WTC towers (3-P). 


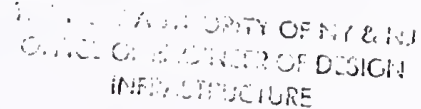

TO:

FROM:

Robert J. Linn, Deputy Director for Physical Facilities, WTD

DATE:

Lester S. Feld

SUBJECT:

January 15, 1987

$$
\text { MOTED I:ECEIVED }
$$

THE WORLD TRADE CENTER - TOWERS \& PLAZA BUILDINGS BFIEHRTRALING PER NYC BUILDING CODE REVISION EFFECTIVE 12-6-68.

REFERENCE: (1) - Memo - M. Levy to File - dated 4-20-65

(2) - Letter - L. Robertson (WSHJ) to M. Levy - dated 4-26-65

(3) - Letter - M. Levy to M. Gerstman (TRCC) - dated 5-14-69

(4) - Office Memo - W. Bracco (TRCC) to J. Endler (TRCC) - dated 5-26-69

(5) - UL Fire Test Report from T. P. Feit - dated 7-26-69

(6) - Letter - A. F. Abbasi (UL) to T. P. Feit (Zonolite) - dated 3-26-70

(7) - Buckslip - V. Dovletian to D. Bais - dated 1-9-87

(8) - Page 4 - Item IC of Issue A entitled "Office Space Design Guide"

COPY TO:

D. Bais, J. Carlock, A. Cracchiolo, V. Dovletian, P. Martinez (

D. Montalbano, A. Preschle, J. Pugh (LERA), L. Robertson (LERA)

A. Vaccaro - All w/Reference $1-8$ attached.

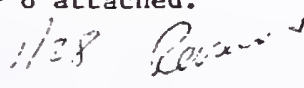

1. On January 13,198Z I contacted Richard Roth, Jr. (ER\&S) regarding the subject fire ratings, normally established by the Architect. Mr. Roth referred me to Phil Martinez for the required information.

2. PhIl's recollection (since ER\&S had given all their WTC tracings to our Planning Division) was as follows:

A. The egress requirement and fire ratings used to design the WTC Towers \& Plaza Bulldings were in accordance with the provisions of the planned NYC Buflding Code revistons effective December 8, 1968. Normally fire ratings are not shown on the Architectural Working Drawings or in the General Notes. The fire ratings are given only on the application forms filed with the plans for wYC Building Department Approval. Since the Port Authority is not subject to the NYC Building Code Requirements, no plans or forms were filed.

B. For office bulldings there is no economic advantage in using Class IA Construction, and ERs $\bar{S}$ used Class 1B Construction for the WTC Towers and Plaza Bulldings which are Occupancy Group " $E$ " (Business) with a fire 1ndex of 2 hours. As such, columns must have 3 hour fire-rating and floor construction with a 2 hour rating.

3. Please note that Reference 3 by Mal Levy was concurred in by W. Bracch (TRCC) in Reference $\$ 4$, with regard to Class $1-B$ Construction cited by Mr. Martinez. In addition, References \#1 \& \#2 (written In 1965) are superseded by References 3 \& 4 (written in 1969).

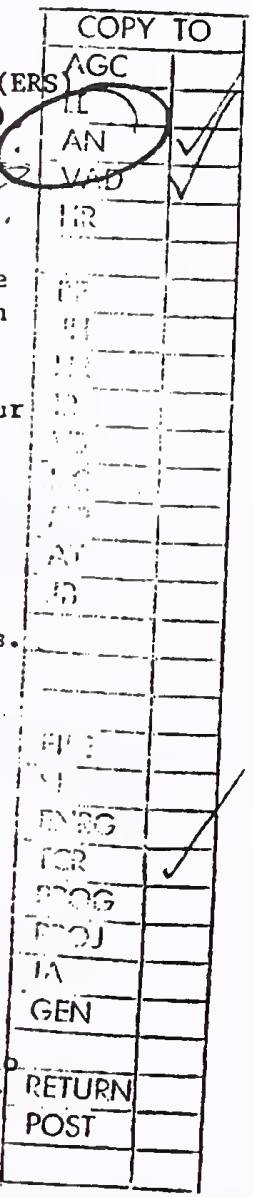

Figure A-7. Port Authority memorandum indicating that WTC towers were classified as Class 1B Construction (3-P). 
4. For your information and use I have also attached References \#5 \& \#6 on the UL Test of floor construction showing a 3 hour rating. Please note that the UL Test is based on the use of 1l/" thick Monokote Fireproofing on joists and $\frac{1}{2} "$ thick Monokote on steel deck. Actually Cafco- Type "D" spray-on was used at the WTC on joists only, in lieu of Monokote. In addition, the UL Test used stone-concrete slab with a thickness of $23 / 4$ " over top of corrugated deck, as compared to the 4" lightweight concrete slab used at the WTC.

5. With regard to Reference $\# 7$, no joists were used in the floor construction of 3 WTC, 4 WTC, or 5 WTC - rolled beam are used in all Plaza Buildings. Mr. Martinez (ER\&S) Mal Levy (Reference \#3) \& TRCC (Reference \#4) all concur that the Plaza Buildings are Class $1 B$ Construction.

6. In addition, Issue " $A$ " of the "Tower Office Space Design Guide" prepared by the WTC Planning and Construction Division (with Errata Sheet \#1 to Issue A - dated March 23, 1970) - Page 4 - Item Cl (attached as Reference il8) verifies that the towers are class 18 Construction.

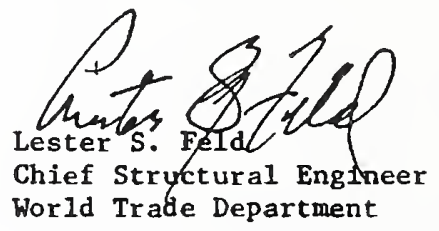

Figure A-7 (Contd.). Port Authority memorandum indicating that WTC towers were classified as Class 1B Construction (3-P). 


\section{COPY}

Mr. Joseph A. Schwertzman

The Port of New York Luthority

111 E.Ighth Avenue

New York, N. Y. 10011

RE: WORLD TRANE CENTER

TONTRS "A" and "B"

SPRAY ON FIRFEROOEING,

Dear Joe:

In checking out your printed copy of the "Spray-On. Fireproofing" specifiration, "it tas been noticed that someone in your offica has taken the liberty of renriting the original specification, maktifg it almost totally un-

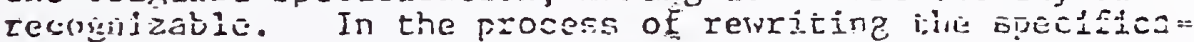
t1cn, a key puragraph secrna to have becr. onitted in its entirety, reading as follors:

'Finished thicknesses of applick material over the varlous component steel farts requiring fireprooflng shali be great enough. to ciualify the flreproofed parts for a three (3) hour roting (sioport beams, steel deck work.) and a four (4) hour rating for all pick-up gircers, if any, and columns.

We cannot be expected to accept responsitility for speciElcatlonis which have been revised in such a manner; that which orjiginally stated clearly and simply, has become a meaninglecs doctuent.

$D F: E r F$

Very truly yours,

FIFRY ROTH \& SONS

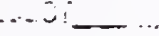

$-$

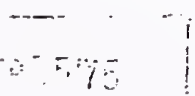

BY

DOUGLAE TIST:I.NLEZ

Figure A-8. Letter from Emery Roth \& Sons to Port Authority regarding specification for sprayed thermal insulation (3-P). 


\section{Standpipe Hose Stations}

6. Several standpipe and auxiliary hose stations do not provide coverage of all portions of all floor areas within the required 145 feet of any given hose's effective reach. Further, some hose racks are equipped with 150 feet of hose in lieu of the standard 125 feet, and provide coverage for 170 feet.

It is recommended that the Port Authority establish a program to survey all tenanted floors to identify areas inadequately covered, and to remediate such inadequacies as quickly as possible.

Also, it is recommended that approval be obtained from the New York City Fire Department for the existing 150 foot long hoses.

\section{Standpipe Telephone Jacks}

7. The requirement that permanent telephone jacks be installed on each floor near standpipe risers has been addressed. Permanent standpipe telephone jacks have been installed and activated on each floor level of all fire stainways in both towers.

\section{Smoke Vents}

8. All closed shafts having a cross-section area exceeding four (4) square feet are required to be equipped with a smoke vent. Although the return air shafts currently have the means to exhaust smoke-laden air directly to the outside by mechanical means, it is recommended that the Port Authority investigate methods by which this overall requirement maybe satisfied.

\section{Sprinkler Protection}

9. At this writing, only four (4) tenanted floors (all in 1 WTC) have not been sprinklered. Of those floors, the sprinklerization of floors 17, 30, and 33 will be completed by the end of this year (1997).

Additionally, as referenced in Item ! above, plans will be made to sprinkler the MER's and the skylobbies in both towers.

All four (4) floors noted above (floor 19 was not mentioned by Mr. Coty of Rolf Jensen) have been completed at this time. Also, the Sky Lobbies sprinklerization are currently underway.

\section{Return Air Smoke Detectors}

10. Although smoke detectors or combination smoke/heat detectors are required at each inlet to a retum air shaft on each floor, our survey indicated that such detectors may not have been installed at all required locations.

This has been addressed via a Port Authority contract which will be handling new, addressable smoke detectors at each return air intake above the suspended ceilings beginning July 1997 and completed by December 1999.

Figure A-9. Excerpt from 1999 code compliance evaluation indicating progress since a similar 1997 evaluation (1999 evaluation is shown in bold-italic text) (161-P). 


\section{$\mathrm{M}_{2} \mathrm{H}$}

The ADA sets forth "recornmended priorities for public accommodations" to be accessible to the disabled. In general, the three priorities are as follows:

1. Access from public sidewalks, parking, or public transportation to a building entrance;

2. Acoess to any areas of goods and services that are made available to the public; and,

3. Access to rest room facilities.

During our tour of the project, we noted the following:

The building's primary entrance is from West Street into the Tower lobby through automatic power operated entrance doors. The path to the elevators is accessible. The Concourse entrance also has 2 sets of automatic doors.

The Plaza Level main entrance has 2 sets of swing doors, without artomatic door opening hardware. Provide dooropening hardware on 1 set of swing doors to make the entrance accessible.

The banks of local elevators and mid-zone express elevators are equipped with car control panels that comply substantially with ADAAG. Two upper zone elevators (19 and 19) are not equipped with complying car controls.

Some (approximately 25\%) toilet rooms have had upgrades for $\mathrm{ADA}$ requirements, but in most rooms observed, there were noncompliant items such as lack of full size ADA toilet stalls, and ADA cormpliant urinals. ADA compliance on most full tenant floors is reportedly the responsibility of the tenant under terms of the lease.

12. Code Compliance

Applicable Code

1968 NYC Building Code as Administered by the Port Authority of New York and New Jersey

Building Construction Classification

Class1-B - noncornbustible, fire-protected, retrofitted with sprinklers in accordance with Local Law 5/1973

Occupancy Type Group E-Business 
Truss Fireproofing Systems

Early discussions for fireproofing systems for the floor truss work covered nearly every conceivable method. Port Authority staff as well as the architectural and structural consultants sought efficient and economical systems; the structural steel industry proposed al ternative methods.

In early 1963 project estimates carried an allowance for a "demountable ceiling" providing the needed fire protection for the steel floor trusses. The problems of fire dampers for such a ceiling were discussed at length.

By late 1964 a series of alternate contact fireproofing systems had been investigated with some cost data assembled.

By late 1965 the use of a spray-on material similar to Cafco or Mono-Kote appears to have been selected. The ERS letters of December 14 and 23, 1965 are clear on this point. Only the required thickness appears to have been in doubt. (see pages 5.1 and 5.2).

"Demonstrations" of fireproofing systcins were carried out by various vendors. For example, on Aug. 7 and 8, 1967, the application on Laclede trusses Mono-hote fireproofing was demonstrated to Mr. Feld and others (1"thickness). In September of 1967 Messrs. Monti and Solomon appear to have wittnessed spray tests making use of U.S. Mineral Products Co. "Cafco".

$-5-$

SKILLING. HELLE, CHRISTIANSEN. ROBERTSON

Figure A-11. Excerpt from April 1, 1975 post-fire report prepared by Skilling, Helle, Christiansen, Robertson (3-P). 


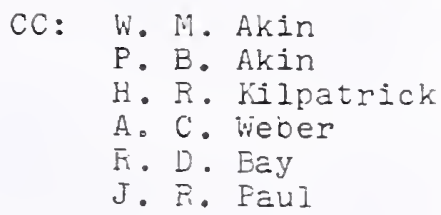

August 10,1957

OFFICE MEVIORANDUE

BLOWN ON FIREFEOOFING

LACIEDE STEEL JOISES

During the past week two test applications of blonn on fireoroofing on Laclede joists and trusses have been accomplished by the $u$. S. Gypsum Company aro the Zonolite Division of W. F. Grace ana Compeny.

This testing, primarily concerned with the floor irusses of the liorld Trade Center, has beer necessany to oroviae information to

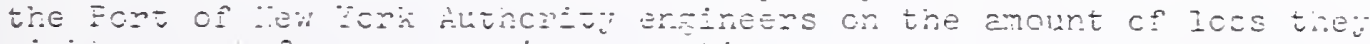

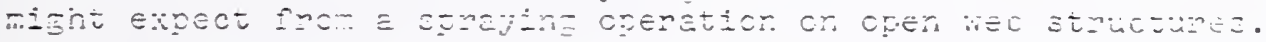

The U. S. Gypsum Company raterials, orimarily a ajosun arc astestcs combination of ribrous material, was apolied at the Cupples Company

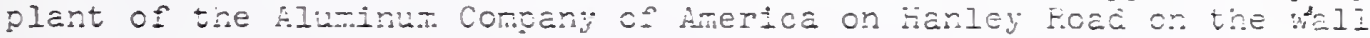
structure that is currently being testec for vind and temerazure variations.

The Zonolite Company matemiaj mace up primarily ồ vermiculite eri Eypsum plaster is a much harder cementaecous coating that seems to apply better than the so-called Cafco (U. S. Gypsum material).

A set of $24 H 8$ joists electro coatec in the same fashion that the world Trace Center joists will be painted were set uD at vadison and witi $1 / 2^{\prime \prime}$ and 3/8" nozzles, the Leroy Thompson Plaster Compary of Eelleville, IIlinois coatec six joists, two of them with only a sirele coat to oemonstrate the material acherence.

It is apparent that a single coating or scratch coat can be applied as quickly as a man can pass across web ana chora sections of the joists leaving a thickness of $3 / 8^{\prime \prime}$ to $1 / 2^{\prime \prime}$ completely incasing all metal.

With a one to tro day drying time, depending on the humidity, a second and final coat to a l" thickness can be easily applied, and accorcine to figures from the Zonolite engineers, a remarkably low percentage of material loss results. Less than $15 \%$ material was shot through the joists and lost. With this low material loss it has been pointea out that the use of material is far less than would be required for solid section beams previously considered for spray insulation and is no more than would be experienced with angle and flat section trusses.

Figure A-12. Intra-office correspondence at Laclede Steel Co. regarding 1967 demonstration of sprayed application of thermal insulation to floor trusses (70-1). 
With the successful application of spray-on insulation an entire new scheme of fire safe builaing construction is possible for steel joists in tinat the fire protection of the joists would permit tre installation of low cost acoustical ceilines with access to utility lines that have not be possible in tre two nour rated builaines before.

It is anticipated that tire $U$. S. Gypsum Company will be aoing further testing on small web trusses at their plant in Stanncpe, New Jersey since kay ronti the Eeneral superintendent of tre licrla Trade Center called yesterajy to ask if we woula provide joists similar to those used by Zonolite for U. S. Cypsum. A liew York plastering contractor that is normally the applicator for U. S. liypsum products in ivew York, Bario DeBcro, is the contractor with whom we would be working if U. S. Gypsum material woula be specified.

i.i. DeEono is to call us with an orcer for eiectro coated $24 "$ trusses, and accorine to the Port Authority, will be gayinf for triem since tris is a resesnci tnat U. S. Gyosum is interize to perform without oiners odservins the results. Fror: what I Eather, various types of surrouncing nozzles are proposed dy the Desono people and they are not anxious to have their competitors learn of their application plans.

In ary event, the fireprocfine of joists seems to be a prodem now solved, and in the world Trade Center as well as in otner steel joist structures, we may be sure that an economical fireproofine can be effected in the fiela without the expense of a heavy ceiline construction.

A. C. Weber

$A C W: p j z$

Figure A-12 (Contd.). Intra-office correspondence at Laclede Steel Co. regarding 1967 demonstration of sprayed application of thermal insulation to floor trusses (70-I). 


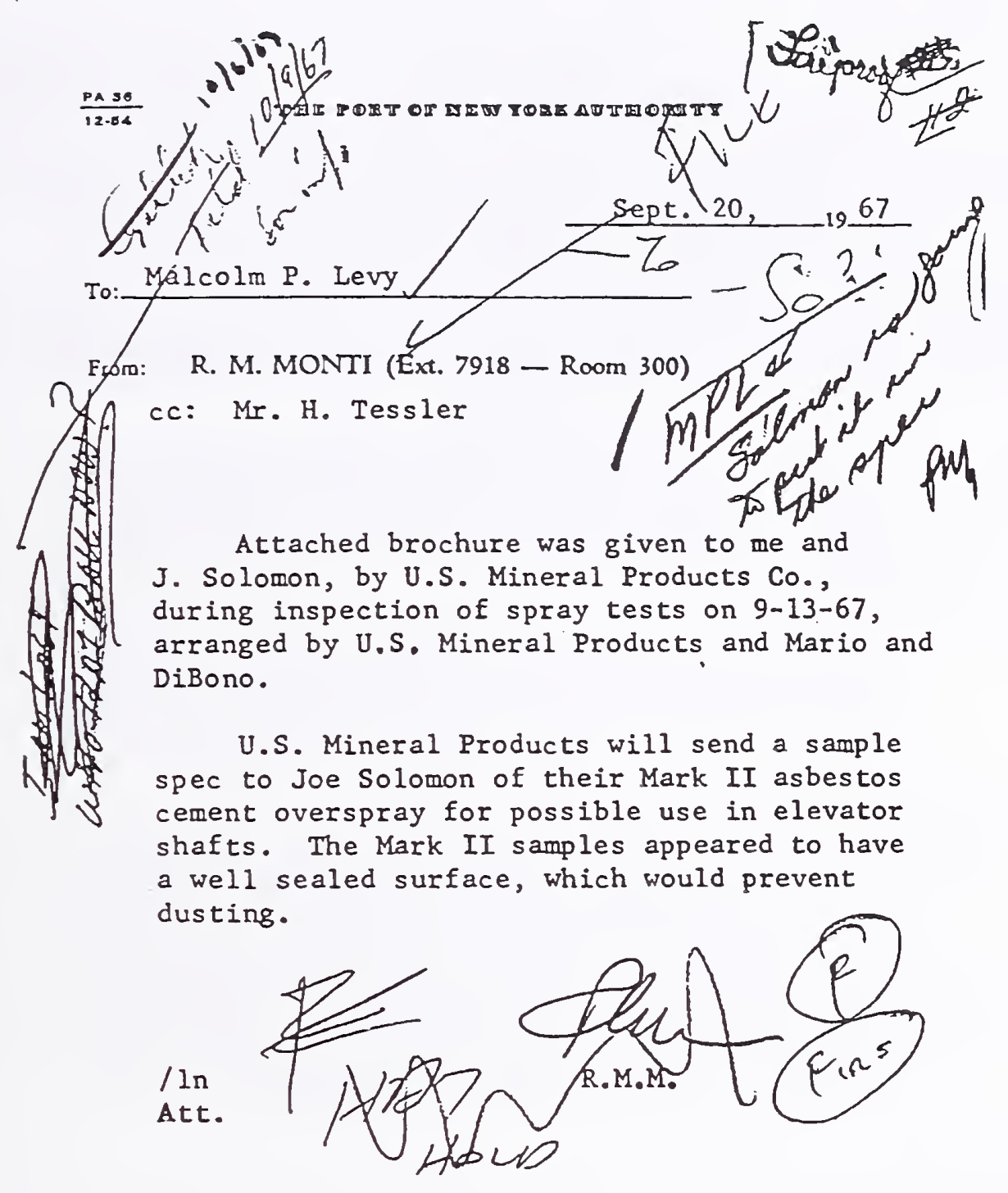

Figure A-13. Port Authority intra-office memorandum indicating demonstration of the application of thermal insulation from U.S. Mineral Products Co. was completed in August 1967 (176-ITK). 


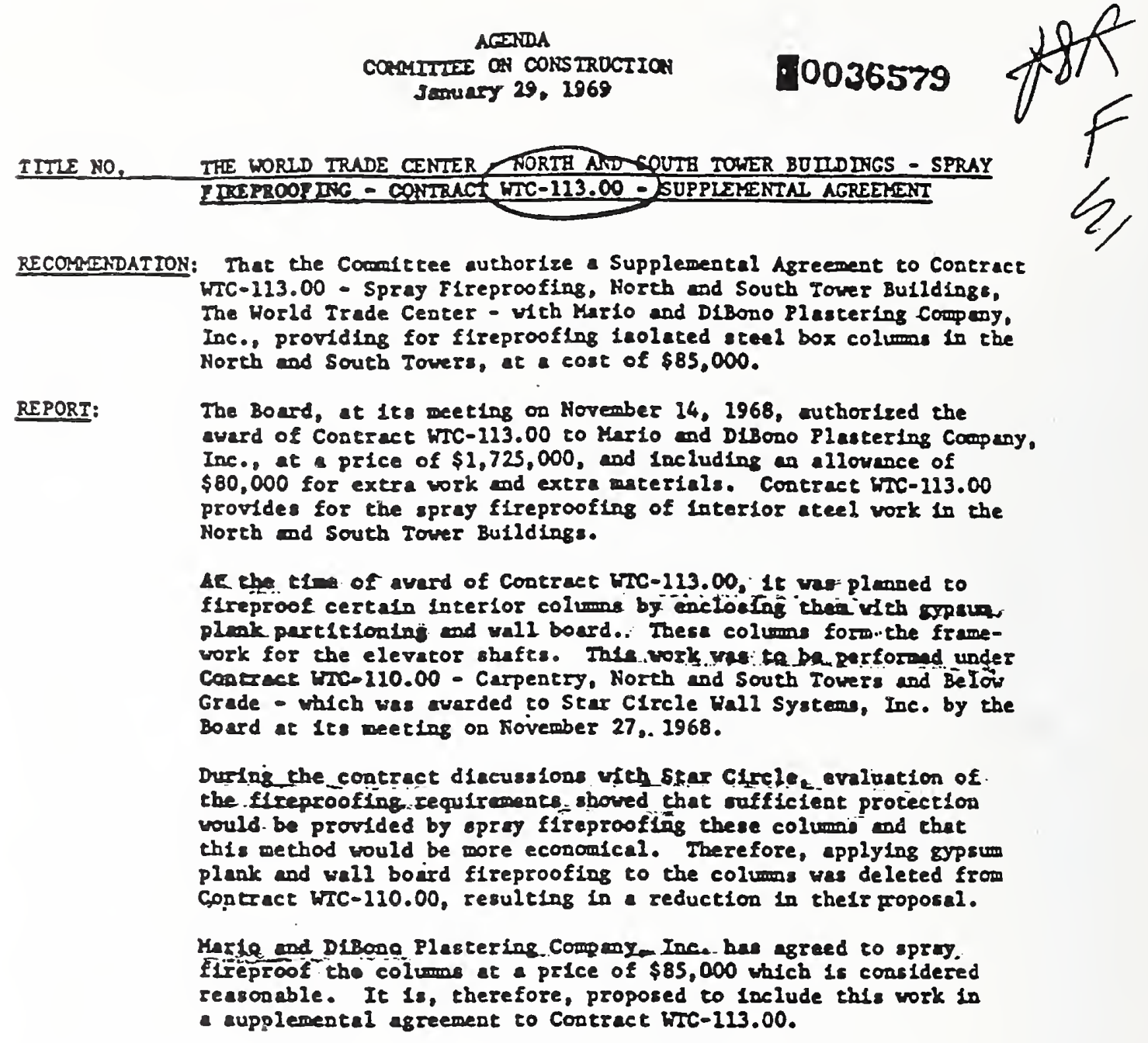

Figure A-14. Agenda item for January 29, 1969 meeting of Committee on Construction regarding modification to sprayed fire protection contract (120-ITK). 


\section{The World Trade Center - North and South Tower Bulldings - Spray Fireproofing - Contract WTC -113.00}

It was reported to the Committee that Contract WTC-113.00 requires the sontractor to spray the structural steel of the North and South Tower Buildings of The dorld Trade Center with a mixture of asbestos, cement and water, which, when hardened, ill provide the necessary fire protection for the structure.

The Board, at its meeting on January 12, 1967, authorized the award of Contract WTC-400.00 - North and South Tower Bulldings, Curtain Wall, The World Trade Center - to Aluminum Company of America. Under this contract, Alcoa will provide spray-on fireproofing and plastering to the exterior columns of the North and South Tower Butldings. Alcoa sub-contracted this work to Mar 10 and DiBono Plastertng Company, Ine., who performed extensive tests of various methods of providing fireproofing which would meet specifications.

The fireproofing mixture will be applied to the erected steel on each floor and must be completed before any other work on a floor can proceed. In view of thls, it was evident that the interlor and exterlor fireproofing applications would have to be closely coordinated. Staff determined that contract administration problems would be minimized and coordination between the fireproofing work on the intertor artuctural steel and the exterlor colums would be facilitated if a single contractor

? to perform such work. Therefore, discussions were held with Marto and Di Bono on tive interior fireproofing work and resulted in the submission of a proposal of $\$ 1,725,000$, including $\$ 925,000$ for work and $\$ 800,000$ for sale.

The Project Estimate for Contract WTC-113.00 is $\$ 1,625,000$, exclustve of an llowance of $5 \%$ for extra work and extra waterials.

Mar1o and DiBono Plastering Company, Inc., is qualified to perform the work under Contract WTC-113.00. In the past, they have provided all interior fintsh plastering, exterior cement plastering and intertor and exterior fireproofing for such projects as the International Arrivals Bullding at Kennedy International Airport; Madison Square Garden; Two Penn Plaza; Rochdale Village, Jamaica, Long Tsland, consisting of twenty 14-story bulldings; and Co-op City in the Bronx, New York.

Recommendation was made that the Commttee recommend to the Board that the Board authorize the award of Contract WTC-113.00 - Spray Fireproofing, North and South Tower Bulldings, The World Irade Center - to Marlo and DiBono Plastering Company, Inc., at a price of $\$ 1,725,000$ and an allowance of $\$ 80,000$ for extra work and extra materials.

Approved and recomended to the Board.

Figure A-15. Excerpt from October 30, 1968 minutes of the Committee on Construction regarding the sprayed fire protection contract (123-ITK). 


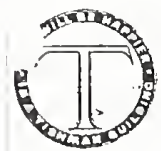

TISHMAN REALTY \& CONSTRUCTION CO.,INC.

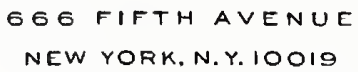

NEW YORK. N.Y. 10019

OWNERS AND BUILDERS SINCE 1898

JUDSON 2-6700

MARCH 30, 1966

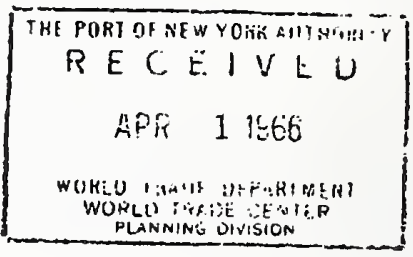

PORT OF NEW YORK AUTHORITY
III EIGHTH AVENUE

NEW YORK, NEW YORK 10011

attention: Mr. R. M. Monti, Res. Engineer - Worlo trade center

RE: Fireproofing Cost COMParison WORL O TRADE CENTER

DEAR RAY:

WE ARE TRANSMITTING HEREWITH OUR COST COMPARISON AND RECOMMENDATIONS FOR SPRAYLD FIREPROOFING. THIS ANalYsis COMPARES THE COSTS ano MERITS of Vonco 2, Cafco Type D, Spray-craft, firecode V ano Monocoat Spray MATERIALS. WE HAVE SLLECTLO FOR COMPARISON, ONLY THOSE SYSTEMS FOR WHICH UNOERWRITLRS' Laboratories INC. AHD/OR NEW YORK BoARo of Standaros AND APPLALS APFROVALS ALREADY EXIST OR LRE IMMINENTLY EXPECTEO.

THE ANALYSIS SHOWS AUTHORITY, STRUCTURAL MEMBER SIZE AND FUNCTIONAL FIRLPROOFING THICKNESS RLQUIRLO, FIRE RATING IN HOURS, AS WELL AS COST PER SQUARE FOOT FOR MATLRIAL ANO LAEOR AT THE INOICATED TMICKNESS. WE HAVE ALSO INTERJECTLO BY NOTE, INFORMATION WHICH WE FELL IS PERTINENT TO PERFORMANCE AS WELL AS POSSIBLE, HIDDEN CCONOMIES OR EXPENSES.

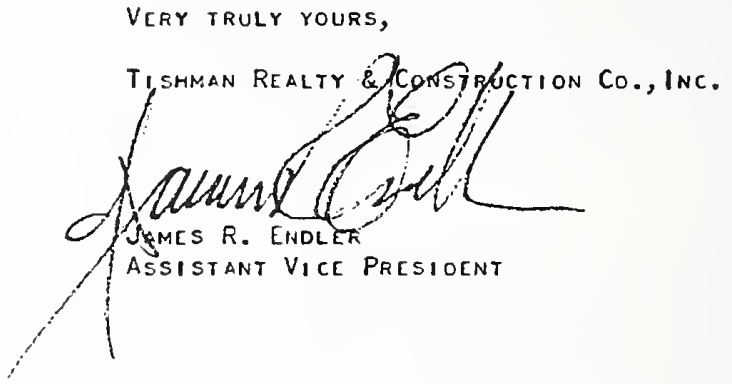

ENCL.

Du

USM-002657

DEFENDANT'S EXHIBIT DX 282

Figure A-16. Correspondence related to economic study of alternative thermal insulation materials (432-P). 


\section{WORLD TRADE CENTER FIREPROOFING COST AINALYSIS}

LABOR AND MATERIAL COSTS REFLECT SPRAYEO SOUARE FOOT CONTACT AREA, INCLUDING OVERHEAO ANO PROFIT AND N.Y.C. SALES TAX FDR THE INDICATED THICKNESS AND ASSUME LAKGE UNCLUTTERED AREAS WHERE FULL FROSDCTION IS ASSURED, GUT DOES NOT PROVIDE FCR EXCESSIVE CLEAN-UP OR ECAFFELDING. THESE CCSTS SHOULD NOT BE USED FOR SPRAY REQUIREMENTS SETWEEN EXTERIOR CELUMN OR SPARDRELS ANE THE CURTAIN WALL, SINCE ACTUAL PRODUCTION CANNOT BE DETERAINED.

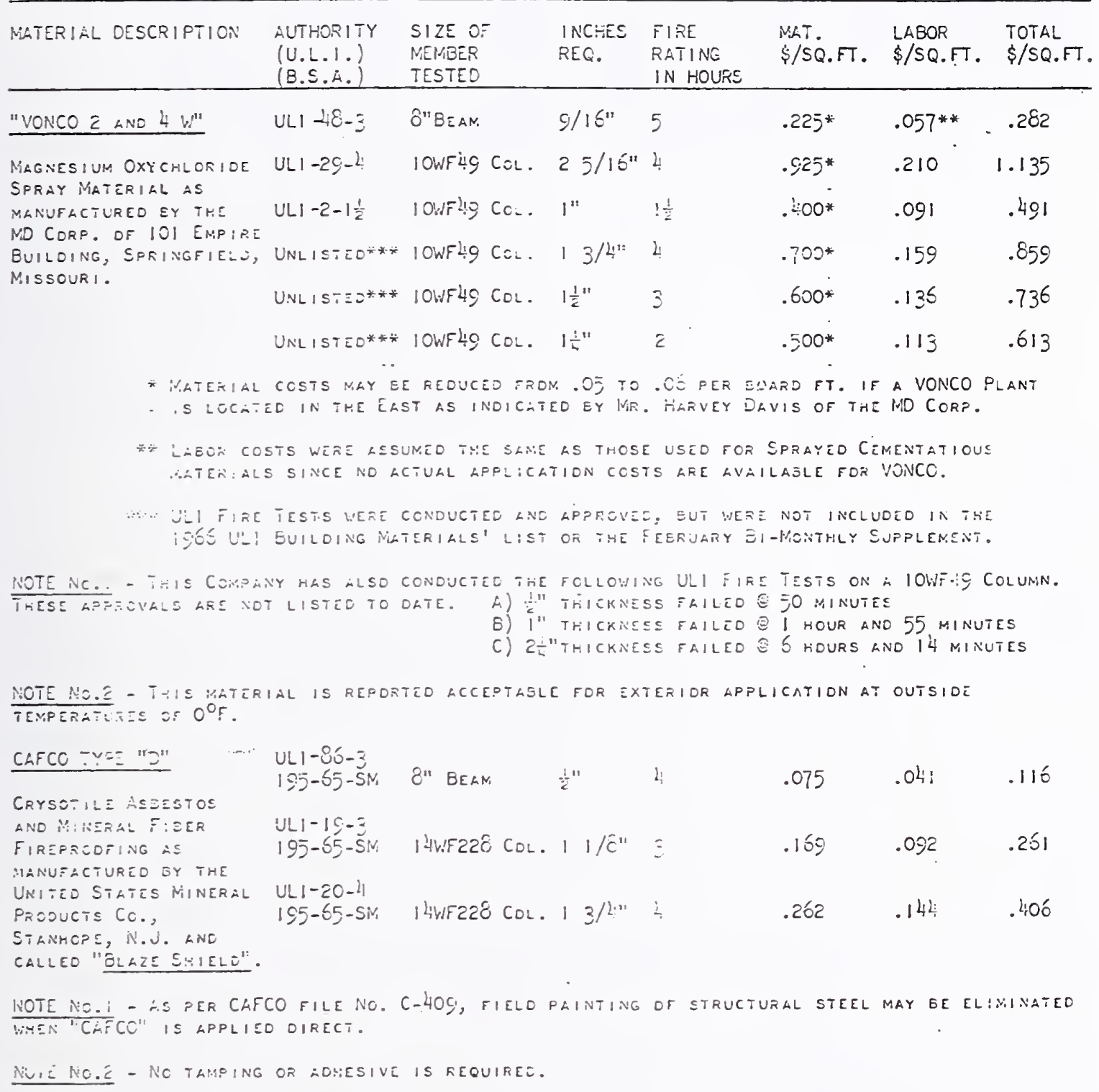

USM-002658

Figure A-16 (Contd.). Correspondence related to economic study of alternative thermal insulation materials (432-P). 
NOTE NO.Z - VAY BE SPRAYEO EY POLE-FIECR-GUN WHICH SHOULD EFFECT SCAFFOLDING COSTS.

\begin{tabular}{|c|c|c|c|c|c|c|c|}
\hline TERIAL DESCRIPTIO: & $\begin{array}{l}\text { AUTHORITY } \\
\text { (U.L.I.) } \\
\text { (B.S.E.) }\end{array}$ & $\begin{array}{l}\text { SIZE OF } \\
\text { MENMBER } \\
\text { TESTED }\end{array}$ & $\begin{array}{l}\text { lNCHES } \\
\text { REG. }\end{array}$ & $\begin{array}{l}\text { FIRE } \\
\text { RATINE } \\
\text { IN HOURS }\end{array}$ & $\begin{array}{l}\text { MAT. } \\
\$ / S C . F T .\end{array}$ & $\begin{array}{l}\text { LABOR } \\
\$ / S Q . F T .\end{array}$ & $\begin{array}{l}\text { TOTAL } \\
\$ / S Q . F T\end{array}$ \\
\hline$\frac{\text { SFRAY CRAFT }}{\text { ASEESTOS FISER }}$ & $\begin{array}{l}U L 1-203-2 \\
502-53-S N_{i}\end{array}$ & 10" BEAM & $\frac{1}{z} " 1$ & $\vdots$ & .075 & .041 & .116 \\
\hline $\begin{array}{l}\text { MANUFACTUREC BY THE } \\
\text { SWITH \& KANZLER CORP., } \\
\text { 14II EAST LINOEN AVENUE }\end{array}$ & ULI $1-81-3$ & 10wF29 Bean. & $7 / \hat{0}^{\prime \prime}$ & 4 & .131 & .072 & $.203^{\circ}$ \\
\hline LINDEN, N.U. & $\begin{array}{l}\text { ULI }-76-3 \\
502-53-5 M\end{array}$ & $10^{\prime \prime}$ ВЕAM & $3 / 4 "$ & 4 & .113 & .062 & .175 \\
\hline & ULI $-25-5$ & 8" BEAM & $17 / 8^{n}$ & 5 & .281 & .154 & .435 \\
\hline & $\begin{array}{l}\text { R2923-1? } \\
\text { (OBSOLETE) }\end{array}$ & COLUMN & $3^{1:}$ & i! & .450 & .246 & .696 \\
\hline & UNL ISTED* & $14 \mathrm{WF} 228 \mathrm{col}$. & $13 / 4 "$ & 5 & .263 & .144 & .407 \\
\hline & UNLISTEO & $14 \mathrm{WF} 228 \mathrm{col}$. & $13 / 16^{\prime \prime}$ & 4 & .178 & .097 & .275 \\
\hline & UNL ISTEO* & $14 \mathrm{WF} \approx 2 E \mathrm{COL}$. & $7 / E^{\prime \prime}$ & $\Xi$ & .131 & .072 & .203 \\
\hline
\end{tabular}

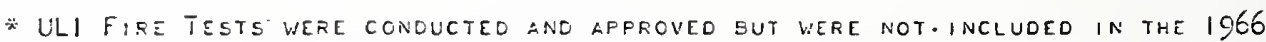
ULI GUILDING MATERIALS LIST OR THE FEgRUARY BI-NONTHLY SUPPLEMENT.

NUTE HO. I - NO TAMPING OR ADHESIVE IS REQUIREE.

NOTE NE. 2 - WAY DE APPLIED WITH POLE-FIEES-GUN, WHICH SHOUID EFFECT SCAFFOLDING COSTS.

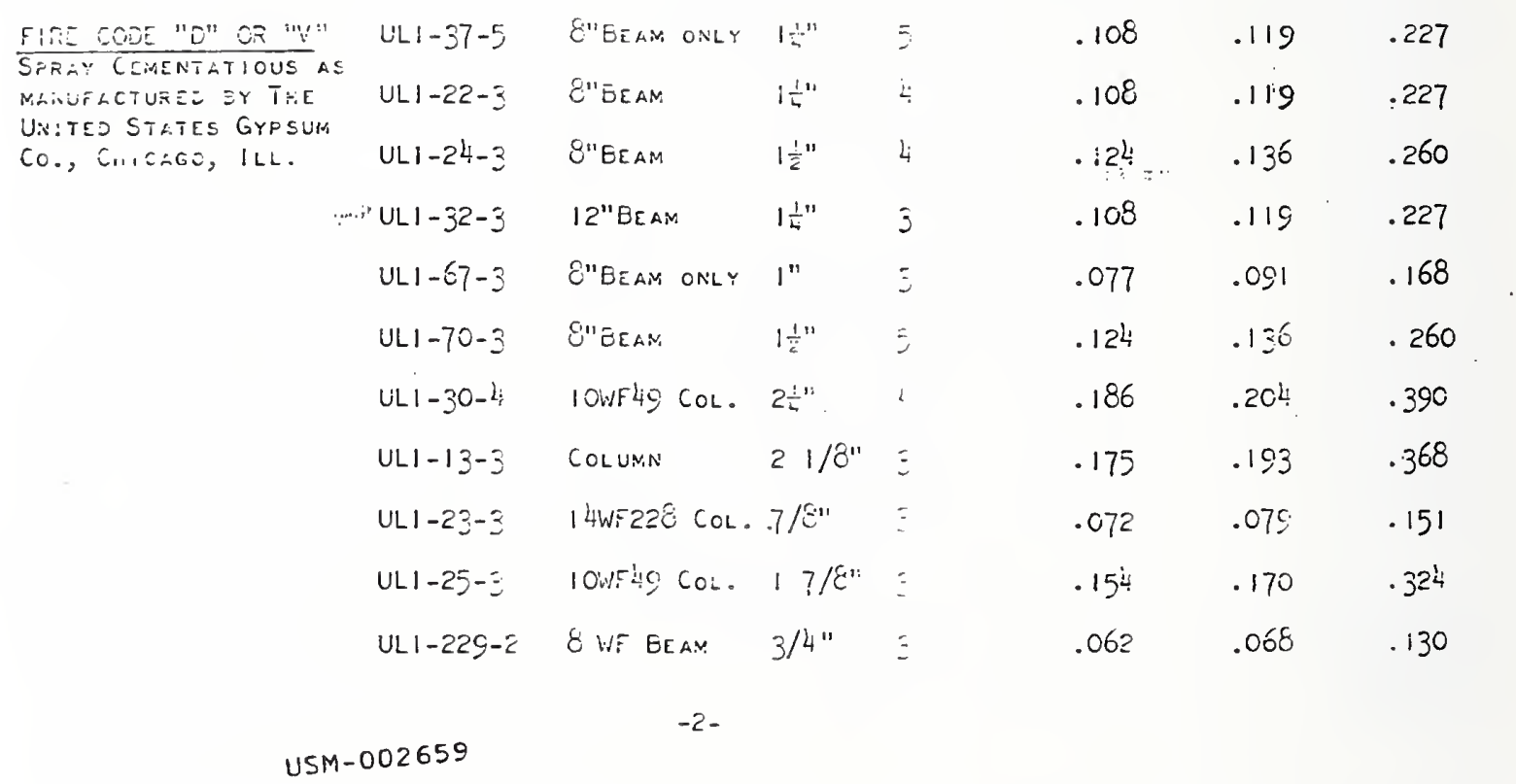

Figure A-16 (Contd.). Correspondence related to economic study of alternative thermal insulation materials (432-P). 


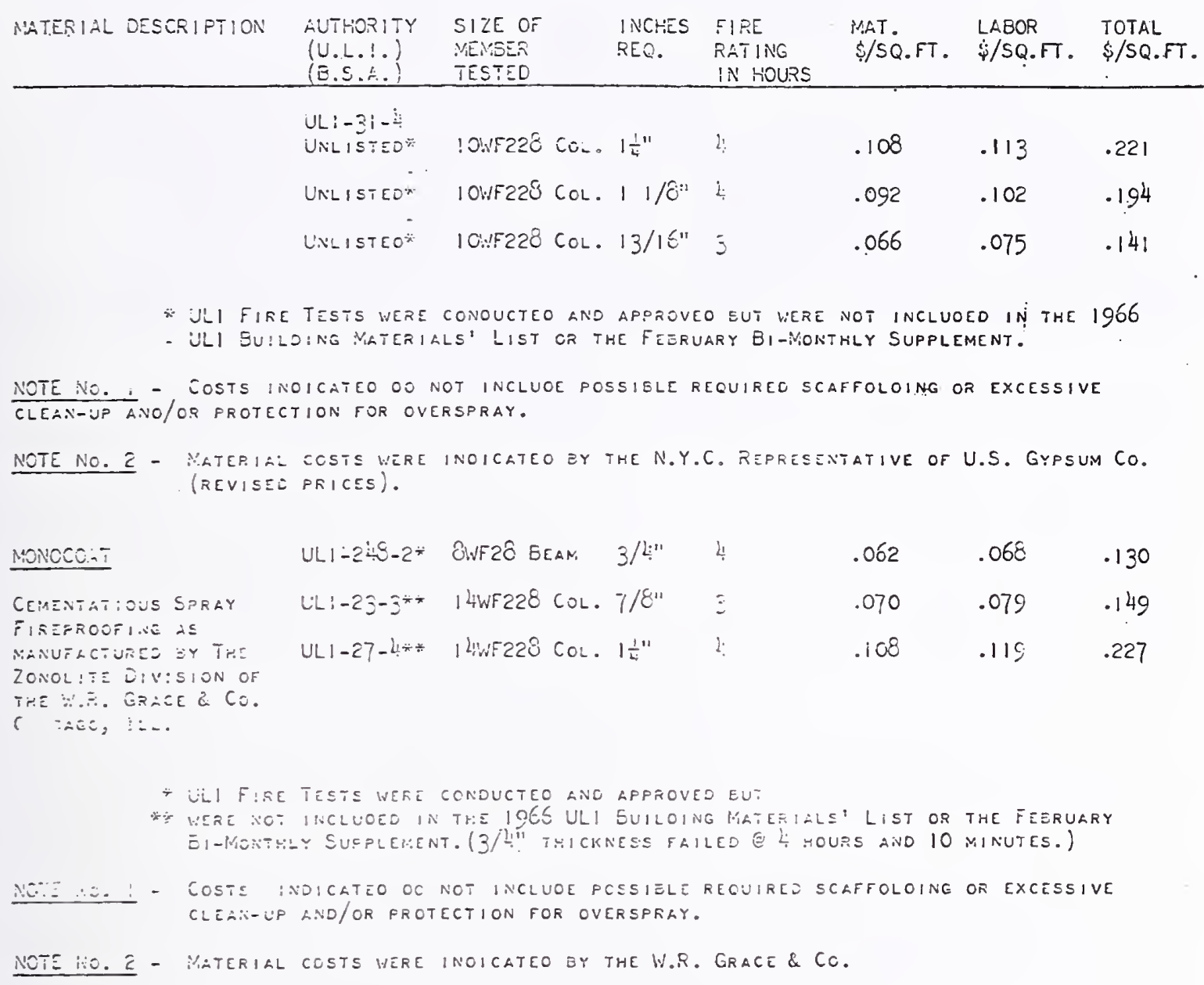

Figure A-16 (Contd.). Correspondence related to economic study of alternative thermal insulation materials (432-P). 


\section{WORLD TRADE CENTER - FIREFROOFING ANALYSIS}

\section{RECONGINDATIONS}

PFesently, it appeafs that the s?Rayed fIEER inaterials (Cafco and spray Chaft) EMJOY A SLIGHTLY HORE ECONOMICAL APPLIEO CCST PER SQUARE FOOT THAN THE SPRAYED CEMENTITIOUS (FIRECODE V AND WONOCOAT) MATERIALS BUT NOT ENOUCH TO PRECLUOE KEEPING SOTH IN COHPETITION UNTIL A FINAL EUY IS KAOE. NOTE THAT THE FIEER SUPPLIERS HAVE NOT CONOUCTED AS EXTEINSIVE A FIRE TESTING PROGRAH AS HAVE THE CEMENTITIOLS MATERIAL HANUFACTURERS. SINCE HORE OATA IS AVAILAGLE IN THE LATTER INSTAUE, WURE ACCURATE INTERPOLATION IS POSSIELE HERE WITHOUT EXPENSIVE AO$01 T 10$ S. TESTING.

TLE TONOVAL OF BOTH THE TAMPING ANO ADHESIVE REQUIREMENTS (BY ACTUAL U.L.I. ALITOA:TY) FRCM THE FIBER APPLICATICNE, THE APPARENT ABILITY TO SPRAY FIEER WITH ACCURACY FRON THE FLOOR USING THE NEVLY OEVELOPEO POLE-FIEER-GUN AND THE RELATIVE EASE UE CLEAN-UP WITHOUT SCRAPING CF CVER SPRAYEO MATERIAL, GENERALLY CCNTRIEUTES TO THE EDGE IN ECONOMY OF THE FIBER MATERIALS.

THE POSSIELE REQUIREMENT (ASSUMING THAT AM EXTERIOR GYPSUN BOARO ASSEMBLY PROVES ITSELF' OF CONEINED SPRAYING EETWEEN THE CURTAIN WALL AND EXTERIOR BOX COLU:HNS AE $\because$ L. AS GETWEEN THE CURTAIN WALL ANS EXTERIOR SPANOREL MEMBERS, COULD GIVE THE FIZER UTERIAL AN AOOEO AOVANTAGE GVER CENENTITIOUS, SINCE FIBER EQUIPMENT AP ERE MOR: VERSATILE AND EASILY MEAPTAELE TO FAN SPRAYS, NOZZLE MIKING OR SLAPY MIXIAS (GROUT), SINPLY EY CHANGING EXISTING SPRAY HEADS OR ADAPTINC NEW HEA2 CONFIGLRATIONS IF EXISTING EQU:FHENT CANHOT BE SATISFACTORILY CONTROLLED.

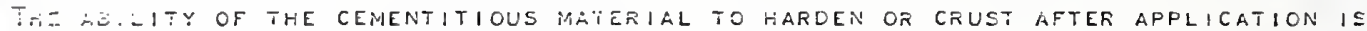
2. - JS FOR THIS MATERIAL SINCE DUCT WORK GENERALLY IS SCHEDULEO FOR INSTALLATION (:Z:EEN TRUSSES) AFTER THE FIFEPEOOFING OF STEEL, WITH RESULTING DAMAEE TO FIRE-

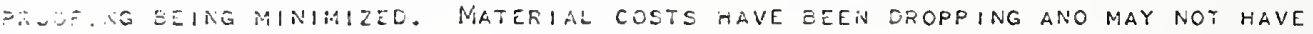
$\therefore E \therefore \Omega=0$ OC:TON.

1- IS RECOHFENOED THAT EOTH SPRAYEO FIEER LND SPRAYEO CEMENTITIOUS SUBCONTRACTURS ZE D‥CEO II Á COMPETITION WITH EACH OTHER WITH INSTRUCTICNS FOR LCGICAL INTERPULATUN OF REQUIRED THICKNESS OF THEIR RESPECTIVE MATERIALS SASEO ON ACTUAL OR UNF JOLISHEC UNOERIVRITERS' LABORATORIES A.PPROVALS.

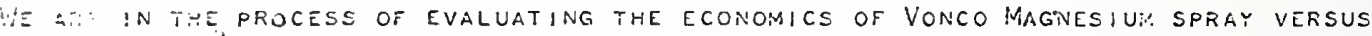
A SPECIAL WATERPSOOFED LAMINATEO ASEEMSLY OF GYPSUM BOARO SHEETS FCR THE ËTERIOR OF T. - COLUMNS AND SPANDRELS ONLY (WIERE MOISTURE OR TEMPERATURE PRECLUDES DEHER METRIALS, IN OUR OPINION, WITHOUT EXCESS (VE RE-WORK).

VONCO IS TSO COSTLY FOR FURTHER CONSIDERATION FOF INTERIOR FIREPROOFINE APPLICATION.

WHEN ITIS ANALYSIS IS COMPLETE, WE WLL RECCMMENO THE HOST ECONOMICAL APPROAC:TO T:- FRCUECT'S EXTERIOR FIREPROOFING REQUIREMENTS. AT THIS TIME, THERE APPEATS UUSTIFICATION TO PURSUE THE INVESTIGATION OF THIS PREFABRICATEL LAMIINATED ASSENSLY OF EITHER THE STANOARO J/E: FIRECCDE GYPSUM BOARD OR A SPECIAL SCARD WAEE C: FIRECOOE V MATERIAL WHICH CONCEIVAELY WILL PERMIT A L HOUR RATING UIT:

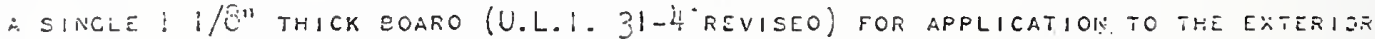
FACE OE THE EXTERIOR BOX COLUMNS, PERMITTING THE ERECTION OF CURTAIN WALL ANO TAE CLOSIUE IN OF THE TOWER STRUCTURE PRIOR TO APPLICATION OF THE INTERIOR SPRAYEJ

USM-002661

Figure A-16 (Contd.). Correspondence related to economic study of alternative thermal insulation materials (432-P). 
FIREPROOFING. IF THE SUILOING CAN BE ENCLOSED EARLY IN THE CONSTRUCTION CYCLE, INTERIOR FIREPROOFING WITH EITHER FIEER OR CEMENTITIOUS MATERIAL WILL BE MORE EFFICIENT ANO THUS MORE ECONONICAL.

Figure A-16 (Contd.). Correspondence related to economic study of alternative thermal insulation materials (432-P). 


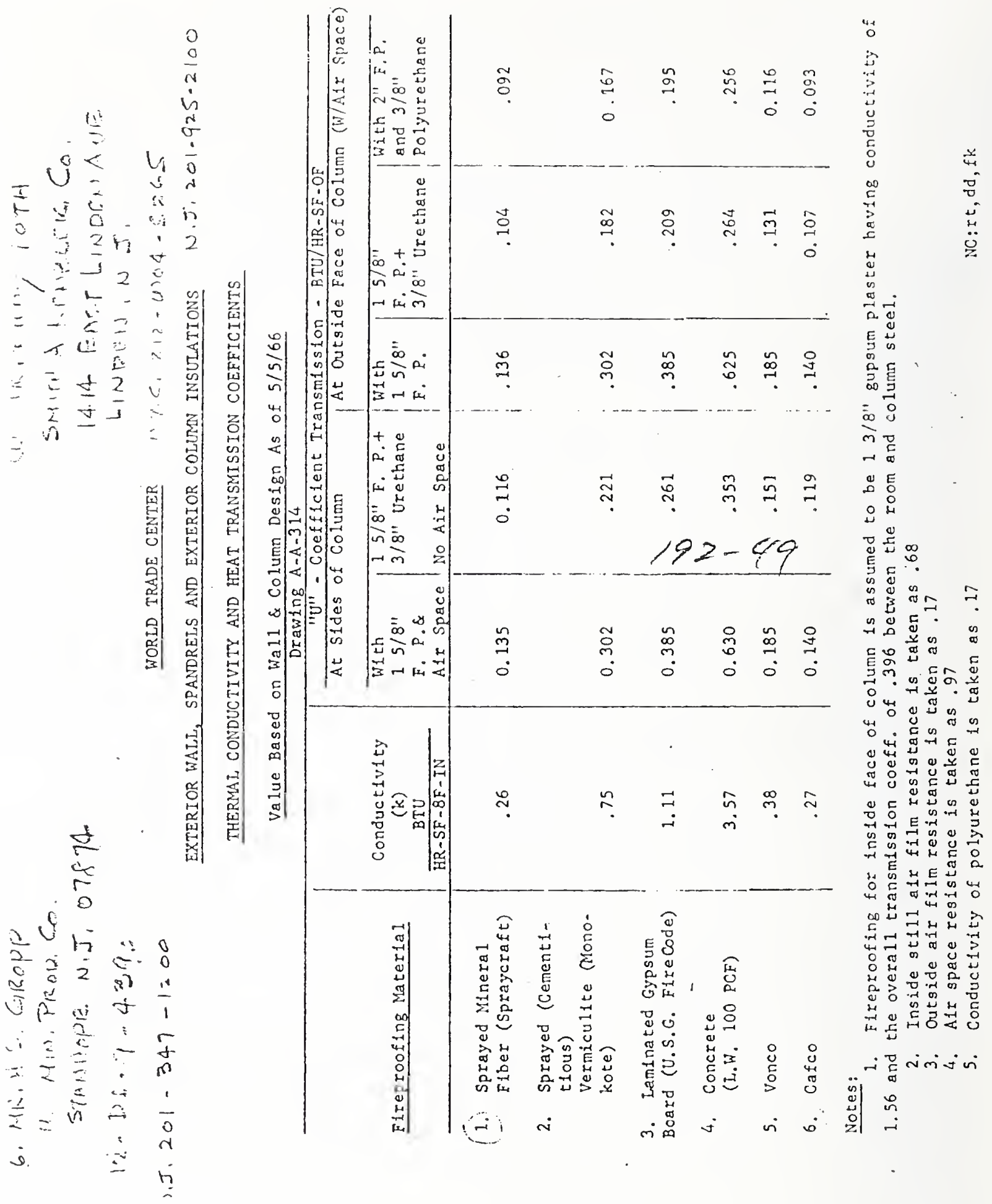

Figure A-17. Thermal conductivity and heat transfer coefficients used in 1966 study of candidate thermal insulation materials for exterior columns (437-P). 
-THERMAL INSULATION

The insulation materials applied to the structural steel components of the wall (columns and spandrels) must serve 10 control column temperature to a minimum of $50^{\circ}$ with $70^{\circ}$ insice and $0^{\circ}$ outside, provide lireprooling to meet a lour hour test on a heavy column, and minimize heat loss and gain to satisty HVAC requirements. Alter extensive testing of many insulating and lireprooting materials, a sprayed mineral fibre has been selecicd to meet all requirements of the three purposes above. It will bo used on the three exterior sides of the column and both sides of the spanorel plate. The room sice of the column will be covered with gypsum plaster to meet lireproosing requirements with a relatively high " $K$ " value 10 permit he at migration to the steel. This migration is necessary to hold steel temperatures above specified minimum during extreme and prolonged cold periods.

\section{Thermal Testing}

The minimum column steel temperatures of $50^{\circ} \mathrm{F}$ requires strategic use of both high " $\mathrm{K}$ " and low " $K$ " fireprooling. Since the required therma! balance results trom a comtination of many fac:ors, calculations can be only a rough guide to design and true pertormance can be determined only by actual test.

Such tests have been performed at Cupples on three 5 ' sections of columns completed in Iult detall typical of the $100 \mathrm{in}$ tloor. Two units were assembled in a dividing partition of the thermal chamber at Cupples with thermocsuples mounted on the steel, top anc toltom and inside to outsice. "Outside" temperature on one side of the partiticn was reduced $100^{\circ} \mathrm{F}$ and "Inside" temperature was controlled at $70^{\circ} \mathrm{F}$ until steel had reached thermal balance when results were recorded. A thurd unit was tested similarly at Pennsylvania Stäie University in the thermal chambers of the Institute :or Building Fesearch.

Complete de:ails of tests and results are included in the pccket at the back of this book.
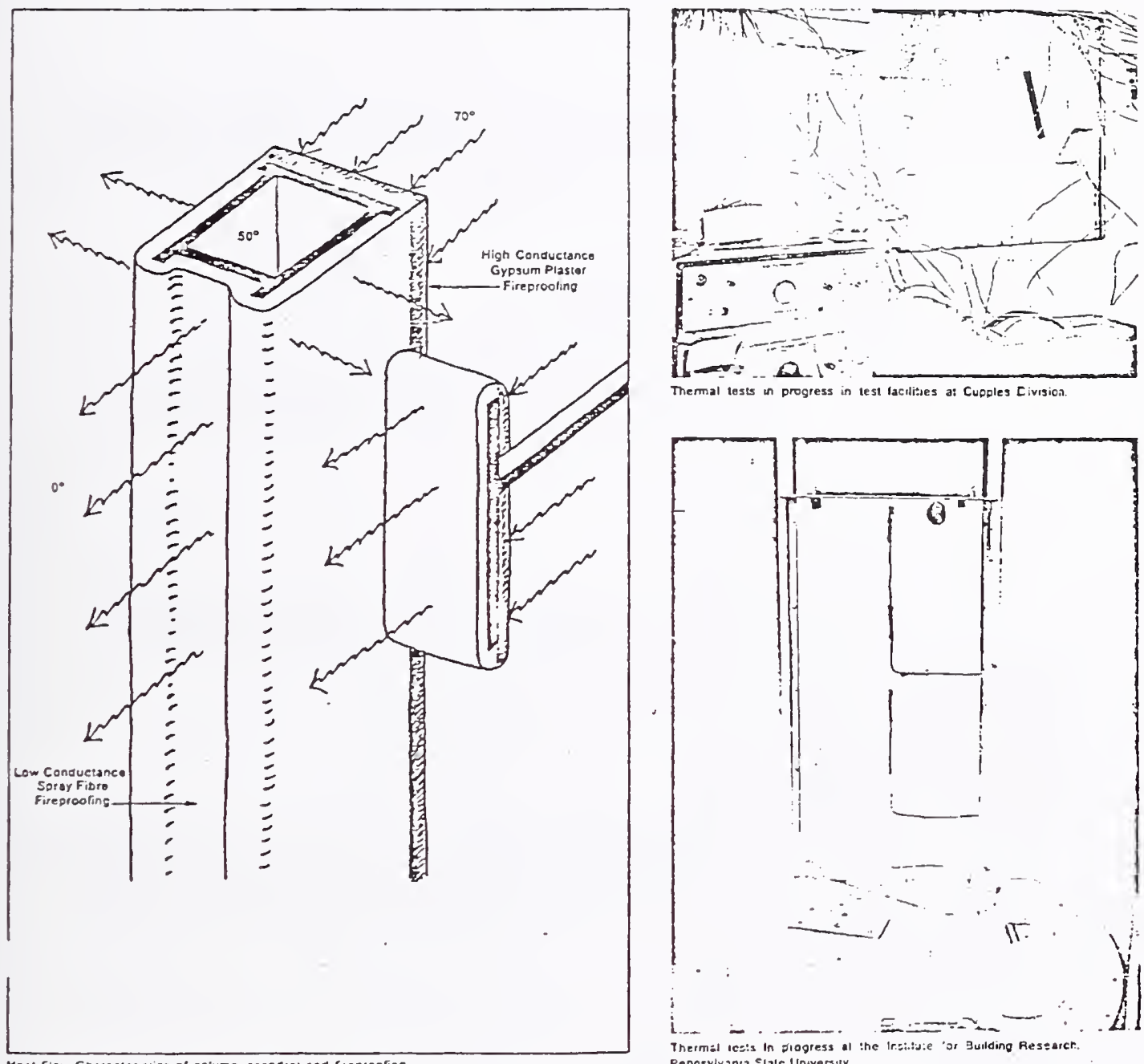
Pennsyivanias slalc Liniversily.

Figure A-18. Excerpts from December 1996 Alcoa proposal for exterior wall of WTC (448-P). 
- Hoistlng-All hoisting would be done after regular working hours from 4 P.M. to approximately 8 P.M. Assuming the inside dimension of the hoist platform to be $7^{\prime} 4^{\prime \prime} \times 13^{\prime} 3^{\prime \prime}$, each llft will include one mobile cart carrying two $1800 \div$ packaçes.

Distribullon and Floor Storago on the designated floor the mobile carts would be moved to storage areas allolted for the purpose. A minimum of six and as many as ten floors of material would be so stored anead of the actual erecticn. Glass would be handled on the inside job hoist in cases weighing $3.600 \mathrm{lb}$. The cases would be handled. moved and stored on the lloors in the same manner as the metal components.

\section{FIREPROOFING}

Sprayed fiber material as manufactured by CAFCO and of a type described in Underwriters Laboratories report $R$ 3749-10 will be applied to three sides of the exterior columns thick enough to provide lour hour fire protestion and to maintain the proper thermal insulations. The required thicknesses to meet fireproofing requirements are $1 \% 10$ " for exterior columns and $1 / 2 \pi$ for spandrels. As space permits, the thickness can be increased to cbtain the required thermal characteristics.

On the inner side of the columns, a high " $K$ " value material will te applied to provide lireprooling while also permitting heat migration Trom room air to column steel.
The sprayed fiber will resist the elements during construction of the curtain wall, remain tirm to the louch and will not reduce in thickness with time. (See copy of CAFCO Bulletin C-940 in pockel at rear of bock). Applica tion would be accomplished with a special nozzle and a transportable cage to sately project the applicator to the exterior of the building. Adjustable verticaliy, the cage would permit complete coverage of the outer laces of columns and spandrel bcams. A screen would be provided around the spray zone to prevent the "blow-by" of fiber material to the exterior of the bulding and the street below.

Fireprooling in progress would be approximately ten floors above the aluminum wall

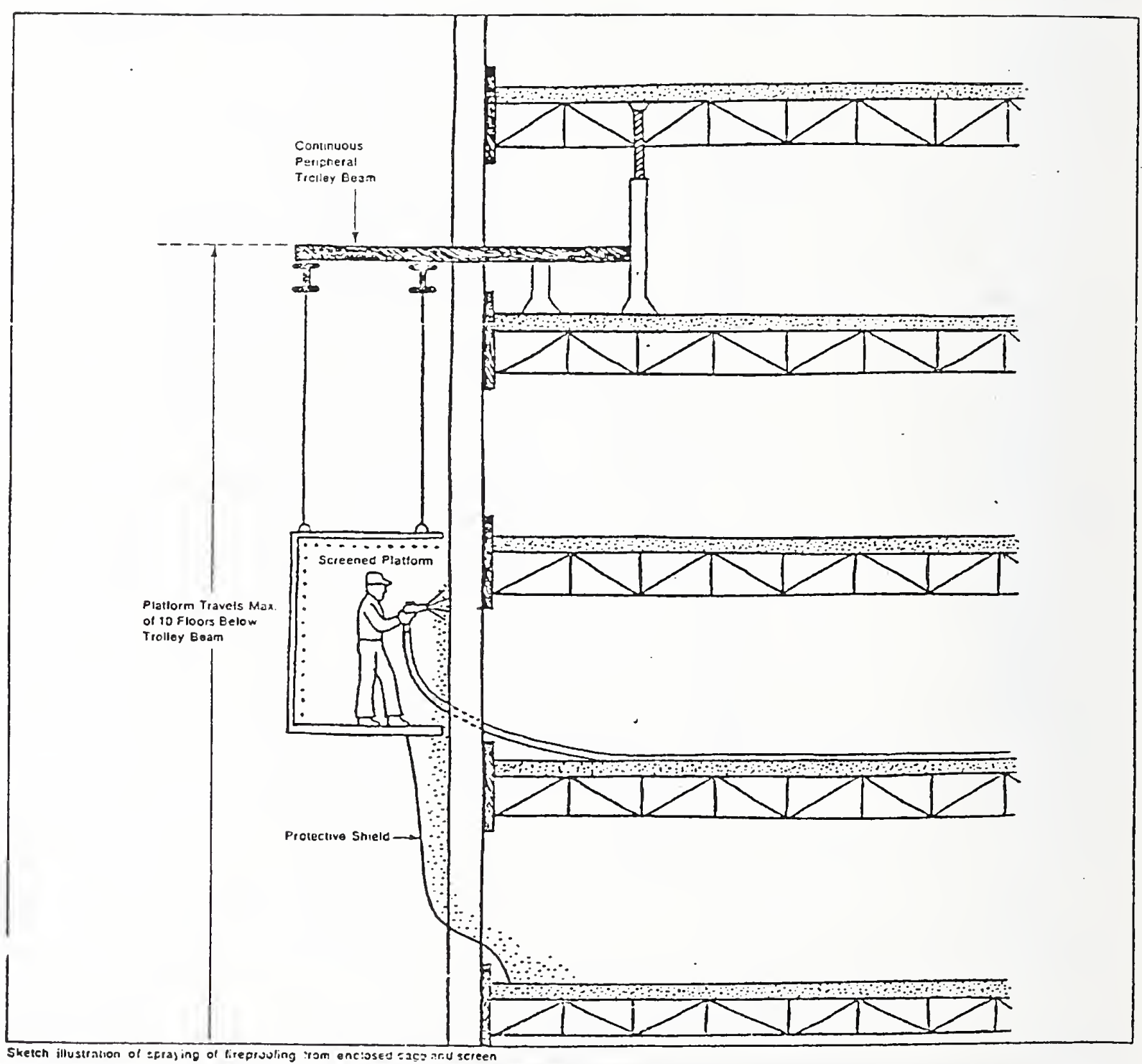

Figure A-18 (Contd.). Excerpts from December 1996 Alcoa proposal for exterior wall of
WTC (448-P). 


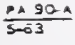

TO:

F⿻一𠃋⿴囗十:

ORTE:

SUEJEC:

REFERENCE:

COPY TO:

\section{MEMORANDUM}

0011788

Mr. R. M. Monti

A. J. Calabrese

August 8,1967

COLUR AID SPANDREL FIREPROOEING OESERVED AT-ALCOA PLANT

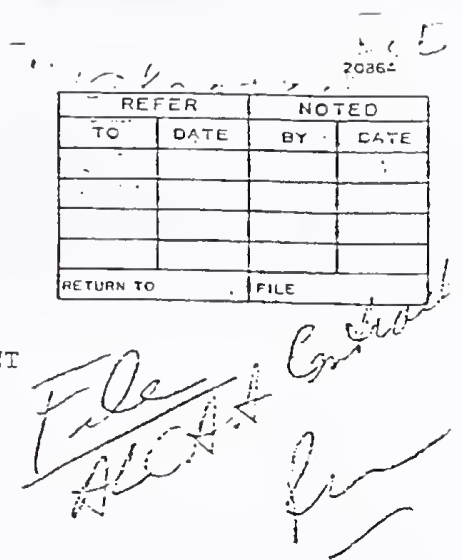

I went to Alcoa-Ctpples plant in St. Louis on August 3, 1967

on an inspection of colum and spandrel fireproofing of mock-up.

Mario and D'bono - plasterer - contractor representative was

a II- Louis D'Bono and Cafco representarive was a Mr. A. Bessemer.

The above mentioned a:.d I vere present when colums and spandrels were sprayed with Cafco Blaze Shield Fireproofing Type "D" on A.izust 3 and $4,1967$.

It is my opinion that the method of applying vas done in a worknansip like manner. It is also my opinion that the method of apolyirg was done with ease and very little spillage.

\section{A. J. Calabrese}

Aucieam

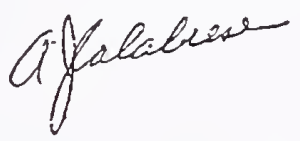

\section{PLAINTIFF'S \\ EXHIBIT \\ $P X-470$}

$$
\begin{aligned}
& A-b-C-F \\
& 1-4-5 F-56 \\
& 51-5 k-6-7-8 \\
& 9-10 b-10 C \\
& \text { II- II3- II4 I2 }
\end{aligned}
$$

Figure A-19. Port Authority correspondence related to demonstration of application of BLAZE-SHIELD Type D to mockup of exterior columns and spandrels (384-P). 


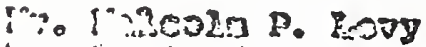

(a) :

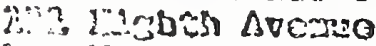

L... Lezis, 17. Y. 20032

Ro: Bprayct-on Flreproot1nt rorla Tendo Contas

\section{$2=-9091398$}

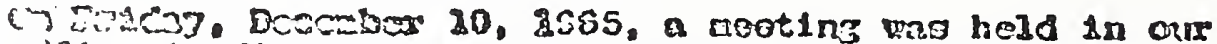

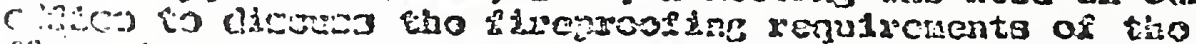

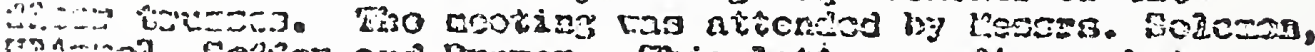

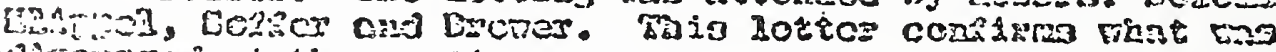
carcouresa at tio mootlas.

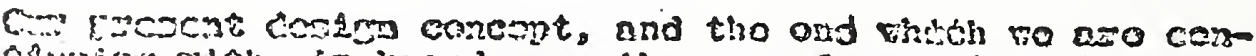

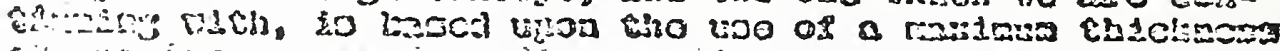

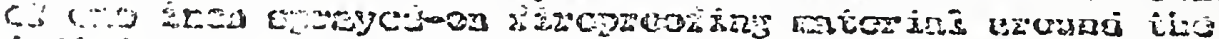
Ar

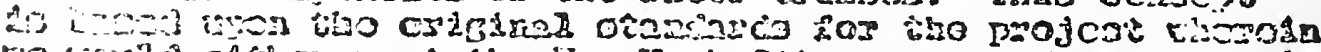

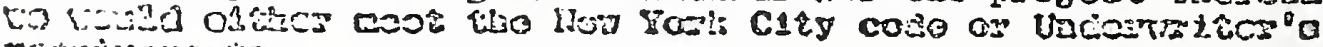

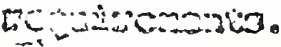

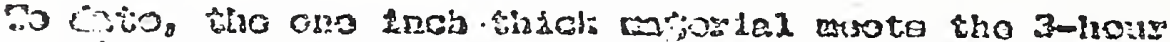

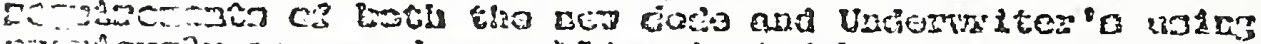

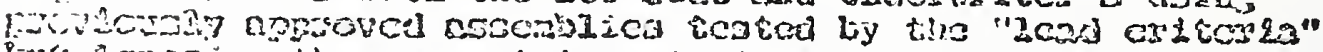

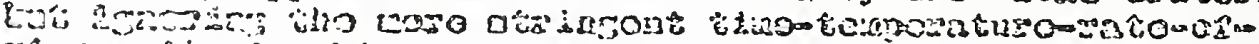

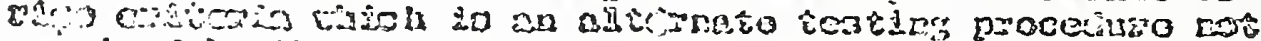

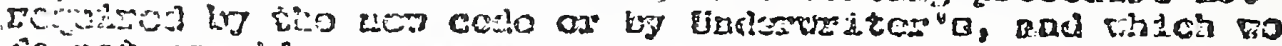

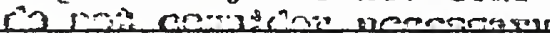

On Friday, December 10,1965, a meeting was held in our office to discuss the fireproofing requirements of the floor trusses. The meeting was attended by Messrs. Solomon, ??????, Soffer, and Brewer. This letter confirms what was discussed at the meeting.

Our present design concept, and the one we are continuing with, is based upon the use of a maximum thickness of one inch sprayed-on fireproofing material around the individual components of the floor trusses. This concept is based upon the original standards for the project where in we would either meet the New York City code or Underwriter's requirements.

To date, the one inch thick material meets the 3 hour requirements of both the new code and Underwriter's using previously approved assemblies tested by the "load criteria" but ignoring the more stringent time-temperature-rate-of-rise criteria which is an alternate testing procedure not required by the new code or by Underwriter's, and which we do not consider necessary.

Figure A-20. Correspondence from Emery Roth \& Sons to Port Authority related to thickness of thermal insulation for floor trusses (text in box was typed by NIST since copy of document is of poor quality) (3-P). 


\section{COPY}

EMERY ROTH E. SONS, ARCHITECTS

B5O THIRD AVENUE

NEW YORK 22, N. Y.
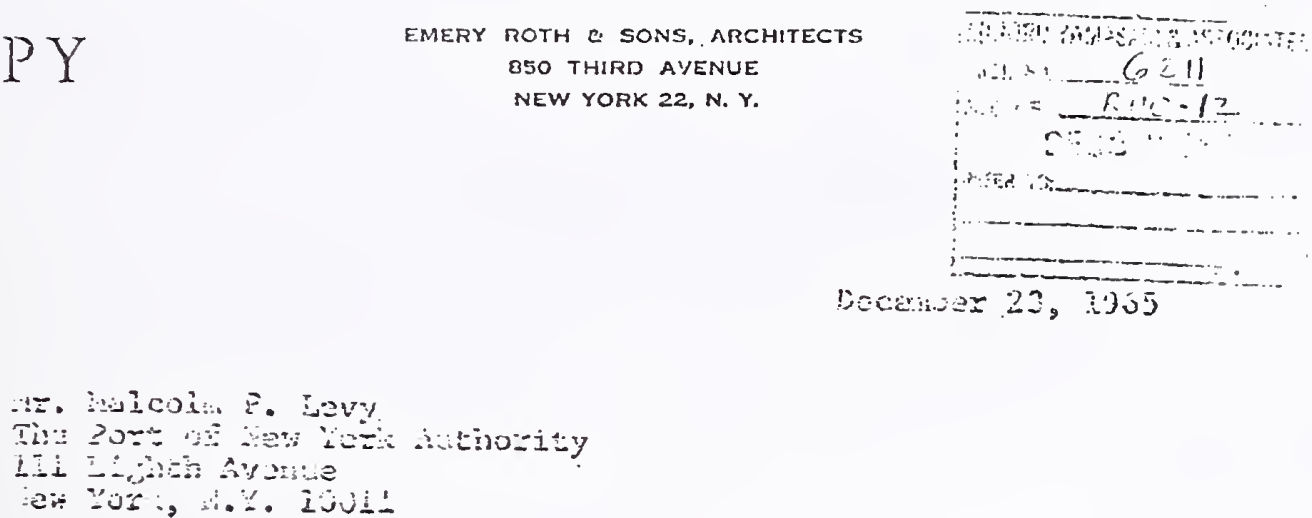

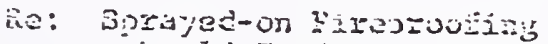

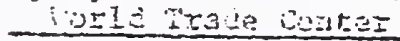

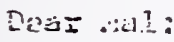

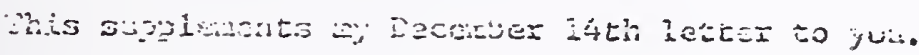

Itละ.

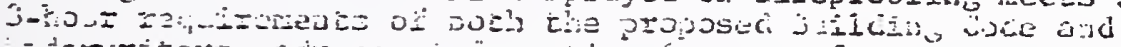

จ

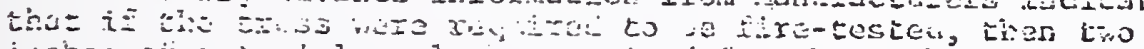

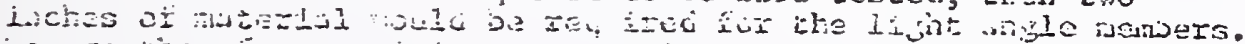

re ule the

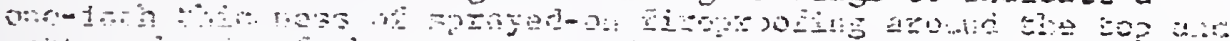

-

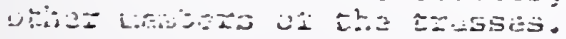

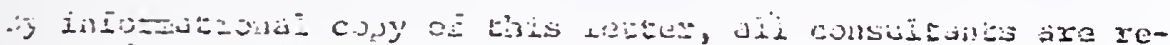

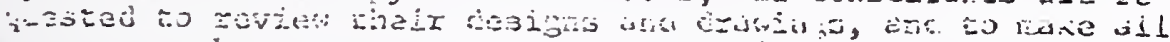

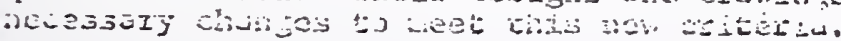

Silisicaly,

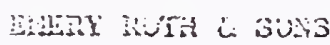

is:

Sitiditivisit

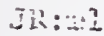

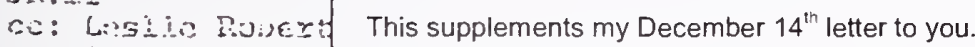

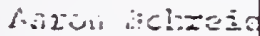

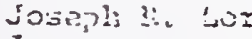

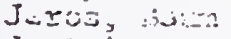

Although the one-inch thick sprayed fireproofing meets the 3 hour requirements of the proposed building code and Underwriters, advance information form the manufacturers

J. indicates that if the truss were required to be fire-tested, the two inches of material would be required for the light angle members. We are therefore revising our working drawings to indicate a one-inch thickness of sprayed-on fireproofing around the top and bottom chords of the trusses, and a two-inch thickness for all other members of the trusses.

By informational copy of this letter, all consultants are requested to review their designs and drawings, and to make all necessary changes to meet his new criteria.

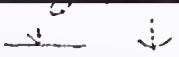

Figure A-21. Correspondence from Emery Roth \& Sons. to Port Authority on thickness of thermal insulation for floor trusses (text in box was typed by NIST since copy of document is of poor quality) (3-P). 


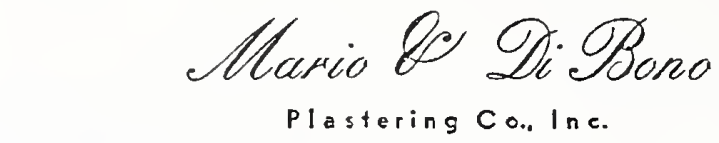

136 LIBERTY STREET NEW YORK, N. Y. 10006

September 15, 1969

Mr. Milt Gerstman

Tishman Realty \& Construction Co., Inc.

30 Church Street

New York, New York

RE: Fireproofing thickness' to be sprayed on steel

Dear Mr. Gerstman:

This list is being submitted for your approval.

1. Beams throughout buildings $-1 / 2$ inch. No tamping or shaping of Cafco type $D$.

2. Columns $13 / 16$ inches. No tamping or shaping of Cafco type D.

3. Elevator columns - 1 inch total including overspray. No tamping or shaping of Cafco type $D$.

4. Bar joist - 1 inch overall thickness. No tamping or shaping of Cafco type D.

Very truly yours,

MARIO \& DI BONO PLASTERING CO., INC.

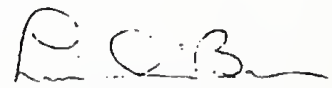

LD/CZ "ISIHIAN FIALTY \& COHST. CO., INC.

Louis Di Bono

ser 151969

DEFENDANT'S

EXHIBIT

DX 434

USM-002883

Figure A-22. Correspondence from thermal insulation contractor to Tishman Realty \& Construction Co. related to insulation thickness (255-ITK). 
$732-5222-3-4$

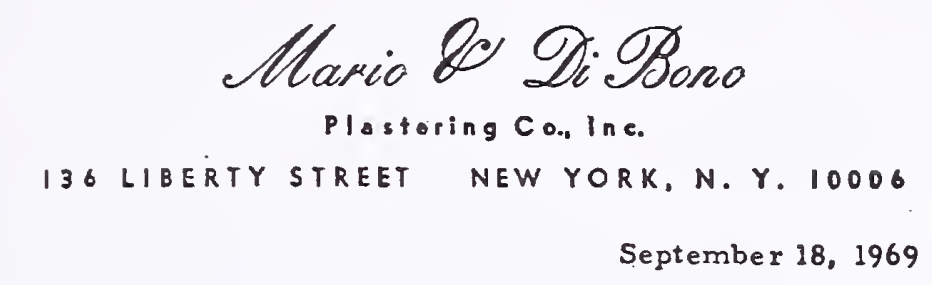

$$
\text { A }-49
$$

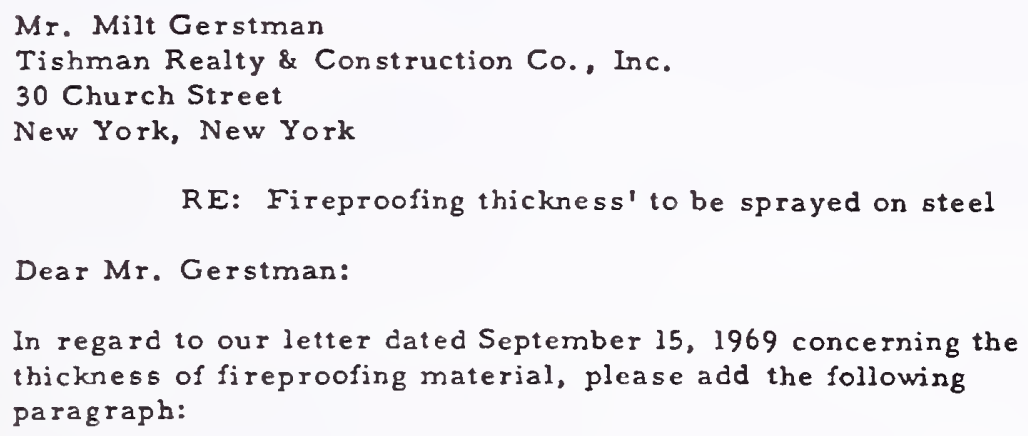

$\mathrm{LD} / \mathrm{Cz}$

5. All beams in MER rooms and utility rooms will be $1 / 2$ inch thickness with overspray. No tamping or shaping of Cafco type D.

Very truly yours,

MARIO \& DI BONO PLASTERING CO., INC.

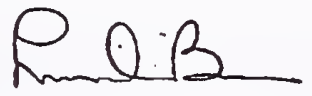

Louis DiBono

DEFENDANT'S

EXHIBIT

DX 438

IISHMAN REAITT \& COHST. CO., JHC.

SEP 221969

USM-002884

Figure A-22 (Contd.). Correspondence from thermal insulation contractor to Tishman Realty \& Construction Co. related to insulation thickness (255-ITK). 
Mr. Louis. Dibono

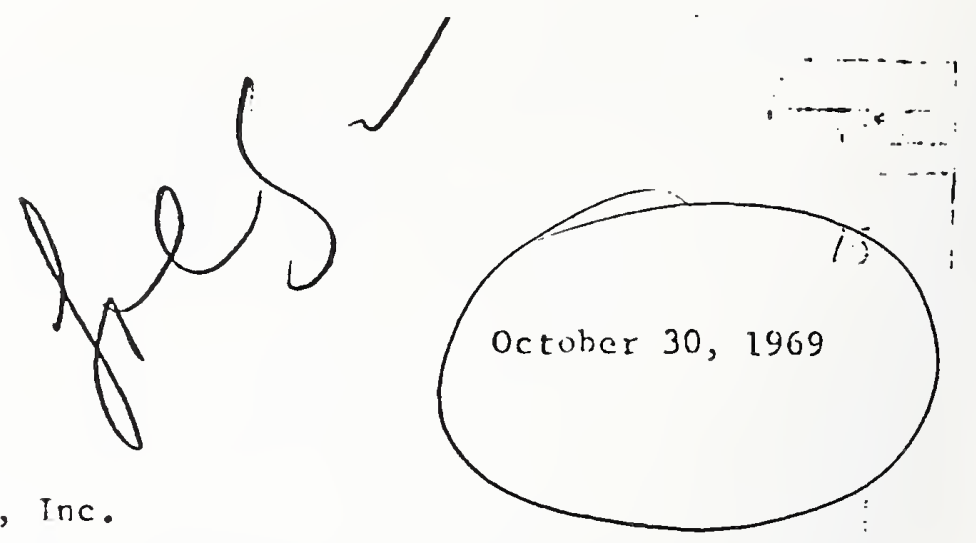

Hario \& Dibrno Plastering, Co., Inc.

3:0 Northern houluverd

Great lick, Lon? Island, Nor York 11021

Re: THF, IYRLD TRADF, CF:PTFR - Conliact IITC 113.00-

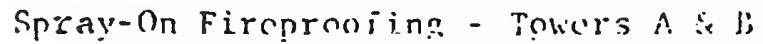

Dea- Lou:

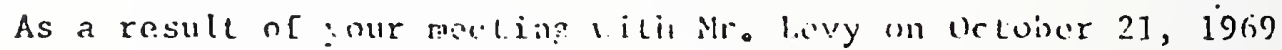

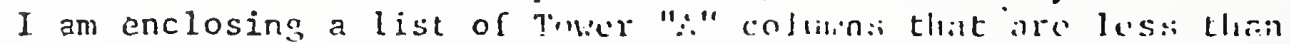

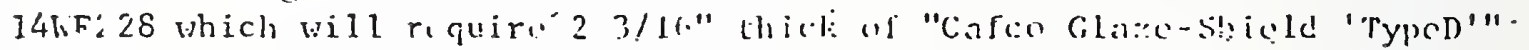

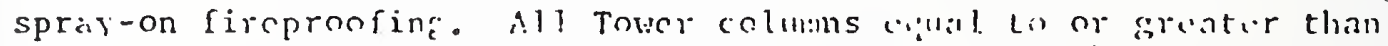

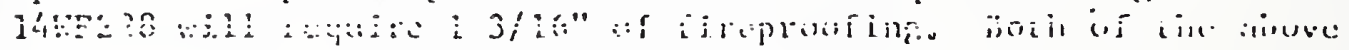

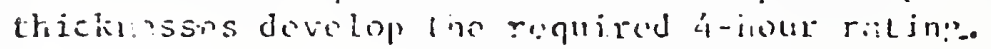

All Tower 1 ams, spandrol:i and bitr joists reguiring:

spray- on rirepronfinf are to have a " coverirs of "Cafeo".

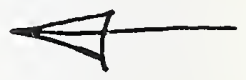

Ine ahove requircments must be adlered to in order to

malntain the Class 1-A Fire Rating of the Ne: lork City liuilding Code.

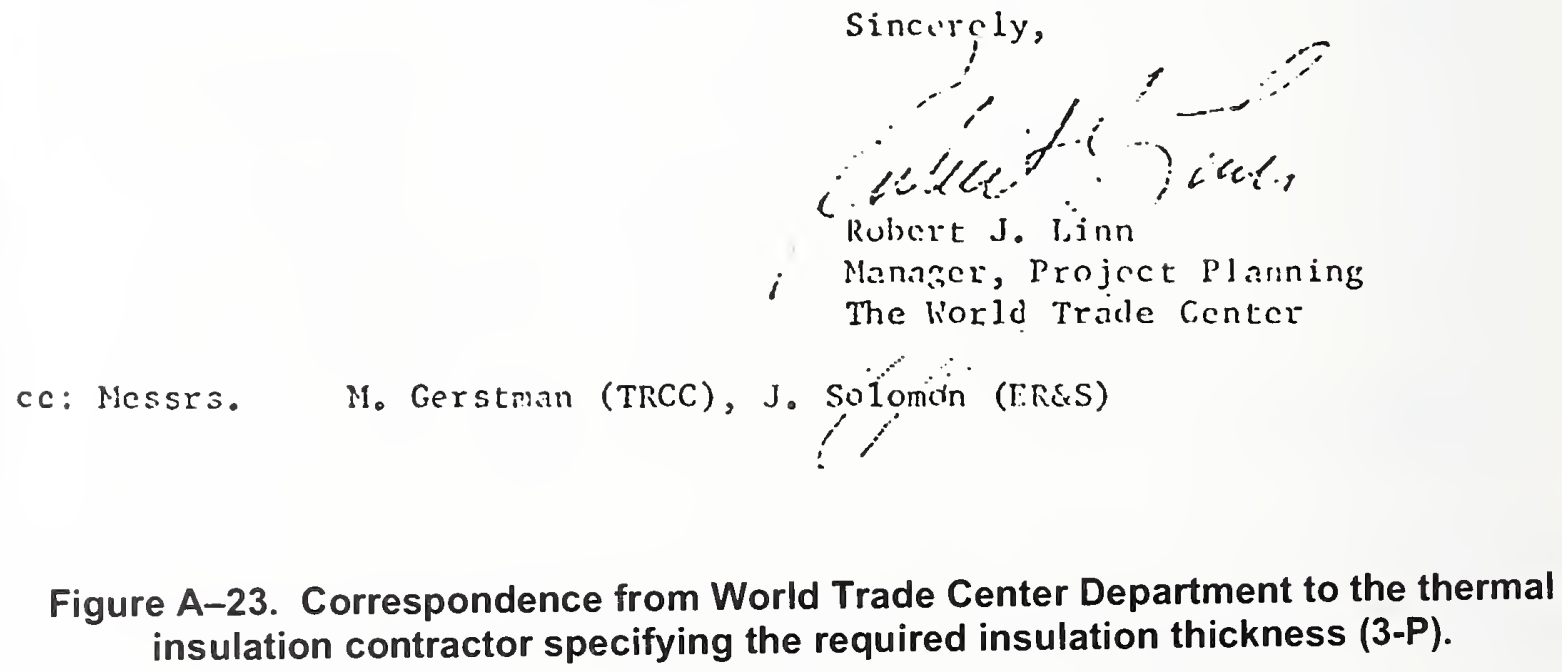




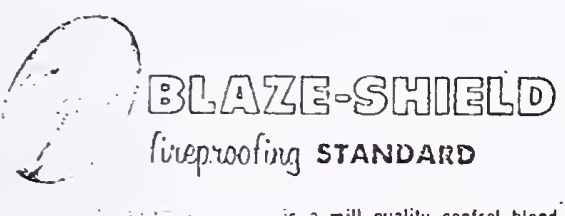

is a mill quality confrol blend of vire:n asvestes fiber, kighty re!ned white mineral liber and propriztary birders. Tested and listed ty Unecturi;ers Laborg.

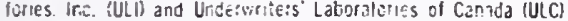
for firsarcofing applications. code acceplance has been registered by $\pi:$ or riuricipal build:-a ceperlisents thrcughout the United Siätes and Cansda and in maty countries overseas.

\section{PRODUCT FEATURES}

$\therefore$... LU, - An impreved SLAZE-SHCLD STAMOARO formu'stion elirinates aoslication Justiness generally associ. ated with conventional sarajed fibar products. Respiratory hazarcs, clean.up time and expenses are minimized.

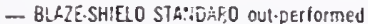
other fireproofing media when exposed to severe tire tempera. tures on major high-rise structures. CAFCO applications have been creciled with restricting fire spread and preveriting serious damage.

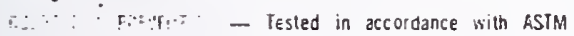
B.117 and Federal Specification Ball.E-5272A, CáfCO protected. shop cainted steel evidenced no corrosion under severe exposure condrt:ons. Rusi prevenfive properties are superior to the combiation of shop and field painting: coslly field painting may t? eliminated.

1:il: - cafco treated spandiels. rcof decks and "jor units reduce heating and ats conditisning costs;

d insulation af roaf sef backs may be etiminated. BLAZE-

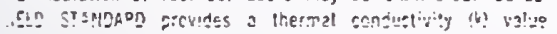

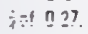

s.: " " j

ALL-VIATHER APPLICATION

PEOUETION IN OEAO LOAD

PERM:AENCE OF PROTECTION

ACCUSTICAL AESORPTION

\section{ARCHITECTURA! SPECIFICATIONS BLAZE-SHIELD STANDARD}

\section{GERSRAL}

5.: - See BLAZE-SHIELO Type 0 specification

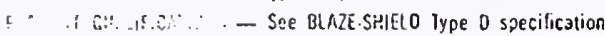

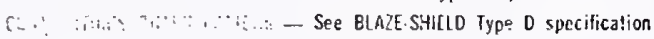

MATERIALS

- Bonding athesice where required, sha!l be a milky while, Ialex.type waier Emulsion which shaft be unefiectrd by waler. walet vapor, condensation, aging or freeziag once it has sel Sha!l be CifCC AOHESIVE as supplicd by the United States Minera Producls Company (Caradian subsidiary--Colunbia Acoustics \& Fireprooling Co. (Canadal Itd.), or approved equal.

- The fiber shall be a lactory quality conirolled and bormusted mix consisting of 100\% inorganic virgin Crycolize asbestos fiber and small pellet, vihite mineral fiter. ccmbined with $1 C 0 \%$ inorganic binters. Fibers shall De CAFCO BLAZE.SHIELO STANOARD as nianufactured by United States Vineral Products Company (Canadian sibsidiary-Colunibia Acoustics \& fireproofine Company (Canacai) (fdi) or acproved equat and stiall be supplied to the job site in sealed bags. precerly niarked and labeled to show the inspection of Underwriters" Laboratories. Inc. or Undenwriters" Laboratories of Canada for the applicaiion specilied.

$\because \quad \therefore$ arn by moislure; shall be CAFCO SEALER as supplied by United States Mineral Products Company (Canadian subsidiary-Columbia Acoustics \& Fireprooling Company (Canada) Ltd.), of approved equral.

WORK OF OTHER SECTIONS

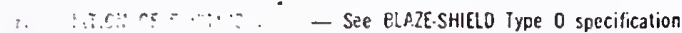

- See BLAZE-SHIELD Type 0 specification

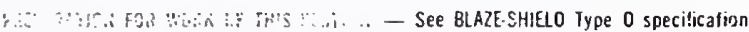

\section{INSTALLATION}

I:3. : : : :

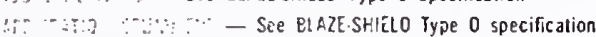

- All surfares fo be treated shall be primed with CAFCO AOHESIVE. Fibers shall be applied and famped to required thichness and oversprayed, where required, with CAFCO SEALER.

C:- - SeE ELAZE.SHIELD Type 0 specification

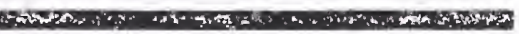

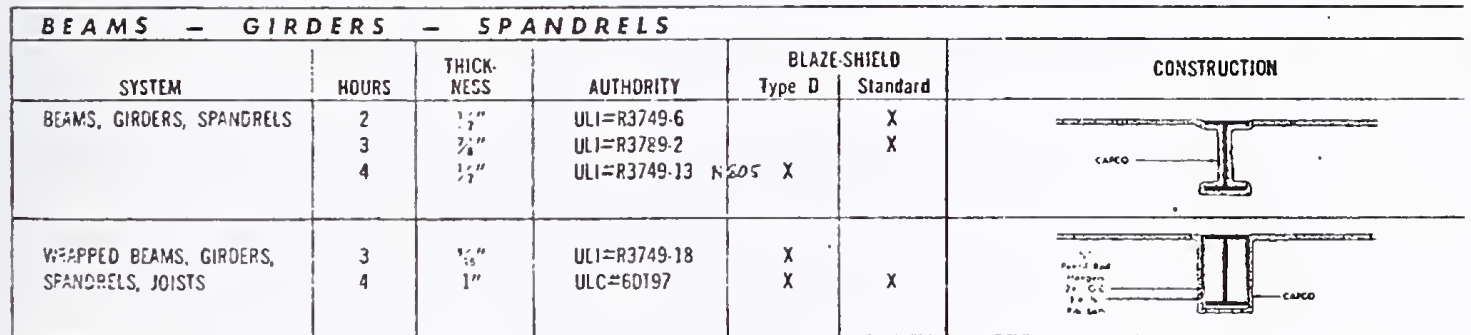

\section{COLUMNS}

CGLUHNS ANO

COLUMIN CAPS

WALIS

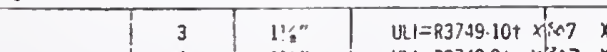

\begin{tabular}{|c|c|}
\hline 3 & $1 ! \cdot 6 "$ \\
\hline 4 & $13{ }^{\prime \prime \prime}$ \\
\hline 2 & $1 \% "$ \\
\hline 3 & $13,4 "$ \\
\hline 4 & $23^{3}$ \\
\hline
\end{tabular}

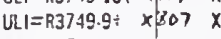

$U L 1=R 3749.19 \times 318 \quad x$

ULI $=R 3749.19 \quad \lambda: 18 \quad x$

$U L 1=0.3749 .19 \times 1901 \times$

\begin{tabular}{|l|l|l|l|l|l|}
\hline W:LLS & 4 & $4^{\prime \prime}$ & ULI=R3749.21 & $x$ & \\
\hline
\end{tabular}

Ing aoplication to colusns 14 biz 278 or greater

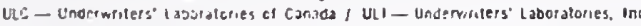

A: tesis conducted in accordance with ASTM E-119

Figure A-24. Excerpt from 1966-67 U.S. Mineral Products Co. catalog for BLAZE-SHIELD indicating thermal insulation thickness for various applications (3-P). 


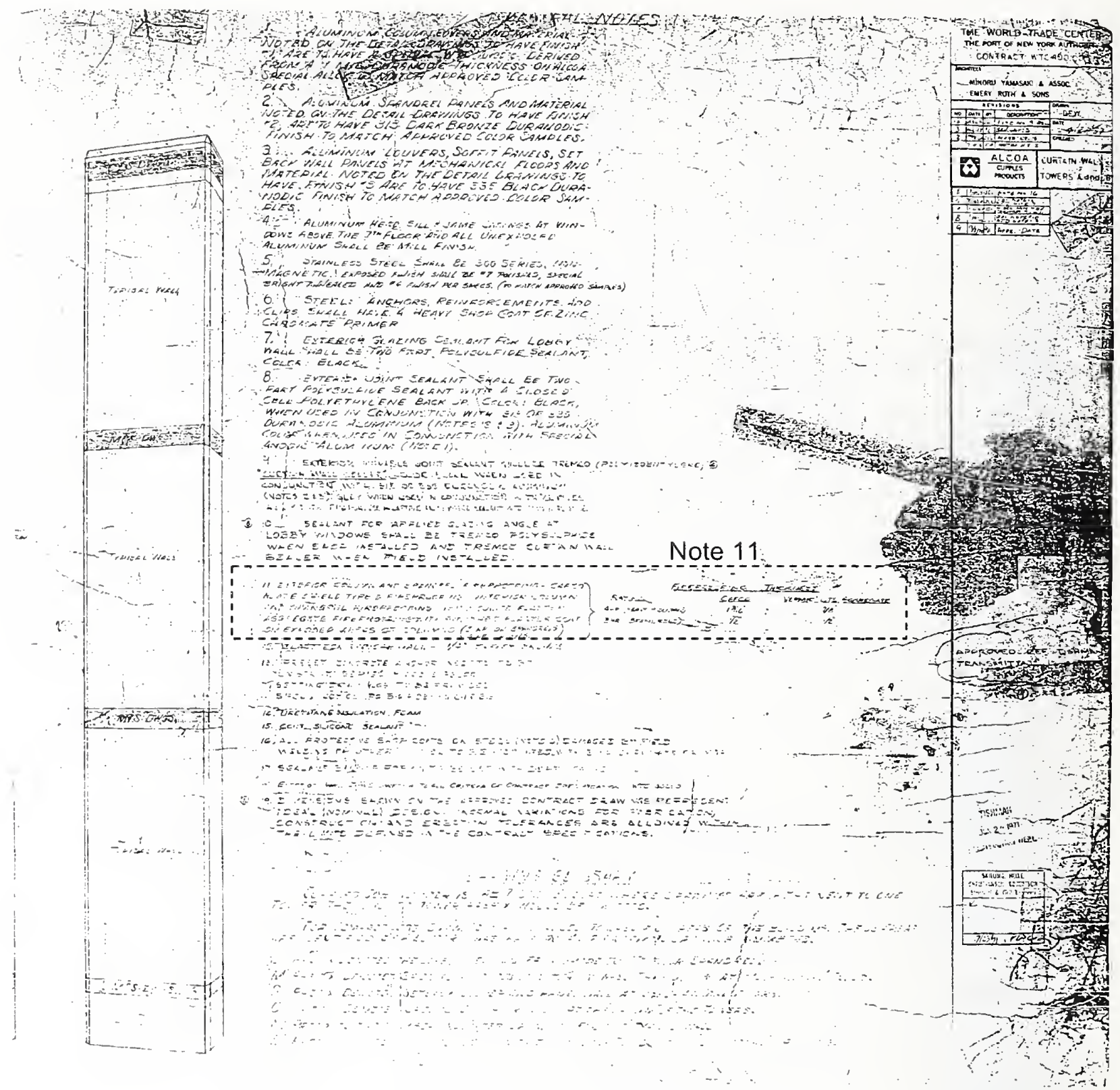

Figure A-25. Portion of "General Notes" page of the Alcoa curtain wall drawings and blow-up of Note 11 indicating the thermal insulation thickness for the exterior columns and spandrels (116-LERA). 


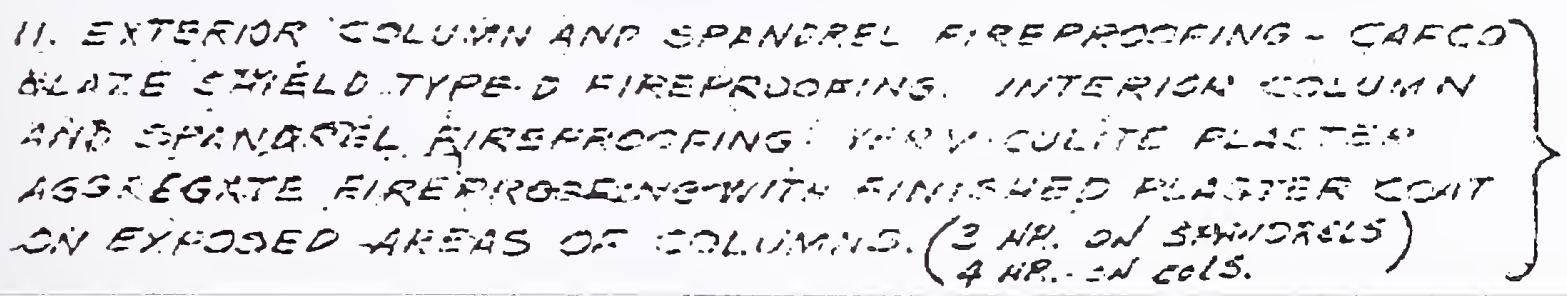
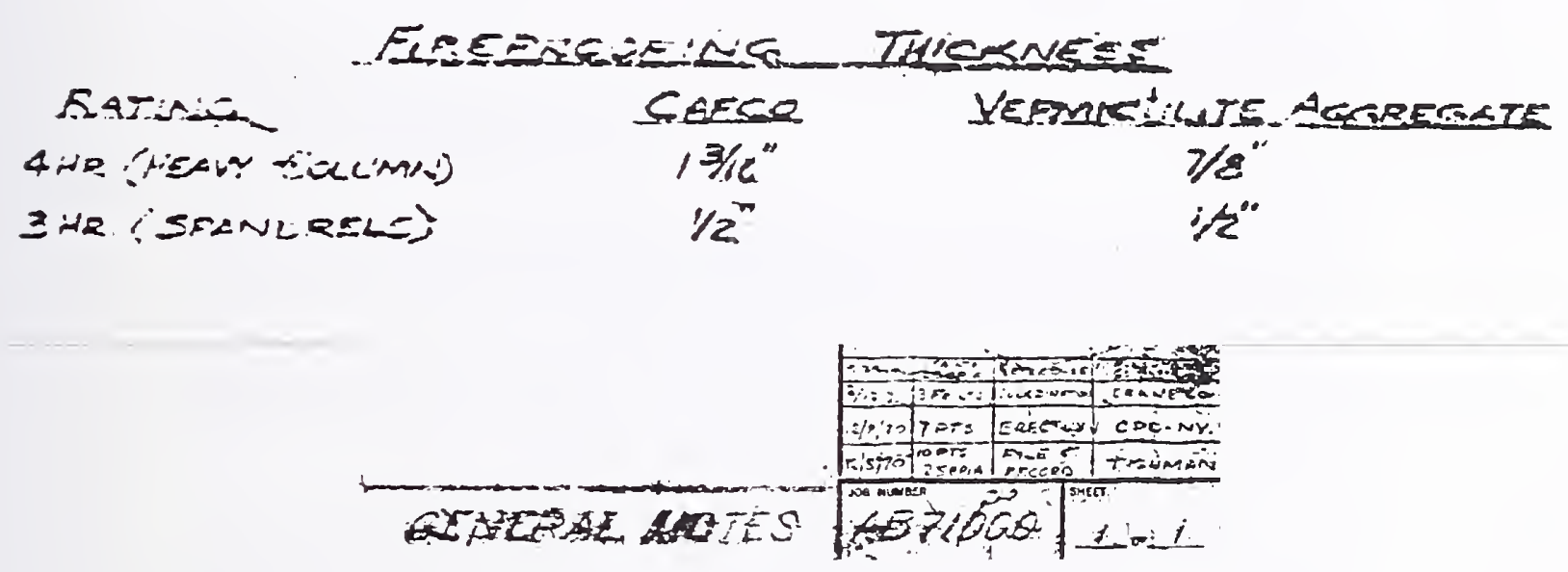

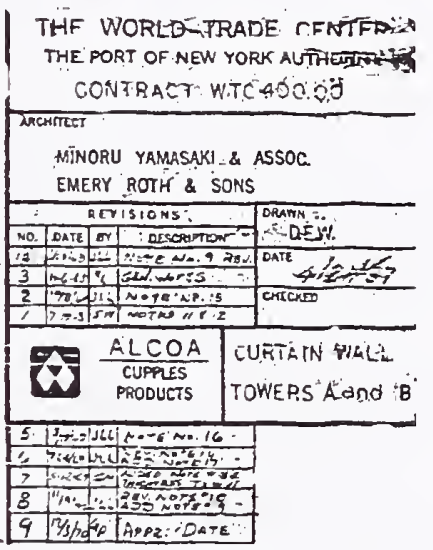

Figure A-25 (Contd.). Portion of "General Notes" page of the Alcoa curtain wall drawings and blow-up of Note 11 indicating the thermal insulation thickness for the exterior columns and spandrels (title blocks of drawing are also shown) (116-LERA). 
COPY
EMERY ROTH ER SONS, MILHITELIS

BDO THIRO AVENUE

NEN YORK 22, N. Y.

$$
\begin{aligned}
& \therefore T C \\
& i ! \\
& \therefore \quad \text { July } 25, \text { 19oo }
\end{aligned}
$$

$$
\text { witi. }
$$

Hr. Halcolon D. Lavy

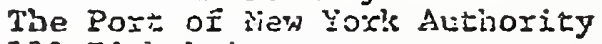

111 Eifinth ivenue

Now Yor?; New yo=k ico11

Leaz Mal:

\section{Re: World Trade Eenter}

In accordayce vith your reguirement that we inform you of any

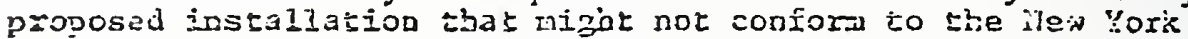
Cliy Buildiag Cocie, I rould like to 2311 yourgatiation to tije floor conarivetion in the tower buildings.

As you hinow, tie propose to pour a 4 " concrera slad over a metal decis which serves oniy as a form and mill have no sicructural value but aill revais in place at complecion. Since the deck Is non-siructural it till not be itize prooied.

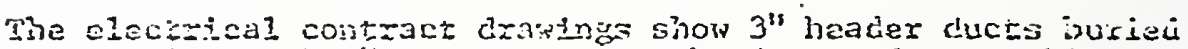
in the siaj sith $1^{\prime \prime}$ conciete oyer the duc' and reruvaja metal

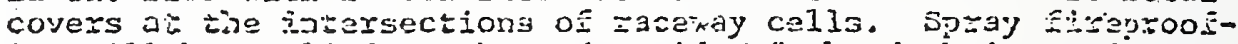
ing will de ap?lied to the under side of tije deck in sizips there headers occur.

The headers, in tum, feed itto electric and telephope racriags which ara $0^{\prime}-3^{\prime \prime}$ cn centers haying floor iaserti $3^{\prime}-4^{\prime \prime} 0 . c_{0}$ and knock-outs for lifritiog below spacéd alternately. Tije cieck under the racenays will not de flreproofed.

Obviously tith so many penetrations of the floox system too fire xating of the fioor construction is of an incereminate value

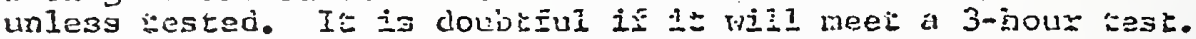

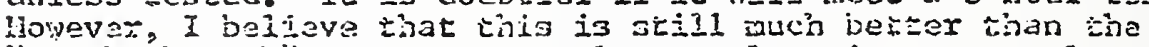

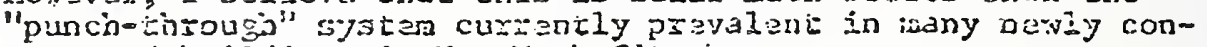

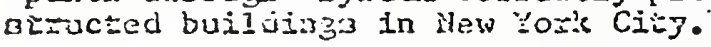

If there is concer for fire rating perhaps spraying the ubder s of the entire dacic nay be a solution. I irould iike to have your thougits an this.

Very truly yours,

EMERY ROTH a sONS

CC Auron Schreier/SISA

Dick I!Lenn/JRIA

HJH:mils

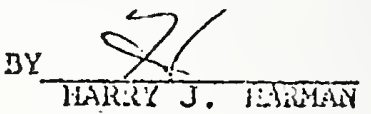

Figure A-26. Letter from Emery Roth \& Sons to Port Authority regarding the application of thermal insulation to the bottom of the concrete floor slabs (3-P). 


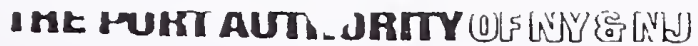

One World Iraje Cente New York. NY, 10048 (212) $466 \cdot 7000$
(201) $622 \cdot 6600$

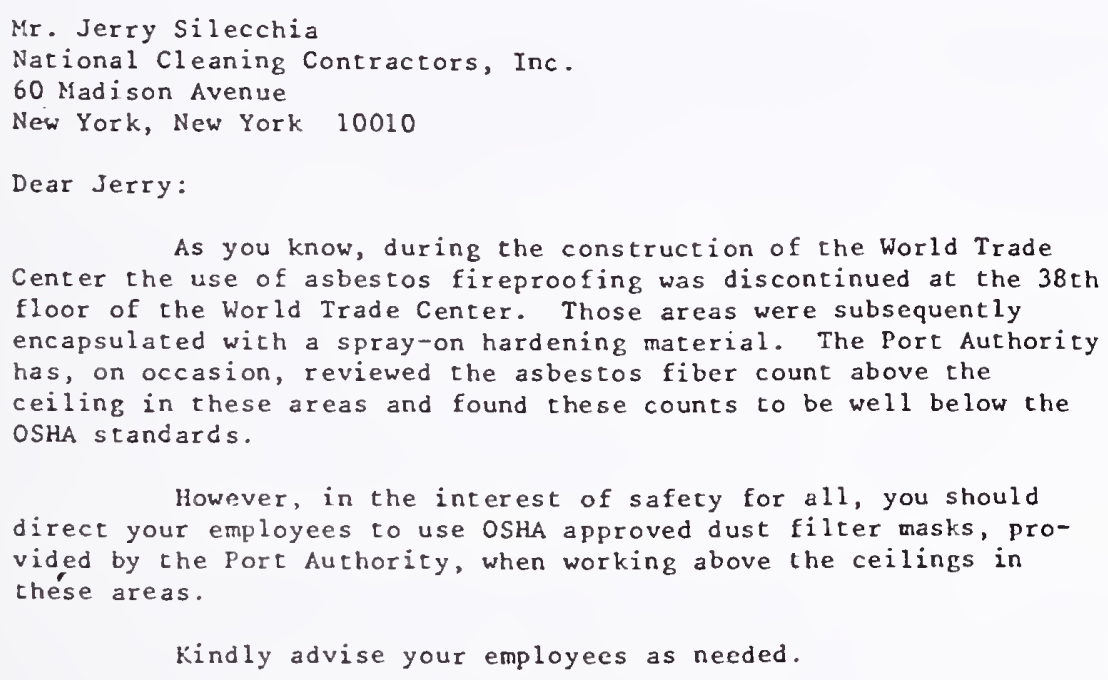

Figure A-27. Correspondence indicating that use of BLAZE-SHIELD Type D was discontinued at the $38^{\text {th }}$ floor of WTC 1 (229-ITK). 
MEMORANDIIM

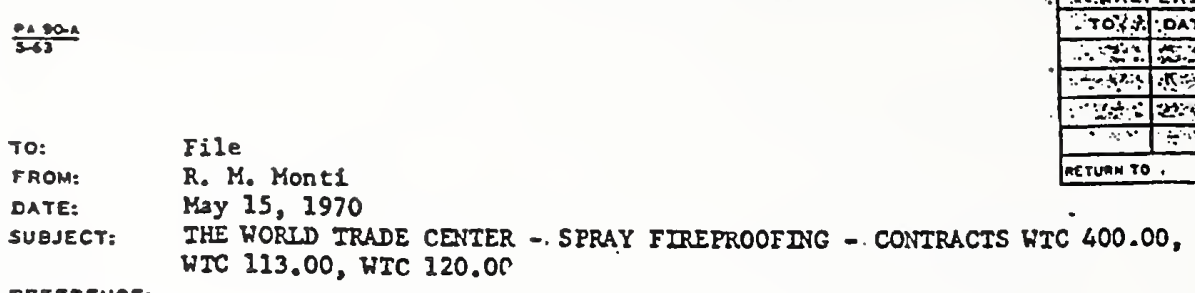

REFERENCE:

COPY TO:

Messrs. Levy, Tozzol1, Falvey, Werneke, Ralola, DeConzo (All.W/Ref.)

At the rpresent time there are $t w 0^{\circ}$ contracts involved in "ispray fireproof Ing: 1) i WTC $: 400.00$ w1 th iLCOA; and 2) Port Authorlty; Contract WTC $113: 00 \div$ for firéproofing of floor,trusses : in the towers; core colum in the towers, below grade areas iof itne bathtub ires; and the Northesst

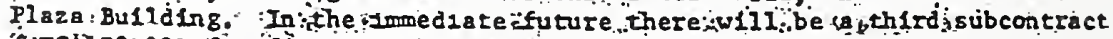

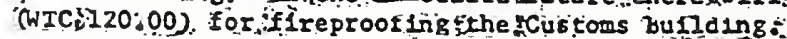

\section{ILCOA: ContrRCE HTC $400: 00$}

From the Inception of rtudies.zon this' contract.ALcan proposed tne, use of carco type iD spray fireproofling iwh ich conforins to the fire. requirements, but, more-2mportant to ALCOA, contorms to the required $K$ factor : tor themal conductivity: Alcos is a perforwance stype fontract and they proposed to use th1s materlal which met their performance sreguiraments and coatained asbestos fibers on all öther contracts sthe Port Authorlty :1.1kewise opeclfied cafco type $D$ spray fireprooting jiticn contained asbëstosidfibèrs.

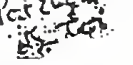

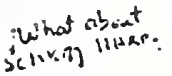

Knev balde thin-Asored

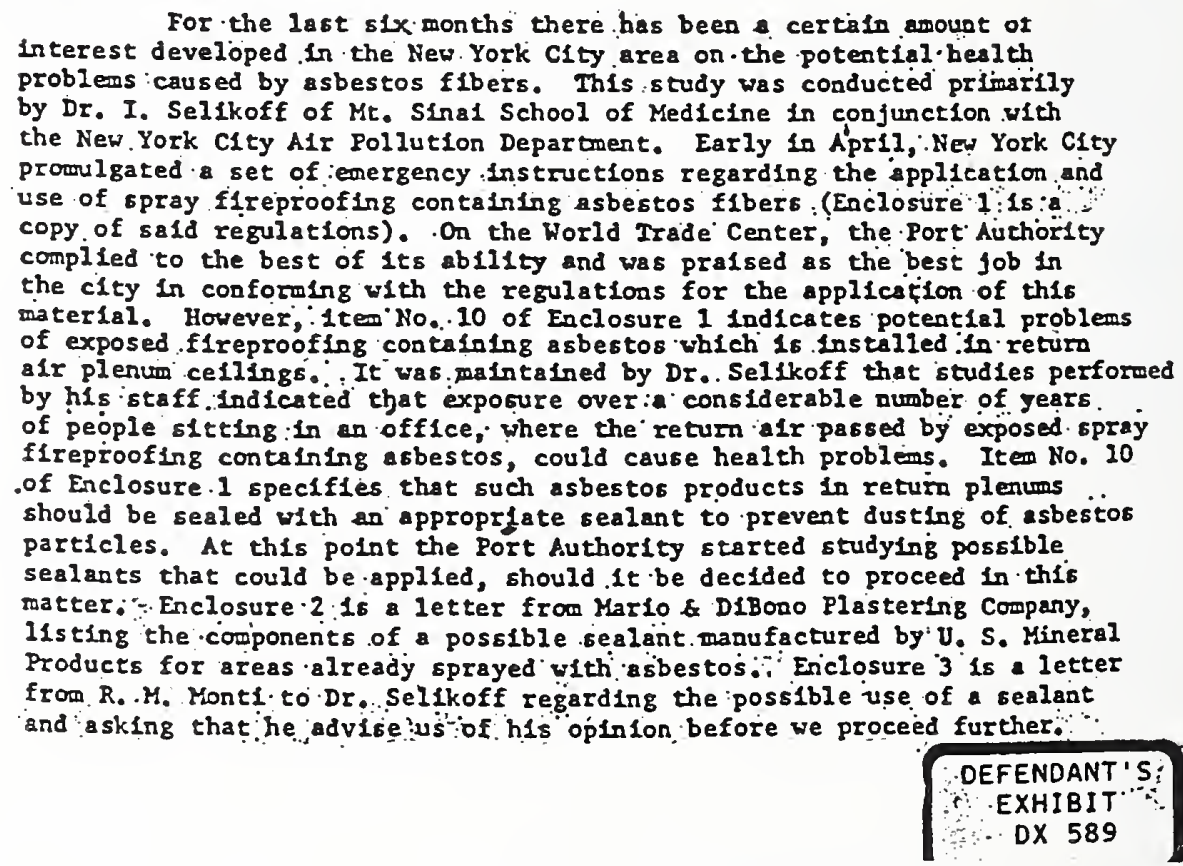
Ual

c.

$+30009$

$\frac{1}{\therefore} \cdot \because$


Enclosure $418^{\circ}$ a letter from Dr. Sellkoff, Mt. Siral School of Medicine, to R. M. Yont1, dated April 16, 1970, Indicating that our proposal to use a sealant on areas sprayed with mineral fireproofing containing asbestos Is the best technical means avallable at this time to prevent dusting, and it has his concurrence.

On April 17, 1970 the spray fireproof contractor, Marlo \& DLBono Plastering $C O$. who is a subcontractor to ALCA under. WIC 400.00 and also the'. Port -Author $1 \overline{y y}^{\prime} \mathrm{s}$ contractor under WTC.113.00, was served with ifive sumionses, one for each day of the week of April 13th: These simonses stated that he was in violation of the regulations-I1sted in Enclosure 1. On April 17 th, Mar10.\& D1Bono al so recelved a Shov Cause jorder retumable

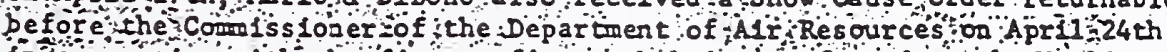
in teonsection with the fireproofing work being perforied at the World Trade Center, as to why the job should not be sealed off. On Apri1, 20, 1970 I was advised by Mario \& DiBono that he had recelved sald Show Cause order and asked my advice: I Inmedlately contacted Pat Falvey, Assistant General

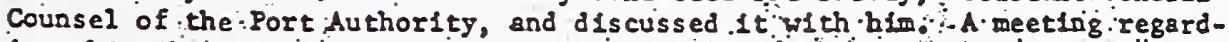
Ing:this !Show Cause order was held with Pat Falvey on Apr11 21, 1970, at which-tine Mr. Falvey called Mr. Fabricant, General Counsel of the New York City Environmerital Protection Administration, and requested that said Show Cause order be indefinitely postponed. Mr. Fabricant agreed, providing he recelved 5 ald request in writing from MI. Falvey. Enclosure:5: Is a copy

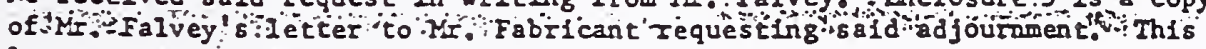
letter states that should te resume spraying with asbestos we would give the City a two day notice, and should we resume spraying with non-asbestos material we would give them one day notice of our intentions.

As of April 20, 1970 all spray fireproofing operations at the World Trade Center site were suspended.

On April 20,.1970 I also went to the offlce of U. S. Mineral Products Corpany in Stanhope, New Jersey where I observed a test demonstration on Cafco type $D$ which had been sealed with sealant to prevent Its dusting. Enclosure 6 is a copy of results of tests conducted on mineral fiber fireproofing in accordance with GSA specifications regarding dusting. $I$ was advised by the Research Director of U. S. Mineral Products that the application of a sealant on top of the Cafco type $D$ would reduce the dusting to a regligible amount. Iests on Cafco type $D$ for dusting, due to alr velocity without a sealant, have been conducted and documented as 115 ted in Enclosure 6. These tests indicated that the amount of asbestos particles dusting off due to alr velocity are well within the standards set by the Environmental Health Department of the United States and also the British standard. It is also concluded and concurred in by Dr. Sellkoff as indicated In the aforenentioned Enclosure 4, that the use of a sealant 1 s the best way to control dusting for work already installed that contains asbestos.

While at Stanhope, New Jersey, I also Inquired into their research of an asbestos free waterial which would perform the same functions as Cafco-D. I was advised that tiey have such a material which had passed

Figure A-28 (Contd.). Port Authority memorandum summarizing the factors considered in choosing BLAZE-SHIELD Type DC/F as a replacement for the asbestos-fiber containing Type D (185-ITK). 
File

prelininary tests and which they were working on final tests for all the requirements. The tests that are required for approval of.this material are as follows:

1. A fire rating test.

2. An adhesion under fire test.

3. A $R$ factor or thermal conductivity test.

4. A bonding strength test.

5. Confirmation regarding the components of the material. that could possibly be alleged to have health hazards.

Cafco-research-1ab-adzised me that they had performed all of the

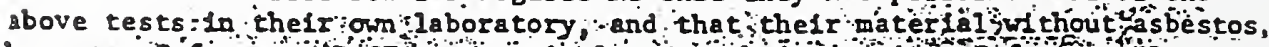

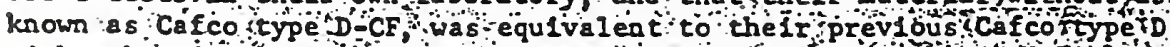
with a sbestós in ali aspects. I advised Cafco représentativesthat ícould not accept on $1 \ddot{y}$ the flindings of their cown laboratory butimist have":independent laboratory tests: They sald they would arrange for all such'teste tand send reports directly to me. : On April 23,. 1970 Cafco called me and advised me that the fire rating tests belng conducted by Undeririters Laboratory in ChIcago had pasied all the réquirements. I requested that this be put in writing. Or Apr11 24; 1970 I recelved a telephone call from en englineer In Underwriters Laboratory, Inc., Mr..S. Bell, who advised me that the fire resistance tests on Cafco type D-CF were at least equivalent and probably. 5\% better than Cafco:type D. I requested confirmation In writing. Attached is Enclosure 7 frot Underiters Laboratory atesting to this finding.

Enclosure 8 is a letter from U. S. Mineral Products dated April 30, 1970 attachlng a copy of a test made by Dynatech of Cambridge, Massachusetts on the thermal conductivity of type D-CF. The test indicates that type D-CF is equivalent or better to regular type $D$.

Cafco-also advised that they had performed bonding.tests on type D-CF and these were successful. However, I requested independent laboratory tests. Enclosure 9 is a report from International Iesting Laboratorles, Inc. of Newark, New Jersey which reports the tensile strength in pounds per square foof of type D-CF to be within a range of 19.9 to 22.40. This tensile strength indicates that type D-CF is able to support its own weight approximately 20 times. Regular type D Cafco is advertised to support 1ts own welght 10 to 12 times. Therefore, type D-CF resylts indicated it to be better than regular type $D$ for bond strength.

I had previously been advised by Cafco representatives that two samples of type D-CF had been sent to Dr. Sellkoff at Mt. Sinal for his examination:: On April 23, 1970 called Dr. Selikoff and asked him if he ever had exanined Type D-CF. He advised me that he had not, but he had examined some similar material and he had found it to contain certain particles of asbestos. He advised that if I were to deliver to him a sample of this type, which I had taken personally out of a bag, he would re-examine same. I had a bag of type.D-CF delivered to wy office and one of my inspectors removed from the bag a one gallon canister of this material with rubber gloves; sealed $1 t$ and delivered it to Ht. Sinal Hospital:

:losure.10.15 a menoraridum to "flle frow my Inspector, R. Kalenborn, iflming säld delivery.

Figure A-28 (Contd.). Port Authority memorandum summarizing the factors considered in choosing BLAZE-SHIELD Type DC/F as a replacement for the asbestos-fiber containing Type D (185-ITK). 
On the afternoon of April 24, $1970 \mathrm{Dr}$. Nicholson, -8ssistant to Dr. Selikoff at Mt. Sinai hospital, called me and advised the that a preliminary analysis of the material indicated that it was free of asbestos fibers except for possibly a few fibers that could have been picked up in the production line of the previous fype D material. Dr. Nicholson gave me a good report on the material and further 5 tated that 1 appeared to be much better in all respects to type D. I asked Dr. Nicholson if he would put this in writing to me: He sald he would and he further stated that in his opinion this material did. not present a health hazard due to asbestos, but of course we should maintain.tarpaulins during installation and thorough cleanup as you vould do with any miterial. He even said that it would not be necessary to comply with the-City regulations 1isted in Enclosure. 1 . For this material. - Dr. Nicholson did say. that he would do further analysis of. the material to check for its other constluent parts I recelved o letter dated Apr11 29,:1970 from Dr. Nichoison; Enclosure 11 hereto, regarding the examination of this materlal; which indicates the material is free from asbestos and excellent in other respects. However, Dr. Nicholson stated that "while no direct evidence exists IInking mineral wool flbers to disease 1ts extensive use has not been of sufflcient duration to say that there could not be such disease" "This sitenent merely allows Mt: Stral to keep the door open on research of this material.

I have also recelved other preliminary verbal reports on extensive previous research performed by independent outside agencles on any deleterious

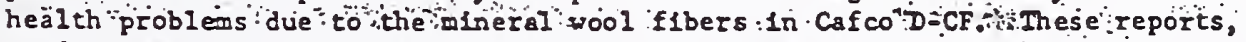
to date, are very encouraging in that they are all negative. When written reports are recelved, coples will be sent to all interested parties.

On April 27, $1970 \mathrm{Mr}$. Sorrell and Mr. Roby of AICOA requested my acquiescence to allow then to resume spraying and/or patching on floors 16 to' 19 with type D-CF to permit continued erection of aluminim colum covers. At this time all the required test reports indicated above had not been received by me and therefore I merely indicated my acquiescence" to their request to proceed with the understanding that this change in material for these floors or for any subsequent change for their materlal under their performance type contract vould not entall any additional costs to the Port Authority. Mr. Sorrell agreed to no cost for floors 16 to 19 but sald "let's not talk about the rest." I repeated my statement that there would be no consideration of additional costs under their performance type contract for changing tho materials. Enclosure 12 hereto 15 a copy bf my letter to ALCOA dated Appil 27, 1970, confirming the aforementioned discussion: and restating the Port Authority's position on no additional compensation for change in materlal, should ALCOA desire to do so. Enclosure 12 was reviewed by Tony Rajola and Bat Falvey of the Port Authority Law Department ppior to 1 ts issuance.

Enclosure 13 attached hereto is a copy of a letter from IICOA to Mr. Tozzol1, dated Apr11 23, 1970, requesting consideration of additional compensation of $\$ 173,000$ for thelr corporate decislonnto change the material to type D-CF. This letter was recelved in Mr. Tozzoli's office on April 27. Th1s is an attenpt by AICQA, $\because \mathrm{a}^{\mathrm{I}} \mathrm{I}$ discussed w1th Mr. Iozzol1, to see If i one letter they. can possibly. get consideration of $\$ 173,000$. I underd that ALCOA has made corporate decision to change this material on

Figure A-28 (Contd.). Port Authority memorandum summarizing the factors considered in choosing BLAZE-SHIELD Type DC/F as a replacement for the asbestos-fiber containing Type D (185-ITK). 
on their own, regardless of the fact whether they get additional compensation, because they do not want to get involved with the bad public relations that would be associated with their continuing the two towers with an asbestos material, even $1 f$ they were able to continue, by confóming to the regulations in Enclosure 1. It is interesting to note that since April 20 all jobs in Neu York City using asbestos material have been 6 topped, and to the best of my knowledge, $a s$ of this date have not resumed spraying. Enclosure 14 is a reply by Mr. Tozzoll to ALCOA dated May 8 substantlating the Port Authority's position as stated in Mr. Mont1?s letter to Mr. Sorrell of ALCOA; dated Apr11 27, 1970, in that the Port Authority does not accept any responsibility for any additionel cósts. ALCOA way incur due to their performance type contract. : On May $1 ; 1970$ Mr. Sorrell of ALCOA hand delivered to me a letter dated May 1,1970 requesting :Port Authority approval to use type D-CF in 1 leu of type $D$ for the entire project. This is Erclosure 15 bereto. Since on May 1:1970 I did not have in my hand sll complete reports isted above, I ariotated sald ALCOA letter and gave verbal approval to proceed with type D-CF only for Iorer. "A" floors 20 through 25 inclusive, pending recelpt of final reportis. Mr. Sorrell concurred with this and advised that by the time he reached the 25 th floor, maybe-all ieports would be in and we could give him an unqualified proceed for the entire two towers.

In the Interim Iishon: Realty \& Construction $C_{0}$, Inc. proceeded on a separate course of investigating other sources of spray materiai shich would be free from asbestos "Ericlosure 16 is a copy of a letter fról Iishran to AlCOA dated May 1, 1970, reporting on their investigations with W. R. Grace Company on a material called Monacote and coming to the concluslons that the $K$ factor of the material that they investigated did not meet the requirements and therefore concluded that Monacote would not be considered any further for application.

\section{Contract WTC 113.00}

Mario \& DIBono Plasterinc Company includes the spraying for Towers "A" \& "B" and below grade. This contract was awarded specifying asbestos spray materlals (Cafco type D) for floor trusses, columns and beams. Certain speciflc colums : In the elevator shafts are required, under the original contract; to be costed with Cafco Mark II hard finish coating due to the high" velocity of air caused by the elevators. Thus, if ve continued spraying with Cafco type $D$, the elevator shafts specified to be hard finlshed are already sealed and would not require sealant on top of same. All other areas which were to be sprayed with type $D$ asbestos material would require sealant.

During the week of April 13, 1970, I started discussions with the contractor regarding the possibllity. Of applying a sealant to all areas of both Towers "A" \& "B" and below grade which are not required to have Cafco Mark II hard finish coating... The contractor originally indicated that the golng price. for sealants per square foot would result in a total compensation of approxinately $\$ 605,000$ for sealing the entire project. The contractor

'icated, however, he was',wlling to icooperate. Using an estimated cost en to me by.Dr. Neuman of Tishran Realty-\& Construction Co., Inc. of

Figure A-28 (Contd.). Port Authority memorandum summarizing the factors considered in choosing BLAZE-SHIELD Type DC/F as a replacement for the asbestos-fiber containing Type D (185-ITK). 
$3 \frac{1}{2}$ cents per square foot as an equitable price, I was able to convince the contractor to agree at a lump sum proposal of $\$ 350,000$ for sealing all areas of Iowers "A" \& " $B$ " and below grade. The contractor also agreed that he would release the Port Authorlty of his existing claim for excessive rust scaling on steel, which is outside of the scope of his contract, and was estimated by his to sun $\$ 160,000$. My staff indlcated to me that based on ISM slips subolited to date that this ite of rewoving excessive rust could rus as high as $\$ 200,000$.

Subsequent to the above discussions, the.probleo of continued use of asbestos materlal arose; therefore, I proceeded to discuss costs of substititing type D-CF fireproofing and only sealing the areas that had previously been sprayed with the asbestos materlal, plus continued release of the claims for excessive risting of the -steel. The contractor's proposal' for this work, including changlng the materlal on the U. S. Customs Building and the Niortheast Buliding, amounted to $\$ 442,425$. . I. offered the contractor $\$ 296,500$. After further review with the contractor and a review of the nimbers. - $1_{\text {th }} \mathrm{Mr}$. Iozzol1, I made a flnal offer to the contractor of $\$ 320,000$. Tne contractor accepted same. This cost covers the following 1tems of work in "Towers: "A" \& "B" and below grade, the Norhteast Plaza Bullding and the U. S.: Custors Bullding:

1. From the times that we 8110 him to proceed to resume spray operations he will use asbestos. free Cafco type D-CF in alI spray work.

2. He wil apply a sealant to all areas that have previously been sprayed with asbestos materlal, except for those areas which recelve Cafco Mark II hard finish, in both Tower "A" and below grade, and should any be done in Tower "B", In that area also.

3. He releases the Port Authorlty by s1gned release from any further clain regarding removal of excessive rusting from the steel. Clause 13.03 subparagraph 2 on page 123 of Contract WTC 113.00 must be amended or deleted so that no further recourse to sald statenents can be made by the contractor.

RM: Id

R. M. Mont1

Construction Manager

The World Trade Center

Figure A-28 (Contd.). Port Authority memorandum summarizing the factors considered in choosing BLAZE-SHIELD Type DC/F as a replacement for the asbestos-fiber containing Type D (185-ITK). 

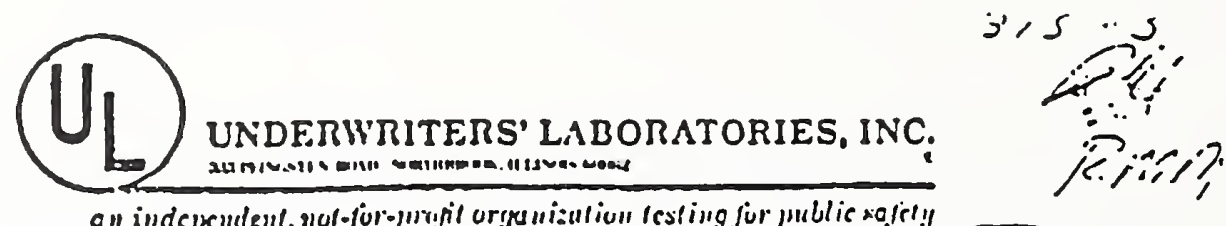

$$
\therefore \text { PII } 24,1970
$$

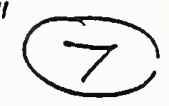

1.3749

Port of liew York Authority

318 th hvenue, d:000 300

liew York, : Eew York

$$
\begin{aligned}
& \text { f.ttentson: his. di. Lontd, Corstruction h.snoger } \\
& \text { iorld Irade Center. } \\
& \text { Eubject: I'sro diec1stance livalustion of losco CF } \\
& \text { Type rij" va carco type ary" }
\end{aligned}
$$

Gentlomen:

Conf1sming our telephone conversation of ipril 23, the inbject inveotigition io npproximitely 80 pes ccnt conficled. :1I of ollo teet results to date indleate that cafco C! Tyge isn sfrrjes sibns is nt lenst ou cood es Carco Type mo" in recard

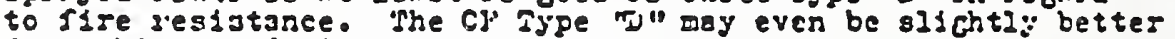
fros thdo stendpoint.

Al thouth ous test results to date are not 100 per cent conclusive, the Indications are that Casco CF Type ijon will be Afproved for all of the $+100 \mathrm{r}$ and Celling Destaris Sor which Carco Type "D" 18 currentiy Ijsted, particulariy those incorporatine a I to I bicnd of celluler and sluted steel decis units and normal weilet concrete.

If you should hove any surther questions regarding this lavestlgation, wo would be happy to try to anewer them for you 80 long a ve have the perwisajon of United states lineral Products Compeny to release our tcoting information.

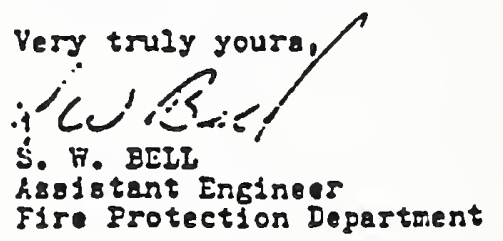

Sii'B/KIr

ec: Hr. Frank K. StumpS

Figure A-29. Correspondence indicating BLAZE-SHIELD Type DC/F as a suitable replacement for Type $D(180-I T K)$. 
SKILLING, HELLE, CHRISTIANSEN, ROBERTSON Consulting Structural and Civil Engineers · 230 Park Avenue, New York, N. Y. 10017 - Nit. 9-8874 John B.Skilling - Helge J. Hellic - John V.Christiansen - Leslie E. R:bertson

April 1, 1975

File: WTC-Fire

Mr. Malcolm P. Levy

Chief, Planning and Construction

Port Authority of New York \& New Jersey

1 World Trade Center - 63rd floor

New York, New York 10048

Dear.Mal:

Attached to this letter is a report dealing with the fire safety of specilic facets of the twin towers of the World Trade Center.

The report deals with the general topic of the fire resistivity of the flow syster. Questions of structural integrity and of heat transmission through: the floor are examined. The report is intended to provide background to the reader as to the develonment nf the fire-recistive standards fui iviiu ilda Center and looks also at the adequacy of the exising systens.

In preparing these documents, SHCR holds itself out as a reporter of facts-as they are presented in communications gleaned from the files of. Port Authority, ERS, MA and SHCR. It does not purport to have any speciai exper "ist not comenonly held by other structural engineers. No new literature search or research was accomplished for purposes of this report.

Finally, the data contained in the report is based on logic and analysis and, as such, is not definitive or conclusive. The orly way to assure the existence of the fire safety of flocr systems is to be found through the participation cf a fire safety engineer and/or fire testing.

Please feel free to call on us should you have any questions.

Very trily yours,

SKILLING, IELLE, CHRISTIANSEN, ROBERTSON

Leslie E. Robertson

Enclosure

LER/amin

:.c. Mr. Julian Roth, Elis (Encl) Mr. M. lamasaki, ivrA (Encl)

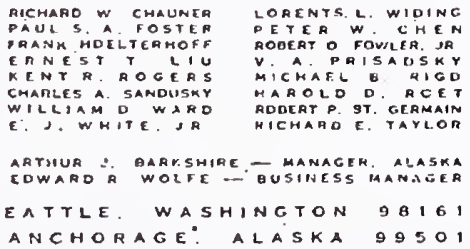

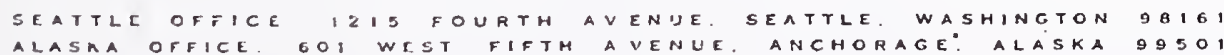

Figure A-30. Excerpts from April 1, 1975 post-fire report prepared by Skilling, Helle, Christiansen, Robertson (3-P). 


\section{MANUFACTURERS CATALOGLES}

The fireproofing contract was accepted on the basis of the Mario and DiBono Plastering Co., Inc. proposal dated March 17, 1969. While SHCR is not privy to the contents of that proposal, it is likely that it contains only finanical and catalogue information.

The only Cafco catalogue available to SHCR (excluding current issues of 1975) is the one supplied by Mr. Monti to Mr. Levy in Septenber 20, 1967 (see -appendix). The catalogue cites ULI \#R3749-6, ULI R3789-2 and ULI \#R3749-13 for the spray fireproofing of beams. From the catalogue one can determine that:

(1) The product has been subject to extensive ULI testing; and

(2) for "beams, girders and spandrels", a thiclsess of $1 / 2$ inch of Blaze-Shicld Typo $D$ (the product used in World Trade Center) proviues a 4 hour rating.

The catalogue does not report on fireproofing of trusses. 


\section{LACLEDE COMPOSITE FI.OOR TRUSSES}

\section{FIRE RESISTIVITY - TOP CHORD}

\section{Introduction}

The Laclede trusses used in the construction of The World Irade Center are a standard product manufactured from specially-rolled angles used in conjunction with round-bar webs. To achieve composite action the webs extend into the concrete $\mathrm{slab}$ so as to effect the required shear transfer.

In The World Trade Center the top chords are not spray fireproofed for selected areas of the work. Specifically, for the most of the one-way span areas directly out from the service core, the top chords are not always spray fireproofed. Also bridging trusses are not spray fireproofed.

This paper addresses itself to reasons of structural engineering às to why spray fireproofing may not be required.

\section{Structural System - Top Chord}

First, a discussion of the role of the steel top chord in the overall structural systen:

1) Construction Period:

a) Acting in conjunction with the bottom chord and the web, the steel top chord completes the trusswork providing primary structural support for the concrete slab unitil such time as the slab has achieved design strength.

Fireproofing of the steel top chord is not required for reasons of construction loading.

b) Acting as a beam, spanning from truss panel point to truss nanel point, the top chord supports a small amount of concrete unitil such time as the concrete has attained design strength.

Fireproofing of the steel top chord is not required for reasons of construction loading.

2) Supporting Gravity Loads:

a) Once concrete strength has been achieved, the capahilities cited under 1) are modified. The concrete slab becomes the dominant element of the top chord. So long as the shear knuckle is maincained, the structural integrity of the steel top chord is not required.

$-13-$

SKILLING. HELLE, CHRISTIANSEN. ROBERTSON

Figure A-30 (Contd.). Excerpts from April, 11975 post-fire report prepared by Skilling, Helle, Christiansen, Robertson (3-P). 
Since the top chord may be cut without loss of structural integrity, we concur that fireproofing of the steel top chord is not required for this purpose.

b) Where a given shear knuckle is not adequate to transfer panel point loads directly into the slab, then an increment of the load must be taken down the steel top chord to the next knuckle. This condition exists only in the corner, two-way portion of the floor. We concur that fireproofing of the steel top chord is required and is provided for this purpose.

3) Assisting in Diaphragm Strength:

a) The concrete slab, with its mesh and bar reinforcing provides for diaphragm strength within the building: As structure sway under wind load increases, the need for diaphragm strength increases. Structural steel top chords provide a kind of reinforcing steel and add to diaphragm strength. While diaphragn strength is not required by Code, we know it to be essential to the proper behavior of the structural system. We do not believe it to be proper to design for the combined circumstance of an extreme wind and an extreme fire with the same factor of safety as that associated with the single event alone.

Since the strutiuioi sitexi tup churi provides oniy a smail increment in the diaphragin strength, we concur that fireproofing may be omitted for this purpose.

Structural System - Bridging

The bridging system is used only to provide for the reduction in floor "tremor" and to reduce the effects of differential deflections associated with heavy gravity loads.

Since it is not required as a part of the structural system, we concur that fireproofing may be omitted for these members.

\section{Conclusions}

Fireproofing of the top chords of floor trusses is required and is provided in the two-way portions of the floor systems.

A logical analysis indicates that fireproofing of the structural steel ton chord and of the bridging is not required so long as the risk of the joint occurrence of an extreme value wind storm and a fire is accepted. Over mich of the two buildings, fireproofing has been provided.

Figure A-30 (Contd.). Excerpts from April 1, 1975 post-fire report prepared by Skilling, Helle, Christiansen, Robertson (3-P). 


\section{PERFORMANCE IN SERVICE}

The fire of February, while reported in the press to have been very hot, did not damage a single primary, fireproofed element. Some top chord members (not needed for structural integrity, some bridging members (used to reduce. floor tremor and the like) and some deck support angles (used only as construction devices) were buckled in the fire--all were unfireproofed steel.

The SHCR report of fire damage, including all repairs, is attached in the appendix.

As requeste by Port Authority Engineering Department and by SHCR, shores were placed in the vicinity of repairwork. This was done, not because of concern for damaged structure, but as a matter of prudence to avoid the accidental destruction of needed structure by over-zealous steel workers.

It is likely that this fire did not provide the ultimate test of fire-resistivity. More severe fires will likely strike the project. However, since only non-essential, non-fireproofed elements of the floor assenbly were damaged, some optimism can be expressed.

Figure A-30 (Contd.). Excerpts from April, 11975 post-fire report prepared by Skilling, Helle, Christiansen, Robertson (3-P). 
March 7, 2003

John L. Gross, Ph.D., P.E.

Leader, Structures Group

National Institute of Standards and Technology

100 Bureau Drive, Stop 8611

Gaithersburg, MD 20899-8611

Re: Confidential and Pre-decisional Communication - Questions on Fire Resistance of the WTC Floor System

Dear John:

Following are the Port Authority (PA) responses to your questions:

Questions to the Port Authority of New York \& New Jersey, February 26, 2003

1. In a letter from ERS (Julian Roth) to PoNYA (Malcolm Levy) dated December 14,1965 , it had apparently been decided that the fire protection of the WTC floor system would involve "the use of a maximum thickness of one inch spray-on fireproofing material around the individual components of the floor trusses." It was further stated that "one inch material meets the 3-hour requirements of both the new code (New York City Building Code under revision in 1965 and ultimately published in 1968) and Underwriter's (Underwriter Laboratories, Inc.) using previously approved assemblies tested by the 'load criteria' method but ignoring the more stringent time-temperaturerate-of-rise criteria which is an alternate testing procedure not required by the new code or by Underwriter's, and which we do not consider necessary."

In a follow-up letter from ERS (Julian Roth) to PoNYA (Malcolm Levy) dated December 22, 1965, the PA is advised that "advance information from manufacturers indicates that if the truss were required to be fire-tested, then two inches of material would be required for light angle members."

In a letter from ERS (Harry Harman) to PoNYA (Malcolm Levy) dated July 25, 1966 , it is stated "Obviously, with so many penetrations of the floor system [4" concrete slab over a metal deck] the fire rating of the floor construction is of an indeterminate value unless tested."

1) Were tests performed on the fire resistance of the composite floor system during the design or construction phase of the project?

PA Response: There are no test records in our files.

Figure A-31. Response from Port Authority regarding the applied thermal insulation (678-P). 
2. In a letter dated October 30,1969 , from PoNYA (Robert Linn) to Mario \& DiBono Plastering Co., Inc, the contractor is directed as follows: "bar joists requiring spray-on fireproofing are to have $1 / 2$ " covering of 'Cafco'."

\section{2) Was $\frac{1}{2}$ inch of Cafco Type-D fireproofing specified for the floor trusses requiring spray-on fireproofing?}

PA Response: Thickness was not specified on the drawings. PA is still trying to locate the original specifications, which NIST is aware of. The letters you reference and quote in your questions are snapshots in time. The culmination of these written exchanges led to what was finally called for in the original specifications that were part of the contract documents. In the absence of the original specifications, we must rely on the actual measured thickness of the fireproofing. Over the years, this has been documented to be a nominal $3 / 4$ inches.

It should be kept in mind that the fireproofing determinations were made in the context of buildings that were to be constructed without a sprinkler system. Following the enactment of Local Law 5 in New York City, a complete sprinkler system was added to the towers over a period of years, thus reducing the overall reliance on the truss joist fireproofing for fire protection.

3. In a report by SHCR prepared for the PANYNJ dealing with "the fire safety of specific facets of the twin towers of the World Trade Center" following the 1975 fire, it is stated that the 4 inch slab exceeds the commonly used (and therefore accepted by the NYC Building Dept.) 3-1/4 inch slab on metal deck without fireproofing.

\section{3) Was the underside of the floor slab (metal deck) fireproofed?}

\section{PA Response: No.}

4. In this same report by SHCR prepared for the PANYNJ, it is stated that, fireproofing of the top chord of the floor trusses is not necessary (except for the two-way portion of the floor). Additionally, it is stated that fireproofing of the bridging system is not required.

4a) In the one-way portions of the floor system, were the top chords of the composite floor trusses fireproofed?

PA Response: Yes.

4b) In the one-way portions of the floor system, were the bridging trusses fireproofed?

Figure A-31 (Contd.). Response from Port Authority regarding the applied thermal insulation. 


\section{PA Response: Yes.}

5. It is our understanding that initially the spray-on fireproofing contained asbestos. We also understand that, at some point, asbestos was not permitted and a Cafco product that contained mineral wool instead of asbestos was substituted.

5a) Is the situation stated here correct?

PA Response: Yes.

If so,

5b) What floors of which towers were fireproofed with the asbestoscontaining product?

PA Response: For the tower floor system, only steel trusses in Zone $1\left(44^{\text {th }}\right.$ floor and below) in Tower 1 were fireproofed with asbestos containing product.

5c) Was the asbestos-containing "fireproofing" removed?

\section{PA Response: Yes.}

I hope these responses are helpful. If you have any further questions please send them to us.

Sincerely,

$\mathbf{o} / \mathbf{s} / \mathbf{b}$

Joseph M. Englot, P.E.

Asst. Chief Engineer/Design

CC: F. Lombardi

Figure A-31 (Contd.). Response from Port Authority regarding the applied thermal insulation. 
$\begin{array}{ll}\text { O: } & \text { B. Weinstlen. Project Managet (TRCC) } \\ \text { FROM: } & \text { D. L. Brown }\end{array}$

DATE: March 25, 1970

SUEJECT: THE HORLD TRADE CENTER CONTRACT 113.00 - MARIO DIBONO PLASTERING CO.

REFERENCE:

SFRAY ON FIREPROOFINC - TOWER A \& B - INSPECTION

COPIES: P. Baldurz1, R. IInn, M. Levy, R. Mont1, I. Calabreae, F. Werneke

\begin{abstract}
Durling a routine Inapection trip on March 19, 1970, I had occosion to diecus ulth Frank Tartacclle, superintendent, the otetur of work under the subject contract. In the course of this conversation I retinded Frank Tartanclla that Morlo DiBono st111 had to complete the core columna sproy-on flreproofing of Tower A core colums up to the $28 \mathrm{th}$ floor as these columna are unsat 1 sfactory having only $\frac{1}{2}^{\prime \prime}$ to $3 / 4^{\prime \prime}$ of flrefroofing na: the $13 / 16$ inches required. He stated that I ohould direct this watter tolifs offlce as he did not plan to do any further work on these werbers. Please ogain reulnd the contractor that this work is not ecceptable to this offlce, also that they are to fireproof the under side of the electrical header ducto.
\end{abstract}

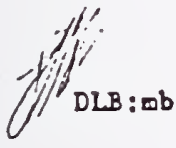

D. L. Brom

Supervising Englneer

The World Trade Center

Figure A-32. Correspondence indicating that thickness of thermal insulation was being checked during construction (256-P). 


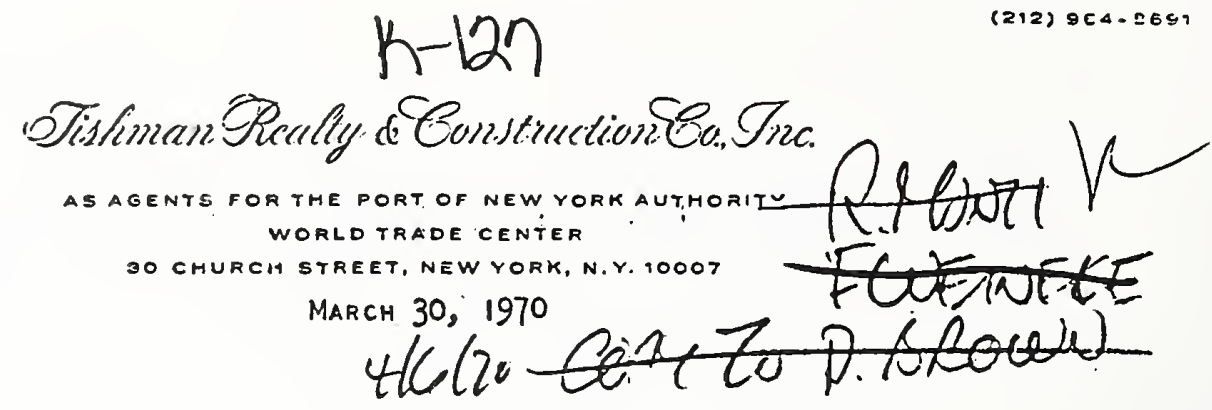

MARIO \& DiBONO PLASTERING

136 LIBERTY STREET

NEW YORK, NEW.YORK. 10006

Attention: Mr. F. TARtamello

RE: $\begin{aligned} & \text { WTC } / 113.00 \\ & \text { INSUFFICIENT THICKNESS }\end{aligned}$

\section{GENTLEMEN:}

REFERENCE IS MADE TO OUR LETTER DATED JANUARY 9, 1970

WITH FOLLOW-UP COPIES SENT DATED JANUARY 19TH AND FEBRUARY 6TH, IN ADDITION TO PHONE CALLS ON THE SUBJECT, ADVISING YOU OF THE INSUFFICIENT THICKNESS OF SPRAY-ON FIREPROOF ING ON CORE COLUMNS.

WE ARE NOW IN RECEIPT OF A COMAIUNICATION FROM THE PORT OF NEW YORK AUTHORITY REITERATING THE SAME ITEM.

BE ADVISED THAT TO CONTINUE TO IGNORE THESE COMMUNICATIONS WILL REQUIRE US TO ADVISE THE PORT OF NEW YORK AUTHORITY TO SEEK COMPENSATION AMOUNTS FROH YOUR CONTRACT PRICE, COMMENSURATE WITH THE WORK WHICH IS INCOMPLETE PLUS ANY COSTS INVOLVED IN REMOVING AND REPLACING WORK BY OTHERS WHICH MAY, DUE TO THIS LONG DELAY, COVER YOUR WORK.

\section{VERY TRULY YOURS,}

TISHMAN REALTY \& CONSTRUCTION CO., INC.

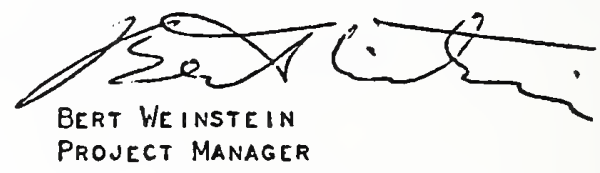

BW/BNS

CC: Messrs. Mont 1, Werneke, P/A

Figure A-32 (Contd.). Correspondence indicating that thickness of thermal insulation was being checked during construction (256-P). 


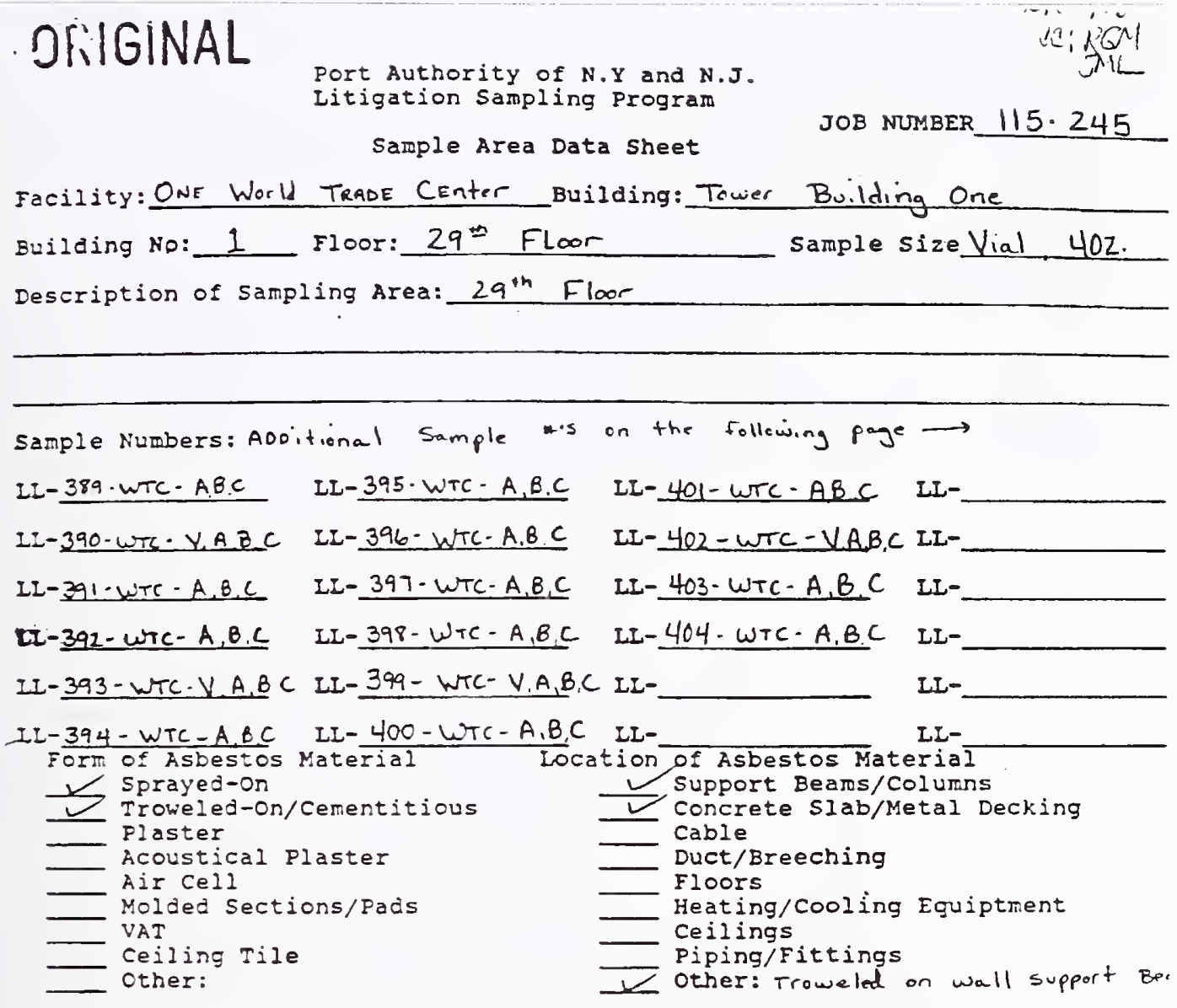

comments: (Indicate any unique characteristics of the material which may help identify the manufacturer.)

Samplo taken by: Frantz Dambreville, Frank Pergela__ Date: 03/12/90. Persons Present Frantz Dambreville..Frank Pergola Charles koadakjio

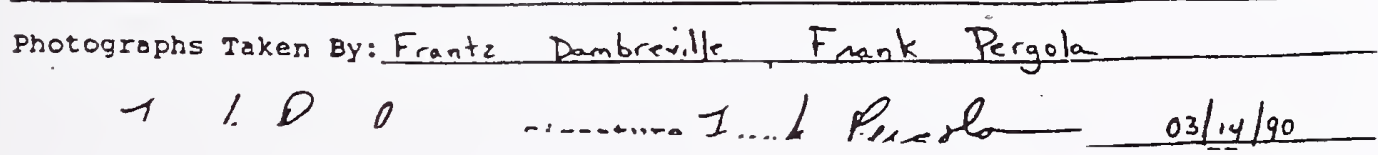

Figure A-33. Example of "Sample Area Data Sheet" used to record condition of sprayed thermal insulation (212 ITK). 


\section{GRIGINAL}

Job Number $115 \cdot 245$

COMMENTS

South West quadrant $\rightarrow$ fluffy spray-on fircprofing coating

the suppert Beams. joists, and deck above the criling. The thicker ef the material on the beams and joists was consistently about $1 / 2 "$. Regarding the deck it ...ranged from very sparce in areas to $1 / 4$ " in other areas. The Areas we sampled were coated with a Light green.encapsulant.

NorthWest guadrant $\rightarrow$ Fiuffy spray-on. Firsproefing. The Beams. and joists were coated with about $1 / 2^{\prime \prime}$ of material. the deck ranged from $/ / 4$ " to Barely nathing. this section was also coated with a Light green encapsilant.

North East quadrant $\longrightarrow$ fluffy Spray-on fire profing the Beams and jeists were coated with $F k^{\prime \prime}$ of material the deck was coated with $Q \% "$ " of material in this sectien. the light green encapsulant was prestnt in' this area. South East quadrant $\longrightarrow$ fluffy spray-on fire proofing. Beams and Joists were coated with $e y_{2}$ " of material the deck was soated_with 1/4" of material. Sample area was coated with. encapsulant. One Sample froma Vertical support Beam on the outermost wall, was. -grayish cementitious material... e $1 / 4 "$ thict.

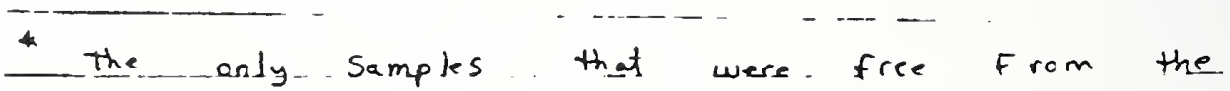
encapsulant ... werc... thise taken from the top. - of the support. Beam. ( $\left.\begin{array}{l}\text { LL }-395-W T C \\ L L-397-W T C\end{array}\right)$

Figure A-33 (Contd.). Example of "Sample Area Data Sheet" used to record condition of sprayed thermal insulation (212 ITK). 


\title{
THE PORT AUTHORTY OF NEW YORK \& NEW JERSEY
}

\author{
MEM OR A N D U M
}

TO: $\quad$ Peter Sweeney, Engineering Program Manager

FROM: Joseph M. Englot

DATE: $\quad$ August 18, 1995

SUBJECT: STEEL JOIST SPRAY-ON REQUIREMENTS FOR NEW CONSTRUCTION IN WORLD TRADE CENTER TOWERS

COPY TO: R Davidson, J. Lin, F. Lombardi, E. Ramabhushanam, O. Suros

Attached is a white paper summarizing a study to determine the spray-on thickness required to achieve the required two hour rating for steel joist trusses in the towers of the World Trade Center. This is intended for any new construction for which the Engineering Department is engineer-of-record. It concludes that $1-1 / 2$ inches of spray-on mineral fiber is sufficient when applied directly to chords and web members.

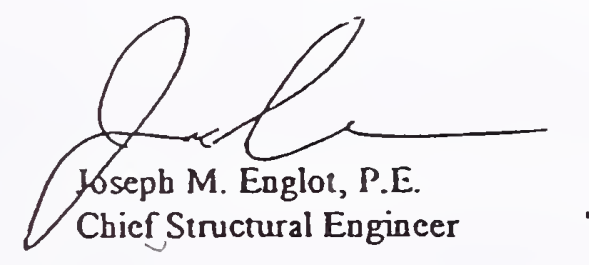

JME:ng

Attachment

Figure A-34. Results of 1995 study of thermal insulation for floor trusses during new construction when tenants vacated spaces (3-P). 


\section{FIREPROOFING REQUIREMENTS FOR WORLD TRADE CENTER TENANT FLOOR JOIST CONSTRUCTION THAT REOUIRES INSTALLATION DUE TO ASBESTOS REMOVAL OR LOCAL REMOVAL TO FACIITATE CONSTRUCTION}

This serves as a basis for determining the minimum requirements for installing sprayed mineral fiber fireproofing on the steel floor joist trusses supporting typical tenant floor areas within the towers of the World Trade Center. Its purpose is to establish requirements for new construction that meet local codes and ordinances.

The technical basis for the fireproofing requirement is Design No. G805 in the Fire Resistance Directory (BXRH) Published by Underwriters Laboratories. This UL design is based upon fire tests conducted as per ASTM E-1 19 which is a basic Reference Standard (No. RSS-2) in the New York City Building Code for structural members and assemblies. Reference standard RS5IF, "Methods of Analytical Determination of Fire Resistance of Load Bearing Steel Truss Assemblies", is not applied since it is intended for large trusses (i.e., deep trusses), too large to fir in the fire test compartments. Since there is a wealth of fire tests on steel joists which approximate the ones used in the World Trade Center, joist test results are interpreted to arrive at an appropriate spray-on protection thickness.

There are various parameters in the G805 design which have to be interpreted or approximated in the case of World Trade Center construction. Each parameter will be discussed individually.

G805: 48 inch and 66 inch spacing.

\section{Joist Spacing}

Actual: Double joist system - average joist spacing is 40 inches (spacing alternates between 8 inches and 72 inches). Conservatively, use values for 66 inches since actual spacing is not uniform.

Metal Deck Protection

G805: Values tabulated with or without spray-on applied to bottom of metal deck.

Actual: Use values without spray-on applied to deck. Spray-on is only used in the World Trade Center below trench headers. Follow design values without protected deck.

\section{Concrete Tepping}

G805: Vahes tabulated for lightweight concrete, 117 pcf unit weight, 3500 psi compressive strength and a thickness of topping over the metal deck of 3-7/8 inches to achieve a 2 hour rat ing.

Actual; Lightweight concrete, 110 pcf unit weight, 3000 psi compressive surength and a thickness of topping over the metal deck of 4 inches. The actual is judged equivalent to the G805 design for 2 hour rating.

Wire Mcsh Location

G805: Provides a thickness of concrete from the top plane of the metal deck to the wire fabric of 1-i $1 / 4$ inches for a 2 hour rating with $1-5 / 16$ inch deep steel form unit.

Actual: Has two layers of wire mesh. Thickness from top plane of $1-1 / 2$ inch melal deck to centcr of wire mesh layers is 1.22 inches. Where rcbar is used instead of wire mesh, $1-1 / 4$ incli unickness

Figure A-34 (Contd.). Results of 1995 study of thermal insulation for floor trusses during new construction when tenants vacated spaces (3-P). 
is provided. This is judged to be equivalent to the G805 design for 2 hour rating.

\section{Steel Joist Parameters}

G805: Composite steel joist with a minimum area of steel (double angles) for top and bottom chords (each) of $0.708 \mathrm{sq}$. inches and minimum steel area of web members of $0.442 \mathrm{sq}$. inches in conjunction with the "thinner" layer of spray-on (1-1/2 inches) applied directly to the joist without lath.

Actual: Mrnimum area of chords is $0.813 \mathrm{sq}$. inches and the minimum area of web steel is $0.665 \mathrm{sq}$. inches with composite behavior. 1-1/2 inches applied directly to the joist steel yields a two hour assembly rating whether restrained or unrestrained.

Ceiling

G805: A ceiling is not relied upon for fire protection in the design.

Actual: All occupied areas in the World Trade Center have ceilings and they will add to the fire rating of the floor system, however, a stringent study of what rating values could be achieved for existing types of ceilings is beyond the scope of this study.

\section{Conclusion}

It is conchuded that a two hour fire rating for the steel floor joist trusses can be achieved by applying a 1-1/2 inch thickness of spray-on mineral fiber fire protection material directly to the steel truss chords and webs. The value of the ceiling as a fire protection element is not relied upon to achieve this fire rating.

Attachments:

1. Excerpted pages from N.Y.C. Building Code.

2. G805 Design from U.L. Directory

Figure A-34 (Contd.). Results of 1995 study of thermal insulation for floor trusses during new construction when tenants vacated spaces (3-P). 
Design No. G805

Restrained Assembly Ratings - 1, 1.1/2, 2 or $3 \mathrm{Hr}$ (See Items 1,4 and 5)

Unrestrained Assembly Ratings - 1, 1-1/2 or $2 \mathrm{Hr}$ (See Items 1,4 and 5)

Unrestrained Beam Ratings - 1, 1-1/2 or $2 \mathrm{Hr}$ (See Item 5 )
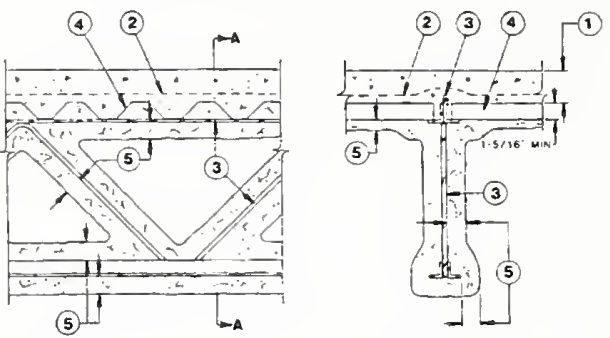

SECTIONA-A

1. Normal-Weight Or Lightweight Aggregate Concrete - Normal weight concrete carbonate or siliceous aggregate, $150 \mathrm{pc}$ unit weight, 3500 psi compressive strength, vibrated. Lightweight concrete, expanded shale, clay or slate aggregate by rotary-kiln method, $117 \mathrm{pcf}$ unit weight 3500 psi compressive strength, vibrated, $2 \mathrm{oz}$ air entrainment per bag of cement. The thickness of concrete topping over the top plane of the steel deck varies according to the spacing of the structural steel members, the hourly ratings and whether or not the steel deck is
protected. When no Spray-Applied Fire Resistive. Materials protection is used on the steel deck, the thickness of concrete topping over the top plane of the steel deck shall be as specified in the following table:

\begin{tabular}{|c|c|c|}
\hline $\begin{array}{l}\text { Restrained or } \\
\text { Unrestrained } \\
\text { Assembly }\end{array}$ & \multicolumn{2}{|c|}{$\begin{array}{l}\text { Nomal Weight } \\
\text { Concrete } \\
\text { Topping Thk In }\end{array}$} \\
\hline Rating Ifr & joist & Joist \\
\hline & $\begin{array}{c}\text { Spacing } \\
48 \mathrm{In} .\end{array}$ & $\begin{array}{c}\text { Spacing } \\
6 \text { oln. }\end{array}$ \\
\hline & OCMax & OCMax \\
\hline$h$ & $3-1 / 8$ & $3-7 / 8$ \\
\hline $1-1 / 2 h$ & $3-7 / 8$ & $3-7 / 8$ \\
\hline $2 \mathrm{~h}$ & $4-5 / 8$ & $4-5 / 8$ \\
\hline
\end{tabular}

\begin{tabular}{|c|c|}
\hline \multicolumn{2}{|c|}{$\begin{array}{l}\text { Lightweighl } \\
\text { Concrete }\end{array}$} \\
\hline Joisl & Joist \\
\hline $\begin{array}{c}\text { Spacing } \\
48 \mathrm{In} .\end{array}$ & $\begin{array}{c}\text { Spacing } \\
\text { 6ot In. }\end{array}$ \\
\hline OCMax & $\propto \subset \operatorname{Max}$ \\
\hline $2-3 / 8$ & $3-7 / 8$ \\
\hline $2-7 / 8$ & $3-7 / 8$ \\
\hline $3-3 / 8$ & $37 / 8$ \\
\hline
\end{tabular}

Min Thk of Concrete From Top Plane of Steet Deck to Bottom of Reinforcernent In 1
$1-1 / 8$
$1-1 / 4$ $1-1 / 4$

When the steel deck is protected with the Spray-Applied Fire Resistive Materials, the min thickness of normal weight or lightweight concrete topping above the top plane of the steel deck, and the min thickness of concrete from the top plane of steel deck to the wire fabric, shall be as follows:

\begin{tabular}{lccc} 
Restrained or & \multicolumn{2}{c}{ Min Concrete Topping } & $\begin{array}{c}\text { Min Thk of } \\
\text { Unrestrained }\end{array}$ \\
Unk In & \multicolumn{2}{c}{ Thk Inte From Top } \\
Assembly & Joist Spacing & Joist Spacing & Plane of Steel \\
Rating Hr & 48 In. OC & 66 In. OC & Deck lo Bottom \\
& Max & Max & of Reinforcement In. \\
$2 \mathrm{~h}$ or less & $2 \cdot 3 / 8$ & $2-3 / 8$ & $1-1 / 8$ \\
$3 \mathrm{~h}$ & $2-3 / 8$ & $3-7 / 8$ & $1-1 / 4$
\end{tabular}

2. Welded Wire Fabric/Reinforcing Bars - As required, to develop the structural capacity of the floor in accordance with the applicable $\mathrm{ACl}$ specifications.

3. Structural Steel Members* - Composite joists with vertical leg of top chord angles embedded in concrete slab. Min area of steel angles for the top and bottom chord members shall be $0.708 \mathrm{sq}$ in. each, and the min area of web members shall be $0.442 \mathrm{sq}$ in. when the sprayed material is applied directly to the joists. Min area of steel angles for the top and bottom chord members may be reduced to $0.560 \mathrm{sq}$ in. each, and the min area of web members to $0.299 \mathrm{sq}$ in. when the joists are protected with greater thickness of Spray-Applied Fire Resistive Materials with or without the metal lath or the nonmetallic fabric, as covered in the Table under ltem 5 . Max joist spacing is 48 or 66 in. O. C. depending on the thickness and type of concrete topping, the hourly ratings, and the thickness of Spray-Applied Fire Resistive Materials applied to the steel deck (see ltems 1 and 5)

VESCOM STRUCTURAL SYSTEMS INC - Type V.

3A. Steel Joists - (Not Shown) - As alternate to ltem 3, Min size $16 \mathrm{~K} 6$ or heavier $K$-Series joist with min $3 / 4$ in. diam or larger cross sectional area web members.

3B. Horizontal Bridging - (Not Shown) - Min $1-1 / 4$ by $1-1 / 4$ by $1 / 8$ in thick steel angles for use with steel joists (Item $3 \mathrm{~A}$ ). Size and spacing per Steel Joist lnstitute specifications. Welded to top and bottom chords of each joist. Min thickness of Spray-Applied Fire Resistive Materials on bridging angles is $1-1 / 2$ in.

4. Steel Floor and Form Units - For max 2 h ratings, nom $1-5 / 16$ in. deep uncoated or galv corrugated steel form units. For $3 \mathrm{~h}$ ratings, composite or noncomposite, $\min 1-1 / 2$ in. deep, 22 gauge uncoated or galv fluted stcel foor units. The steel floor and form units are not considered in calculating the load carrying capacity of the floor.

5. Spray-Applied Fire Resistive Materials* - All surfaces to which material is applied must be free of dirt, loose scale and oil before spraying. Applied by mixing with water and spraying in more than one coat to the required thickness on the joists and the steel form units as tabulated below:

\begin{tabular}{|c|c|c|c|c|c|c|c|}
\hline \multirow{3}{*}{$\begin{array}{l}\text { Min Area } \\
\text { of loist } \\
\text { Chord }\end{array}$} & \multirow{3}{*}{$\begin{array}{l}\text { Min Area } \\
\text { of Joist } \\
\text { Web }\end{array}$} & \multicolumn{2}{|c|}{$\begin{array}{l}\text { Thk of Spray Applied } \\
\text { Fire Resistive Mil } \\
\text { In. on Steel Deck }\end{array}$} & \multirow[b]{2}{*}{$\begin{array}{l}\text { on } \\
\text { joist }\end{array}$} & \multirow{3}{*}{$\begin{array}{l}\text { Restrained } \\
\text { Assembly }\end{array}$} & & \multirow{3}{*}{$\begin{array}{l}\text { Unrestrained } \\
\text { Beam }\end{array}$} \\
\hline & & $\begin{array}{l}\text { Normal } \\
\text { Weight }\end{array}$ & $\begin{array}{l}\text { Lighlweighl } \\
\text { Concrete }\end{array}$ & & & $\begin{array}{l}\text { Hi Rating } \\
\text { Unrestrained }\end{array}$ & \\
\hline & & $\begin{array}{l}\text { Concrete } \\
\text { Topping }\end{array}$ & Topping & & & $\begin{array}{l}\text { Assembly } \\
\text { Raling Hr }\end{array}$ & \\
\hline & $\begin{array}{l}S q \ln . \\
0.44 ?\end{array}$ & $\begin{array}{c}\text { Topping } \\
3 / 8\end{array}$ & - & $1 \cdot 1 / 2$ & $\begin{array}{c}\text { Rating Hit } \\
1\end{array}$ & 1 & $\begin{array}{c}\text { Kaling Hir } \\
1\end{array}$ \\
\hline 0.708 & 0.442 & $3 / 4^{*}$ & $3 / 8$ & $1 \cdot 1 / 2$ & 2 & $2^{*}$ & $2^{\circ}$ \\
\hline 0.708 & 0442 & $1-1 / 4$ & 1 & $1.1 / 2$ & 3 & 2 & 2 \\
\hline 0.560 & 0.299 & $3 / 8$ & - & $2 \cdot 1 / 2^{*}$ & 1 & 1 & 1 \\
\hline 0.560 & 0.299 & $3 / 4$ & $3 / 8$ & $2 \cdot 1 / 2^{* *}$ & 2 & 2 & 2 \\
\hline
\end{tabular}

Min avg and min ind density of $13 / 11$ pef, respectively for Types 11 or DC/F $\mathrm{Min}$ avg and min ind densities of 22 and $19 \mathrm{pcf}$, respectively, for Type HP. For method of density determination, see Design Information Section, Sprayed Materials.

"The $3 / 4$ in. thickness may be reduced to $1 / 2$ in. when (a) the joist spacing does not exceed 48 in. $O$. C. or (b) the Unrestrained Assembly and Beam ratings are reduced from 2 to $1-1 / 2 \mathrm{~h}$.

**The 2-1/2 in. thickness of Spray-Applied Fire Resistive Materials shown may be reduced to $2 \mathrm{in}$. when the metal lath or the nonmetallic fabric mesh is used ISOLATEK INTERNATIONAL - Type D-C/F, HP or Type II, Type EBS or Type X adhesive/sealer optional

6. Metal Lath - (Optional, not shown) - Metal lath may be used to facilitate the spray application of Spray-Applied Fire Resistive Materials to steel bar joists. The diamond mesh, $3 / 8$ in. expanded steel lath, 1.7 to $3.4 \mathrm{lbs}$ per sq yd should be secured to one side of each steel joist with 18 SWG galv steel wire at joist web and bottom chord members, spaced 15 in. O. C. max. When used, the metal lath is to be fully cov. ered with Spray-Applied Fire Resistive Materials with no min thickness requirements.

7. Non-Metallic Fabric Mesh - (Optional, not shown) - As an alternate to metal lath, glass fiber fabric mesh - weighing approximately $2.5 \mathrm{oz}$ per sq yd, polypropylene fabric mesh - weighing approximately 1.25 oz per sq yd, or equivalent, may be used to facilitate the spray application. The mesh should be secured to each joist web member and/or the chords to hold the mesh and the Spray-Applied Fire Resistive Materials material in place during application. One method for attaching the mesh is by embedding it in $1 / 4$ in. long beads of hot melted glue spaced a max of 12 in. $O$. C. along the top chord of the bar joist. Another method is by using 1-1/4 in. long by $1 / 2 \mathrm{in}$. wide halrpin clips formed from 18 SWG or heavier steel wire.

* Bearing the UL Classification Mark

Figure A-35. Underwriters Laboratories Design No. G805 used as the basis for Port Authority determination of retrofit thermal insulation thickness for floor trusses (213-1). 


\section{THE PORT AUTHORITY OF NEW YORK AND NEW JERSEY}

BUCKSLIP

TO: John Castaldo, Kent Piatt

FROM: Alan L. Reiss

DATE: $\quad$ March 24, 1999

SUBJECT: World Trade Center Fireproofing Guidelines For Tenant Spaces

COPY TO: E. McGinley, T. Kobel, F. Lombardi J. Richardson, J. Napolitano,

R. Rafferty, L. Menno, E. Moscovitz, C. Nanninga, N. Seliga, T. Stam

In order to establish clear and consistent guidelines regarding fireproofing repairs, replacement, and upgrades at the World Trade Center Towers, the following guidelines have been established with the concurrence of the Chief Engineer.

1) Full floors being demolished for new construction or renovation shall have the fireproofing on trusses checked and upgraded if it has not already been done to the attached 1995 Engineering Department Engineered Solutions Standard. Adequate time must be allowed in any schedule to accommodate this work, typically two weeks. This work may be performed by either the tenant or us but is a landlord obligation and reimbursable to the tenant (typically \$5/sq. $\mathrm{ft}$.) if the work is performed by the tenant. Refireproofing requires removal of existing material to insure adequate bonding and is subject to a controlled inspection.

2) Tenant spaces that are less than a full floor, undergoing either new construction or renovation, need only meet the original construction standard. Fireproofing shall be inspected and patched as required to the greater of $3 / 4 "$ or to match existing (it may already have been upgraded to the Engineered Solutions Standard.)

3) On a new lease, trusses requiring patching at the time of tender of the space are a landlord obligation, however, we normally will reimburse fair and reasonable costs if performed by the tenant after authorization. For existing tenant space being renovated, careful judgement should be used to determine if the need for the work arose as a result of a tenant action, i.e. previous construction work, or our obligation because of our work over the years in the ceiling. Any recommendation should be discussed with project and property management prior to being discussed with the tenant.

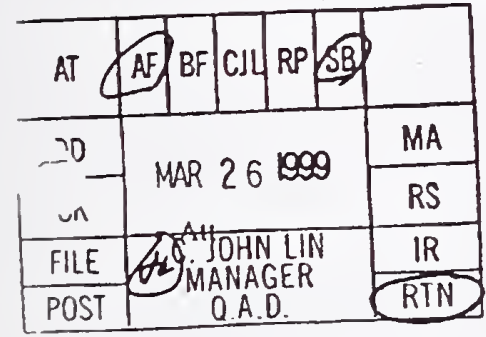

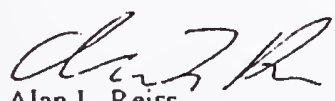

Alan L. Reiss

Director

Worid Trade Department

Figure A-36. Port Authority 1999 guidelines for thermal insulation on floor trusses (3-P). 

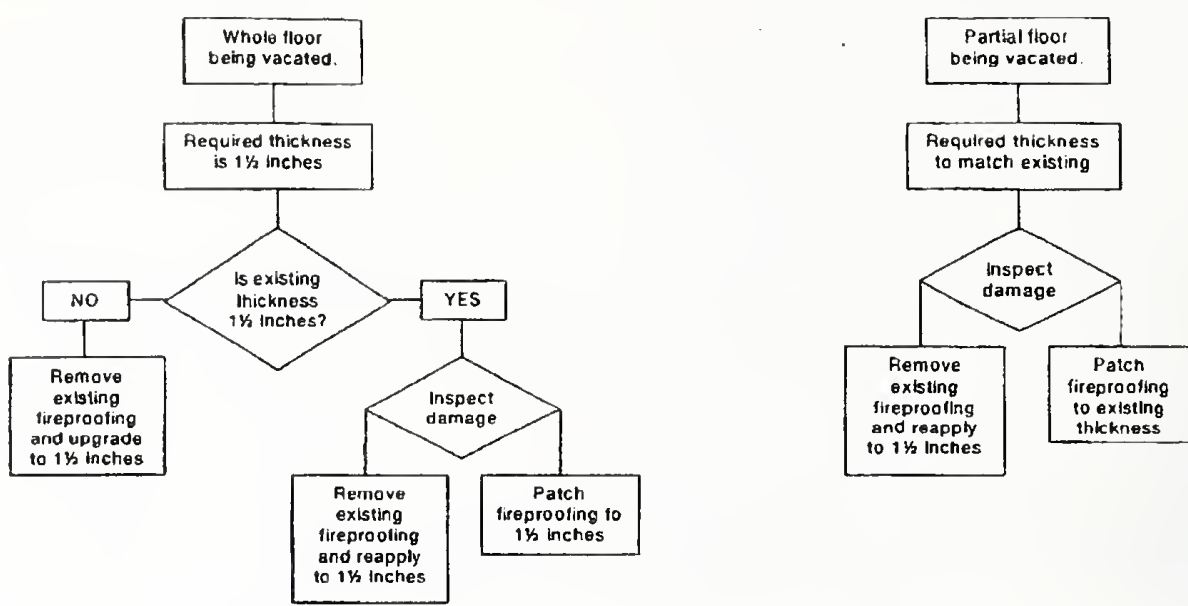

Figure 1: Fireprooting assessment process

Damage of existing fireproofing

Significant amounts of damage to the existing fireproofing occur during demolition after tenants move out. The product used in the past can be easily dislodged as ductwork, partitions, hangers, etc. are removed. Additional damage that happened during tenant fit-out or later modifications that may not have been repalred at the time.

As we understand it, in the majority of cases, the existing fireproofing requires so much patching that it is more cost-effective to replace it.

\section{Repairs}

If the damaged fireproofing is to be patched rather than replaced, the cementitious Monokote product is generally used regardless of what the in sltu fireproofing material is. This can result in joists that are fireproofed by a combination of materials. This patching is generally done by hand rather than spray application. Repairs are made such that a constant thickness of fireproofing is provided to all joist members.

\section{Removal}

The Cafco Blaze-Shield fireproofing is readily removed using a high-powered water jet. The water from the jet is soaked up by the fireproofing which falls to the floor in a damp state. Usually all the water is absorbed by the fire proofing, however, on occasion water does leak onto the floor below. The floor is covered with protective sheets. The fireproofing is collected from these sheets and transported in waste buckets to a waste disposal area.

Any portlons of fireproofing that are not removed by the jet are scraped away by hand. This often happens if there are sections of Monokote fireproofing and in the troughs that are formed at the bottom flange of the joist by the back-to-back angles. If the Monokote cannot be removed by hand, it is assumed to be fixed in place and is covered by the new fireproofing applications.

\section{Application}

When the fireproofing needs replacing, new fireproofing is applied to a thickness of $1 \frac{1}{2}$ inches. While equivalent products are permitted, Cafco Blaze-Shield mineral fiber spray is generally used as the replacement fireproofing.

It is estimated that $60-70 \%$ of the material is lost to overspray.

It can take 2-3 passes to apply $1 \frac{1}{2}$ inches. If it is done in fewer passes, the fireproofing tends to fail the adhesion tests that are conducted after application. Sometimes ten feet fall off at once when tested.

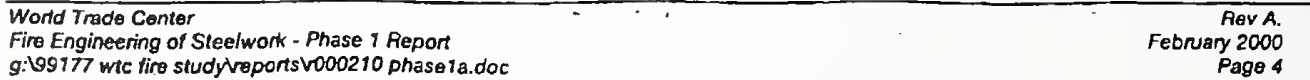

\section{Figure A-37. Excerpt from draft report on the assessment of thermal protection of steel in WTC (73-LERA).}




\section{SECTON OZOO - AREPROONRO}

Wert include, but is not necoscrily limitud to, the following:

Paching froprouting damaged ty thatllation of now condruetion

Patching of rephecting of odeding of now fireproofing where naquind to meat cods.

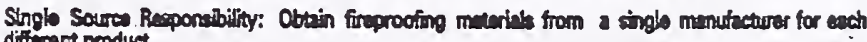
different product.

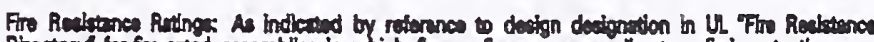

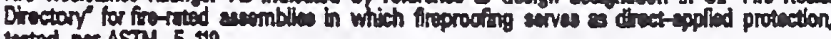
rated Par ASTM E Tit.

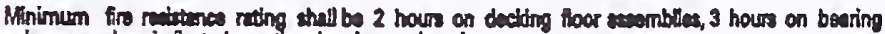
columns, unless incicend on the drowinge otherwise.

Provido approprias MEASSA numbers for appovid us in Now York City.

Underwiturs Laboratorien, ba - Fise Realsanes Indiax

\section{JOB CONOMONS}

Provide ventintion in aree to recaive sprayod firproofing, introducing froth of and extsusting air cortinuousty during and 24 hours after application to maintein non-toxic, unpoluted, uto worting are.

Provide temporery anclowers to provert eproy from contuntinating it. WARRANTY

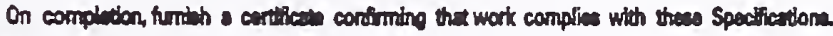
AFIRROOFNO MATERTLS

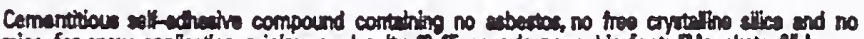

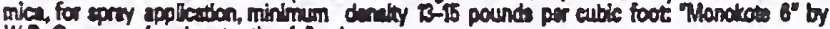
W.R Grice, contorming to the folowing:

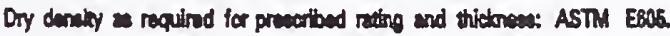

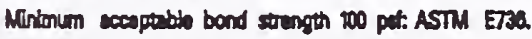

No cocting or deleminution under delietion of K20 of epan of under impact of BOL: ASTM ETE, ET

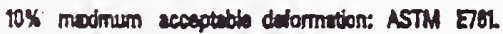

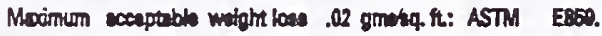

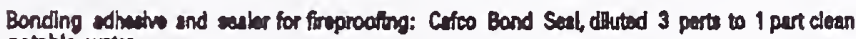
potable wear.

MLCES: in accordance when manufacturers hasuctions.

APPUCATION

Apply bonding edhedve or primer to rubetrato as recommended by manufectuser.

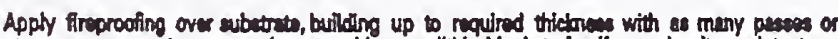

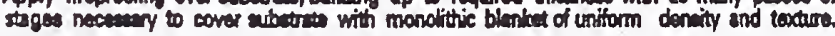

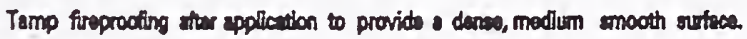

Apply ceale or aring compound to eurtece of fireproofing of recommended by manutecturer, in - epeco savito u o planem

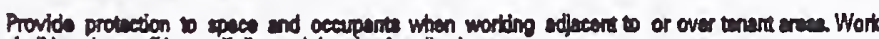
thall be don of hours if dinceed by the Landord

Finterting

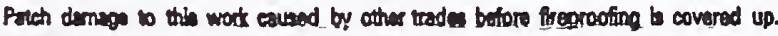

Uncover work covered before find approval for inspection before acceptence is granted

Puch adating apreyed freprooting which has been romoved for atuechmont of now

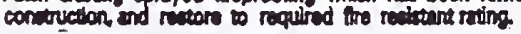

Figure A-38. Excerpt from 1998 specification related to SFRM for upgrade of public corridors and bathrooms on $15^{\text {th }}, 18^{\text {th }}$, and $22^{\text {nd }}$ floors of WTC 2 (3-P). 


\section{SECTION 07250 - FIREPROOFING}

SUMMARY

1. Patch fireproofing disturbed by remodeling operotions.

PRODUCTS

1. Fire Performance: ASTM E 119, and local regulotions. Cementitious Type for Conceoled Use:

15 pounds per cubic foot dry density.

2. ASTM E 605.

3. Minerol Fiber Type for Concealed Use: 15 pounds per cubic foot ory density. ASTM E 605.

4. Exposed Sproyed-On Fireproofing: Motch existing.

\section{INSTALLATION}

1. Insfect existing and new structurol members for proper fireproofing prior to close-in of ceilings and wolls.

2. Provide moterial thicknesses necessory to provide fire-resistonce ratings indicoted or required by outhorities hoving jurisdiction.

\section{SECTION 07270 - FIRESTOPPING SUMMARY}

1. Provide Firestopping ot the Following Locotions: Penetrotions through fire-resistonce-roted floor and roof construction; Penetrotions through fire-resistonce-roted walls ond portitions:

Penetrations through smoke borriers ond construction enclosing comportmentolized oreos: Seolant joints in fire-resistonce-rated construction.

\section{PRODUCTS}

1. Fire Performance: ASTM E 119, ASTM E 814, and locol regulotions.

2. Through-Penetration Firestop Systems: Coromic-Fiber and Mostic Cooting; Endothermic, Lotex Compounds: Intumescent Latex Seolant; Intumescent Putty.

3. Fire-Resistive Elostomeric Joint Seolonts: Single-component, neutrol-curing, silicone sealont; Multicomponent. nonsog. urethane sealont; Single-component, nonsog, urethone sealont.

INSTALLATION

1. Inspect existing and new work for proper firestopping prior to close-in of ceilings ond walls.

2. Provide materiol thicknesses necessory to provide fire-resistonce rotings indicated or required by outhorities hoving jurisdiction.

Figure A-39. Excerpt from 2001 specification related to SFRM for upgrade on $48^{\text {th }}$ floor of WTC 2 (3-P). 


\section{Executive Summary}

The development of fire safety engineering and in particular the performance of structure during fire has been developing rapidly over the last 5 years. Buro Happold has identified the value and benefits of this work to many of our global clients. This has required major investment in research and development, involvernent with the development of new codes, working with government and the employment of staff as part of a technology transfer from the universities carrying out this research. The ultimate aim is to ensure that the research and development is used in practical way for real buildings in a short but realistic time scale. The extent to which fire safety engineering can be used in this respect has to be based on the local code development, the attitude of the client and the authorities having juris diction.

The USA has been party to this development and now has its own performance based design codes. Historically fire safety engineering in the USA has only been done on special or difficult projects. However as the benefits are understood and are more widely accepted the quantity of performance based design is likely to increase significantly. This work on the World Trade Centre is significant and well contained example of what is possible now as a relatively low risk early development.

The components of this global development that have been most important from the point of view of the World Trade Centre are.

1. Better understanding and the analysis of natural fires.

2. Analysis of structures at high temperatures during fire.

3. Improving relationship and understanding between the supplier and the designer

4. More data relating to the performance of materials.

5. The developmenl of the fire safety engineering discipline and the risk assessment process.

On the basis of the current calculations and the risk assessment whilst laking a reasonably conservative view the following conclusions can be drawn for the open web joists on the tenant floors of World Trade Center Towers 1 and 2.

- The structural design has sufficient inherent fire performance to ensure that the fire condition is never the critical condition with respect to loading allowances.

- A single coat application is possible.

- Significant savings are possible.

- The target reduction of fiber content and increased long term durability can be achieved.

- Altemative materials should be considered. 


\section{$7 \quad$ Recommendations}

The calculations, the reliability of information, thc conservative assumptions, and the risk assessment have been carefully judged to determine a reasonable compromise between the following: -

- Compliance with the defined performance criteria and a reasonable level of safety.

- Value engineering to reduce costs or improve performance. Performance can be based on long term durability and robustness, reduction in fibre content, insulalion of steelwork during fire uind ease of ispiiuntivin.

- The need for margins of safety to erisure that the decision mialing and the approvials process are more straightforward. This in combination with the sensitivity tests covers the fact that the calculations and predictions for the phenomena of fire can never be exact.

If the most optimistic assumptions are made the thickness of the fire protection can be as low as $30 \%$ of the current thickness. However taking into account the variables, the followirig recomnmendations can be nade.

\subsection{Thickness}

For the existing material, there is some uncertainty about the performance of this material due to lack of available data. If the material performs to the insulation standard defined at ambient temperature in the manufacturers data a thickness of 0.5 inches can be used whilst still maintaining a reasonable margin of safety. If however the material does degrade to some extent as suggested by the UL listings then a greater thickness of up 101.3 inches is recommended. Furllier tests or lest data would be required to achieve the lower thicknesses. The issues of reduced fiitre cunteill all.j long term durability have not been addressed with this selection. II is likely that only a single coat will be required for the 0.5 inch case

\subsection{Choice of System}

The true cost of a system can only be accurately determined following a miarket test. The long term costs are a complex and are a function of the following:

- Material cost

- Required thickness

- Maximum thickness per application

- Time before the next layer can be applied

- Volume of dry material required

- Volume of water required in spraying procedure

- Overspray and other wastage

- Durability

- Etc.

An assessment of a variety of materials has been carried out in this report and judging from the results alternative materials should be considered for use in the World Trade Center. For example, the Carboline Pyrocrete 239 could be applied to a thickness of 0.75 inches, subject to receipt of confirmatory test data. This product is significantly more durable than the current product and therefore could reduce the overall life-cycle costs of the fireproofing system. 


\section{$\mathrm{M}_{2} \mathrm{H}$}

The building structures appear to be in adequate overall condition. Major structural repairs following the 1993 bomb blast were successfully completed and signed-off by a Permit to Occupy or Use issued by the Port Authority Office of the Chief Engineer on October 10, 1997. The repairs appear to have been properly engincered and executed. Following the bombing incident, stringent security measures were implemented at the vehicular eatrances to the Plaza and subgrade facilities.

In the buildings we observed only minor cracking in some slabs, partitions or in stairwells of the buildings. Some minor slab cracks have been noted which should be monitored by the PA's structural consultant. The slabs at the truck dock and delivery area on level B-1 have deteriorated due to ice-melting salts that enter the building on vehicles daring the winter. A slab replacement program is ongoing and should be continued until all of the damaged slabs are replaced. The monitoring of the visco-elastic movement dampers in the two Towers is an essential program that bas been strongly recommended for continuation by the PA's outside structural consultant. Building movement is monitored by analysis of measurements taken and recorded by devices located in the 108th floor of 1 WTC. Analysis of these records is done by the Port Authority's independent engineer (LERA) and should continue in the future. In addition, physical sampling and analysis of the condition of the visco-elastic dampers is reportedly continuing on a 5-year cycle, with the next sampling to be done in 2001. The slumy wall that surrounds and contains the subgrade levels of the complex has some seepage that is contained by curbing and leaders, and is discharged by sump pumps in the lowest levels.

The slurry wall and the adjacent floor slabs that brace the wall are inspected on an ongoing basis to ensure that unsafe conditions do not develop. Structural Integrity Inspection (SII) Report I-38, dated April 3, 1998, provided in the Data Room, found the conditions to be acoptable. These periodic inspections should continue.

The rating of the structural fireproofing in the Towers and subgrade has been judged to be an adequate 1-bour rating considering the fact that all Tower floors are now sprinldered. An ongoing program of re-fireproofing the structural steel to the full thicloness for 2-hour rating is in place. This work is done on a lease rollover basis whenever there is a full floor of space being built out for new occupancy. To date approximately 30 floors have been completed in the two towers. The PA will require this program to continue. The presence of asbestos containing 
CGé A. C. HEUER

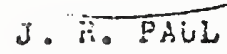

A. uizust 10,1967

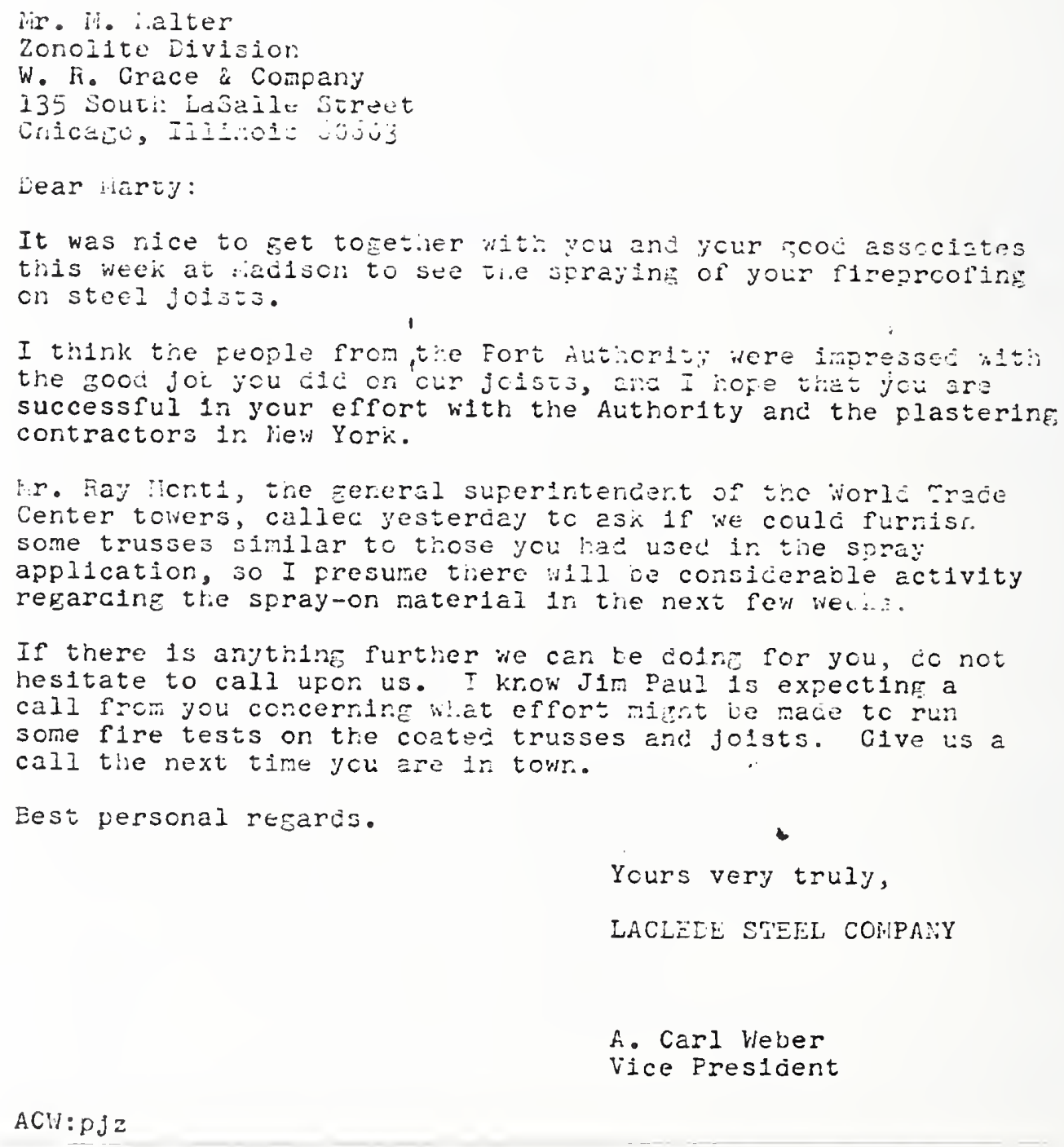

Figure A-42. Example of correspondence referring to fire endurance testing of coated floor trusses (70-I). 
While not advocating the omission of fire testing, it is clear that numerous examples of non-tested assemblies are incorporated into major buildings--under the watchful eye of responsible building officials and with the full knowledge of designers, builders and constructors. Obvious examples include:

(1) The floor assembly of the Sears Tower; and

(2) Typical composite beams supporting composite deck construction, with unsprayed steel deck.

The latter is an example of industry "standard" construction, accepted on a nationwide basis, but not supported by fire testing.

Reasons for this lack of testing of special construction (such as Sears and World Trade Center floors) is not to be found on account of a lack of desire on the part of designers or builders. The problem is quite straightforward:

(1) It is not possible to test all products and all combirations of products prior to contract award. For example, Leclede trusses were accepted on October 4, 1967 and Cafco fireproofing on March $26,1969$.

(2) Proper testing of the one-way World Trade Center floors would have required a floor furnace capable of testing an assembly $60^{\prime} \times 15^{\prime}$.

(3) Proper testing of the two-way World Trade Center floors would have required a floor furnace capable of testing an assembly $60^{\prime} \times 80^{\prime}$.

(4) With the limited availability of such furnaces, it is nearly impossible to schedule a test program in time to meet construction requirements.

These special fioor assemblies would best be fire tested--since actual testing is the only known, reliable method known to assure compliance with fire resisting requirements. At the sane time the writer knows of no example wherein testing has been acconplished--the problems of time and scheduling appear to preclude such testing.

-10-

SKILLING. HeLle, CHRISTIANSEN, ROBERTSON

Figure A-43. Excerpts from 1975 post fire report indicating need for fire endurance testing to establish a fire rating for the floor system (3-P). 
Early drafts of the revised Code required the 3-hour rating. Later drafts and the final version of the Code allow a 2-hour rating.

It is unlikely that a fire test of the 4-inch World Trade Center slab, making use of materials actually incorporated into the work, will pass a 3-hour test. It will almost surely pass a 2-hour test and would not be challenged on this account.

The World Trade Center construction of 4-inch reinforced concrete slab atop $11 / 2$ inch steel deck formwork is more fire-resistive then the most commonly used construction of today (1975)--a $31 / 4$ inch slab atop $11 / 2$ inch composite steel deck without benefit of spray fireproofing.

\section{Available Fire Rating}

The fire resistive requirements for the project were subjected to continuous muification as a rosult of the develonment of the new Building Cocie.

The decision to provide for $1 / 2$ inch of Cafco was made in full realization that:

(1) the floor slab provided only a 2-hour rating; and

(2) the new Code provided for a 2 -hour rating.

We presume, but do not know, that the Cafco decision was based on the need for a 2-hour rating. Even without benefit of full scale testing we do know that a 3 -hour rating cannot be achieved by the floor slab. We know also that the basic World Trade Center floor slab is superior to construction provided commonly throughout the country and does exceed a 2-hour requirement. Without benefit of a full-scale fire test we cannot cstablish a rating for the floor assembly.

Fire Performance

The construction performed as expected during the fire of February, 1975. While some reports indicated that the fire was very hot, no evidence of temperatures reached is available to the writer. In any event, at the very least, it can be said that the February fire provided no evidence that the construction was not satisfactory for its intended purpose.

We hope that this report will provide some insight into the fire-

SKILLING, HELLE. CHRISTIANSEN, ROBERTSON

Figure $A-43$ (Contd.). Excerpts from 1975 post fire report indicating need for fire endurance testing to establish a fire rating for the floor system (3-P). 


\section{Fire Testing}

While it is difficult to document through the media of project correspondence, the question of full scale fire testing occupied the minds of the planners and designers of The World Trade Center.

In March of 1964 Mr. C. H. Yuill, Manager Fire Research Section, Southwest Research Institute wrote to SHCR in response to its inquiry. The tone of the letter reflects a little the many problems associated with such tests; size of furnace, non-standard test procedures, long waiting time and the like (see page 8.1 and 8.2).

In June 2, 1965, SHCR transmitted truss loads for use in a fire test by U.S. Mineral Products Co. Designs of that era assumed conventional trusses--not the Laclede variety actually incorporated into the work. While not privy to the results of the test we understand(from discussions with $\mathrm{Mr}$. Soffer of Port Authority) that another test program was carried out in small scale using Mono-Kote spray-on materials.

The Underwriters" Laboratories, Inc., test of July 26, 1969

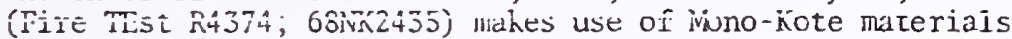
and laclede trusses and proviäes a 3-hour rating. A copy of that report is attached (appendex). The test is not completely representative of World Trade Center trusses in that the members are lighter, the span is shorter $\left(16^{\prime}-10^{\prime \prime}\right)$ and the trusses are shallower. (see page 8.3). It should be noted also that the test was conducted subsequent to the contracting for World Trade Center fireproofing. There is no evidence of when the report came to the attention of Port Authority; it was given to SHCR on March 24, 1975.

Figure A-44. Excerpt from April, 11975 post-fire report referring to fire endurance test of floor truss system with sprayed thermal insulation (3-P). 
GRACE

ZONOLITE

INSTRUCTION PRODUCTS DIVISION

$\underline{G} \underline{E} \underline{N} \underline{E} \underline{R} \underline{A} \underline{L}$

The subject of this report is a 3-hour fire endurance rated assembly composed of Laclede Composite Joists supporting a concrete slab over corrugated steel centering, protected with Mono-Kote cementitious fireproofing spray-applied directly to the surfaces of the joists and to the underside of the steel centering.

The object of the investigation was to establish a 3 -hour fire resistance classification for the assembly, constructed with the materials and in the manner as herein described, by means of the Fire Test of Building Construction and Materials, ASTM E-119 (UL 263).

MATERIALS:

The following materials were used in the test assembly.

Laclede Composite Joists - Type 10H5C, spaced $3 \mathrm{ft}$. 6 in. on center with a $16 \mathrm{ft}$. 10 in. clear span.

Corrugated Centering - No. 28 gauge steel attached to joistswith welding washers.

Concrete - Average 28 day strength of 4290 psi, readymixed concrete, poured to a thickness of $2-3 / 4^{\prime \prime}$ as measured over the crests of the corrugated centering.

Temperature Reinforcement - No. 8 SWG, 6 in. by 6 in. wire mesh.

Mono-Kote Cementitious Spray-Applied Fireproofing Applied directly to the surfaces of the joists to a thickness of $1-1 / 2$ " and to the underside of the centering to a thickness of 1/2", following the contours of the joists and the corrugated centering. Bags of Mono-Kote contained the UL label for "Cementitious Mixture."

Figure A-45. Reports of 1970 fire endurance test of floor truss system with sprayed thermal insulation (3-P). 


\section{GAACE}

ZONOLITE

INSTRUCTION PRODUCTS DIVISION

\section{ERECTION OF TEST ASSEMBLY:}

The assembly was constructed at the Northbrook, Illinois, testing facility of Underwriters' Laboratories, Inc. in accordance with the attached construction drawing Nos. UL 100-1 and -2 , dated $2 / 27 / 70$, under the observation of members of the staff of Underwriters' Laboratories, Inc.

\section{FIRE ENDURANCE TEST:}

The test was conducted in accordance with the Fire Test of Building Construction and Materials, ASTM E-119 (UL 263 test method).

The assembly was loaded to provide a uniformly distributed live load of 126 psf or a combined live and dead load of 169 psf, producing a maximum stress of $30,000 \mathrm{psi}$ in the joists.

$$
\underline{R} \underline{E} \underline{\mathrm{S}} \underline{\mathrm{U}} \underline{\mathrm{L}} \underline{\mathrm{T}} \underline{\mathrm{S}}
$$

Observations of the Exposed Surface - All of the MonoKote cementitious fireproofing remained in place throughout the 3 hour 13 minute test duration.

Temperatures of the Assembly - The initial average tempe ratures of the unexposed surface was $69 \mathrm{~F}$. Based, therefore, on a maximum average temperature rise of $250 \mathrm{~F}$ and a maximum individual temperature rise of $325 \mathrm{~F}$, the average limiting temperature was $319 \mathrm{~F}$ and the individual maximum limiting temperature was $394 \mathrm{~F}$. At 180 minutes ( 3 -hours), the average limiting temperature of $319 \mathrm{~F}$ was reached. At this time the maximum individual temperature was $352 \mathrm{~F}$.

Figure A-45 (Contd.). Reports of 1970 fire endurance test of floor truss system with sprayed thermal insulation (3-P). 


\section{GRACE}

\section{ZONOLITE}

NSTRUCTION PRODUCTS DIVISION

$\begin{array}{cc}\text { Deflection of the Assembly } \\ \text { Time } & \text { Deflection } \\ 60 \mathrm{~min} & 2 \\ 90 \mathrm{~min} & 2-1 / 2 " \\ 120 \mathrm{~min} & 3 \\ 150 \mathrm{~min} & 3-3 / 8^{\prime \prime} \\ 180 \mathrm{~min} & 4-3 / 4^{\prime \prime}\end{array}$

\begin{tabular}{|c|c|c|c|c|}
\hline Time & $\begin{array}{c}\text { Top } \\
\text { Chord } \\
\end{array}$ & $\begin{array}{c}\text { Diagonal } \\
\text { Web }\end{array}$ & $\begin{array}{l}\text { Bottom } \\
\text { Chord } \\
\end{array}$ & Average \\
\hline $\begin{array}{r}60 \mathrm{~min} \\
90 \mathrm{~min} \\
120 \mathrm{~min} \\
150 \mathrm{~min} \\
180 \mathrm{~min}\end{array}$ & $\begin{array}{l}235 \mathrm{~F} \\
395 \mathrm{~F} \\
486 \mathrm{~F} \\
550 \mathrm{~F} \\
622 \mathrm{~F}\end{array}$ & $\begin{array}{l}485 \mathrm{~F} \\
915 \mathrm{~F} \\
972 \mathrm{~F} \\
1,200 \mathrm{~F} \\
1,280 \mathrm{~F}\end{array}$ & $\begin{array}{l}485 \mathrm{~F} \\
1,150 \mathrm{~F} \\
1,243 \mathrm{~F} \\
1,543 \mathrm{~F} \\
1,580 \mathrm{~F}\end{array}$ & $\begin{array}{l}301 \mathrm{~F} \\
814 \mathrm{~F} \\
900 \mathrm{~F} \\
1,095 \mathrm{~F} \\
1,160 \mathrm{~F}\end{array}$ \\
\hline
\end{tabular}

$\underline{C} \underline{O} \underline{N} \underline{C} \underline{L} \underline{U} \underline{S} \underline{I} \underline{O} \underline{N} \underline{S}$

The assembly achieved a 3 -hour fire endurance rating in accordance with ASTM E-119 and as verified by the attached letter dated March 26, 1970, from A. F. Abbasi of Underwriters' Laboratories, Inc.

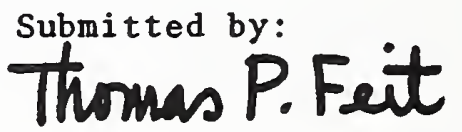

Thomas P. Feit - Manager

Technical Services

$\mathrm{TPF} / \mathrm{jac}$

Figure A-45 (Contd.). Reports of 1970 fire endurance test of floor truss system with sprayed thermal insulation (3-P). 


\section{UNDERWRITERS' LABORATORIES, INC.}

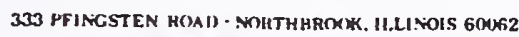

an independent, not-for-profit organization lesting for public safety

AIR IFAIL

in reply. please refer to

R4374

$68 N K 2453$

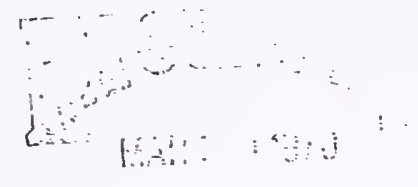

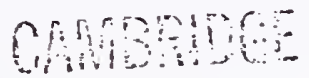

March 26, 1970

Zonolite Construction Products Div.

Vi. R. Grace \& Co.

62 Wittemore Ave.

Cambridge, ilassachusetts 02140

Subject: Fire Endurance Test of Composite Bar Joist and Concrete Deck

Attention: In. T. P. Feit

Gentlemen:

This letter summarizes the results of the fire endurance test of floor assembly of the subject matter.

The floor assembly was constructed according to Drawing No. ISIOIUL dated July 26, 1969 of Laclede Steel Company. It consisted of 3 bar joists type 10H5C with $3 \mathrm{ft} 6$ in. spacing on centers and $16 \mathrm{ft} 10 \mathrm{in.}$ clear span, supporting concrete deck over corrugated centering. The thickness of concrete was $23 / 4$ in. over the crests and $31 / 4$ in. over the valleys, and was reinforced with 6 by 6 in. No. 8/8 wire mesh. The bar joists and the corrugated centering were sprayed with Hono-Kote MK of the following thicknesses:

1. Bar Joists - An average of $11 / 2$ in. thick directly appiied over all the exposed surfaces of bottom and top chords and webs.

2. Corrugated Centering - An average of $1 / 2$ in. thick following the contours of the exposed surface of the corrugations.

The average strength of concrete at 28 days was $4290 \mathrm{psi}$. The equivalent uniform live load of 126 p. 8. $f$. was applied on the assembly. The total live and dead load was $169 \mathrm{p}$. s. $\mathrm{f}$. which produced a maximum stress of 30,000 psi in the bottom chord of the bar joist.

Figure A-45 (Contd.). Reports of 1970 fire endurance test of floor truss system with sprayed thermal insulation (3-P). 
UNDERWRITERS' LABORATORIES, INC.

$$
\text { - } 2 \text { - March 26, } 1970
$$

The floor assembly was tested on February 27, 1970, and the test was continued for 3 hours 13 minutes and i0 seconds. The structural performance of the floor assembly during the test was considered satisfactory. The average temperature of the unexposed surface before the fire test vias $69 \mathrm{~F}$. At 3 hours of test time the average temperature of the unexposed surface reached $319 \mathrm{~F}$ and the maximum individual temperature was $352 \mathrm{~F}$. The maximum deflection of the unexposed surface at 3 hours was 4.76 in.

The assembly was further loaded with an additional live load of $126 \mathrm{p}$. s. f. on liarch 2, 1970 which increased the maximum deflection by 0.35 in. without any apparent structural damage.

We shall be preparing a formal report which will contain details of the test.

Very truly yours,

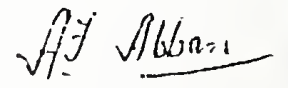

A. F. ABBASI

Fire Protection Department

AFA: ck

Figure A-45 (Contd.). Reports of 1970 fire endurance test of floor truss system with sprayed thermal insulation (3-P). 


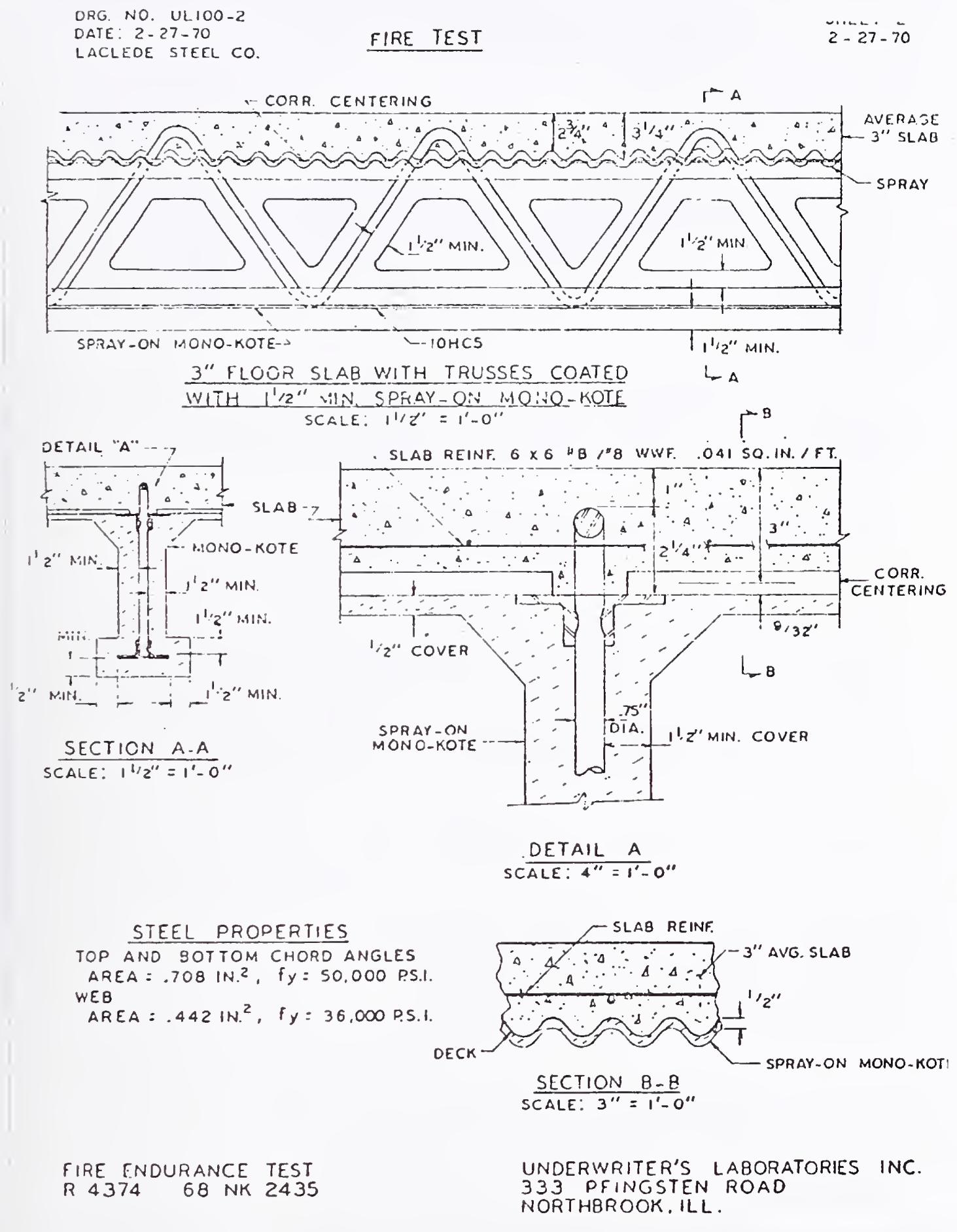

Figure A-45 (Contd.). Reports of 1970 fire endurance test of floor truss system with sprayed thermal insulation (3-P). 


\section{THEORETICAL CONSIDERATIONS}

Port Authority specified in a letter dated October 30, 1969, to Mario \& DiBono Plastering Co., Inc., 0.50 inch thickness of Cafco Blaze-Shield Type D for the steel beams, spandrels and bar joists. In the ULI report of July 26, 1969, for 3-Hour Fire Endurance Assembly with Mono-Kote Spray-applied Cementitious Fireproofing and Laclede Composite Joists, the test assembly achieved a 3 -hour fire endurance rating in accordance with ASTM E-119.

In the test assembly the Mono-Kote fireproofing was $0.50^{\prime \prime}$ on the steel deck formwork and $1.50^{\prime \prime}$ on the surfaces of the joists with $0.75^{\prime \prime}$ diam. webs and 1.50"' $\times 1.25^{\prime \prime} \times 0.135^{\prime \prime}$ chord angles.

With many simplifying assumptions, the required thiclesess of Cafco Blare-Shicld for the WTC floor trusses the same 3-hour fire rating may be extrapolated in a very approximate way on the basis of the thermal conductivity of the two materials.

The thermal conductivity in units of BTU/HR-FT ${ }^{2}-1^{\circ} \mathrm{F} / \mathrm{IN}$, is 0.27 for Cafco Blaze-Shield and 0.61 for Mono-Kote. The required thickness of Cafco Blaze-Shield is computed to be $0.50^{\prime \prime}$ for the Laclede trusses with 1 " $\emptyset$ webs and chord angles thicker than $3 / 16 "$ " $5 / 8$ "thickness would be needed for $3 / 4 \emptyset$ web members. It must be emphasized, however, that theoretical extrapolation of fire endurance tests must be viewed with caution.

$-12-$

SKILLING. helle. CHRISTIANSEN, ROBERTSON

Figure A-46. Excerpt from 1975 post-fire report indicating interpretation of 1970 fire endurance test of truss floor system with sprayed thermal insulation (3-P). 


\begin{tabular}{|c|c|c|c|}
\hline REV. & $\begin{array}{l}\text { LERA LESLIE E. ROBERTSON ASSOCIATES } \\
\text { CONSULTING STAUCTURAL ENGINEEAS }\end{array}$ & $\mathrm{P} 1003114$ & \multirow{3}{*}{$\begin{array}{c}\text { DRAWING NO. } \\
1 / 37\end{array}$} \\
\hline & WTC - REFIREPRDOF ELEUATOR SWATS 12$\} 13$ & DPATT & \\
\hline & \multirow{2}{*}{ INTRODUCTION } & DESIGN UPM & \\
\hline & & CHECK & $1 / 2 / 9 / 92$ \\
\hline
\end{tabular}

PuRpOSE: THe purpose of THUS CALCulation is to DETERMINE THE THHCKNESS OF TIREPROOENG REQUIRCD FOR THE EXPOSED BEAMS AUD COLUMNS IN THE WORLD TRADE CEUTER ELEVATOR SHAFTS PE 12 ANO PEI3.

RESULT:

VARIOUS THCKNESSES OF FIREPROOFING ARE REQUIRED. THE WARABAILITY IS DUE TO THE USE OF THREE DIEFERENT MATELALS AND THE CHANOES IN BEAM AND COCUMN SIZES. FROM FlODK TO FLOOR. THE THUCKNESSES ARE NOT GISTR HERE IN ORDER TO SAVE SPACE AND MAY OL FOUND IN THE BODY OK DREE CALCULATION.

Discussion: Regireproofing of BEAMS AND COLUMNS IN

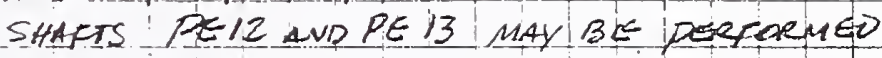
WITH ANY OP THE 3 MATSCIALS LISTEO BELOW:

1. MONOKOTE TYPE Z-106, MANUFACTRES BY W.R. Grace E. Co.

2. CAFCO 560 manufactureo ay ISOLARE industries

3. Albi Dunaspray or ALBI Tuzaspeay 30 MANUFARRED DV SANCHEM INC.

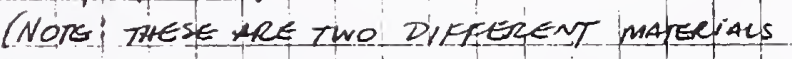
WIPH DIEFERENT THUCKNESSES REQUIRAD EOR EACH.)

THE CACCuATION'S WERE PERTORMES USING THE UNDERWRIERS CABORHIORY Fire Resistance Directory, Rsforence (A):

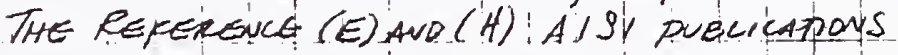
ARE ALSO VERY HELPRUL.

Figure A-47. Excerpts from 1992 report on thermal insulation thickness for repair of missing insulation (240-LERA). 


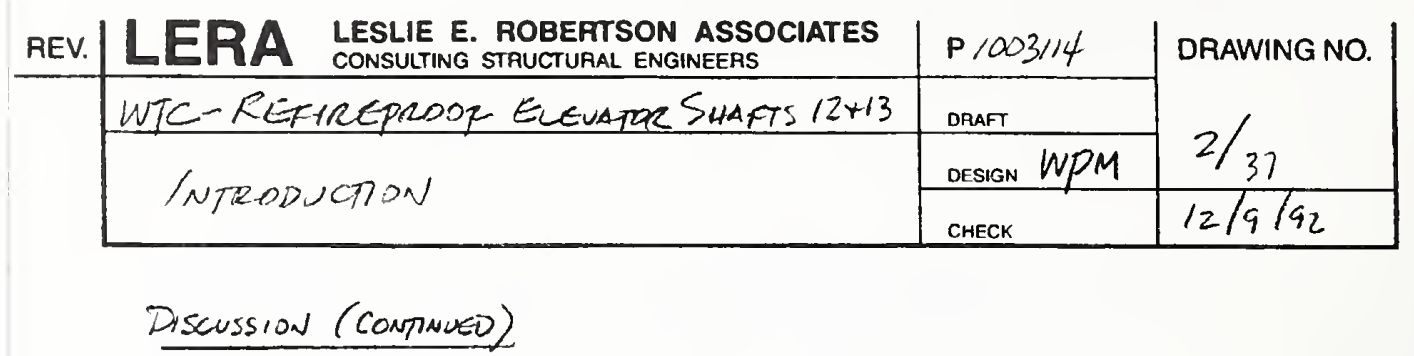

A REVIEW OF TAE APPROPRIATE DRAWINGS, REFERENCES (B), (D), (F) AND (G) IDENTREED WHICH BEAMS AND COCUMNS WERE ACCESSABLE FROM INSIDE THE GLVATDR SHAFTS. BEAMS SEPARATNG SHAFTS PEIZ \& PE 13 ARE NOT FIREPROOFED.

Assumptions: THE FOCLOWING ASSUMPTIONS WERE USED IN TRHS. CAcculation:

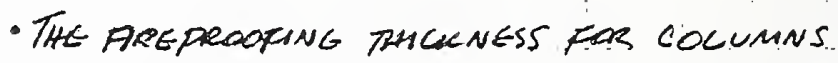
WAS CALCULATEO FOR GROUPS OF FLOORS IN ORDER TO SAVE TMME. THE GROUP'S WERE: DETERMANED BY LUMPING TOGETHER ALC COUMNS WITH PUAT THECNESSES WITHN Y/2" of EACH ONHER. BECAUSE FREPROOFING THCKNESS INCREASES WIMH IMALER CROSY-SGCTONS THE SMACLEST CROSS SECTON IN EACH COLOUP WAS USEO.

- Some beAmS haD ADDIMONAL StRFFENING PLATES AND MOUNTING BRACKETS WELDED TO A PORTION OF DHEIR SPAN. THIS EXIMA MAFERML WAS NOT INCCUPEO IN THE CHeviation AGAYN TASS WAS DONE TO SAUE TMME AND IT SHOUCO BE NOTED DIAT THE ADDIRON OS THESE REATES WOUD TEND TO UNCREASE TRE BEAMS CROSS SECTION ANO THEEES\% REDUE THE RHCLNGSS DF FMEPROOFNG REPUIRGD.

- A zhour rating for beams is repured Bequs ARE RESTRAINED ACOANST THERMAL EXPANSION.

- A 3 Hour ranng for cquUnins is required.

Figure A-47 (Contd.). Excerpts from 1992 report on thermal insulation thickness for repair of missing insulation (240-LERA). 
Referenced Documents

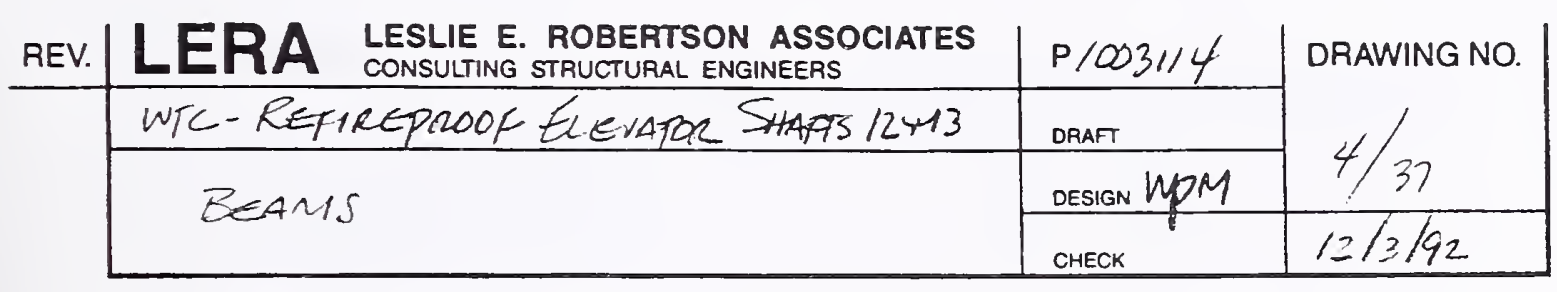

BEAMS

THE FOLlOWING CALCUMATON' WILL DETERMINE THE THICKNESS OF GREPRCOFING REQUIRED FAR BEAMS EXPOSED IN ELEVATOR SHATIS PEI 2 \& PE 13. FR EM THE SKETCM BELOW, THERE aRe 5 BEAMS ExpOS SO in THE SHAFTS. BEAMS. A AUD E ARE NARMAUY ENCLOSE IN CONCRETE AND DO NOT REQUIRE SPRAY ON FIREPROOFING. BEAM C SEPARATES THE Elevator shat is and is nOT fireproofed. ONCY BEAMS B AND D RGQUIILE SPRAY ON FIREPROOFING.

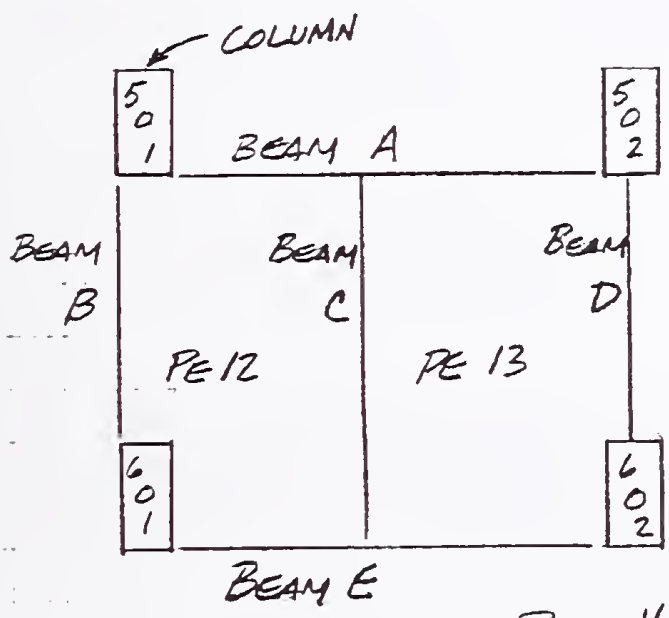

RAW VIEW

SeE REFERENCE (D) for EXTENT of Fireproopincs on BEAMS.

A. 2 hour rating for beams (restrained) is desired.

See References (F) and (G) for beam details.

Figure A-47 (Contd.). Excerpts from 1992 report on thermal insulation thickness for repair of missing insulation (240-LERA).

NIST NCSTAR 1-6A, WTC Investigation

211 


\begin{tabular}{|c|c|c|c|}
\hline REV. & LERA LESLIE E. ROBERTSON ASSOCIATES & $\mathrm{P} / \infty 03 / 14$ & \multirow{2}{*}{ DRAWING NO. } \\
\hline & WT-REFinCRROOF ELEVARR SHAFS $12+13$ & DRAFT & \\
\hline & \multirow{2}{*}{ PEAMS } & DESIGN upM M & \\
\hline & & CHECK & $12 / 3 / 82$ \\
\hline
\end{tabular}

BeAM B

THERE ARE SEVERAL CROSS-SECTIONS USED IN THHS COCADON.

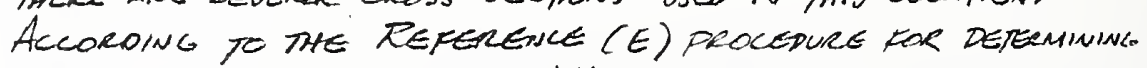
FREPROOFING THCSENESS, THE W/D RADO FOR THESE DIFFERENT CrROSS-SECDONS IS REQUIRED. AFTER THS RATIO IS COMPARED TO DHE W/D ATIO FOR THE BEAM USED IN DHE RERERENCE(A) FIRE TEST, THE REFERENCE (A) FIREPRDOFING THCKNESS MAY BE AOJUSIED UP OR Dow.

$w / D$ RATOS

- W12.72 used AT ELSV 294'

$W / D=1.2$ (REFGRENEE)

.24 I 79.9 USED AT ELEN 310' AND FloOR? SIMILARTO $S 24 \times 80$

$$
\begin{aligned}
& w=8016 / \mathrm{ft} \\
& D=36 f+2 d-2 t_{w}=3(7)+2(24-.5)=68 \\
& W / D=80 / 68=1.18
\end{aligned}
$$

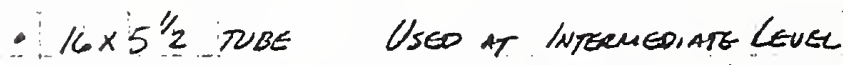

fabricated section, SeE Reference (F)

Conculation. LONG. DON'T INCLUDE IN

$$
\begin{aligned}
& D=16(2)+5.5+2(1.5)=40.5 \\
& W / D=\frac{88.5}{40.5}=2.18
\end{aligned}
$$

Figure A-47 (Contd.). Excerpts from 1992 report on thermal insulation thickness for repair of missing insulation (240-LERA). 


\begin{tabular}{|c|c|c|c|}
\hline REV. & $\begin{array}{l}\text { LERA LESLIE E. ROBERTSON ASSOCIATES } \\
\text { CONSULTING STRUCTURAL ENGINEERS }\end{array}$ & $\mathrm{P} / 003114$ & \multirow{3}{*}{$\begin{array}{c}\text { DRAWING NO. } \\
\$ / 37\end{array}$} \\
\hline & WTC-REFIREPROOF ELEUATOR SAAFTS $12+13$ & DRAFT & \\
\hline & \multirow{2}{*}{ BeAM $B$} & DESIGN WPM & \\
\hline & & CHECK & $12 / 3 / 92$ \\
\hline
\end{tabular}

NOW, DETERMINE THE THCKUESS OF FIREPROCFING FOR EACH OF THE THREE MATERIALS.

MONOKOTE TYPEZ-106 BeAM B

UL DESIGN (REFERENCE (A)) N720

ZHAN RESTRANED TEST BEAY WBX28, W/D $=.80$

ALL BEAMS WITH W/O GREATER THAN .80 MAY USE THE NT2O SPECIFIES THACENESS OF $15 / 16 "$.

Acternatively, THIS THCKNESS MAY bE REOUCED BY USING THE REFERENLE (A') BEAM SUBSTIUTION EQUATION:

$$
h_{1}=\left[\frac{w_{2} / D_{2}+0.6}{w_{1} / D_{1}+0.6}\right] h_{2}
$$

NOTE:

WHERE:

$$
h=\text { THICKNESS OF }
$$
SuBSCrAPT I = SUBSTINTE BeaM VALUES SUBScRIPT $2=$ UL DESION

\begin{tabular}{|c|c|c|c|}
\hline FLeOR & $w / D$ & REVISEO & THCKNESS - BEAM SUBSTIMTION \\
\hline Ever 294' & 1.2 & $3 / 4^{\prime \prime}$ & EAUATTON USEO. \\
\hline EuEV $310^{\prime}$ & 1.18 & $3 / 4 "$ & \\
\hline INTERMEDIATE & 2.18 & $1 / 2 "$ & \\
\hline 2 & 1.28 & $3 / 4^{\prime \prime}$ & \\
\hline $3-6$ & 1.78 & $9 / 16^{\prime \prime}$ & \\
\hline
\end{tabular}
0.8 , THE ABOUE EQUATION MUST BE USED TO INCREASE THE FIREPROOFING THHCWNESS.

Figure A-47 (Contd.). Excerpts from 1992 report on thermal insulation thickness for repair of missing insulation (240-LERA). 


\begin{tabular}{|c|c|c|c|}
\hline REV. & $\begin{array}{l}\text { LRA LESLIE E. ROBERTSON ASSOCIATES } \\
\text { CONSULTING STRUCTURAL ENGINEERS }\end{array}$ & P 1003114 & \multirow{3}{*}{$\begin{array}{l}\text { DRAWING NO. } \\
10 / 37\end{array}$} \\
\hline \multirow{3}{*}{$\ldots$} & WTE-REFIREPROOF ELENARR SHAFIS 12413 & DRAFT & \\
\hline & \multirow{2}{*}{ BEAY B } & DESIGN WPM & \\
\hline & & CHECK & $12 / 4 / 52$ \\
\hline
\end{tabular}

Beam B, CAFCo 560 material

UL DESIGN N714

ZHOMR RESTRANGD TEST BEAM W $8 \times 28, W / D=.80$

AS BEFDRE, SUL FLOORS EXCEPT THE 8 TI MAY USE DESIGN NTI4 DHCKNESS of $7 / 8$ ".

FloOR 8 REquires an INCREASE IN THCKNESS AND THE REMATNING FIOORS MAY BE REOUCED, ALU BY USING THE BEAM SUBSTIUTION EQUUATION.

REVISED Thacknesses (USE THE BEAM substution Equation)

\begin{tabular}{|c|c|c|c|c|c|}
\hline FLOR & $w / 0$ & THECNESS & Floor & $w / D$ & Thuckness \\
\hline $\operatorname{ELV} 294$ & 1.2 & $11 / 16 "$ & $41,43,44$ & 1.03 & $13 / 16^{11}$ \\
\hline $\operatorname{Ees} 310^{\circ}$ & $1 \% 18$ & $3 / 4^{\prime \prime}$ & 42 & .85 & No Chance $7 / 8$ " \\
\hline INTER. & 2.18 & $1 / 2 "$ & $45-66$ & 1.01 & $13 / 16^{\circ}$. \\
\hline 2 & 1.28 & $11 / 16 "$ & 67 & 1.26 & $" 1 / 16 "$ \\
\hline $3-6$ & 1.78 & $9 / 16^{i 1}$ & $68-74$ & 1.01 & $13 / 16^{\prime \prime}$ \\
\hline 7 & 1.18 & $3 / 4 "$ & 75 & 1.28 & $11 / 16^{\prime \prime}$ \\
\hline 8 & .57 & (1/6"RESO & 76 & .85 & No cuance $7 / 8$ " \\
\hline$q$ & 1.13 & $3 / 4 "$ & 77 & 1.28 & $11 / 16 "$ \\
\hline $10-39$ & 1.26 & $11 / 6 "$. & 78 & 1.65 & $9 / 16 "$ \\
\hline 40 & 1.01 & $13 / 16 "$ & 79 & 1.43 & $5 / 81$ \\
\hline
\end{tabular}

Figure A-47 (Contd.). Excerpts from 1992 report on thermal insulation thickness for repair of missing insulation (240-LERA). 


\begin{tabular}{|c|c|c|c|}
\hline REV. & LERA LESLIE E. ROBERTSON ASSOCIATES & $\mathrm{P} / 003 / 14$ & \multirow{3}{*}{$\begin{array}{l}\text { DRAWING NO. } \\
1 / 37\end{array}$} \\
\hline & WTC-REAREPROOF ELEVATDR SWATHS $12+13$ & DPAFT & \\
\hline & \multirow{2}{*}{ BeAM B } & DESIGN WPM & \\
\hline & & CHECK & $12 / 4 / 52$ \\
\hline
\end{tabular}

BEAM B ALBI DURASPRAY

UL DESIGN NTII

ZHOUR RESTRAHED TEST BEAM WBX2B W/D $=.80$

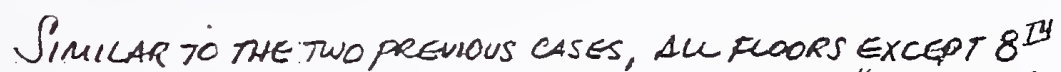
MAY: USE THE NTII DESIGN THCKNESS OK $/ "$. FlodR 8 REQUIRES AN INCREASED THCKNESS.

THE REVISED THHCKNGSSES, AND THE REPUIREMEUT FOR FLOR8 ARE BELOW.

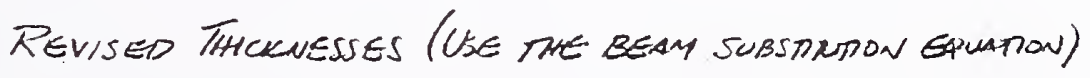

\begin{tabular}{|c|c|c|c|c|c|}
\hline Floor & $w / p$ & THECKNESS & Foor & $w / D$ & THeMnESS \\
\hline Elev 294 & 1.2 & $13 / 16^{11}$ & 42 & .85 & No change I" \\
\hline$t a \in v 310^{\prime}$ & 1.18 & $13 / 16^{4}$ & $45-66$ & $1.01^{\circ}$ & $7 / 8$ \\
\hline INTER: & 2.18 & $1 / 2 "$ & 67 & 1.26 & $13 / 16^{\prime \prime}$ \\
\hline 2 & 1.28 & $3 / 4^{\prime \prime}$ & $68-74$ & 1.01 & $1 / 84$ \\
\hline $3-6$ & 1.78 & $5 / 8$ & 75 & 1.28 & $3 / 4^{4} \vdots$ \\
\hline-7 & 1.18 & $13 / 16 "$ & 76 & .85 & No Cunvet I! \\
\hline 8 & .57 & $114 \pi$ & 77 & 1.28 & $3 / 4^{\prime \prime}$ \\
\hline 9 & 1.13 & $13 / 16 "$ & 78 & 1.65 & $5 / 8 "$ \\
\hline $10-39$ & 1.26 & $13 / 16 "$ & 79 & 1.43 & $3 / 4 "$ \\
\hline 40 & 1.01 & $7 / 8 "$ & & & \\
\hline $41,43,44$ & 1.03 & $7 / 8 "$ & & & \\
\hline
\end{tabular}

Figure A-47 (Contd.). Excerpts from 1992 report on thermal insulation thickness for repair of missing insulation (240-LERA). 


\begin{tabular}{|c|c|c|c|}
\hline REV. & LEAA LESLIE E. ROBERTSON ASSOCIATES & $P 1003114$ & \multirow{3}{*}{$\begin{array}{l}\text { DRAWING NO. } \\
19 / 37\end{array}$} \\
\hline & W/C-REFIREPRDOF ELEVATOR SHAFTS $12+13$ & DRAFT & \\
\hline & \multirow[b]{2}{*}{ Caumn 601} & DESIGN WPM & \\
\hline & & CHECK & $12 / 8 / 92$ \\
\hline
\end{tabular}

Counns

THE FOCOWING CACULATIONS WICL DETEUMNE THE THCKNESS

ge FIREPROOFING RESUIRGD fOR COLUMNS 601, 602, 501 AND

502 for AC 3 fieEprogeing MATERIALS. CoLUMN

SIZES ARE FrOM. RefERENCG (B).

A) Mowokotz Type $z-106$, Manufactures BY W.R. GRace Columan 6ol

\section{UL DESICON: X738}

THE UL DIRECTORY, REFERENCE (A), PROUIDES AN Equation for PETERMINING THE THCENESS OF TYPE 106 MATERAAL REPUIRED. THS EQMAION IS BASED ON THE W/D RATIO. BECAUSE THS COLUMN'S CCOSS SECTION CHAUGES OVER 175 HEIOHT, SO WIU THE W/D R47no:

IS AN ATREMPT TO REDUCE PHE NUMBER OF THCKNESS CUMULGS, JHE WID RATIO WIL BE CAC CULATED FO GROUPS OF COCUMNS WHOSE PLATE THACKNESSES ARE WTHWN "L" OF EACH ORER. BECAUSE FREPROOFING THCKNESS INCREASES WITH SMAWER WID RATIOS; THE LWHTEST COCUMN IN EACY GROUP WIL BE USED.

ALAJOUGH DIFGERENT SIDES OF THE SAME COCUMN ARE EXPOSED TI DIFFERENT ELEVADONS WITHN THE SHAFT, DAE CALCurtion WIL ASSUME A. FIRE AROUND DIE FULC PERMETER QF THE COCWMN. THAS IS CONSERVATIVE AS IT WILL TEND TO LOWER DHE W/D RADO.

Figure A-47 (Contd.). Excerpts from 1992 report on thermal insulation thickness for repair of missing insulation (240-LERA). 


\begin{tabular}{|c|c|c|c|}
\hline REV. & $\begin{array}{l}\text { ERA LESLIE E. ROBERTSON ASSOCIATES } \\
\text { CONSULTING STRUCTURAL ENGINEERS }\end{array}$ & $P 1003114$ & \multirow{3}{*}{$\begin{array}{l}\text { DRAWING NO. } \\
20 / 37\end{array}$} \\
\hline & WTL-RESIREPROOA ELEUATORSAAFT 12+13 & DRAFT & \\
\hline & \multirow{2}{*}{ Cocunan 601} & DESIGN YPM & \\
\hline & & CHECK & 121 \\
\hline
\end{tabular}

THE UL EquATION TO dETERMINE TYPEZ-106 FiRG-PROOFING 15 :

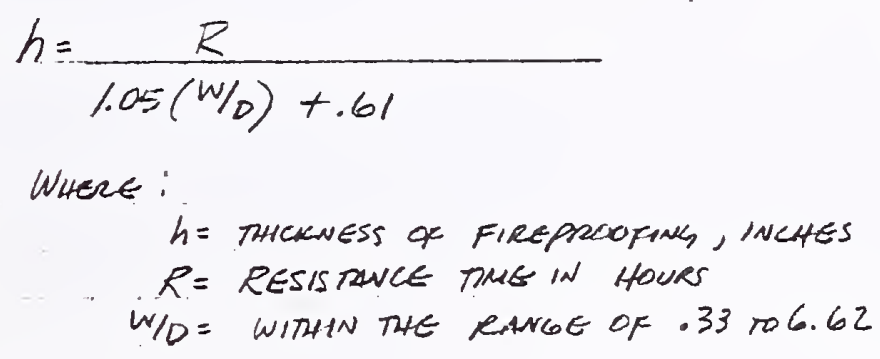

NOTE THAT THE USE OF THHS ELUATION IS NOT MANDATDRY FOR WIO RATIOS GREATER THAN THOSE IN TNE UL DESIGN. IT MUST BE USED FER WID DATIOS SMACLER TMAN THOSG IN PHE UL DESIION.

\section{Flooes $69 \rightarrow 79$}

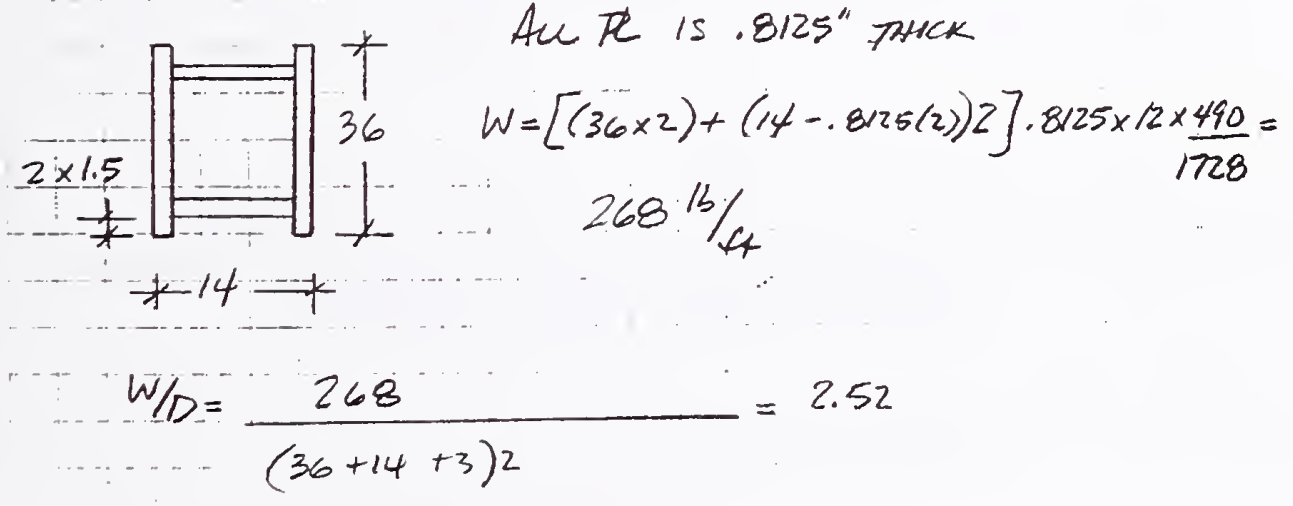

THE UL DESIION THACNESS IS $15 / 16 " \ldots$ Applying the equation $h=.92$ use $15 / 16 "$

Figure A-47 (Contd.). Excerpts from 1992 report on thermal insulation thickness for repair of missing insulation (240-LERA). 


\begin{tabular}{|c|c|c|c|}
\hline REV. & LERA LESLIE E. ROBERTSON ASSOCIATES & $\mathrm{p} / 0031 / 4$ & \multirow{3}{*}{ DRAWING NO. } \\
\hline & 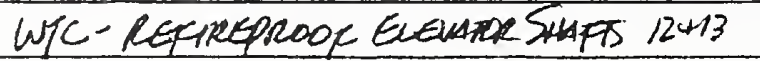 & ORAFT & \\
\hline & \multirow{2}{*}{ Cocumas } & OESIGN WPM & \\
\hline & & CHECK & $12 / 9 / 92$ \\
\hline
\end{tabular}

(B) CAFCO 560, manufactrRed BY kolatek International UL DESILN X767

No equations are provided in tue UL CODE, Reperence (A), FOR REPUCING THE RHCKNESS SPECIFIED IN DESIGN X767. THE VENDOR ALSO STATED THAT THE FWL THACKNESS SPECIFIED IN THAS DESIION SHOULD BE USED. FOR A 3HOUR RATNG, DESIGN X767 SPECIFIES A THACKNESS OF 2 "16" FOR ALC COCUMNS.

CHECK ${ }^{w / O}$

THE TEST COWNA IS A $4 \times 4 \times 3 / 8$ TUBE

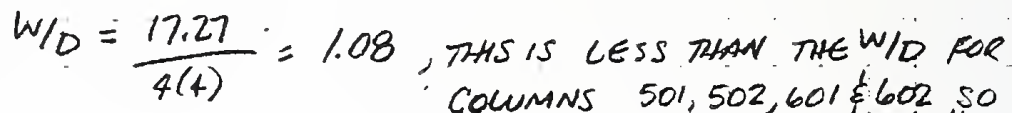

$$
\begin{aligned}
& \text { THE TEST THCONESS IS ACCEPTABCE. }
\end{aligned}
$$

Figure A-47 (Contd.). Excerpts from 1992 report on thermal insulation thickness for repair of missing insulation (240-LERA). 


\begin{tabular}{|c|c|c|c|}
\hline REV. & $\begin{array}{l}\text { LEA Leslie E. ROBERTSON ASSOCIATES } \\
\text { CONSULting StRUCtURAL ENGINEERS }\end{array}$ & $\mathrm{P} 10031 / 4$ & \multirow{3}{*}{$\begin{array}{l}\text { DRAWING NO. } \\
28 / 37\end{array}$} \\
\hline & 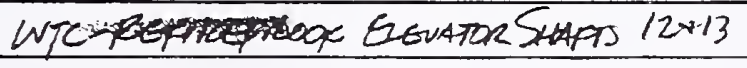 & OPAFT & \\
\hline & \multirow[b]{2}{*}{ Cocunans } & DESIGN WPM & \\
\hline & & CHECK & $12 / 9 / 92$ \\
\hline
\end{tabular}

c) ALBI Dura spray manupacared by Stanchem, luc AND DLPASPRAY 30

UL DESIGN $X-730$

ACTHOUCH THS DESUON IS FOR A MERAL CAMH ENCLOSED W-SHAPE COLUMN, THE VENDOR RECOMMENDS THHS DESIGN

FOR TUBE COLUMNS. FOR A 3 HOUR RATING, THE DESION SPECIFIG THCRNESS IS

I"/6" FOR ALL COLUMNS.

CHECK $W / D$

THE TEST COWMN is a W10X49, ENCWOSED IN A BOX.

THIS SHAPE HAS A HGGNT AND FIAUEG WIOTH OF 10 ".

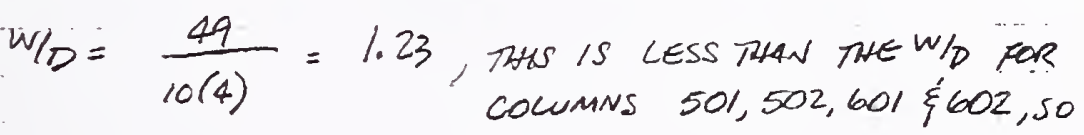

THE TEST THUCKNESS IS ACCEPTABLE.

No equations are aVATCABLE FOR REDUCING THAS

THCHNESS.

Figure A-47 (Contd.). Excerpts from 1992 report on thermal insulation thickness for repair of missing insulation (240-LERA). 


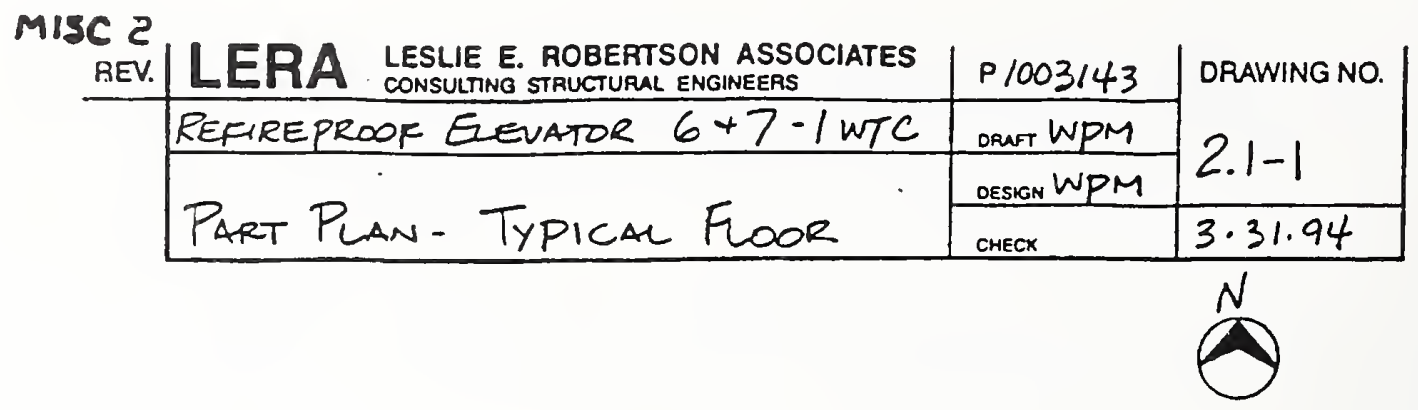

DOOR OPENING

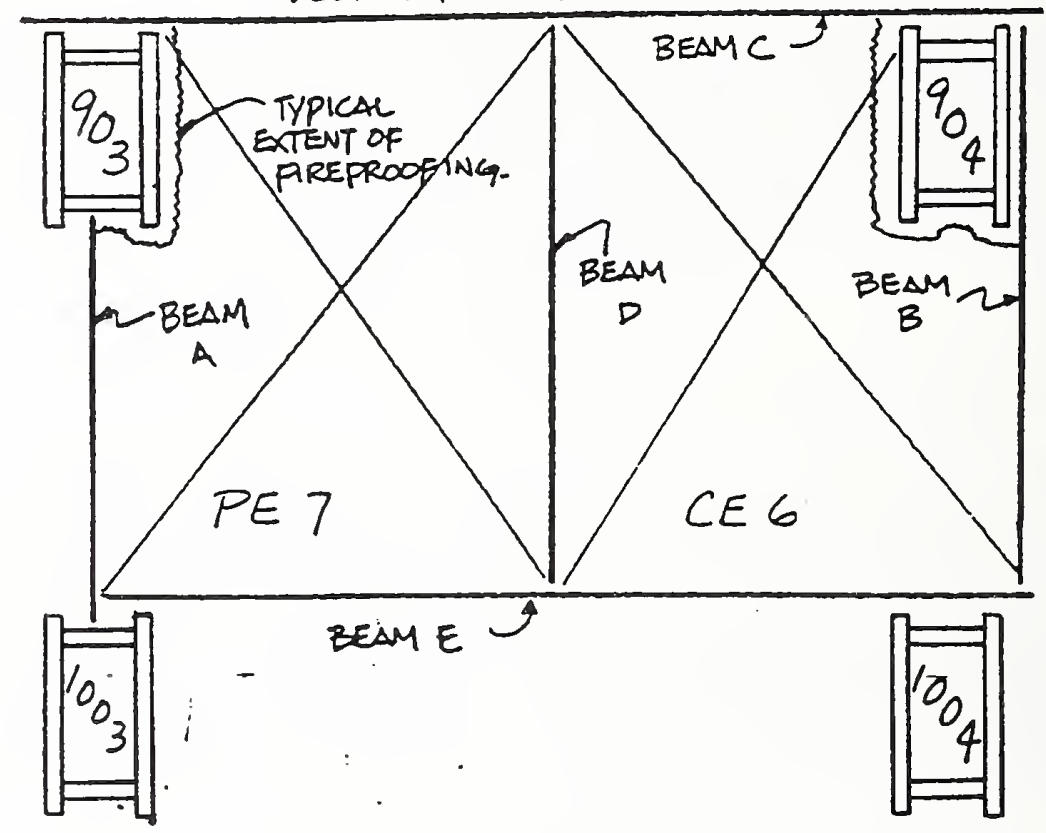

- Beamis A and B, and Columns 903 and 904 TO be fiReproOfed. SEe SCHEDULE ON PAGE 2.2-1.

- Beams Cano e aré concrete encaseo and do not RECEIVE FIREPROOFIV. BEAM D IS NOT FIREPROOFED.

- Coumns 1003 and 1004 are not accessirue from THE ELEVATOR SHAFTS.

Figure A-48. Excerpt from 1994 design document related to reapplication of SFRM to accessible members in elevators shafts of WTC 1 (659-P). 
$\begin{array}{llll}\text { TO: } & \text { M. Gerstman } & \text { DATE: Apr11 } 12,1973 \\ \text { EROM: } & \text { E. J. BOLAnd }\end{array}$

SUBJECT: THE WORID TRADE CENTER - CONTRACT WTC 320.00 - ELEVATORS AND CONTRACT

ITTC 113.00 - SPRAY-ON FIREPROOFING - TOWERS A \& $B$

REFERENCE: LETLE H. Gerstman to Ot10 - dated $3 / 22 / 72$

COPIES: R. Belsky, R. Inn, C. A. Smith, F. H. Werneke; G. Hughe日, B. Wednstelin (TRCC); File
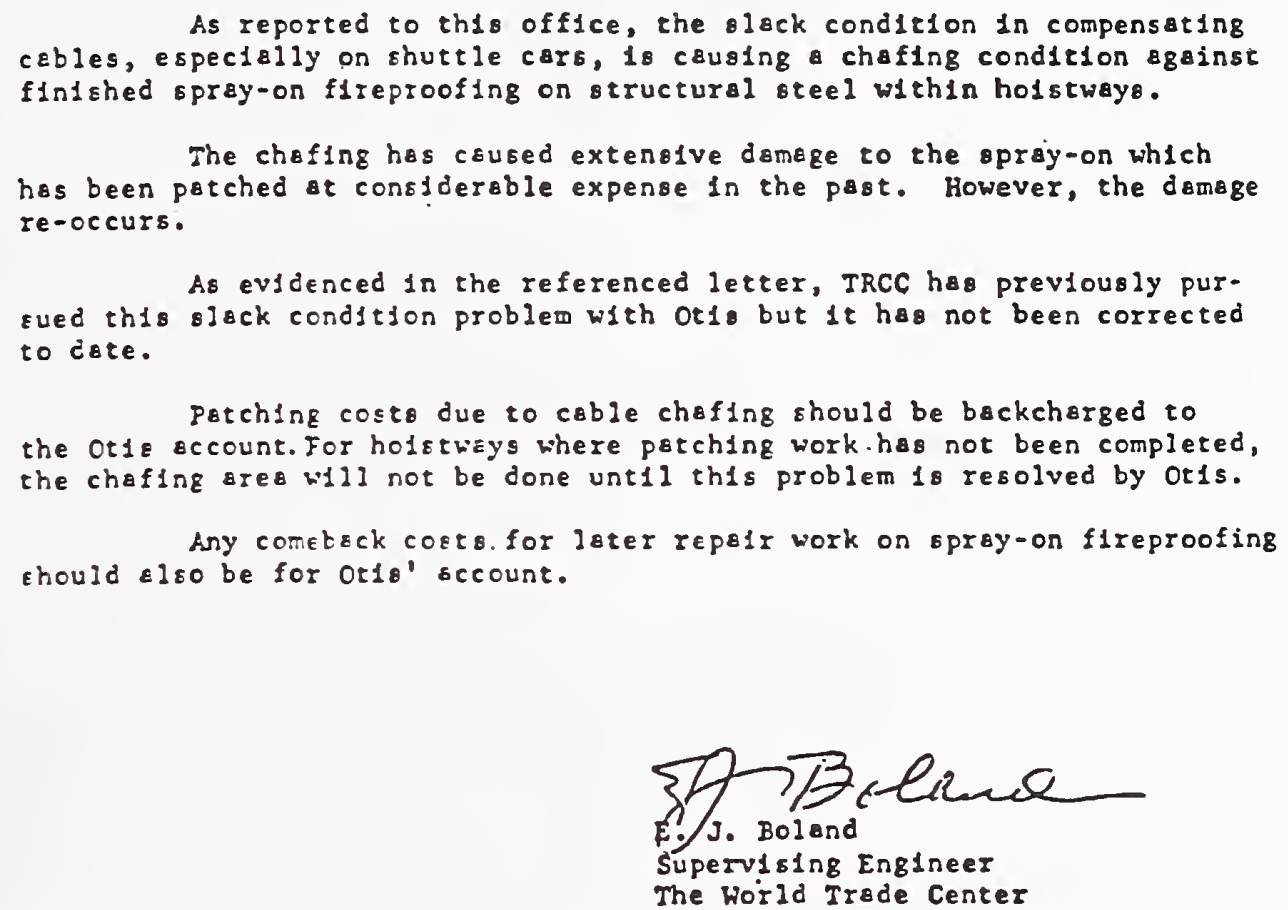

Figure A-49. Correspondence indicating that slack cables within elevator shafts damaged the thermal insulation (246-1). 
B. 2. Schiocoer

P. H. Stromp

Ints 29. 1960

CAfCO Bood Stronsth

In our rocert Fibration torts wo hare notod soso poor bood charscter-

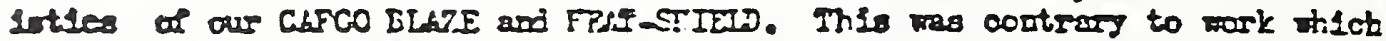
w bed done in the past on laboratory elres. Since th.1s difference was botod

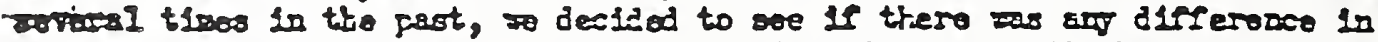

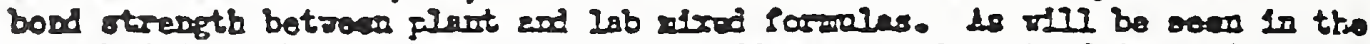

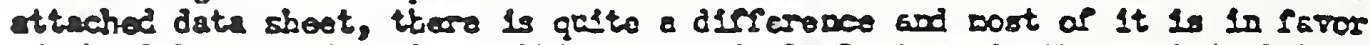
of tho leb ired formles. Itis is certlecierls trie in the colticel lor

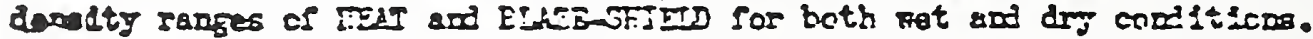

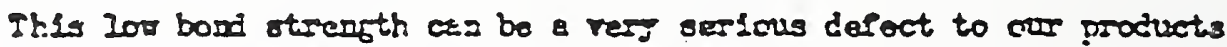

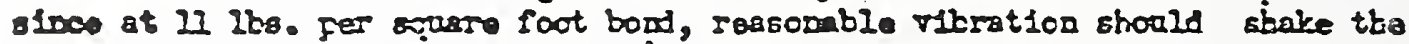

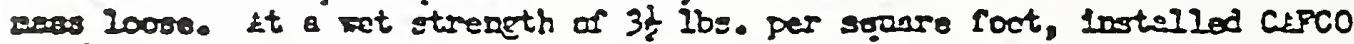

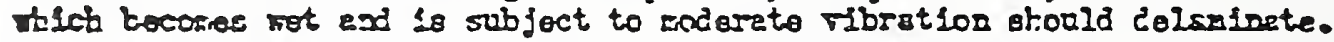

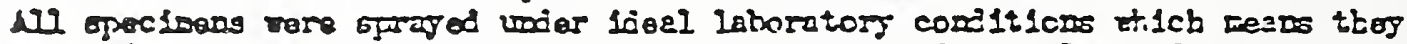

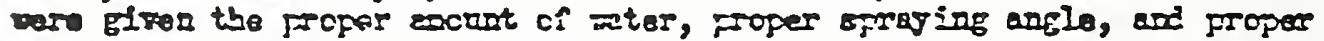
tarping. In the riald, rost of these coniltions are not net ri:Ich would further indicato peor forferwedeo of tho prociet. It fust heffens that C.JCO

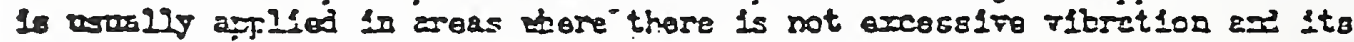
reight is teior the 3 Ibs. per seivere foct renge.

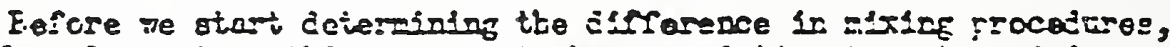

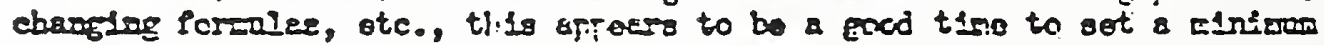

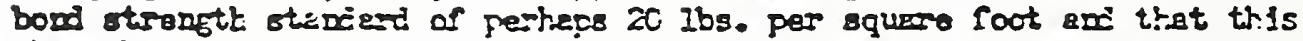
cteck to a fart of th:e quelity cortrol procodure. Kext, me ean atudy the

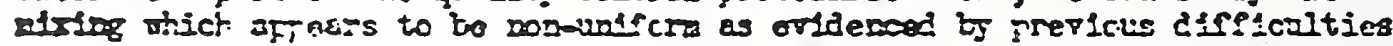

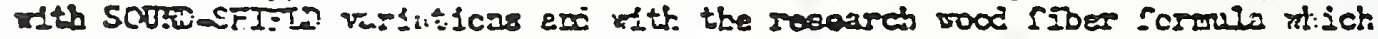

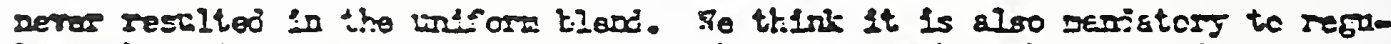
Iate the nodule size of 2001 entering the cirar ratter then doremine upon

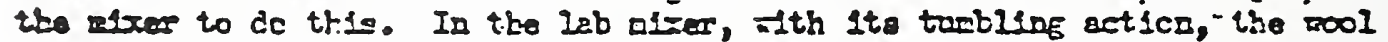

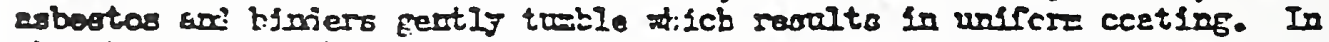
the plent Ixer it:e constint krestinf op of the nool nowule is seper per-

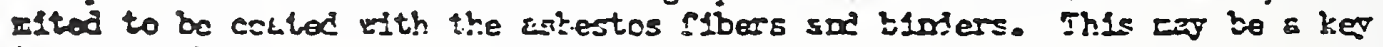
to ow rrit? er.

Dnder secticn E of the atteched dsta shoet is dsta of kend tests

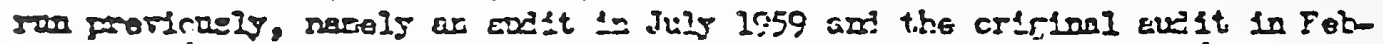

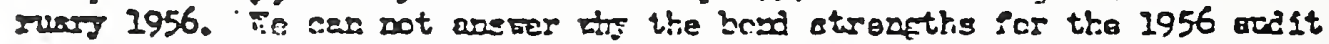

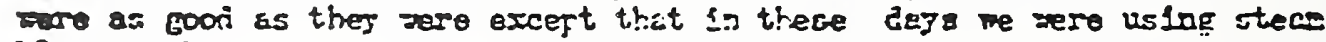
blown mocl.

FES/ed

CC - J. T. Terhalea
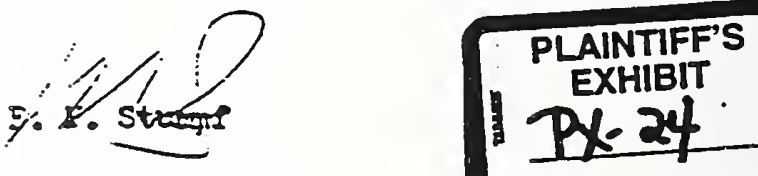

Figure A-50. Correspondence indicating poor bond performance of sprayed thermal insulation during vibration testing (51-ITK). 


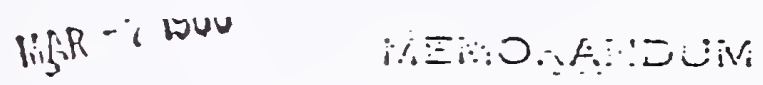

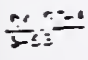

\section{.0011814}

テะ

F.スニะ,

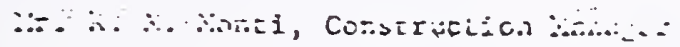

ปกัยะ:

F. H. H:incirc

Sルミ:ミこ丁：

$==c-6,1505$

REFERERICE:

COPY TO: ".ressrs. Levy w/att., Endler (TKCC) w/att.

The attached are letters 2 tec $\because E=c h 1, i 56 \varepsilon$, froc toth i-aftea

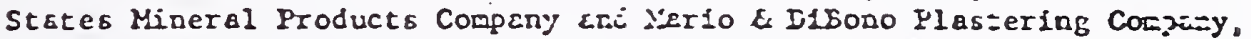
plus a merorandum from. Tony Calebrese, ieted Jarch 4, 1968, reiative to an "on-the-job" application of Cafco sproy-on insuleting naterial. Tr.a cosseats of all are facturl with no exaggeretion. I was truly arazed at the ebllity of this material to adhere to the steel and to itself ucher adverse weather conditions. I exanined lhe material agein on this dete and found it to be le tact.

In my opinion this materiai cen ie epplate successfully is ti:

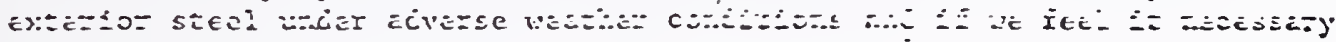
I cas. re:

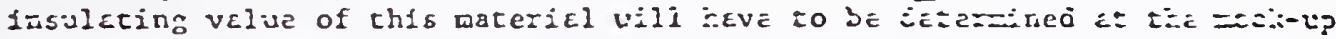
teSt La ST. EOLIS.

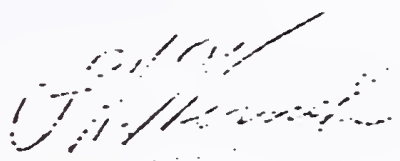

F. H. Heznicie Assistent Construction jeneger The horld Trade Ceater

Fris/eso

Figure A-51. Correspondence indicating acceptable performance of BLAZE-SHIELD Type D when applied under adverse weather conditions (250-P). 
Jamer 26,1970

\author{
Itr. Jouph Iesre \\ Depors Candenlenses

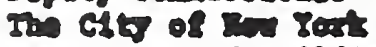

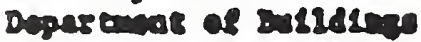 \\ 2 infaretes 8triest \\ ace rert, Ine rast 10008

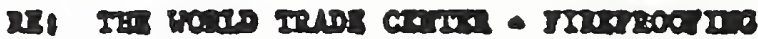

iv dear conderlocers

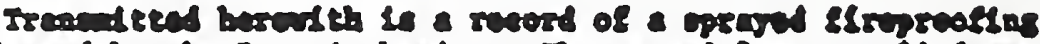

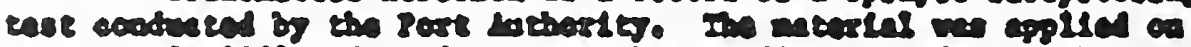

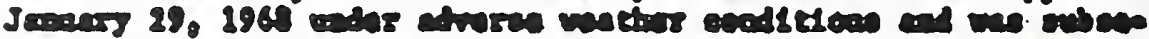

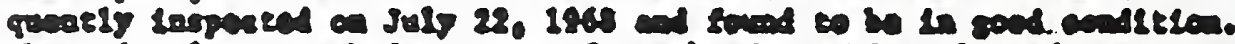

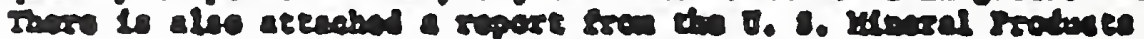

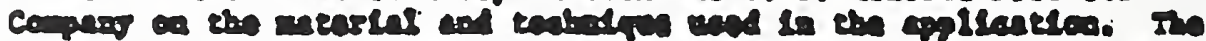

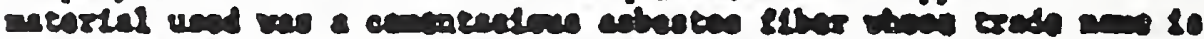

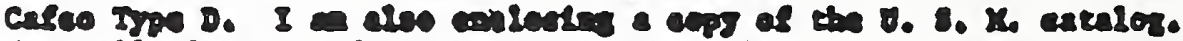

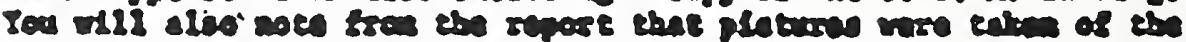

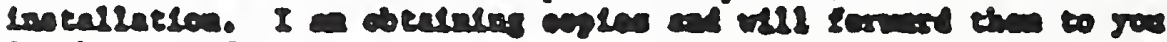
In tho mase suture.

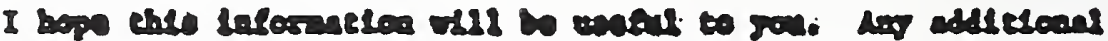

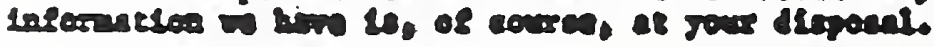

elmasty.

Mecolu R. In

ton.

MPL:fg:jtm

bec: Messrs. J. Kyle, R. Mont1

Figure A-52. Correspondence sent to New York City Department of Buildings in 1970 providing information on the performance of BLAZE-SHIELD Type D (92-ITK). 
IYILISURTILL AI:MUIENOUIS

S.8. Verbulen

$\therefore$ narry Cropo

Dolor Doc. 11. 1969

- Lat shlposnt of gecelal Iypo D to Losld Trado Conter

Th.0 last 800 bag ahlpesnt (20 tons) shlppod to tho Horld Irado Cares was aprayod on Frlday. Dee. Sth, Saturday. Doc, beh and hass of Sunday, Dee. 7th.

Of the 20 cons of materlal sprayod to the loth 1 loor extorlor colums on thla projoct, approxlately $600-700$ bage of tho wtorlal wathud off al clean as a whlstle lrom the exterlor colume on thls job.

On reporting thls experlence to Frank Stumps, ho couldn't bollove that thlo could heppen. On Dcs. 9th, 1969, Trank Stump and Slggy Sunskl vislced tho Horld Trade Centor in the company of Allen Bessosar to vlny thls n..........

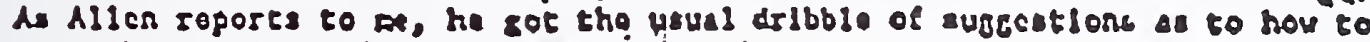

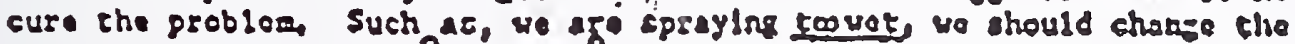
deperser tlp frod $60^{\circ}$ to a $75^{\circ} \mathrm{tlp}$ and there was too guch hose on the 8 loor.

A. AIlen knous, as I knos, as you know, as Frank Stumpl knous, and al Bob Reth know, nono of those suggestlans aro golns to cure what de the roel probloss of chls saterlal on the Horld Trade Canter. Slnce we all knor the problem but unfortunately don't have tho guts to tall each othor in our oun cospany. un know that the real problom is the busy. poor, sub-ctandard product thnt wo are trylne to get our cuetoress to accopt ard apply, and don't of vo wo that the veatlier may

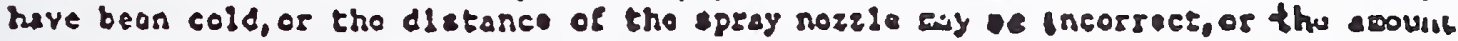
it tho blover prescure eay bo off, or the.dlaporser ilp asy be tho vrons ono, bocalise all of theso thlass have bocn actually flold trled on thl sob and ve are hoadod lor potentlal dlsaster - to put it very bluntly.

Is this company doesn't reallze nov, that the product wo are shlpplns to ous custorara Is poor quility. Infcrior quality lor whlch te are asklns list prlcos or prlces above whet is akkod for by our competitors, and for unlch ve are askins our, applicators to apply 20 to 30 per cent wore meterlal for, and for whleh ve havo no rlght or rasion to axk a greater prlco for, no wetter how you look at it, then ve hed bette? vake up very, very soon to thls tact.

I can no longoi accept chet ve aro trylng very hard to overcon our problens. Our custoners realiy con't glye a dep how hard foremin or superlitendent vorks in our plant. It doosm't sean two good das to hla that a saperlatendent 1. loating. truck. All he vanta, and he has o porfect rlght to expect. Ineo

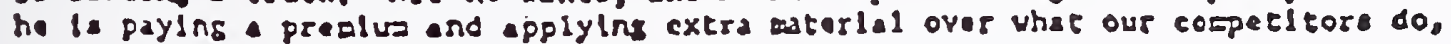
1. a product that coes what vo say 16 ulll do.

Whethor wo have the daliy IBM Invontory report, or whethur ve cosure comothlus on silde rule realiy isn't perelnent to our real corporate problezs. Tho sooner we begln to lcam what our real problems are, then and only than vild ve bo able to achleve prolltable alos.

Figure A-53. Intra-office correspondence dealing with adhesion problems during spraying of exterior columns in WTC 1 (248-ITK). 
For ovar one year, the Salua Dopartmeat has livod ulth sub-standard,-sub-par, balou qualsty meorlel producte. Hy. ma, and myels, have overcome complaint upon complalat ulth vory lor contractorr coklng for compenention for oxporleneas due to rock3, ulra, nute, boles, lath, paper bass in the product. I foel we have cone to the end of the IIno. Orr contractora seel we have como to the ond of the Ilne. Plouse, no further emblguss excuses. Tou vant a company - thos let's sake the product.

\title{
Rines Gropp
}

\author{
$\operatorname{cel}$ R. Rish \\ P. Stump \\ A. Bosseges \\ X\& D P B? \\ YIC IdI \\ HSG
}

Figure A-53 (Contd.). Intra-office correspondence dealing with adhesion problems during spraying of exterior columns in WTC 1 (248-ITK). 
MEMORANDUM

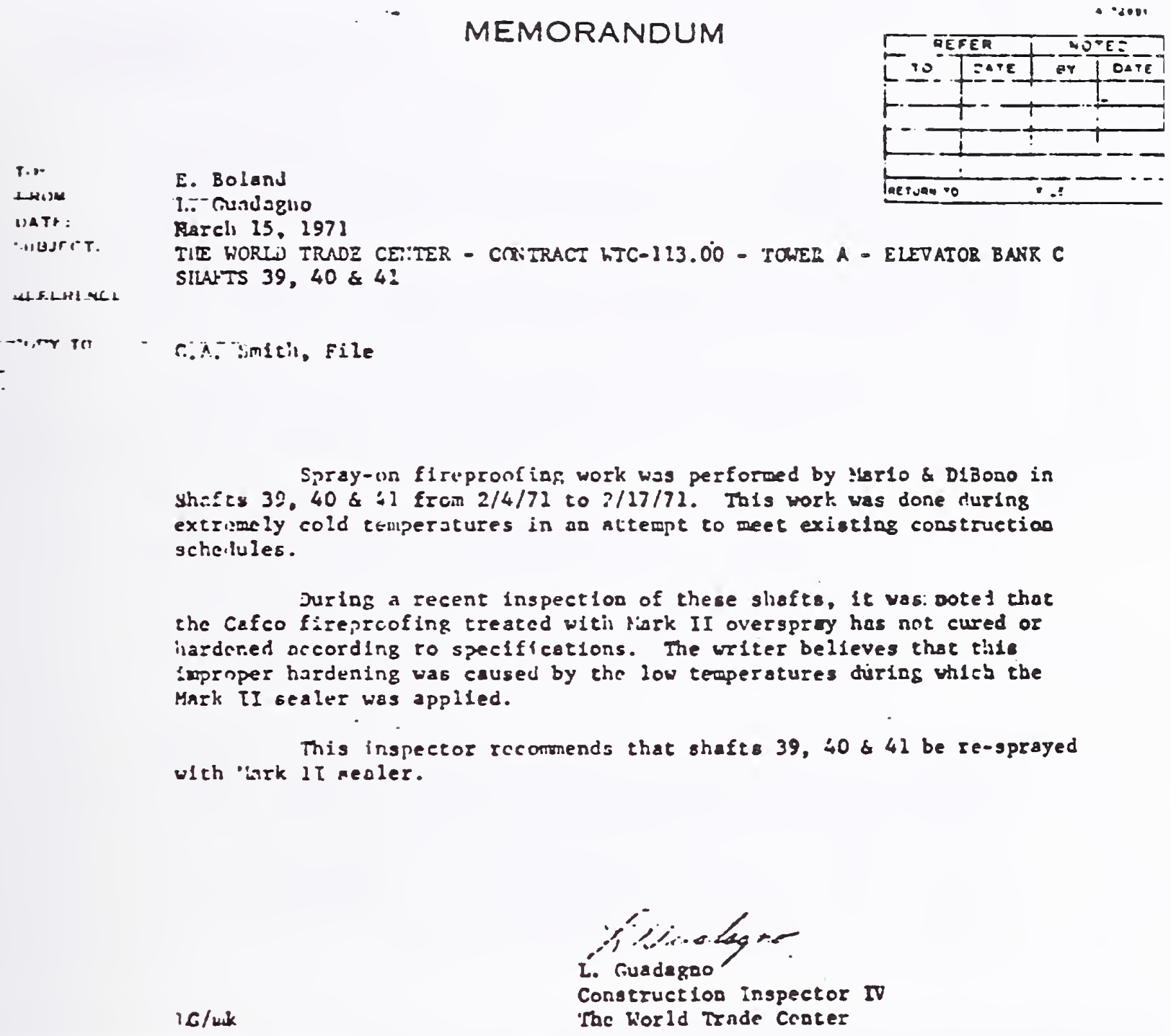

Figure A-54. Correspondence related to inadequate hardening of thermal insulation applied to core columns (660-P). 
TO: $\quad \int_{\text {D. Meyers }}$

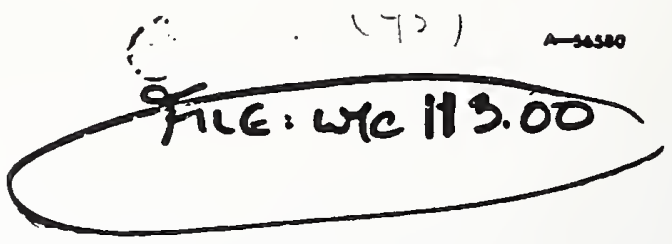

FROM: $\quad$ E. J. Bol and

SUBJECT: THE WORLD IRADE CENIER - CONTRACT WTC 113.00 - TOWER "B" EIEVATOR SHAFTS

\#10 $i$ \#II - LOOSE AND FALIING SPRAY-ON FIREPROOFING

Photos attached, B-1, B-2, B-3, B-4

COPIES:

R. LInn, C. A. Smith; B. Heinstein (IRCC); F1le

Our inspection of the above mentioned shafts indicates that the spray-on fireproofing has been improperly applied in several areas.

The flreproofing has come loose and fallen at floors 35,40 and 43 in shaft 410 and at floor 31 In shaft 11 . Also several small sections have come loose from perimeter box beams in both shafts.

He request that you direct the contractor Marlo \& DiBono, to re-spray the above mentloned areas as reguired under their Contract. Please refer to Chapter II, Page 123, Section 13.03 - Product Qualifications."...the material shall resist the normal abuse resulting from the construction work of subsequent trades, shall not crack, craze, dust or disintegrate and shall adhere to the base surfaces with sufficlent strength to insure against any loosing and falling off of applied material." And Page 126, Section 13.07 - Workmanship "4. The sprayed-on fireproofing and sprayed-on Insulation, when completed, shall be free from seams, staging breaks, holes, apalls, cracks, flaking and dusting action, and other defects of any kind."

RV/ Ip
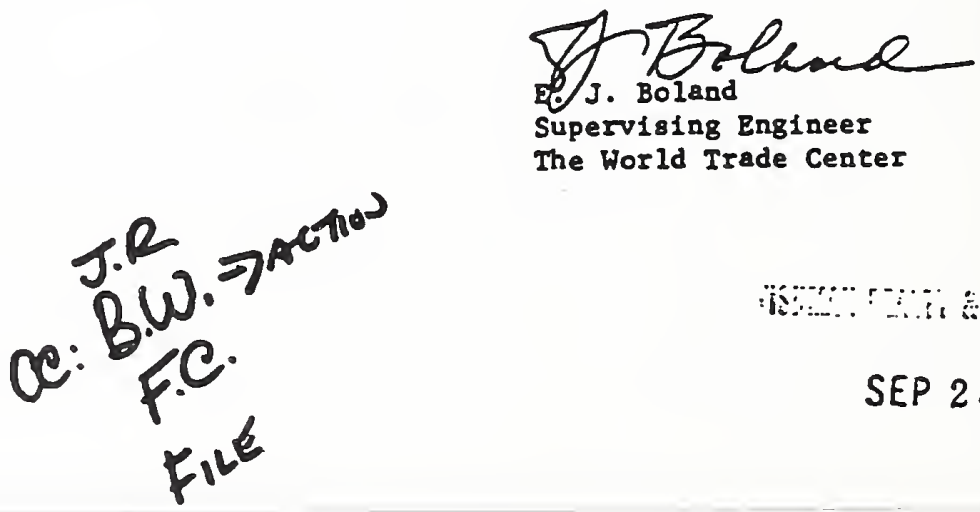

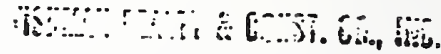

SEP $2 \leq 19 / 3$

Figure A-55. Correspondence related to dislodged thermal insulation within elevator shafts of WTC 2 (658-P). 


\title{
LERA
}

WORLD TRADE CENTER

Structural Integrity Inspection

Accessible Columns $\& 1,2,4$ and 5 WTC

\author{
P1103904 3927 \\ 29 January 1993 \\ Page 1 of 9
}

\section{EXICOTIVI SUMAARY}

This report details the findings of the inspection of accessible columns in the elevator shafts of 1,2 and 5 world Trade center.

No structural deficiencies such as cracking or bowing were found in any of the columns inspected.

The most common irregularities observed were missing fireproofing and light surface rusting of exposed steel.

We recommend that fireproofing be repaired on all columns in the elevator shaft

Figure A-56. Excerpts from 1993 structural integrity inspection report related to condition of thermal protection on accessible columns (16-FEMA). 


\section{LERA}

WORLD TRADE CENTER

Structural Integrity Inspection

Accessible columns $e 1,2,4$ and 5 WTC
P1103904\& 3927

29 January 1993

Page 5 of 9

\section{PROCEDURE \& IIST OI INSPECTED COLOMNS}

The visual assessment of the accessible columns in the elevator shafts was carried out from top of the elevator cars. The elevator was operated by a field inspector from National Elevators.

The operator ran the elevator at a very slow speed from top to bottom and if any irregularity was noticed the car was stopped and the defect was duly noted and, at times, recorded using a $35 \mathrm{~mm}$ camera.

A total of 10 elevator shafts were selected. This selection included 8 local elevators and 2 express elevators. Table $A$ gives a listing of all the elevators and columns inspected during this survey.

Figure A-56 (Contd.). Excerpts from 1993 structural integrity inspection report related to condition of thermal protection on accessible columns (16-FEMA). 


\section{LERA}

WORID TRADE CENTER

Structural Integrity Inspection

Accessible columns $\mathrm{e}, 2,4$ and 5 WTC
P1103904 3927

29 January 1993

Page 6 of 9

TABLE A

\begin{tabular}{|c|c|c|c|c|}
\hline Tomer & $\begin{array}{c}\text { Slevator } \\
\text { Shaft Number } \\
\end{array}$ & $\begin{array}{c}\text { Eloors } \\
\text { Inspected }\end{array}$ & $\begin{array}{c}\text { Adjacent } \\
\text { Colunon Number }\end{array}$ & $\begin{array}{c}\text { Face of Column } \\
\text { Inspectod }\end{array}$ \\
\hline \multirow[t]{10}{*}{$\begin{array}{ll} & A \\
(1 & \text { WTC })\end{array}$} & 21 & $4-78$ & 606 & East \\
\hline & & $4-78$ & 607 & West \\
\hline & 36 & $1-32$ & 701 & East, South \\
\hline & & $1-32$ & 801 & East, North \\
\hline & 63 & $45-67$ & 701 & East, South \\
\hline & & $45-67$ & 801 & East, North \\
\hline & 73 & $43-74$ & 703 & North, West \\
\hline & & $43-74$ & 803 & North, West \\
\hline & 83 & $78-93$ & 701 & East, South \\
\hline & & $78-93$ & 801 & East, North \\
\hline \multirow[t]{8}{*}{$\left.\begin{array}{rl} & B \\
(2 & \text { WTC }\end{array}\right)$} & 15 & $4-78$ & 602 & North \\
\hline & & $4-78$ & 603 & South, west \\
\hline & 29 & $1-16$ & 707 & South, East \\
\hline & & $1-16$ & 806 & South, West \\
\hline & 56 & $45-54$ & 707 & South, East \\
\hline & & $45-54$ & 806 & South, West \\
\hline & 78 & $78-86$ & 707 & South, East \\
\hline & & $78-86$ & 806 & South, West \\
\hline $\begin{array}{l}\text { Northeast } \\
\text { Plaza } \\
\text { (5 WTC) }\end{array}$ & $\frac{E-7}{28}$ & $1-9$ & $\frac{E-7}{28}$ & w \\
\hline
\end{tabular}

See Appendix $A$ for the plan locations of the above columns.

Figure A-56 (Contd.). Excerpts from 1993 structural integrity inspection report related to condition of thermal protection on accessible columns (16-FEMA). 


\section{LERA}

HORLD TRADE CENTER

Structural Integrity Inspection

Accessible Columns $1,2,4$ and 5 WTC
P1103904\&3927

29 January 1993

Page 7 of 9

\section{OBSERVATION}

Appendix B-2 shows the typical cross sections of columns used in elevator shafts. These columns are encased with sprayed on fireproofing. (Photo 1)

The most common irregularity in the express elevator shafts was spalling o missing fireproofing. The probable cause of this spalling may be attribute to:

- rubbing of the hoist cables against the face of column.

- air pressuresinduced due to high speed of the elevators moving up and down the shafts

Photograph 2 shows a patch of missing fireproofing at support brackets for conduits and elevator hardware. It appears that the fireproofing was removed when this bracket was installed.

Photograph $3,4 \& 5$ show typical patches of spalled fireproofing caused probably by rubbing of hoist cables against the girder and column faces.

Large areas of fireproofing were missing from the faces of column 606 and 607 in one World Trade Center.

The columns in local elevator shafts were generally well protected by fireproofing.

Isolated areas of spalling fireproofing were noticed on some of the columns in the local elevator shafts. (Photo $7,8,9$ )

Photograph 10 shows large areas of damaged and spalling fireproofing on colums E-7/28 in the North East plaza building.

Light surface rusting was typically noticed in areas of exposed steel.

Figure A-56 (Contd.). Excerpts from 1993 structural integrity inspection report related to condition of thermal protection on accessible columns (16-FEMA). 
One and Two World Trade Center Strucural Integrity Inspection Accessible Columns
14 April 1995

File: P1113903

Page 1 of 10

\section{Executive sumary}

Leslie E. Robertson, R.I.L.P., (LERA) carried out a survey of the accessible columns in the elevator shafts of one and Two World Trade center as part of the ongoing structural integrity inspections. This survey was undertaken for the purpose of ascertaining the condition of the accessible columns in the elevator shafts in terms of the overall structural integrity of the accessible column, for signs of rust or cracking, bowing, or deviation from plump, to identify specific locations of structural distress or damage, to identify locations of damage to the fireproofing envelopes, for lateral displacement or rotation of the column about a vertical axis where the column is braced directly on only one axis by connecting beams or abutting concrete slabs due to large beam offset dimensions, for signs of rust, or deformation of the slabs on ground surrounding each column at sub-level, and to provide recommendations for remedial work for both structural and fireproofing damage.

Most of the information presented in this report originates from on-site observations of selected columns within elevator shafts made by LERA during March 1995. The visual assessment of the accessible columns in the elevator shaft was carried out from the top of the elevator cars, by a field inspector. A total of 24 (Twenty-four) elevator shafts and 56 (Fifty-six) elevator pits were selected, this selection included 10 local elevators and 14 express elevators.

The accessible colums in the selected elevator shafts of One and Two World Trade center are generally in good condition, no structural deficiencies such as cracking or bowing were found, the most common irregularities observed were missing fireproofing and light surface rusting of the exposed steel.

Based on our observation and our evaluations of the inspection, we believe that the structural integrity of the accessible columns within the selected elevator shafts are satisfactory. Areas of concern, in terms of remedial work to be taken, are the fireproofing envelopes and the corrosion of the exposed steel. We recommend that the fireproofing be repaired on all columns within the selected elevator shafts. We also recommend that the exposed areas of steel be cleaned orior to re-fireproofing.

Figure A-57. Excerpts from 1995 structural integrity inspection report dealing with accessible columns (17-FEMA). 


\section{LERA}

One and Two World Trade Center Strucural Integrity Inspection Accessible Columns
14 April 1995

File: P1113903

Page 5 of 10

\section{INSPECTION NETHODOLOGY}

Since the concurrent visual inspection of all the accessible columns or even a major portion of them is not a practical goal, a statistical approach is followed. This approach involves the sampling of those components and systems which are more important to structural integrity, and at locations with a relatively higher potential for occurrence of defects or problems. A visual inspection of the accessible columns located in the rectangular core (the elevator area) was made from the top of the elevator cars and from a walk-through of the elevator pits. The elevator car was operated by a field inspector from A.C.E. Elevator Co. The operator ran the elevator car at a very slow speed from the top of the car. within the bounds of the suggested sampling procedure, the inspection frequency and the building layout, it was anticipated that the inspection work could be organized to proceed in a more or less linear sequence to minimize both wasted motion and duplication of effort, and to help assure that no important item was missed. The inspection team carried a set of reduced drawings, individual field notebook, a camera and a flashlight, methods and procedures were conformed strictly to the port Authority safety regulations.

Visual inspection was supplemented by the use of simple hand tool such as a screw driver as needed. Where structural steel columns or the connecting beams were covered by sprayon fireproofing, removal of loose, cracked or rust-stained cover material was provided to examine the steel. A number of on-site visits were made to obtain the current condition of the accessible columns. No lifts were used for the inspection. The inspection findings were recorded on copies of architectural drawings. The accessible columns were not directly visible due to their fireproofing; therefore, the focus of the visual observations depended largely on the condition of the fireproofing. However, in several instances, the structural columns and the connecting beams were visible for inspection purposes or due to spaliing of fireproofing.

Figure A-57 (Contd.). Excerpts from 1995 structural integrity inspection report dealing with accessible columns (17-FEMA). 


\section{LERA}

One and Two World Trade Center

14 April 1995

Strucural Integrity Inspection

File: P1113903

Accessible Columns

Page 7 of 10

\section{DETAILED INSPECTION FINDINGS}

This report details the findings of the inspection of the selected accessible columns within elevator shafts. Our inspection findings and our opinions concerning the findings and our recommendations for remedial action are summarized below. Detailed inspection findings can be found in Appendix $E$ and $F$.

The inspection was undertaken to ascertain the condition of the columns in the elevator shafts in terms of the overall structural integrity. Columns were observed for signs of rust or cracking, bowing, or deviation from plump, to identify specific locations of structural distress or damage, to identify locations of damage to the fireproofing envelopes, for lateral displacement or rotation of the column about a vertical axis where the column is braced directly on only one axis by connecting beams or abutting concrete slabs due to large beam offset dimensions, for signs of rust, or deformation of the slab on ground surrounding each column at sub-level, and to provide recommendations for remedial work for both structural and fireproofing damage.

Most of the information originated from on-site observations of selected columns within elevator shafts made by LERA during March 1995. The visual assessment of the accessible columns in the elevator shafts was carried out from the top of the elevators cars, by a field inspector. A total of 24 (Twenty-four) elevator shafts and 56 (Fifty-six) elevator pits were selected, this selection included $10(\mathrm{Ten})$ local elevators and 14 (Fourteen) express elevators.

The accessible columns in the selected elevator shafts of One and Two World Trade center are generally in good condition, no structural deficiencies such as cracking or bowing were found, the most common irregularity in both the express and the local elevator shaft were spalling \& missing of fireproofing, the probable cause of this spalling may be attribute to rubbing of the hoist cables against the face of column, or air pressure induced due to high speed of the elevator cars moving up and down the shaft, or due to testing purposes. The exposed steel revealed only light to moderate surface rust.

Figure A-57 (Contd.). Excerpts from 1995 structural integrity inspection report dealing with accessible columns (17-FEMA). 
LERA

One and Two World Trade Center Strucural Integrity Inspection

14 April 1995

Accessible Columns

File: P1113903

Page 9 of 10

\section{CONCLUSIONS AND RECOMMENDATIONS}

Our opinions concerning the findings and our recommendations for remedial action are summarized below. Detailed suggested remedial action can be found in Appendix $B, E$ and $F$.

Based on the survey data we collected and our evaluations of this data, we believe that the structural integrity of the accessible column in the selected elevator shafts is satisfactory. We recommend that remedial action to be taken where spray fireproofing is damaged, deteriorated or missing and where there is corrosion of the column base due to water leaks in the elevator pits.

The following are our specific recommendations for the structural and fireproofing damage we observed.

\section{Spalling, Missing and Damaged Fireproofing}

We recommend that the exposed areas of steel be properly cleaned and then protected with fireproofing. The existing spray fireproofing may contain asbestos, therefore, adequate measures need be undertaken to ascertain the presence of asbestos and to ensure both the protection of personnel and the proper handling of the material.

\section{Water Leaks, Corrosion and Accumulation of Debris in Elevator Pits}

At express and local elevator pits of both 1 WTC and 2 WTC, where evidence of past or present water leaks has occurred, we recommend that the following action be taken:

- areas of current water leaks be drained;

- where steel has been corroded, chip away the floor concrete surrounding corroded steel to a depth where corrosion no longer exists:

- clean and inspect all the steel, welds and bolts at these locations to determine the extent of corrosion;

- repair steel, welds and bolts as required; and

- prior to re-fireproofing steel, paint with a zinc-rich paint.

We also recommend that the accumulation of jebris in elevator pits be removed and a maintenance program involving cleaning be provided.

Figure A-57 (Contd.). Excerpts from 1995 structural integrity inspection report dealing with accessible columns (17-FEMA). 
TO:

FROM:

DATE:

SUBJECT:

REFERENCE:

COPY TO:
E. Ramabbushanam

S.M. Solomon

March 17. 1994

WTC Existing Fireproofing

As requested, the Chemical Division performed numerous thicioness measurements on existing fireproofing located on the 23rd and 24th floors of the WTC North.

Damaged and/or absent fireproofed areas on the 23rd Floor were repaired with patch material; These areas were not measured. Truss members located adjacent to the outside walls (within 3 feet) are devoid of fireproofing material. Visual inspection of the truss members on the 24th floor was not possible, as this area still has a lowered ceiling in place. Tests were taken through areas where ceiling tiles were removed. Thickness readings were taken on. 16 random truss members on each floor. Measurements were taken from both flanges and webs of the truss member.

At each of these locations, a total of six individual measurements were made and averaged. These mini averages are listed on the attached table along with a total average, standard deviation, high value and low value for each floor.

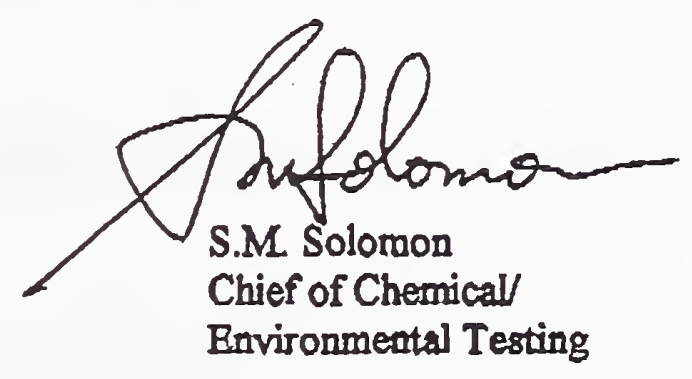

RG

Figure A-58. Correspondence and data related to 1994 measurements of thermal insulation thickness on floor trusses for $23^{\text {rd }}$ and $24^{\text {th }}$ floors in WTC 1(3-P). 
MPR-17-1995 16:31 FROM PA MATERIALS DIU. TO

NUMBER TWO WTC EXTSTING FIREPROOFNG THICKNESS

$180555^{\circ}$..... P

\begin{tabular}{|l|r|r|}
\hline & & \\
\hline & & \\
Readings, inches; & 0.60 & 0.76 \\
\hline & 0.53 & 0.70 \\
\hline & 0.70 & 0.60 \\
\hline & 0.76 & 0.90 \\
\hline & 0.88 & 0.72 \\
\hline & 0.89 & 0.64 \\
\hline & 0.83 & 0.80 \\
\hline & 1.17 & 0.68 \\
\hline & 0.88 & 0.65 \\
\hline & 0.71 & 0.67 \\
\hline & 0.82 & 0.77 \\
\hline & 0.52 & 0.86 \\
\hline & 0.69 & 0.66 \\
\hline & 0.52 & 0.65 \\
\hline Average & 0.64 & 1.11 \\
\hline Standard Deviation & 0.52 & 0.95 \\
\hline High & 0.73 & 0.56 \\
\hline Low & 0.14 & 0.76 \\
\hline
\end{tabular}

Figure A-58 (Contd.). Correspondence and data related to 1994 measurements of thermal insulation thickness on floor trusses for $23^{\text {rd }}$ and $24^{\text {th }}$ floors in WTC 1 (3-P). 
From:

Sent:

To:

Subject:
Lombardi, Frank

Tuesday, February 12, 2002 3:03 PM

'edepaola@severud.com'

WTC - 1 1/2" SPRAY-ON FIREPROOFING UPGRADE

\section{Fireproofing Upgrade}

The 1 $1 \frac{2}{2}$ " spray-on fireproofing was established in 1995 , to address any new construction for which the PA's Engineering Department was the Engineer-of-Record and to acknowledge that

$11 / 2$ " of spray-on mincral fiber was sufficient when applied directly to chord and web members of the floor trusses to provide the 2 -hour fire rating for the floor.

It was required on all full floors being demolished for new construction or renovation either by the tenant or the PA. Because it was a landlord obligation, reimbursement was made to the tenant if the work was performed by the tenant.

Tenant spaces that were less than a full floor, undergoing either new construction or renovation, needed only to meet the original construction standard. Fireproofing had to be inspected and patched as required to the greater of $3 / 4$ " or to match existing (it may already have been upgraded to the $1 \frac{1}{2}$ ").

The PA was also responsible to test the application of the sprayed-on fireproofing for conformance with ASTM E-605, "Thickness and Density" and ASTM E-736, "Adhesion/Cohesion". The tests were also in conformance with the NYC Building Code.

Here's the information about the 11/2" upgrade in the upper third zone of both Towers ( $77^{\text {th }}$ floor and above).

Based on our records, a total of 18 floors in Tower 1 and 13 in Tower 2 were upgraded with $1 \frac{1}{2}$ " spray-on fireproofing.

The entire impact zone for Tower 1 (92-99) was upgraded with the $1 \frac{1}{2}$ " spray-on fireproofing. Only the $78^{\text {th }}$ floor was upgraded with the $11 / 2$ " spray-on fireproofing within the impact zone in Tower $2(78-84)$.

We're still working on the population and should have it to you shortly.

Figure A-59. Port Authority correspondence indicating number of floors where thermal insulation on floor trusses was upgraded to $1 \frac{1}{2}$ in. (73-LERA). 


$\begin{array}{ll}\text { TO: } & \text { Eli Moscovitz } \\ \text { FROM: } & \text { Dorian Bailey } \\ \text { DATE: } & \text { September 28, } 1999 \\ \text { SUBJECT: } & \text { World Trade Center: Test of Fire Resistive Material } \\ & \text { Contract WTC - 697.00 W.O. \#4682 Charge \#W02-857090 } \\ \text { COPY TO: } & \text { C. Bognacki, J. Bullard, P. Ortiz, J. Shanahan, M.Young, E.F. }\end{array}$

As requested, the Materials Engineering Division has tested the application of the sprayed-on fireproofing, CAFCO Blaze-Shield II for conformance to Port Authority specifications. The material was applied at the $102^{\text {ed }}$ floor of WTC \#1.

The tests were performed in accordance with ASTM E-605, "Thickness and Density" and ASTM E-736 "Adhesion/Cohesion" of Sprayed Fire Resistive Materials Applied to Structural Steel Members".

The results are as follows:

\begin{tabular}{|c|c|c|c|}
\hline & $\begin{array}{l}\text { Density } \\
\underline{\text { lb./cu. ft. }} .\end{array}$ & $\begin{array}{l}\text { Adhesion/ } \\
\text { Cohesion } \\
\text { lb./sq.ft. }\end{array}$ & $\begin{array}{l}\text { Thickness } \\
\text { Inches }\end{array}$ \\
\hline Minimum Requirements & $\underline{15.00}$ & 150 & $\underline{1.50}$ \\
\hline $\begin{array}{l}\text { TEST AREA \#1 } \\
1 \text { WTC } 102^{\text {nd }} \text { Floor } \\
\text { Truss } 131 \text { North } \\
\text { Bottom of truss }\end{array}$ & 16.47 & 333 & 3.25 \\
\hline $\begin{array}{l}\text { TEST AREA } \# 2 \\
1 \text { WTC } 102^{\infty} \text { Floor } \\
\text { Truss } 231 \text { East } \\
\text { Bottom of truss }\end{array}$ & 16.87 & 333 & 3.25 \\
\hline $\begin{array}{l}\text { TEST AREA } \# 3 \\
1 \text { WTC } 102^{* d} \text { Floor } \\
\text { Truss } 313 \text { South } \\
\text { Bottom of truss }\end{array}$ & 15.93 & 315 & 2.11 \\
\hline
\end{tabular}

Figure A-60. Example of test report on upgraded thermal insulation for floor trusses (3-P). 
The test results indicate that the applied fireproof material, CAFCO Blaze-Shield II meets Port Authority specifications. Therefore the Materials Engineering Division recommends the acceptance of the fireproofing material.

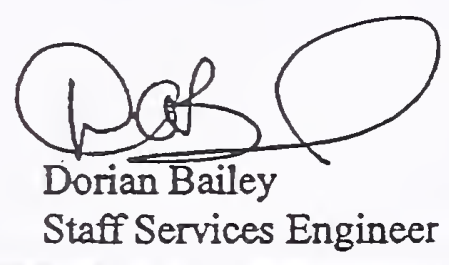

Figure A-60 (Contd.). Example of test report on upgraded thermal insulation for floor trusses (3-P). 


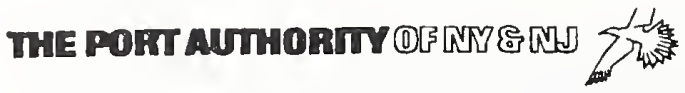

March 23, 2004
FRANCIS J. LOMBARDL P.E.

CHAEF ENGINEER

225 PARK AVENUE SOUTH, 18TH FLOOR NEW YORK, NY 10003

(212) $435-7449$

(212) 435-6089 tAX

flombord@ponyni.gov

John L. Gross, Ph.D., P.E.

Leader, Structures Group

United States Department of Commerce

National Institute of Standards and Technology

Gaithersburg, MD 20899-0001

Dear Dr. Gross:

Following are responses to your questions, which are repeated here in bold italics. The PDF file attached has information previously submitted to NIST as a reference to some of your questions.

In 1994, the Port Authority's Chemical Division carried out measurements of existing fireproofing on the $23^{\text {rd }}$ and $24^{\text {th }}$ floors of WTC 1 . Averages of 6 individual measurements at 16 random locations on each floor (for a total of 32 locations) were reported in a memorandum of 17 March, 1994. While the information reported is useful, additional information is necessary to determine the true statistics of the fireproofing thickness. NIST would like to request the following:

1. Please provide individual measurements, rather than the averages, for all the tested locations.

The current supervisor and staff of our Chemical/Environmental Testing Laboratory cannot find the supporting information for Mr. Solomon's memo of March 17, 1994. They do, however, state that the procedures similar to those described below in response to question 2 were followed at the time to establish the average thickness data listed in the table.

Construction audit reports of upgraded fireproofing thickness (floors 92-100 of WTC 1 and floors 77-78, 88-89, 92, 96-97 of WTC 2) indicate that thickness measurements were performed in accordance with ASTM E-605. There is, however, a discrepancy between the required procedure established by ASTM and the Port Authority's audit report data, which states that values were recorded only at the "Bottom of Truss" (see for example, memorandum of November 24, 1999, regarding material applied on 79th floor of WTC 1). Regarding th is discrepancy, NIST would like to request the following:

Figure A-61. Correspondence from Port Authority addressing questions related to thickness of thermal insulation on floor trusses (681-P) 


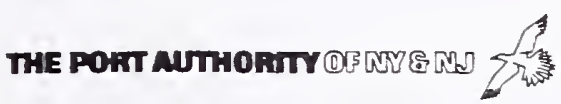

John L. Gross, Ph.D., P.E.

National Institute of Standards and Technology

March 23, 2004

Page 2

\section{Please clarify specifically what procedures were used to measure the fireproofing thickness.}

A depth gage is used to determine thickness as follows: A thickness probe made of a needle that extends out along a measured scale is inserted into the fireproof material and stopped at the surface of the steel. The reading of how deep the needle extended into the fireproofing material is shown on the probe and recorded by an inspector. Thickness measurements are taken around the entire member. For the report in question of $11 / 24 / 99,8$ discrete measurements were taken to support the result of an average thickness measurement of 2.36 inches.

\section{Please clarify why only data from the "Bottom of Truss" were reported.}

The labeling of "Bottom of Truss" pertains to the location of collection of the physical sample, not field-testing of thickness. A test sample was obtained from the bottom of the truss for density testing, and also represents the location of the pull test. Fireproofing thickness measurements were taken from the truss diagonals as well as the upper and lower truss members, not only at the "Bottom of Truss".

\section{Please provide individual measurements rather than averages.}

The original thickness measurements taken from this report are: $21 \frac{1}{8}, 2 \frac{1}{4}, 21 \frac{1}{2}, 23 / 4,11 \frac{1}{2}, 13 \frac{13}{4}, 13 \frac{3}{4}, 21 \frac{1}{4}$ inches.

Finally, in 1995 the Port Authority stated in a memorandum and white paper (memorandum dated August 18, $1995 \mathrm{by}$ 'Joseph M. Englot) that 1.5 inch thickness of spray-on mineral fiber was required to achieve a 2-hour rating for steel joist trusses in WTC 1 and 2. Based on the 1995 information, guidelines for fireproofing repairs were established in 1999 (buckslip dated March 24, 1999 by Alan L. Reiss).

5. Please clarify what is meant by the requirement that 1.5 inches of spray on fireproofing was to be required only on "new construction."

The term "new construction" means any construction performed in the World Trade Center through a contract or work order that required the application of fireproofing. For example, refireproofing floors that have had asbestos mitigation, or otherwise re-fireproofing truss joists where the removal of old ceilings, ducts, light fixtures, and installation of new finishes required significant repair or replacement of the old fireproofing material.

6. Please clarify the technical basis for permitting tenant spaces where less than a full floor was being renovated to be patched to $3 / \%$ " of spray-on fireproofing rather than the 1.5 " required to achieve a 2-hour rating.

Figure A-61 (Contd.). Correspondence from Port Authority addressing questions related to thickness of thermal insulation on floor trusses (681-P). 


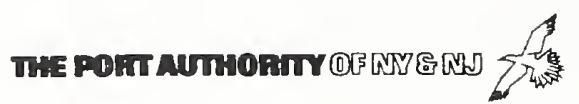

John L. Gross, Ph.D., P.E.

National Institute of Standards and Technology

March 23, 2004

Page 3

For questions $5 \& 6$, the NIST investigative team needs to understand that the guidelines that were developed for upgrading the fireproofing were developed as part of an overall fire safety program that looked at active and passive fire protection along with operating procedures, developed in consultation with outside fire protection experts by the Port Authority's Engineering, Risk Management, and World Trade Departments.

To understand the rationale developed for the fireproofing, one needs to go back to the early $90 \mathrm{~s}$. The Port Authority had been relocating tenants in the first zone of One WTC, performing asbestos abatements of the fireproofing on the trusses, re-fireproofing and installing sprinkler loops. The Meridian Plaza fire in Philadelphia caused the Port Authority to accelerate this program and to ninimize the number of contiguous floors that were not sprinklered since the benefits of sprinklers were well known and their effectiveness was dramatically shown during the One Meridian Plaza fire.

Subsequent to the 1993 terrorist attack on the World Trade Center, the PA performed a critical self evaluation of the World Trade Center and decided on a number of upgrades including new decentralized fire alarm systems for the complex, fire command consoles in the lobby of each tower staffed around the clock by FDNY certified fire safety directors, continued acceleration of the sprinkler installation within the towers, including the sky lobbies, and increasing the fireproofing requirements for the trusses.

The new fireproofing thickness requirements were incorporated immediately into contracts being written for the abatement and re-fireproofing of floors in the first zone of One WTC and whenever space was demolished and made ready for potential re-leasing. Subsequent to J. Englot's 1995 memo, questions, though, continued to arise regarding whether or not the fireproofing upgrade was required during minor alterations done by tenants. Tenants were required to file Tenant Alteration Applications (TAAs) before any work was performed in their space to make sure the PA could inspect the work. While there were some major alterations, there were many more minor alterations such as the installation of computer and communication network cabling, sprinkler head relocation, adding an air conditioner for a conference room, lighting upgrades, etc. To properly apply the new thickness, at least two sprayed on applications with a sufficient drying time between applications was required. This was not practical in occupied office space where the work consisted of minor alterations such as just installing additional data and voice lines. The implementation of the new 1.5" standard during these minor alterations resulted in situations where ten feet of a single truss, where the ceiling tiles were removed, was upgraded while the balance remained untouched. There was ongoing consideration given to the question of how to properly upgrade the fireproofing if tenant partitions were still standing up to the underside of the slab. As a result, overall benefit of the partial upgrade was brought into question.

Figure A-61 (Contd.). Correspondence from Port Authority addressing questions related to thickness of thermal insulation on floor trusses (681-P). 


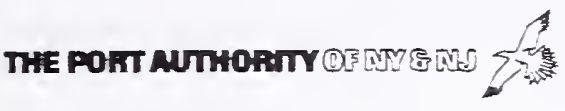

John L. Gross, Ph.D., P.E.

National Institute of Standards and Technology

March 23. 2004

Page 4

Therefore, in consultation with the Office of the Chief Engineer, the 1999 policy was developed to address this issue. It was based on an overall fire-engineering approach, namely:

1. The sprinklerization of tenant spaces.

2. The new redundant decentralized fire alarm systems with consoles located in each tower.

3. Monitoring of the tower fire alarm systems around the clock by FDNY.

4. Certified fire safety directors (whose only responsibility was watching the fire alarm system). Port Authority Police who were stationed at the WTC were trained in structural fire fighting and were immediately notified of any alarm.

5. PA Police had a direct hot line with the Manhattan Fire Dispatchers so they knew what they were responding to, i.e. water flow alarm on a floor or multiple smoke detectors, etc.

6. The removal from the lobbies for tenanted space such as the airline counters and package counters.

7. Periodic testing of the sprinkler system and its components.

There were many occasions where small sections of the original fireproofing had been dislodged by work in the ceiling and it was feasible to patch these areas using a troweled-on patch to the original 3/4" thickness, but not to 1.5 inches. Hence, the 1999 policy was developed with the above factors in mind, along with operational test procedures. This provided a process for the phased upgrade of the entire fireproofing system in the World Trade Center in accordance with the Chief Engineer's new requirements. while ensuring the overall safety program was maintained.

These requirements were written into the net lease documents for the World Trade Center to make sure the process continued after the transition from Port Authority operation and management of the WTC. The following is from section 6.2.1:

1. One World Trade Center and Two World Trade Center Fireproofing - The existing policy of the Port Authority to upgrade steel fireproofing to 11\%" thick (based on UL Guideline G508) on the earlier to occur of (i) a full floor becoming vacant, (ii) a full floor being completely renovated or (iii) for any remaining non-compliance office space, within twenty-five (25) years from the Commencement Date, unless the tenant never does a major alteration, shall be applicable to the Lessee, provided the following standards remain in force:

a) all floors in One World Trade Center and Two World Trade Center, including Mechanical Equipment Rooms (once the work described in paragraph 7 of Schedule 6.2.3 has been completed) and Shy Lobbies, are sprinkled in conformance with the Port Authority Manual and NFPA 13;

b) the Fire Command Centers in the lobby shall be (i) staffed with a New York City Cerified "Fire Safety Director" at all times, and (ii) a total video surveillance system is installed and operating and is being monitored at all times, then the sprinkler plan may exclude the

Figure A-61 (Contd.). Correspondence from Port Authority addressing questions related to thickness of thermal insulation on floor trusses (681-P). 


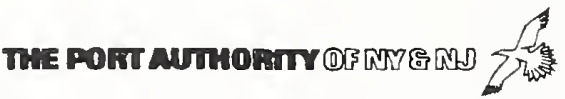

John L. Gross, Ph.D., P.E.

National Institute of Standards and Technology

March 23, 2004

Page 5

310 level of both One World Trade Center and Two World Trade Center. There will be no other permanent or temporary uses within the lobby, other than (i) the Command Center(s), visitors' desk(s), and mail boxes, provided each such area contains steel frames with marble fronts and composite/laminate tops, and (ii) temporary holiday displays composed of non-flammable materials;

c) the Lessee continues the current programs and implements additional programs as necessary to ensure the inspection, testing, and maintenance procedures of and for the sprinkler systems and the components thereof, which include, but are not limited to, the water supply, fire pumps, gravity tanks, piping and valving.

These programs shall be designed to comply with the intent of NFPA 25 and the other requirements contained in the Port Authority Manual; and

d) when the Lessee is performing the testing of the sprinkler system's water flow and alarm transmission, the specific system pressure indicated at the gage downstream of the pressure-reducing valve shall be recorded at the time of such testing, to ensure conformance with the minimums/maximums indicated on the valves.

If the practices described in clauses (a) through (d) above are not adhered to, the Lessee shall immediately begin such fireproofing, even if such work causes the Lessee to relocate the affected Space Tenants.

I hope this answers your questions. Please call or reply otherwise if you need further information.

Very truly yours,

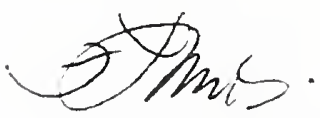

Francis J. Lombardi, PE

Chief Engineer

Attachment

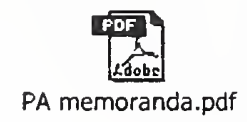

Figure A-61 (Contd.). Correspondence from Port Authority addressing questions related to thickness of thermal insulation on floor trusses (681-P). 


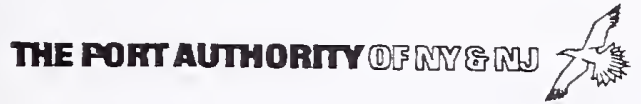

April 14, 2004

John L. Gross, Ph.D., P.E

Leader, Structures Group

United States Department of Commerce

National Institute of Standards and Technology

Gaithersburg, MD 20899-0001

Dear Dr. Gross:
FRANCIS J. LOMBARDL P.E. CHIEF ENGINEER

225 PARK AVENUE SOUTH, 18TH FLOOR NEW YORK, NY 10003

(212) 435.7449

(212) 435-6089 FAX

Hombardopanynj.gor

Following are responses to your questions in your letter to Joe Englot dated April 5, 2004, which are repeated here in bold italics.

By this letter, I am requesting information from The Port Authority on fireproofing of the interior and exterior columns of the World Trade Center towers. Specifically, please provide the following:

1) Fireproofing material and thicknesses for the exterior columns as follows:

- Plates 1 and 2 (these plates face the outside of the building and were covered by the aluminum column panels)

- Plate 3 (interior plate within the occupied space)

- Plate 4 (spandrel), both interior and exterior surfaces

2) Fireproofing material and thicknesses for the core area box columns.

3) Confirmation that the wide flange column sections were specified to be fireproofed as follows using Cafco Type DC/F:

- Columns smaller than 14WF228 - 2-3/16 in

- Columns greater than or equal to 14WF228-1-3/16 in.

In response to your first three questions, Mr. Englot inquired throughout the Port Authority and was not able to find any information related to these questions other than that information already tumed over to NIST.

4) Any information the Port Authority has regarding measurements of the in-place fireproofing material thickness.

We have no records in our Materials Division of ever repairing or replacing fireproofing on exterior columns due to their inaccessibility and, therefore, have no recent thickness measurements of any re-applied fireproofing.

Figure A-62. Correspondence from Port Authority dealing with thermal insulation on WTC columns (672-P). 


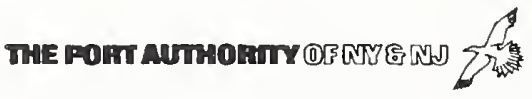

John L. Gross, Ph.D., P.E.

National Institute of Standards and Technology

April 14, 2004

Page two

We have no records in our Materials Division of ever repairing or replacing fireproofing on core columns due to their inaccessibility (other than columns which are accessible within the elevator shafts) and, therefore, have no recent thickness measurements of any re-applied fireproofing for core columns.

The only records of thickness measurements we could find were for the columns that are accessible within the elevator shafts. The Port Authority Materials Engineering Division took thein and they correspond to World Trade Center I Tower l elevator shafts. Discrete readings were taken at shaft $10 / 11$ from the basement to the $45^{\text {th }}$ Floor in Tower 1 in a report dated 4/7/1999. Mean thickness values were found for shaft $14 / 15$ from the basement to the $80^{\text {th }}$ Floor in Tower 1 in a report dated 8/4/1997. These measurements cover the full extent of these two elevator shafts. One was an express from the concourse lobby to 44 with a machine room on 47 and the other was express from the concourse to 78 with an EMR on 81. The readings for both of these shafts are attached (Excel file).

Discussions with Engineering Department staff and former World Trade Department staff indicate that these two shafts had asbestos abatement and were re-fireproofed. The measurements also show a "Minimum Thickness Required" of fireproofing. Staff members recall that there was a schedule of replacement fireproofing thickness that was prepared by the firm Leslie E. Robertson Associates (LERA). One staff member located a copy of one schedule, which will be forwarded under separate cover as a sample. We have contacted William Faschan of LERA and it appears that the "Minimum Thickness Required" is the thickness called for in a schedule that appeared in documents for the work that was prepared by LERA. The sample schedule indicates that the fireproofing applied was "Type Z-106". We will try to locate the specification book for this material. This information may be among the documents that LERA assembled for NIST at the Port Authority's 225 Park Avenue South office. We will continue to search for more complete sets of this information.

In the meanume, I hope this answers your questions. Please call or reply otherwise if you need further information.

Very truly yours,

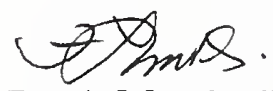

Francis J. Lombardi, PE

Chief Engineer

Att.

Figure A-62 (Contd.). Correspondence from Port Authority dealing with thermal insulation on WTC columns (657-P). 
Physical Performance*

\begin{tabular}{|c|c|c|c|c|}
\hline & \multirow{2}{*}{ ASTM Method } & \\
\hline & & BLATE-SHIELO DCF & BLARE-SHIELD II & BLATE-SHIELD HP \\
\hline Surface Burning & $\begin{array}{c}\text { CAN/ULC.S102 } \\
\text { E84 }\end{array}$ & $\begin{array}{l}\text { Flame: } 0 \\
\text { Smoke: } 0\end{array}$ & $\begin{array}{l}\text { Flame: } 0 \\
\text { Smohe: } 0\end{array}$ & $\begin{array}{l}\text { Flante } 0 \\
\text { Smoke } 0\end{array}$ \\
\hline Combustibility & $\begin{array}{c}\text { CAN4-S114 } \\
\text { E136 }\end{array}$ & Nuncombistible & Noncombustible & Noncombustible \\
\hline Density & E605 & $\begin{array}{c}13 \text { pct } \\
\text { (208 he: }\end{array}$ & $\begin{array}{c}150 \mathrm{pm} \\
(250 \mathrm{~kg} / 11\end{array}$ & $\begin{array}{c}2122 \mathrm{bct} \\
0.1192+2 m)\end{array}$ \\
\hline Cohesion/Adhesion & $E 736$ & $\begin{array}{l}295051 \\
i 142 \mathrm{hPal}\end{array}$ & $\begin{array}{l}360 \mathrm{pst} \\
(172 \mathrm{hPa})\end{array}$ & $\begin{array}{l}\text { 1. 2!1 psi } \\
\text { (6s kpa) }\end{array}$ \\
\hline Deflection & $E 759$ & Pro Cracks of Dabammatio:1s & No Crachs or Delam!nainila & No Crachs of Chommartans \\
\hline Bond Impact & $E 760$ & No Craciss or Deidmurations & No Cracks or Delamunatimas & No Ciachs ue Delammations \\
\hline Compressive Strength & E761 & $\begin{array}{c}828 \mathrm{psf} \\
(39.6 \mathrm{kPa})\end{array}$ & $\begin{array}{l}2.380 \mathrm{pst} \\
(113.9 \mathrm{kPa})\end{array}$ & $\begin{array}{l}7.980 \mathrm{ps} ! \\
(382 \mathrm{hPas})\end{array}$ \\
\hline Air Erosion Resistance & $E 859$ & $\begin{array}{c}0.000 \mathrm{~g} / 11 \\
(0.000 \mathrm{~g} / \mathrm{ml})\end{array}$ & $\begin{array}{c}0.000 \mathrm{~g} / \mathrm{ft}^{\circ} \\
(0.000 \mathrm{~g} / \mathrm{lll})\end{array}$ & $\begin{array}{c}0000 \mathrm{n} / \mathrm{ft}^{\circ} \\
(0.000 \mathrm{~g} / \mathrm{mr})\end{array}$ \\
\hline Corrosion Resistance & $\begin{array}{c}E 937 \\
\text { ur Mil Sid } 810\end{array}$ & $\begin{array}{l}\text { Does Not Promote } \\
\text { Comosion of Steel }\end{array}$ & $\begin{array}{l}\text { Does Not Promote } \\
\text { Corrosion of Steel }\end{array}$ & $\begin{array}{l}\text { Dives Not Promate } \\
\text { Comosm of Steel }\end{array}$ \\
\hline Sound Absorption & C423 & $\begin{array}{c}0.85 \mathrm{NRC} \\
1 / 2^{\prime \prime}(12.7 \mathrm{~mm}) \\
\text { onto dech \& beam }\end{array}$ & $\begin{array}{c}075 \mathrm{NRC} \\
1 / 2 "(12.7 \mathrm{~mm}) \\
\text { onto deck \& beam }\end{array}$ & $\begin{array}{c}\text { 1) } 85 \text { NRC } \\
\text { l/7" (1\%.7 mm) } \\
\text { unto derch \& bam }\end{array}$ \\
\hline Thermal Conductivity & C518 & $3.45 \mathrm{R}$ Value & $3.33 \mathrm{R}$ Valur & $2.93 \mathrm{~F}$ Value \\
\hline
\end{tabular}

Figure A-63. Excerpt from manufacturer's product catalog showing properties of BLAZE-SHIELD DC/F obtained from independent testing under controlled conditions (Source: www.buildcore.com/c0cafco.htm). 
Pacific Car and Foundry Company

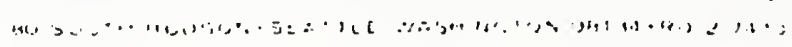

March S, 1968 F'CF $\$ D 606-64$

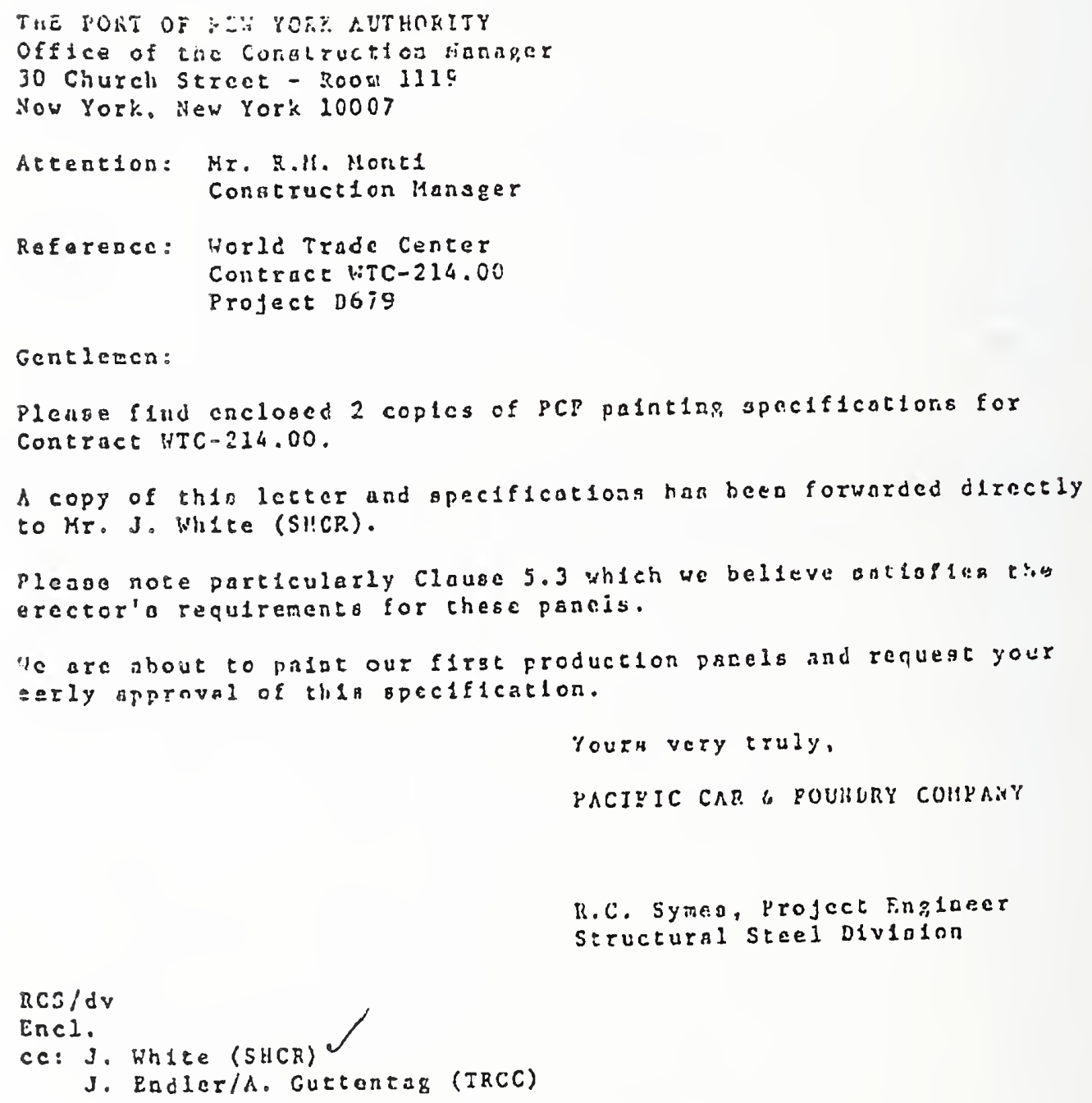

Figure A-64. Letter from Pacific Car and Foundry regarding painting specification and excerpt from that specification (656-P). 


\subsection{PMINT, IMHEBITORS MUD PRESERVAITVES}

5.l Tnemec 99 Red Metal primer is the only paint approved for use on this project.

5.2 Hilled surfaces and bevels for fiejd welds shall be treated with one cuat icraco pla rust proofing compound.

5.3 All panels shall be stencllied, showing full cneincering panel number and reight of panel in tons, thus:

$$
103-22-19\left(12^{T}\right)
$$

Weight shall be taken to nearest con above actual vefght. Stencilled marks shall be placed on plate 3 , center column of panel, directiy above the bottom hand-hole. Tnemec 99-G Green Metal Priner shall be used for all stencilled marks and letters and mubcrs shali be $3 "$ high.

Figure A-63 (Contd.). Letter from Pacific Car and Foundry regarding painting specification and excerpt from that specification. 
This page intentionally left blank. 


\section{Appendix B \\ Thermophysical PRoperties Test Data}

Table B-1. Specific heat capacity results of the three SFRMs from Laboratory B DSC.

\begin{tabular}{|c|c|c|c|}
\hline \multirow[b]{2}{*}{ Temperature $\left({ }^{\circ} \mathrm{C}\right)$} & \multicolumn{3}{|c|}{ Specific heat capacity (J/kg K) } \\
\hline & BLAZE-SHIELD DC/F & BLAZE-SHIELD II & Monokote MK-5 \\
\hline 35 & -...-- & ------- & 1204 \\
\hline 40 & 939 & 1009 & 1243 \\
\hline 45 & 972 & 1047 & 1276 \\
\hline 50 & 1004 & 1087 & 1302 \\
\hline 55 & 1034 & 1134 & 1325 \\
\hline 60 & 1064 & 1186 & 1355 \\
\hline 65 & 1094 & 1237 & 1391 \\
\hline 70 & 1130 & 1295 & 1423 \\
\hline 75 & 1175 & 1355 & 1415 \\
\hline 80 & 1227 & 1417 & 1348 \\
\hline 85 & 1284 & 1479 & 1279 \\
\hline 90 & 1369 & 1546 & 1253 \\
\hline 95 & 1491 & 1623 & 1236 \\
\hline 100 & 1663 & 1755 & 1183 \\
\hline 105 & 1892 & 1945 & 1122 \\
\hline 110 & 2187 & 2199 & 1100 \\
\hline 115 & 2495 & 2528 & 1290 \\
\hline 120 & 2740 & 2908 & 1851 \\
\hline 125 & 2756 & 3298 & 3094 \\
\hline 130 & 2074 & 3672 & 5117 \\
\hline 135 & 1658 & 3293 & 7488 \\
\hline 140 & 1785 & 2235 & 8589 \\
\hline 145 & 2050 & 1937 & 6528 \\
\hline 150 & 2062 & 2038 & 4713 \\
\hline 155 & 1763 & 1934 & 5146 \\
\hline 160 & 1536 & 1796 & 4459 \\
\hline 165 & 1437 & 1700 & 1629 \\
\hline 170 & 1375 & 1637 & 1244 \\
\hline 175 & 1328 & 1587 & 1162 \\
\hline 180 & 1289 & 1546 & 1152 \\
\hline 185 & 1254 & 1506 & 1161 \\
\hline 190 & 1220 & 1466 & 1174 \\
\hline
\end{tabular}




\begin{tabular}{|c|c|c|c|}
\hline \multirow[b]{2}{*}{ Temperature ("C) } & \multicolumn{3}{|c|}{ Specific heat capacity $(\mathrm{J} / \mathrm{kg} \mathrm{K})$} \\
\hline & BLAZE-SHIELD DC/F & BLAZE-SHIELD II & Monokote MK-5 \\
\hline 195 & 1190 & 1414 & 1196 \\
\hline 200 & 1167 & 1368 & 1226 \\
\hline 205 & 1145 & 1320 & 1251 \\
\hline 210 & 1125 & 1284 & 1266 \\
\hline 215 & 1110 & 1248 & 1283 \\
\hline 220 & 1094 & 1217 & 1309 \\
\hline 225 & 1077 & 1183 & 1332 \\
\hline 230 & 1063 & 1149 & 1364 \\
\hline 235 & 1050 & 1112 & 1393 \\
\hline 240 & 1035 & 1082 & 1428 \\
\hline 245 & 1022 & 1053 & 1460 \\
\hline 250 & 1006 & 1025 & 1492 \\
\hline 255 & 991 & 996 & 1521 \\
\hline 260 & 977 & 961 & 1544 \\
\hline 265 & 965 & 926 & 1567 \\
\hline 270 & 958 & 891 & 1590 \\
\hline 275 & 956 & 857 & 1622 \\
\hline 280 & 945 & 807 & 1636 \\
\hline 285 & 936 & 765 & 1656 \\
\hline 290 & 924 & 729 & 1669 \\
\hline 295 & 911 & 701 & 1673 \\
\hline 300 & 899 & 675 & 1665 \\
\hline 305 & 888 & 649 & 1651 \\
\hline 310 & 878 & 627 & 1625 \\
\hline 315 & 876 & 613 & 1578 \\
\hline 320 & 877 & 610 & 1512 \\
\hline 325 & 880 & 620 & 1400 \\
\hline 330 & 893 & 642 & 1245 \\
\hline 335 & 911 & 682 & 1042 \\
\hline 340 & 932 & 734 & 892 \\
\hline 345 & 955 & 789 & 940 \\
\hline 350 & 975 & 857 & 1042 \\
\hline
\end{tabular}


Table B-2. Specific heat capacity of 5/8 in. gypsum panel A.

\begin{tabular}{|c|c|c|c|}
\hline $\begin{array}{c}\text { Temperature } \\
\left({ }^{\circ} \mathrm{C}\right) \\
\end{array}$ & $\mathrm{Cp}(\mathrm{J} / \mathrm{kg} \mathrm{K})$ & $\begin{array}{c}\text { Temperature } \\
\left({ }^{\circ} \mathrm{C}\right) \\
\end{array}$ & $\mathrm{Cp}(\mathrm{J} / \mathrm{kg} \mathrm{K})$ \\
\hline 50 & 1248 & 192 & 3569 \\
\hline 100 & 1416 & 196 & 5020 \\
\hline 125 & 1608 & 200 & 8087 \\
\hline 135 & 2155 & 202 & 9200 \\
\hline 140 & 3118 & 204 & 9356 \\
\hline 142 & 3890 & 206 & 8816 \\
\hline 144 & 5210 & 208 & 7948 \\
\hline 146 & 7428 & 210 & 6497 \\
\hline 148 & 11148 & 212 & 4496 \\
\hline 150 & 15341 & 214 & 2771 \\
\hline 152 & 18490 & 216 & 2010 \\
\hline 154 & 19671 & 218 & 1695 \\
\hline 156 & 19648 & 220 & 1550 \\
\hline 158 & 18822 & 225 & 1389 \\
\hline 160 & 17476 & 250 & 1156 \\
\hline 162 & 15728 & 300 & 1094 \\
\hline 164 & 13734 & 350 & 1089 \\
\hline 166 & 11553 & 400 & 1046 \\
\hline 168 & 9436 & 415 & 890 \\
\hline 170 & 7034 & 430 & 453 \\
\hline 172 & 5107 & 445 & 506 \\
\hline 174 & 3501 & 460 & 808 \\
\hline 176 & 2768 & 475 & 966 \\
\hline 178 & 2417 & 500 & 1104 \\
\hline 180 & 2297 & 550 & 1192 \\
\hline 184 & 2544 & 600 & 1245 \\
\hline 188 & 2923 & & \\
\hline
\end{tabular}




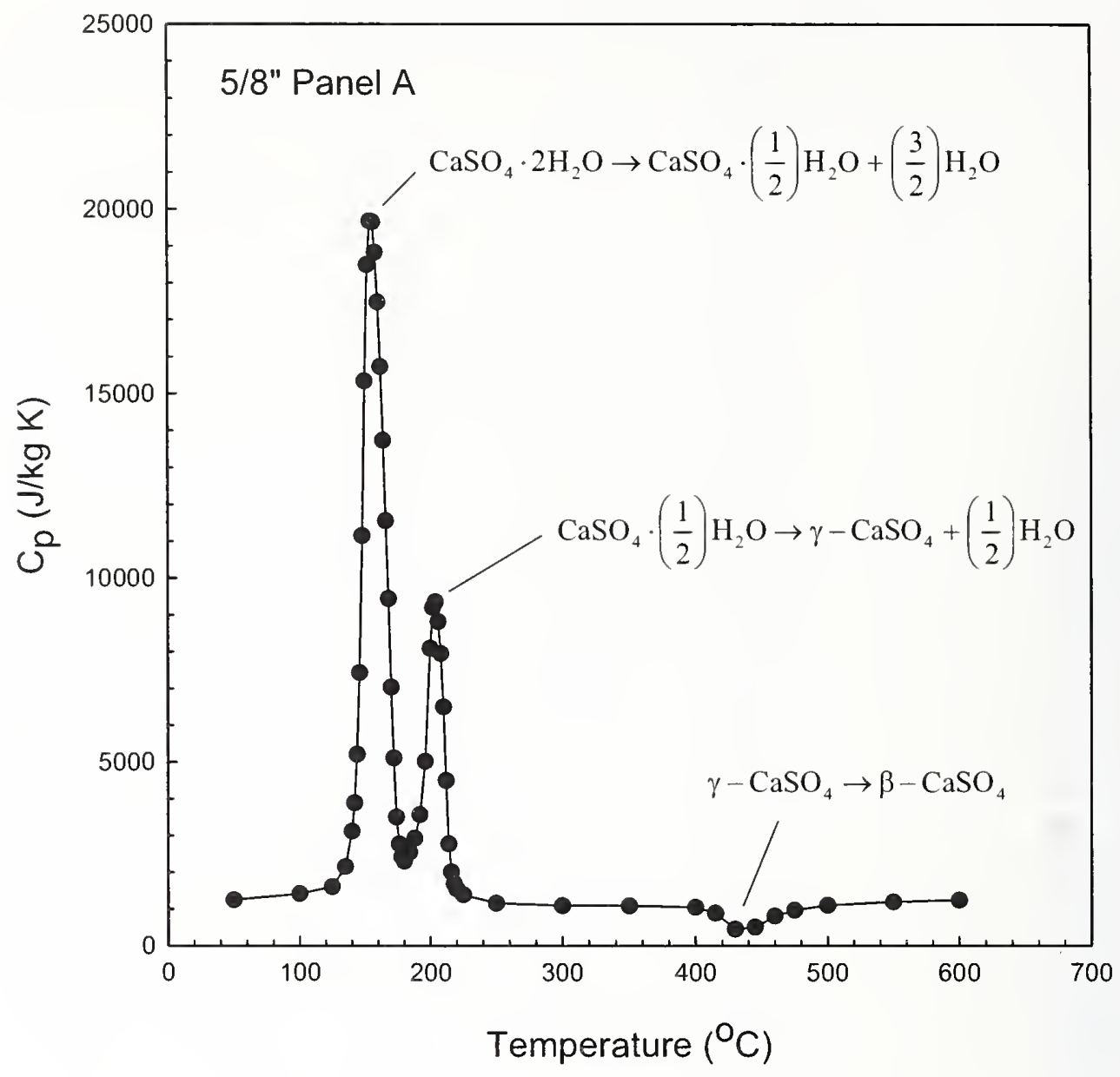

Figure B-1. Specific heat capacity of 5/8 in. gypsum panel A. 
Table B-3. Specific heat capacity of $1 / 2$ in. gypsum panel.

\begin{tabular}{|c|c|c|c|}
\hline $\begin{array}{c}\text { Temperature } \\
\left({ }^{\circ} \mathrm{C}\right)\end{array}$ & $\mathrm{Cp}(\mathrm{J} / \mathrm{kg} \mathrm{K})$ & $\begin{array}{c}\text { Temperature } \\
\left({ }^{\circ} \mathrm{C}\right)\end{array}$ & Cp (J/kg K) \\
\hline 50 & 1325 & 192 & 3693 \\
\hline 100 & 1544 & 196 & 4957 \\
\hline 125 & 1764 & 200 & 7730 \\
\hline 135 & 2457 & 202 & 8774 \\
\hline 140 & 3801 & 204 & 9088 \\
\hline 142 & 4769 & 206 & 8644 \\
\hline 144 & 6418 & 208 & 7693 \\
\hline 146 & 8787 & 210 & 6364 \\
\hline 148 & 12015 & 212 & 4487 \\
\hline 150 & 15429 & 214 & 2888 \\
\hline 152 & 17532 & 216 & 2090 \\
\hline 154 & 18399 & 218 & 1828 \\
\hline 156 & 18349 & 220 & 1672 \\
\hline 158 & 17769 & 225 & 1495 \\
\hline 160 & 16776 & 250 & 1278 \\
\hline 162 & 15564 & 300 & 1185 \\
\hline 164 & 13895 & 350 & 1188 \\
\hline 166 & 12124 & 400 & 1159 \\
\hline 168 & 10357 & 415 & 1015 \\
\hline 170 & 8263 & 430 & 667 \\
\hline 172 & 6180 & 445 & 642 \\
\hline 174 & 4459 & 460 & 930 \\
\hline 176 & 3383 & 475 & 1091 \\
\hline 178 & 2768 & 500 & 1235 \\
\hline 180 & 2545 & 550 & 1350 \\
\hline 184 & 2632 & 600 & 1416 \\
\hline 188 & 3006 & & \\
\hline
\end{tabular}




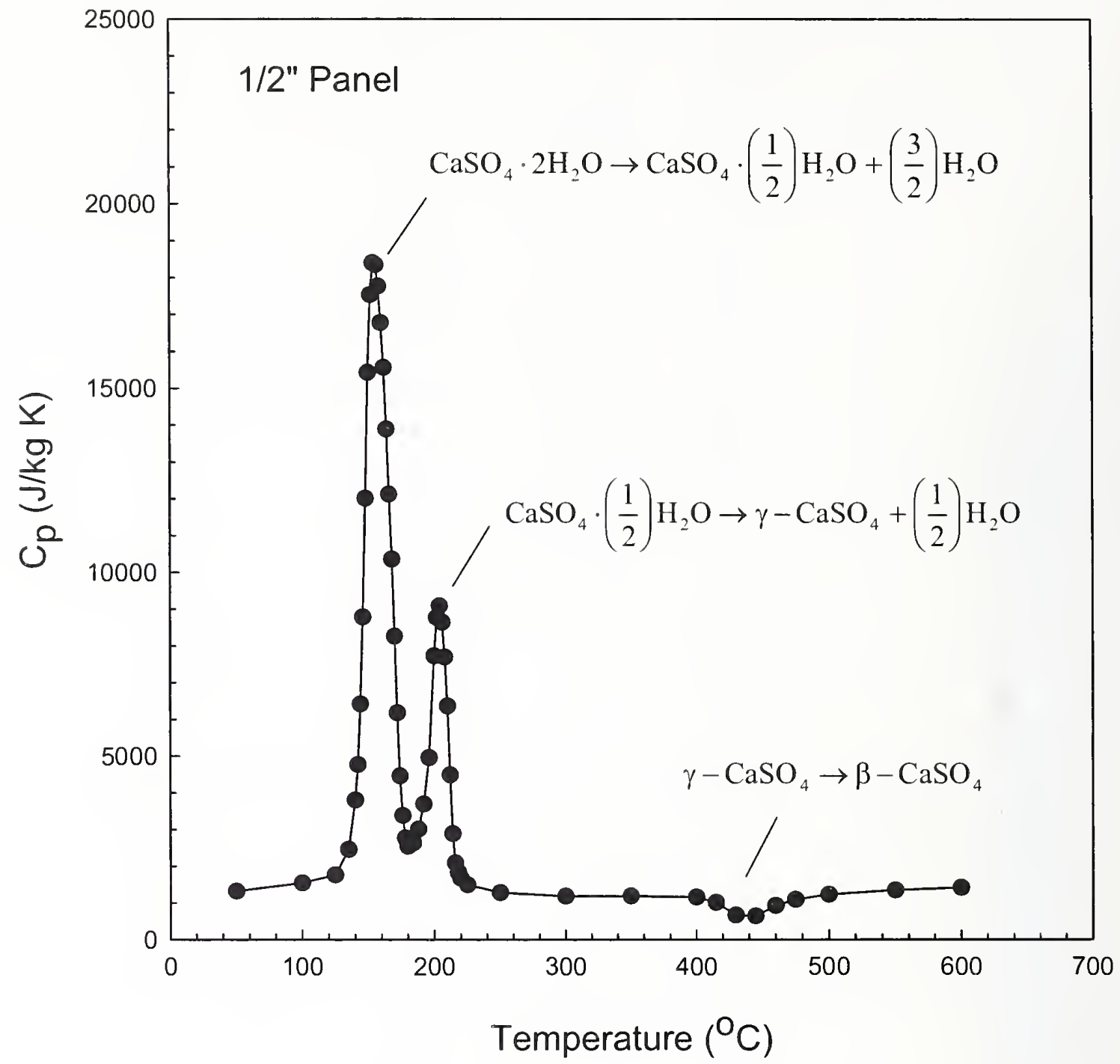

Figure B-2. Specific heat capacity of $1 / 2$ in. gypsum panel. 
Table B-4. Specific heat capacity of 5/8 in. gypsum panell B.

\begin{tabular}{|c|c|c|c|}
\hline $\begin{array}{l}\text { Temperature } \\
\left({ }^{\circ} \mathrm{C}\right)\end{array}$ & Cp (J/kg K) & $\begin{array}{c}\text { Temperature } \\
\left({ }^{\circ} \mathrm{C}\right)\end{array}$ & $\mathrm{Cp}(\mathrm{J} / \mathrm{kg} \mathrm{K})$ \\
\hline 50 & 1250 & 192 & 3624 \\
\hline 100 & 1507 & 196 & 4886 \\
\hline 125 & 1711 & 200 & 7769 \\
\hline 135 & 2486 & 202 & 8848 \\
\hline 140 & 3966 & 204 & 9102 \\
\hline 142 & 5001 & 206 & 8727 \\
\hline 144 & 6728 & 208 & 7705 \\
\hline 146 & 9142 & 210 & 6210 \\
\hline 148 & 12341 & 212 & 4342 \\
\hline 150 & 15681 & 214 & 2775 \\
\hline 152 & 17740 & 216 & 2052 \\
\hline 154 & 18550 & 218 & 1770 \\
\hline 156 & 18374 & 220 & 1621 \\
\hline 158 & 17667 & 225 & 1451 \\
\hline 160 & 16401 & 250 & 1233 \\
\hline 162 & 14914 & 300 & 1148 \\
\hline 164 & 13190 & 350 & 1168 \\
\hline 166 & 11251 & 400 & 1130 \\
\hline 168 & 9096 & 415 & 984 \\
\hline 170 & 7108 & 430 & 568 \\
\hline 172 & 5091 & 445 & 646 \\
\hline 174 & 3658 & 460 & 930 \\
\hline 176 & 2814 & 475 & 1084 \\
\hline 178 & 2516 & 500 & 1232 \\
\hline 180 & 2364 & 550 & 1347 \\
\hline 184 & 2567 & 600 & 1432 \\
\hline 188 & 2936 & & \\
\hline
\end{tabular}




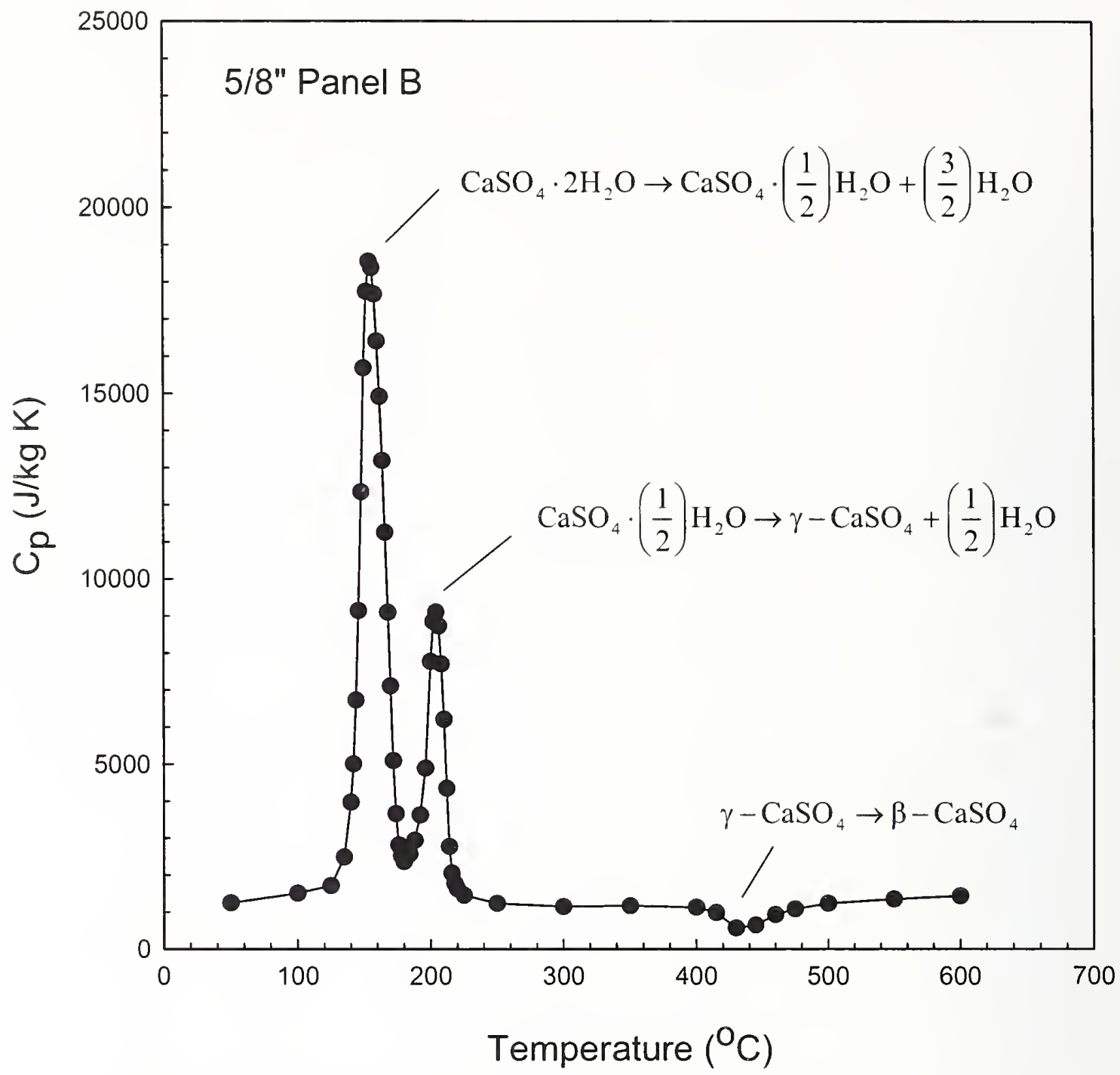

Figure B-3. Specific heat capacity of 5/8 in. gypsum panel B. 
Table B-5. Specific heat capacity of 1 in. gypsum liner panel.

\begin{tabular}{|c|c|c|c|}
\hline $\begin{array}{c}\text { Temperature } \\
\left({ }^{\circ} \mathrm{C}\right)\end{array}$ & $\mathrm{Cp}(\mathrm{J} / \mathrm{kg} \mathrm{K})$ & $\begin{array}{l}\text { Temperature } \\
\left({ }^{\circ} \mathrm{C}\right)\end{array}$ & $\mathrm{Cp}(\mathrm{J} / \mathrm{kg} \mathrm{K})$ \\
\hline 50 & 1192 & 192 & 3583 \\
\hline 100 & 1495 & 196 & 4876 \\
\hline 125 & 2293 & 200 & 7346 \\
\hline 135 & 3766 & 202 & 8360 \\
\hline 140 & 5548 & 204 & 8872 \\
\hline 142 & 6987 & 206 & 8787 \\
\hline 144 & 8876 & 208 & 8164 \\
\hline 146 & 11092 & 210 & 6847 \\
\hline 148 & 13303 & 212 & 5256 \\
\hline 150 & 15076 & 214 & 3305 \\
\hline 152 & 15999 & 216 & 2260 \\
\hline 154 & 16160 & 218 & 1787 \\
\hline 156 & 15787 & 220 & 1597 \\
\hline 158 & 14949 & 225 & 1408 \\
\hline 160 & 13925 & 250 & 1192 \\
\hline 162 & 12577 & 300 & 1137 \\
\hline 164 & 10840 & 350 & 1146 \\
\hline 166 & 8755 & 400 & 1060 \\
\hline 168 & 6481 & 415 & 822 \\
\hline 170 & 4676 & 430 & 609 \\
\hline 172 & 3296 & 445 & 794 \\
\hline 174 & 2685 & 460 & 971 \\
\hline 176 & 2369 & 475 & 1079 \\
\hline 178 & 2252 & 500 & 1200 \\
\hline 180 & 2288 & 550 & 1306 \\
\hline 184 & 2577 & 600 & 1378 \\
\hline 188 & 2959 & & \\
\hline
\end{tabular}




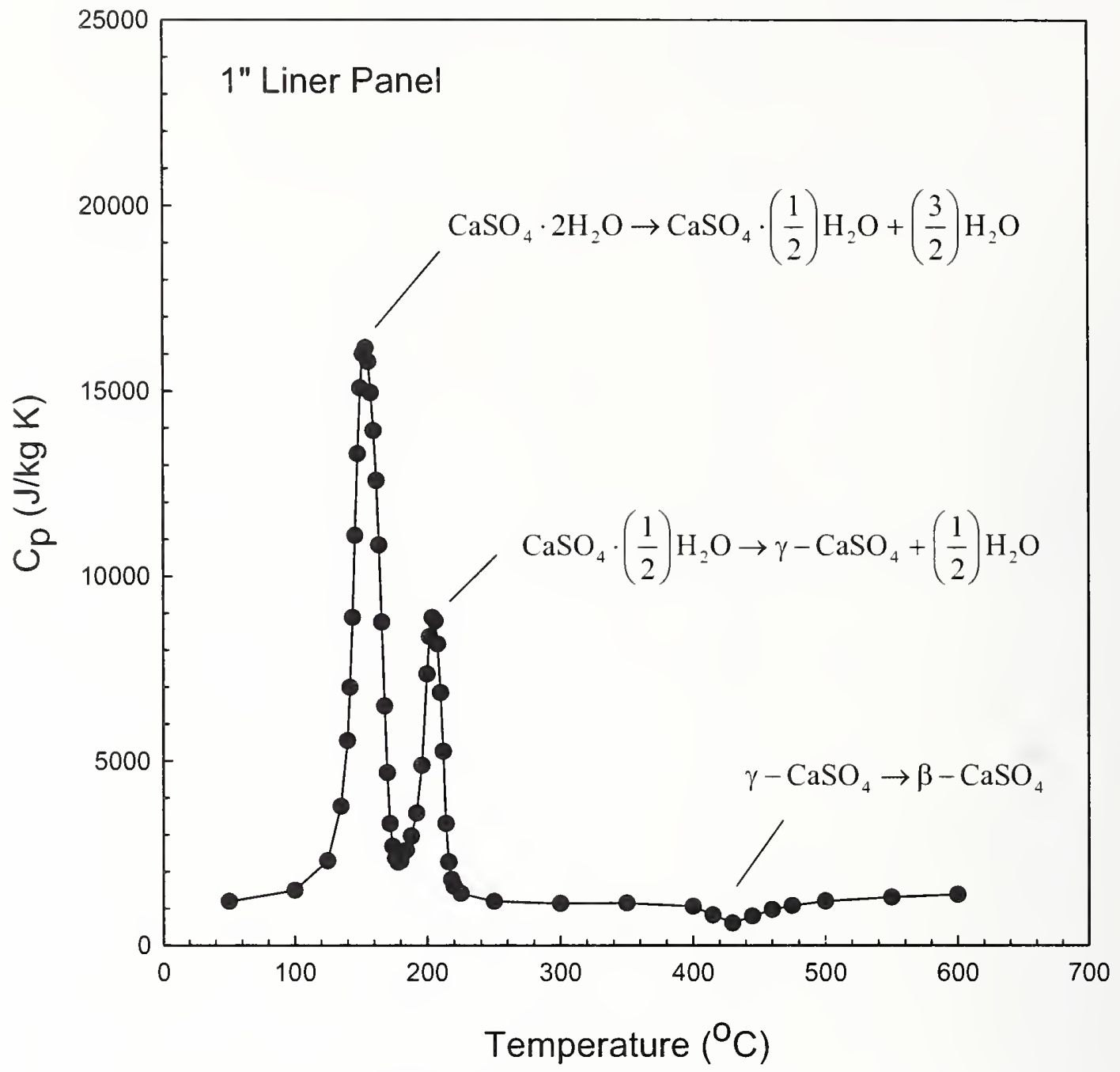

Figure B-4. Specific heat capacity of gypsum 1 in. liner panel. 


\section{Appendix C \\ DEBRIS IMPACT TESTS OF BLAZE-SHIELD DC/F \\ SPRAYED FIRE-RESISTIVE MATERIAL}

\section{INTRODUCTION}

This appendix presents experimental observations obtained from a series of debris impact tests on steel plates and bars with the sprayed fire-resistive material (SFRM) BLAZE-SHIELD DC/F. The tests were performed to provide evidence regarding the assumption that, within the debris field created by the aircraft impact into WTC 1 and WTC 2, the SFRM used for thermal insulation of structural members was damaged and dislodged.

Engineering judgment, based on the aircraft impact damage analysis (NIST NCSTAR 1-2), was used to develop test parameters that were also within the limitations of the experimental facility. Two sets of controlled experiments were designed: a high-speed low-mass test, which used uniform size lead pellets (buckshot) for debris and high-speed impact, and a low-speed high-mass test, which used a lower speed and several types of projectiles to simulate a random debris size distribution.

The SFRM on the steel plates and bars was subjected to a field of impacting projectiles fired from a universal receiver (a modified gun) at various orientations. For the high-speed low-mass impact, a debris field was simulated by buckshot fired from a modified shotgun. Since firing of conventional shotgun shells would result in average buckshot speed in excess of $682 \mathrm{mph}(304 \mathrm{~m} / \mathrm{s})$, controlled firing with custom-made shot shells was needed to reduce the impact speed within the range found for the debris field in the aircraft impact analyses of the WTC towers (NIST NCSTAR 1-2).

The speed of the aircraft at impact was estimated to be $443 \mathrm{mph}(198 \mathrm{~m} / \mathrm{s})$ for WTC 1 and $542 \mathrm{mph}$ $(242 \mathrm{~m} / \mathrm{s})$ for WTC 2. Therefore, the speed of the debris field in each tower ranged between the maximum aircraft speed at impact and zero, when the debris came to a rest. As no single speed or debris size could represent the debris field in the towers, a range of debris speeds and sizes were selected that were within the limitations of the test facility, as noted above. An average speed of $341 \mathrm{mph}(152 \mathrm{~m} / \mathrm{s})$ was chosen for the debris impact velocity for the high-speed low-mass impact tests. For low-speed highmass impact tests, an average speed of the projectiles ranging between $112 \mathrm{mph}(50 \mathrm{~m} / \mathrm{s})$ and $201 \mathrm{mph}$ $(90 \mathrm{~m} / \mathrm{s})$ was selected.

The desired impact speed was achieved but the universal receiver could only accommodate small projectiles, which did not represent actual debris shapes and sizes. Therefore, the impact kinetic energies from the projectiles were significantly lower than those from actual impacting debris in the WTC towers due to differences in size (mass). However, when the impact kinetic energies were normalized by the impact area, the impact conditions used in the tests approximated those in the towers, based on the following order-of-magnitude analysis.

The kinetic energies of the two aircraft before they impacted the WTC towers differed somewhat, but were of the same order of magnitude. Based on the aircraft masses and initial speeds reported in NIST NCSTAR 1-2, the kinetic energy of the impacting aircraft were approximately $3.4 \times 10^{9} \mathrm{ft} 1 \mathrm{~b}\left(2.5 \times 10^{9} \mathrm{~J}\right)$ 
and $5 \times 10^{9} \mathrm{ft} \mathrm{lb}\left(3.7 \times 10^{9} \mathrm{~J}\right)$ for WTC 1 and WTC 2, respectively. Based on the aircraft impact analysis (NIST NCSTAR 1-2), the speed of the aircraft fragments as they approached the core wcre about 0.4 to 0.7 of the initial impact speed for WTC 1 and WTC 2, respectively (energy is proportional to the square of the speed). In addition, portions of the aircraft masses were stopped prior to reaching the core. As a result, it might be expected that the energy associated with the aircraft debris at the core were on the order of $10^{8} \mathrm{ft} \mathrm{lb}$ to $10^{9} \mathrm{ft} \mathrm{lb}\left(10^{8} \mathrm{~J}\right.$ to $\left.10^{9} \mathrm{~J}\right)$.

For thc purpose of this study, it was assumed that the energy of the debris impacting the SFRM was distributed throughout a debris area that was about five floors high (60 ft or $18 \mathrm{~m})$ and $150 \mathrm{ft}(45 \mathrm{~m})$ wide, or an area of about $9 \times 10^{3} \mathrm{ft}^{2}\left(8 \times 10^{2} \mathrm{~m}^{2}\right)$. Thus, the energy per unit area would be on the order of $O\left(10^{4}\right.$ to $\left.10^{5} \mathrm{ft} \mathrm{lb} / \mathrm{ft}^{2}\right)\left(O\left(10^{5}\right.\right.$ to $\left.\left.10^{6} \mathrm{~J} / \mathrm{m}^{2}\right)\right)$. The total kinetic energy of the buckshot impact per unit area in the experiments was estimated, based on an average pellet size of $0.33 \mathrm{in}$. ( $8.4 \mathrm{~mm})$, a mass of $0.1 \mathrm{oz}$ $(3.5 \mathrm{~g})$, and a speed of $341 \mathrm{mph}(152 \mathrm{~m} / \mathrm{s})$, to be of the same order of magnitude, $O\left(10^{4}\right.$ to $\left.10^{5} \mathrm{ft} \mathrm{Jb} / \mathrm{ft}^{2}\right)$ $\left(O\left(10^{5}\right.\right.$ to $\left.\left.10^{6} \mathrm{~J} / \mathrm{m}^{2}\right)\right)$. Therefore, the impact parameters (impact speed and kinetic energy per unit area) used in the experiments are considered representative of these parameters in the aircraft impact analysis of the WTC towers. However, the debris impact test condition simulated an instantaneous impact by a burst of debris whereas the actual scenario involved a three dimensional field of debris, with a depth, width, and height, continuously impacting the target(s) for a finite duration over a large area. In addition, since the samples used in the tests were not restrained in the same way as actual structural elements would be, the response of the steel component and SFRM to debris impact in terms of dislodgement of SFRM may differ somewhat from that of an actual structural member.

\section{EXPERIMENTAL APPARATUS AND TEST PROCEDURE}

The experimental set-up and procedure used to perform the debris impact tests are described here. All ballistic tests on the SFRM were performed at the ballistic research test facility at NIST.

\section{Ballistic research test facility}

The facility consists of two pieces of ballistic firing equipment (small and large universal receivers), an optical device (two optical interrupters) to measure average projectile speed, an adjustable platform to mount the target, and a projectile trap. Figure $\mathrm{C}-1$ shows a schematic of the facility.

The small universal receiver was configured to a 12-gauge shotgun using a custom-made barrel. This universal receiver was rcmotely triggered in the adjacent control room. The shells used No. 00 lead buckshot with a diameter of $0.33 \mathrm{in} .(8.4 \mathrm{~mm})$. The shot shells were specifically tailored to achieve nominal average projectile speeds between $307 \mathrm{mph}(137 \mathrm{~m} / \mathrm{s})$ and $375 \mathrm{mph}(168 \mathrm{~m} / \mathrm{s})$ by adjusting the amount of gunpowder and the number of buckshot used in the shells. For all tests using the small universal receiver, $0.3 \mathrm{oz}$ (10 g) of gunpowder (Hodgdon Titegroup) and $2 \mathrm{oz}$ (63 g) of buckshot were used.

The large universal receiver was configured to have a custom-made barrel with an inside diameter of $3.15 \mathrm{in} .(80 \mathrm{~mm})$. The receiver was air operated and could bc triggered only at the gun station. The shot shells consisted of two halves of Styrofoam wads that held $2.2 \mathrm{lb}(1,000 \mathrm{~g})$ of projectiles. The projectiles were comprised of a random combination of steel bolts and hexagon nuts that were larger and heavier than the buckshot (the largest nut size was $2 \mathrm{in} .(50 \mathrm{~mm})$ wide by $1.2 \mathrm{in} .(30 \mathrm{~mm})$ thick hexagon nuts for a $11 / 4 \mathrm{in}$. $(32 \mathrm{~mm})$ bolt). Air pressure was adjusted to achieve nominal average projectile speeds between 
$112 \mathrm{mph}(50 \mathrm{~m} / \mathrm{s})$ and $201 \mathrm{mph}(90 \mathrm{~m} / \mathrm{s})$. Thus, the large receiver simulated impact by fields of projectiles with larger mass density than those of the small receiver, but at slower speeds. Photos of the typical shot shells for ballistic impact tests using the large universal receiver are shown in Fig. C-2.

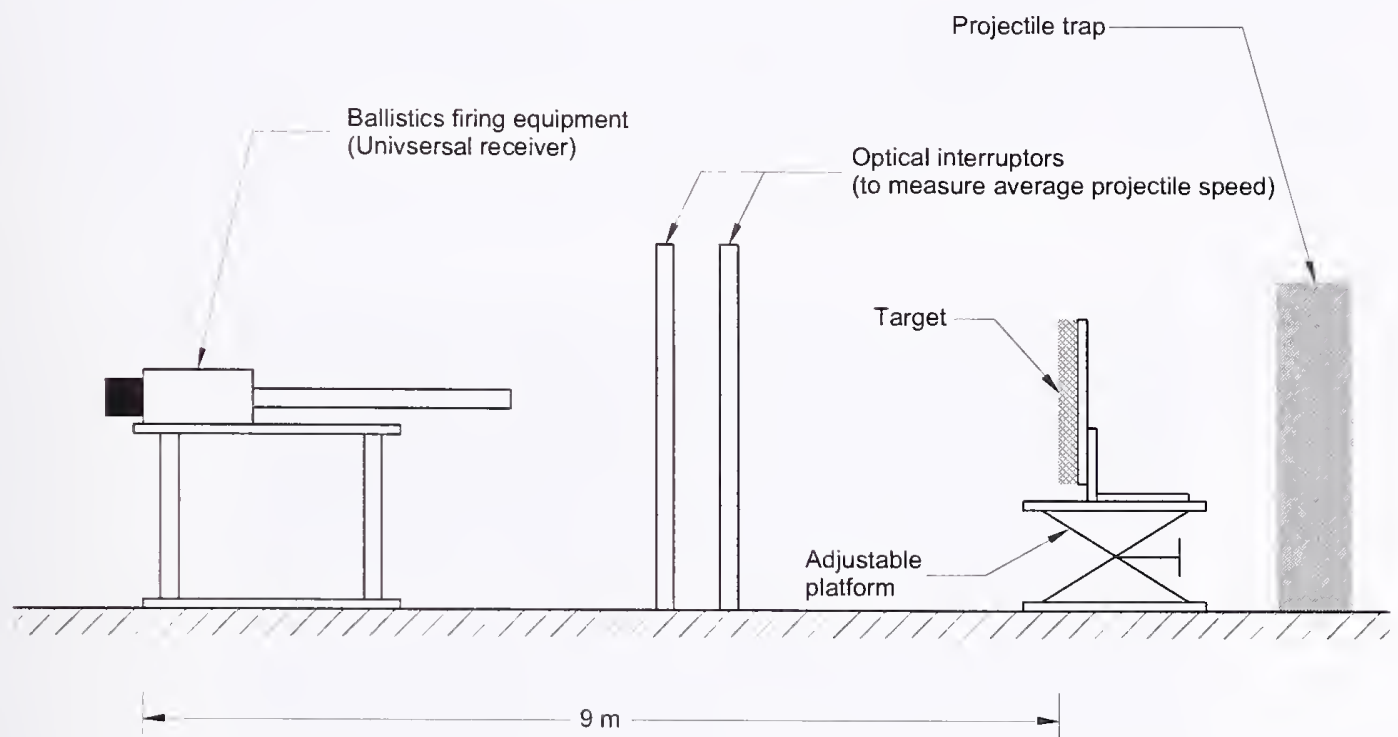

Figure C-1. Schematic of the ballistic research test facility.

Figure C-2. Typical shot shells used in the large universal receiver. A penny is also shown for comparison.

The target was mounted $29.5 \mathrm{ft}(9 \mathrm{~m})$ from the universal receiver for testing of the steel plate specimens and $15.7 \mathrm{ft}(4.8 \mathrm{~m})$ for testing of the steel bar specimens. A plywood enclosure was built around the target area to contain ricocheted buckshot. A laser sight was used to position the target area with respect to the barrel. The impact angle was varied from a 0 degree (target perpendicular to the barrel) to 60 degree angle (measured from the 0 degree position). 


\section{Sample (impact target) preparation}

The steel plates were $1 / 4$ in. $\times 12$ in. $\times 12$ in. $(6 \mathrm{~mm} \times 300 \mathrm{~mm} \times 300 \mathrm{~mm})$ and unprimed. Four nuts, arranged in a square pattern, $8 \mathrm{in} . \times 8 \mathrm{in} .(200 \mathrm{~mm} . \times 200 \mathrm{~mm})$, were welded on one side of the plate to mount the sample for testing. The $1 \mathrm{in} .(25.4 \mathrm{~mm})$ diameter bars were $20 \mathrm{in}$. $(508 \mathrm{~mm})$ long for the small universal receiver tests and $36 \mathrm{in.}(914 \mathrm{~mm})$ long for the large universal receiver tests. The steel plates and the 36 in. long bars were shipped to Isolatek, Inc. in Stanhope, New Jersey, for application of BLAZE-SHIELD DC/F to a thickness of $1.5 \mathrm{in}$. $(38 \mathrm{~mm})$. The $20 \mathrm{in.}(0.5 \mathrm{~m})$ long bars had been previously prepared and sprayed by Isolatek at NIST with a nominal thickness of $1.5 \mathrm{in}$. (38 mm). Figure C-3 shows a steel plate with SFRM mounted in the ballistic research test facility ready for a test.

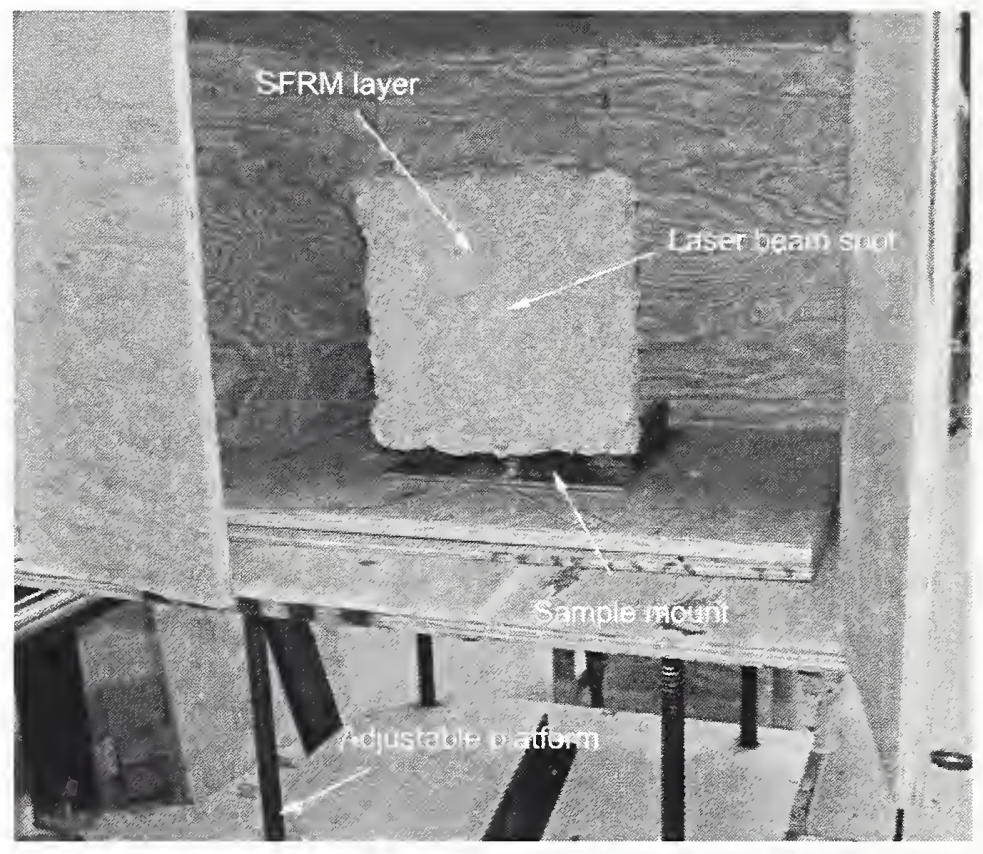

Figure C-3. Photograph of a steel plate with SFRM mounted in the ballistic research test facility.

\section{Test matrix}

Table C-1 summarizes the tests conducted in the debris impact tests.

Table C-1. Test matrix.

\begin{tabular}{|c|c|c|c|c|c|c|c|}
\hline \multirow{2}{*}{ Debris speed/mass } & \multirow{2}{*}{$\begin{array}{l}\text { Universal } \\
\text { receiver }\end{array}$} & \multirow{2}{*}{ Test Specimen } & \multicolumn{5}{|c|}{ Impact Angle } \\
\hline & & & $0^{\circ}$ & $20^{\circ}$ & $30^{\circ}$ & $45^{\circ}$ & $60^{\circ}$ \\
\hline \multirow{3}{*}{ High speed/low mass } & Small & Steel plate (unprimed) & $x x x x$ & $x x$ & & $x x$ & $x x$ \\
\hline & Small & Steel bar (unprimed) & $x$ & & & & \\
\hline & Small & Steel bar (primed) & $x x$ & & & & \\
\hline Low speed/high mass & Large & Steel bar (unprimed) & $x x$ & & & & \\
\hline
\end{tabular}

$' x$ ' 1 run 


\section{Test procedure}

Each sample was photographed before and after each test. The steel plate or bar test sample was first mounted on two parallel L-brackets at the target location. The L-brackets were attached to a base plate, which could be rotated to adjust the impact orientation. A laser sight was then loaded into the chamber to center the target with respect to the barrel. The sample impact angle ( 0 degree, 20 degree, 30 degree, 45 degree, or 60 degree) was set using a protractor. Impact angle was measured with respect to the leading edge of the adjustable platform, which was set to be perpendicular to the laser beam. A 0 degree impact angle was defined as the target oriented perpendicular to the direction of the projectiles. Other impact angles were measured with respect to 0 degree.

After the impact angle was set, the laser sight was removed from the chamber of the barrel. The shot shells were prepared in the ammunition laboratory. The receiver was fired and the average projectile speed was recorded. The impact tests were viewed through a bulletproof observation window in the control room. After the test, the sample was examined and photographed to assess damage to the SFRM by the projectiles.

The nominal impact area by the buckshot fired from the small universal receiver at a distance of $29.5 \mathrm{ft}$ $(9 \mathrm{~m})$ had a diameter of approximately $6 \mathrm{in}$. to $8 \mathrm{in}$. $(0.15 \mathrm{~m}$ to $0.2 \mathrm{~m})$. For the large universal receiver, the nominal impact area by the projectiles (bolts, nuts, and buckshot) had a diamcter of approximately 24 in. $(0.6 \mathrm{~m})$. For the steel bars, the impact area was reduced to about a 4 in. $(0.1 \mathrm{~m})$ diameter, which was approximately the diameter of the SFRM layer on the bar, by moving the bar closer to the receiver to increase the likelihood of projectiles hitting the target.

\section{TEST RESULTS AND DISCUSSION}

In this section, damage to the SFRM due to debris impact is assessed and photographic evidence is provided.

\section{Steel plate and SFRM specimens}

All tests on steel plates were performed using the small universal receiver (high-speed low-mass). In these tests, the impact area was much smaller than the sample surface area. Table C-2 summarizes the test parameters for the steel plates with an SFRM layer. The kinetic energy per unit impact area was estimated based on the projectile speed, an average pellet mass of $0.1 \mathrm{oz}(3.5 \mathrm{~g})$, and an impact area equivalent to the cross section area of the pellet $0.09 \mathrm{in}^{2}\left(5.52 \mathrm{~mm}^{2}\right)$. Tests at a 0 degree impact orientation had damage to the SFRM at the points of projectile impact, which was marked by distinct, approximately circular indentations on the layer. The vibration of the plate caused by the impact was severe enough to break the adhesive bond and completely separate the SFRM from the unprimed steel plate (see Figure C-4). Similar observations were made for tests at a 20 degree and 40 degree impact angle, as shown in Figure C-5 and Figure C-6, respectively. However, at a 60 degree impact orientation, the SFRM remained attached to the steel plate. Several projectile exit points were notcd, which were duc to projectiles ricocheting off the steel surface. Figure C-7 shows the entry points of the projectiles and the damage to the SFRM, and illustrates the size of the debris impact field relative to the specimen size. Two 0 degree impact tests were also conducted with the four edges of the SFRM laycr taped to the steel plate (see Figure C-8) to simulate better adhesion to the plate and to prevent the separation of the SFRM from 
the plate upon impact of the projectiles. However, when the tape was carefully removed after the test, no adhesion of the SFRM to the steel plate was found; this also occurred for the 0 degree impact test without duct tape.

Table C-2. Summary of test parameters for using unprimed steel plates with SFRM.

\begin{tabular}{|c|c|c|c|c|}
\hline \multicolumn{2}{|c|}{ Test \# } & $\begin{array}{l}\text { Impact orientation } \\
\text { (degree) }\end{array}$ & $\begin{array}{l}\text { Average projectile speed } \\
\qquad(\mathrm{ft} / \mathrm{s}(\mathrm{m} / \mathrm{s}))\end{array}$ & $\begin{array}{c}\text { Kinetic energy per impact area } \\
\left(\mathrm{ft} \mathrm{lb} / \mathrm{ft}^{2}\left(\mathrm{~J} / \mathrm{m}^{2}\right)\right)\end{array}$ \\
\hline \multirow{10}{*}{ 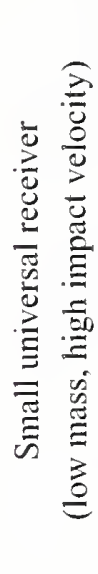 } & PL01 & 0 & $511(155.8)$ & $5.3 \times 10^{4}\left(7.7 \times 10^{5}\right)$ \\
\hline & PL02 & 55 & $346(105.5)$ & $2.4 \times 10^{4}\left(3.5 \times 10^{5}\right)$ \\
\hline & PL03 & 60 & $574(175)$ & $6.7 \times 10^{4}\left(9.7 \times 10^{5}\right)$ \\
\hline & PL04 & 0 & $541(165)$ & $5.9 \times 10^{4}\left(8.6 \times 10^{5}\right)$ \\
\hline & PL05 & 20 & $469(143)$ & $4.5 \times 10^{4}\left(6.5 \times 10^{5}\right)$ \\
\hline & PL06 & 20 & $563(171.6)$ & $6.4 \times 10^{4}\left(9.3 \times 10^{5}\right)$ \\
\hline & PL07 & 40 & $561(171)$ & $6.4 \times 10^{4}\left(9.3 \times 10^{5}\right)$ \\
\hline & PL08 & 40 & $568(173)^{*}$ & $6.5 \times 10^{4}\left(9.5 \times 10^{5}\right)$ \\
\hline & ${\mathrm{PL} 09^{* *}}^{* *}$ & 0 & $558(170)$ & $6.3 \times 10^{4}\left(9.2 \times 10^{5}\right)$ \\
\hline & PL10 ${ }^{* * *}$ & 0 & $225(69)$ & $1.0 \times 10^{4}\left(1.5 \times 10^{5}\right)$ \\
\hline
\end{tabular}

* Receiver misfired initially at $102 \mathrm{ft} / \mathrm{s}(31 \mathrm{~m} / \mathrm{s}) ;$ a few shots hit but there was no visible damage to SFRM; sample reused for $2^{\text {nd }}$ shot.

** The edges of the SFRM layer were taped to the steel plate using duct tape.

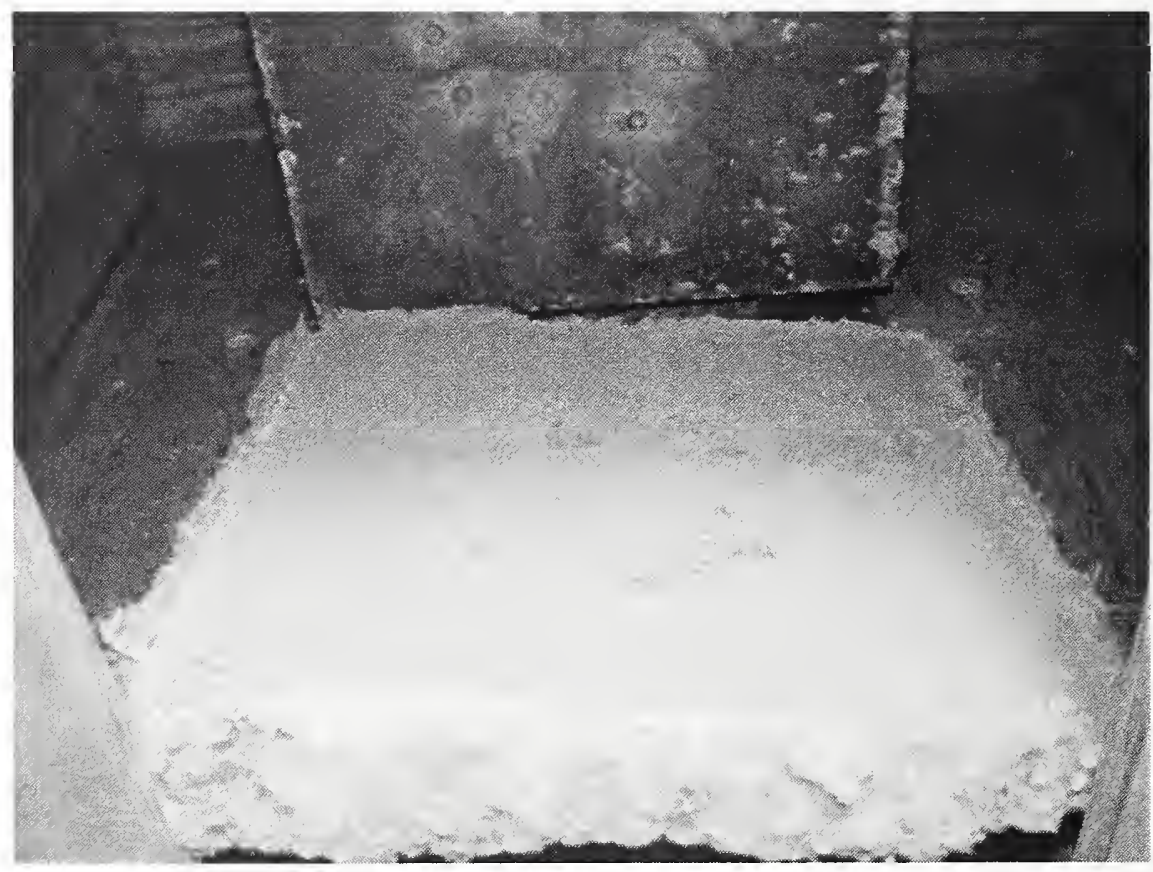

Figure C-4. Photograph showing damage to the SFRM after a ballistic impact at 0 degree. The SFRM layer completely separated from the steel plate. 


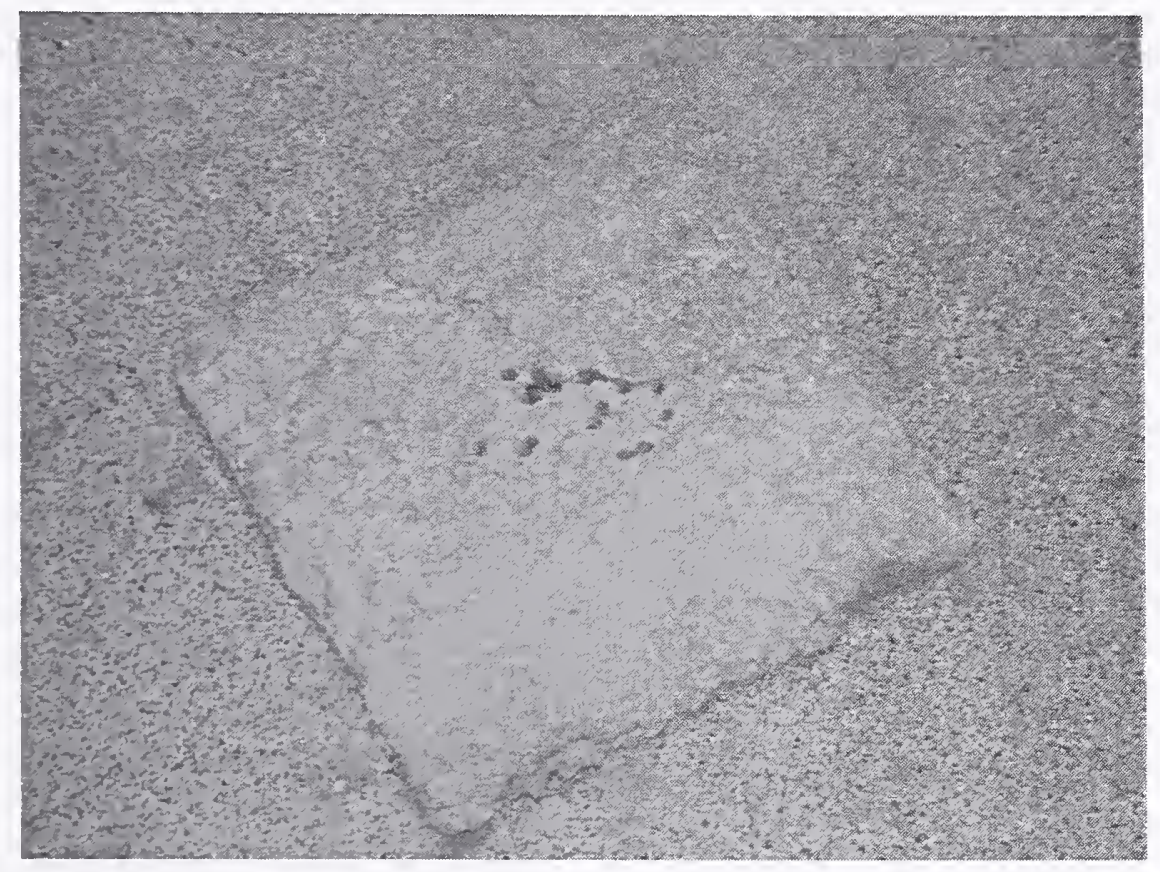

Figure C-5. Photograph showing damage to the SFRM after a ballistic impact at 20 degree. The SFRM layer completely separated from the steel plate and landed on the floor.

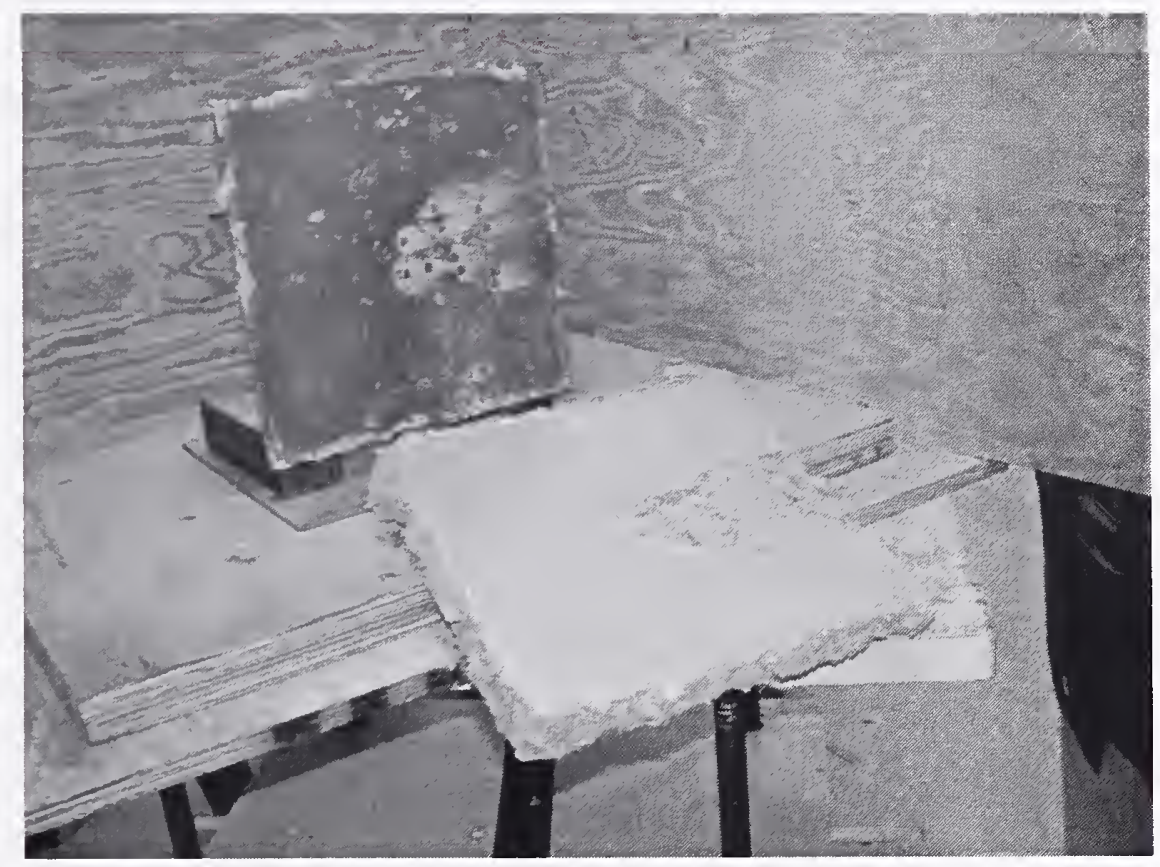

Figure C-6. Photograph showing damage to the SFRM after a ballistic impact at 40 degree. The SFRM layer completely separated from the steel plate. 


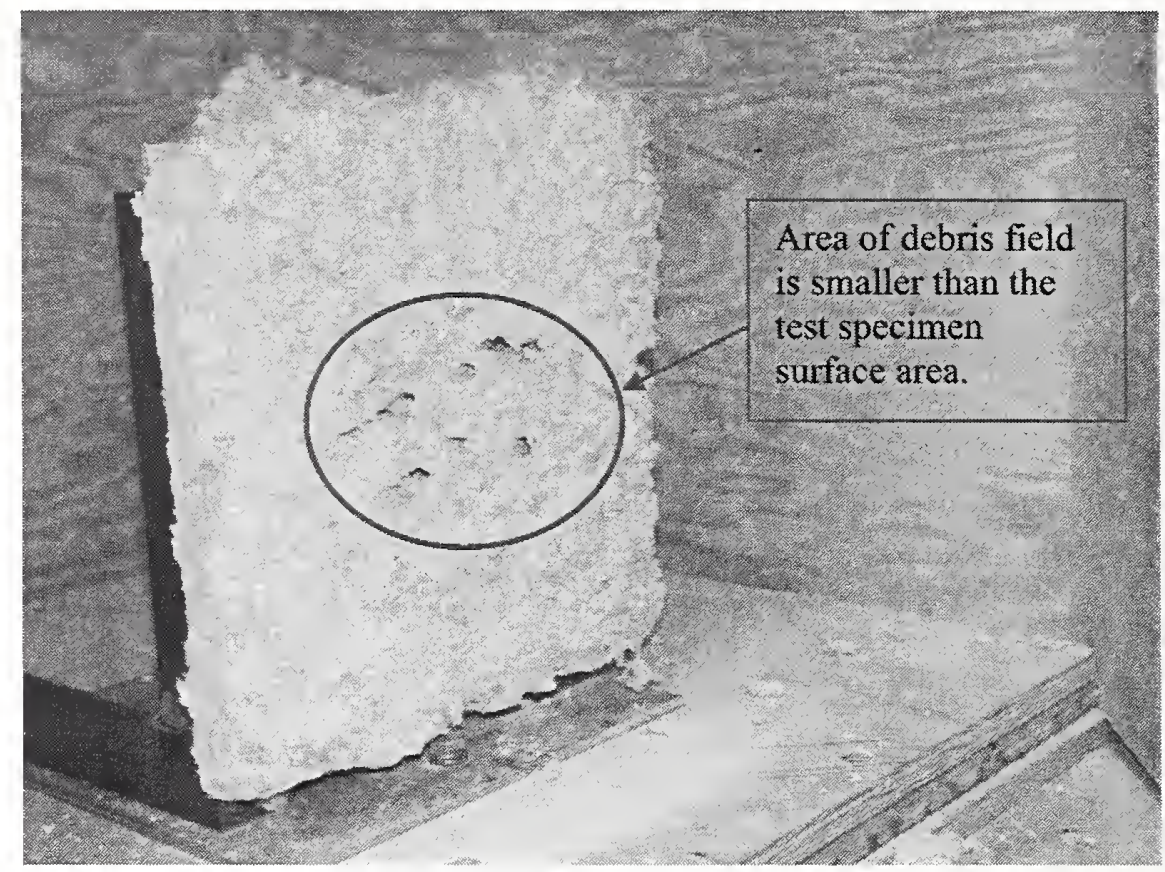

Figure C-7. Photograph showing damage to the SFRM after a ballistic impact at 60 degree. The SFRM layer did not separate from the steel plate.

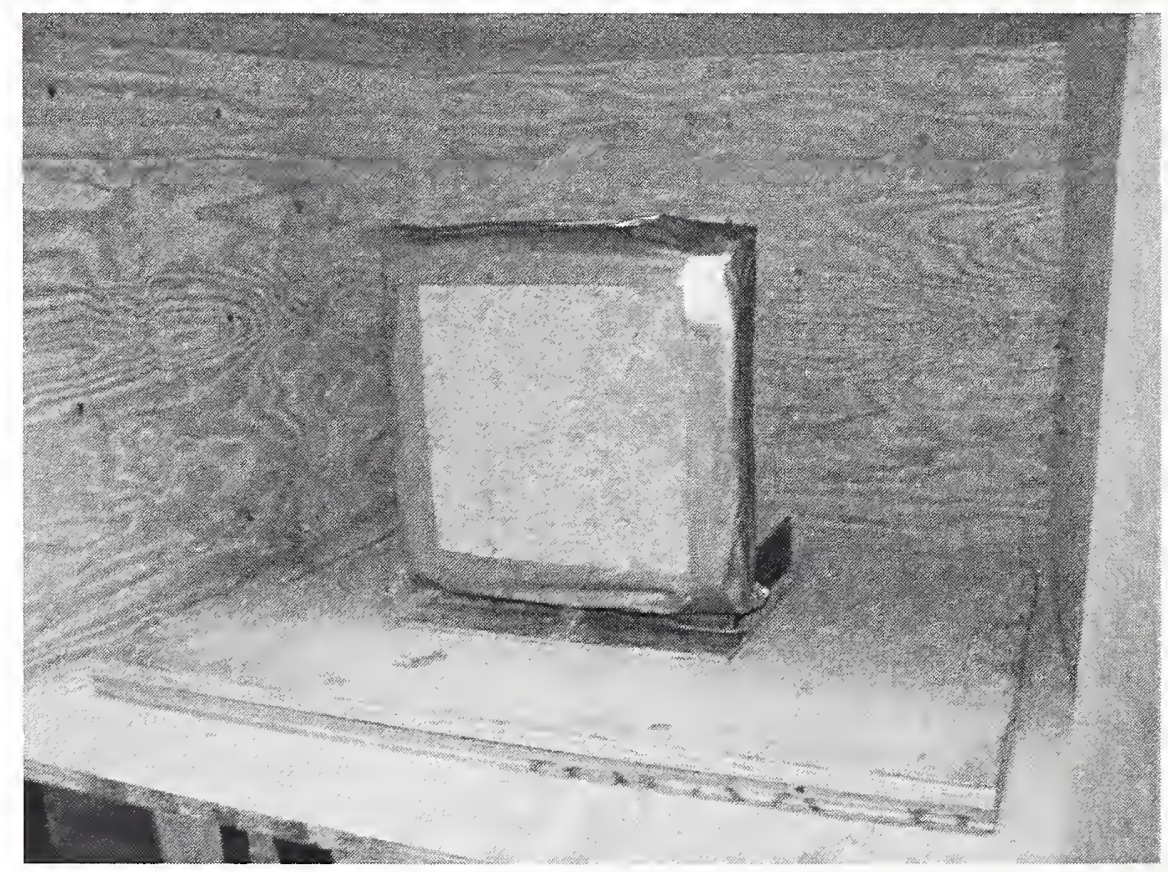

Figure C-8. Photograph showing the edges of the SFRM duct taped to the steel plate before the ballistic tests at 0 degree. 


\section{Steel bar and SFRM specimens}

The ballistic impact tests for the steel bars were performed using both the small and large universal receivers. A summary of the test parameters used for the steel bars with SFRM is given in Table C-3. For these tests, the adjustable mounting table was moved closer to the receiver to reduce the number of projectiles that might have missed the target bar. The distance from the chamber of the universal receivers to the target was $15.7 \mathrm{ft}(4.8 \mathrm{~m})$.

In tests using the small universal receiver (high-speed low-mass), the projectiles dislodged the SFRM completely at the impact area of both the primed and unprimed bars, exposed the steel bar, and resulted in loss of adhesion (not cohesion) of the remaining SFRM on the bar. After the ballistic impact, the remaining SFRM rotated freely with respect to the bar. Figure C-9 and Figure C-10 show the damage to the SFRM on the unprimed and primed bars, respectively, which were tested with the small universal receiver. In Figure C-9, the projectiles impacted the upper portion of the bar specimen and missed the center and lower portions.

Similar results were observed for tests with the large universal receiver (low-speed high-mass). The projectiles dislodged the SFRM completely at the impact area of the bars, resulting in exposed steel bar and loss of adhesion of the remaining undamaged SFRM on both sides of the impact area. Figure C-11 and Figure C-12 show the damage to the SFRM on unprimed steel bars tested with the large universal receiver. In Figure C-12, the projectiles also missed the lower portion of the specimen.

Table C-3. Summary of test parameters used for the steel bars with SFRM.

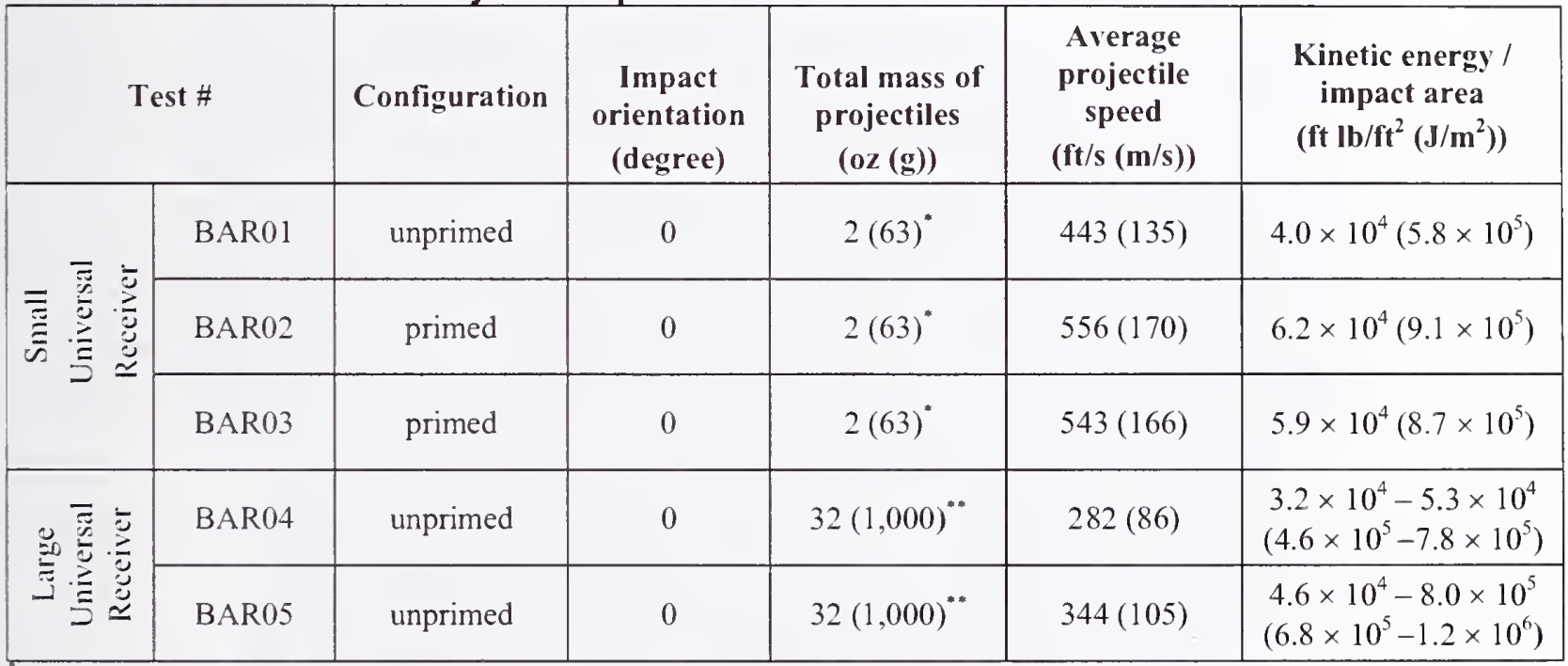

Projectiles consisted of only No. 00 lead buckshot.

"Projectiles consisted of a combination of hexagon steel nuts of different sizes. The minimum and maximum kinetic energy per unit impact area were estimated based on the smallest and the largest nuts and the minimum and maximum nut cross sections as impact areas. 


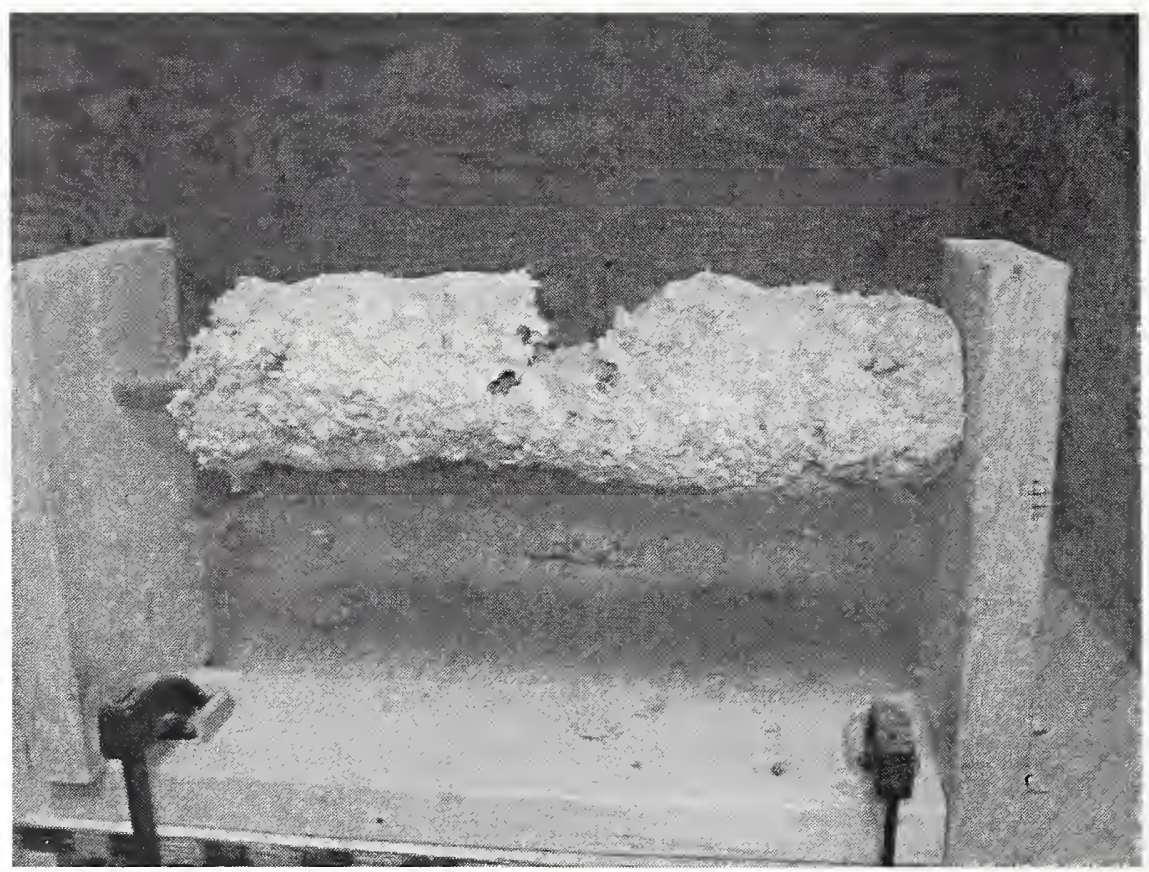

Figure C-9. Photograph showing damage to the SFRM on an unprimed steel bar (BAR01) after a ballistic impact at 0 degree using the small universal receiver.

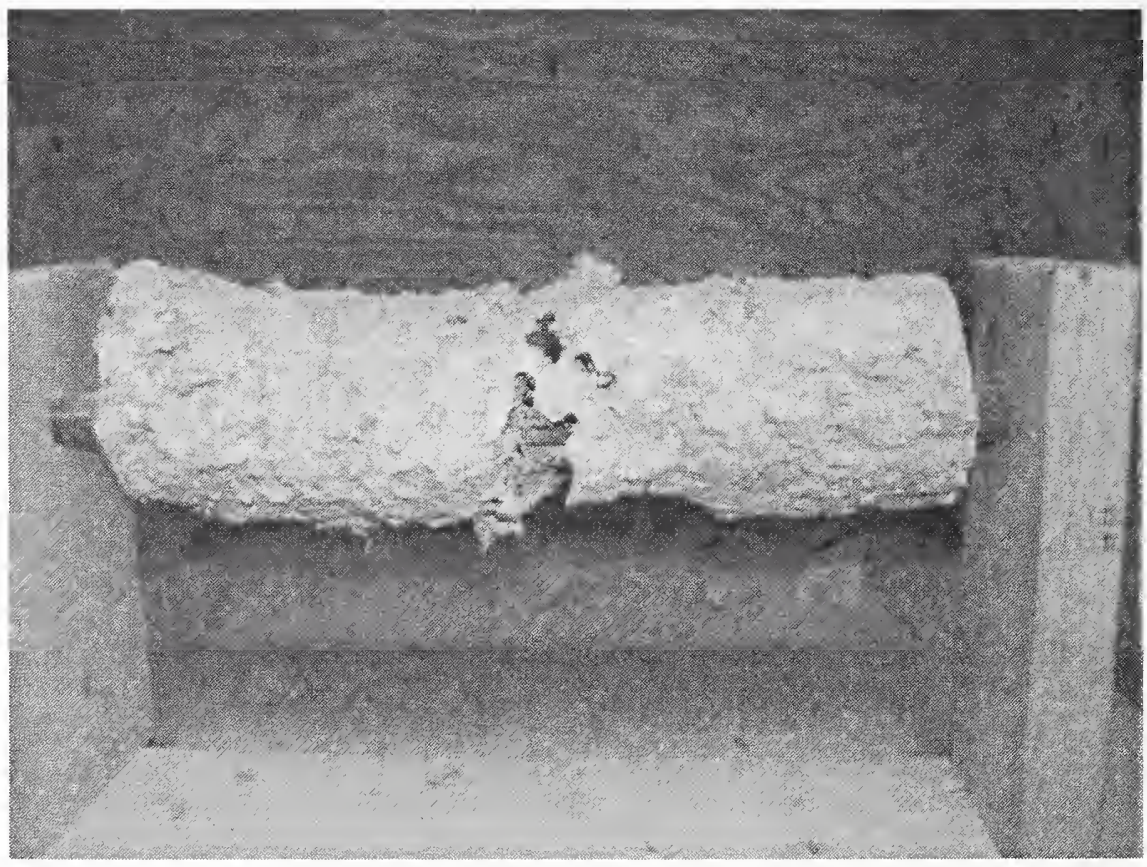

Figure C-10. Photograph showing damage to the SFRM on a primed steel bar (BAR02) after a ballistic impact at 0 degree using the small universal receiver. 


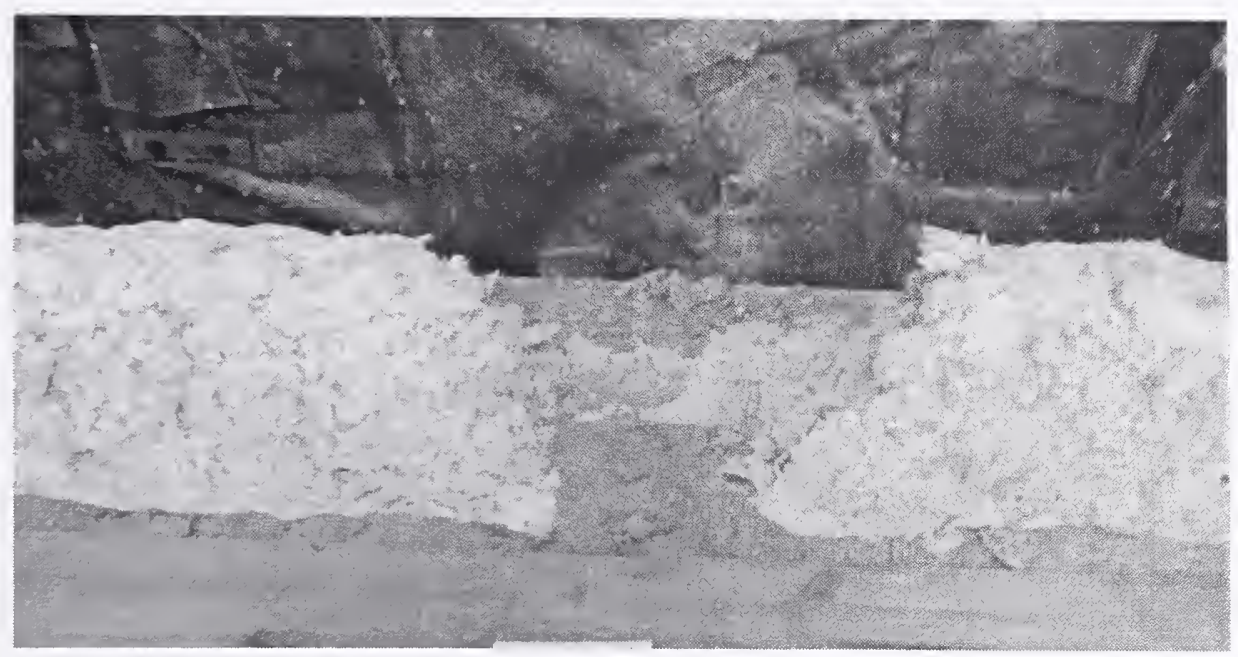

Figure C-11. Photograph showing damage to the SFRM on unprimed steel bar (BAR04) after a debris impact at 0 degree using the large universal receiver.

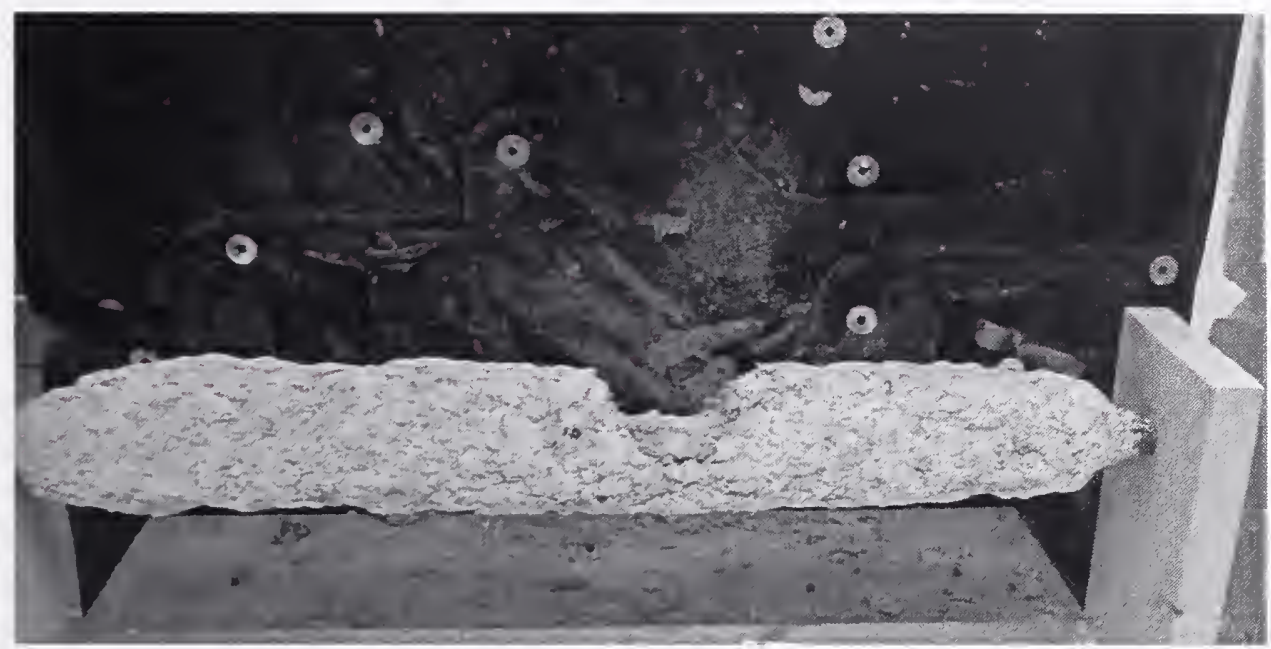

Figure C-12. Photograph showing damage to the SFRM on unprimed steel bar (BAR05) after a debris impact at 0 degree using the large universal receiver.

\section{SUMMARY OF FINDINGS}

Based on the observations made in the ballistic impact tests, the SFRM was dislodged by direct impact with solid objects that had a kinetic energy per unit impact area approaching $10^{4}$ to $10^{5} \mathrm{ft} \mathrm{lb} / \mathrm{ft}^{2}\left(10^{5}\right.$ to $10^{6} \mathrm{~J} / \mathrm{m}^{2}$ ). In addition, SFRM that was not dislodged after the debris impact lost its adhesion to the steel surface in all but one test. The SFRM on the steel plate was dislodged upon impact of the projectiles, except for the ballistic impact at a 60 degree angle to the plate. When the SFRM was taped to the steel plate and the tape carefully removed after debris impact at 0 degree, no adhesion of the SFRM to the steel plate was found, the same result found for the 0 degree impact test without duct tape. For SFRM on steel bars, the remaining SFRM after impact rotated freely with respect to the bar. 
When the debris field dimensions were similar to the specimen dimensions, the SFRM was dislodged completely from the steel component. For instance, the SFRM was dislodged over the width of the steel bar specimen when the debris field was centered over the specimen width. However, the steel plate dimensions were much larger than the debris field dimensions and the SFRM was damaged only where the impact occurred; the surrounding SFRM remained cohesively intact but lost its adhesive bond to the steel plate.

The test results demonstrated that there was dislodgment of SFRM at locations subject to direct debris impact. For direct debris impact up to a 60 degree orientation, the SFRM adhesive bond to the steel component was lost, but there was no loss of the SFRM cohesive bond.

In the WTC towers, where the debris fields were larger than the dimensions of steel components (i.e., such as trusses, beams, and columns), these tests show that SFRM would have been dislodged for a wide range of debris sizes and speeds. The test results support the assumption that, within the debris field created by the aircraft impact into WTC 1 and WTC 2, the SFRM used for thermal insulation of structural members was damaged and dislodged. 



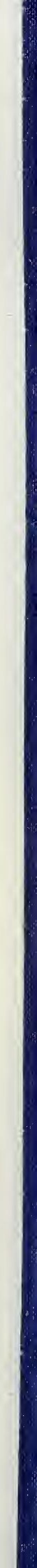

